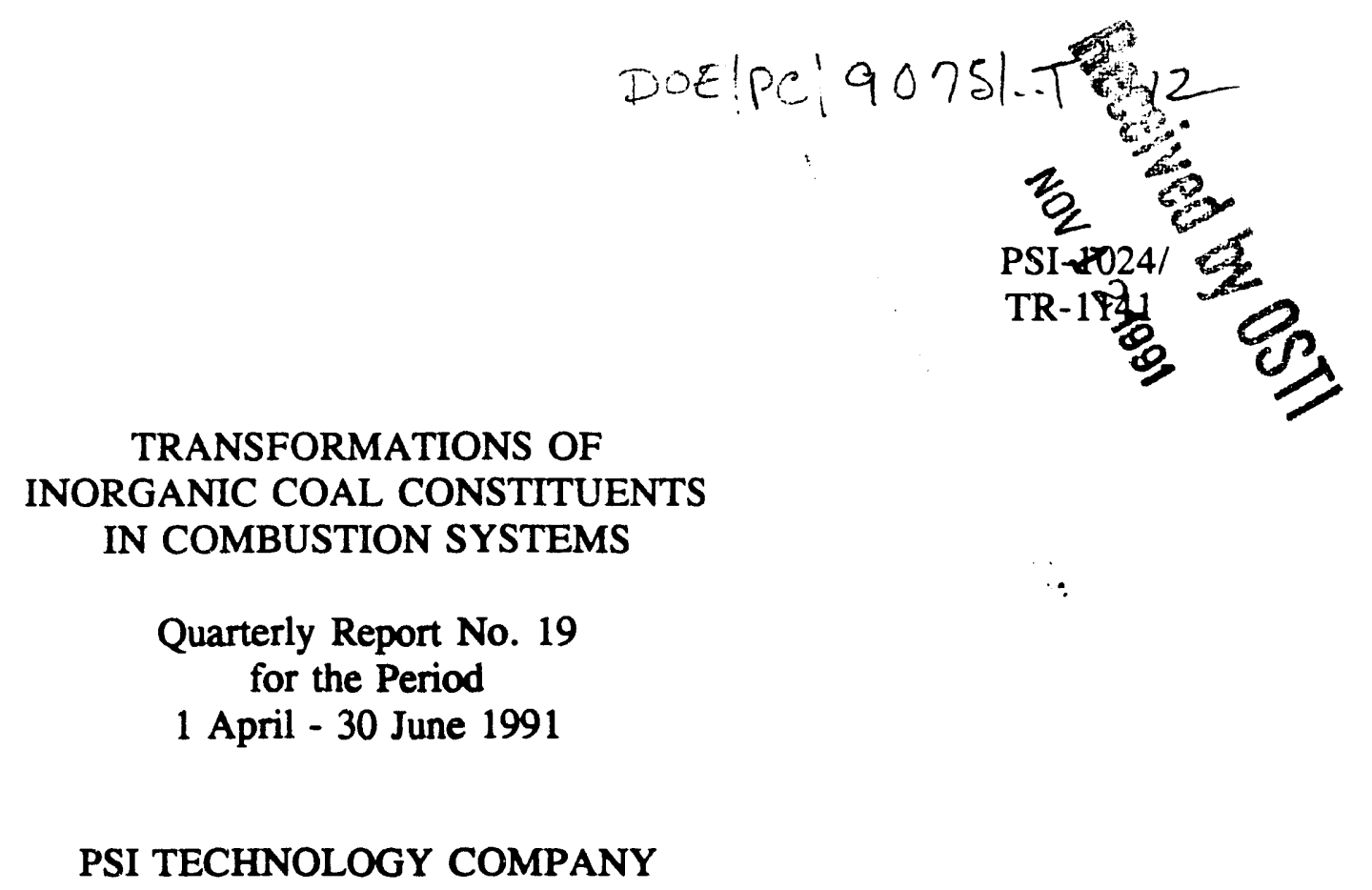

Principal Authors:

Dr. Joseph J. Helble, Dr. Srivats Srinivasachar, Dr. Gerald Wilemski, and Dr. Arthur A. Boni PSI Technology Company

Dr. Shin-Gyoo Kang, Prof. Adel F. Sarofim, and Prof. Janos M. Beér Massachusetts Institute of Technology

Prof. Thomas W. Peterson, Prof. Jost O.L. Wendt, Mr. Neal B. Gallagher, and Mr. Larry Bool

University of Arizona

Dr. Naresh Shah, Prof. Frank E. Huggins, and Prof. Gerald P. Huffman

University of Kentucky

DATE PUBLISHED - SEPTEMBER 1991

Prepared Under

Contract No. DE-AC22-86PC90751

U.S. DEPARTMENT OF ENERGY

Pittsburgh Energy Technology Center

P.O. Box 10940

Pittsburgh, PA 15236-0940 
This book was prepared as an account of work sponsored by an agency of the United States Government. Neither the United States Government nor any agency thereof, nor any of their employees, make any warranty, express or implied, or assumes any legal liability or responsibility for the accuracy, completeness, or usefulness of any information, apparatus, product, or process disclosed, or represents that its use would not infringe privately owned rights. Reference herein to any specific commercial product, process, or service by trade name, trademark, manufacturer, or otherwise, does not necessarily constitute or imply its endorsement, recommendation, or favoring of the United States Government or any agency therefore. The views and opinions of authors expressed herein do not necessarily state or reflect those of the United States Government or any agency thereof.

\title{
TRANSFORMATIONS OF INORGANIC COAL CONSTITUENTS IN COMBUSTION SYSTEMS
}

Quarterly Report No. 19

for the Period

1 April - 30 June 1991

\section{PSI TECHNOLOGY COMPANY}

Principal Authors:

\author{
Dr. Joseph J. Helble, Dr. Srivats Srinivasachar, \\ Dr. Gerald Wilemski, and Dr. Arthur A. Boni \\ PSI Technology Company
}

\author{
Dr. Shin-Gyoo Kang, Prof. Adel F. Sarofim, and Prof. Janos M. Beér \\ Massachusetts Institute of Technology \\ Prof. Thomas W. Peterson, Prof. Jost O.L. Wendt, Mr. Neal B. Gallagher, \\ and Mr. Larry Bool \\ University of Arizona
}

\author{
Dr. Naresh Shah, Prof. Frank E. Huggins, and Prof. Gerald P. Huffman \\ University of Kentucky
}
DATE PUBLISHED - SEPTEMBER 1991
Prepared Under

Contract No. DE-AC22-86PC90751

U.S. DEPARTMENT OF ENERGY
Pittsburgh Energy Technology Center

P.O. Box 10940

Pittsburgh, PA $15236-0940$ 
Section No.

Page

1.

EXECUTIVE SUMMARY

$1-1$

2.

INTRODUCTION AND OVERVIEW OF PROGRAM TASKS

$2-1$

3.

COAL ACQUISITION AND CHARACTERIZATION

4.

ADVANCED TECHNIQUES FOR COAL, MINERAL AND

4.1 ASH CHARATERCIZATION

Introduction

5.

FUNDAMENTAL STUDY OF MINERAL MATTER

5.1

VAPORIZATION AND RESIDUAL ASH FORMATION

Synthetic Char Preparation

Model Mineral Matter Preparation

Char from Grinding Pyrolyzed Char Cake

Char from Pyrolysis of Instability - Induced Droplets

$5-4$

5.1 .3

Comparison of the Char Preparation Methods

$5-4$

5.1 .4

5.2

5.2 .1

Ash Coalescence Studies

$5-6$

Theory

$5-6$

Experimental

5-8

5.2 .2

Results and Discussion

$5-9$

5.2 .3

References

6.

BEHAVIOR AND EFFECTS OF COAL MINERAL

MATTER IN A LABORATORY PULVERIZED COAL COMBUSTION

Introduction

Fate of Iron During Combustion

Pyrite Char Coagulation

Future Work

6.2

Burn 47-50: Impactor and PCSV Samples

$6-17$

6.2 .1

Burn 47: Illinois No. 6

6-18

Burn 48: Beulah Lignite

$6-28$

Bum 49: Loy Yang 2301

6-36

Bum 50: Loy Yang 1953

6-48

Burns 51-5.4: Cleaned Coals

6-52

Burns 51 and 54: CB Kentucky No. 9 SOAP 6-52

Burns 52 and 53: CB Kentucky No. $9 \quad 6-58$

6.3 .2

6.4

Conclusions and Results 
Section No. PARTICLE FORMATION AND SURFACE STICKINESS Combustion Testing of Chemically Cleaned Pittsburgh No. 8

Characterization of the Coal

Ash Particle Formation During the Combustion of CB

Overview of Test Program

$7-23$

7.4 .2

Illinois No. 6 (Parent)

$7-23$

7.4 .3

Temperature Comparisons

$7-24$

Joint PSIT/SECV Pilot Scale Testing

$7-29$

7.5

7.5 .1

7.5 .2

Background

$7-31$

Overview of Test Program

$7-31$

Preliminary Ash Particle Size and Composition Results

$7-32$

7.5.3

7.5 .4

7.6

Initial Deposition Results

$7-38$

Trace Element Concentration: Effects of Coal Benefication

$7-50$

7.7

References

$7-51$

$7-58$

8.

DEVELOPMENT OF AN ENGINEERING MODEL OF ASH FORMATION DURING PULVERIZED COAL COMBUSTION

8.1

Appendix A

A-1

Appendix B

B-1 


\section{LIST OF FIGURES}

Figure

Page

4-1

Montmorillonite

Montmorillonite

Nepheline

Nepheline

4-9

Nepheline

Beulah Lignite Ash Probe (Combustion Chamber)

Beulah Lignite Ash Probe (Horizontal Duct)

Loy Yang Test 1 Ash Probe (ring 7), Untreated

Loy Yang Test 4 Ash Probe (Horizontal Duct), Untreated

C1 XANES of Loy Yang Coals

C1 XANES of Loy Yang Ashes

C1 XANES of Loy Yang Ash

Beulah Ash with Ion Exchange, 1 s Residence Time

Schematic Diagram of Time-Temperature History of Silica Growth (upper); scanning electron micrograph of silica particles growth by the method discussed in the test (lower) 


\section{LIST OF FIGURES (Continued)}

Figure

Page

Pore Size Distributions of Sucrose/Carbon Black Char and PFA/Carbon Black Char Obtained form Mercury Porosimetry

Fusion Curves of Alkali and Alkaline - Earth Silicates (upper), and the Viscosity Change of Silica with Alkali Metal Addition (lower)

Typical Ash Particles Collected from the Combustion of (a) sample BA and (b) sample K3

Typical Ash Particles Collected from the Combustion of (a) sample $\mathrm{K} 2$ and (b) sample $\mathrm{K} 1$

Cumulative Particle Size Distributions of the Primary Particles (upper) and Volume Mean Particle Size Change with the Composition (lower)

XRD Spectrum from Illinois No. 6 Ash Trap Sampie

XRD Spectrum of Plate-Like Particles

XRD Spectrum of Large Beam-Stable Particles

XRD Spectrum of Needle-Like Particles in Composition Particles 
LIST OF FIGURES (Continued)

Figure

Page

6-13

Fe Map, Agglomerate in Fig 6-10

6-13

$6-14$

Si Agglomerate in Fig 6-10

6-14

6-15

Agglomerate in Fig 6-12 Under Lower Magnification

6-14

6-16

Pyrite-Char Interactions

6-15

$6-17$

Temperature Profile for Bum 47

6-19

6-18

Fraction Oxide for $1.3 \mathrm{~kg} / \mathrm{hr}$ Feed Rate

6-20

6-19

Fraction Oxide for $2.4 \mathrm{~kg} / \mathrm{hr}$ Feed Rate

6-20

$6-20$

Ash Concentration for $1.3 \mathrm{~kg} / \mathrm{hr}$ Feed Rate

6-21

Ash Concentration for $2.4 \mathrm{~kg} / \mathrm{hr}$ Feed Rate

6-22

Fraction Oxide for $1.3 \mathrm{~kg} / \mathrm{hr}$ Feed Rate at Port 5

$6-22$

Fraction Oxide for $2.4 \mathrm{~kg} / \mathrm{hr}$ Feed Rate at Port 5

$6-23$

$6-24$

Fraction of Alkali in the Small Sizes for the High Feed

Rate (Hi) and the Low Feed Rate (Lo) form Port 5 and 11

Samples

Ash Concentrations for $1.3 \mathrm{~kg} / \mathrm{hr}$ Feed Rate

$6-24$

Ash Concentrations for $2.4 \mathrm{~kg} / \mathrm{hr}$ Feed Rate

$6-25$

Mass Distributions for Burn 47

6-26

Area Distributions for Burn 47

6-29

Number Distributions for Bura 47

$6-30$

Impactor and PCSV for Bum 47

$6-30$

Impactor and PCSV for Burn 47

$6-28$ 
LIST OF FIGURES (Continued)

Figure

Temperature Profiles for Burn 486-29

Fraction Oxide for $1.65 \mathrm{~kg} / \mathrm{hr}$ Feed Rate

Fraction Oxide for $2.8 \mathrm{~kg} / \mathrm{hr}$ Feed Rate

Ash Concentration for $1.65 \mathrm{~kg} / \mathrm{hr}$ Feed Rate

Fraction Oxide for Burn 48 Port 5

Ash Concentration for Burn 48 Port 5

Mass Distribution for Burn 48 Low Feed Rate 


\section{LIST OF FIGURES (Continued)}

Figure

$\underline{\text { Page }}$

6-52

Mass Distribution for Burn 49 Low Feed Rate

6-42

$6-53$

Mass Distribution for Burn 49 High Feed Rate

$6-43$

6-54

Mass Distribution for Burn 49

6-43

6-55

Area Distribution for Burn 49

6-44

6-56

Number Distribution for Burn 49

6-44

6-57

Impactor and PCSV for Burn $49(1.8 \mathrm{~kg} / \mathrm{hr})$

4-45

6-58

Impactor and PCSV for Burn $49(2.8 \mathrm{~kg} / \mathrm{hr})$

4-46

6-59

Imp w/o 8+AF and PCSV for Burn $49(1.8 \mathrm{~kg} / \mathrm{hr})$

Temperature Profile for Burn 50

6-48

6-61

Fraction Oxide for $2.5 \mathrm{~kg} / \mathrm{hr}$ Feed Rate

Ash Concentration for $2.5 \mathrm{~kg} / \mathrm{hr}$ Feed Rate

Sodium Cumulative Fraction for Burn 49 and 50

Mass Distribution for Burn 50

Area Distribution for Burn 50

Number Distribution for Burn 50 


\section{LIST OF FIGURES (Continued)}

Figure

Ash Concentration for Burn 51

Ash Concentration for Burn 54

Moisture Analysis of Chemically Beneficiated Kentucky No. 9

Temperature Profile for Burn 52

Ash Concentration Versus Impactor Plate for Kentucky No. 9 Burn 36

CCSEM Mineral Analysis of CB Pittsburgh \#8, showing all particles containing greater than 60 atom \% $\mathrm{K}+\mathrm{Cl}+\mathrm{S}$ on an Oxygen-Free Basis.

Mineral and Ash Size Distributions for CB Pittsburgh 8, determined by CCSEM at UNDEERC

Quartz Mineral and Ash Size Distributions for CB Pittsburgh 8, determined by CCSEM at UNDEERC.

CCSEM Ti-Al-Si ternary for CB Pitts 8, showing all minerals containing $\geq 50$ atom $\% \mathrm{Ti}+\mathrm{Al}+\mathrm{Si}$ 


\section{LIST OF FIGURES (Continued)}

Figure

Page

7-7

CCSEM Ti-Al-Si ternary for ash particles generated during combustion of CB Pitts $8(<90 \mu \mathrm{m}), 1500 \mathrm{mC} 7 \% \mathrm{O}_{2}$

Cascade impactor mass distribution obtained from combustion of CB Pitts. \#8

Mineral and Ash Size Distribution for Illinois \# 6 SOAP

Fe-Al-Si Ternary Diagrams for Illinois 6 SOAP without $2 \leq \mathrm{dp}<80 \mu \mathrm{m}, \mathrm{Fe}+\mathrm{Al}+\mathrm{Si} 80$ atom $\%$

K-Al-Si Ternary Diagrams for Illinois 6 SOAP without $2 \leq$ $\mathrm{dp}<80 \mu \mathrm{m}, \mathrm{Fe}+\mathrm{Al}+\mathrm{Si} 80$ atom \%

Ca-Al-Si Ternary Diagrams for Illinois 6 SOAP without $2 \leq$ $\mathrm{dp}<80 \mu \mathrm{m}, \mathrm{Fe}+\mathrm{Al}+\mathrm{Si} 80$ atom \%

Collection Efficiency, Illinois \#6 SOAP

UA Laboratory Combustor

Illinois \#6 Parent Cumulative Mass Distributions

Beulah Ligite Cumulative Mass Distributions (low load)

Beulah Ligite Cumulative Mass Distributions (high load)

Loy Yang 2301 Low Load Cumulative Mass Distributions

Loy Yang 2301 High Load Cumulative Mass Distributions

Cumulative Ash PSD's (mass basis) Measured in-situ at 


\section{LIST OF FIGURES (Continued)}

\section{Figure}

Loy Yang 2301 Load Comparison

Schematic of SECV Furnace Showing Sampling Locations

Beulah Lignite Ash PSD Measured with the PCSV-P, ring 7 combustion chamber centerline

Beulah Lignite Ash Na-Al-Si Ternary plots by CCSEM showing all particle with $\mathrm{Na}+\mathrm{Al}+\mathrm{Si} \geq 80$ atom $\%$ (oxygen-free basis).

Ca-Al-Si Ternary for Beulah ash, Ring 7 Combustion Chamber Centerline

Loy Yang 1953 Coal PSD Measured $50 \mathrm{~mm}$ From the Wail of the Combustion Chamber (7 Ring) with the PCSV-P

Loy Yang Ash PSD Measured $50 \mathrm{~mm}$ From the Wall of the Combustion Chamber (7 Ring) with the PCSV-P

Na-Al-Si Ternary, Loy Yang 1963 Ash Extracted from the Horizontal Duct

Mg-Al-Si Ternary, Loy Yang 1963 Ash Extracted from the Horizontal Duct

Zn-Al-Si Ternary, Loy Yang 1963 Ash Extracted from the Horizontal Duct

Loy Yang 1953 Treated Ash PSD Measured at Ring 8 Combustion Chamber (Centerline) with the PCSV-P 


\section{LIST OF FIGURES (Concluded)}

Figure

Page

$7-38$

Comparison of Ash Particle Size Distribution Measured with the CSSV-P at SECV

Comparison of CCSEM Ash Particle Size Distribution

Ottained from Sampling in the Horizontal Duct

Test Bank Deposits, Beulah Lignite

Combustion Chamber (top) and Test Bank (bottom) Deposits

Combustion Chamber and Test Bank Deposits Treated LY 1953

Two-Dimensional Schematic of Interaction Region Swept Out by Mineral Particles of Diameter Di and Dj During Burnout

Two-Dimensional Illustration of Conical Volume Swept out by 2 Mineral Particles Due to Spherical Shape of Char Particles 


\section{LIST OF TABLES}

Table

Page

Analysis of Blend and Blend Parent Coals

70/30 Eagle Butte/Kentucky \# 9 Blend Coal Particle

Size Distribution (Malvern Analysis)

Analysis of Phase I Eagle Butte and Kentucky \#9

Analysis of Illinois \#6 SOAP, and Loy Yang 1953 Coals

CCSEM of Illinois \#6 SOAP (U. Kentucky)

CCSEM of Illinois \#6 SOAP (U. Kentucky*)

Sample 593 Loy Yang Test 1 Ash Probe (Ring 7), Untreated

Sample 594 Loy Yang Test 4 Ash Probe (Horizontal Duct), Untreated

Sample 595 Loy Yang Test 3 Ash Probe (Horizontal Duct), Treated

Sample 596 Beulah Lignite Ash Probe (Combustion Chamber)

4-9 Sample 551 PSI Beulah Ash without Ion Exchange, 3s 
LIST OF TABLES (Continued)

Table

Page

4-10

Mössbauer Analysis of UA and PSIT/SECV Samples

(Continued)

$5-1$

Synthetic Char Samples Prepared for the Study

$5-10$

6-1

Comparison of Iron Analysis for Ash from Various Coals

6-4

6-2

Major XDS Angles for Magnetite and Hematite

Summary of Experiments and Acquired Samples

$6-18$

6-4

Summary of Experiments and Acquired Samples

6-54

$7-1$

Coal and Ash Analysis - CB Pittsburgh No. 8 Coal

$7-2$

Chemical Fractionation of CB Pittsburgh No. 8 by UNDEERC

CCSEM Mineral Analysis of CB Pittsburgh No. 8 wt\% of Mineral Matter

CCSEM Mineral Size Distribution CB Pitts. \#8 (Area \% of Minerals)

Average Discrete Mineral Composition - CB Pitts. \# 8 (CCSEM, Atom percent, O-Free basis)

Chemical Composition of Combustion-Generated CB Pittsburgh \#8 Ash (Cross-sectioned Samples)

Comparison of Surface and Cross-sectional CCSEM-CB Pittsburgh No. 8 Ash

Stickiness Testing of CB Pittsburgh \#8 (As Received Coal, $21 \% \mathrm{O}_{2}$ )

CB Pittsburgh \#8 Deposit Composition $1500^{\circ} \mathrm{C}, 21 \% \mathrm{O}_{2}$ ' (Coal-as received) (wt \%)

Ash Analysis of Illinois \#6 SOAP by CCSEM at UNDEERC

(XS Area $\%=$ Volume $\%$ ) 
LIST OF TABLES (Continued)

Table

Page

Chemical Composition of Illinois \#6 SOAP Ash by CCSEM

SOAP Deposit Composition by SEMPC

Loy Yang 1953 Deposit Composition by SEMPC

Operating Parameters Ranges for SEVC 35 kg/hr Furnace

Malvern Coal PSD-Beulah

Malvern Coal PSD-Loy Yang 1953

Malvern Coal PSD-Treated Loy Yang 1953

Furnace Parameter for SECV Coal Tests

Brink Cascade Impactor Data

Relative Ranking of Phases Observed in Beulah Lignite Testing - XRD Analysis

Chemical Analysis of Beulah Lignite Ash and Deposit

Samples

Relative Ranking of Phases Observed in Beulah Lignite Testing - XRD Analysis

Chemical Analysis of Beulah Lignite Ash and Deposit Samples (wt\%)

Relative Ranking of Phases Observed in Beulah Lignite Testing - XRD Analysis 


\section{LIST OF TABLES (Concluded)}

Table

Trace Element Analysis, Beulah Coal and Ash

$8-1$

Size Distribution for Each Flyash Type (Number \% in Each Flyash Type) for Illinois \#6 Coal

8-2

Coal Particle Number Distribution and Number of Ash Particles Produced for Illinois \#6 Coal 


\section{SECTION 1}

\section{EXECUTIVE SUMMARY}




\section{EXECUTIVE SUMMARY}

The technical objectives of this project are:

a. To: 1) define the partitioning of inorganic constituents associated with raw coal particles among producis (including vapors, aerosols, and residual char/ash particles) formed under conditions representative of pulverized coal flames as a function of the specific (intrinsic and extrinsic) characteristics of the raw coal and the environment in which the transformations occur; and 2) characterize the resultant spectrum of products in detail.

b. To elucidate and quantify the fundamental processes (involving basic principles of physics, chemistry, thermodynamics) by which transformations of the inorganic constituents occur.

c. To develop, based on the information required in a. and b. above, a tractable "process" model capable of predicting the significant features of the transformation process, most importantly, the nature and distribution of products.

The contract approach and description of each task is included in Section 2 of this report. This report summarizes work accomplished during the nineteenth quarter of this project.

The work discussed herein highlights recent accomplishments: at the University of Kentucky (UK), in CCSEM, XAFS, and Mössbauer analyses of mineral and ash samples generated at PSIT, the University of Arizona, and at the Herman Research Laboratories of the State Electricity Commission of Victoria in joint PSIT/SECV testing; at the Massachusetts Institute of Technology (MIT), in studying the rate of ash coalescence in combustion experiments conducted with synthetic chars prepared with ash inclusions and atomically dispersed inorganic species; at the University of Arizona (UA), in examining interactions between iron oxide and aluminosilicate ash particles, in comparing optically determined ash particle size distributions with those obtained from extractive sampling, in examining sodium evolution from the second Loy Yang coal sample (LY 1953) obtained from SECV, and in analyzing the ash products formed during combustion of chemically beneficiated Kentucky 9 coal and physically beneficiated Illinois $\# 6$ coal (oil agglomeration process); at PSI Technology Company (PSIT), in examining the variation of ash particle size distributions with coal type in joint experimental programs conducted at UA and at the SECV $35 \mathrm{~kg} / \mathrm{hr}$ pilot-scale combustor, and in characterizing the ash formed from chemically beneficiated Pittsburgh 8 and physically beneficiated Illinois \#6 coals; and at PSIT, in adding an algorithm that simulates the effects of char fragmentation to the Engineering Model for ash particle formation.

In Section 3, ultimate and proximate analyses for Illinois 6 SOAP, Illinois 6, Loy Yang 1953, Eagle Butte (new), Kentucky 9 (new), and the Kentucky 9/Eagle Butte blend are 
compiled. Much of this data was generated by the University of North Dakota EERC through a co-operative agreement with DOE/PETC.

In Section 4, CCSEM analysis of pulverized natural nepheline and montmorillonite samples is reported by the University of Kentucky. Experimentation with both samples in the PSIT combustion facility was discussed previously (Quarterly Report 18). Analysis of the nepheline sample indicated the presence of anorthite as a minor constituent, while analysis of the montmorillonite confirmed the presence of potassium and iron in the mineral sampis.

CCSEM analysis of ash samples extracted from the exit of the radiant section of the SECV pilot scale combustor is also reported in Section 4. Samples of Beulah lignite ash demonstrated the presence of a 1/1/1 sodium aluminosilicate phase (nepheline; previously identified in experiments with this coal at PSIT and UA. Experiments with Loy Yang 1953 coal indicated the presence of extraneous quartz as well as a refractory magnesium and aluminum rich phase. Chlorine XANES analysis of Loy Yang 1953 coal and ash samples also obtained in PSIT/SECV testing indicated a significant presence of sodium chloride in solution in the parent coal, and crystalline sodium chloride in the ash product. Crystalline $\mathrm{NaCl}$ comprised approximately $60 \%$ of the chlorine-bearing ash phases for treated and untreated Loy Yang 1953, with one or more unidentified phases making up the remainder.

In Section 5, initial results from an experimental study of the competition between the rates of ash coalescence and char combustion conducted at MTT are presented. Spherical and angular synthetic char particles containing monosized $1.4 \mu \mathrm{m}$ silica particles and $0-1.5 \%$ atomically dispersed potassium were prepared by two techniques. The char samples were then combusted at $1650 \mathrm{~K}$ in $20 \%$ oxygen, and the degree of coalescence of the resulting ash examined to determine the influence of alkali on silicate coalescence rates. The char containing only silica inclusions showed no coalescence of ash particles, while the synthetic char containing silica plus $1.5 \%$ potassium showed nearly complete coalescence of ash. Intermediate values of potassium (at approximately fixed silica concentration) demonstrated intermediate levels of ash coalescence. The change in ash behavior was ascribed to a change in ash particle viscosity induced by potassium-silica interactions.

In Section 6, the results of a University of Arizona study of the interactions between iron oxide ash particles and aluminosilicate - derived ash particles are presented. Using high resolution electron microscopic techniques, it was determined that iron oxides associate with aluminosilicates by coagulation during combustion; coalescence or dissolution, however, is incomplete. Little evidence for iron recrystallization from an aluminosilicate melt was found for the Beulah lignite and Illinois 6 ashes examined. For the Beulah lignite, with a high percentage of large and presumably excluded pyrite, interactions with aluminosilicate ash particles were not expected. Calculations performed with the MAEROS aerosol dynamics code indicated that coagulation between extraneous pyrite-derived particles and combusting char particles could occur in the UA combustor, but to a limited extent as described in Section 6. 
Also in Section 6, in-situ particle size distribution measurements obtained by PSIT using a commercial optically-based instrument at the UA facility are compared with extractive particle size distributions using a cascade impactor. Excellent agreement was obtained from the Beulah lignite, which showed relatively low levels $(6.5 \%)$ of unburnt carbon in the residual ash. For the Illinois 6 coal, which yielded carbon in ash levels of 27\%, and for Loy Yang 2301 with produced approximately $45 \%$ of the ash $<3 \mu \mathrm{m}$ in diameter, larger differences were noted between techniques. Qualitative trends were, however, consistent from sample to sample.

Also in Section 6, baseline combustion experiments conducted with three of the Phase II coals - Loy Yang 1953, Illinois 6 SOAP, and chemically cleaned Kentucky 9 (CB Ky 9) are discussed. The Loy Yang 1953, as compared to Loy Yang 2301, produced a submicron ash containing a smaller fraction of the total sodium in the ash. This was attributed to a higher silica to sodium ratio for the Loy Yang 1953. The chemically cleaned coal produced submicron ash enriched in sodium and potassium, likely originating from the beneficiation process used to treat the parent coal.

In Section 7, recent PSIT experimental results obtained during combustion testing of a chemically beneficiated Pittsburgh 8 (CB Pitts 8) and a physically beneficiated Illinois 6 (IIl. 6 SOAP) are discussed. Minimal coalescence of CB Pittsburgh 8 inorganics was observed during combustion, although titanium-containing aluminosilicates were observed in the ash. Their formation was attributed to the interaction of very small titania and aluminosilicate minerals during combustion. For the Illinois 6 SOAP, iron aluminosilicates were the dominant ash species forming. Iron aluminosilicate levels in the ash were greater at $1500^{\circ} \mathrm{C}$ than at $1250^{\circ} \mathrm{C}$, suggesting more extensive agglomeration and/or coalescence at the higher gas temperature.

Also in Section 7, initial results from the joint PSIT/SECV combustion testing program are presented. Loy Yang 1953, Beulah lignite, and a treated Loy Yang 1953 were all examined in the SECV $35 \mathrm{~kg} / \mathrm{hr}$ furnace.

In Section 8, the incorporation of an algorithm addressing the effects of char fragmentation on ash release into the Engineering Model (EM) for ash formation is described. Initial efforts focused on treatment of the ash formation process for cenosphereforming bituminous coals. Those studied in this program - Illinois 6, Kentucky 9, Kentucky 11, and Upper Freeport - all have moderate-to-high tendencies to form cenospheric char. The approach taken assumes that as a cenospheric shell burns and becomes thinner, mineral inclusions at the surfaces contact newly exposed inclusions and coalesce. To determine the final size and composition of ash particles formed, the number of collisions occurring among the various sizes and classes of minerals are tracked. Char fragmentation is simulated via scaling arguments which compare mineral size with cenosphere shell thickness, and coalescence lengths with mineral separation lengths to determine which particles are separated during combustion. Initial simulations conducted with the Illinois 6 studied under this program yielded reasonable agreement with experimental results. 
SECTION 2

INTRODUCTION AND OVERVIEW OF PROGRAM TASKS 


\section{INTRODUCTION AND OVERVIEW OF PROGRAM TASKS}

This project consists of an integrated series of experimental and modeling tasks performed by PSI Technology Company (PSIT) and three subcontractors (identified below) to achieve the project objectives. Additional work is to be conducted jointly with the University of North Dakota Energy and Environmental Research Center (UND EERC) and the State Electricity Commission of Victoria, Australia (SECV) through cooperative agreements. Important elements of this work include coal and ash characterization using advanced analytical techniques, testing in small scale furnaces, testing in moderate to large-pilot scale units, adaptation of fundamental submodels developed previously to beneficiated coal systems, and integration of these submodels and experimental findings into an engineering model used to predict ash particle composition and size distributions. A breakdown of the work to be performed in each task is presented below.

\section{Task 1 - Program Planning, Management, Reporting, and Peer Review}

This task, to be performed by PSIT, consists of: (1) preparation and annual updating of a Program Plan; (2) overall coordination, management, and integration of the subcontracts and project results; (3) preparation of project monthly reports; (4) integration and final preparation of project quarterly reports; and (5) conduct of semi-annual peer review and project coordination meetings of the project Principal Investigators.

\section{Task 2 - Coal Selection. Preparation, and Characterization}

This task will be performed by PSIT using the guidelines for mineralogy-based coal selection developed by Foster Wheeler Development Corporation (FWDC) during the first phase of this project. Five parent coals plus one beneficiated sample of each coal with an optional two sets of additional coals will be selected to permit an experimental determination of beneficiation related variables on inorganic transformations during combustion. Emphasis will be placed on obtaining both eastern and western coals, cleaned with currently accepted and advanced beneficiation strategies. Coals will be acquired by PSIT, pulverized as necessary by an independent contractor on a purchase order basis, and shipped to the various investigators.

\section{Task 3 - Advanced Techniques for Coal and Mineral Characterization}

The University of Kentucky (UK) will apply advanced analytical techniques to determine the form, size, and associations of the coal minerals and the resulting ash particles. Work to be performed in this broad area can be broken down into three Subtasks. Under Subtask 3.1, UK will work with other research groups to make improvements in the computer controlled scanning electron microscopy (CCSEM) technique. This will include software improvements to permit the CCSEM to distinguish between extranenus and included mineral matter in an automated fashion. Under Subtask 3.2, UK will apply CCSEM, Mössbauer spectroscopy, $x$-ray absorption fine structure analysis (XAFS), and scanning transmission electron microscopy (STEM) to analyze the mineral forms in the parent coals 
and the resulting ash products. X-ray diffraction will also be used as needed for mineral analysis. Under Subtask 3.3, UK will develop an in-situ XAFS capability at the Brookhaven National Laboratories (BNL) Light Source, to be used to determine the associations of inorganic species in ash particles and initial sticky particle layers without the complications posed by quenching and extractive sampling.

Task 4 - Fundamental Studies of Selected Ash Vaporization. Nucleation, Condensation, and Coagulation Phenomena

Task 4, to be performed by PSIT, involves thermochemical modeling of the inorganic species expected to be present in the parent coal particles, the beneficiated coal narticles, and the final ash particles at various combustion conditions.

\section{Task 5 - Fundamental Studies of Mineral Matter Vaporization and Residual Ash Formation}

Experimental and modeling studies are to be conducted at the Massachusetts Institute of Technology (MIT) on two Subtasks. Under Subtask 5.1, drop tube furnace combustion experiments will be conducted with parent coals, beneficiated coals, and model chars to assess the importance of the various mechanisms which control residual ash formation. Emphasis will be placed on the expected increasing importance of char fragmentation in shaping the djstribution, both experimentally and through adaptation of thie percolative fragmentation model developed in the first phase of this project. In Subtask 5.2, the extent of vaporization of inorganic species contained in the parent and beneficiated coals will be examined experimentally. Vaporization models developed previously will be utilized to interpret results from beneficiated systems.

\section{Task 6 - Pulveriaxd Coal Combustion Studies of Ash Enrichment by Volatiles}

The objectives of this task, to be performed at the University of Arizona (UA) self-sustained reactor facility, are to determine the different fume amounts, compositions, and structures resulting from various beneficiation processes. Mechanistic descriptions of the size and surface composition of the submicron fume formed during combustion will be developed. Testing will occur on selested parent and cleaned coals, chosen subsequent to initial screening in the PSIT reactor facility. As part of this effort, the size of the residual ash particles will be measured in-situ using an optical single particle measuring instrument provided by PSIT. A model capable of describing the general ash particle size distribution including the effects of fume formation and char fragmentation will also be developed.

Task 7 - Idealized Combustion Determination of Ash Particle Formation and Surface Stickiness

In this task, PSIT will employ an idealized combustion system to determine ash particle size and composition distributions for comparison with results obtained at MTT and UA. Emphasis will be placed on quantifying the amount of fume, and the amount and chemical composition of ash generated from the various beneficiated coals. Particle 
stickiness as it pertains to inertial impaction and thermophoretic deposition will be addressed. Particle size will be analyzed by several means as part of the task, including CCSEM, laser diffraction, and aerodynamic impaction. In addition, the combustor portion of an in-situ XAFS cell will be designed and constructed. Experiments utilizing this cell will be conducted with UK and BNL at the BNL Light Source to determine ash composition and sticky particle composition in-situ.

\section{Task 8 - Model Development and Integration}

In this task, PSIT will synthesize the mineral redistribution, char particle fragmentation, and mineral transformation models developed under the various tasks into an overall ash formation model. The result of this synthesis will be an engineering model capable of describing the size and, more importantly, the chemical composition of residual ash generated during pulverized coal combustion and the quantity and composition of the ash fume. The information provided by this model will then be used to assess the benefits of coal cleaning though a parametric study of ash properties resulting from selective mineral removal. 
SECTION 3

\section{COAL ACQUISITION AND CHARACTERIZATION}

Task 2

J.J. Helble

PSI Technology Co. 


\section{COAL ACQUISITION AND CHARACTERIZATION}

In this section, the ultimate and proximate analyses for six of the Phase II coals Eagle Butte (new), Kentucky 9 (new), 70/30 Eagle Butte/Kentucky No. 9 blend, Illinois \#6 parent, Illinois No. 6 spherical oil agglomeration product (SOAP), and Loy Yang 1953 (obtained from the State Electricity Commission of Victoria) are summarized. Malvern coal particle size distribution analysis of the blend is also presented (Illinois \#6 parent and SOAP have appeared previously; see Quarterly Report 18 of this project). Analysis of all samples was provided by the University of North Dakota Energy and Environmental Research Center (UNDEERC) under a co-operative agreement with the DOE Pittsburgh Energy Technology Center unless otherwise roted.

Table 3-1 contains analysis of the Eagle Butte sub-bituminous, Kentucky 9 bituminous, and 70/30 blend samples as reported by UNDEERC. A 70/30 mixture was selected to examine ash formation from a blended coal, and is not meant to represent any specific compliance coal blend. Also presented for comparison are the properties of a 70/30 mixture based upon a weighted average of the two parent $r$ " $\varsigma$. The agreement between calculated and measured blends indicates that a 70/30 Eagle b. 'e/Kentucky 9 mixture was achieved. The coal particle size distribution for this 70/30 blended fuel is presented in Table 3-2. Analysis of the E?gle Butte and Kentucky 9 coals studied in Phase I of this program, reprinted from the Phase I Final Report, is presented in Table 3-3 for comparison.

Analysis of the Illinois \#6 parent bituminous coal, Illinois \#6 SOAP, and Loy Yang 1953 Australian brown coal is presented in Table 3-4. CCSEM analysis of the Illinois 6 SOAP by U. Kentucky is presented in Table 3-5. CCSEM analysis of the SOAP parent, also by $U$. Kentucky, is presented in Table 3-6. Note that this is a corrected version of Table 3-4 of the previous Quarterly Report (\#18). 
Table 3-1. Analysis of Blend and Blend Parent Coals

\begin{tabular}{|l|r|r|r|r|}
\hline & & & \multicolumn{1}{|c|}{$\begin{array}{c}70 / 30 \text { Blend } \\
\text { EB/Ky \#9 }\end{array}$} & $\begin{array}{c}\text { Calculated } \\
70 / 30 \text { Blend }\end{array}$ \\
\hline \hline Proximate & & & & \\
Moisture & 27.3 & 6.5 & 21.8 & 21.1 \\
Volatile Matter & 35.0 & 37.3 & 34.5 & 35.7 \\
Fixed Carbon & 33.5 & 42.3 & 36.3 & 36.2 \\
Ash & 4.2 & 13.8 & 7.3 & 7.1 \\
\hline Ultimate & & & & \\
$\mathrm{H}$ & 5.1 & 4.8 & 5.0 & 5.0 \\
$\mathrm{C}$ & 71.2 & 68.2 & 68.8 & 70.3 \\
$\mathrm{~N}$ & 0.87 & 1.3 & 1.0 & 1.0 \\
$\mathrm{~S}$ & 0.50 & 4.4 & 1.9 & 1.7 \\
$\mathrm{O}$ & 16.6 & 6.5 & 13.9 & 13.6 \\
\hline Ash & & & & \\
$\mathrm{SiO}_{2}$ & 23.8 & 41.5 & 30.1 & \\
$\mathrm{Al}_{2} \mathrm{O}_{3}$ & 14.0 & 18.1 & 15.1 & \\
$\mathrm{Fe}_{2} \mathrm{O}_{3}$ & 5.9 & 22.3 & 14.2 & \\
$\mathrm{TiO}_{2}$ & 1.3 & 0.59 & 0.86 & \\
$\mathrm{P}_{2} \mathrm{O}_{5}$ & 0.77 & 0.48 & 0.56 & \\
$\mathrm{CaO}^{\mathrm{MgO}}$ & 25.7 & 7.0 & 15.8 & \\
$\mathrm{Na}_{2} \mathrm{O}$ & 9.0 & 1.4 & 3.3 & \\
$\mathrm{~K}_{2} \mathrm{O}$ & 1.2 & 0.71 & 1.2 & \\
$\mathrm{SO}_{3}$ & 0.34 & 1.8 & 1.2 & \\
\hline${ }^{*}$ dry basis & 18.1 & 6.1 & 17.7 & \\
\hline
\end{tabular}


Table 3-2. 70/30 Eagle Butte/Kentucky \#9 Blend Coal Particle Size Distribution (Malvern analysis)

\begin{tabular}{|c|c|c||r|r|r|l|}
\hline $\begin{array}{c}\text { Size } \\
\text { Microns }\end{array}$ & Under & $\begin{array}{c}\% \text { in } \\
\text { Band }\end{array}$ & $\begin{array}{c}\text { Size } \\
\text { Microns }\end{array}$ & Under & $\begin{array}{c}\% \text { in } \\
\text { Band }\end{array}$ & \\
\hline \hline 188.0 & 100.0 & 0.7 & 17.7 & 34.4 & 3.5 & \\
162.0 & 99.3 & 2.1 & 15.3 & 30.9 & 3.0 & \\
140.0 & 97.2 & 3.2 & 13.2 & 27.9 & 2.4 & \\
121.0 & 94.0 & 4.4 & 11.4 & 25.5 & 2.9 & \\
104.0 & 89.6 & 5.0 & 9.8 & 22.6 & 3.9 & \\
89.9 & 84.6 & 5.8 & 8.5 & 18.6 & 3.7 & \\
77.5 & 78.8 & 5.9 & 7.3 & 15.0 & 2.6 & \\
66.9 & 72.9 & 5.5 & 6.3 & 12.4 & 1.6 & \\
57.7 & 67.4 & 4.5 & 5.4 & 10.8 & 1.5 & $\mathrm{D}(\mathrm{v}, 0.5)=31.4 \mu \mathrm{m}$ \\
49.8 & 62.8 & 3.8 & 4.7 & 9.2 & 2.3 & $\mathrm{D}(\mathrm{v}, 0.9)=105.3 \mu \mathrm{m}$ \\
42.9 & 59.0 & 3.8 & 4.1 & 6.9 & 2.8 & $\mathrm{D}(\mathrm{v}, 0.1)=5.0 \mu \mathrm{m}$ \\
37.1 & 55.2 & 4.6 & 3.5 & 4.1 & 2.0 & $\mathrm{D}(4,3)=43.5 \mu \mathrm{m}$ \\
32.0 & 50.6 & 4.6 & 3.0 & 2.1 & 0.9 & $\mathrm{D}(3,2)=15.7 \mu \mathrm{m}$ \\
27.6 & 46.0 & 4.0 & 2.6 & 1.2 & 0.6 & \\
23.8 & 42.1 & 3.8 & 2.2 & 0.5 & 0.2 & \\
20.5 & 38.2 & 3.8 & 1.9 & 0.4 & & \\
\hline
\end{tabular}


Table 3-3. Analysis ${ }^{\dagger}$ of Phase I Eagle Butte and Kentucky \#9

\begin{tabular}{|l|r|r|}
\hline & $\begin{array}{c}\text { Fagle } \\
\text { Butte }\end{array}$ & $\begin{array}{c}\text { Kentucky } \\
\$ 9\end{array}$ \\
\hline \hline Proximate & & \\
Moisture & 25.2 & 8.3 \\
Volatile Matter & 33.8 & 34.5 \\
Fixed Carbon & 36.2 & 42.9 \\
Ash & 4.8 & 14.3 \\
\hline Ultimate & & \\
$\mathrm{H}$ & & 4.7 \\
$\mathrm{C}$ & 67.2 & 65.4 \\
$\mathrm{~N}$ & 1.4 & 1.8 \\
$\mathrm{~S}$ & 0.46 & 3.9 \\
$\mathrm{O}$ & 19.5 & 8.6 \\
\hline Ash & & \\
$\mathrm{SiO}_{2}$ & 28.4 & 44.6 \\
$\mathrm{Al}_{2} \mathrm{O}_{3}$ & 15.5 & 20.6 \\
$\mathrm{Fe}_{2} \mathrm{O}_{3}$ & 6.1 & 22.4 \\
$\mathrm{TiO}_{2}$ & 0.9 & 1.1 \\
$\mathrm{P}_{2} \mathrm{O}_{5}$ & 0.7 & 0.1 \\
$\mathrm{CaO}^{\mathrm{MgO}}$ & 26.4 & 3.1 \\
$\mathrm{Na}_{2} \mathrm{O}$ & 6.2 & 1.1 \\
$\mathrm{~K}_{2} \mathrm{O}$ & 2.0 & 0.9 \\
$\mathrm{SO}_{3}$ & 0.2 & 2.6 \\
\hline${ }_{\text {analysis by R. Bryers, }}$ & Foster-Wheeler \\
dry basis & & \\
\hline
\end{tabular}


Table 3-4. Analysis of Illinois \#6, SOAP, and Loy Yang 1953 Coals

\begin{tabular}{|c|c|c|c|}
\hline & $\begin{array}{c}\text { Illinois \#6 } \\
\text { Parent }\end{array}$ & $\begin{array}{c}\text { Illinois \#6 } \\
\text { SOAP }\end{array}$ & $\begin{array}{c}\text { Loy Yang } \\
1953\end{array}$ \\
\hline $\begin{array}{l}\text { Proximate } \\
\text { Moisture } \\
\text { Volatile Matter } \\
\text { Fixed Carbon } \\
\text { Ash }\end{array}$ & $\begin{array}{r}11.1 \\
34.7 \\
45.8 \\
8.4\end{array}$ & $\begin{array}{r}23.2 \\
31.4 \\
42.6 \\
2.8\end{array}$ & $\begin{array}{r}31.5 \\
36.1 \\
30.4 \\
2.0\end{array}$ \\
\hline $\begin{array}{c}\text { Ultimate } \\
\mathbf{H} \\
\mathbf{C} \\
\mathbf{N} \\
\mathbf{S} \\
\mathbf{O} \\
\mathrm{Cl}^{\dagger}\end{array}$ & $\begin{array}{r}4.9 \\
68.3 \\
1.2 \\
3.3 \\
12.9 \\
-\end{array}$ & $\begin{array}{r}5.3 \\
75.3 \\
1.4 \\
2.9 \\
11.4\end{array}$ & $\begin{array}{c}4.6 \\
64.2 \\
0.85 \\
0.40 \\
27.0 \\
0.25\end{array}$ \\
\hline $\begin{array}{c}\text { Ash }^{*} \\
\mathrm{SiO}_{2} \\
\mathrm{Al}_{2} \mathrm{O}_{3} \\
\mathrm{Fe}_{2} \mathrm{O}_{3} \\
\mathrm{TiO}_{2} \\
\mathrm{P}_{2} \mathrm{O}_{5} \\
\mathrm{CaO} \\
\mathrm{MgO} \\
\mathrm{Na}_{2} \mathrm{O} \\
\mathrm{K}_{2} \mathrm{O} \\
\mathrm{SO}_{3}\end{array}$ & $\begin{array}{r}50.6 \\
21.6 \\
18.4 \\
0.9 \\
0.0 \\
2.1 \\
1.2 \\
0.5 \\
2.1 \\
2.2\end{array}$ & $\begin{array}{r}39.0 \\
18.6 \\
27.1 \\
2.7 \\
0.2 \\
3.6 \\
1.4 \\
1.4 \\
2.4 \\
3.5\end{array}$ & $\begin{array}{r}11.8 \\
5.2 \\
15.9 \\
0.3 \\
0.5 \\
3.4 \\
22.2 \\
13.5 \\
0.7 \\
26.5\end{array}$ \\
\hline
\end{tabular}




\section{SECTION 4}

Task 3

\section{ADVANCED TECHNIQUES FOR COAL, MINERAL, AND ASH CHARACTERIZATION}

F.E. Huggins, N. Shah, and G.P. Huffman

University of Kentucky 


\section{ADVANCED TECHNIQUES FOR COAL, MINERAL, AND ASH CHARACTERIZATION}

\section{$4.1 \quad$ Introduction}

This quarter has been largely devoted to obtaining CCSEM and other data for various mineral standards and for ash samples collected in combustion tests performed on Beulah and Loy Yang coals in the combustion units at the University of Arizona and the Research Laboratories of the State Electricity Commission of Victoria (SECV), Australia. In addition, some new findings are reported for ash samples prepared in the PSI drop-tube using Beulah coal in which potassium had been ion-exchanged for carboxyl-bound calcium. In late July, XAFS data were obtained at the $\mathrm{Cl}, \mathrm{Ca}$, and $\mathrm{K} \mathrm{K}$-edges for some 30 samples; at this time, data will be presented only for chlorine in Loy Yang coals and ashes and the other data will be analyzed during the next quarter. Similarly, Mossbauer analysis has started on a large suite of ash samples; a preliminary account of these results is presented in this report in tabular form.

\section{CCSEM Characterization of Mineral Standards and Ash}

CCSEM analysis was carried out on two pure minerals and several ash samples. The pure minerals to be used as standards obtained from PSI were nepheline and montmorillonite. Analysis on three batches of ash samples were carried out. Two batches of Loy Yang (three samples) and Beulah lignite (two samples) ashes were collected in the nominal $35 \mathrm{~kg} / \mathrm{hr}$ pilot scale furnace of the SECV. These samples were extractive samples collected near the outlet of the radiant section of the SECV facility. Ash samples from three tests on Loy Yang coal collected at the electrostatic precipitation were also analyzed. Four ash samples of Beulah lignite coal that had been combusted in PSI's drop tube furnace under 7\% oxygen and at $1500^{\circ} \mathrm{C}$ for one and three seconds residence times, were also analyzed. For all the above samples CCSEM results are presented in tabular form in Tables 4-1 through 4-9.

CCSEM analysis has been carried out on two standard minerals, namely montmorillonite and nepheline. Ternary plots (number basis) of the abundant elements show the expected compositional characteristics of each mineral (Ca-aluminosiclicate phase and $\mathrm{Na}-\mathrm{K}$ aluminosilicate phase, respectively). But the CCSEM data also showed the presence of impurities. Potassium and iron were the principal impurities in montmorillonite, where as a calcium-containing phase was the principal impurity in nepheline. However, both the K-Al$\mathrm{Si}$ and the Fe-Al-Si plots (Figure 4-1) for montmorillonite have an Al:Si composition identical to that of the Ca-Al-Si phase shown in Figure 4-2 and only a very minor amount of iron or potassium. These observations would appear to imply that the montmorillonite may contain significant potassium and iron in addition to calcium. For nepheline, the $\mathrm{Ca}-\mathrm{Al}-\mathrm{Si}$ ternary plot indicates a composition near $\mathrm{CaAl}_{2} \mathrm{Si}_{2} \mathrm{O}_{8}$, suggestive of anorthite, Ca feldspar (Figure 4-3). Such a separate phase was noted in a manual SEM examination of the nepheline sample. The K-Al-Si ternary plot for nepheline is shown in Figure 4-4. A second $\mathrm{K}$-Al-Si phase appears to be present as indicated by the small cluster of points to the right of the main cluster. The Na-Al-Si ternary diagram for nepheline is shown in Figure 4-5. 
Table 4-1. Sample 593 Loy Yang Test 1 Ash Probe (ring 7), Untreated Total particels 1199

Species Volume $\% \quad 0.0-2.5 \quad 2.5-5.0 \quad 5.0-10 . \quad 10 .-20.20 .-40.40 .-80.80 .-500$.

$\begin{array}{lrrrrrrrr}\text { Al Ca Mg } & 11.6 & 17 & 58 & 20 & 6 & 1 & 0 & 0 \\ \text { Si Al Ca } & 4.4 & 21 & 51 & 17 & 4 & 2 & 5 & 0 \\ \text { Al Mg Ca } & 15.2 & 30 & 41 & 17 & 12 & 0 & 0 & 0 \\ \text { Mg Ca Al } & 7.0 & 18 & 60 & 21 & 2 & 0 & 0 & 0 \\ \text { Others } & 11.3 & 26 & 36 & 22 & 16 & 0 & 0 & 0 \\ \text { Others } & 50.6 & 25 & 30 & 26 & 11 & 6 & 2 & 0\end{array}$

$\begin{array}{lllllllll}\text { Totals } & 100 . & 24 & 39 & 23 & 10 & 3 & 1 & 0\end{array}$

Table 4-2. Sample 594 Loy Yang Test 4 Ash Probe (Horizontal Duct), Untreated Total particels 1199

Species Volume $\% \quad 0.0-2.5 \quad 2.5-5.0 \quad 5.0-10 . \quad 10 .-20.20 .-40.40 .-80.80 .-500$.

$\begin{array}{lrrrrrrrr}\text { Si } & 12.2 & 1 & 12 & 10 & 40 & 28 & 10 & 0 \\ \text { Al Mg Ca } & 8.7 & 33 & 51 & 14 & 1 & 1 & 0 & 0 \\ \text { Mg Ca Al } & 5.3 & 21 & 52 & 23 & 4 & 0 & 0 & 0 \\ \text { Al Ca Mg } & 5.6 & 17 & 58 & 14 & 12 & 0 & 0 & 0 \\ \text { Others } & 10.3 & 39 & 37 & 12 & 12 & 0 & 0 & 0 \\ \text { Others } & 57.8 & 21 & 34 & 23 & 15 & 6 & 1 & 0 \\ & & & & & & & & \\ \text { Totals } & 100 . & 21 & 35 & 19 & 16 & 7 & 2 & 0\end{array}$

Table 4-3. Sample 595 Loy Yang Test 3 Ash Probe (Horizontal Duct), Treated Total particels 1199

Species Volume \% $0.0-2.5$ 2.5-5.0 5.0-10. 10.-20. 20.-40. 40.-80. 80.-500.

$\begin{array}{lrrrrrrrr}\mathrm{Si} & \mathbf{4 . 3} & 1 & 15 & 14 & 44 & 18 & 7 & 0 \\ \mathrm{Al} \mathrm{Zn} \mathrm{Ca} & \mathbf{5 . 0} & 12 & 40 & 32 & 15 & 1 & 0 & 0 \\ \mathrm{Al} \mathrm{Zn} \mathrm{Mg} & 9.0 & 20 & 37 & 32 & 12 & 0 & 0 & 0 \\ \text { Al Zn S } & 5.5 & 21 & 33 & 36 & 9 & 0 & 0 & 0 \\ \text { Al Zn Fe } & \mathbf{6 . 6} & 26 & 21 & 44 & 9 & 0 & 0 & 0 \\ \text { Al Zn Si } & 7.8 & 33 & 27 & 34 & 6 & 0 & 0 & 0 \\ \text { Others } & 11.7 & 23 & 28 & 26 & 24 & 0 & 0 & 0 \\ \text { Others } & 50.2 & 23 & 18 & 31 & 20 & 7 & 3 & 0 \\ \text { Totals } & 100 . & 22 & 23 & 31 & 18 & 4 & 2 & 0\end{array}$


Table 4-4. Sample 596 Beulah Lignite Ash Probe (Comb. Chamber)

Total particels 1199

Species Volume $\% \quad 0.0-2.5 \quad 2.5-5.0 \quad 5.0-10.10 .-20.20 .-40.40 .-80.80 .-500$.

$\begin{array}{lrrrrrrrr}\mathrm{Ca} & 6.1 & 6 & 12 & 27 & 46 & 8 & 0 & 0 \\ \mathrm{Fe} & 5.1 & 11 & 64 & 17 & 7 & 2 & 0 & 0 \\ \mathrm{Si} \mathrm{Al} & 4.8 & 2 & 45 & 23 & 22 & 8 & 0 & 0 \\ \mathrm{Ca} \mathrm{S} & 6.7 & 6 & 24 & 27 & 33 & 10 & 0 & 0 \\ \mathrm{Ca} \mathrm{Si} \mathrm{Al} & 6.4 & 12 & 60 & 17 & 6 & 5 & 0 & 0 \\ \mathrm{Si} \mathrm{Al} \mathrm{Ca} & 9.2 & 26 & 26 & 13 & 31 & 5 & 0 & 0 \\ \mathrm{Si} \mathrm{Al} \mathrm{Na} & 12.1 & 42 & 38 & 12 & 7 & 1 & 0 & 0 \\ \text { Ca S Fe } & 4.4 & 5 & 53 & 25 & 17 & 0 & 0 & 0 \\ \text { Others } & 45.2 & 20 & 46 & 21 & 11 & 2 & 0 & 0 \\ \text { Totals } & 100 . & 19 & 42 & 20 & 16 & 4 & 0 & 0\end{array}$

Table 4-5. Sample 597 Beulah Lignite Ash Probe (Horizontal Duct)

Total particels 1199

Species Volume \% $0.0-2.5$ 2.5-5.0 5.0-10. 10.-20. 20.-40. 40.-80. 80.-500.

$\mathrm{Si} \mathrm{Al} \mathrm{Ca}$

$\mathrm{CaS}$

9.1

13

56

28

3

$\begin{array}{lll}0 & 0 & 0\end{array}$

Si Al Na

6.6

640

$31 \quad 23$

$0 \quad 0$

$\mathrm{Ca}$

11.2

20

54

20

6

$5 \quad 45$

33

16

0

0

Others

69.0

15

48

32

5

0

0

Totals

100.

15

49

30

7

0

$0 \quad 0$

Table 4-6. Sample 548 PSI Beulah Ash Without Ion Exchange, 1s Residence Time Total particles 1199

Species Volume $\% \quad 0.0-2.5 \quad 2.5-5.0 \quad 5.0-10$. 10.-20. 20.-40. 40.-80. 80.-500.

$\begin{array}{lrrrrrrrr}\mathrm{Si} \mathrm{Al} \mathrm{Ca} & 10.1 & 30 & 18 & 30 & 16 & 6 & 0 & 0 \\ \mathrm{Si} \mathrm{Al} & 4.7 & 27 & 38 & 23 & 10 & 3 & 0 & 0 \\ \mathrm{Ca} \mathrm{Si} \mathrm{Al} & 31.3 & 19 & 31 & 36 & 12 & 1 & 1 & 0 \\ \mathrm{Ca} \mathrm{S} \mathrm{Si} & 4.2 & 24 & 12 & 46 & 16 & 2 & 0 & 0 \\ \mathrm{Si} \mathrm{Ca} \mathrm{Al} & 4.9 & 34 & 22 & 39 & 3 & 3 & 0 & 0 \\ \mathrm{Ca} \mathrm{S} & 5.4 & 6 & 33 & 26 & 32 & 3 & 0 & 0 \\ \mathrm{Ca} & 7.7 & 7 & 19 & 36 & 33 & 4 & 1 & 0 \\ \text { Others } & 31.5 & 25 & 19 & 33 & 17 & 5 & 1 & 0 \\ \text { Totals } & 99.8 & 22 & 24 & 34 & 16 & 3 & 1 & 0\end{array}$


Table 4-7. Sample 549 PSI Beulah Ash Without Ion Exchange, 3s Residence time Total particles 1199

Species Volume $\% \quad 0.0-2.5 \quad 2.5-5.0 \quad 5.0-10.10 .-20.20 .-40.40 .-80.80 .-500$.

$\begin{array}{lrrrrrrrr}\text { Ca Si Al } & 38.6 & 38 & 45 & 12 & 3 & 1 & 0 & 0 \\ \text { Si Al Ca } & 12.7 & 40 & 34 & 10 & 6 & 5 & 4 & 0 \\ \text { Ca } & 12.1 & 7 & 65 & 11 & 11 & 5 & 0 & 0 \\ \text { Si Al Na } & 6.7 & 34 & 49 & 9 & 6 & 2 & 0 & 0 \\ \text { Si Ca Al } & 7.2 & 34 & 46 & 8 & 4 & 0 & 2 & 6 \\ \text { Others } & 22.6 & 21 & 37 & 16 & 13 & 9 & 4 & 0 \\ \text { Totals } & 99.9 & 30 & 45 & 12 & 7 & 4 & 2 & 0\end{array}$

Table 4-8. Sample 550 PSI Beulah Ash With Ion Exchange, 1s Residence Time Total particles 1199

Species Volume \% $\quad 0.0-2.5 \quad 2.5-5.0 \quad 5.0-10$. 10.-20. 20.-40. 40.-80. 80.-500.

$\begin{array}{lrrrrrrrr}\text { Ca K Si } & 6.2 & 7 & 7 & 34 & 42 & 10 & 0 & 0 \\ \text { Ca Si K } & 7.5 & 11 & 31 & 25 & 20 & 12 & 0 & 0 \\ \text { Ca Si Al } & 12.8 & 22 & 42 & 16 & 17 & 2 & 2 & 0 \\ \text { Si Al K } & 6.5 & 26 & 34 & 11 & 20 & 7 & 3 & 0 \\ \text { Ca K S } & 10.7 & 7 & 19 & 38 & 34 & 3 & 0 & 0 \\ \text { Ca } & 5.1 & 9 & 33 & 25 & 23 & 10 & 0 & 0 \\ \text { Ca S K } & 4.3 & 19 & 28 & 37 & 14 & 1 & 0 & 0 \\ \text { Others } & 46.8 & 16 & 28 & 21 & 21 & 10 & 4 & 0 \\ \text { Totals } & 100 . & 15 & 28 & 24 & 23 & 8 & 2 & 0\end{array}$

Table 4-9. Sample 551 PSI Beulah Ash With Ion Exchange, 3s Residence Time Total particels 1199

Species Volume \% $\quad 0.0-2.5 \quad 2.5-5.0 \quad 5.0-10.10 .-20.20 .-40.40 .-80.80 .-500$.

$\begin{array}{lrrrrrrrr}\text { K Si Al } & 14.4 & 27 & 37 & 12 & 7 & 9 & 5 & 2 \\ \text { Ca Si K } & 4.1 & 9 & 22 & 18 & 26 & 12 & 6 & 7 \\ \text { Si K Al } & 4.1 & 23 & 35 & 12 & 4 & 11 & 4 & 12 \\ \text { Ca } & 4.2 & 23 & 45 & 21 & 0 & 9 & 2 & 0 \\ \text { K Ca S } & 4.2 & 5 & 0 & 20 & 45 & 11 & 18 & 0 \\ \text { Ca Si Al } & 20.3 & 22 & 43 & 16 & 8 & 6 & 3 & 1 \\ \text { Others } & 48.7 & 11 & 21 & 17 & 21 & 11 & 14 & 5 \\ \text { Totals } & 100 . & 16 & 29 & 16 & 16 & 10 & 9 & 4\end{array}$



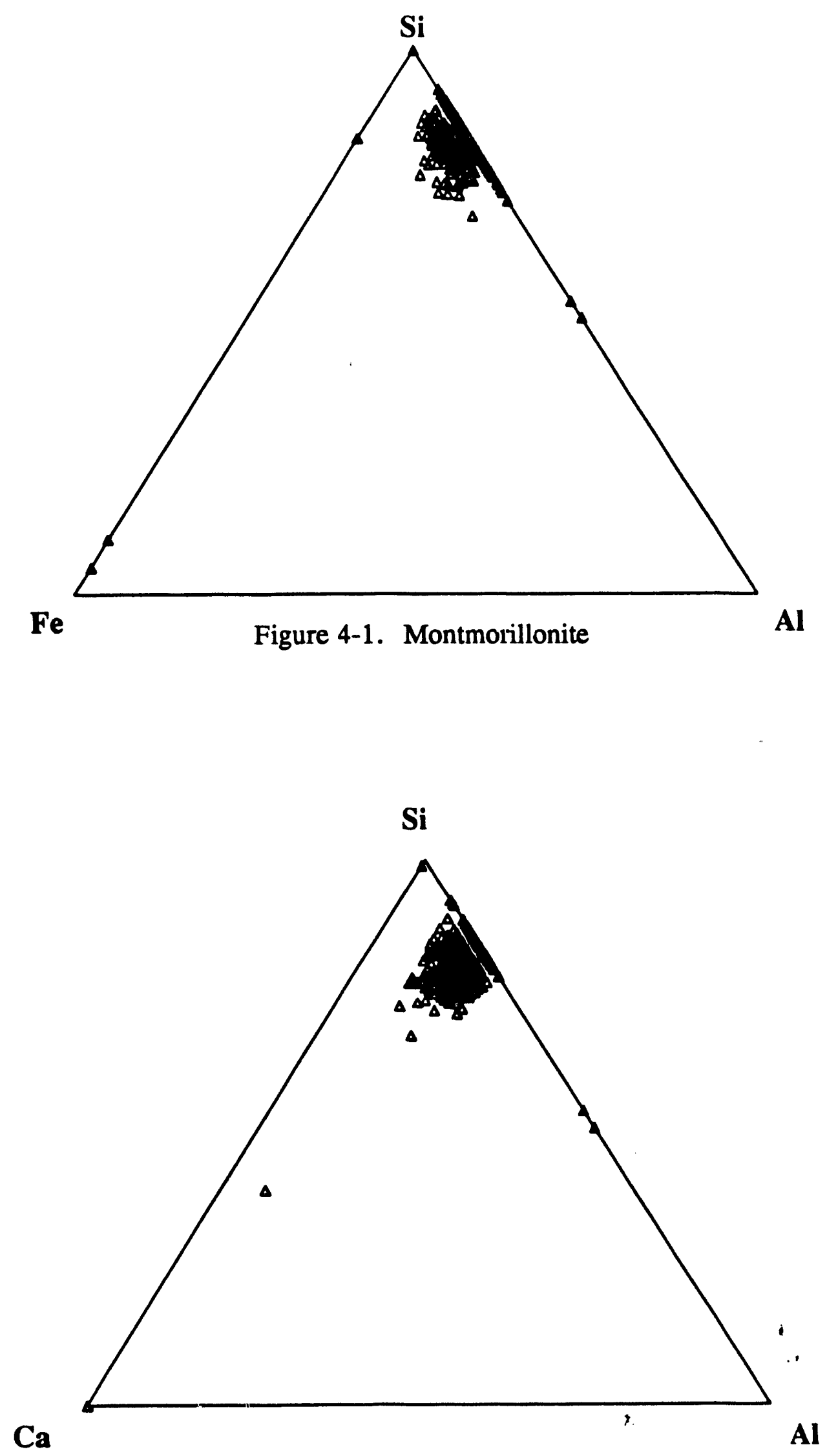

Figure 4-2. Montmorillinite 


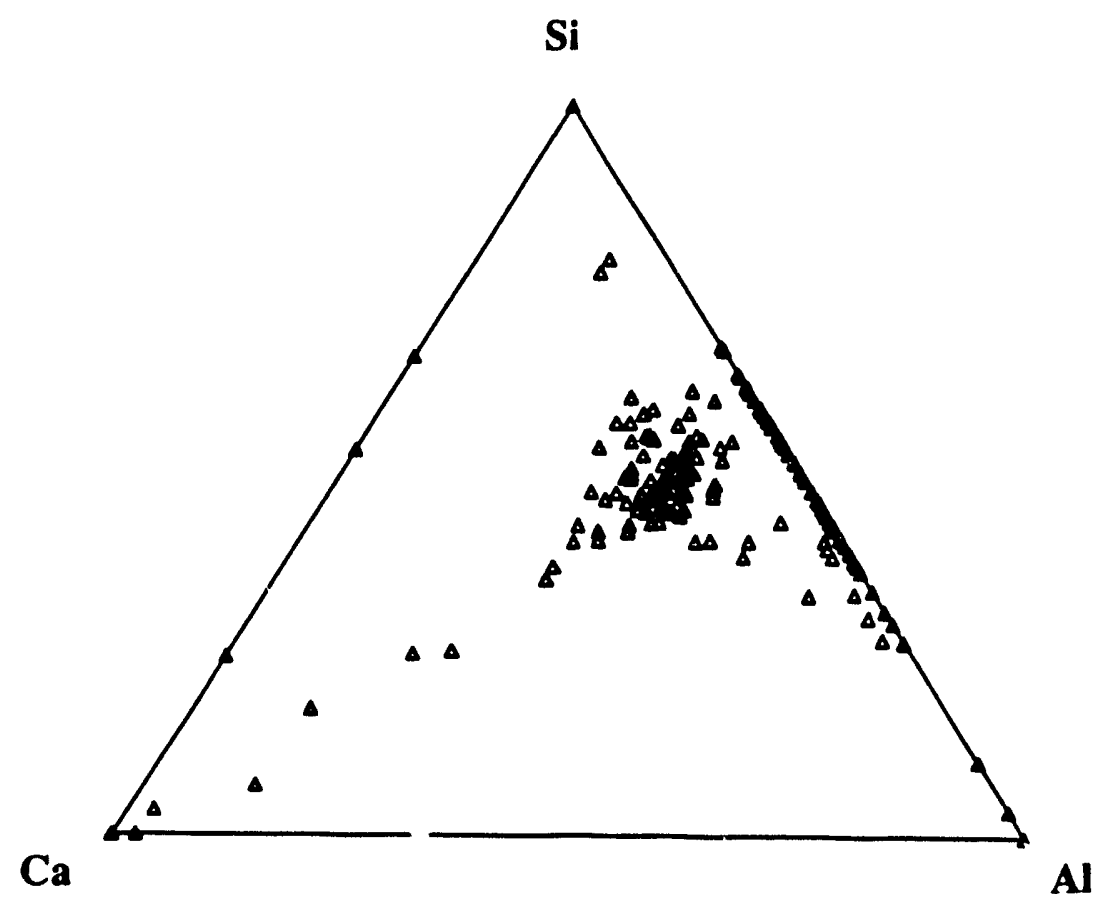

Figure 4-3. Nepheline

Further discussion of the nepheline sample is presented below in connection with ash samples of potassium ion-exchanged Beulah coal.

In addition, CCSEM was carried out on several ash samples. Beulah lignite ash probe samples obtained from the combustion chamber and from the horizontal duct of the SECV pilot-scale combustion unit showed the formation of a prominent nepheline phase (NaAl-Si phase, Figure 4-6), similar to that seen previously in samples from smaller scale furnaces. Calcium, which is derived from the carboxyl group in the coal, forms a Ca-S phase (probably $\mathrm{CaSO}_{4}$ ) with little or no interaction with iron (pseudo 3D plots, number basis, Figures 4-7 and 4-8). The ash obtained from the combustion chamber showed less mixing between the $\mathrm{Fe}$-rich and $\mathrm{Ca}-\mathrm{S}$ rich phases as compared to the ash obtained from the horizontal duct.

Both of the untreated Loy Yang coal ashes from test 1 and test 4 show similar distribution of a $\mathrm{Mg}+\mathrm{Al}$ rich phase. The $\mathrm{Mg}+\mathrm{Al}-\mathrm{Si}-\mathrm{Ca}$ ternary plots for both of the untreated coals are shown in Figures 4-9 and 4-10. A substantial amount of quartz was found in the test 4 ash sample of the unreacted coal collected from the horizontal duct, whereas that pure mineral phase was not present in the test 1 ash sample. The ternary plots appear to show the absence of aluminosilicates (clays) in this coal. A lot of zinc contamination was found in the treated Loy Yang coal ash sample that was collected from the ash probe of the horizonial duct. Figure 4-11 and Table 4-3 show that the contamination of zinc is virtually throughout the whole sample.

Sample preparation procedure modifications are now completed and checked for consistency in the results. We are currently in the process of running different coals supplied by PSI. 


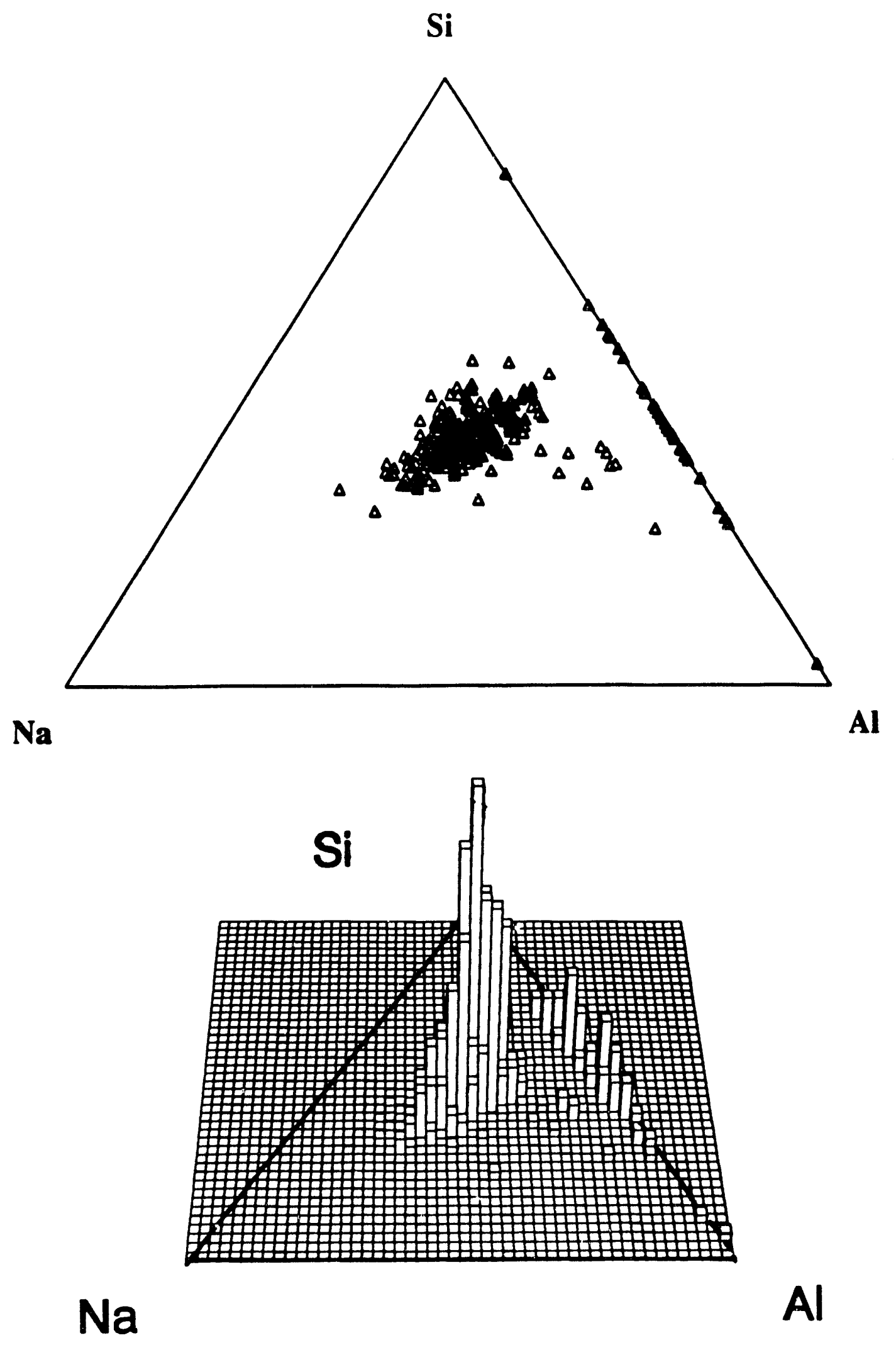

Figure 4-4. Nepheline 

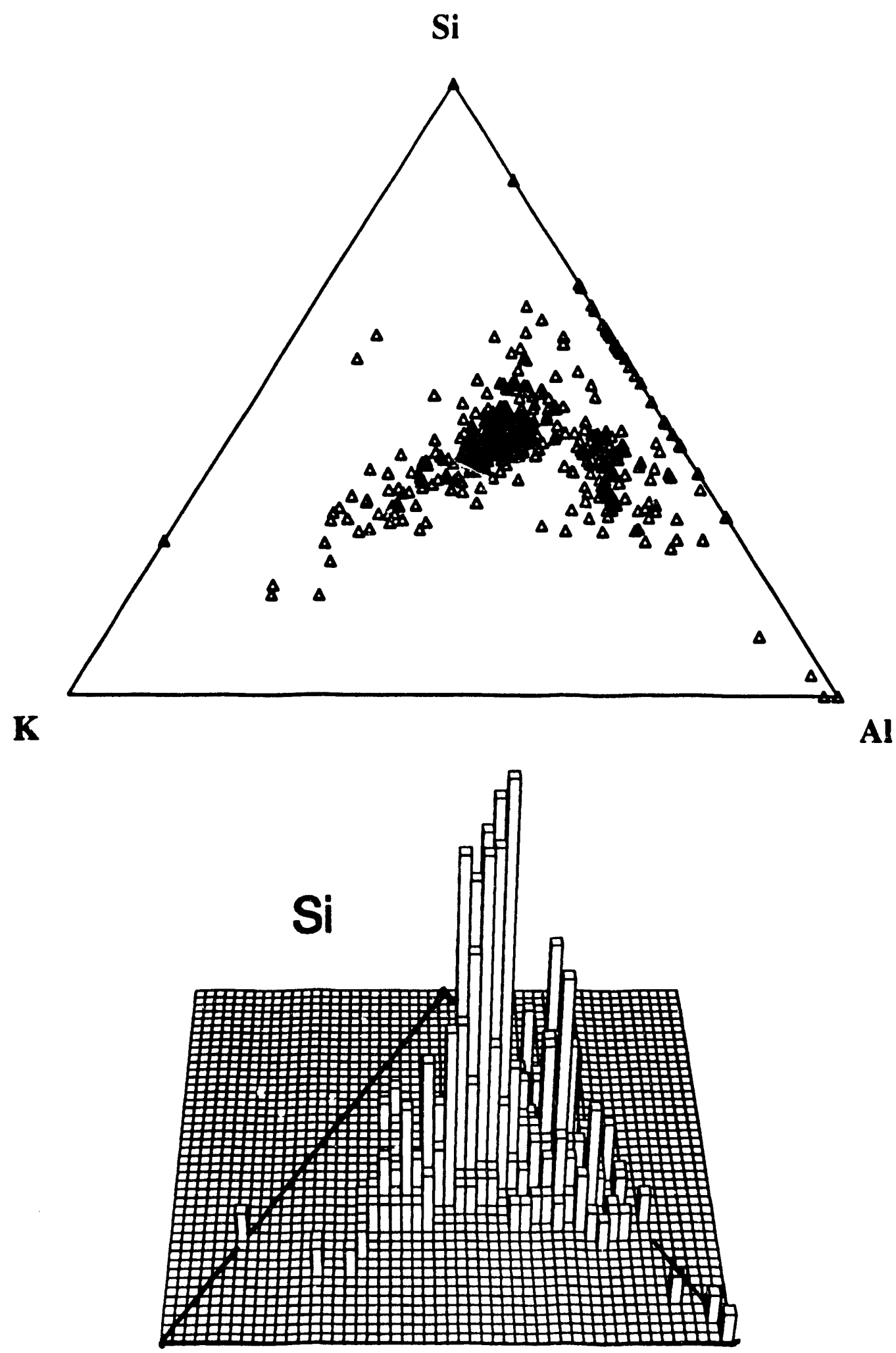

K

Figure 4-5. Nepheline 


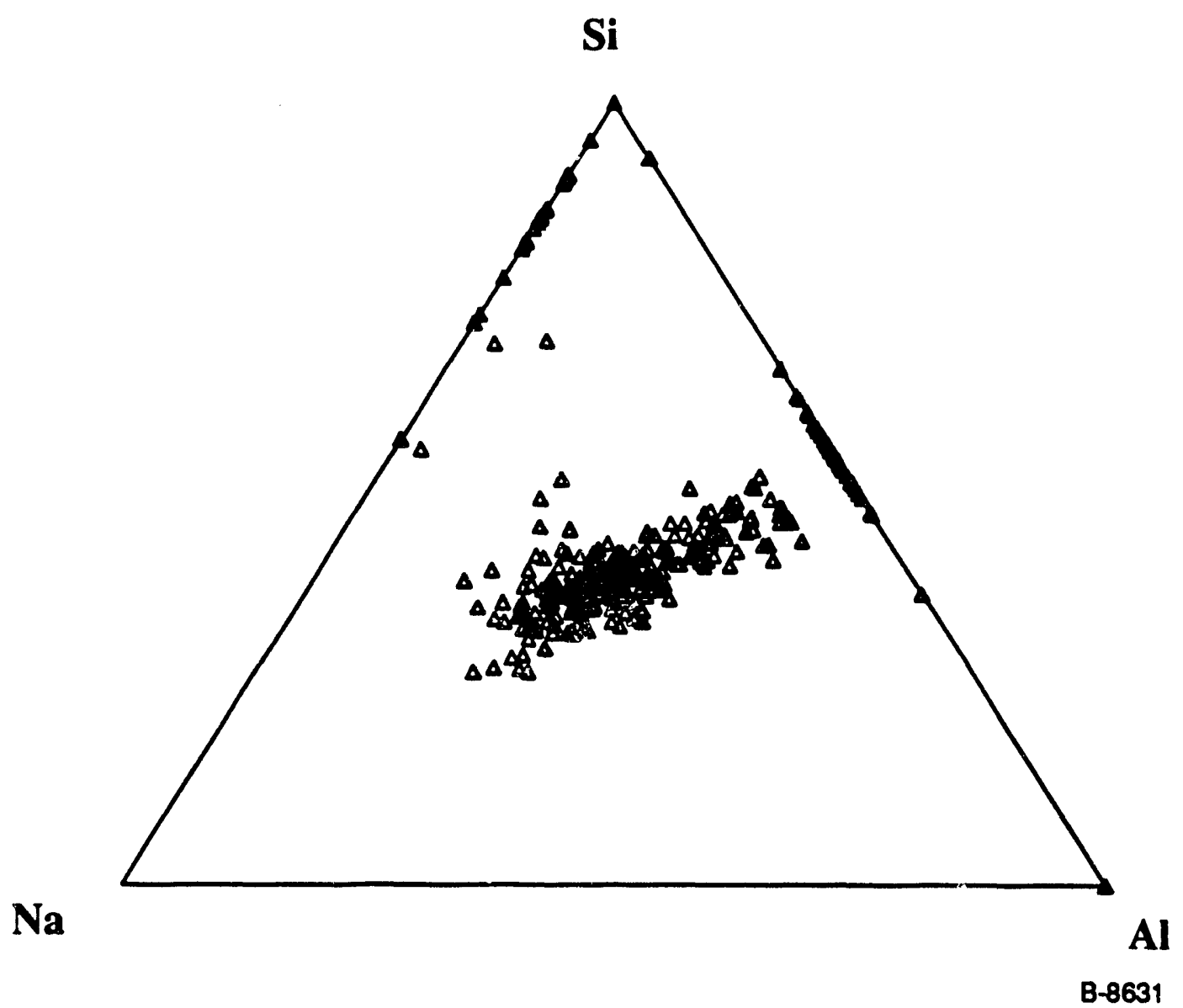

Figure 4-6. Beulah Lignite Ash Probe (Comb. Chamber)

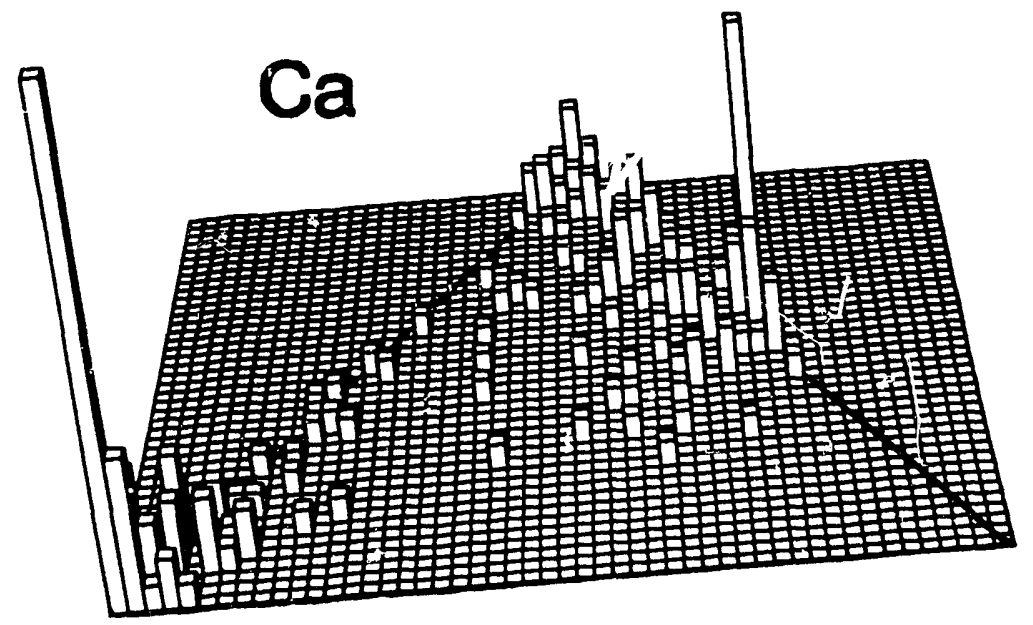

$\mathrm{Fe}$

Figure 4-7. Beulah Lignite Ash Probe (Comb. Chamber) 


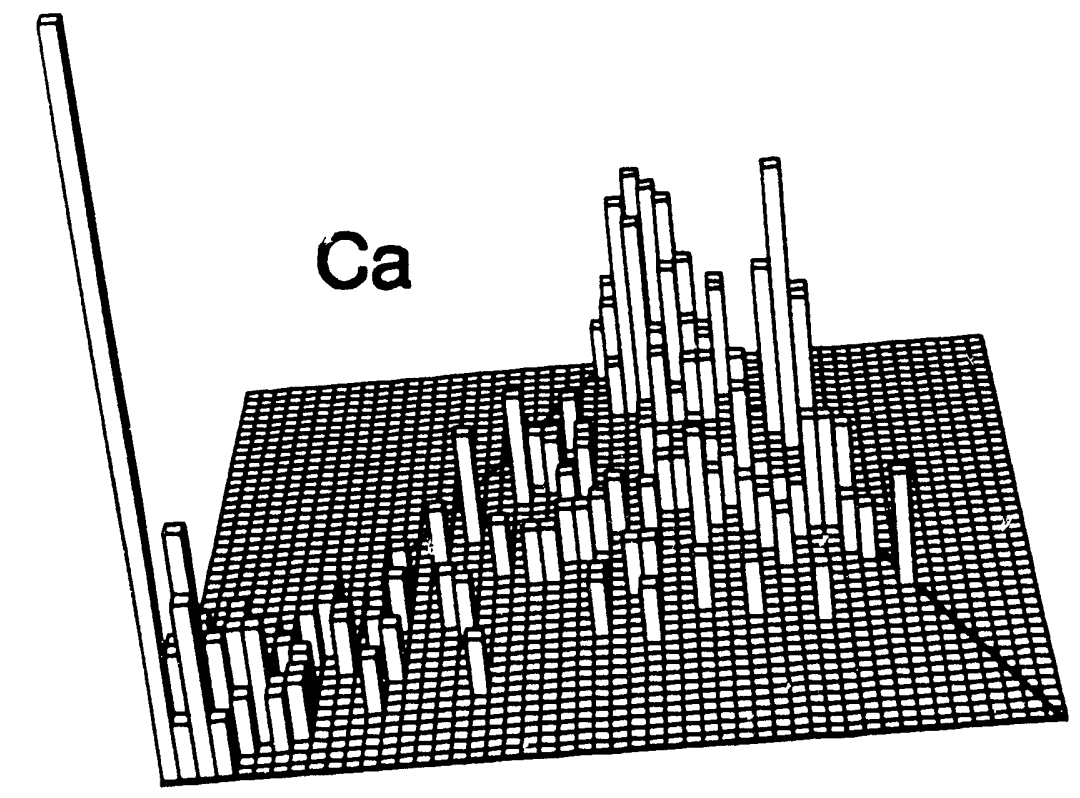

$\mathrm{Fe}$

B-8633

Fiugre 4-8. Beulah Lignite Ash Probe (Horizontal Duct)

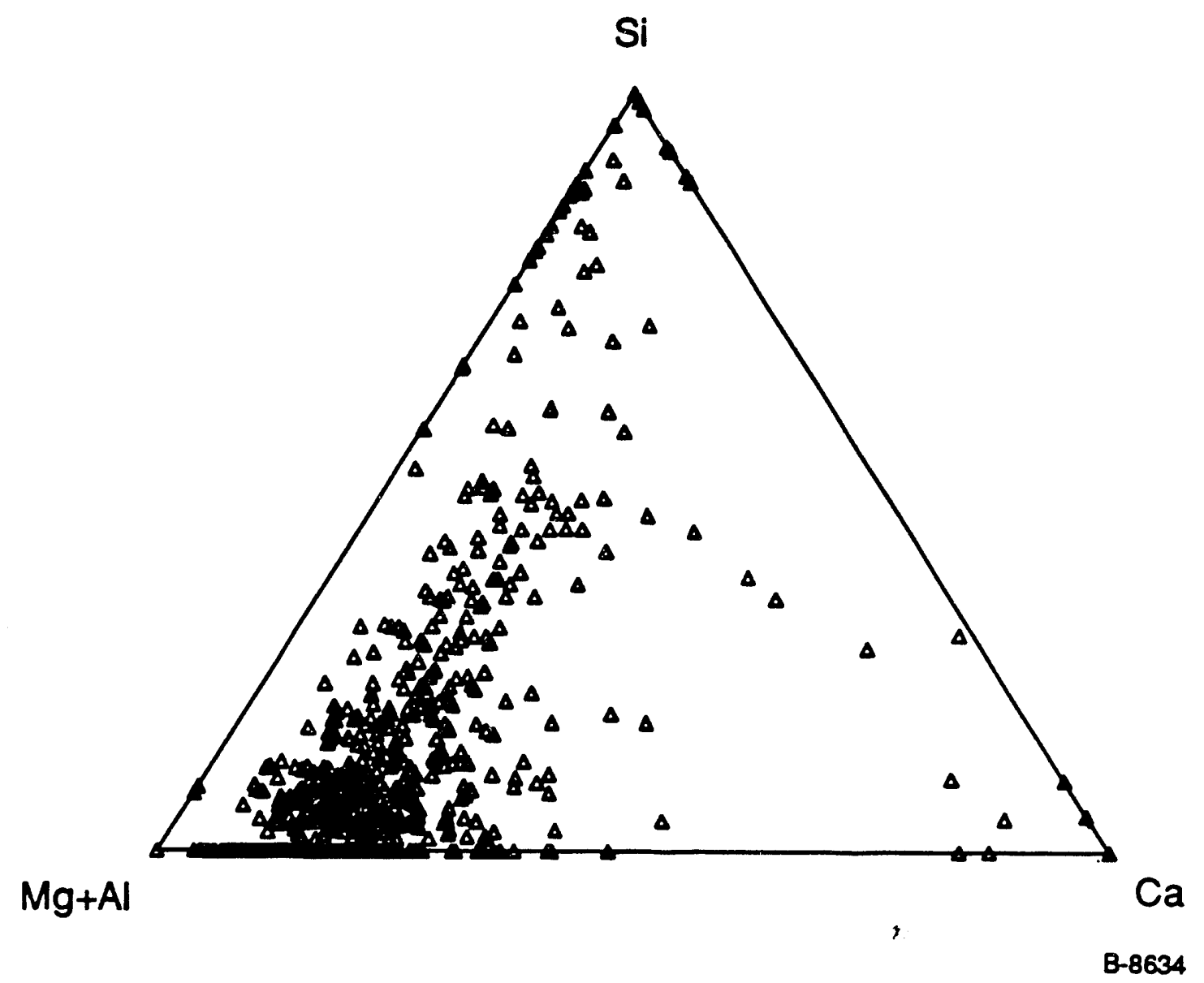

Figure 4-9. Loy Yang Test 1 Ash Probe (ring 7), Untreated 


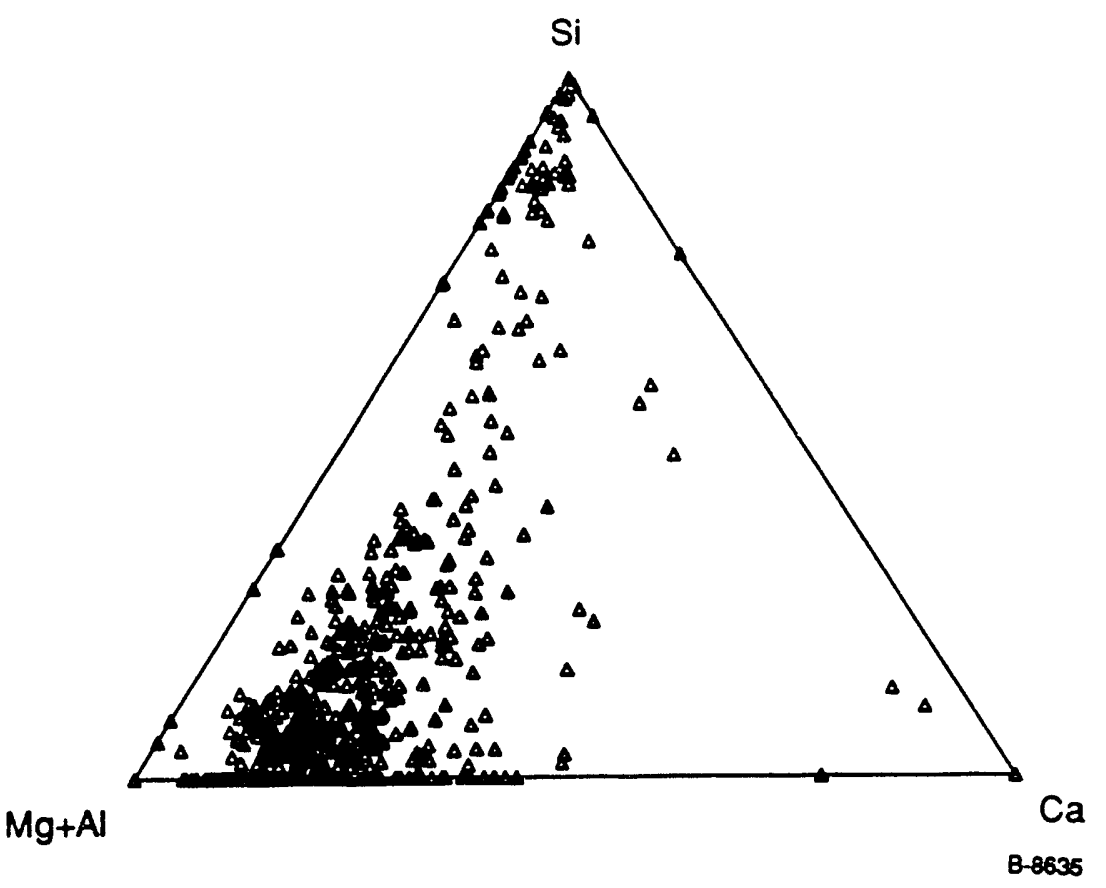

Figure 4-10. Loy Yang Test 4 Ash Probe (Horizontal Duct), Untreated

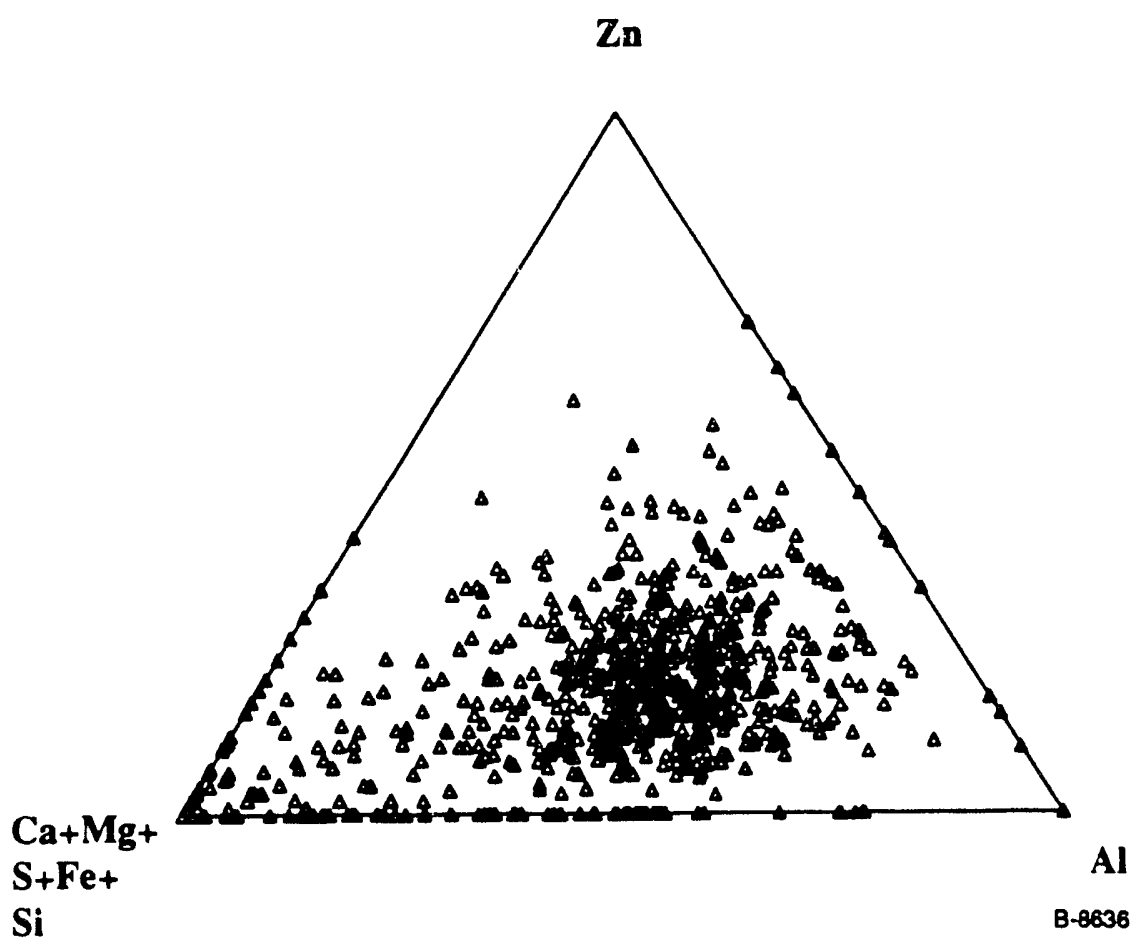

Figure 4-11. Loy Yang Test 3 Ash Probe (Horizontal Duct), Treated 


\section{XAFS Analysis}

In our last XAFS run at the National Synchrotron Light Source (NSLS) (7/21-7/29), we acquired data on several samples from the University of Arizona, MIT and PSI/SECV. A short list of samples for which data was collected is as follows:

Ca XAFS:

Beulah lignite coal and combustion chamber ash probe deposit of Beulah coal from PSI/SECV test run

MIT synthetic chars with $\mathrm{Ca}$ loading (7 samples with varying particle size, furnace temperature and residence times)

- University of Arizona burns of Beulah (48-B and 48-F), Ill \#6 (47-B and 47-F), and Ill \#6 SOAP (51-B). All samples were from cup and impactor \#1. These samples were classified as high priority by University of Arizona.

\section{K XAFS:}

MIT synthetic chars with $\mathrm{K}$ loading (14 samples with varying particle size, furnace temperature and residence times)

- University of Arizona burns of IIl \#6 and Ill \#6 SOAP coals (47-B, 47-F and 51-B). These samples were also from cup and impactor \#1.

\section{Cl XAFS:}

Untreated (tests 1 and 4) and $\mathrm{Mg} / \mathrm{Al}$ treated Loy Yang coal and their respective precipitator ashes from PSI/SECV test runs

- University of Arizona burn of Loy Yang 2301 coal (49-B)

We were planning to carry out some additional high temperature in-situ XAFS studies on the ash but due to shortage of beam time were unable to do so. We have scheduled such high temperature experiments during our upcoming beam time assignment in the first week of November. We are currently analyzing the $\mathrm{Ca}$ and $\mathrm{K}$ XAFS data collected during our last run and will provide the complete set of results in the next report.

\section{XAFS of Loy Yane coals and ashes}

Figure 4-12 shows the Cl XANES of Loy Yang coals used for three tests carried out during PSI/SECV test run. Cl XANES of untreated Loy Yang coals used in tests \#1 and \#4 show a good similarity between themselves and with the $\mathrm{Cl}$ XANES for $\mathrm{NaCl}$ solution. $\mathrm{Cl}$ XANES of treated Loy Yang coal, besides providing weaker signal, shows some similarity 


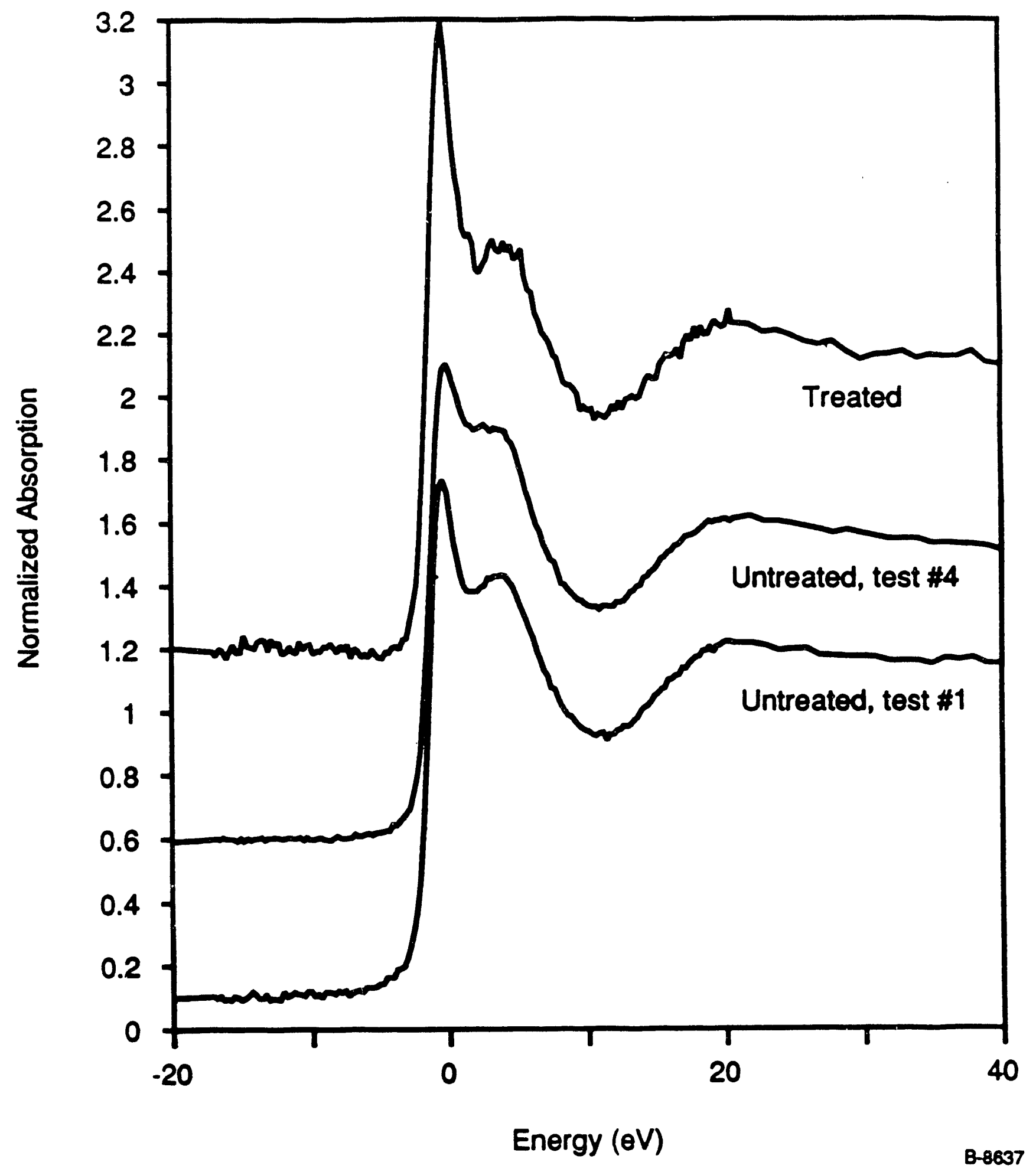

Figure 4-12. Cl XANES of Loy Yang Coals 
with the $\mathrm{NaCl}$ solution. There also appears to be some other form of $\mathrm{Cl}$ present in this sample. Unfortunately, due to poor signal/noise ration, we are unable to positively identify the other phase present.

Figure 4-13 shows the Cl XANES of the ashes from the same three coals shown in Figure 4-12. Both the Cl XANES spectra for tests \#1 and \#4 show $\mathrm{Cl}$ present in crystalline $\mathrm{NaCl}$ form. It appears that water molecules surrounding the $\mathrm{NaCl}$ solution are driven off during the combustion process and the $\mathrm{NaCl}$ phase crystallizes without undergoing any major phase transformations. Treated Loy Yang coal ash also shows the presence of a crystalline $\mathrm{NaCl}$ phase. Our preliminary estimate is about $60 \%$ of the signal is due to $\mathrm{NaCl}$ phase and $40 \%$ of the signal is due to some other, yet unidentified, $\mathrm{Cl}$ phase.

Figure 4-14 shows the comparison of the Cl XANES of Loy Yang coal ashes from two different furnace locations of SECV/PSI test run and the ash from University of Arizona combustor. Ash probe deposits near ring 7 (test 1) show crystalline $\mathrm{NaCl}$ present while the horizontal duct ash probe (test 3 ) shows the presence of hydrous $\mathrm{NaCl}$ phase (similar to that in the original coal). This may be due to reabsorption or condensation of moisture by a hygroscopic chloride phase during sampling. Ash from University of Arizona combustor impactor 1 and cup also showed $\mathrm{Cl}$ present as the $\mathrm{Cl}$ solution phase. This sample visibly showed a lot of unburnt coal and char present and the Cl XAFS signal (which is very similar to that of coal) may be from remaining coal or from condensation of water on the sample.

\section{Further Analysis of Potassium Ion-Exchanged Beulah Ash Samples}

In last quarter's report, we discussed the potassium K-edge XANES spectra of potassium in ash samples that had been prepared from Beulah coal in which potassium had been ion-exchanged for calcium. It was noted that the potassium XANES spectra were distinctly different from those of ashes of bituminous coals in which potassium is originally present as illite. Further, the XANES spectra did not appear to resemble that of potassium in an aluminosilicate glass. Hence, it was proposed that the behavior of the ion-exchanged potassium would be similar to that of sodium in Beulah coal, which appears to react readily with kaolinite to form a specific phase, nepheline $\left(\mathrm{NaAlSiO}_{4}\right)$, via reaction of a sodium vapor-phase species with the clay. By analogy with sodium, it was proposed that the potassium phase that would be formed in this manner would be kalsilite, $\mathrm{KAlSiO}_{4}$.

Some further investigation of the potassium-derived samples has been performed in the current quarter. It has been demonstrated with CCSEM data for ashes formed from the potassium ion-exchanged Beulah lignite in the PSI drop-tube furnace that the K-rich species formed from the ion-exchanged coal do indeed form a 1:1:1 cluster for the elements $\mathrm{K}: \mathrm{Al}: \mathrm{Si}$ that would be expected for a potassium analogue to nepheline. This is seen most readily from Figures 4-15 and 4-16, in which the K-Al-Si rich particles are shown to oluster around this composition on ternary plots.

In an attempt to confirm this conclusion, potassium K-edge XAFS experiments have been performed on the nepheline sample provided to us by PSI for CCSEM characterization. 


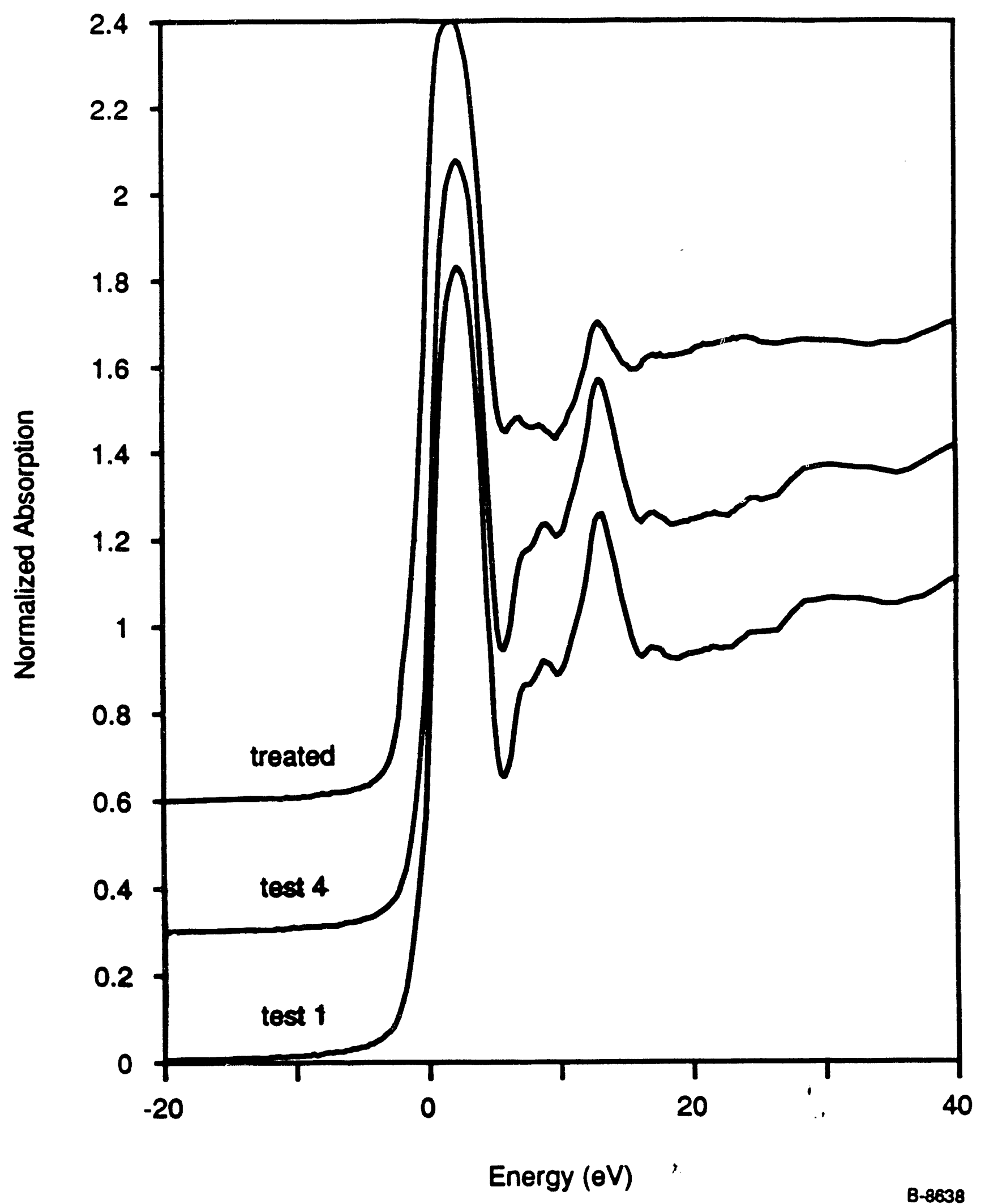

Figure 4-13. Cl XANES of Loy Yang Coal Ashes 


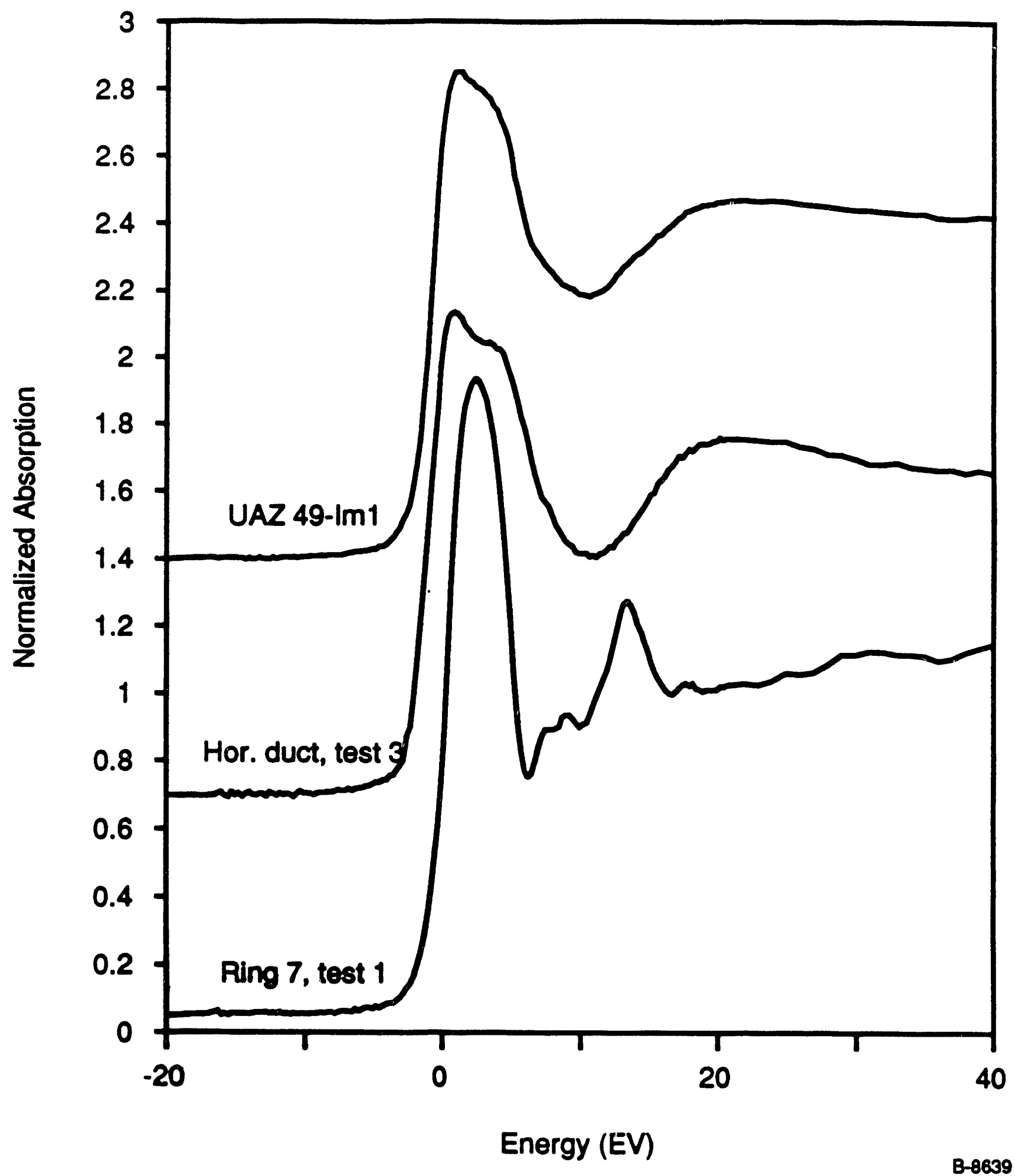

Figure 4-14. Cl XANES of Loy Yang Ash 


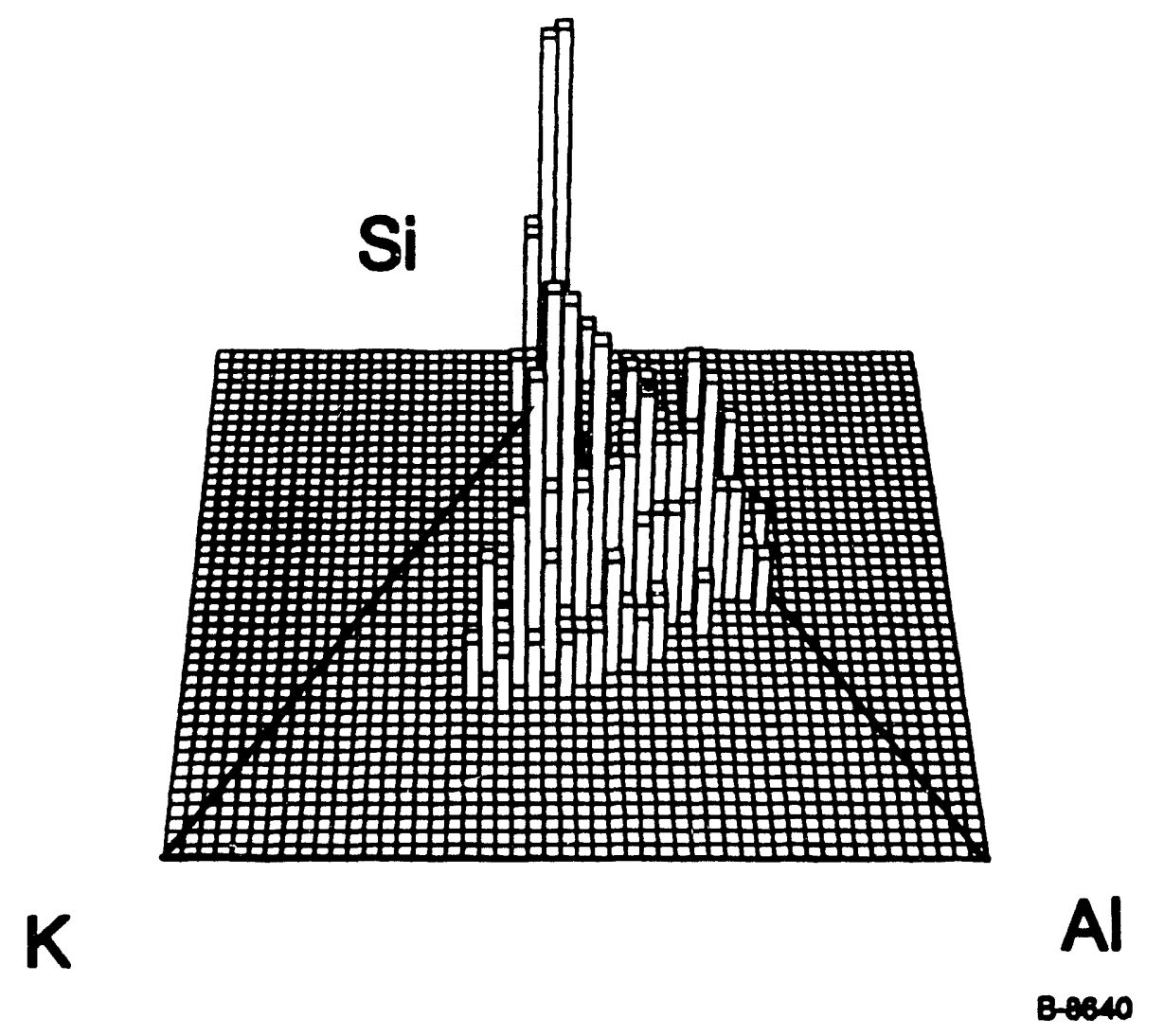

Figure 4-15. Beulah Ash with Ion Exchange, 1s Residence Time

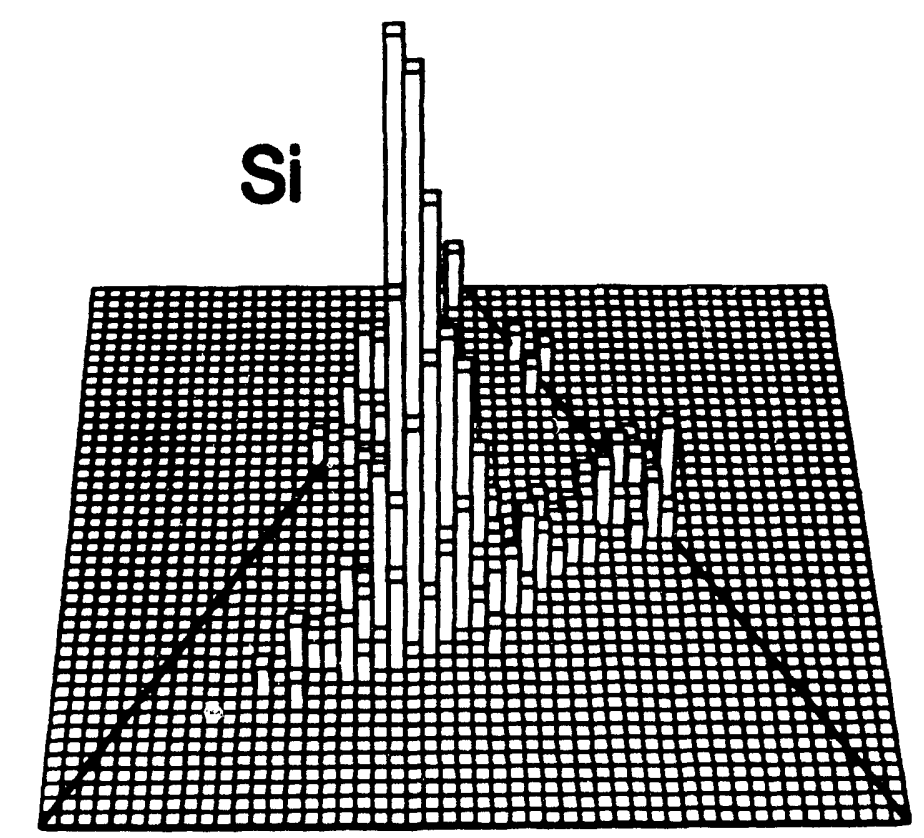

$\mathrm{K}$

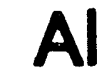

B-8641

Figure 4-16. Beulah Ash with Ion Exchange, 3s Residence time 
In the CCSEM characterization, it was noted that the nepheline contained significant potassium (as most natural nepheline samples do) as well as an appreciable amount of impurity minerals (Ca-rich aluminosilicates, Fe-rich oxides?). Figures 4-4 and 4-5 show ternary plots for $\mathrm{Na}-\mathrm{Al}-\mathrm{Si}$ and $\mathrm{K}-\mathrm{Al}-\mathrm{Si}$ compositions derived from the nepheline sample. As can be seen from the cluster of points on the Al-Si axis in the $\mathrm{Na}-\mathrm{Al}-\mathrm{Si}$ plot, there is a significant amount of other aluminosilicate species present in the sample. The potassium XANES spectrum for this sample of nepheline is shown in Figure 4-17, along with similar spectra of potassium feldspar $\left(\mathrm{KAlSi}_{3} \mathrm{O}_{8}\right)$ and leucite $\left(\mathrm{KAlSi}_{2} \mathrm{O}_{6}\right)$. Comparison of these spectra with the potassium XANES of the ion-exchanged Beulah ash samples (Figure 4-6, Quarterly Report 18, 1991) shows that none of these potassium-containing aluminosicates is appropriate for the potassium in the ash samples. It should be noted, however, that the structures of nepheline, $(\mathrm{Na}, \mathrm{K}) \mathrm{AlSiO}_{4}$, and kalsilite, $\mathrm{KAlSiO}_{4}$, are not identical despite their apparent chemical similarity. Specifically, in the nepheline structure, the sodium and potassium ions are segregated into smaller and larger cation sites, respectively, that are present in the structure in a 3:1 ratio. We therefore need to obtain the K XANES spectrum of a sample of kalsilite in order to complete this comparative investigation based on XANES spectroscopy alone.

\section{Mossbauer Analysis of Ash Samples}

${ }^{57} \mathrm{Fe}$ Mossbauer analysis has been performed on various samples from the University of Arizona combustor and the SECV pilot-scale combustion unit. Only a preliminary summary will be given here as we have many more samples in these sample suites to be run. The results are shown in Table 4-10. As in previous studies of similar samples, the iron in the samples appears to be distributed between iron oxides and aluminosilicate glass. The dominant oxidation state of the iron is ferric, although some ferrous is present in magnetite and possibly also in the glass to minor extent. The iron oxide appears to be largely a substituted hematite, although it is sometimes difficult to distinguish between the substituted hematite and magnetite components. In the case of the ash sample derived from the Illinois \#6 SOAP coal, the oxide is either very highly substituted or consists of very small particles as the oxide exhibits behavior characteristic of superparamagnetic iron oxides. 


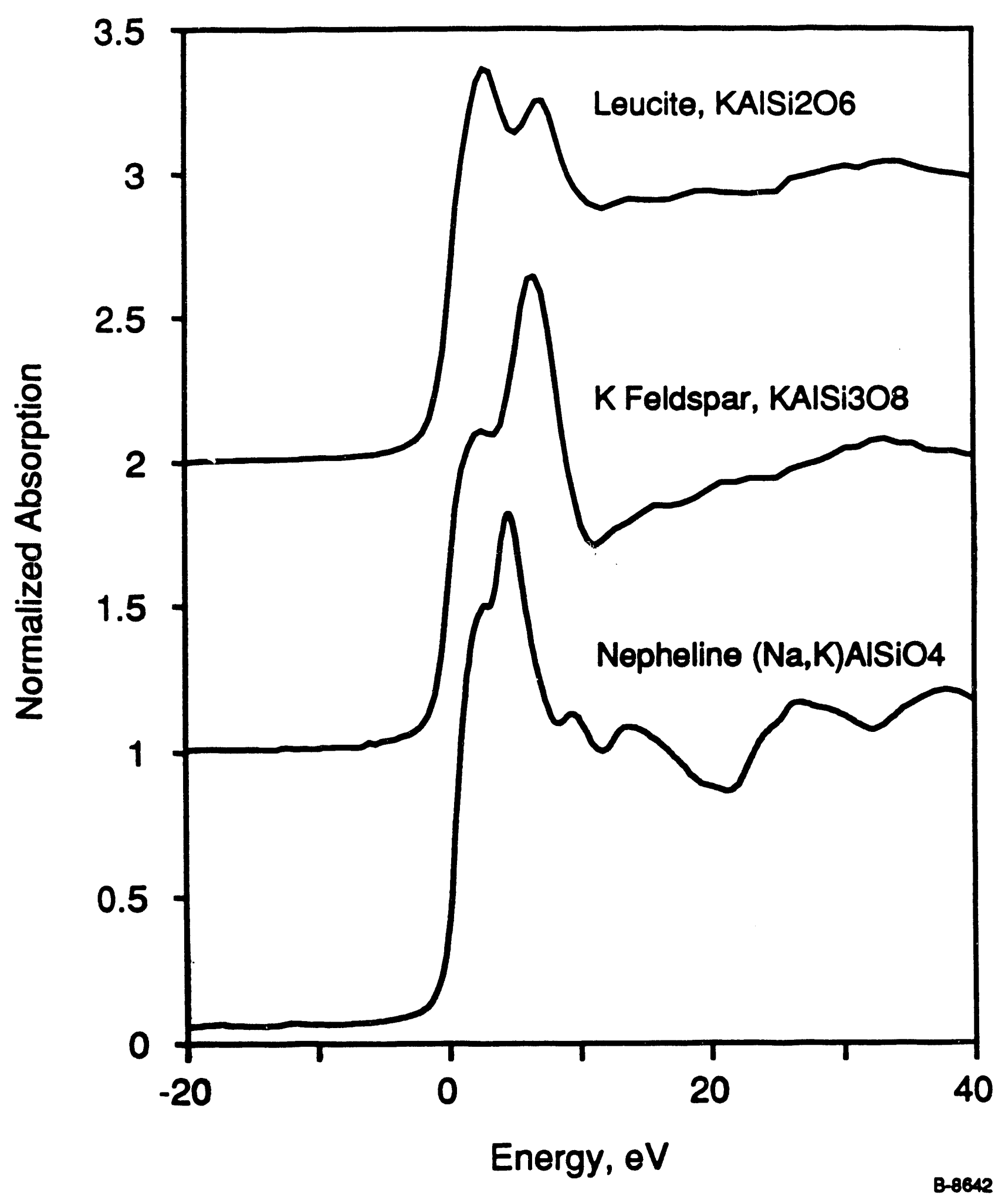

Figure 4-17. K XANES of Potassium Aluminosilicate Minerals 
Table 4-10. Mössbauer Analysis of UA and PSIT/SECV Samples

\begin{tabular}{|c|c|c|c|c|c|}
\hline SAMPLE & $\mathbf{H}$ & I.S. & Q.S. & \& $\mathrm{Fe}$ & PHASE \\
\hline $\begin{array}{l}\operatorname{Im1,} \text { I } 11 \# 6 \\
\text { SOAP } \\
\text { CFFLS \#582 }\end{array}$ & $\begin{array}{l}472 \\
425 \\
376 \\
263 \\
---\end{array}$ & $\begin{array}{l}.35 \\
.48 \\
.36 \\
.33 \\
.35\end{array}$ & $\begin{array}{l}--- \\
--- \\
--- \\
--- \\
.85\end{array}$ & $\begin{array}{l}28 \\
12 \\
14 \\
18 \\
23\end{array}$ & $\begin{array}{c}\text { spm oxide } \\
" \text { " } \\
\text { Fe3+ gl. }\end{array}$ \\
\hline $\begin{array}{l}\text { Im1, I II \#6 } \\
\text { CFFLS \#552 }\end{array}$ & $\begin{array}{l}512 \\
489 \\
459 \\
401 \\
---\end{array}$ & $\begin{array}{l}.36 \\
.32 \\
.56 \\
.44 \\
.38\end{array}$ & $\begin{array}{l}--- \\
--- \\
--- \\
--\overline{-} \\
.98\end{array}$ & $\begin{array}{l}18 \\
12 \\
38 \\
9 \\
18\end{array}$ & $\begin{array}{c}\text { Hematite } \\
\text { Magnetite } \\
\text { Fe3+ gl. }\end{array}$ \\
\hline $\begin{array}{l}\text { Im1, Beulah } \\
48-1-\text { im1-B' } \\
\text { CFFLS \#564 }\end{array}$ & $\begin{array}{l}488 \\
456 \\
418 \\
--- \\
---\end{array}$ & $\begin{array}{l}.36 \\
.66 \\
.59 \\
.24 \\
.23\end{array}$ & $\begin{array}{l}--- \\
--- \\
--- \\
.87 \\
1.65\end{array}$ & $\begin{array}{l}38 \\
16 \\
9 \\
16 \\
21\end{array}$ & $\begin{array}{c}\text { Magnetite } \\
\text { sil/glass }\end{array}$ \\
\hline $\begin{array}{l}\text { Im1, Beulah } \\
48-1-i m 1-F 1 \\
\text { CFFLS } \# 570\end{array}$ & $\begin{array}{l}490 \\
453 \\
418 \\
--- \\
---\end{array}$ & $\begin{array}{l}.36 \\
.59 \\
.62 \\
.24 \\
.21\end{array}$ & $\begin{array}{l}--- \\
--- \\
--- \\
.84 \\
1.51\end{array}$ & $\begin{array}{l}42 \\
13 \\
7 \\
12 \\
26\end{array}$ & $\begin{array}{c}\text { Magn. + Hem. } \\
\text { sil/glass }\end{array}$ \\
\hline $\begin{array}{l}\text { LY Test } 4 \\
\text { ash probe } \\
\text { CFFLS \#594 }\end{array}$ & $\begin{array}{l}514 \\
492 \\
447 \\
---\end{array}$ & $\begin{array}{l}.41 \\
.35 \\
.62 \\
.27\end{array}$ & $\begin{array}{l}-.06 \\
.-- \\
--- \\
.78\end{array}$ & $\begin{array}{l}20 \\
24 \\
19 \\
34\end{array}$ & $\begin{array}{l}\text { Hematite } \\
\text { Magnetite } \\
\text { sil/glass }\end{array}$ \\
\hline $\begin{array}{l}\text { LY Test } 3 \\
\text { (Treated) } \\
\text { ash probe } \\
\text { CFFLS \#595 }\end{array}$ & $\begin{array}{l}514 \\
468 \\
---\end{array}$ & $\begin{array}{l}.40 \\
.44 \\
.27\end{array}$ & $\begin{array}{l}-.09 \\
--- \\
.73\end{array}$ & $\begin{array}{l}25 \\
24 \\
47\end{array}$ & $\begin{array}{l}\text { Hematite } \\
\text { Magnetite } \\
\text { sil/glass }\end{array}$ \\
\hline $\begin{array}{l}\text { Beulah } \\
\text { ash probe } \\
\text { comb. cham. } \\
\text { CFFLS \#596 }\end{array}$ & $\begin{array}{l}514 \\
487 \\
442 \\
--- \\
---\end{array}$ & $\begin{array}{l}.42 \\
.38 \\
.52 \\
.23 \\
.22\end{array}$ & $\begin{array}{l}--- \\
--- \\
--- \\
.88 \\
1.66\end{array}$ & $\begin{array}{l}21 \\
24 \\
26 \\
17 \\
11\end{array}$ & $\begin{array}{l}\text { Hematite } \\
\text { Magnetite } \\
\text { sil/glass }\end{array}$ \\
\hline
\end{tabular}


Table 4-10. Mössbauer Analysis of UA and PSIT/SECV Samples (Continued)

\begin{tabular}{|c|c|c|c|c|c|}
\hline SAMPLE & H & I.S. & Q.8. & $\% \mathrm{Fe}$ & Phase \\
\hline $\begin{array}{l}\text { Beulah } \\
\text { cooled probe } \\
\text { CFFLS \#602 }\end{array}$ & $\begin{array}{l}511 \\
450 \\
-\end{array}$ & $\begin{array}{l}.39 \\
.40 \\
.30\end{array}$ & $\begin{array}{l}-.09 \\
.10 \\
.83\end{array}$ & $\begin{array}{l}48 \\
18 \\
35\end{array}$ & $\begin{array}{l}\text { Hem. + Magn. } \\
\text { sil/glass }\end{array}$ \\
\hline $\begin{array}{l}\text { Beulah dep. } \\
\text { bank } 1 \\
\text { CFFLS \#603 }\end{array}$ & $\begin{array}{l}514 \\
455 \\
403 \\
---\end{array}$ & $\begin{array}{l}.40 \\
.31 \\
.29 \\
.30\end{array}$ & $\begin{array}{l}-.08 \\
--- \\
-- \\
.89\end{array}$ & $\begin{array}{l}37 \\
16 \\
16 \\
31\end{array}$ & $\begin{array}{c}\text { Hematite } \\
\text { sil/glass }\end{array}$ \\
\hline $\begin{array}{l}\text { Beulah dep. } \\
\text { bank } 3 \\
\text { CFFLS \#604 }\end{array}$ & $\begin{array}{l}515 \\
481 \\
426 \\
---\end{array}$ & $\begin{array}{l}.40 \\
.36 \\
.37 \\
.28\end{array}$ & $\begin{array}{l}-.05 \\
--- \\
--- \\
.95\end{array}$ & $\begin{array}{l}41 \\
12 \\
16 \\
41\end{array}$ & $\begin{array}{c}\text { Hematite } \\
\text { sil/glass }\end{array}$ \\
\hline
\end{tabular}




\section{SECTION 5}

Task 5

FUNDAMENTAL STUDIES OF MINERAL MATTER VAPORIZATION AND RESIDUAL ASH FORMATION

Adel F. Sarofim, Janos M. Beér, and Shin-Gyoo Kang

Department of Chemical Engineering

Massachusetts institute of Technology 


\section{FUNDAMENTAL STUDIES OF MINERAL MATTER VAPORIZATION AND RESIDUAL ASH FORMATION}

During the last quarter, the existing synthetic char preparation techniques were refined and new techniques were explored for better-controlled combustion experiments. Some of the samples were utilized for residual ash formation and growth studies. Part of the results is reported in the quarterly report. The rest will be reported as soon as the analysis of the experiments is available.

\subsection{Synthetic Char Preparation}

The first step of synthetic char preparation was to make well-defined mineral impurities. The second step was to make synthetic char particles with model impurities in an inert, high temperature environment. A liquid solution was made by mixing the model impurities with carbon-based compounds that would yield later the carbon matrix of the synthetic char.

Two different methods were adopted for the second, char generation step. One was first to have the liquid solution be pyrolyzed in a specially designed oven to produce a solid char cake, and then to have the char cake be ground down to the desired size. The other was first to have a jet of the liquid solution be divided into fine, narrow-sized droplets by externally inducing a periodic instability, and then to have the droplets be pyrolyzed in a furnace.

\subsubsection{Model Mineral Matter Freparation}

Coal has its mineral impurities in two different forms: atomically dispersed mineral matter, and discrete mineral inclusions dispersed randomly throughout coal particles. As an ideal model compound of mineral matter, the material has to be well defined in its dispersity, shape, size and composition.

For the simulation of the atomically dispersed mineral matter, chemicals of desired elements were utilized which are readily soluble to the solvents used for the preparation. For the discrete mineral inclusions, monosized and spherical silica seed particles (Stöber et al., 1968) were generated by a sol-gel technique by mixing a solution of pure alcohol (ethanol) containing a small amount of water and a base catalyst (ammonia) with a silicon alkoxide (tetraethyl orthosilicate) for the study. The concentration of water and ammonia in EtOH was set to produce the maximum size of silica particles ( $-0.6 \mu \mathrm{m}$ in diameter). These seed particles were grown further to the desired size by the addition of tetraethyl orthosilicate (TEOS) solution. The detailed procedure is discussed in the following section.

A solution was made by mixing $340 \mathrm{ml}$ of ethanol (EtOH) with $160 \mathrm{ml}$ of $35 \%$ ammonia solution $\left(\mathrm{NH}_{4} \mathrm{OH}\right)$ in a 2- $\ell$ Erlenmeyer flask. In the room temperature, $6 \mathrm{ml}$ of TEOS was added to the solution. The solution was stirred moderately throughout the 
synthesis using a magnetic stirring bar. After 1 to $5 \mathrm{~min}$, the solution became turbid, which is a sign of nucleation of silica embryos. The solution was stirred for $24 \mathrm{hr}$, after which $100 \mathrm{ml}$ of TEOS-EtOH solution (50/50 by volume) was added. One hundred milliliters of TEOS-EtOH solution was added to the initial solution at eight $24 \mathrm{hr}$ intervals. The time-concentration history of silica growth is shown schematically in Figure 5-1 (upper). In order to maintain the $\mathrm{pH}$ of the solution at 10 , ammonia solution was replenished to the TEOS-EtOH solution between batches. The final solution was centrifuged and washed several times with EtOH. The final silica particles thus obtained were $1.41 \mu \mathrm{m}$ in diameter. The SEM of the silica particles is shown in Figure 5-1 (lower).

\subsubsection{Char From Grinding Pyrolyzed Char Cake}

Sucrose and carbon black were mixed in a ratio of 2:1 by mass in a beaker. Isopropyl alcohol was added to the beaker. The sucrose-carbon black-isopropyl alcohol slurry was well stirred while heating. Silica particles dispersed in water were added to the slurry. When atomically dispersed mineral impurities had to be simulated, acetates of desired chemical elements (e.g., $\mathrm{Na}, \mathrm{K}, \mathrm{Mg}$, and $\mathrm{Ca}$ ) were dissolved in water and were added to the slurry. The slurry was sonicated for 30 min and heated while stirring until it became very viscous. The slurry was then poured into a ceramic boat and put in a pyrolysis oven. The slurry was heated in an inert condition $\left(\mathrm{N}_{2}\right)$ in the pyrolysis oven at $250^{\circ} \mathrm{C}$ for an hour followed by at $600^{\circ} \mathrm{C}$ for one and a half hours. A cake of char was made from the slurry after pyrolysis. The cake was ground and sieved to the desired size ranges (75 to $90 \mu \mathrm{m}$ and 90 to $106 \mu \mathrm{m})$.

\subsubsection{Char From Pyrolysis of Instability-Induced Droplets}

Generation technique of narrow-sized char particles with monosized mineral inclusions was developed in collaboration with Levendis at Northeastern University. The atomization technique of Levendis and Flagan (1987) was adopted and modified to generate narrowly-sized spherical char particles with mineral impurities. Furfuryl alcohol was first partially polymerized at $60^{\circ} \mathrm{C}$ under constant stirring for $20 \mathrm{~min}$ with p-toluene sulfonic acid as a catalyst. The polymer thus generated, poly (furfuryl alcohol) (PFA), was dissolved in acetone. The volume ratio of PFA to acetone was 1 to 10 . When mesopores were desired, carbon black was added to the PFA-acetone solution to create mesopores (20 to $500 \AA$ in diameter). The amount of carbon black was usually $20 \%$ of the initial PFA mass. Monosized silica particles were dispersed in the PFA-acetone solution. The solution was sonicated for $30 \mathrm{~min}$ before the particle generation.

The details of the particle generation system can be found in Levendis and Flagan (1987). The particle generation system is composed of a droplet generator and a thermal reactor. The droplet generator is a conical chamber with a 75 to $150 \mu \mathrm{m}$ diameter outlet orifice. The roof of the chamber is made of a metallic sheet on which a piezoelectric crystal is cemented. The metallic sheet vibrates at the frequency of 10 to $20 \mathrm{kHz}$, which causes the instability of the liquid stream out of the chamber through the outlet orifice. The generation of the monosized droplets was confirmed by changing the frequency until the droplets being 

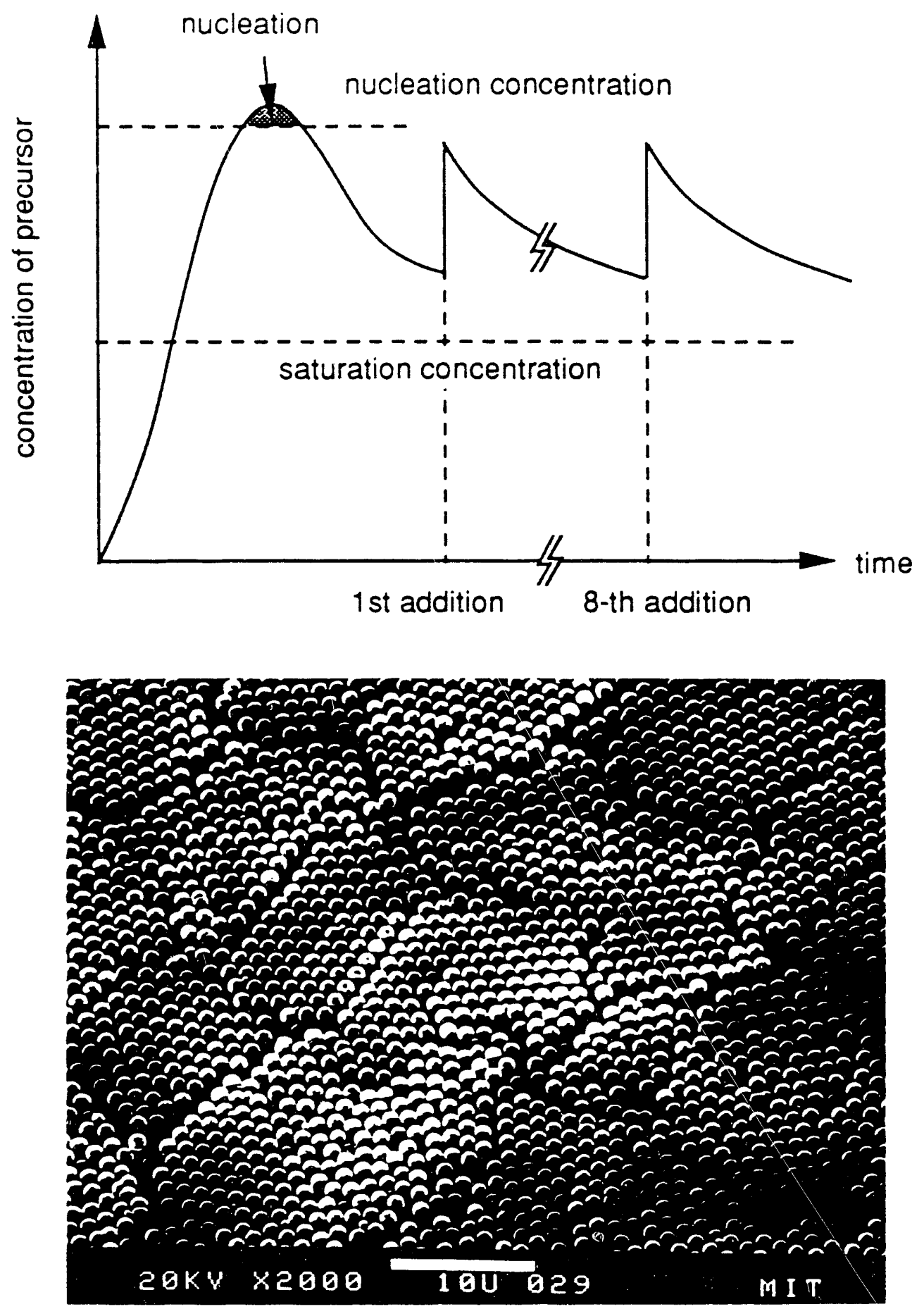

Figure 5-1. Schematic Diagram of Time-Temperature History of Silica Growth (upper); scanning electron micrograph of silica particles grown by the method discussed in the text (lower) 
pushed away from the direction of the stream by a constant flow of nitrogen form another single stream.

Narrowly-sized droplets thus formed were fed into the thermal reactor section and were pyrolyzed at temperatures between $250^{\circ}$ to $350^{\circ} \mathrm{C}$. Samples were collected on a filter and cured in an oven at $600^{\circ} \mathrm{C}$ for an hour. Figure 5-2 (upper) shows char particles generated by the technique and Figure 5-2 (lower) shows the cross-section of a particle.

\subsubsection{Comparison of the Char Preparation Methods}

The two preparation techniques have advantages and disadvantages of their own. The advantages of one technique are the disadvantages of the other.

Model char particles should be very well-defined in its shape and size. When char particles are made by pyrolysis followed by grinding, however, a lot of unnecessary fine particles are also produced. The shape of the ground char particles, like pulverized coal particles, is often edged and random. The production rate of this technique is fairly high, and is only limited by the size of the boats. Using sucrose and carbon black as the source for carbon, the elements to be incorporated can be introduced as in acetates; they are atomically dispersed and can be added in high concentrations.

Char samples generated from the instability-induced droplets, on the other hand, have much better defined shapes, and contain virtually no fine particles. But the char production rate from the technique is extremely low, and is especially so when the feed solution to the system contains quite a loi of solid materials. Since the atomically dispersed mineral matter is usually incorporated to the char samples by impregnation, the amount and distribution of atomically dispersed mineral matter is limited. This problem of limited incorporation of the organically bound mineral matter may be solved by using a material with a high concentration of ion-exchangeable, active sites as a source of carbon.

\subsection{Ash Coalescence Studies}

Residual flyash particles form and grow by the coalescence as they get close to touch each other with the progress of the char reaction. The degree of coalescence of touching surface ash particles is dependent upon their viscosity, and surface tension. The viscosity and the surface tension are affected by the temperature of the burning char particle, and the chemical composition of the ash particles on the surface. The temperature of burning char particles determine the physical state of ash particles, i.e., either molten or solid. The chemical composition of the ash particles determine the ash fusion temperature, the surface tension, and the viscosity. It is a well known fact that the presence of alkali and alkaline-earth metals dramatically lowers the viscosity of aluminosilicates.

The objective of this work is to investigate the effect of alkali, and alkaline-earth metals on the formation and growth of ash. Synthetic char samples of different mineral 

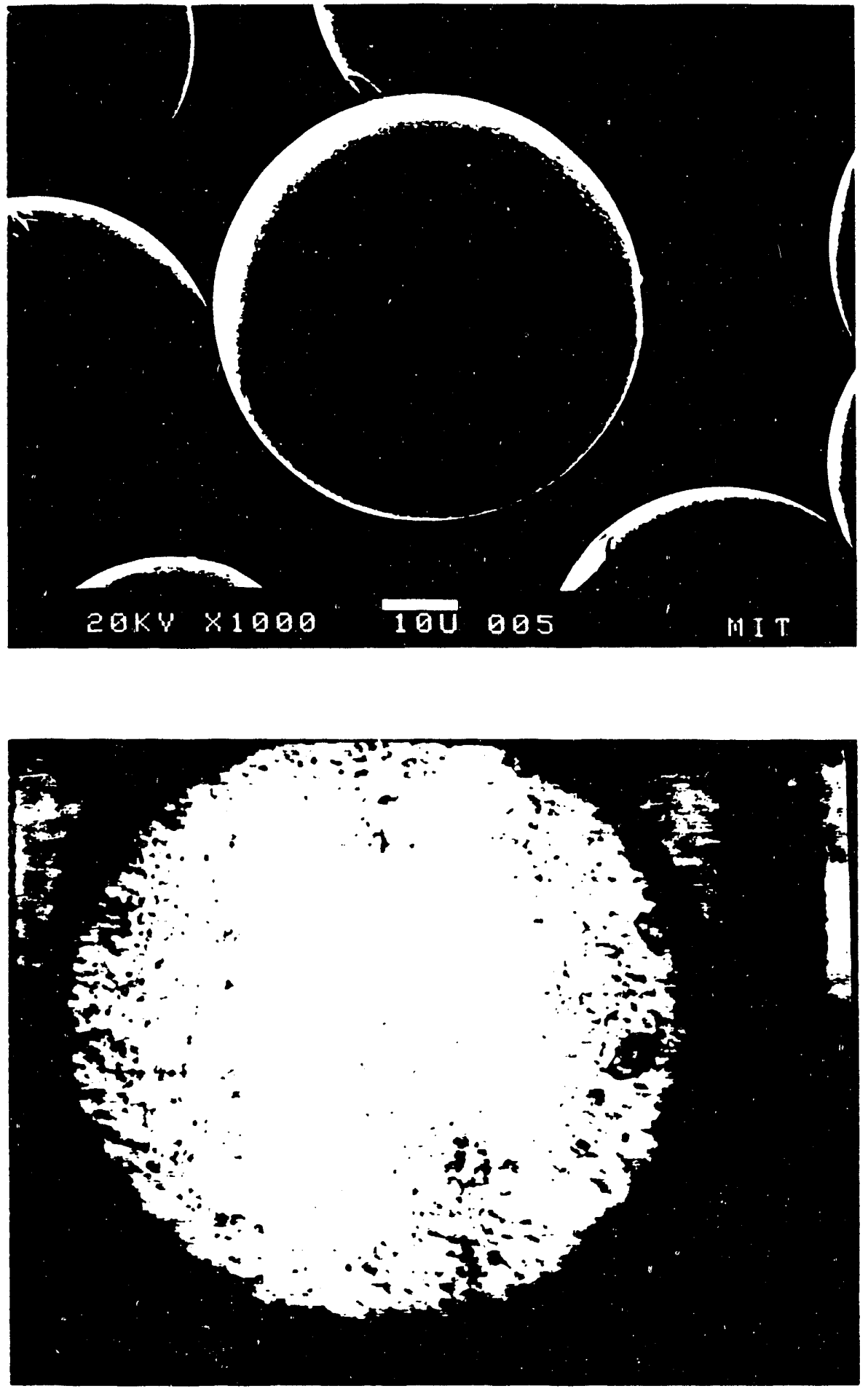

Figure 5-2. Scanning Electron Micrographs of PFA-Based Char Particles (upper) and the Cross Section (Lower) 
impurities contents were prepared. Both of the char preparation techniques were adopted for the study.

\subsubsection{Theory}

In order for residual ash particles to grow in size during coal combustion, they have to satisfy the following requirements. They first have to stay on the burning char surface, they have to get drawn closer to each other as the reaction goes along, and then they have to reach high enough surface tension and low enough viscosity so that surface-tension-driven coalescence is possible. On top of all these, for any significant growth of residual ash to take place the coalescence rate should be so fast that the complete coalescence of all the available mineral impurities can take place within the time scale of char burnout.

This naturally leads to the comparison of two characteristic time scales in the ash coalescence mechanism for the extent of ash coalescence: ash coalescence and char reaction time scales. The two time scales can be expressed by the physical and chemical properties of the char and mineral matter.

Let's first consider the coalescence time scale, $\tau_{0}$. Sintering behavior of two touching spherical particles has been studied by many researchers (Frenkel, 1945; Kuczynski et al., 1970; Hiram and Nir, 1983). Frenkel derived a simple relationship for the growth of the interface between two spherical particles by viscous flow, which can be written as,

$$
\chi^{2}=\frac{3 \gamma}{2 \mu} \mathrm{rt}
$$

or

$$
\mathrm{t}=\frac{2 \mu}{3 \gamma} \mathrm{r}\left(\frac{x}{r}\right)^{2}
$$

where $\chi$ is the radius of the interface, $r$ the original radius of the sphere, $\gamma$ the surface tension, $\mu$ the viscosity, and $t$ the time for sintering. The relationship can be applied only for early stage of sintering, i.e., $\chi / r<0.3$. When we define the coalescence time, $\tau_{0}$, as the time required for $\chi / r$ to reach 0.3 , we find that

$$
\tau_{\mathrm{c}} \propto \frac{\mu}{\gamma} \mathrm{r}
$$

The coalescence time, therefore, is proportional to the viscosity and the initial size of ash, and is inversely proportional to the surface tension. 
Now let's consider the reaction time scale, $\tau_{\mathrm{r}}$. When a particle burns in the external diffusion controlled regime, the char burnout time becomes inversely proportional to the diffusion rate of the gaseous reactant, which is proportional to the reactant concentration, i.e.,

$$
\tau_{\mathrm{r}}=0.06 \frac{1}{\mathrm{D}_{\mathrm{O}_{2}} \mathrm{P}_{2}}
$$

where $\mathrm{D}_{\mathrm{O}_{2}}$ and $\mathrm{P}_{\mathrm{O}_{2}}$ are the diffusion coefficients and partial pressure of oxygen, respectively.

Taking the ratio of the two time scales, $\tau_{\mathrm{r}}$ and $\tau_{\mathrm{C}}$, we define a coalescence parameter, $\Lambda_{\mathrm{r} / \mathrm{c}}$, as

$$
\begin{gathered}
\Lambda_{\mathrm{r} / \mathrm{c}} \equiv \frac{\tau_{\mathrm{r}}}{\tau_{\mathrm{c}}} \\
\propto \frac{\gamma}{\mathrm{D}_{\mathrm{O}_{2}}{ }^{\mathrm{P}_{\mathrm{O}_{2}}{ }^{\mu \mathrm{r}}}} \\
\propto \frac{\gamma}{\mu \mathrm{r}} .
\end{gathered}
$$

This parameter gives basic information on ash coalescence during char burnout. When the coalescence is very fast compared with the char bumout time, i.e., $\Lambda_{\mathrm{r} / \mathrm{c}}>>1$, mineral impurities in a coal particle readily coalesce within the reaction time. On the other hand, if the coalescence time is too long compared with the char burnout time, i.e., $\Lambda_{\mathrm{r} / \mathrm{c}}<<1$, mineral impurities would barely coalesce or sinter only partially and result in a lacy cluster of spheroidal ash particles.

Among the parameters which define the coalescence parameter, surface tension and viscosity are the ones that are affected by the change of the chemical composition of mineral impurities.

\subsubsection{Experimental}

Samples of different mineral content were prepared by the preparation techniques discussed in the previous section. Silica particles of size $1.41 \mu \mathrm{m}$ were used for the char. Calcium acetate and potassium acetate were used to atomically distribute calcium and potassium in the char particles. Table 5-1 lists the sample preparation techniques, sample size, and the chemical composition for each of the samples used for the study. 
Table 5-1. Synthetic Char Samples Prepared for the Study

\begin{tabular}{|c|c|c|c|c|c|c|c|}
\hline \multirow[b]{2}{*}{$\begin{array}{l}\text { Sample } \\
\text { Number }\end{array}$} & \multirow[b]{2}{*}{$\begin{array}{c}\text { Preparation } \\
\text { Technique }\end{array}$} & \multirow[b]{2}{*}{$\begin{array}{l}\text { Size } \\
(\mu \mathrm{m}) \\
\end{array}$} & \multirow[b]{2}{*}{$\begin{array}{l}\text { ASTM Ash } \\
(w t \%)\end{array}$} & \multicolumn{3}{|c|}{ Composition 1} & \multirow[b]{2}{*}{$\begin{array}{l}\mathrm{Mol} \% \\
\mathrm{SiO}_{2}^{2} \\
\end{array}$} \\
\hline & & & & $\% \mathrm{~K}$ & $\% \mathrm{Ca}$ & $\% \mathrm{SiO}_{2}$ & \\
\hline BA & Grinding & $90 / 106$ & 3.35 & N/A & N/A & N/A & 100 \\
\hline$K 1$ & Grinding & $90 / 106$ & 6.65 & 1.54 & - & 4.87 & 80.8 \\
\hline $\mathrm{K} 2$ & Grinding & $90 / 106$ & 5.14 & 0.81 & - & 4.44 & 88.0 \\
\hline $\mathrm{K} 3$ & Grinding & $90 / 106$ & 4.08 & $<0.8$ & - & 4.10 & 87.2 \\
\hline $\mathrm{CA} 1$ & Grinding & $90 / 106$ & 6.85 & - & 1.45 & 3.09 & 58.7 \\
\hline $\mathrm{CA} 2$ & Grinding & $90 / 106$ & 6.03 & - & 0.90 & 3.95 & 74.5 \\
\hline $\mathrm{CA} 3$ & Grinding & $90 / 106$ & 6.40 & - & 0.78 & 4.99 & 81.0 \\
\hline $\mathrm{PFA} / \mathrm{K}$ & Droplets & $75 / 90$ & 23.5 & $<0.4$ & - & 25.11 & 98.8 \\
\hline
\end{tabular}

The base material for carbon for the first seven synthetic char samples was sucrose and carbon black ( 1 to 1 by weight), and that for the last was PFA. The pore size distributions of the two types of char are shown in Figure 5-3. The samples are non-macroporous, and therefore are free from any char fragmentation by macroporosity (Helble and Sarofim, 1987; Kang et al., 1988).

Laminar flow reactor runs were made with the samples. The gas temperature was $1650 \mathrm{~K}$, and the oxygen roncentration was $20 \%$. Combustion products were collected on Fluoropore filters, and were analyzed by EDAX-SEM, and image analyzer. Primary ash particle size was determined by measuring and averaging the sizes of 500 to 1000 particles. The final ash particle size distribution was also determined using an Andersen Mark II cascade impactor.

\subsubsection{Results and Discussion}

Figure 5-4 shows the fusion curves of alkali silicates, and the viscosity change of silica with the addition of alkali metals, respectively. The presence of the alkali and alkaline-earth metals lowers the fusion temperature of most of aluminosilicates. They also lower the viscosity of the aluminosilicates by several orders of magnitude. The viscosity of a melt is sensitive to its ionic or molecular structure. A great decrease in viscosity with the addition of about $10 \mathrm{~mol} \%$ of alkali metal oxides (or 20 mol\% of alkaline-earth metal oxides) is a manifestation of a major breakdown in the silicate network to a smaller silicate anion groups. The surface tension of silica increases with the addition of potassium, and decreases 


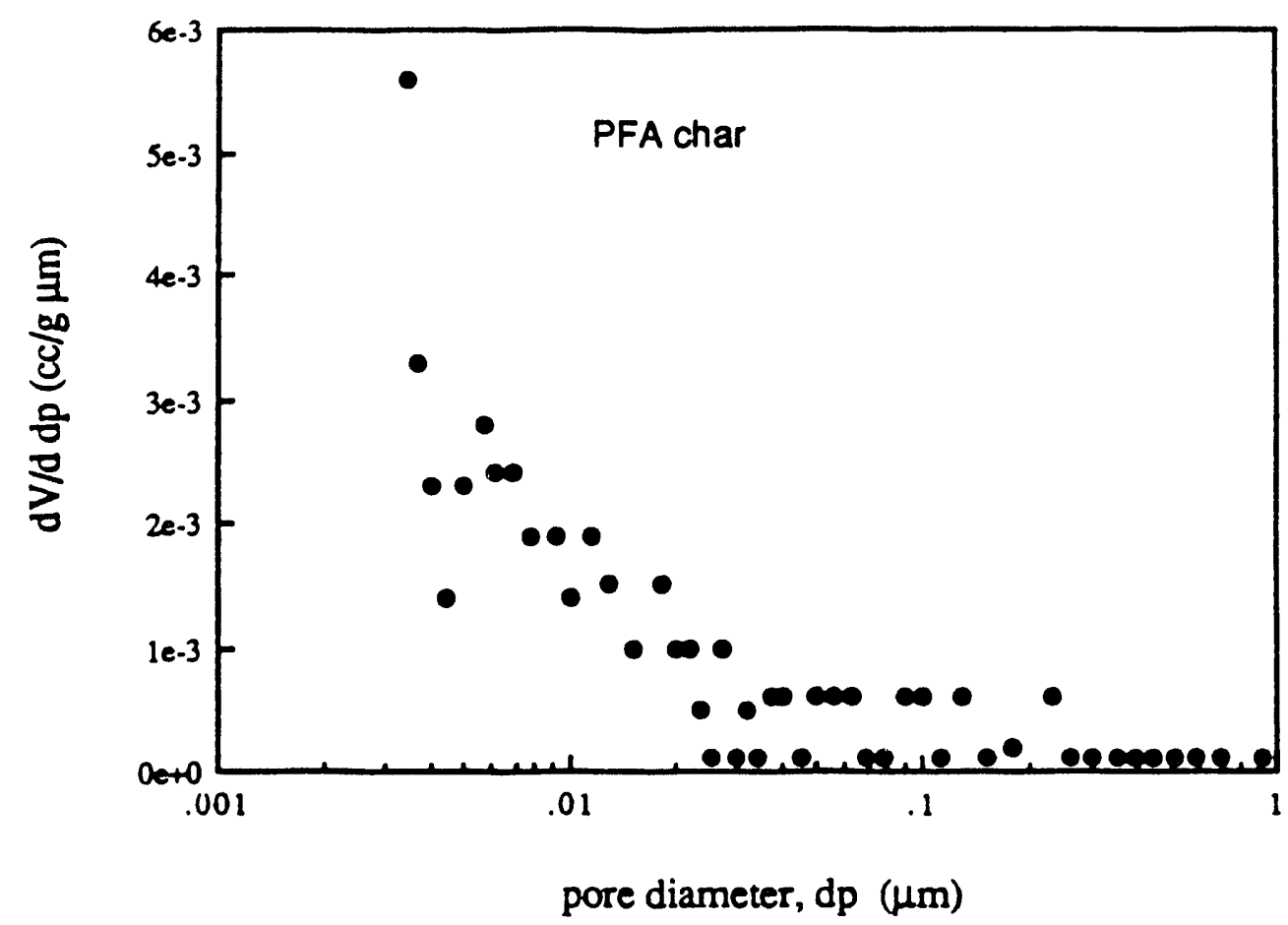

Figure 5-3. Pore Size Distributions of Sucrose/Carbon Black Char and PFA/Carbon Black Char Obtained From Mercury Porosimetry

with the addition of lithium or sodium. However it does not vary as much as the viscosity. It is therefore mainly by the change of the viscosity that the ash coalescence behavior is dramatically affected by the compositional change of the minerals.

Some of the typical ash particles are shown in Figures 5-5 and 5-6 after complete combustion of each of the samples. The figures sequentially show the effect of potassium. The final ash particles produced varied in their size and shape depending upon the composition of the mineral impurities.

Figure 5-5(a) shows a cluster of silica particles whose primary particles (particles that comprise the cluster) are of the size of initial silica inclusions. This cluster was generated from the char BA, which does not contain any potassium. Initial char particles are loosely attached to each other and form a fragile, and random-shaped cluster. The degree of sintering shows a general dependence on its relative location from the center of the cluster, central ash particles having grown larger than particles on the perimeter. This is probably because silica particles located at the center of an initial char particle experience the maximum char temperature for a longer period of time than those outside.

Samples K2 and K3 produced partially coalesced silica clusters. Addition of potassium enhanced the coalescence. Figure 5-5 (b) shows final ash particles from the char K3. The cluster also shows a trend of smaller -- nearly of the initial silica size -- silica particles being located outside and larger ones inside. This can be explained by the fact that the amount of potassium incorporated to the network of a silica particle is approximately proportional to the sweeping char volume of the silica particle as it recedes. Figure 5-6(a) shows a cluster of 

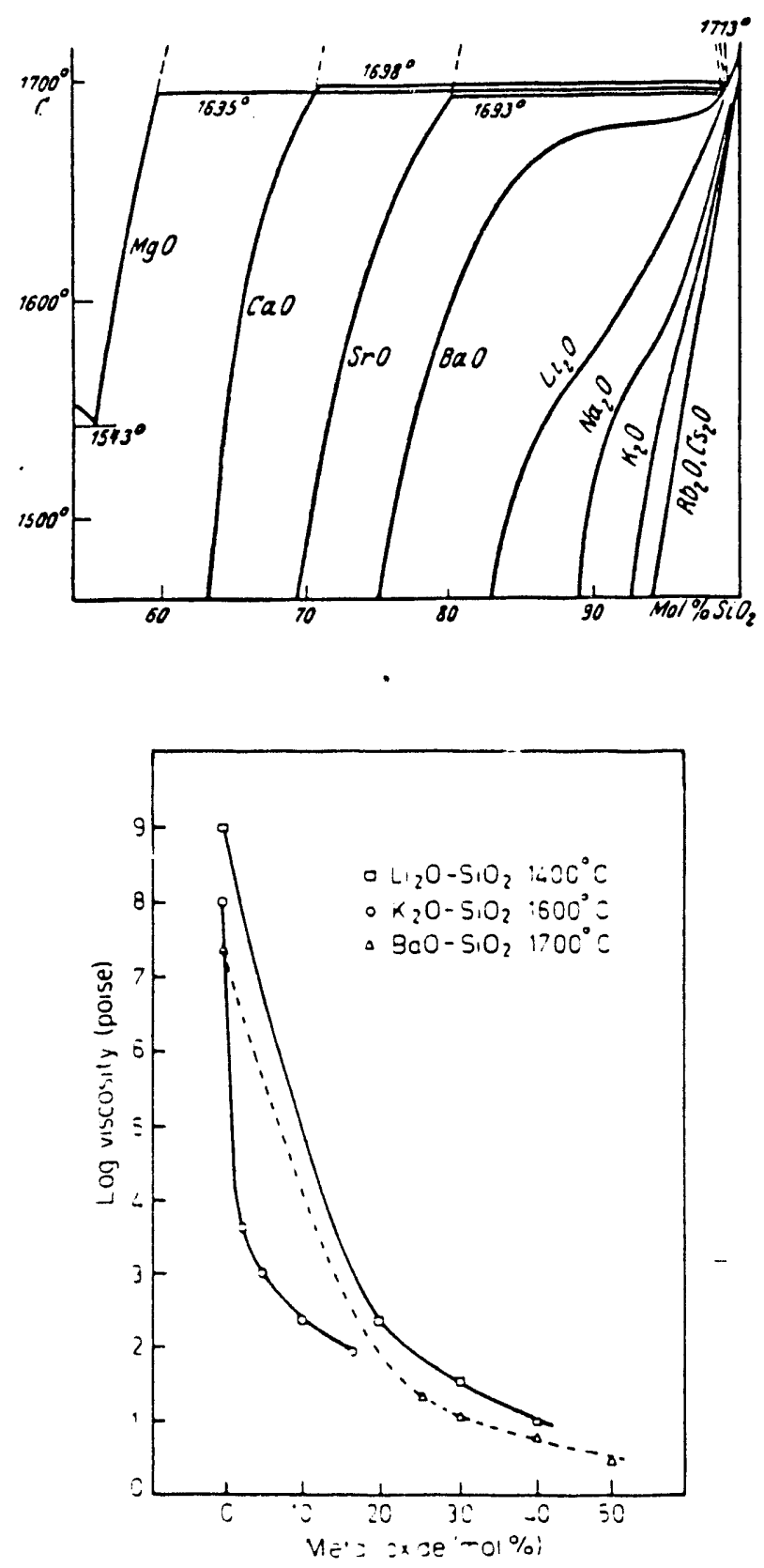

Figure 5-4. Fusion Curves of Alkali and Alkaline-Earth Silicates (upper), and the Viscosity Change of Silica with Alkali Metal Addition (lower). From Eitel (1954) (upper) and Paul (1982) (lower). 

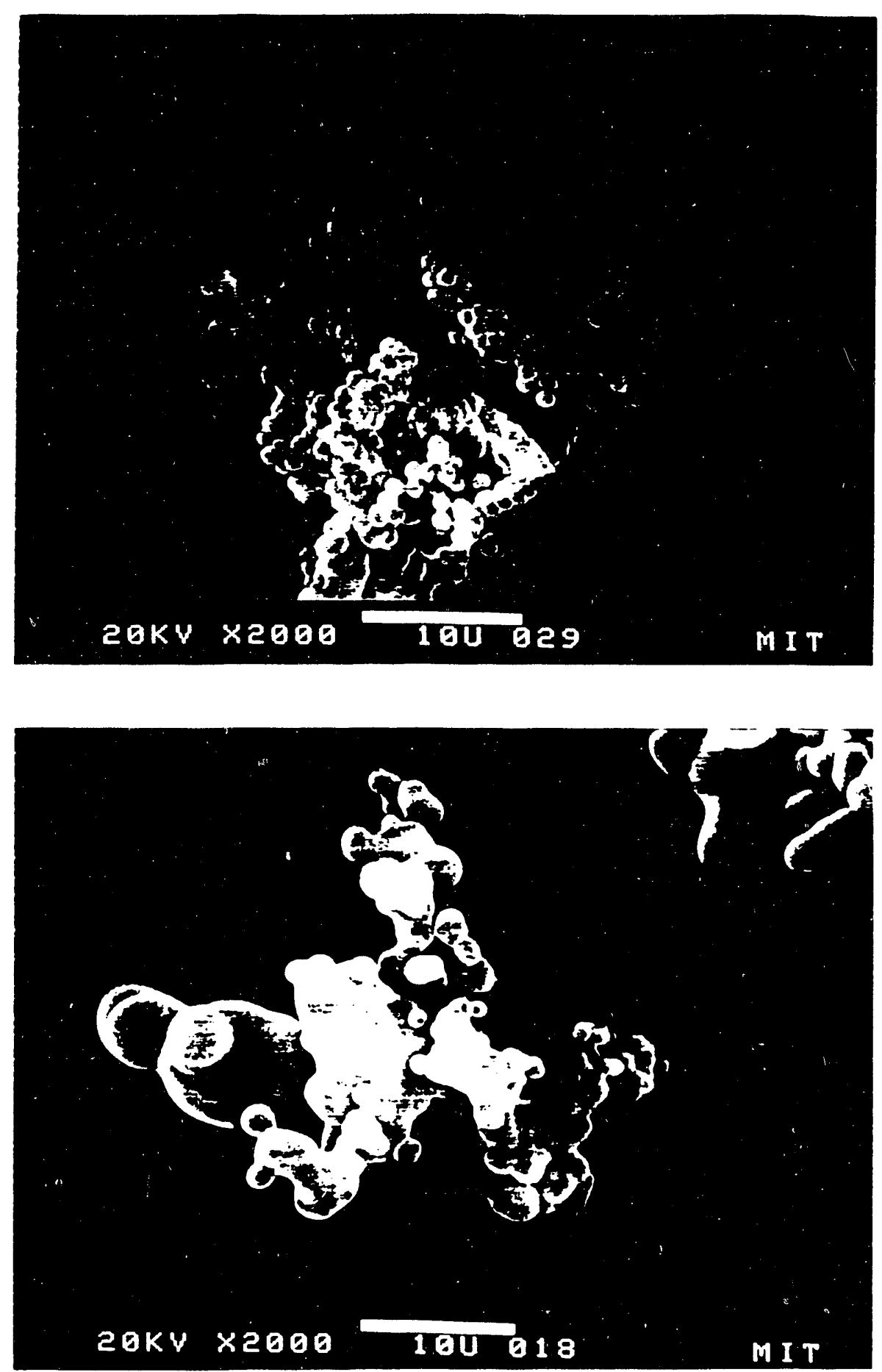

Figure 5-5. Typical Ash Particles Collected from the Combustion of (a) sample $\mathrm{BA}$ and (b) sample $\mathrm{K} 3$ 

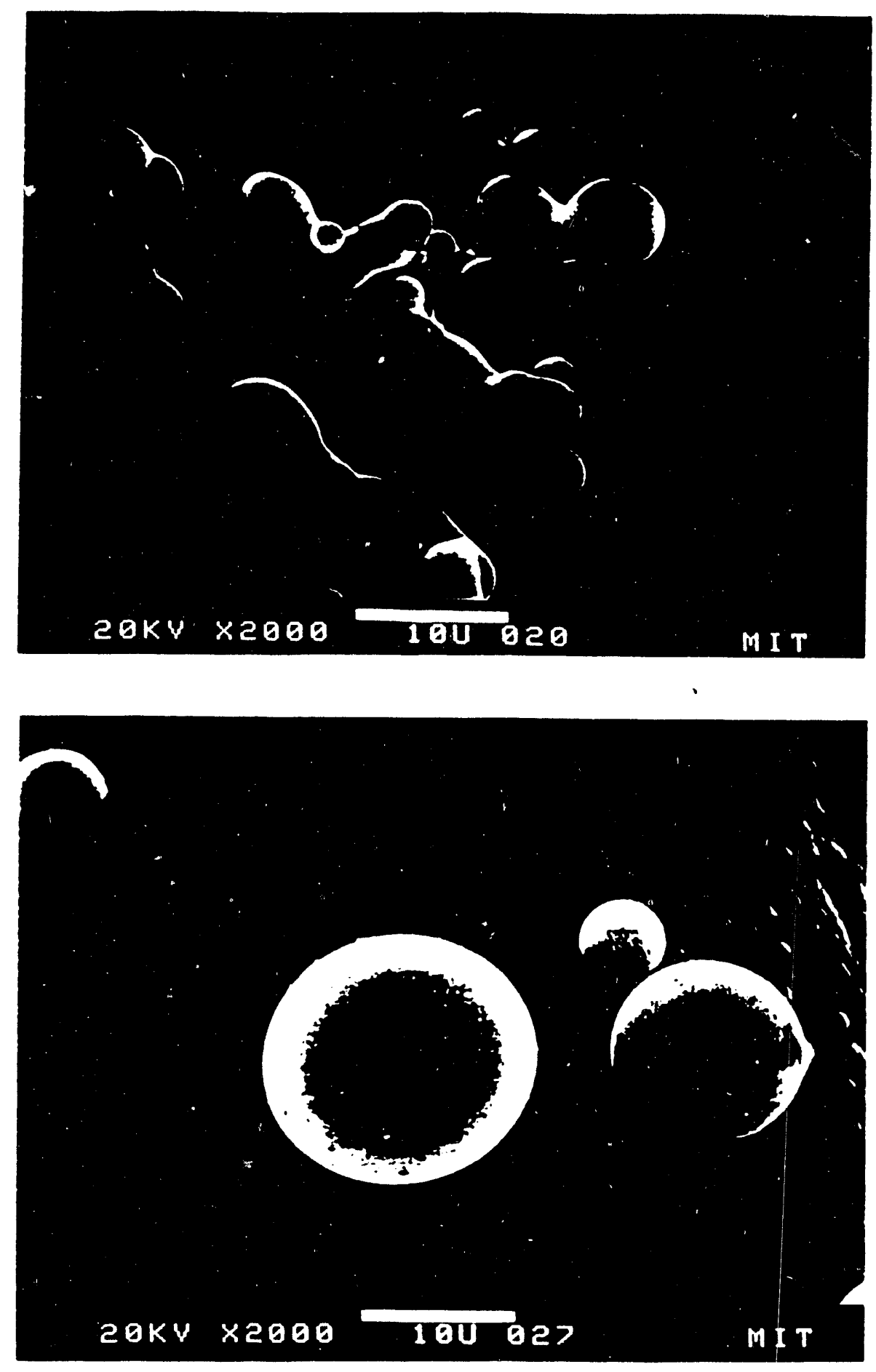

Figure 5-6. Typical Ash Particles Collected from the Combustion of (a) Sample K2 and (b) sample $\mathrm{K} 1$ 
final ash particles from the char $\mathrm{K} 2$. The shape and size are very similar to those of silica particles from the sample $\mathrm{K} 2$. The primary particles, whose size ranges from 1.4 to $10 \mu \mathrm{m}$, did not coalesce completely. About half of the final ash from the char $\mathrm{K} 2$, however, were spherical, and non-clustered.

Figure 5-6(b) shows spherical particles obtained from the char K1. Nearly all of the particles examined were spherical and non-clustered. The primary particle size cistributions of all these samples and the volume mean diameter of the primary particles are shown in Figure 5-7 (upper) and Figure 5-7 (lower), respectively.

The size distributions clearly show the increase in the size of the primary particles with the increase of mineral impurities (potassium in the study) in the char matrix.

For each case the coalescence parameter was calculated. The calculation was carried out with the surface tension of 230 dynes/cm (Shartsis and Spinner, 1951), and the viscosity data in Figure 5-4. The char burnout time was assumed to be $100 \mathrm{~ms}$ (Helble, 1987). For the sample BA $\Lambda_{\mathrm{r} / \mathrm{c}}$ was $0.11(<1)$, and for sample $\mathrm{K} 3 \Lambda_{\mathrm{r} / \mathrm{c}}$ was $1.7 \times 10^{4}$, which was much greater than unity. Samples $\mathrm{K} 2$ and $\mathrm{K} 1$ gave values of the same order as sample K3.

According to the calculatio:, the sample BA would not coalesce and the samples K1, $\mathrm{K} 2$, and $\mathrm{K} 3$ would readily coalesce to form single particles from each of the char samples. The prediction was correct only for the samples having composition on the extreme ends, i.e., samples BA (no potassium) and $\mathrm{K} 1$ (high in potassium). The two intermediatecomposition samples -- samples K2 (medium in potassium) and K3 (low in potassium) -behaved differently than the prediction by the coalescence parameter. The following are the possible explanations for the behavior.

Silica particles incorporate potassium into themselves while they recede and scavenge the newly exposed potassium, which was buried in the carbon matrix. However since potassium has a very high vapor pressure at the temperature of the char burnout, most of the potassium vaporizes during the char burnout forming a cloud of potassium vapor. Now the interaction of the silica particles with potassium becomes limited to what is left in the carbon matrix, and what is vaporized and surrounds the char particle as a cloud. The more the initial content of the potassium is, the more the amount of it left in the char matrix.

According to Figure 5-4, the amount needed to reduce the viscosity by 4 to 5 orders of magnitude is about $5 \mathrm{~mol} \%$. Based on this argument, the amount of potassium incorporated to silica pirticles of sample $\mathrm{K} 1$ is greater than $5 \mathrm{~mol} \%$ while that incorporated to silica particles of samples $\mathrm{K} 2$ and $\mathrm{K} 3$ is between 2 and 5 mol\%.

The argument above and the use of the viscosity data for the calculations, of course, are all based on the assumption that the silica particles on the char surface are thermally in equilibrium. This is not necessarily true. For any given temperature, the transient viscosity of a polymeric melt measured during continuous cooling (heating) of the melt is always lower (higher) than the equilibrium viscosity obtained after holding the melt for some time at the temperature of the measurement. This difference is due to the sluggish rate of structural 
change in response to the change of temperature. If this relaxation rate is so low that the silica particles do not reach the thermal equilibrium within the char burnout time scale, the silica particles would behave very differently than those in equilibrium. Hetherington et al. (1964) showed the above behavior with vitreous silica.

A minor point to consider is the degree of mixing of potassium incorporated in the silica network. If the mixing is not complete down to the molecular level, the network breakdown would not be enough to lower the viscosity, and the coalescence behavior is not predictable with the given equilibrium data.

With all this argument, it is not trivial to quantitatively predict the degree of coalescence of silica particles in the presence of highly vaporizable potassium.

Additional studies with potassium-containing char samples were and are being carried out. These are the interaction of potassium with silica particles in the molecular level by XAFS, and aerodynamic behavior of the final ash particles by a cascade impactor. Results on the studies will be reported in the next quarterly report.

\subsection{References}

Eitel, W. (1954), Physical Chemistry of the Silicates, p. 630, Univ. of Chicago Press, Chicago.

Frenkel, J. (1945), J. Phys. (Moscow), 2, 385.

Helble, J.J., and Sarofim, A. F. (1989), Combust. Flame, 76, 183.

Hetherington, G., Jack, K.H., and Kennedy J.C. (1964), Phys. Chem. Glasses, 5, 130.

Hiram, Y. and Nir, A. (1983), J. Colloid Interface Sci., 25, 462.

Kang, S.G., Helble, J.J. (1988), 22nd Symposium (International) on Combustion, 231, The Combustion Institute, Pittsburgh.

Kuczynski, G.C., Neuville, B., and Toner, H.P. (1970), J. Appl. Polym. Sci., 14, 2069.

Levendis, Y. A. and Flagan, R.C. (1987), Comb. Sci. Tech., 53, 117.

Paul, A. (1982), Chemistry of Glasses, Chapman and Hall, London, p. 82.

Shartsis, L., and Spinner, S. (1951), J. Research NBS, 46, 385.

Stöber, W., Fink, A., and Bohn, E. (1968), J. Colloid Interface Sci., 26, 62. 


\section{SECTION 6}

Task 6

\section{BEHAVIOR AND EFFECTS OF COAL MINERAL MATTER IN A LABORATORY PULVERIZED COAL COMBUSTOR}

Neal B. Gallagher, Lawrence E. Bool III, Thomas W. Peterson, and Jost O.L. Wendt

Department of Chemical Engineering

University of Arizona 


\section{BEHAVIOR AND EFFECTS OF COAL MINERAL MATTER IN A LABORATORY PULVERIZED COAL COMBUSTOR}

\subsection{Introduction}

This report discusses some of the work performed during the last quarter studying inorganic matter transformations during pulverized coal combustion at the University of Arizona. Subsection 6.1.1 discusses work related to the fate of iron. Several imaging techniques were used on extracted flyash samples to deduce the form of iron oxide in the ash. Conclusions drawn from this work suggested that agglomeration of iron oxide particles with existing aluminosilicate particles was an important mechanism associating iron oxide with the silicate matter. Additional modelling work suggested that coagulation of extraneous pyrite with existing char particles may also be important.

Subsection 6.1.2 discusses recent burns of four coals performed in cooperation with a visiting investigator from PSI Technology Company. Extracted size segregated flyash samples were acquired using the cascade impactor sample system as in previous burns. In addition, an in-situ particle sizer from PSI was used to acquire optically measured flyash size distributions. Comparisons show fairly good agreement for samples with a significant fraction of the mass in the large particles sizes $(9$ to $10 \mu \mathrm{m})$, but differences between the two techniques grew more substantial as the fraction of sample mass in the micron and submicron range increased.

Finally, Subsection 6.1.3 discusses recent burns of cleaned coals in the down-fired combustor. Two burns of Illinois No. 6 SOAP proved difficult, perhaps due to softening of the coal at relatively low temperatures. Inspection of the burner showed extensive fouling of the cooling tubes with a black carbonaceous material. Two burns of chemically cleaned Kentucky No. 9 were more successful. Although the as-received coal contained approximately fifty percent moisture, the dried coal showed good feeding and combustion characteristics. The results of the elemental analysis of extracted flyash samples from combustion of the cleaned Kentucky No. 9 showed a significant enrichment of both potassium and sodium in the small size classes. However, the measured ash concentration was lowered by at least an order of magnitude compared to the parent coal.

\subsubsection{Fate of Iron During Combustion}

Two interesting issues arise from the examination of Mössbauer and CCSEM analyses of ash samples from various combusted coals. The first issue relates to how iron associates with silicates in the ash. One possibility is that iron may exist as discrete iron oxide particles agglomerated with discrete silicate particles. Another possibility is that the iron in the ash exists primarily as crystals in a silicate matrix. To resolve this question various solid techniques utilized to determine the iron-silicate association in the flyash. 
The second issue presented by the data relates to the likelihood of pyrite/iron oxide particles coagulating with the burning char. This question has been addressed in a simplified manner using an aerosol modeling code (MAEROS). The evidence initiating the investigation into these issues, the results obtained to date, and the future work to be done, are discussed.

\subsubsection{Iron Oxide Crystallization Versus Agglomeration}

Initial inspection of Mössbauer and CCSEM data for the Illinois No. 6 coal (see Table 6-I) presented a rather surprising discrepancy between the two techniques. According to the Mössbauer analysis approximately $84 \%$ of the iron was present as iron oxide. The CCSEM data , however, indicated that only $43 \%$ of the iron was found as "pure iron" (defined as containing a minimum of $90 \%$ iron on an oxygen free basis). Two possible mechanisms were hypothesized to explain this discrepancy (see Figure 6-1). The first hypothesis was that the iron and silicates exist as a melt in the combustion zone. Subsequent cooling then causes crystallization of iron oxide out of the melt, resulting in iron oxide crystals embedded in a glassy silicate matrix. The second hypothesis suggested that a discrete iron oxide particle could agglomerate with discrete silicate particles. In both cases the CCSEM would "see" the agglomerate as a single large particle containing silicon and iron. The Mössbauer, on the other hand, would still recognize the iron oxide as discrete particles (e.g., not chemically bound to the silicates). Thus, tie CCSEM would indicate a lower "pure iron" percentage than the Mössbauer. In order to differentiate between the two mechanisms described above a range of analytical tools was brought to bear on the ash samples.

Table 6-1 Comparison of Iron Analysis for Ash from Various Coals

\begin{tabular}{|c|c|c|}
\hline 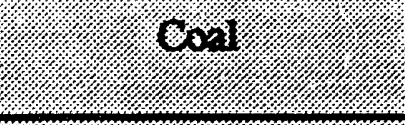 & 9.160 .040 & $\begin{array}{l}\text { Five Onide } \\
\text { (cesEu) }\end{array}$ \\
\hline Ilines No. 6 & 84 & 43 \\
\hline Geuran IIgane & 71 & 42 \\
\hline Eigl-mollt & 46 & 25 \\
\hline Sertudy II & 75 & 31 \\
\hline 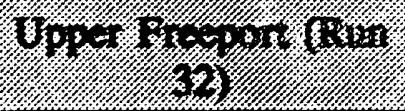 & 70 & 16 \\
\hline Upper Irourit (Rin & 60 & \\
\hline
\end{tabular}




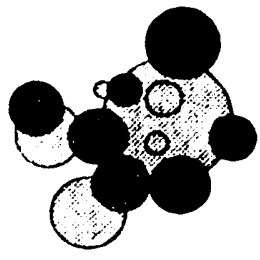 \\ Agglomerate of \\ Iron Oxide and Silicate Particles \\ Char With Included Minerals \\ Iron Oxide Crystals in Silicate Matrix}

Figure 6-1. Iron-Silicate Interactions

The first analytical tool used was an SEM coupled with an X-Ray detector. Approximately 11 particle agglomerates from an ash sample from a Beulah Lignite run were analyzed. Individual particles in each agglomerate were analyzed and their iron concentrations (relative EDX peak height) were compared. Of the 11 particles analyzed, only one showed any evidence of an iron oxide particle agglomerated with silicate particles. In this agglomerate a large particle was very enriched in iron as compared to other particles in the agglomerate. However, other agglomerates analyzed were found to contain either no appreciable iron or only a small, relatively constant, iron concentration. These findings would seem to support both proposed hypotheses to some degree, and thus were somewhat inconclusive.

When it became apparent that the EDX-SEM work alone was not sufficient to determine which mechanism may be dominant, a new technique, XRD (X-Ray Diffraction) was utilized to confirm the presence of iron oxide crystals. This technique involved spreading a small amount of ash (collected from the ash trap of an Illinois No. 6 run) on a glass or plastic slide. The sample was then bombarded with $x$-rays at various angles. The intensity of the $x$-rays emitted for various angles allows the determination of the crystalline form of a species. The spectra shown in Figure 6-2 when compared with Table 6-2, indicate that iron oxide crystals were indeed present.

When the XRD data indicated that, at least for the Illinois No. 6 coal, iron oxide particles did indeed exist, Auger mapping and sputtering was utilized to attempt to find the crystals in the silicate lattice. However, no appreciable iron was found in any of the particles analyzed by this method so the next method was utilized. 


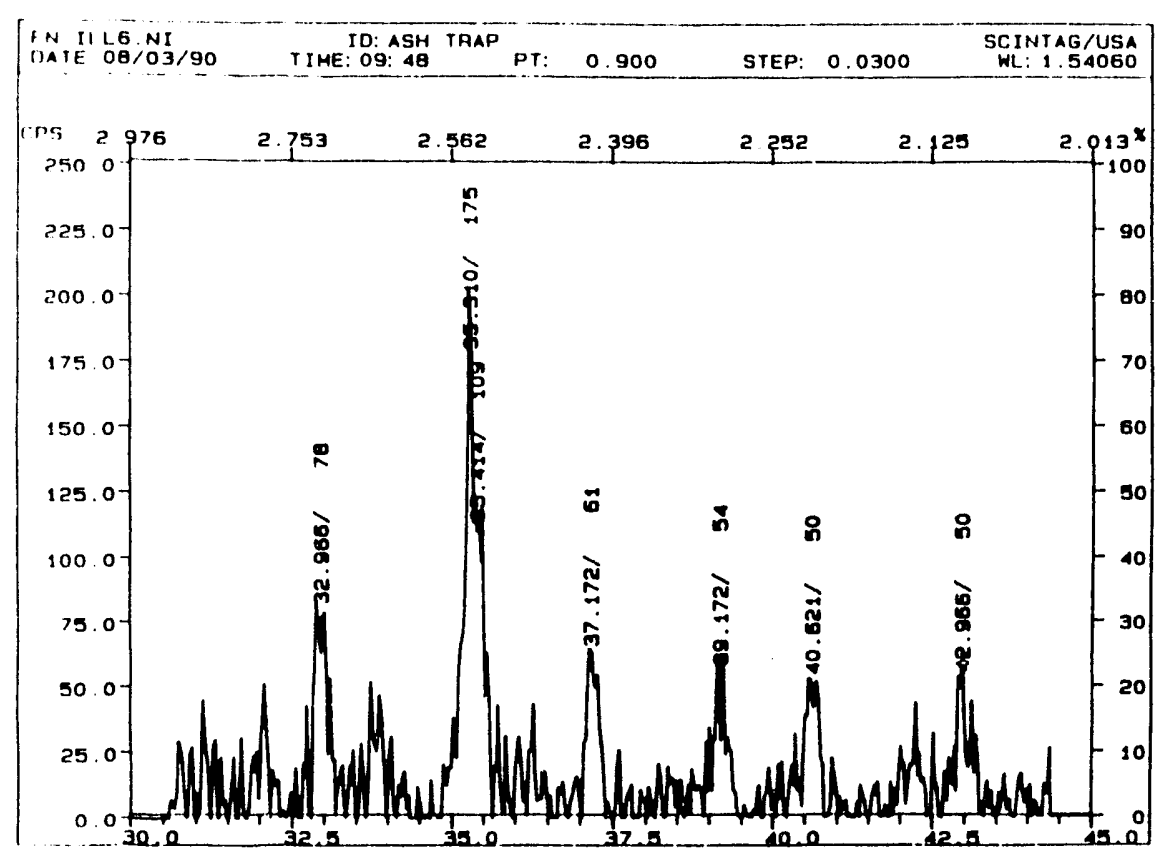

(a)

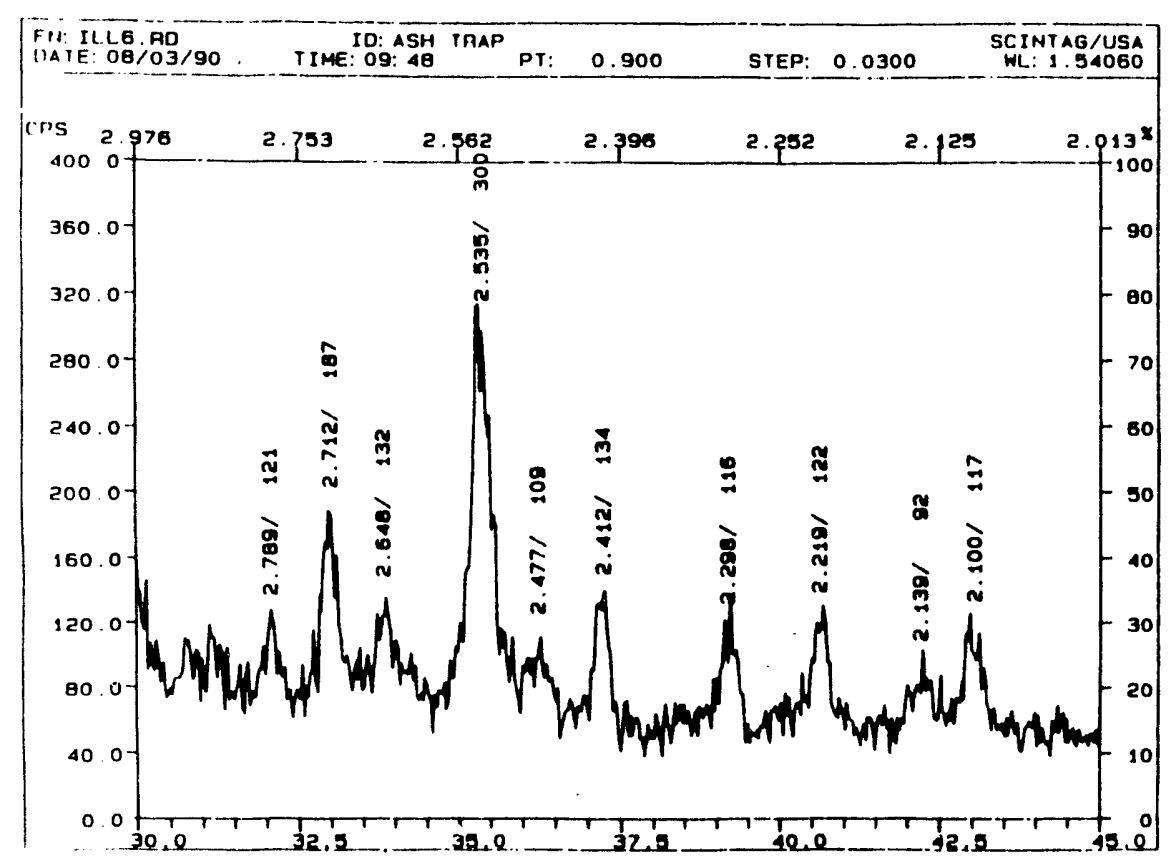

(b)

Figure 6-2. XRD Spectrum from Illinois No. 6 Ash Trap Sample 
Table 6-2. Major XDS Angles for Magnetite and Hematite

\begin{tabular}{|c|c|c|}
\hline $80=2101$. & 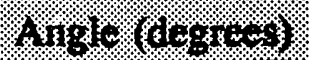 & 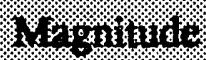 \\
\hline \multirow[t]{3}{*}{ 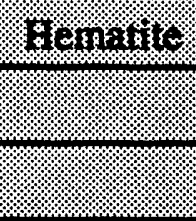 } & 33.15 & 100 \\
\hline & 35.61 & 70 \\
\hline & 40.86 & 20 \\
\hline \multirow[t]{3}{*}{ 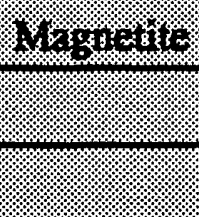 } & 30.10 & 30 \\
\hline & 35.42 & 100 \\
\hline & 43.06 & 20 \\
\hline
\end{tabular}

The next analytical tool utilized was a TEM (Transmission Electron Microscopy) at the High Resolution Electron Microscopy (HREM) Facility at Arizona State University. A small amount of ash (collected from the same ash sample used in the XRD analysis above) was introduced into a small amount of propanol and ground into a fine powder. The maximum thickness that can be used in this technique is on the order of 0.1 to $0.2 \mu \mathrm{m}$. A drop of the slurry was then placed on a carbon membrane supported by a copper grid and allowed to dry. The sample was then analyzed.

The initial investigations, conducted by Roger Graham and Larry Bool on the Philips 400T at the HREM facility found the following;

1. Large glassy particles (fairly common)

2. Clusters of plate-like crystals, beam sensitive (easily damaged by the beam), (common)

3. Large particles of beam stable material, giving convergent beam electron diffraction patterns (CBED) with good detail, (uncommon)

4. Composite particles of small, needle-like, beam stable crystalline material embedded in a glassy matrix (rare).

A subsequent session found the following;

1. The large glassy particles contained predominantly $\mathrm{Si}, \mathrm{Al}, \mathrm{Ca}, \mathrm{K}, \mathrm{Fe}$ (see Figure 6-3)

2. The clusters of plate-like particles were predominantly $\mathrm{Ca}, \mathrm{S}, \mathrm{Si}$ (see Figure 6-4) 


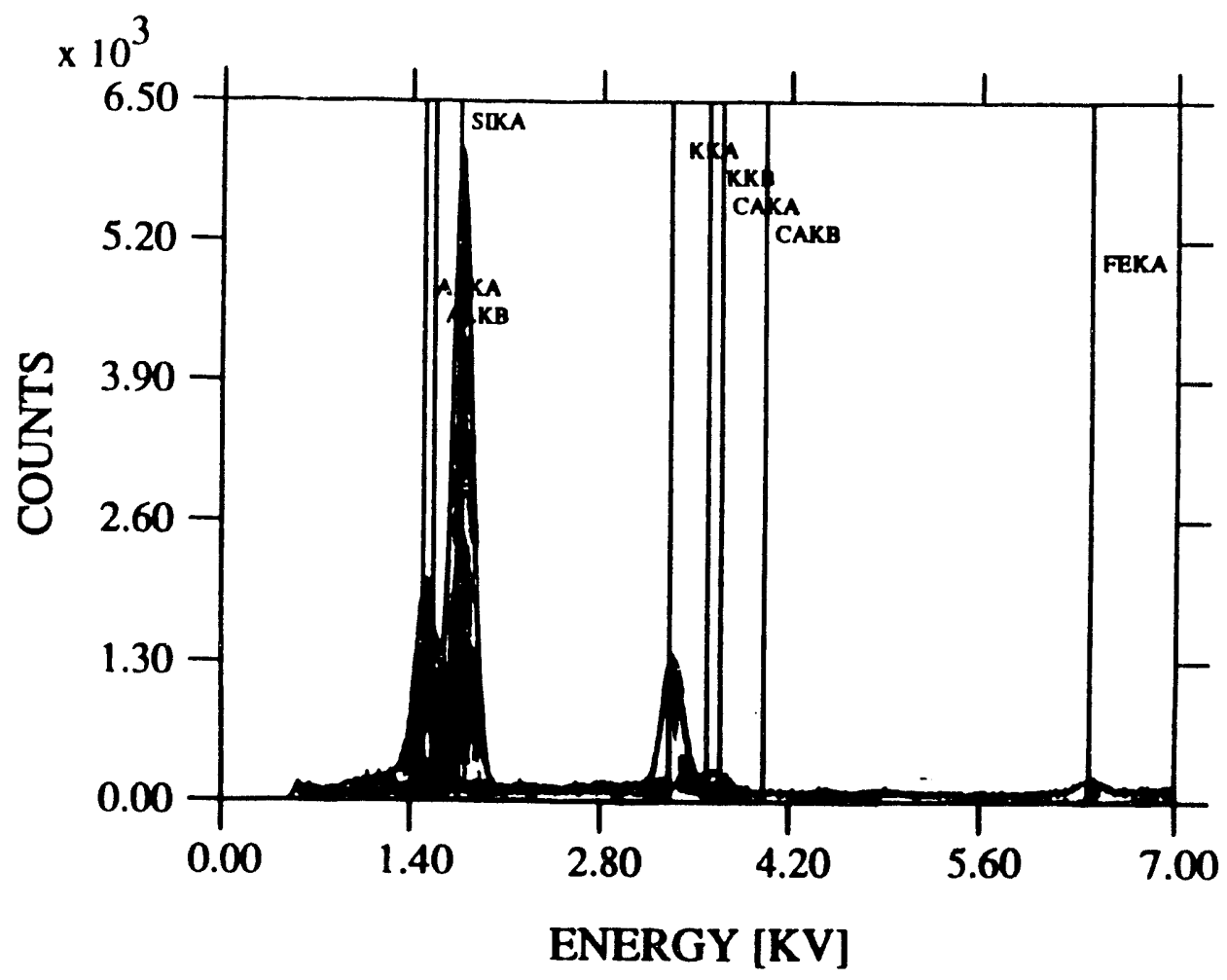

Figure 6-3. EDX Spectrum of Large Glassy Particles

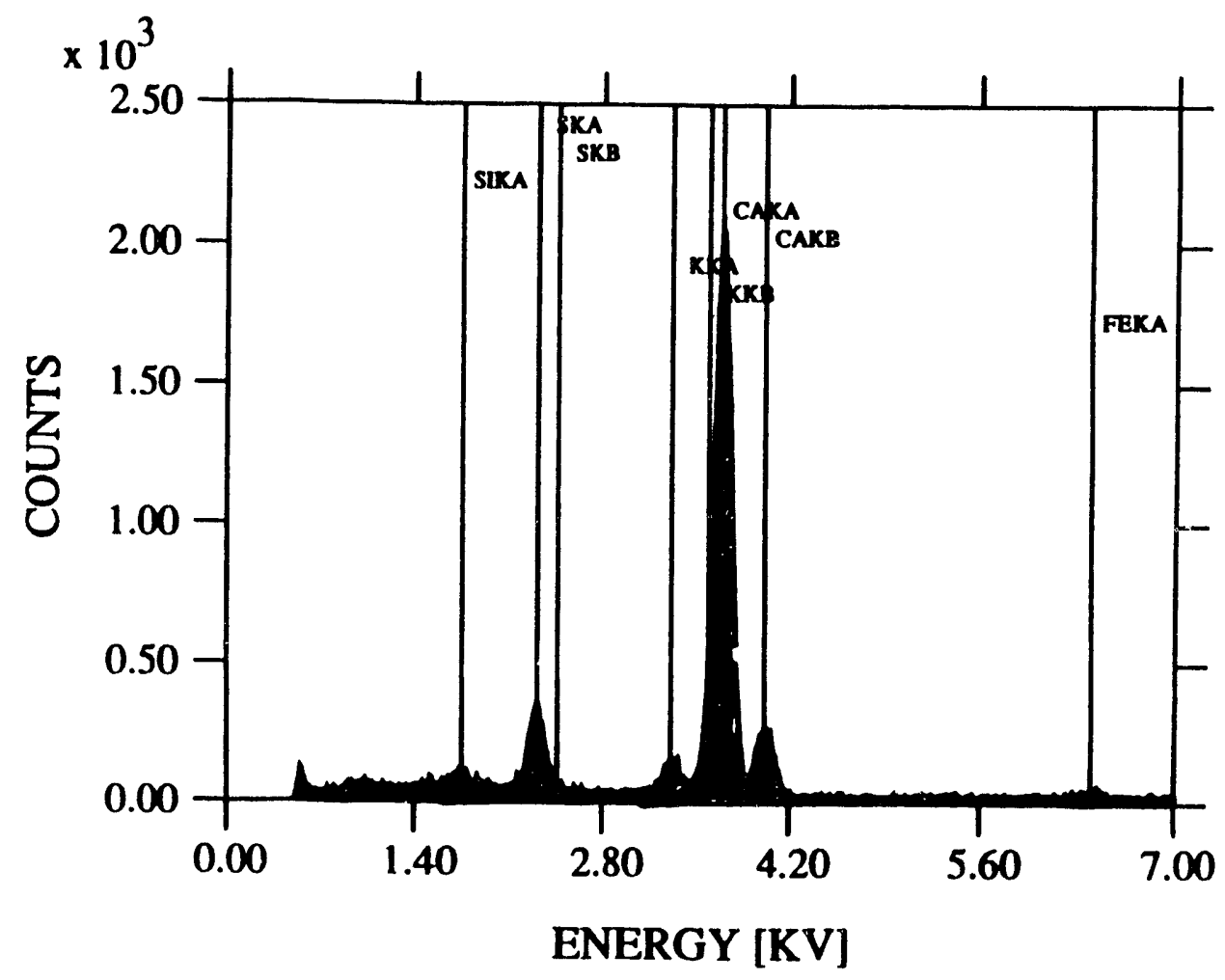

Figure 6-4. EDX Spectrum of Plate-Like Particles 


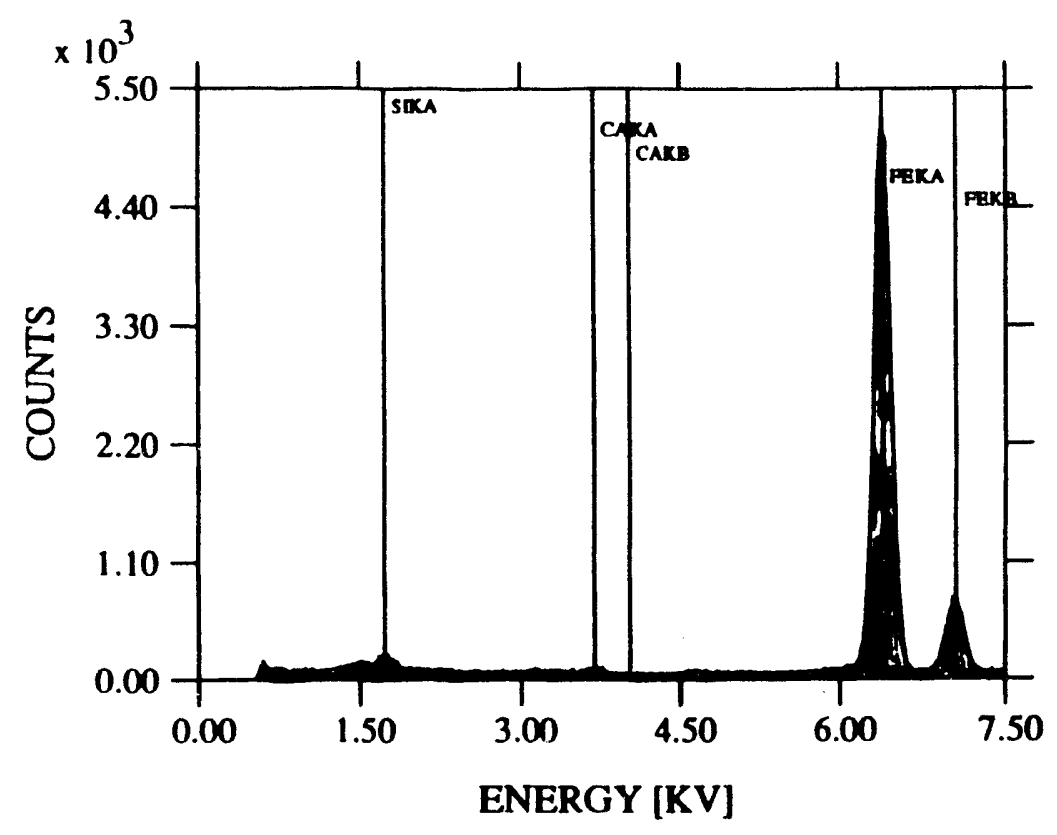

Figure 6-5. EDX Spectrum of Large Beam-Stable Particles

3. The large particles of beam stable material were almost completely pure Fe (see Figure 6-5)

4. The glassy matrix of the composite particles was made up of $\mathrm{Al}, \mathrm{Si}, \mathrm{Ca}, \mathrm{Fe}$ while the small needle-like particles contained the same species but contained less iron and more aluminum than the matrix (see Figures 6-6 and 6-7)

5. A group of small needle-like particles (not in a matrix) not noted in the initial investigation contained almost pure $\mathrm{Ca}$, may have been a result of water absorption by a hygroscopic Ca species during the layover between sessions.

In addition, the particles mentioned in (3) above were assumed to have come from a discrete iron oxide particle as the typical dimensions were $1 \mu \mathrm{m}$ by $0.3 \mu \mathrm{m}$. The CBED spectrum collected from this particle also identified it as $\mathrm{Fe}_{2} \mathrm{O}_{3}$. Thus, this evidence would seem to support an agglomeration mechanism as the only iron crystals found were determined to have been part of a discrete particle. This analysis was also performed on ash from the Beulah Lignite coal with similar results.

After the TEM results were obtained, the particles were analyzed utilizing an X-Ray mapping routine. An agglomerate was analyzed and mapped for $\mathrm{Fe}, \mathrm{Si}, \mathrm{Al}, \mathrm{Ca}, \mathrm{Mg}, \mathrm{K}, \mathrm{Na}$. Areas of apparently enriched iron were then magnified and reanalyzed until the source of the iron enrichment was determilned. In almost all cases the source of enrichment was one or more "pure" ir(ul particles (as evilentual hy the EDX maps) agglomented with sillicate particles. This behavior can be seen in lifgures 6-8 through 6-15. In addition, this behavior was notad in both the study coals analyzed (Beulat, /,ignite and Illinois No. 6). This evidence suggests that the agglomeration mechanisn, " $/ s$ she dominant pathway for ironsilicate interactions within the char matrix. In addition, beth the improbability (much less 


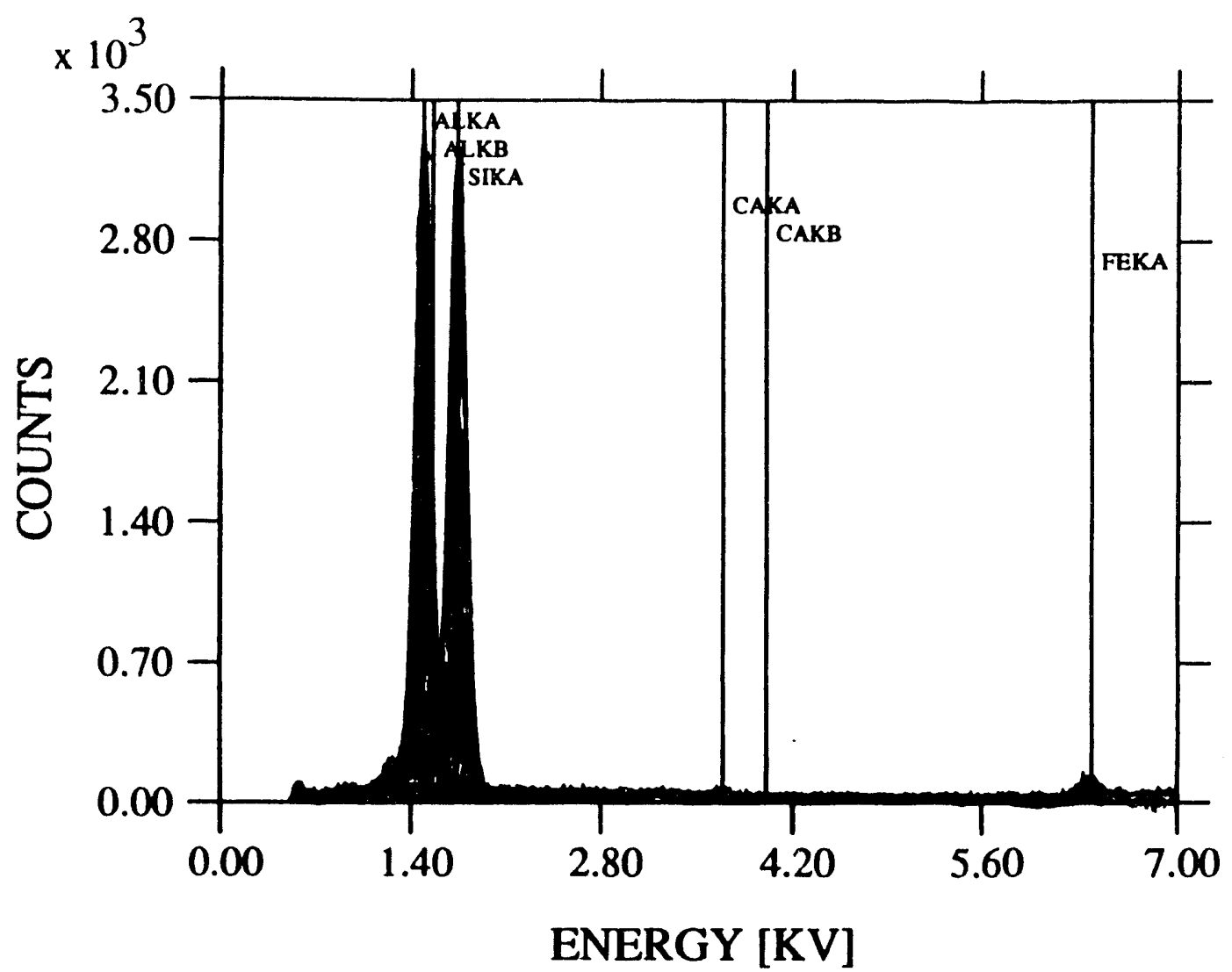

Figure 6-6. EDX of Needle-Like Particles in Composite Particles

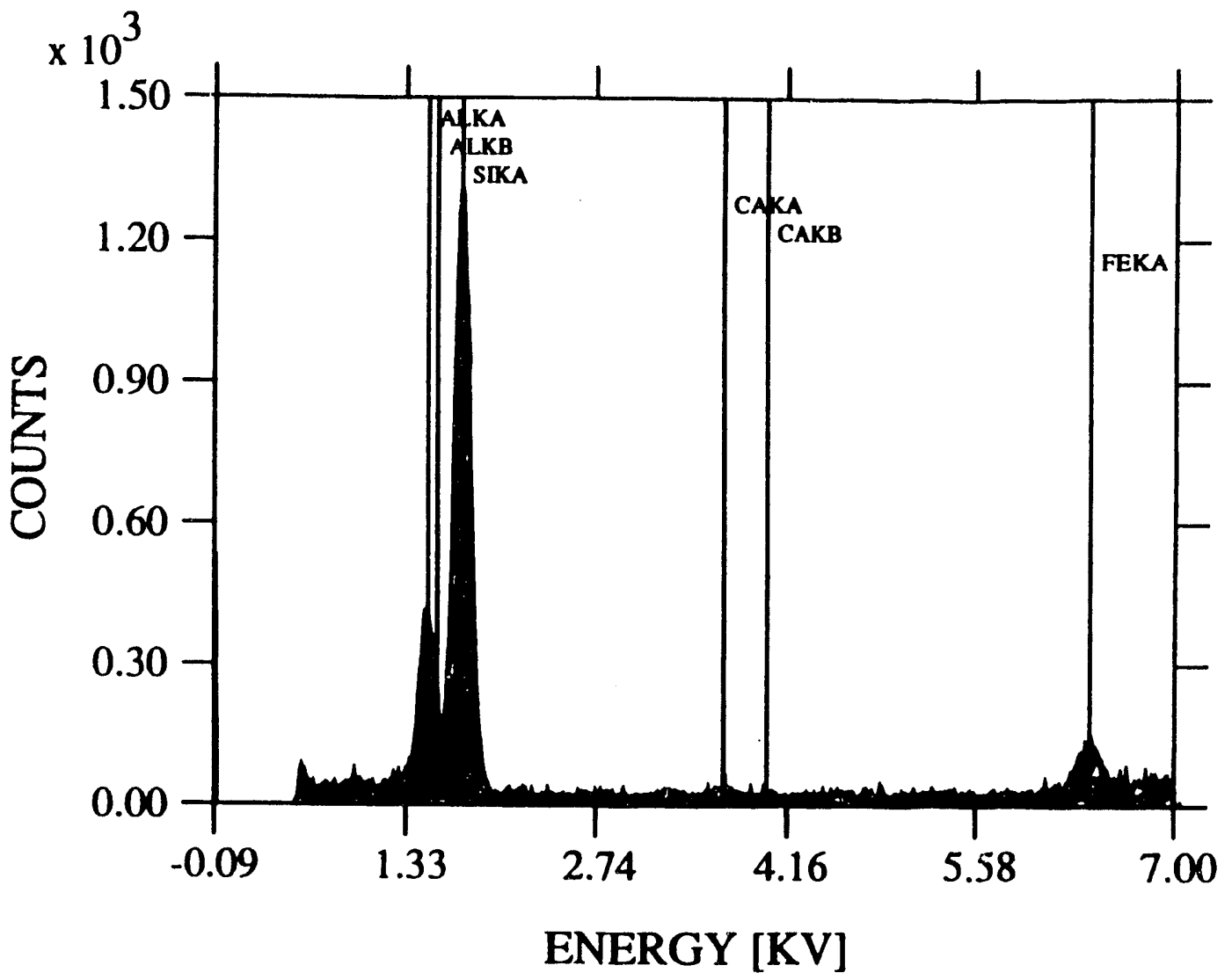

Figure 6-7. EDX of Glassy Matrix of Composite Particles 


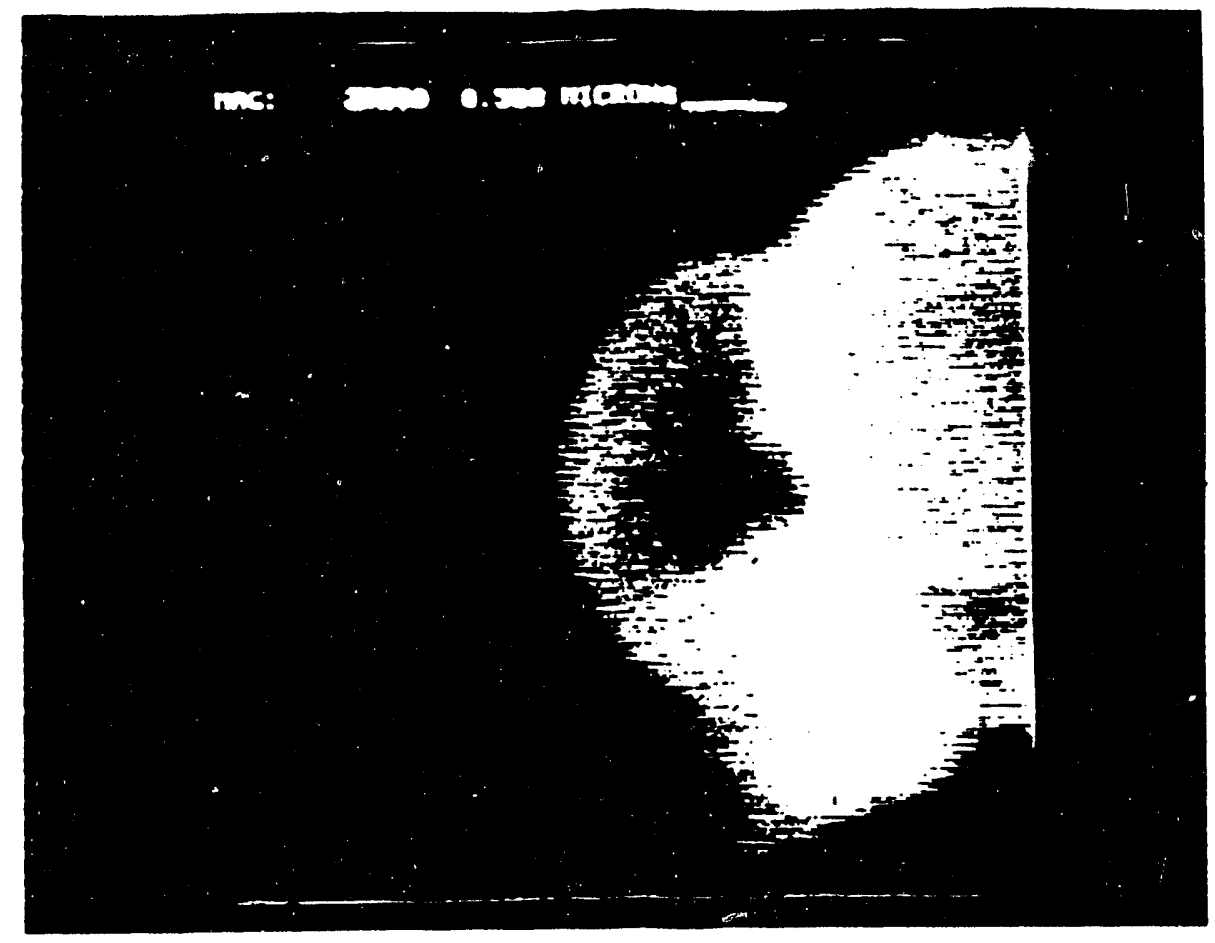

Figure 6-8. Ash Agglomeration from Beulah Lignite, Plate 1

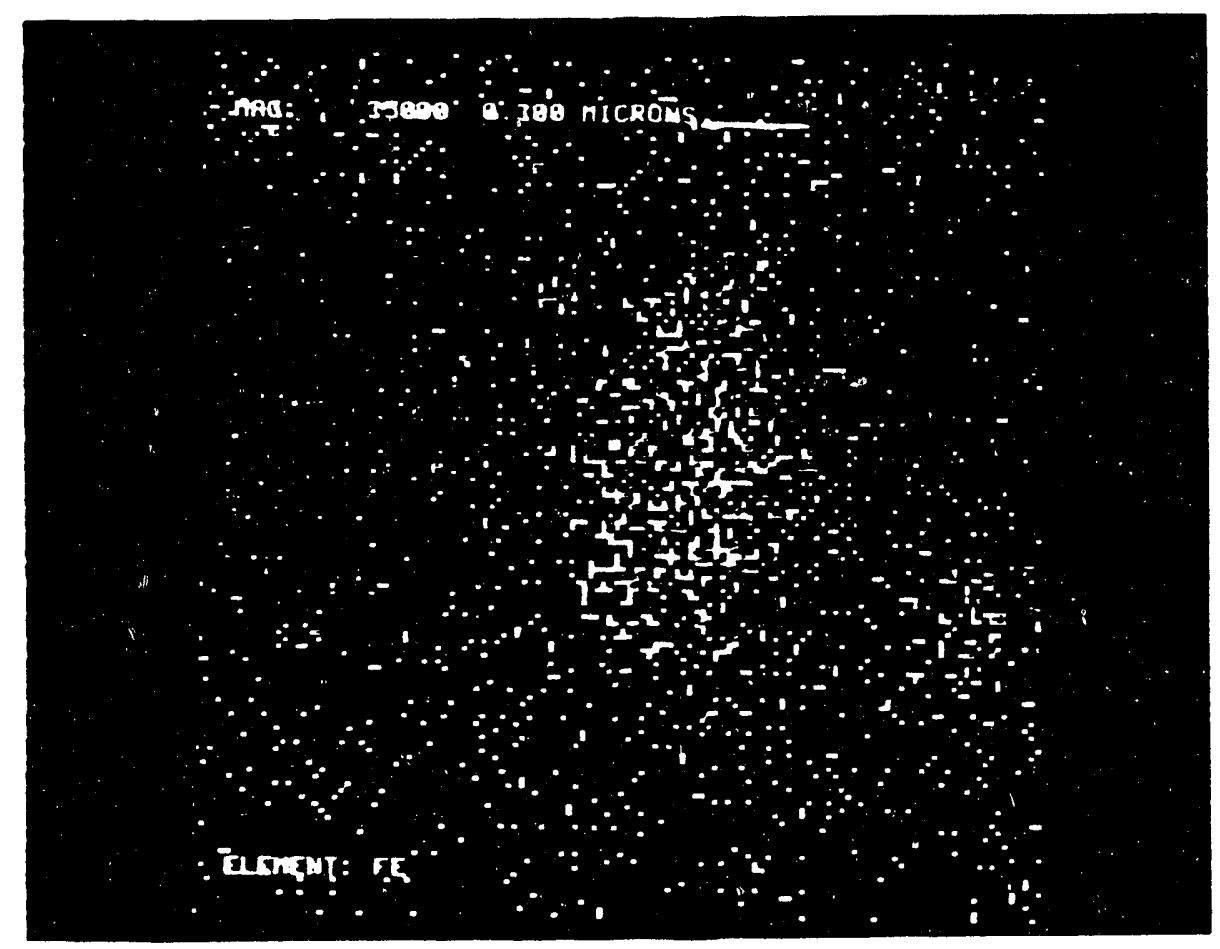

Figure 6-9. Fe Map, Agglomerate in Figure 6-8 


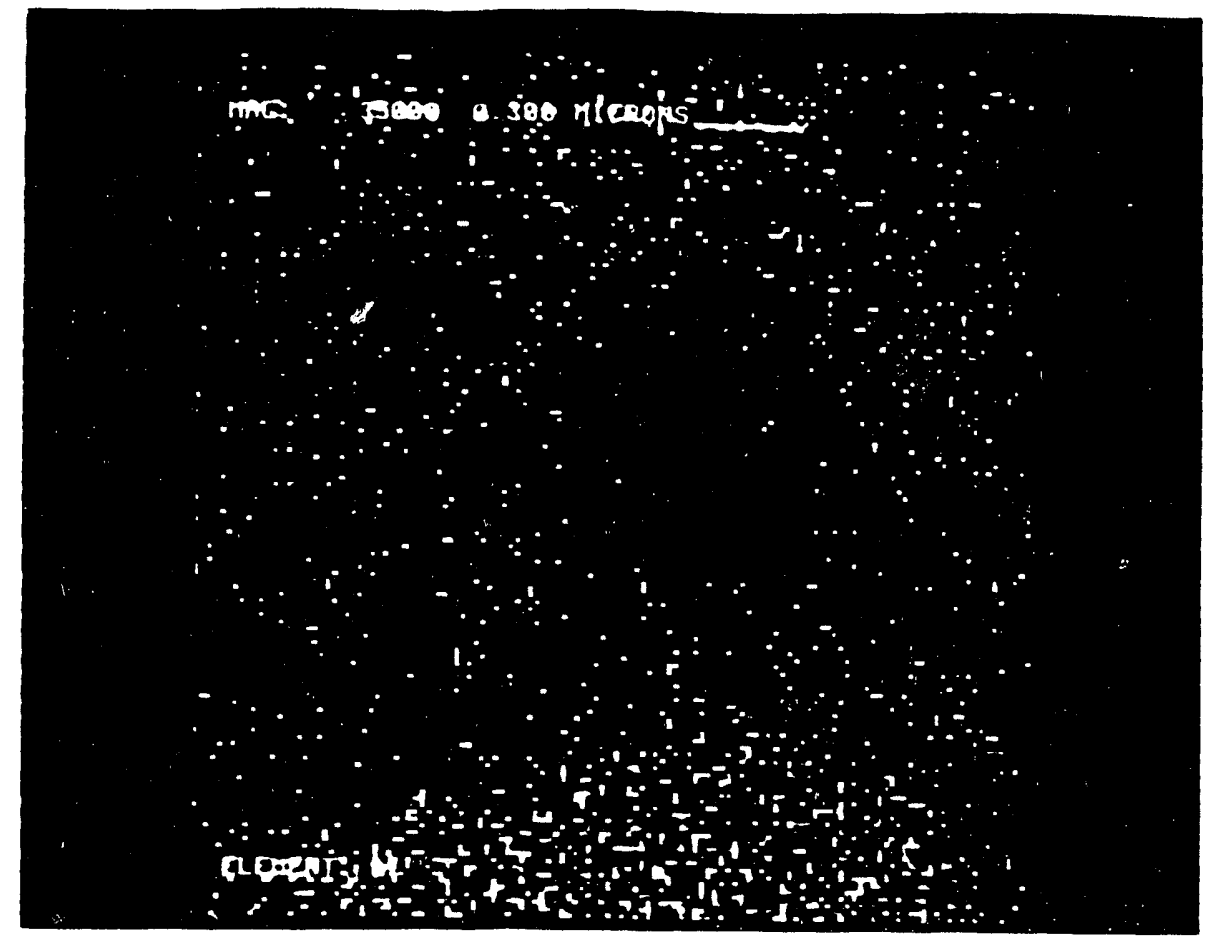

Figure 6-10. Si Map. Agglomerate in Figure 6-8

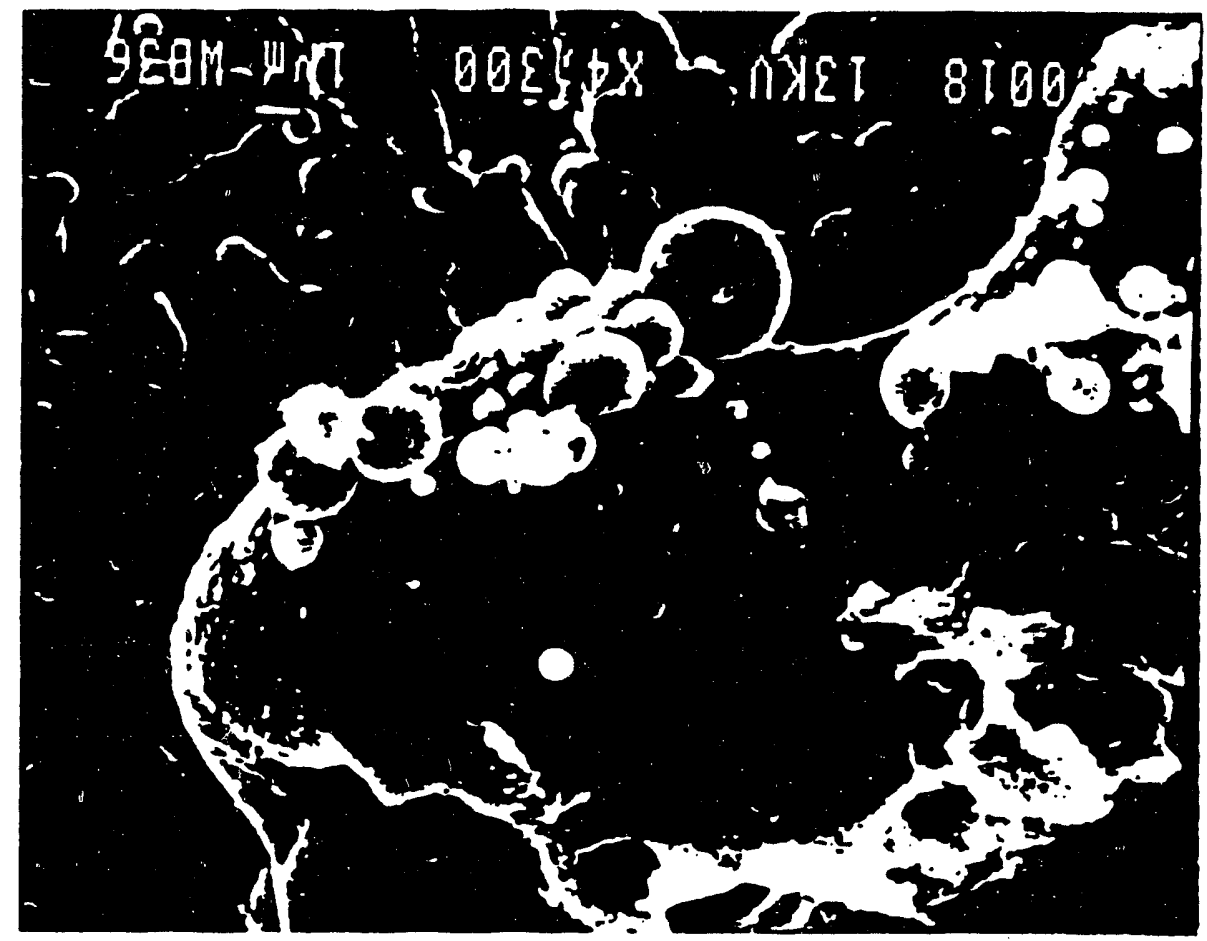

Figure 6-11. Agglomerate in Figure 6-8 Under Lower Magnification 


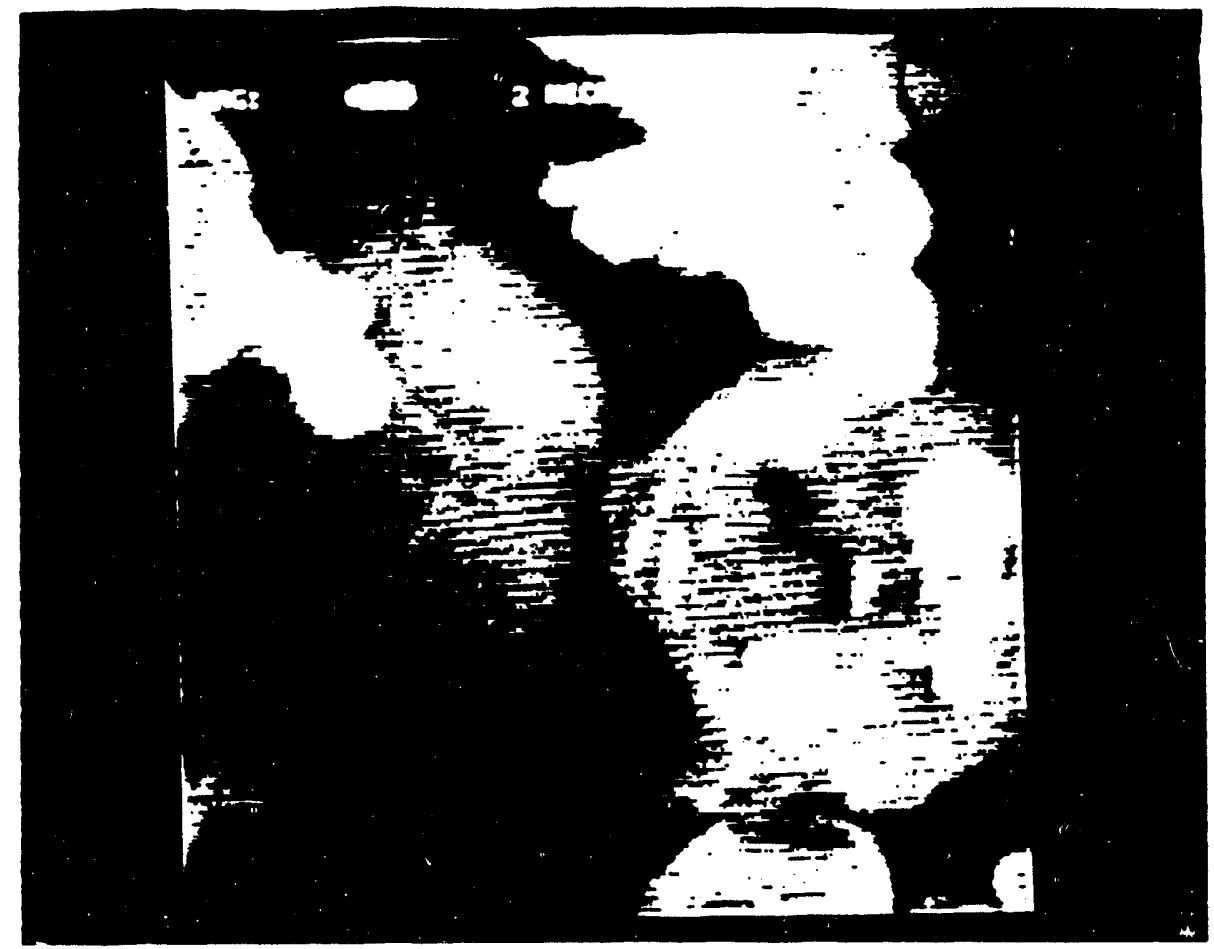

Figure 6-12. Ash Agglomerate from Illinois No. 6, Plate 1

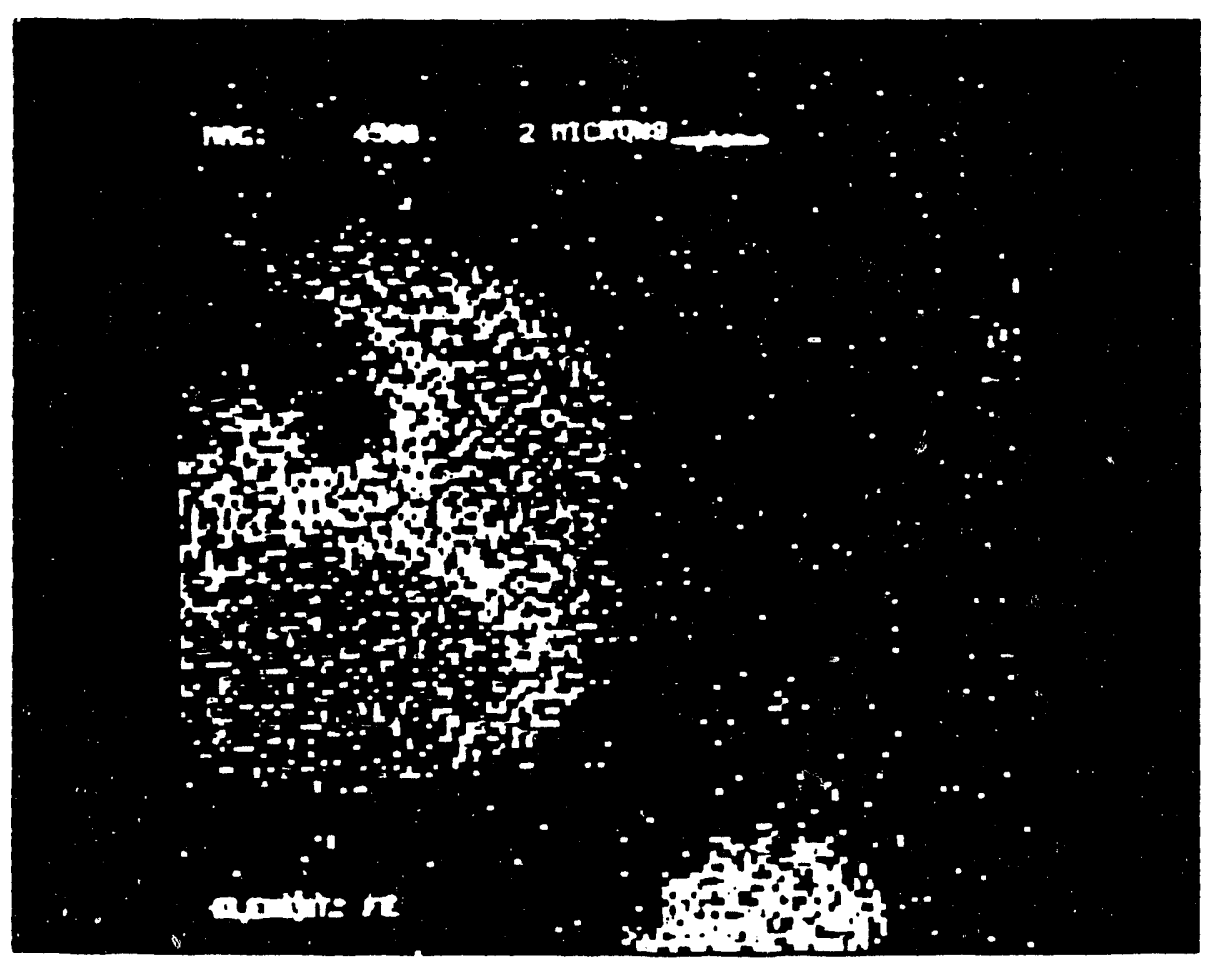

Figure 6-13. Fe Map, Agglomerate in Figure 6-10 


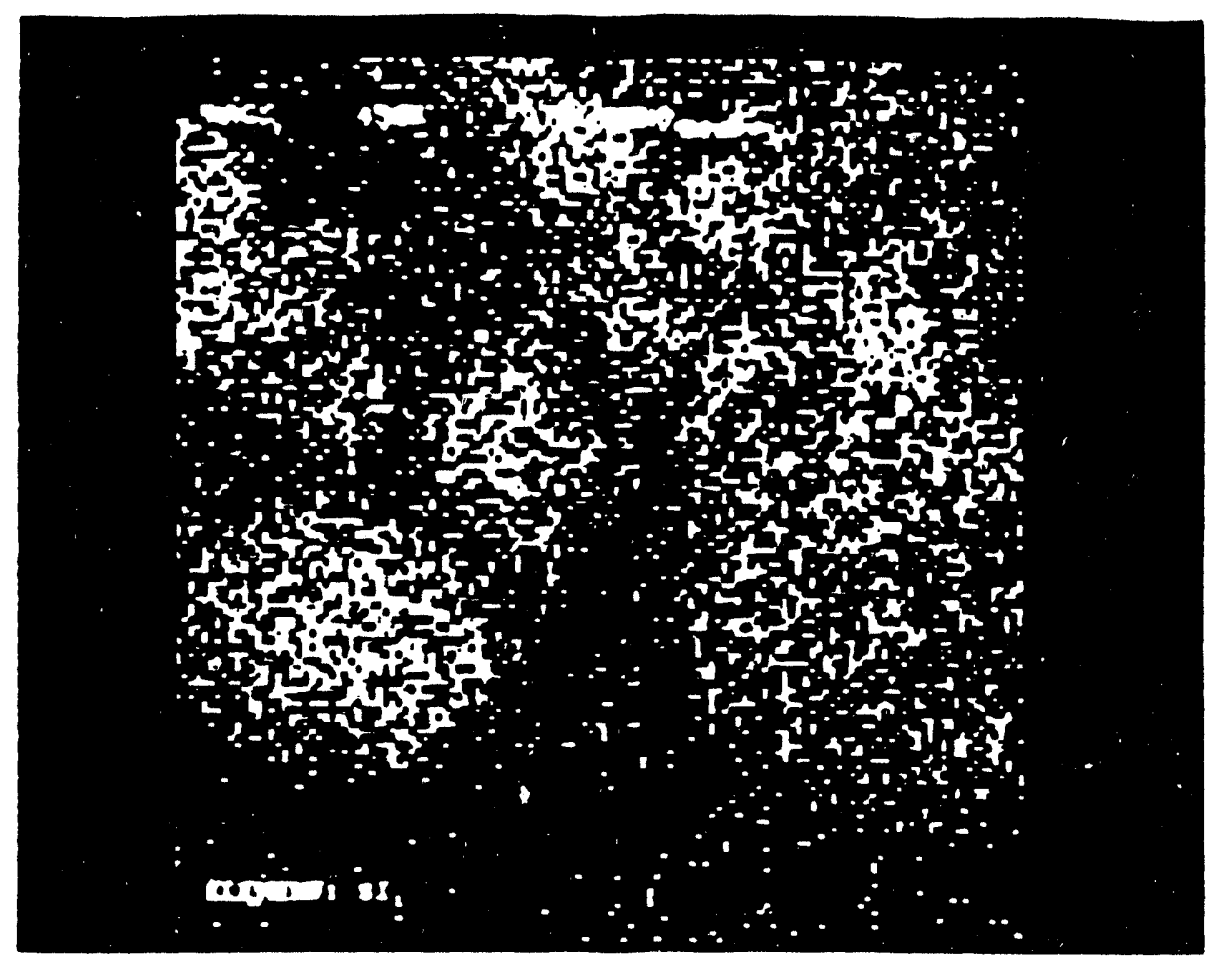

Figure 6-14. Si Map, Agglomerate in Figure 6-12

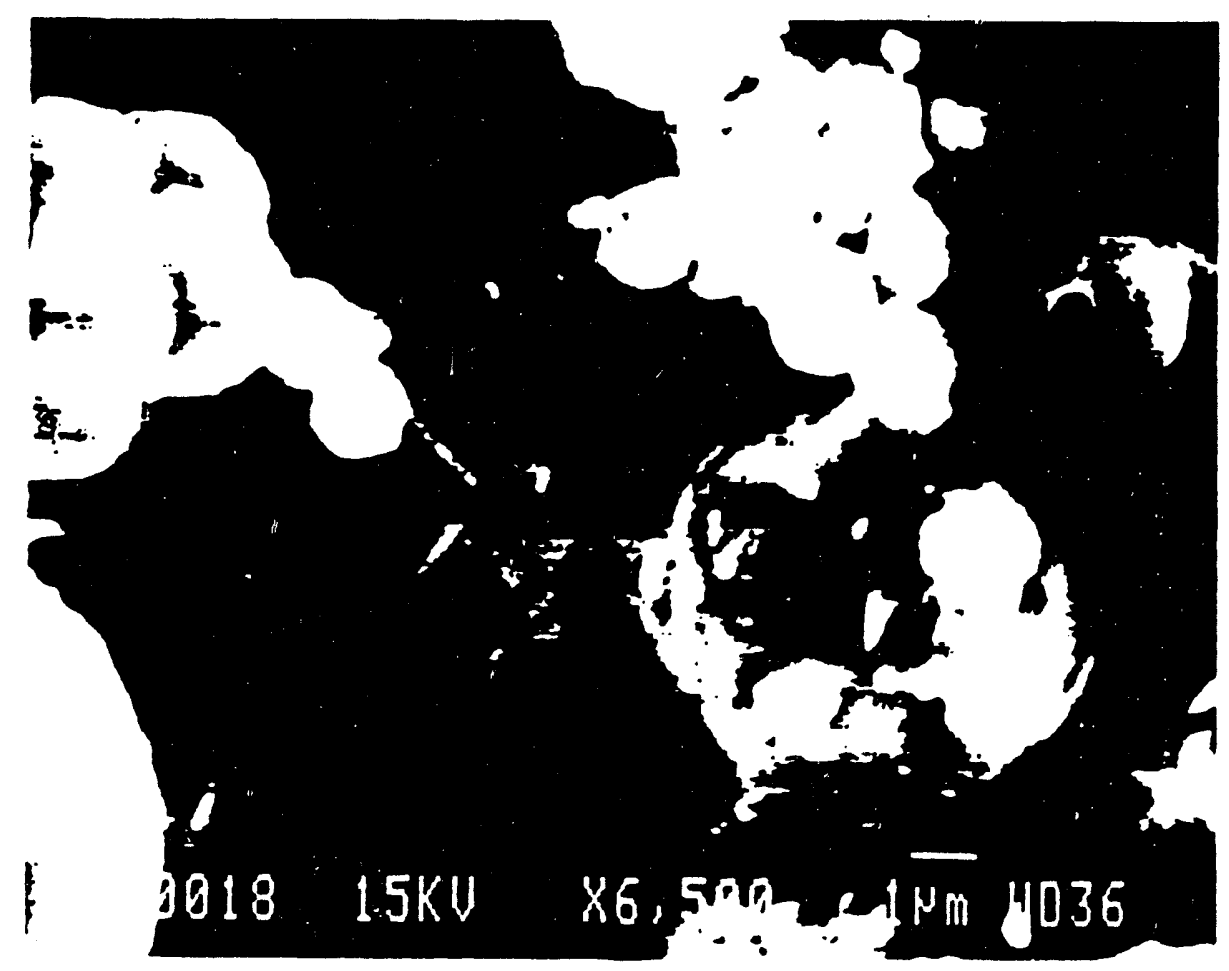

Figure 6-15. Agglomerate in Figure 6-12 Under Lower Magnification 
than $10 \%$ ) of iron particles of these sizes impacting on the first impactor plate, and the relatively low particle temperatures (approximately room temperature) during size classification indicate that the agglomerates were formed during the combusticn process, not as an artifact of the sampling technique.

\subsubsection{Pyrite-Char Coagulation}

Another interesting issue was raised while looking at the Mössbauer and CCSEM data discussed above and shown in Table 6-1. Although approximately 56\% of the pyrite initially in the Beulah Lignite coal (the only source of iron for this coal) was larger than $40 \mu \mathrm{m}$ and thus can be reasonably assumed to be extraneous to the char matrix, only $40 \%$ of the iron was shown to be iron oxide by the CCSEM. Thus, there would seem to be some mechanism by which the pyrites are coming in contact with the silicates. The only reasonable mechanism for this pyrite-silicate interaction is coagulation of the pyrites (either before or after fragmentation) with the char, as shown in Figure 6-16. To test this hypothesis a number of "back of the envelope" calculations were performed using the data for the Beulah lignite coal runs. These initial estimates showed that differential settling is the only mechanism causing appreciable coagulation. The same Beulah lignite system was then modeled using the MAEROS program. However, it was first necessary to calculate particle density as a function of size.

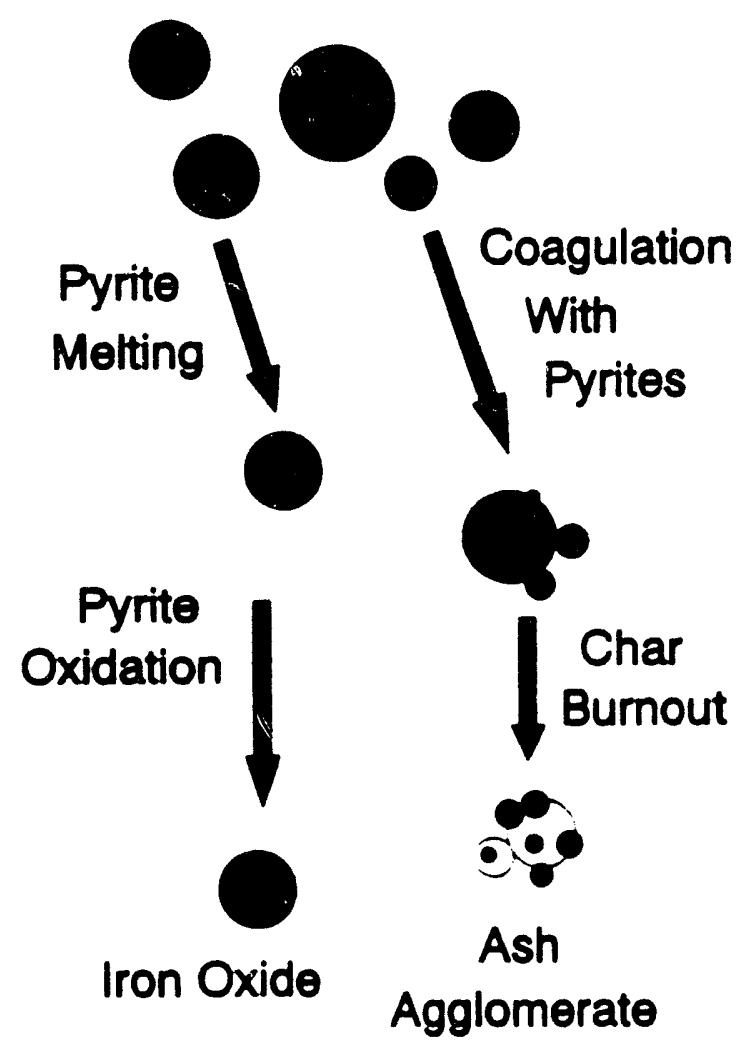

Figure 6-16. Pyrite-Char Interactions 
First it was assumed that the pyrite particles were less than $50 \mu \mathrm{m}$, the char around $71 \mu \mathrm{m}$. Then, by assuming that any single char particle could coagulate with several pyrites, but that the converse was not possible, it was then possible to calculate a mass or volume averaged density for particles formed from the coagulation of the char and the pyrites. The results indicated that in 1.23 seconds (approximately the residence time for char burnout) approximately $12 \%$ of the mass moved into the size range larger than the char, indicating that approximately $12 \%$ of the discrepancy noted above may be due to the coagulation of pyrites with the char. It should be noted, however, that the size of the char was not allowed to shrink due to burnout. Thus, the calculated coagulation rate may by higher than the true rate. These estimates suggest that some char-pyrite coagulation may take place but probably not to a large degree.

\subsubsection{Future Work}

Future work in this area includes performing experiments with a coal that is doped with a known amount of extraneous pyrite. The logical choice would be to utilize a coal that contains no extraneous mineral matter (e.g., a cleaned coal) specifically the Illinois No. 6 SOAP, for these experiments. If coagulation in the dispersed phase does take place, the amount of iron as iron oxide (from CCSEM) would be significantly lower than the amount of extraneous pyrite added. If no coagulation takes place, the amount of iron as oxide (from CCSEM) would be the same as for the base case plus the added pyrite. The necessary pyrite has been obtained and the experiments should be conducted shortly.

Initial attempts to burn the Illinois No. 6 SOAP coal, however, have been relatively unsuccessful due to coal sticking to the bumer plenum. Initially, higher velocities through the plenum (from addition of approximately $50 \%$ more nitrogen) were attempted to reduce sticking. This method was unsuccessful. The coal was then dried for approximately $26 \mathrm{hr}$ in an oven at $75^{\circ} \mathrm{C}$. Unfortunately the same results were obtained when the burn was attempted again. It was decided that the asphalt binder in the coal was probably causing the problems. In the future, burns will be attempted such that the peak temperature in the furnace will be artificially moved down the furnace (as opposed to the top of the furnace as discussed later in Subsection 6.3.1). It is hoped that the lower temperatures at the plenum will reduce the sticking problems.

The silicon-iron agglomeration pathway described in Subsection 5.1 .1 will also be utilized to propose a model to predict the final form of iron in the ash. The model should be based on a competition between molten iron sulfide either agglomerating with molten silicates (forming a glass) or oxidizing, crystallizing, and subsequently agglomerating (forming the agglomerates previously discussed). Important variables are, therefore, the coal composition, temperature, and oxygen partial pressure. Model development, and experiments to determine model parameters, continues. 


\subsection{Burns 47 - 50: Impactor and PCSV Samples}

Size distributions of flyash samples extracted from a combustor may be affected by the extraction process itself. For example, the high quench rate in a sample extraction probe can cause existing vapor species to condense homogeneously and heterogeneously. Other factors, including coagulation of flyash particles in sample lines, can influence the resulting size distribution which is measured. It would be desirable to compare flyash size distributions measured by extraction and collection via cascade impactor with in-situ optical size distribution measurements. Measurements of size distributions with the two techniques might yield some information on distribution biasing due to extractive sampling. Presented below are results from measurements of extracted flyash samples and measurements made in-situ.

Ash particle size distributions were measured during a series of burns conducted in the down-fired combustor at the University of Arizona. During the burns of four coals, ash samples were acquired using the cascade impactor sample system discussed previously (Boni, et al, 1990), and ash size distributions were measured using an in-situ particle counting sizing and velocimetry (PCSV) instrument (Insitec). Samples were collected with the cascade impactor for analysis by atomic absorbance (AA) at the $\mathrm{U}$ of $\mathrm{A}$, and samples were sent to the University of Kentucky for computer controlled scanning electron microscopy (CCSEM) analysis. Impactor samples analyzed by AA, inversions of cascade impactor data, and PCSV distributions are presented and discussed.

Modifications to the down-fired combustor were required to allow utilization of the PCSV. Sample port 14 was removed and a four inch diameter hole was cut into the fire tube (nominal port size was two inches) such that the top of the PCSV was approximately $5.05 \mathrm{~m}$ down from the burner. Refractory was cast and mated to the fire tube for mechanical support of the PCSV. Refractory plugs were also cast to seal the four inch port when not in use by the PCSV and also to seal the fire tube when the refractory supports were removed.

CCSEM and Mössbauer analysis require relatively large sample mass in comparison to AA analysis. However, typical impactor samples have a large percentage of the collected mass on the top impactor plate (stage 1). In some cases $90 \%$ of the mass may be found on the top plate. In an effort to increase the sample mass in the smaller sizes for CCSEM analysis, several of the lower impactor plate: were combined and sample acquisition times were increased. Cascade impactor samples acquired for CCSEM analysis consisted of three size segregated samples: plate 1, plates 2 through 4 , and plates 5 through the after-filter. Visual inspection of the samples suggested that particle bounce and re-entrainment may have occurred with the extended sample times due to an inordinate amount of mass on the top stage. Particle bounce in the impactor would tend to shift the mass distribution to smaller sizes.

Each of the four coals burned in this set of experiments focussed on mechanisms that were important in a different particle size range. Previous results suggested that large flyash particle interactions could be studied with burns of Illinois No. 6. Beulah Lignite showed 
interesting behavior in all size ranges and Loy Yang was of interest due to the significant production of small flyash particles with this coal. Table 6-3 summarizes the experiments and samples acquired during each burn. Impactor samples for AA and CCSEM analysis were acquired from combustor sample port 11 as in all previous burns (Boni, et al, 1990). In addition samples were collected from sample port 5 in burns 47 and 48.

Ideally an in situ probe would not affect combustion conditions. However, it should be noted that the relative size of the PCSV compared to the inside diameter of the fire tube could significantly affect flow in the combustor. Inserting the isokinetic sample probe into the combustor reduced the flow area to approximately $90 \%$ of the original whereas the PCSV reduced the flow area to approximately $37 \%$ of the original. In addition, radiation losses to the relatively large water cooled jacket surrounding the PCSV (4 inch outside diameter compared to the 6 in. inside diameter of the fire tube) could change the temperature profile observed by the evolving flyash size distribution.

Table 6-3. Summary of Experiments and Acquired Samples

\begin{tabular}{|c|c|c|c|}
\hline $\begin{array}{l}\text { Burn } \\
\text { No. }\end{array}$ & Coal & $\begin{array}{c}\text { Feed Rate } \\
\text { (kg/hr) }\end{array}$ & Samples \\
\hline 47 & $\begin{array}{l}\text { Illinois } \\
\text { No. } 6\end{array}$ & 1.3 & $\mathrm{AA}^{*}, \mathrm{CCSEM}^{*}, \mathrm{PCSV}$ \\
\hline 47 & $\begin{array}{l}\text { Illinois } \\
\text { No. } 6 \\
\end{array}$ & 2.4 & $\mathrm{AA}^{*}, \mathrm{CCSEM}^{*}$ \\
\hline 48 & $\begin{array}{l}\text { Beulah } \\
\text { Lignite }\end{array}$ & 1.6 & $\mathrm{AA}^{*}, \mathrm{CCSEM}^{*}, \mathrm{PCSV}$ \\
\hline 48 & $\begin{array}{l}\text { Beulah } \\
\text { Lignite }\end{array}$ & 2.8 & AA, CCSEM, PCSV \\
\hline 49 & Loy Yang 2301 & 1.8 & AA, CCSEM, PCSV \\
\hline 49 & Loy Yang 2301 & 2.7 & AA, CCSEM, PCSV \\
\hline 50 & Loy Yang 1953 & 2.5 & AA, CCSEM, PCSV \\
\hline
\end{tabular}

\subsubsection{Burn 47: Illinois No. 6}

Burn 47 used Illinois No. 6 coal at two different feed rates (approximately 1.3 and $2.4 \mathrm{~kg} / \mathrm{hr}$ ). Cascade impactor samples were acquired for AA and CCSEM analysis from ports 11 and 5 for both fecod rates. PCSV distribubutions were measured for the lower feed rate only. Figure 6-17 shows the uncorrected temperature profiles for the two feed rates. 


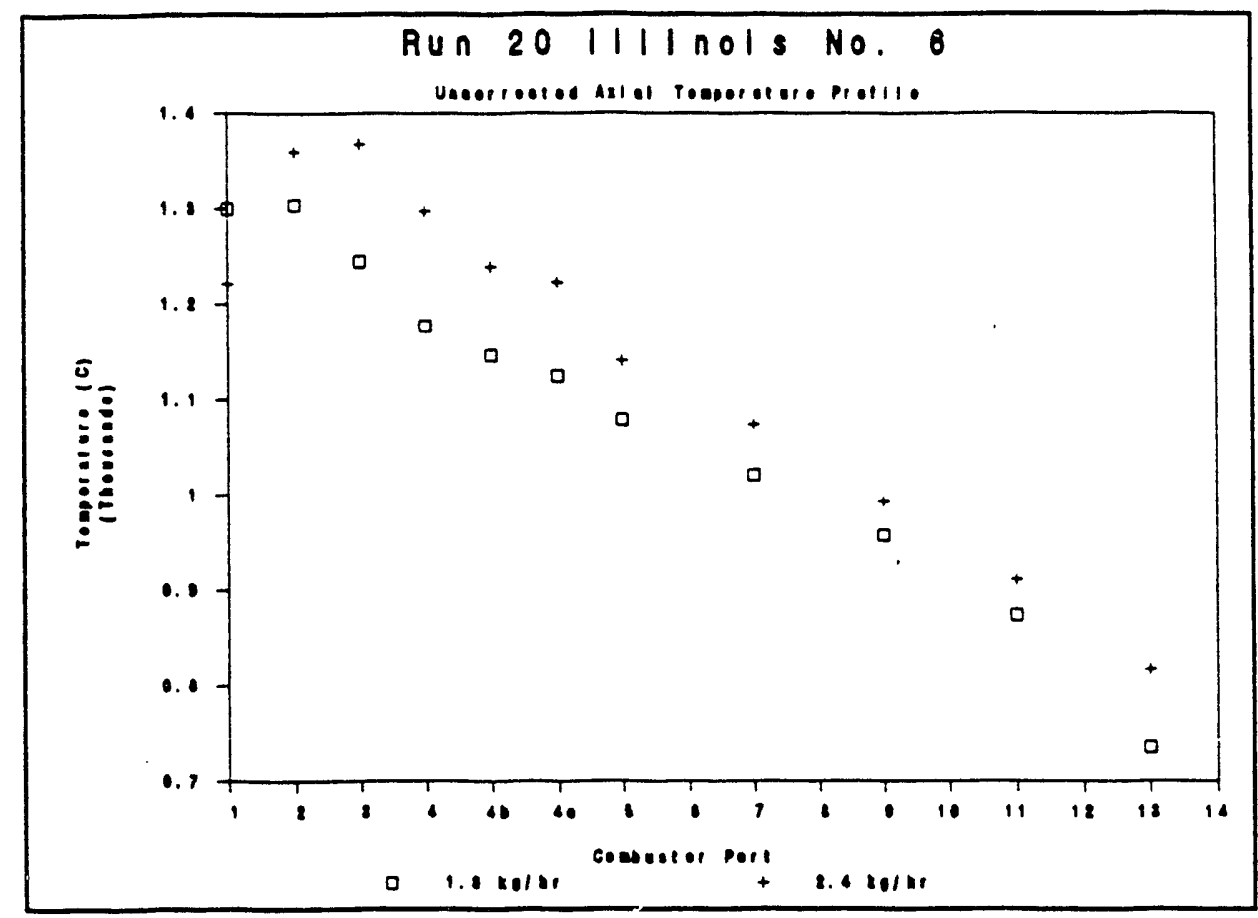

Figure 6-17. Temperature Profile for Burn 47

\subsubsection{Impactor Results}

\subsection{Sample Port 11}

Figure 6-18 shows the AA results as fraction oxide of the ash versus cascade impactor stage for the lower feed rate. The largest size class is the third bar from the left of the plot (stage 1), and the smallest size class is on the right (after-filter). The first bar on the left is the ash analysis and the second bar from the left is the mathematical addition of the results from all impactor stages or total filter. Seven elements were measured ( $\mathrm{Si}, \mathrm{Al}, \mathrm{Ca}, \mathrm{Fe}, \mathrm{Na}$, $\mathrm{K}, \mathrm{Mg}$ ) and are presented as oxides. Since the graphics allowed only six oxides to be plotted the seventh, magnesium, is the difference between the top of the bar and one. The ash fraction oxide plot for the higher feed rate, and higher temperature, is shown in Figure 6-19.

The total filter of the fraction oxide plots agrees well with the ash analysis.

Figures 6-18 and 6-19 are aiso consistent with results presented previously for the Illinois No. 6 in burns 19 and 20 (Boni, et al, 1990). The plot for the lower feed rate, and lower peak temperature, shows a slight sodium enrichment in the smaller size ranges suggesting vaporization. Sodium enrichment in the small sizes is not as evident for the higher feed rate, and higher peak temperature, which is consistent with previously reported results for Beulah Lignite suggesting capture of the sodium by chemical reaction with silicate matter (Boni, et al, 1990, Gallagher, et al, 1990). 


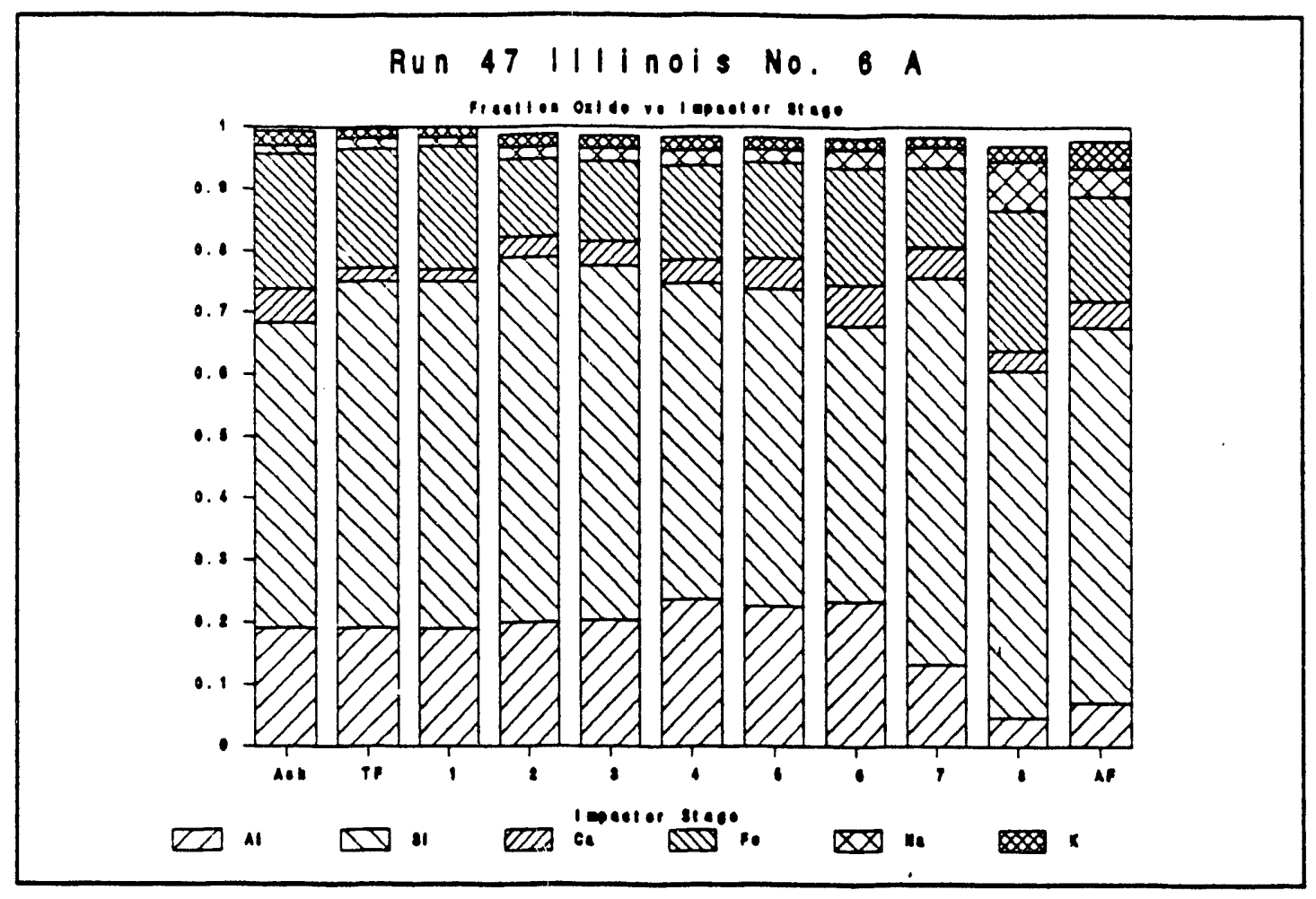

Figure 6-18. Fraction Oxide for $1.3 \mathrm{~kg} / \mathrm{hr}$ feed rate

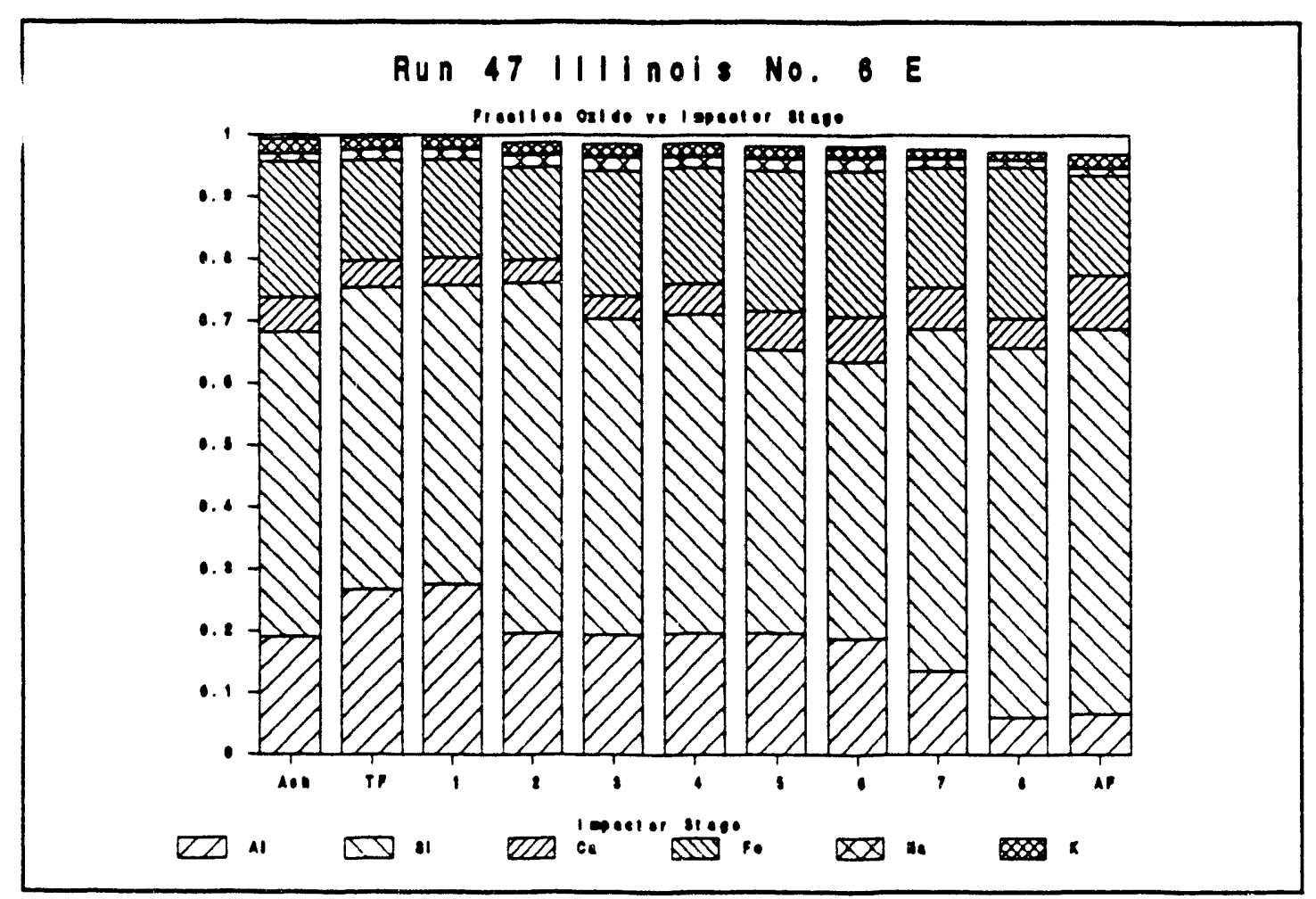

Figure 6-19. Fraction oxide for $2.4 \mathrm{~kg} / \mathrm{hr}$ feed rate 
Figures 6-20 and 6-21 show the concentration of ash in $\mathrm{mg} / \mathrm{sm}^{3}$ for the cascade impactor samples. For both cases the ash concentration was lower than that calculated from the ash analysis of the coal and were consistent with concentrations reported for burns 19 and 20 (Boni, et al, 1990). Errors in the measurements of concentrations were dominated by determination of sample volumes for the larger size cuts and was estimated at less than approximately $\pm 5 \%$. For the smaller size cuts errors in measurements of silicon and aluminum also contribute due to their lower concentrations and difficulty in measurement. Errors are estimated at less than $\pm 12 \%$ for the smaller size ranges. Although the effect of temperature on the ash concentration was slight it does appear that a small shift of mass to the smaller sizes was noted for the higher coal feed rate relative to the lower feed rate.

\subsection{Sample Port 5}

Figure 6-22 shows the fraction oxide plot for the impactor sample acquired from port 5 at the lower feed rate, and Figure 6-23 is for the higher feed rate. Comparison of Figures 6-22 and 6-23 to Figures 6-18 and 6-19 shows a more marked enrichment of sodium and potassium in the smaller sizes for the samples acquired from port 5 . This is likely due to a higher concentration of unreacted and uncondensed alkali species existing in the vapor during sampling at port 5 relative to port 11. Condensation and nucleation of the vapor species most likely occurred in the sample probe at port 5.

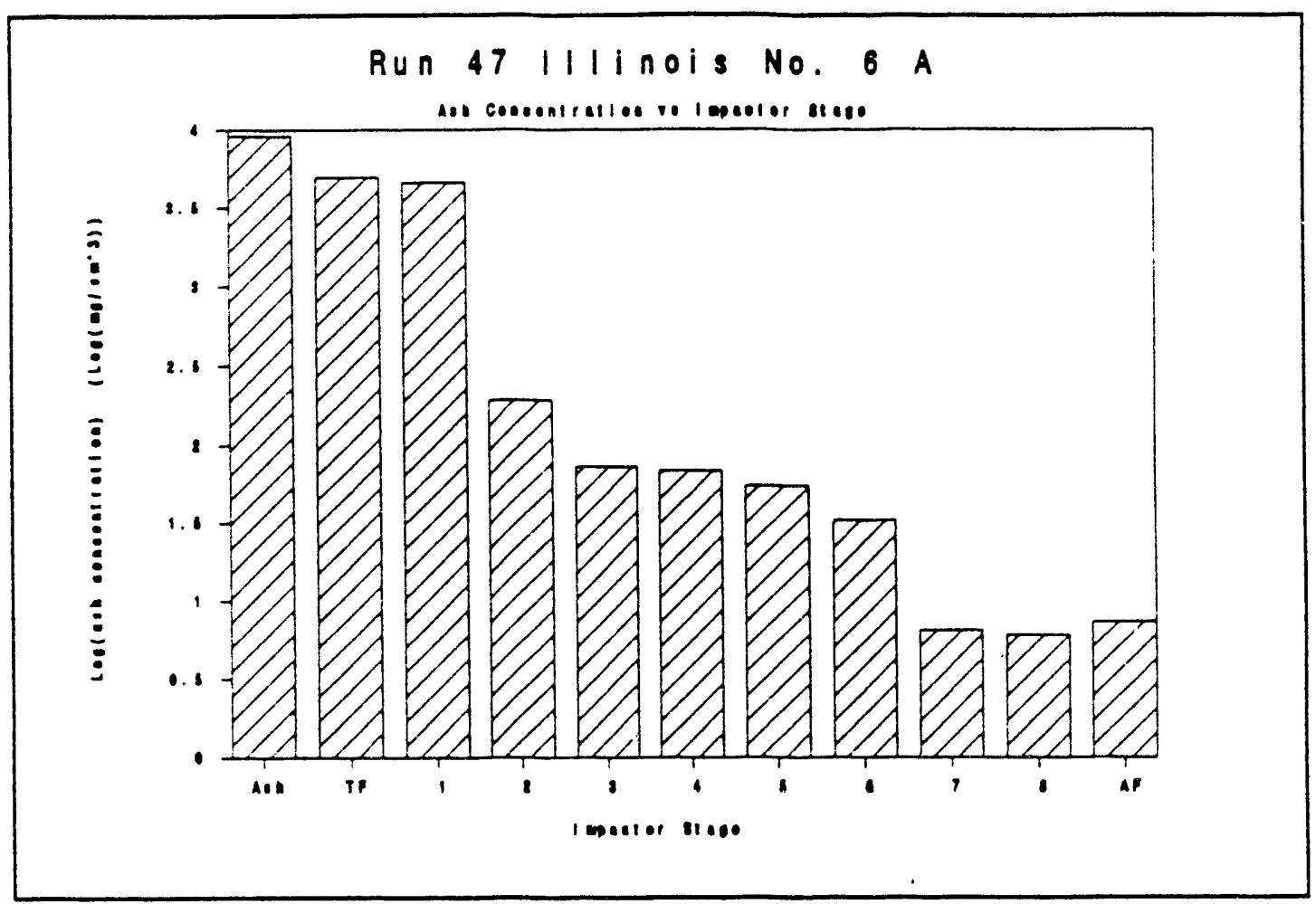

Figure 6-20. Ash Concentration for $1.3 \mathrm{~kg} / \mathrm{hr}$ feed rate 


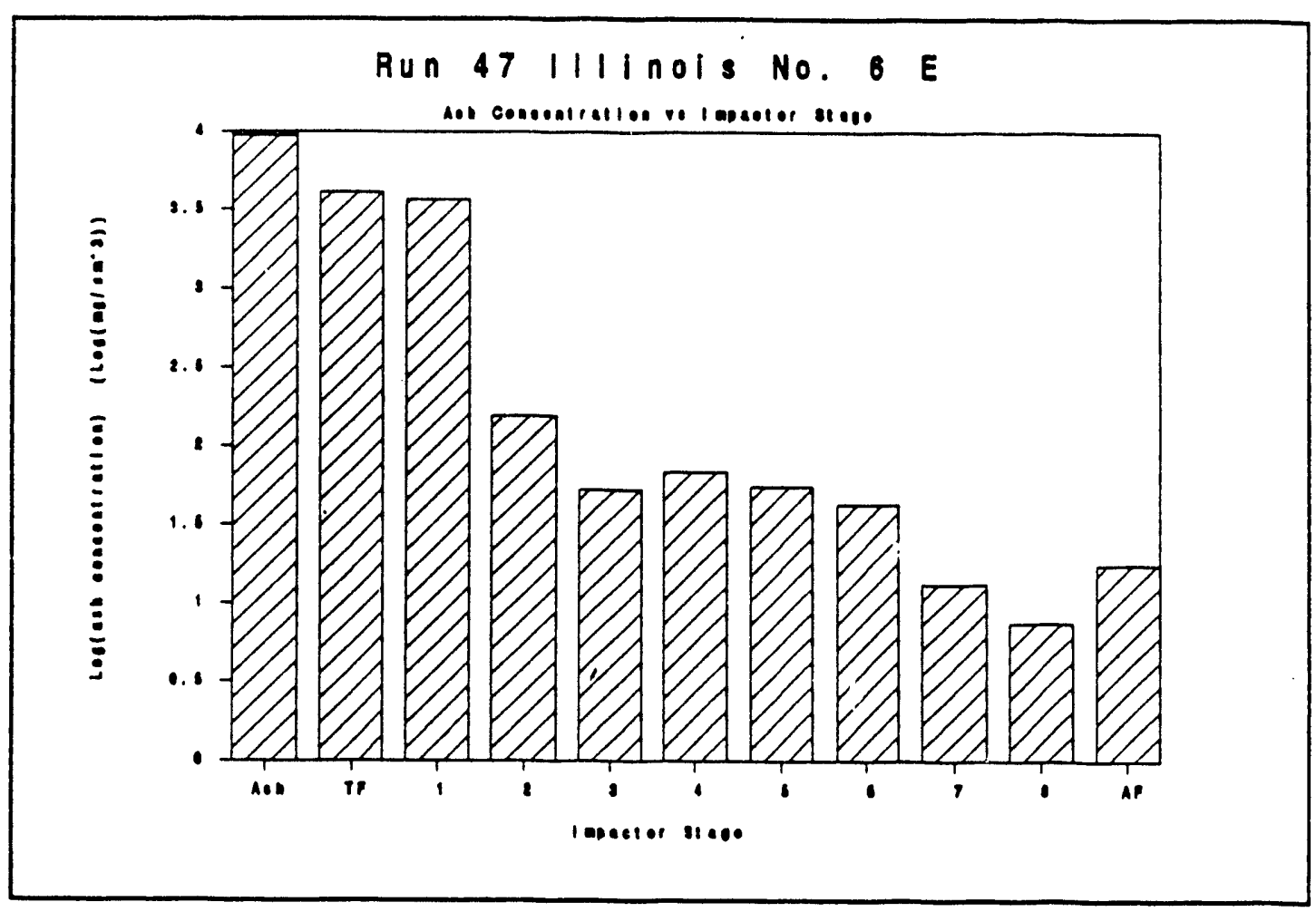

Figure 6-21. Ash Concentration for $2.4 \mathrm{~kg} / \mathrm{hr}$ feed rate

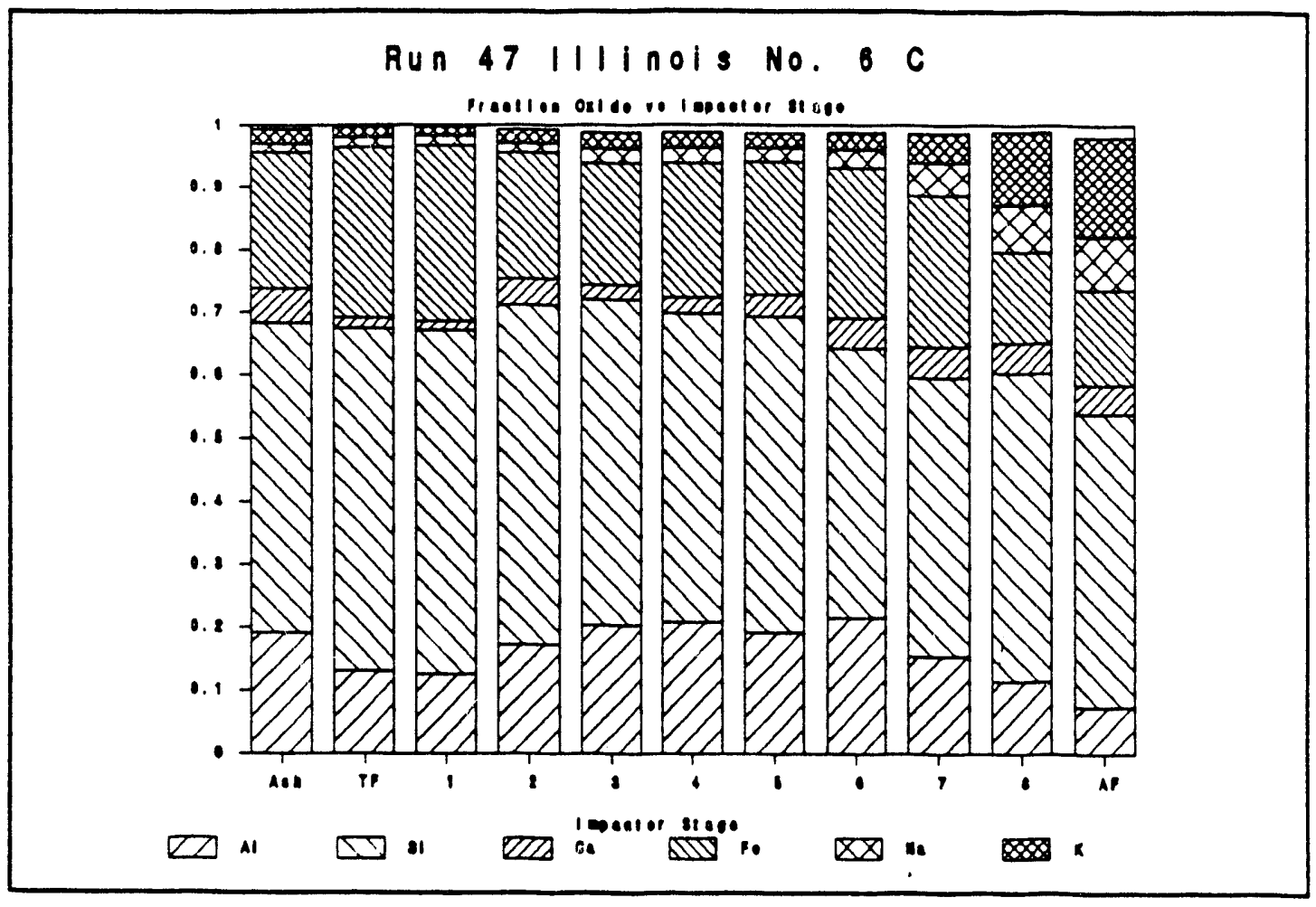

Figure 6-22. Fraction Oxide for $1.3 \mathrm{~kg} / \mathrm{hr}$ feed rate at port 5 


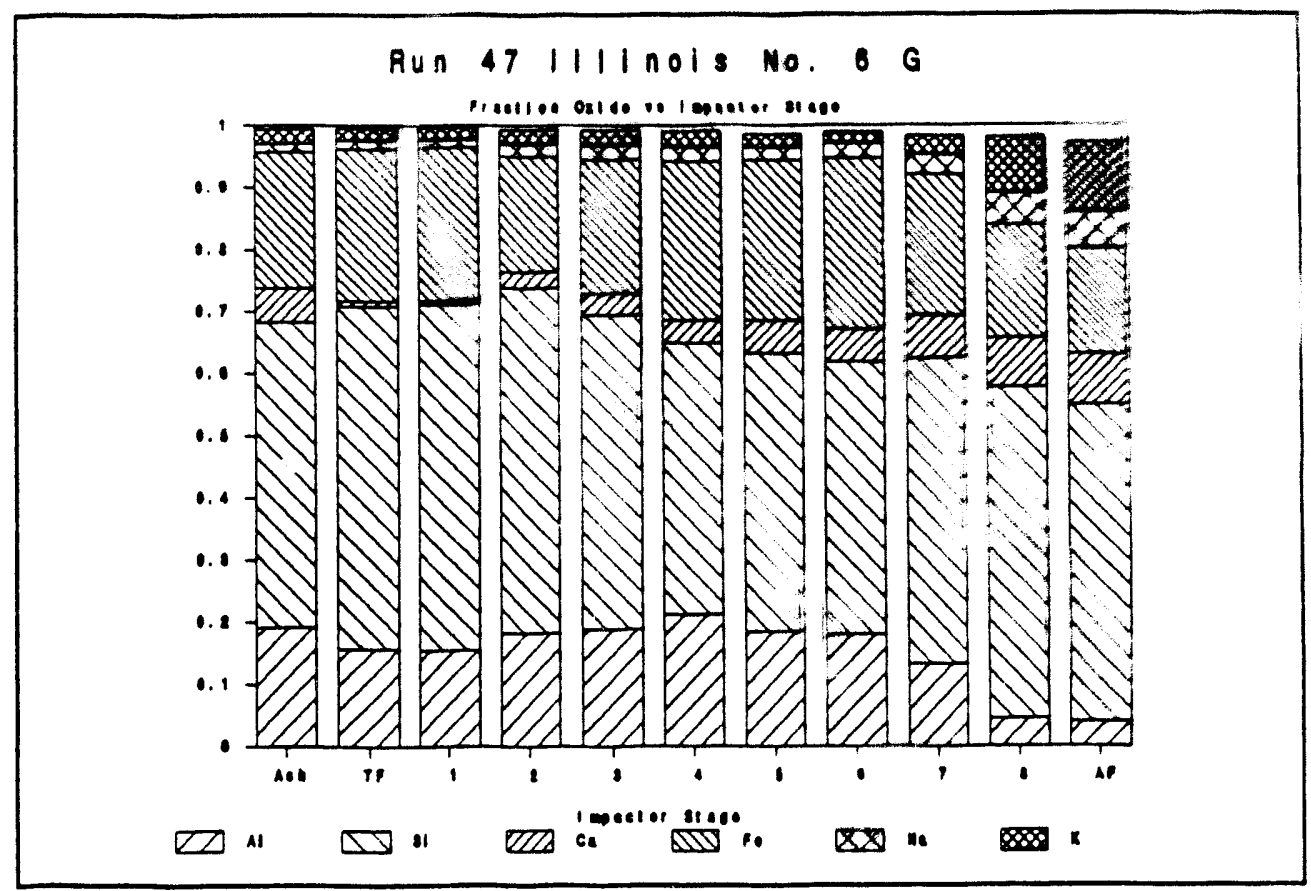

Figure 6-23. Fraction Oxide for $2.4 \mathrm{~kg} / \mathrm{hr}$ feed rate at port 5

For samples acquired in both ports 11 and 5 enrichment of alkali in the small sizes was more pronounced for the lower coal feed rate, and lower temperature, than for the higher coal feed rate. This might suggest that a significant fraction of alkali capture (due to chemical reaction with silicate matter) occurred before port 5. Figure 6-24, however, shows the fraction of the sampled alkali that appears in the small sizes (impactor plate 8 plus the after-filter) was higher in the port 5 samples for the higher feed rate. This was most likely due to the shorter residence time for the higher feed rate. After port 5 the subsequent reduction of the fraction of alkali in the small sizes was greater for the higher feed rate, and higher temperature. Capture of alkali due to chemical reaction with silicate matter is the most likely explanation for the reduction of alkali in the small sizes since condensation would be less likely at the higher temperatures observed at the higher feed rate.

Although the mass of alkali in the small sizes was greater for the high feed rate, the fraction oxide shows that a greater fraction of the mass in the small sizes for the low feed rate was due to alkali. The greater relative enrichment of sodium in the small sizes for both low temperature (low feed rate) samples compared to the high temperature samples can be explained by a shift of non-alkali mass to the small sizes ror the high temiperature burns. The slight shift of mass to the small sizes was shown for samples acquired in both ports 5 and 11. The ash concentration plots for port 5 samples are shown in Figures 6-25 and 6-26, and for port 11 samples in Figures 6-20 and 6-21 for 1.3 and $2.4 \mathrm{~kg} / \mathrm{hr}$ feed rates respectively. Inspection of oxide cumulative fraction plots (not shown here) and fraction oxide plots suggest that calcium might be a least partially to blame for the greater mass in the small sizes for the high temperature burn, but aluminum was not. 


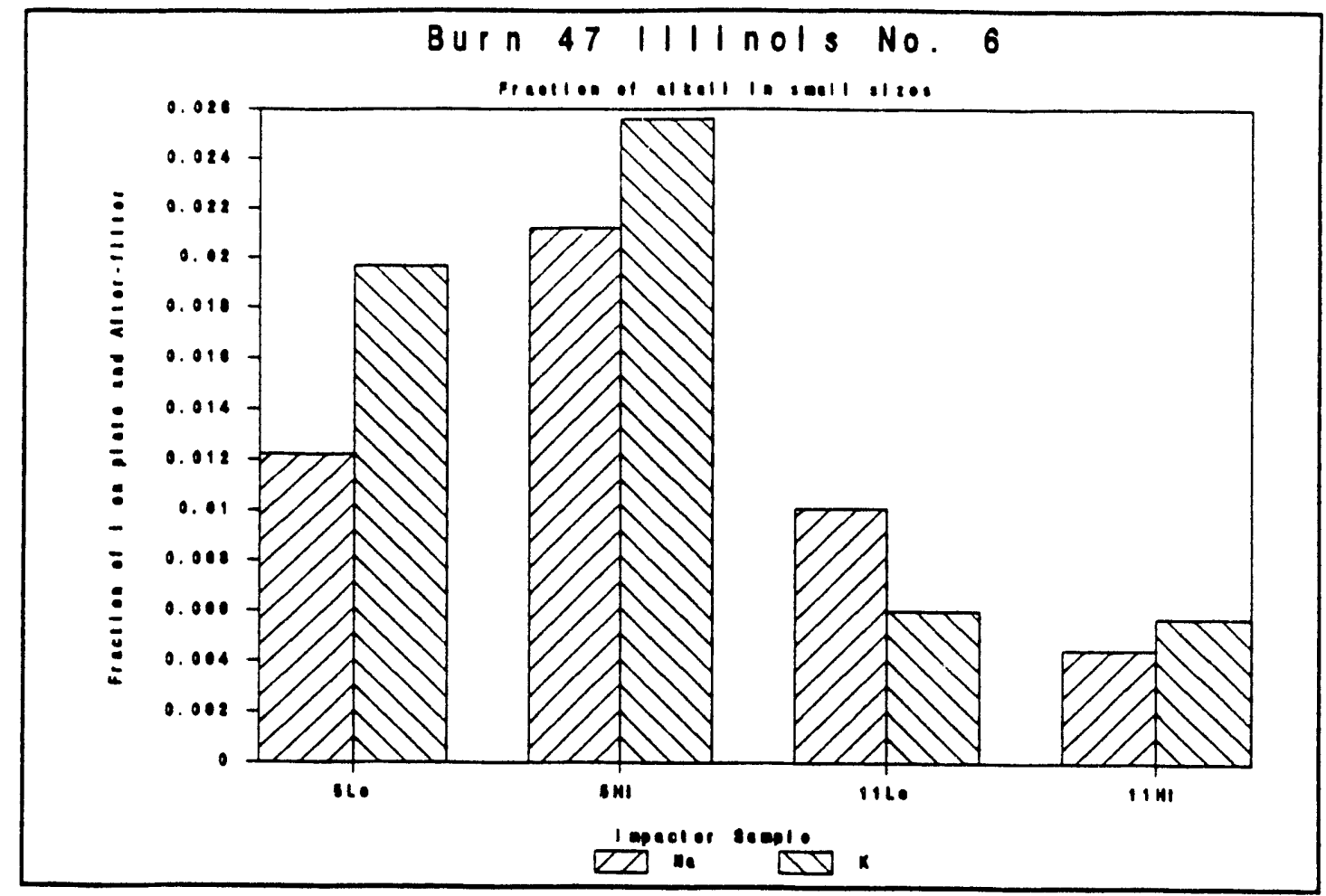

Figure 6-24. Fraction of Alkali in the Small Sizes for the High Feed rate (HI) and the Low Feed Rate (LO) from Port 5 and 11 Samples

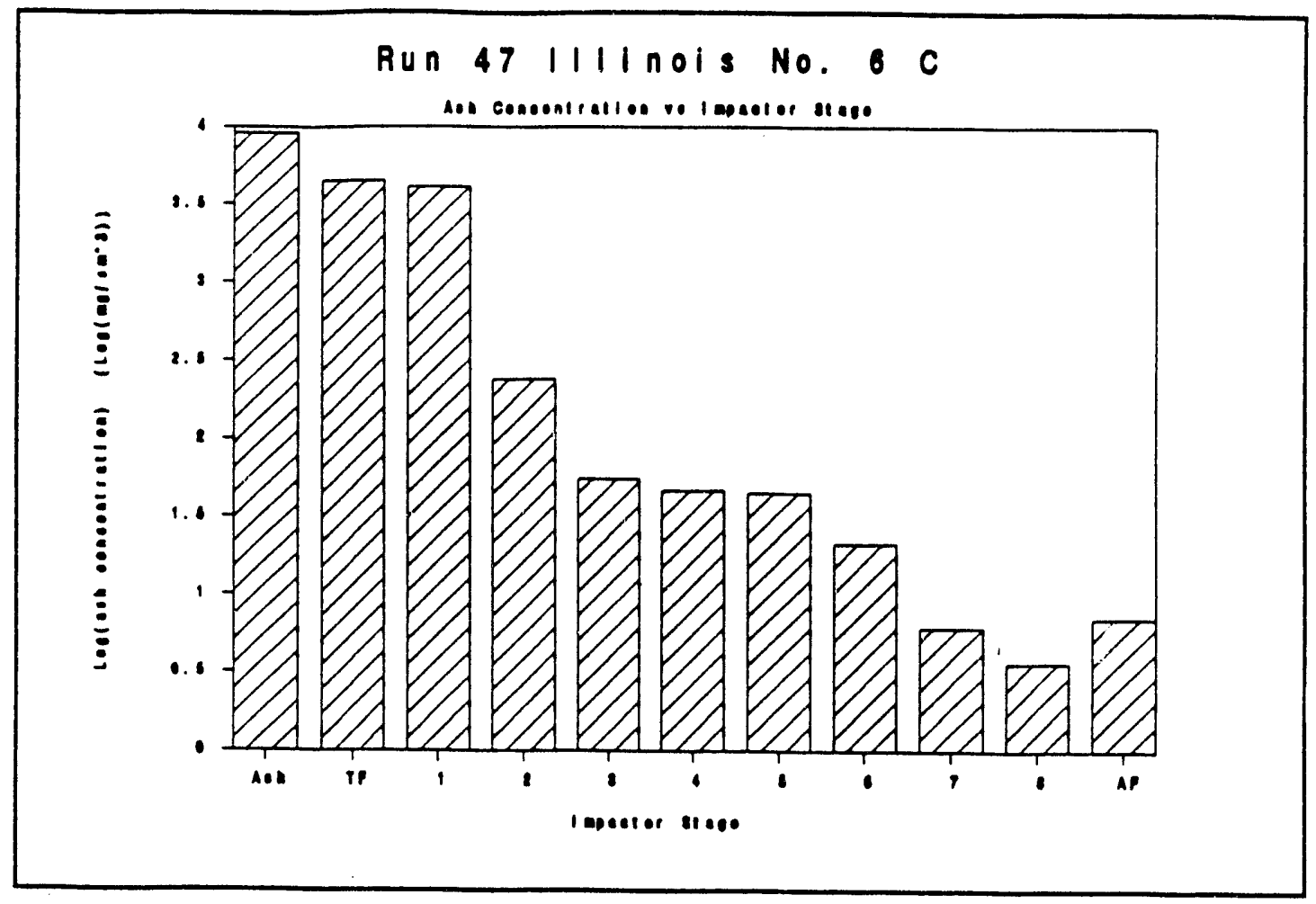

Figure 6-25. Ash Concentration for 1.3 kg/hr Feed Rate 


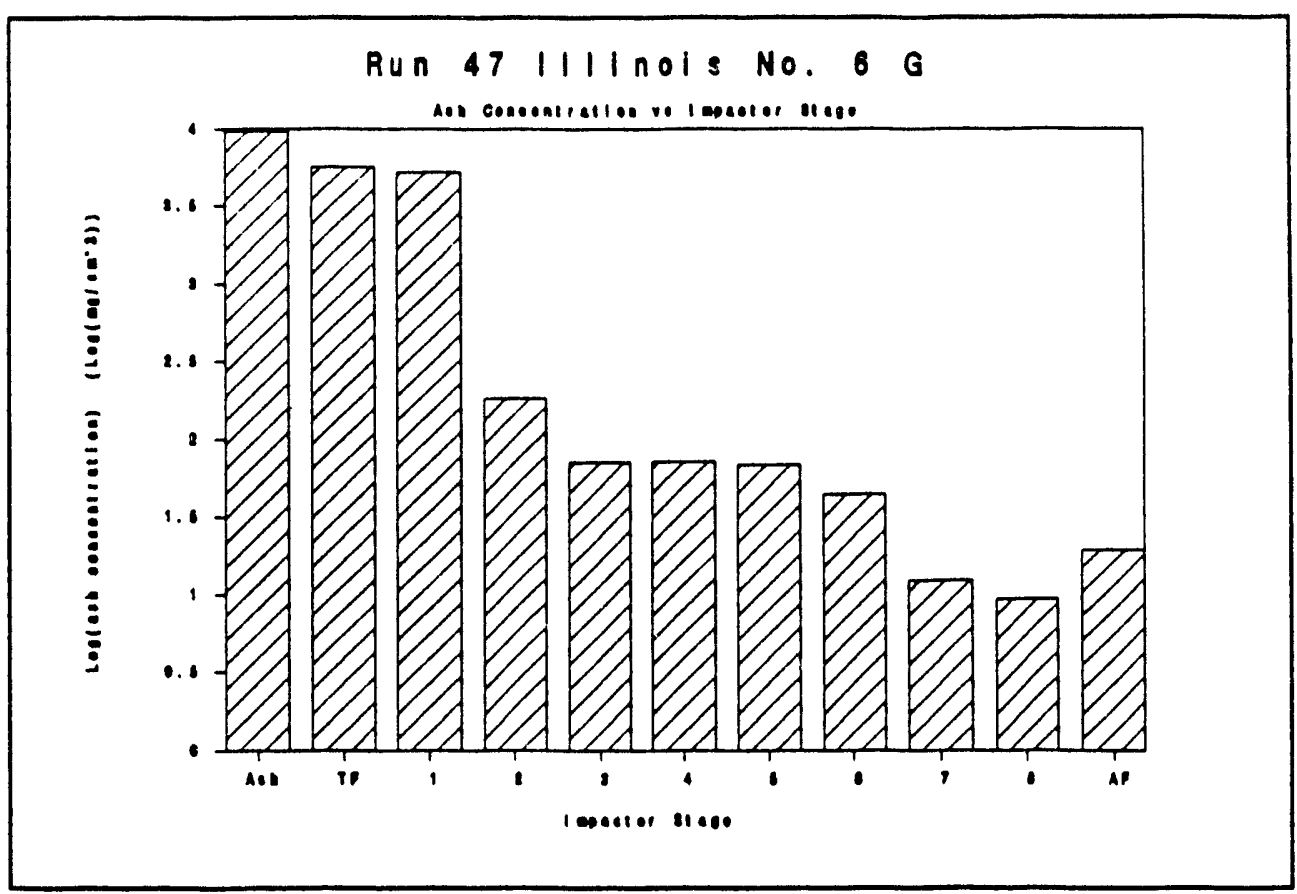

Figure 6-26. Ash Concentration for $2.4 \mathrm{~kg} / \mathrm{hr}$ Feed Rate

\subsubsection{PCSV Results}

Figure 6-27 shows the normalized cumulative and density mass distributions for samples acquired with the PCSV during the Illinois No. 6 burn. Since the range varied from sample to sample the mean was determined only over an overlapping range. Distributions were normalized over the abbreviated range and averaged together. The averaging technique allowed for presentation of only one distribution when making comparisons but it shortened the range and slightly shifted the cumulative distribution to larger sizes. In addition, PCSV distributions were not weighted to account for different sample measurement times. For these reasons a plot of all the PCSV mass distributions with respective means are presented below for the PCSV results. Figure 6-28 shows the mean of the area distribution and Figure 6-29 shows the mean of the number distribution for burn 47.

A comparison of the PCSV mean mass distribution, mass as determined from AA analysis of impactor samples, and the impactor inversion is shown in Figures 6-30 and 6-31. A top size of $100 \mu \mathrm{m}$ was assumed in the inversion. PCSV mass distributions were determined from the number distributions by assuming a particle density of one. The PCSV counted char particles as well as ash particles. AA analysis does not measure the carbon content and thus does not measure actual particle distributions but inorganic matter size distributions using aerodynamic diameters. If there was a significant amount of unburned char in the ash, the two measurements could differ. It would be expected, however, that unburned char would be relatively large $(>9 \mu \mathrm{m})$ and would be collected on the top two stages of the impactor. In addition, the PCSV did not measure the finest particles which were collected on the after-filter of the cascade impactor. The smallest sizes typically reported with the PCSV were $0.4 \mu \mathrm{m}$ and the impactor after-filter was a $0.2 \mu \mathrm{m}$ flouropore 


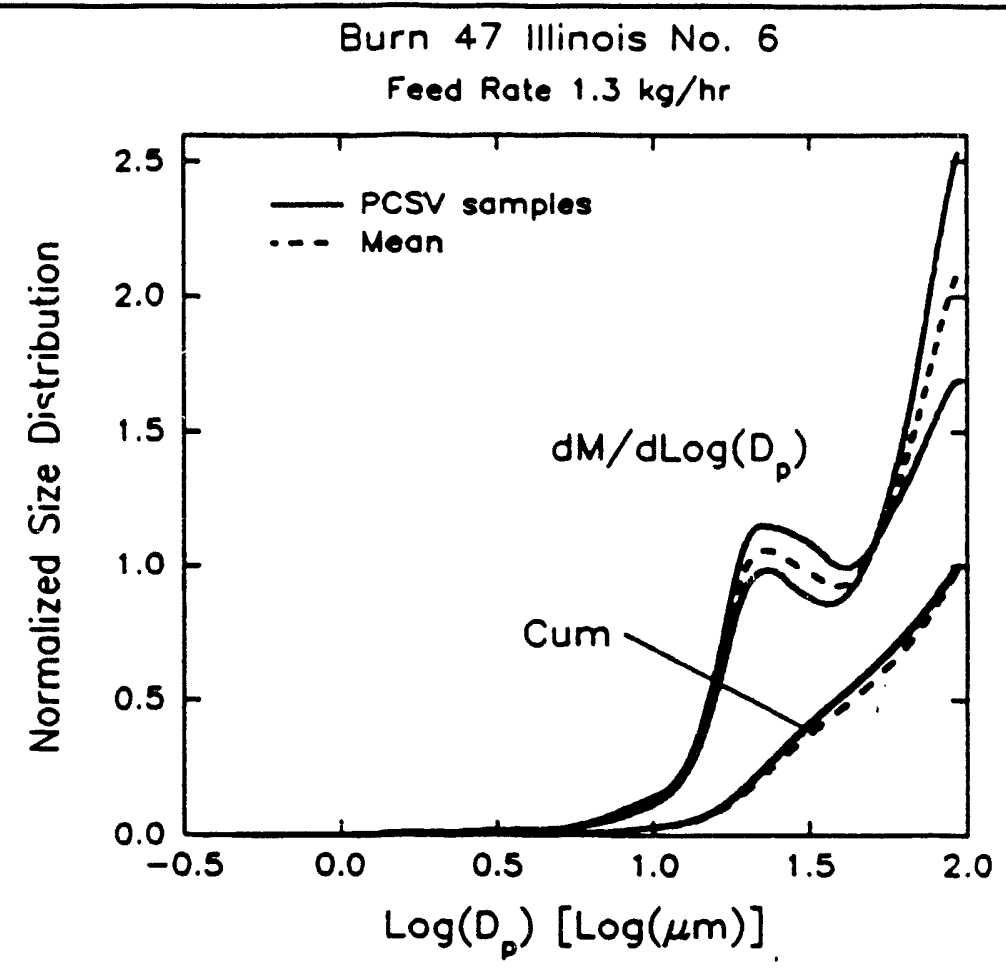

Figure 6-27. Mass Distributions for Bum 47

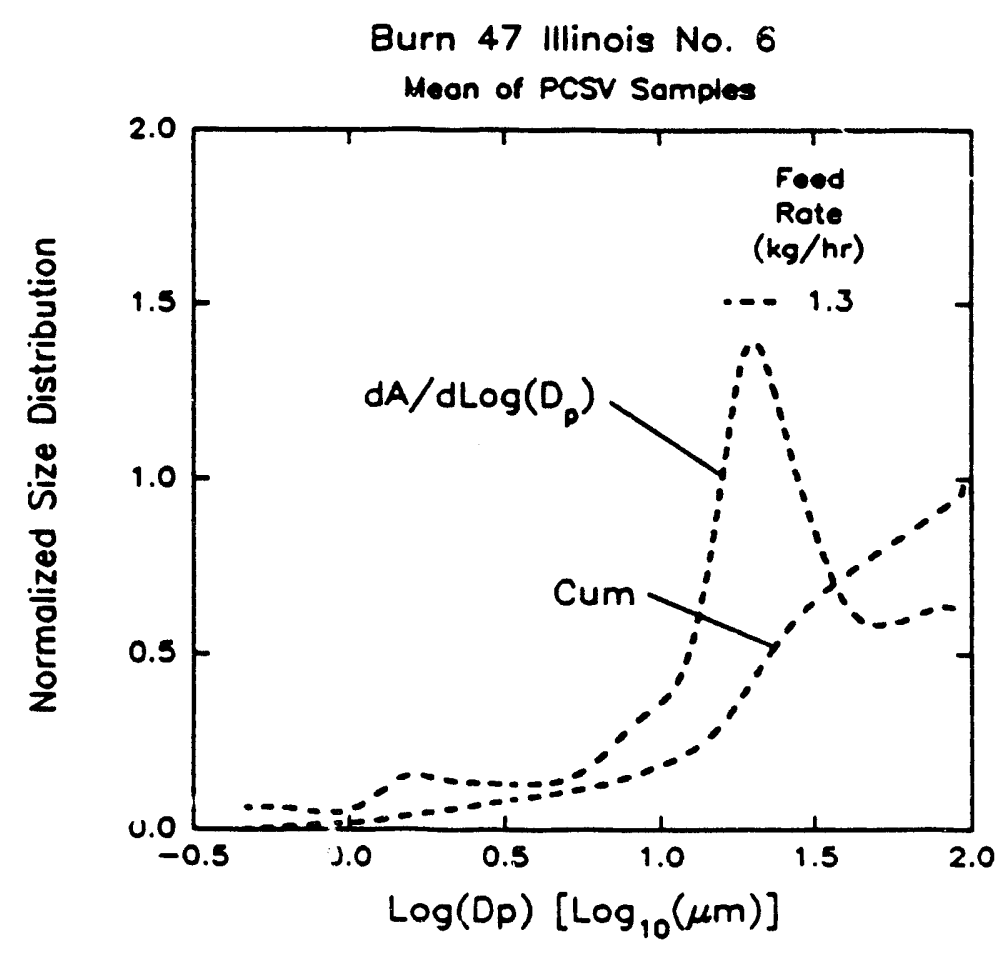

Figure 6-28. Area Distribution for Burn 47 


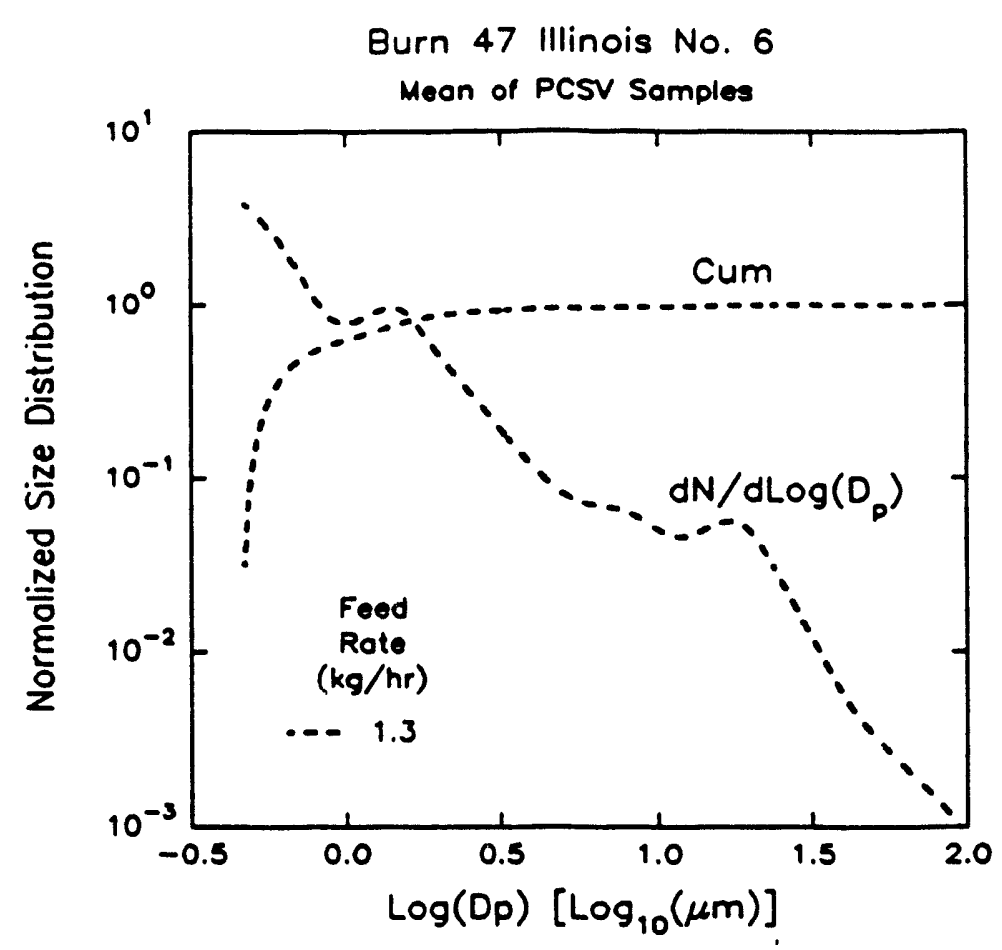

Figure 6-29. Number Distributions for Burn 47

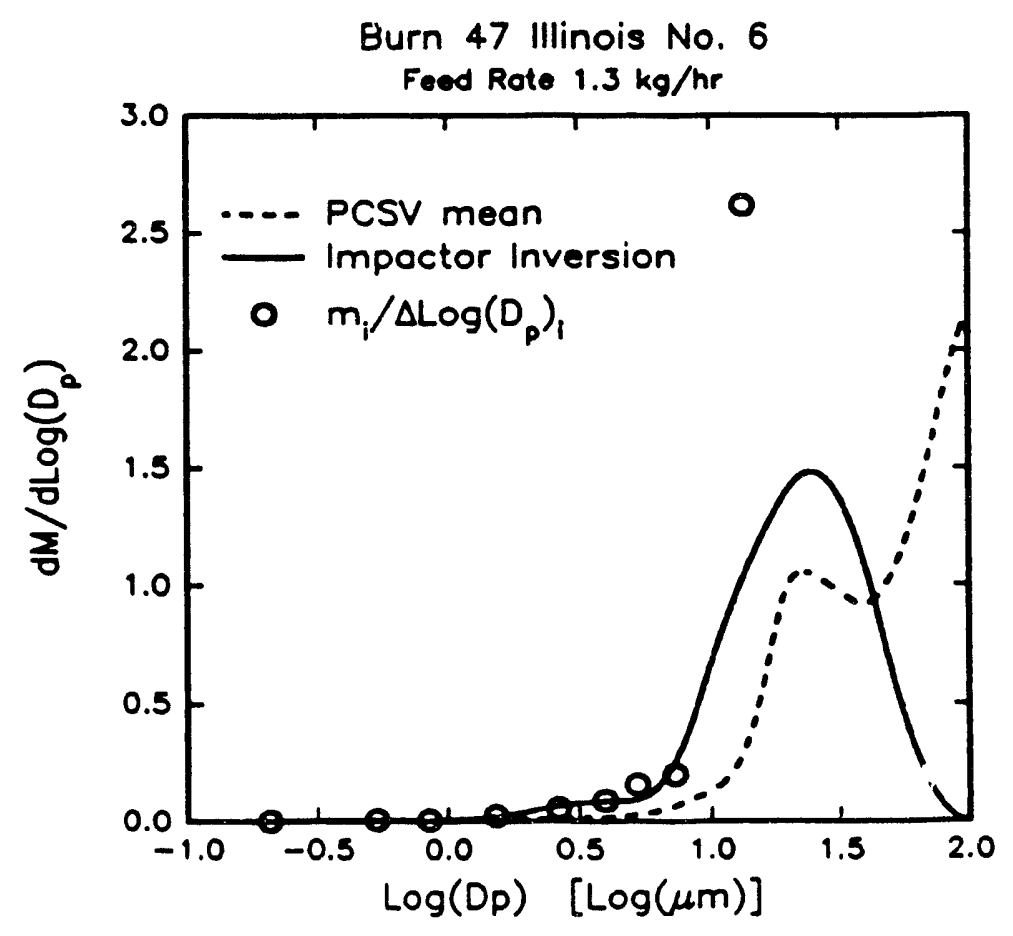

Figure 6-30. Impactor and PCSV for Burn 47 


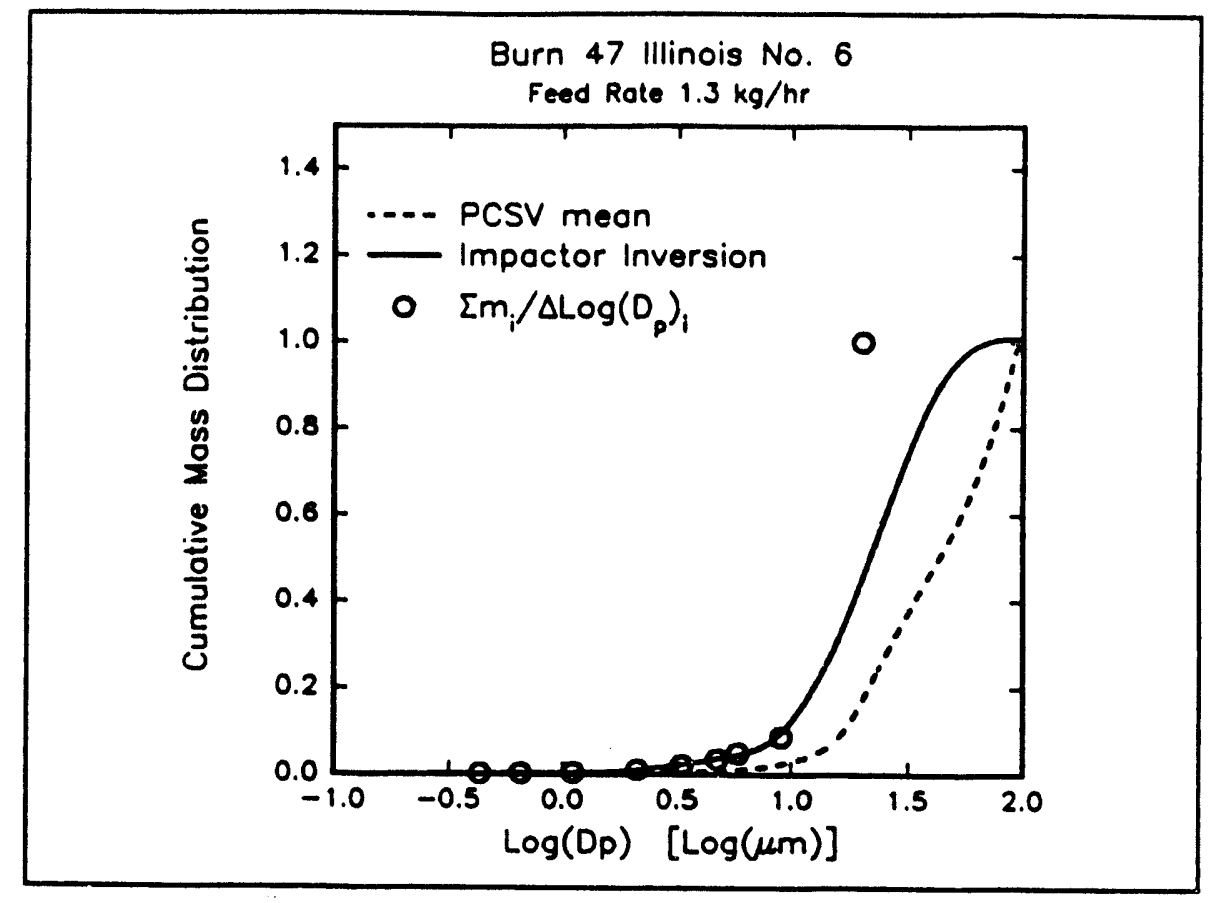

Figure 6-31. Impactor and PCSV for Burn 47

filter. If there was a significant number of small particles, the results from the PCSV would report a size distribution shifted to the larger particles when compared to the AA results. Results from Figures 6-30 and 6-31 show fairly good agreement considering the impactor cutoff diameter for the top stage is $9 \mu \mathrm{m}$. However, approximately $90 \%$ of the mass measured in the impactor was on the top stage.

\subsubsection{Burn 48: Beulah Lignite}

Burn 48 used Beulah Lignite coal at two different feed rates of approximately 1.65 and $2.8 \mathrm{~kg} / \mathrm{hr}$. Cascade impactor samples were acquired for AA and CCSEM analysis from port 11 for both feed rates, and at port 5 for the lower feed rate. PCSV distributions were measured for both feed rates. Figure 6-32 shows the uncorrected temperature profiles for the two feed rates.

\subsubsection{Impactor Results}

\subsection{Sample Port 11}

Figure 6-33 shows the AA results as a fraction oxide versus cascade impactor stage plot for the lower feed rate. The fraction oxide plot for the higher feed rate is shown in Figure 6-34. The total filter of the fraction oxide plots differs from the ash analysis, however Figures 6-33 and 6-34 are consistent with results presented previously for Beulah Lignite in burns 13,14, and 38 (Boni et al, 1990). The fraction of silicon, however, does appear slightly higher in burn 48 . Plots for both feed rates shows sodium enrichment in the 


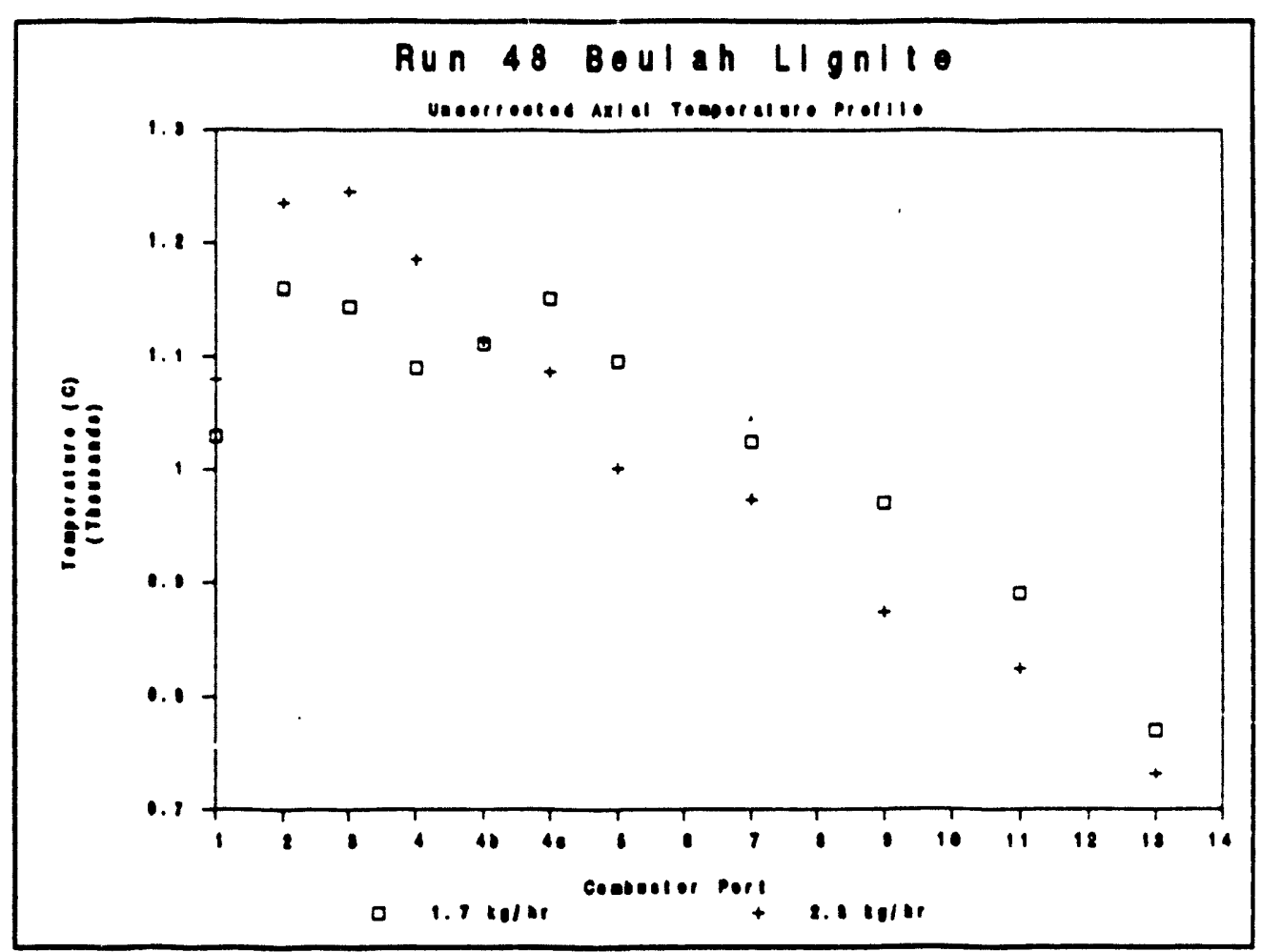

Figure 6-32. Temperature Profiles for Burn 48

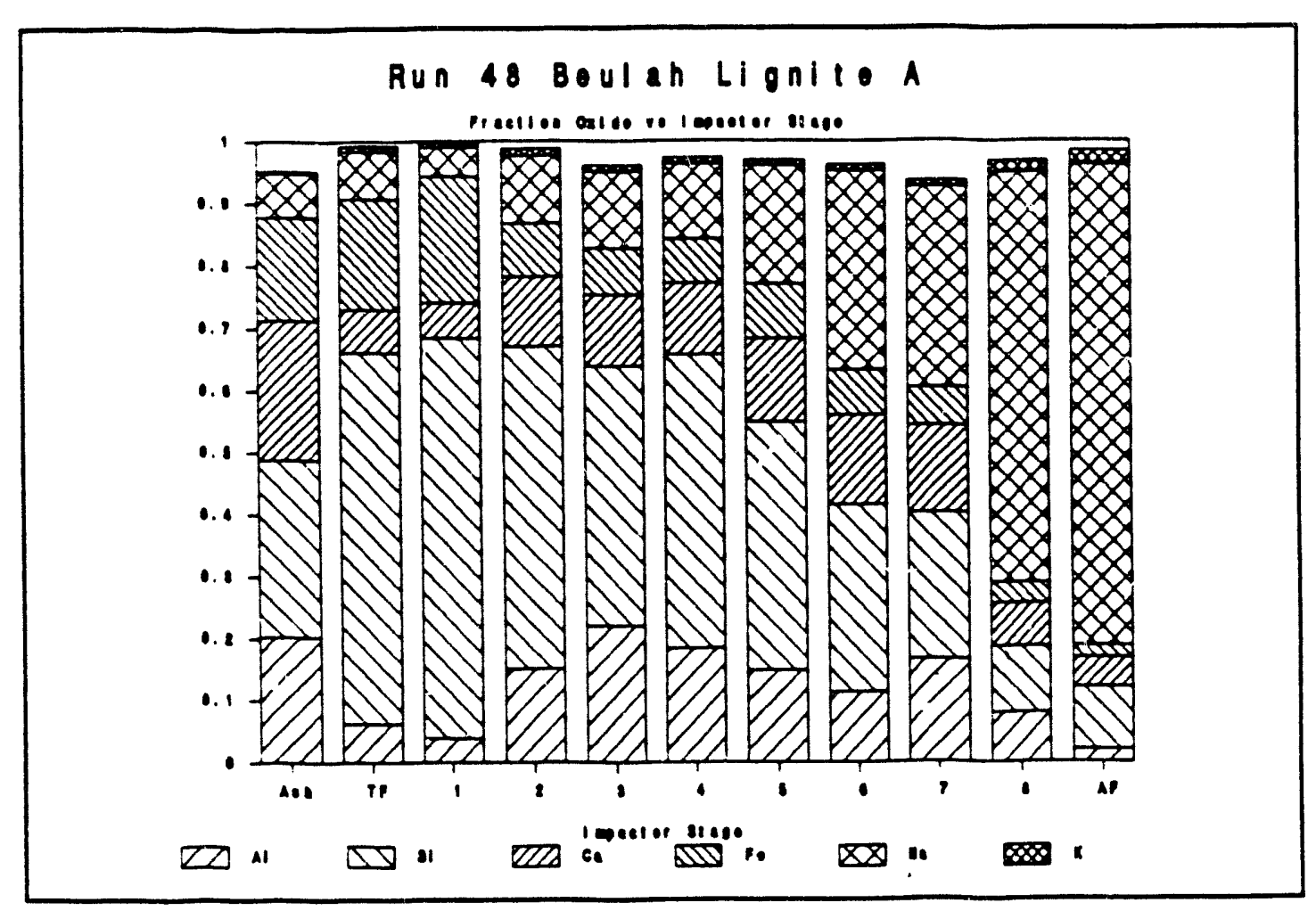

Figure 6-33. Fracticn Oxide for $1.65 \mathrm{~kg} / \mathrm{hr}$ Feed Rate 


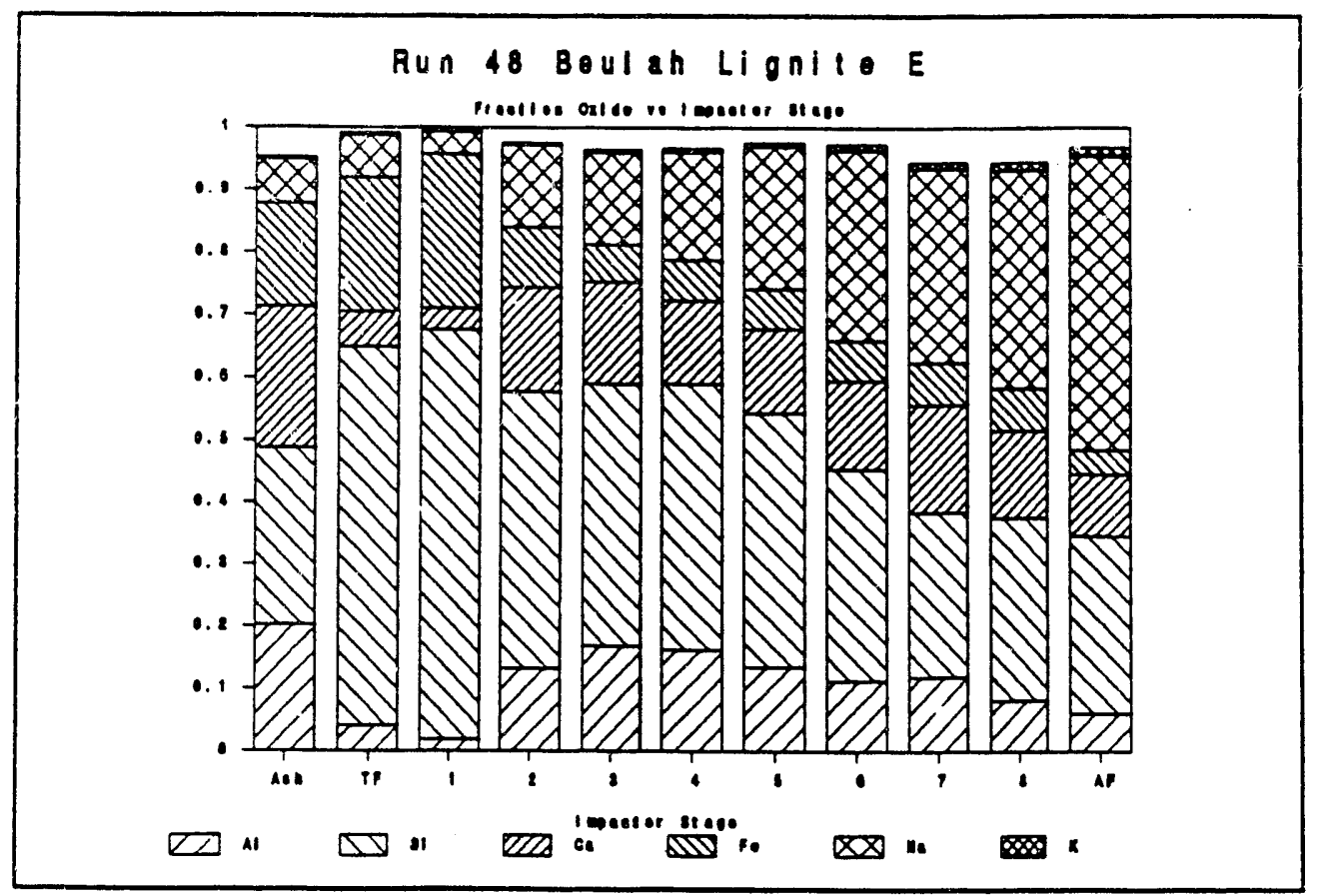

Figure 6-34. Fraction Oxide for $2.8 \mathrm{~kg} / \mathrm{hr}$ Feed Rate

smaller size ranges suggesting vaporization. Sodium enrichment in the small sizes was not as marked for the higher feed rate, and higher peak temperature. These results were consistent with previous bums of Beulah Lignite which suggested capture of the sodium due to chemical reaction with silicate matter. Faster reaction and capture would occur at the higher temperature resulting in less sodium appearing in the small sizes due to condensation and nucleation.

Figures 6-35 and 6-36 show the concentration of ash in $\mathrm{mg} / \mathrm{sm}^{3}$ for the cascade impactor samples. As with burn 47 , the ash concentration was lower than that calculated from the ash analysis of the coal, but was consistent with concentrations reported for burns 13,14 , and 38. Errors in the measurements of concentrations for the larger size cuts was estimated at less than approximately $\pm 5 \%$. For the smaller size cuts errors were estimated at less than $\pm 6 \%$. The mass of sample on plate 8 and the after-filter was less for the high temperature burn. Inspection of the sodium distribution, which is not presented, suggests that less mass in the small sizes for the high temperature burn was likely due to capture of sodium by particles in the larger size classes.

\subsection{Sample Port 5}

The fraction oxide plot for the impactor sample acquired at the lower feed rate is shown in Figure 6-37. The ash concentration plot is shown in Figure 6-38. As with Figure 6-33, Figure 6-37 shows a significant enrichment of sodium in the small sizes. Comparison of Figures 6-35 and 6-38 shows more mass on the after-filter for the sample acquired at port 5. Attributing a cause for a higher observed masis on the after-filter for the port 5 sample with respect to the port 11 sample proved difficult perhaps, due to competing 


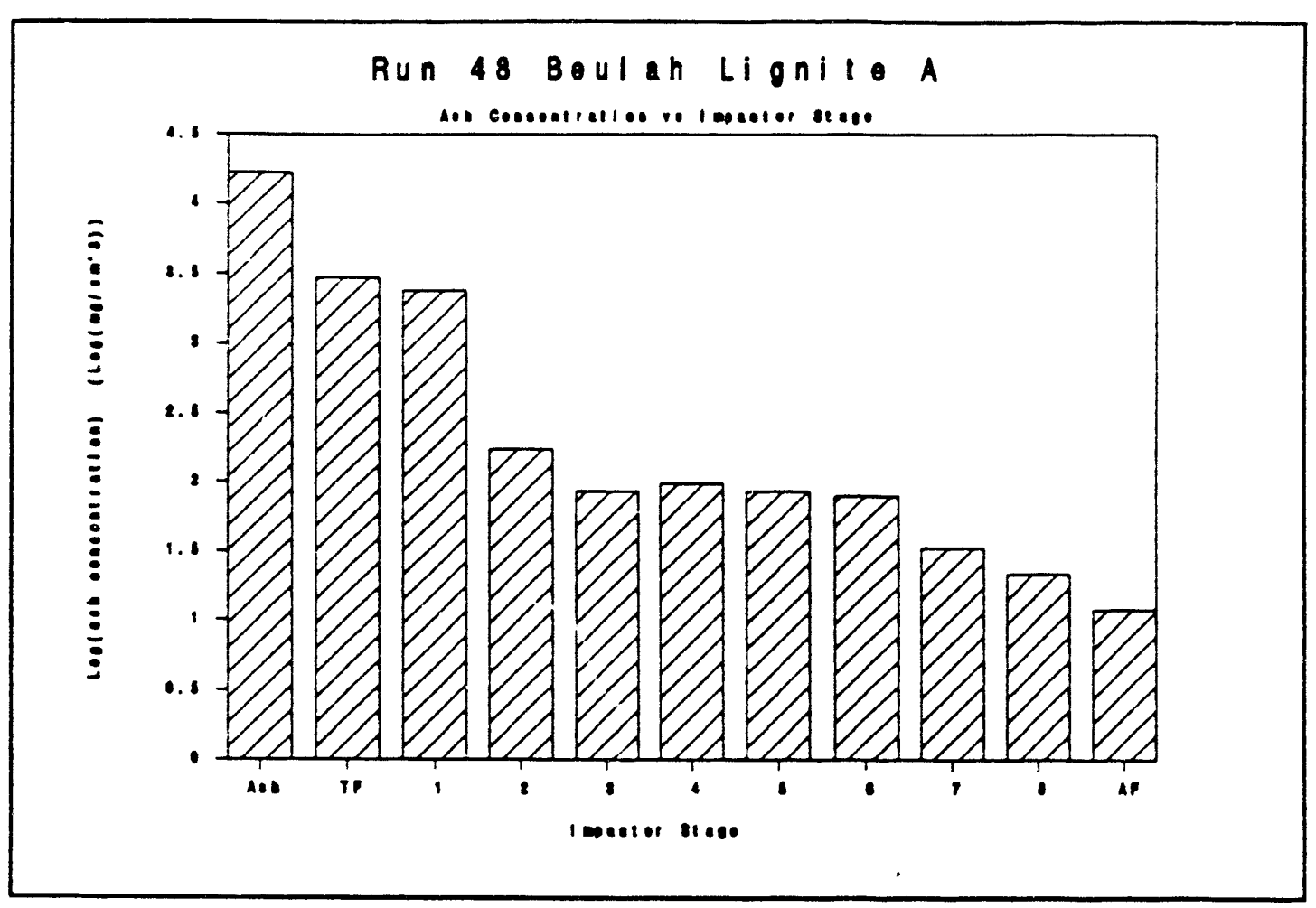

Figure 6-35. Ash Concentration for $1.65 \mathrm{~kg} / \mathrm{hr}$ Feed Rate

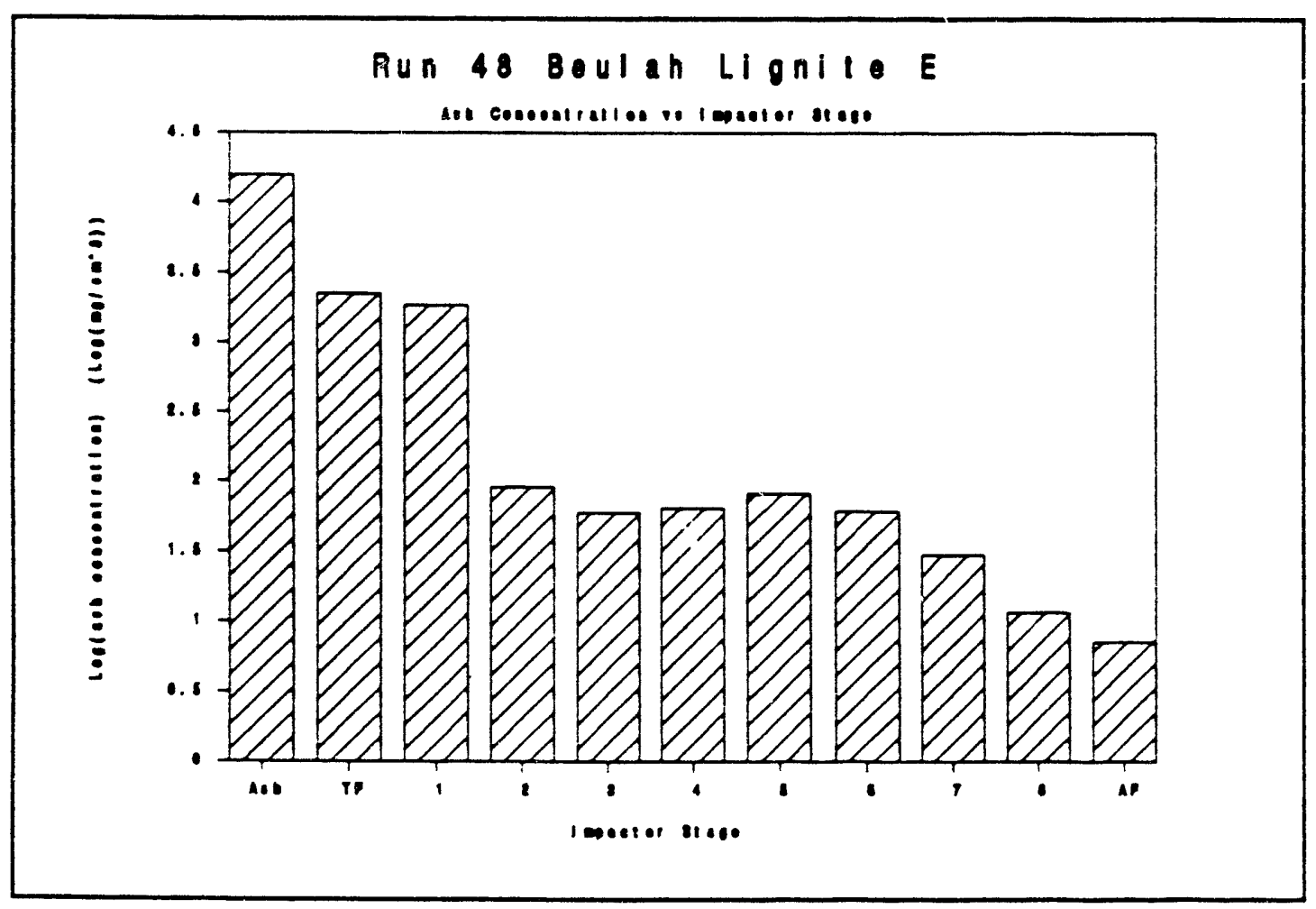

Figure 6-36. Ash Concentration for $2.8 \mathrm{~kg} / \mathrm{hr}$ Feed Rate 


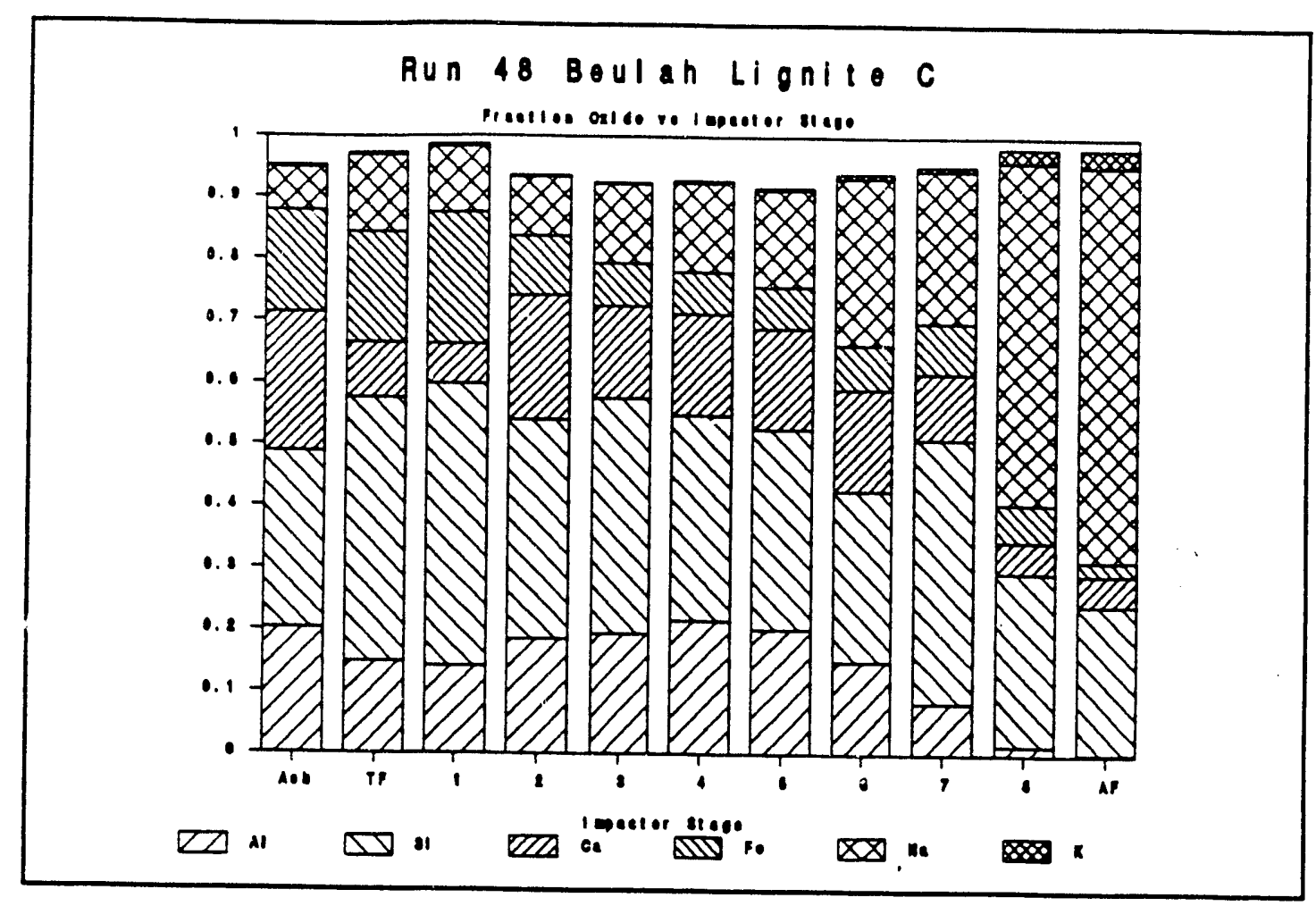

Figure 6-37. Fraction Oxide for Burn 48 Port 5

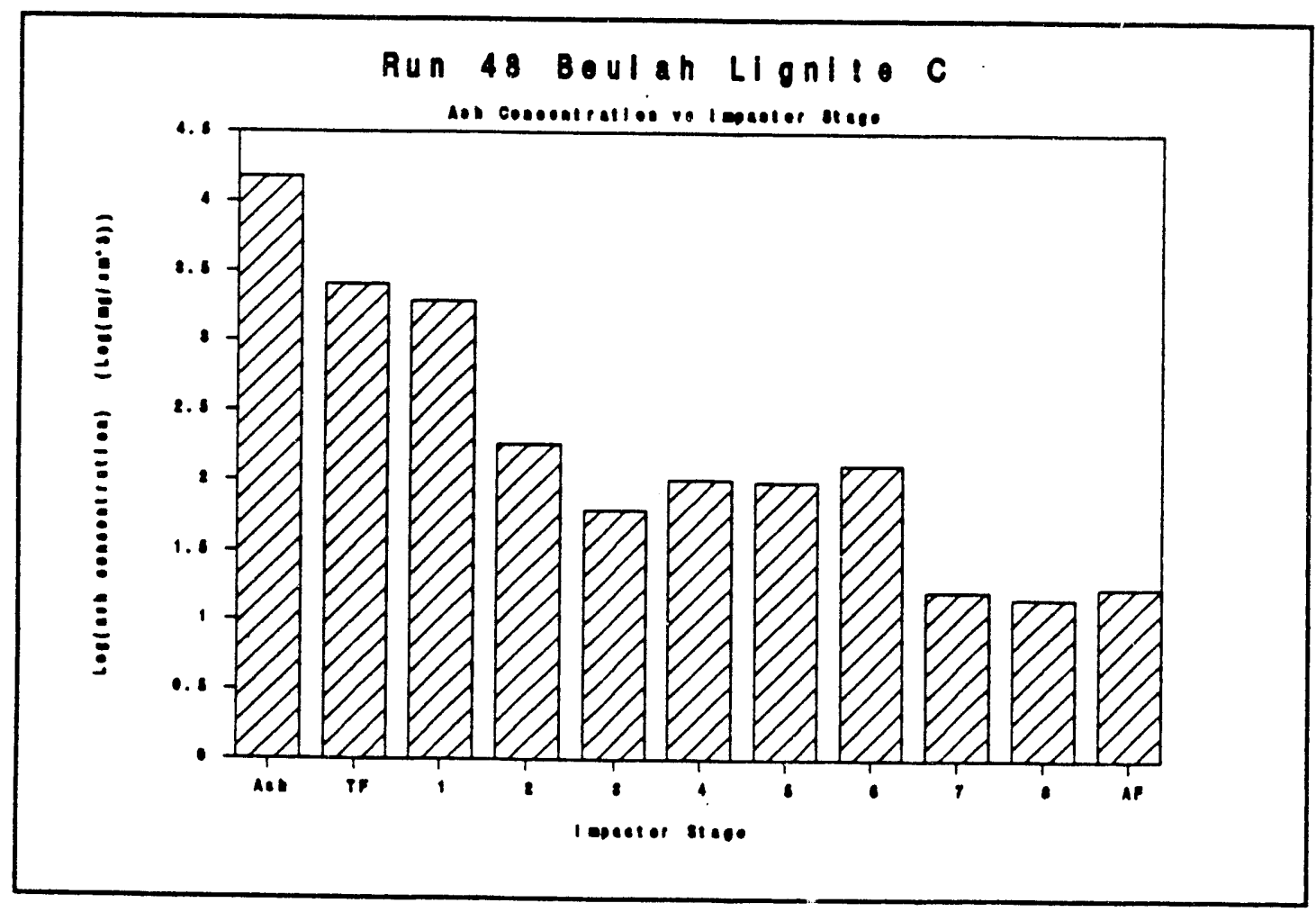

Figure 6-38. Ash Concentration for Burn 48 Port 5 
effects. Inspection of elemental distribution plots, which are not included here, suggest that the sodium may not have completely vaporized when the sample was acquired at port 5: the fraction of sampled sodium in the small sizes was higher for the port 11 sample.

Vaporization of sodium would move more sodium to the smaller measured sizes when sampling at port 11 in comparison to port 5, however capture of sodium appears to have increased the mass of sodium in the one to two micron sized particles. In addition, a greater fraction of the sampled silicon appeared on plate 8 and the after-filter for the port 5 sample. Although the mass of silicon in the small sizes is slight, it did appear that coagulation or agglomeration of small silicon containing particles may have moved the silicon mass to the larger sizes for the port 11 sample.

\subsubsection{PCSV Results}

Figures 6-39 and 6-40 show the normalized cumulative mass and mass density distributions acquired with the PCSV during low and high feed rates of Beulah Lignite respectively. The mean distributions are also presented in these figures. A comparison of the mean mass distributions is shown in Figure 6-41 for the two feed rates. Figure 6-42 shows the mean of the area distributions and Figure 6-43 shows the mean of the number distributions. Distributions at the higher coal feed rate appear to have more mass in the 2 to $10 \mu \mathrm{m}$ range and less in the 0.4 to $2 \mu \mathrm{m}$ than at the lower feed rate. This is consistent with AA impactor results from samples obtained at port 11 shown in Figure 6-44.

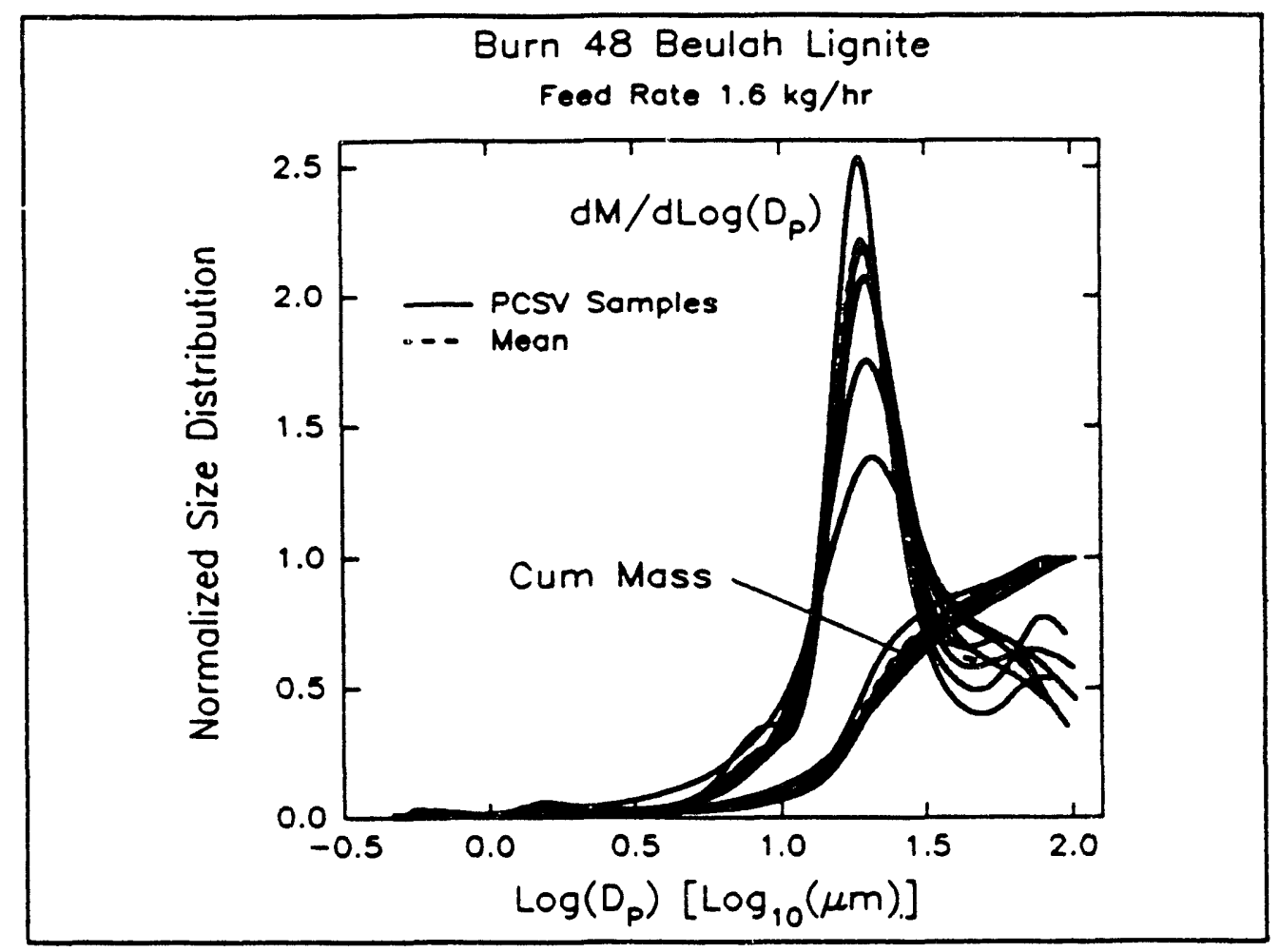

Figure 6-39. Mass Distribution for Bum 48 Low Feed Rate 


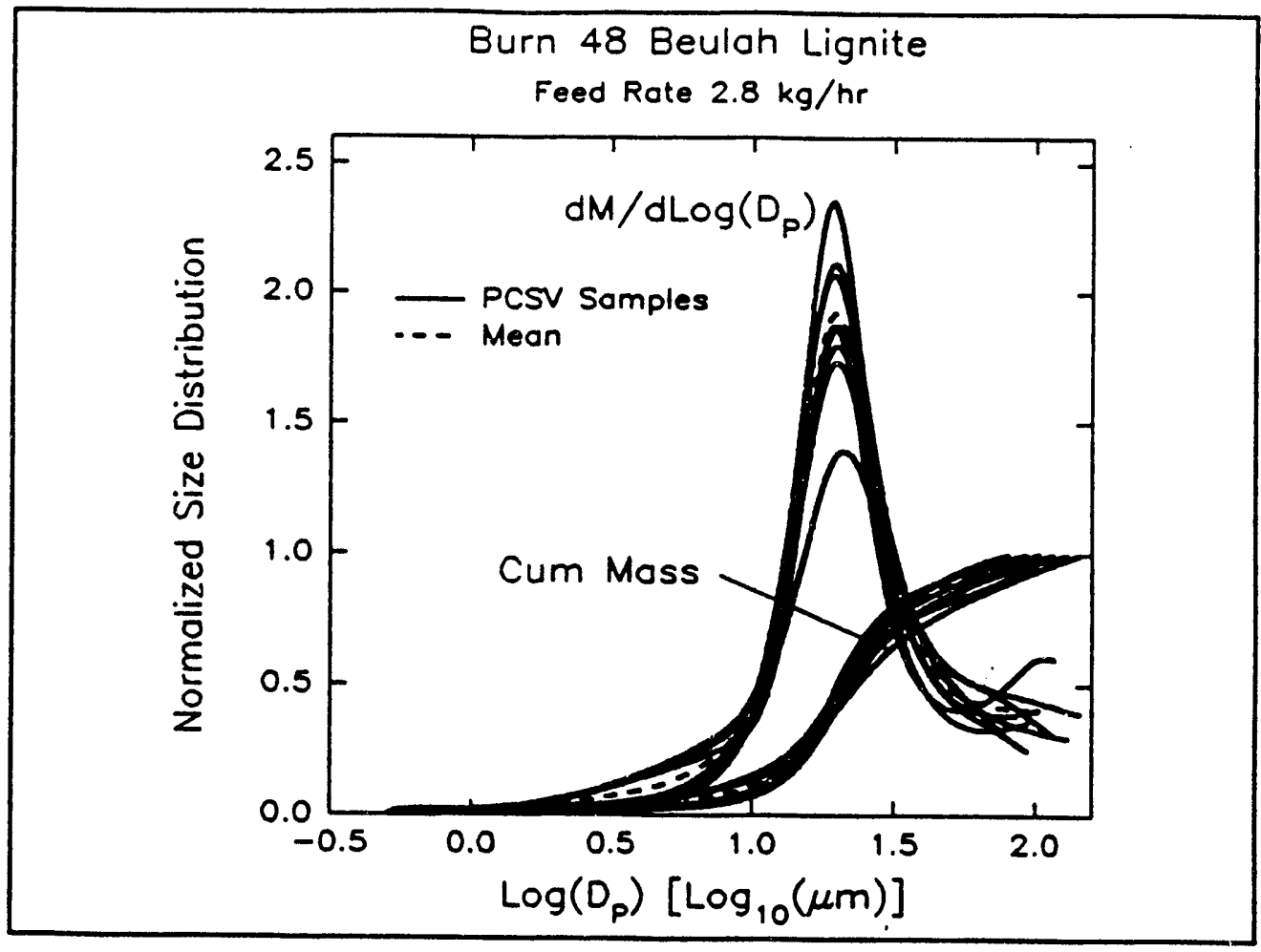

Figure 6-40. Mass Distribution for Burn 48 High Feed Rate

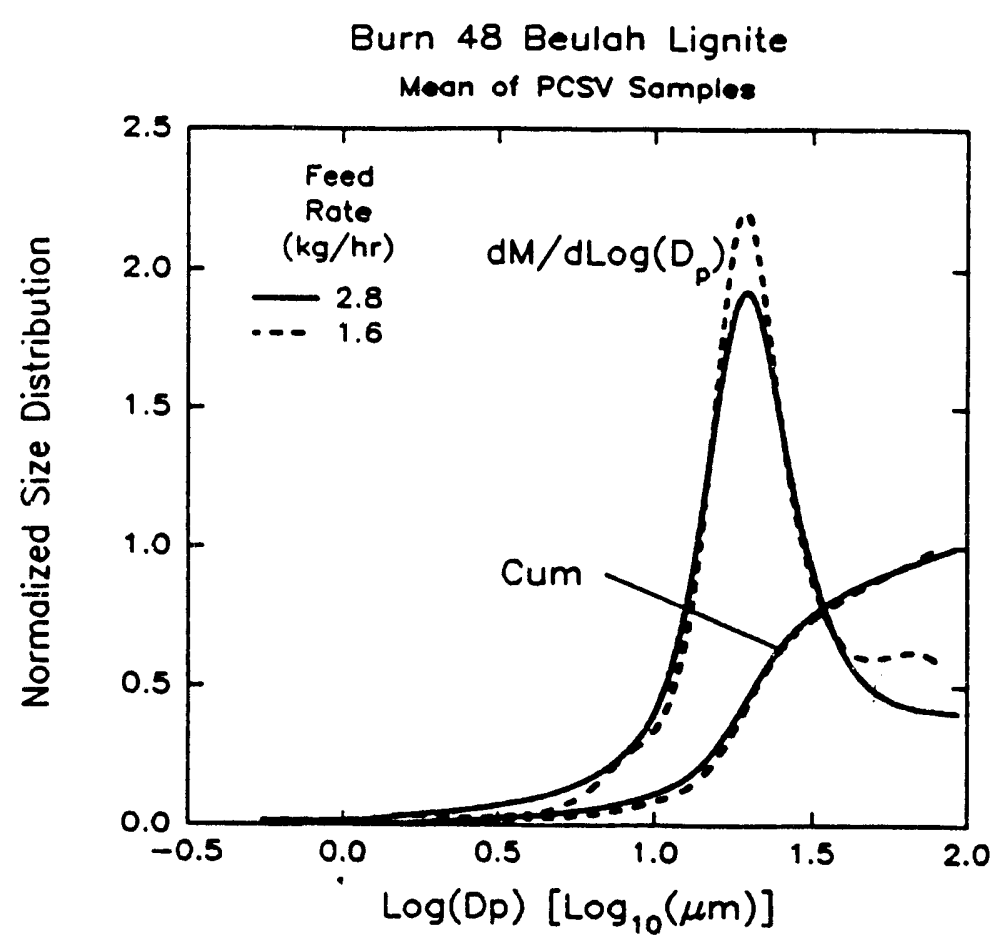

Figure 6-41. Mass Distribution for Burn 48 


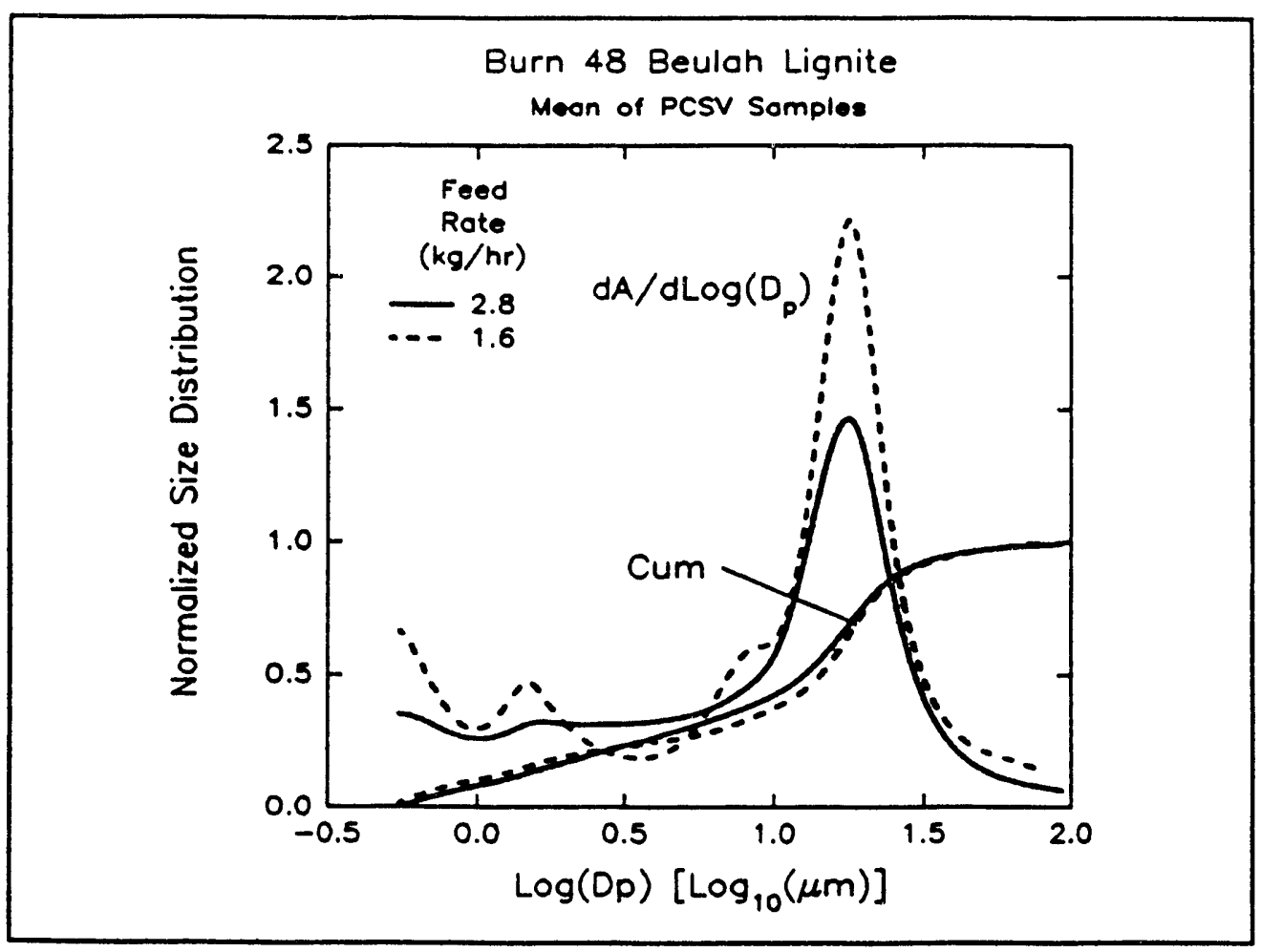

Figure 6-42. Area Distribution for Burn 48

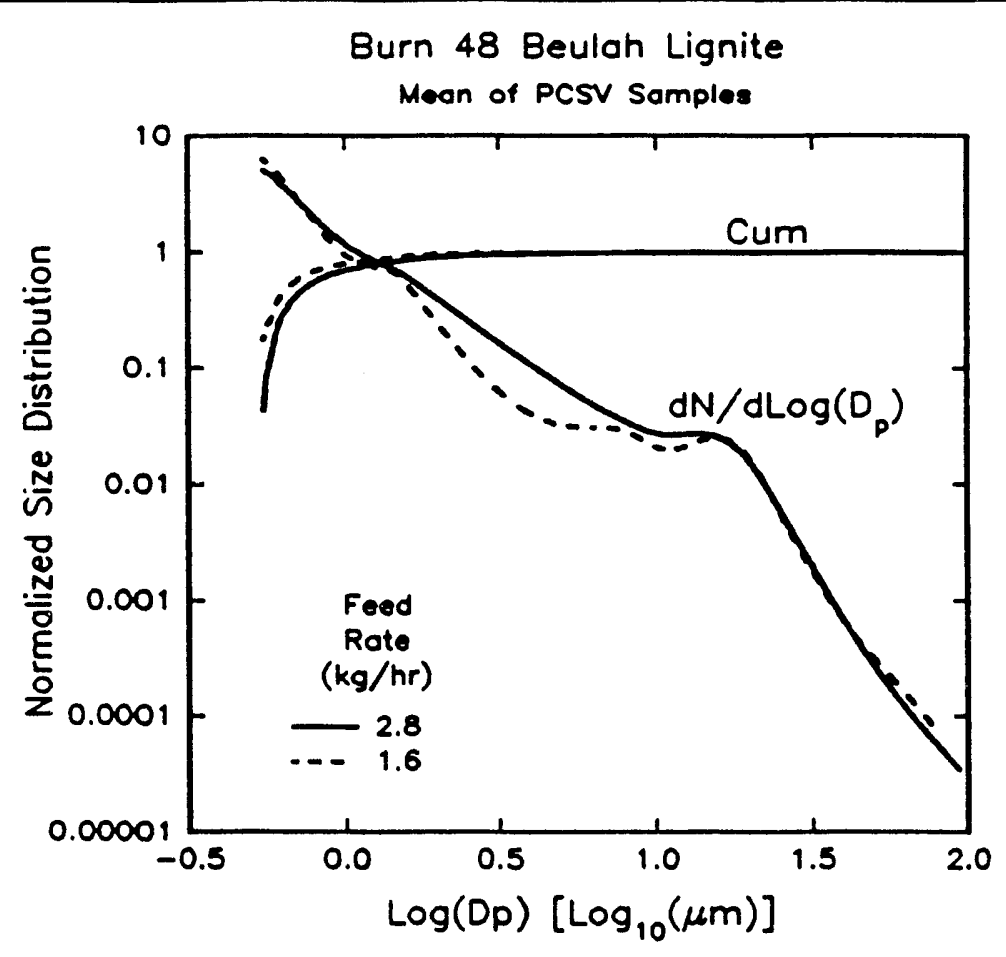

Figure 6-43. Number Distribution for Bum 48 


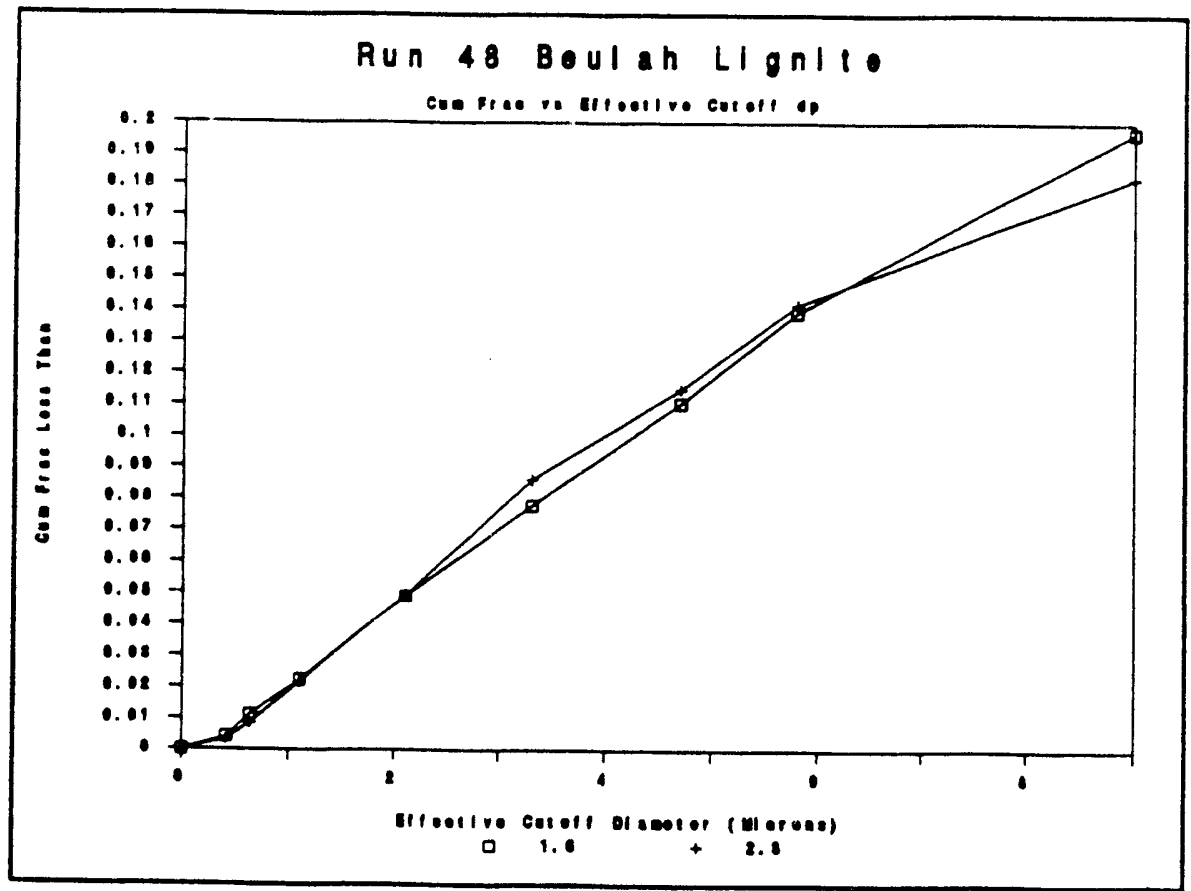

Figure 6-44. Cum Mass Versus Cutoff Diameter for Burn 48

A comparison of the PCSV mean mass distributions, mass as determined from AA analysis of the impactor samples, and the impactor inversion are shown in Figures 6-45 and 6-46 for both feed rates. Although the distributions are in general agreement, comparison of the impactor data to the PCSV distributions shows a shift to smaller sizes for the impactor results. Also, the impactor inversion shows a more marked increased mass in the middle sizes for higher coal feed rate relative to the lower feed rate than the PCSV distributions. Both measurement techniques do show modes less than $10 \mu \mathrm{m}$ for the low feed rate shown in Figure 6-45. The impactor distribution in Figure 6-46 at the higher feed rate would seem to suggest that there are modes less than $10 \mu \mathrm{m}$ whereas the PCSV distribution shows a tail in the same size range.

\subsubsection{Burn 49: Loy Yang 2301}

Burn 49 used pulverized Loy Yang 2301 coal at two different feed rates of approximately 1.8 and $2.7 \mathrm{~kg} / \mathrm{hr}$. This coal arrived in a pulverized state. Previous burns of Loy Yang 2301 used a crushed coal that was pulverized at the University of Arizona. Prior to pulverizing, several extraneous shards of broken glass were found and removed from the coal. During burn 49 cascade impactor samples were acquired for AA and CCSEM analysis from port 11, and PCSV distributions were measured for both feed rates. Figure 6-47 shows the uncorrected temperature profiles for the two feed rates. 


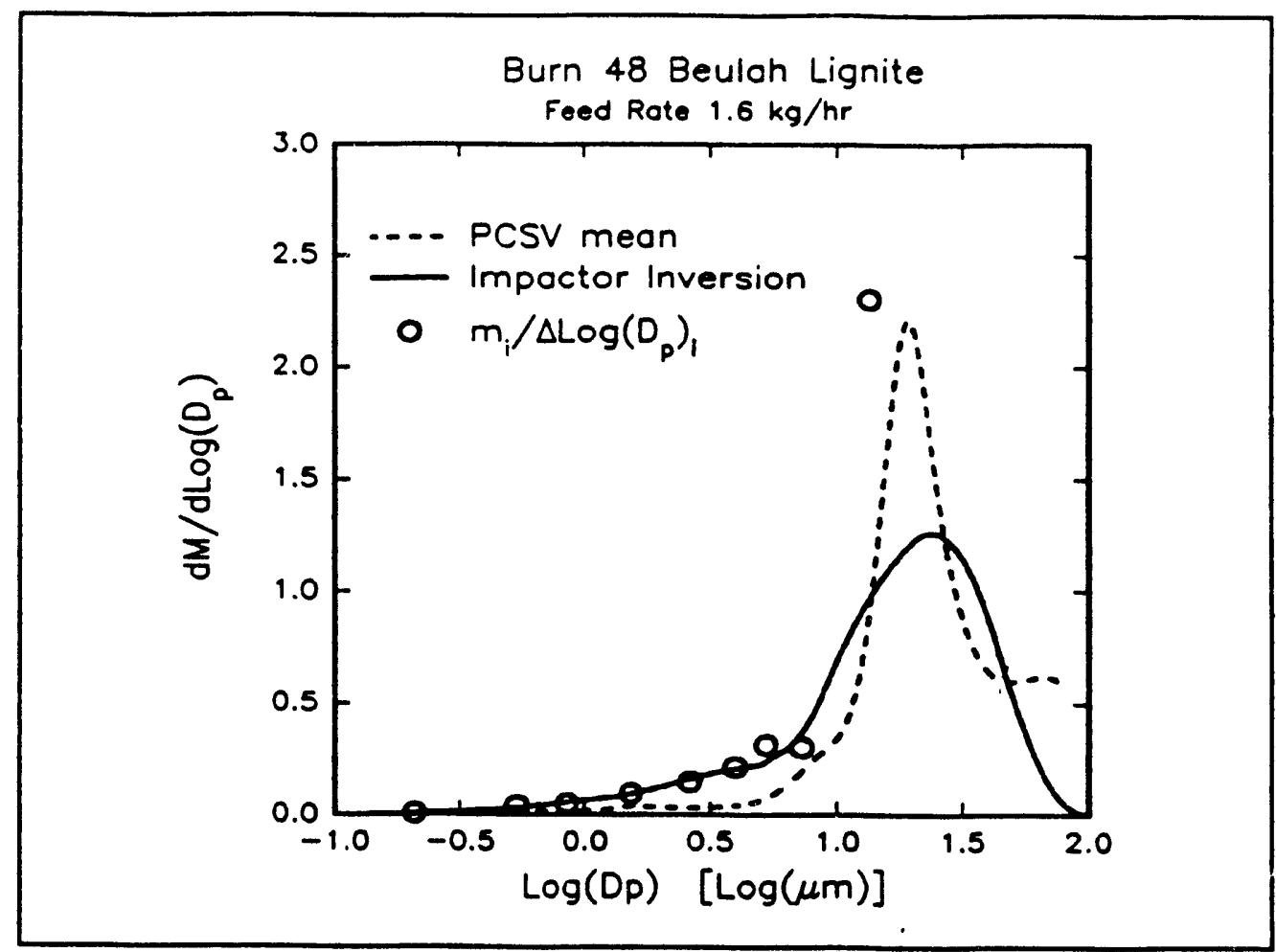

(a)

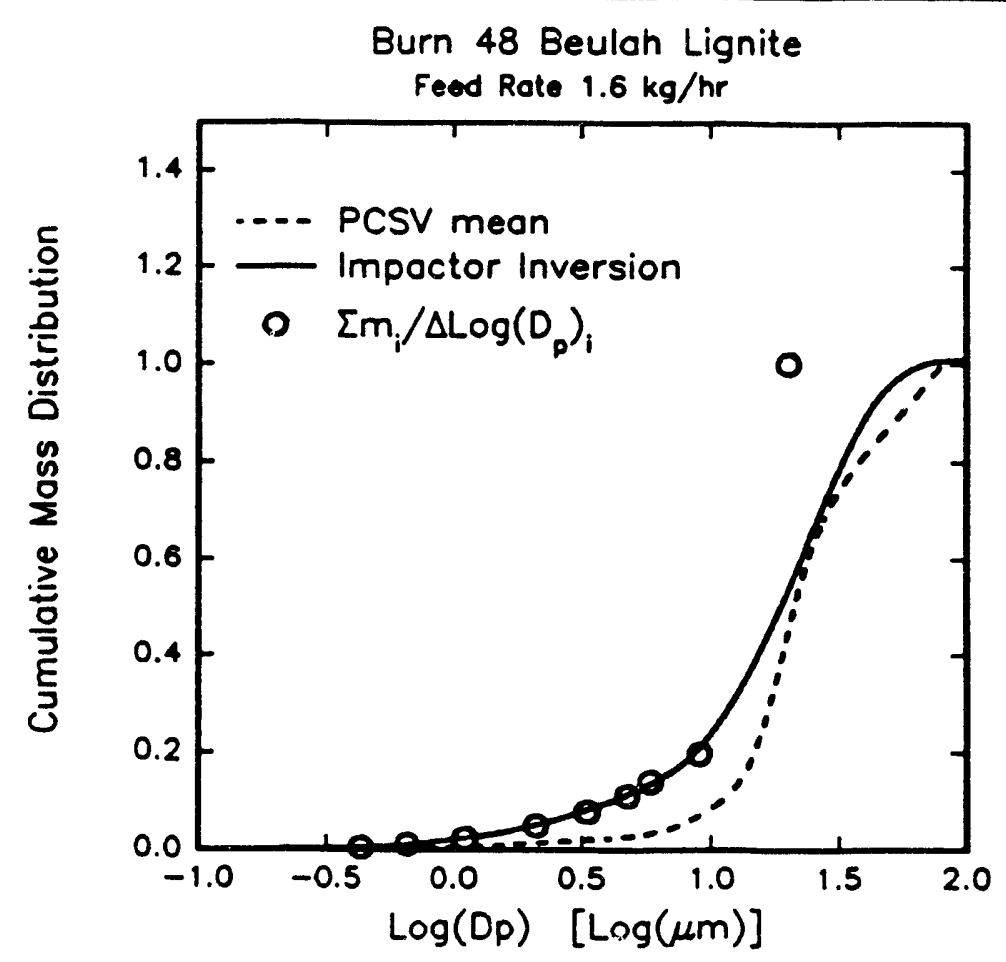

(b)

Figure 6-45. Impactor and PCSV for Burn 48 (feed rate $1.6 \mathrm{~kg} / \mathrm{hr}$ ) 


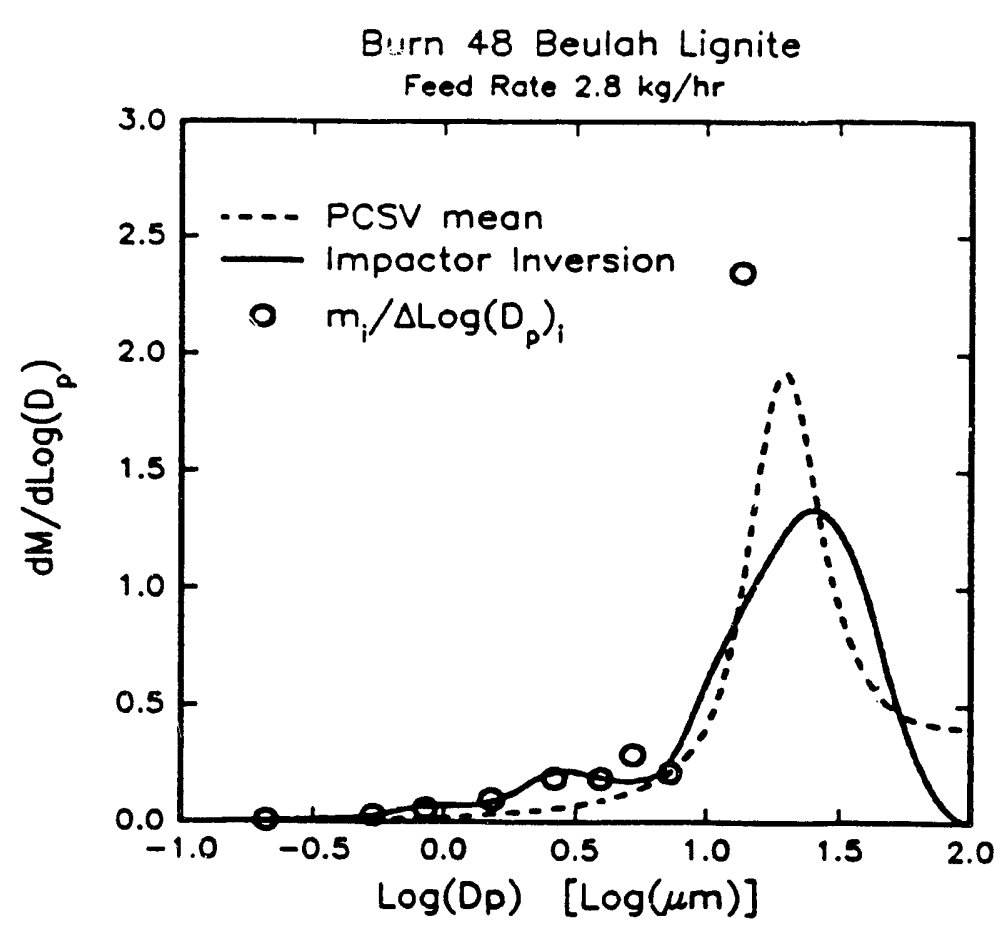

(a)

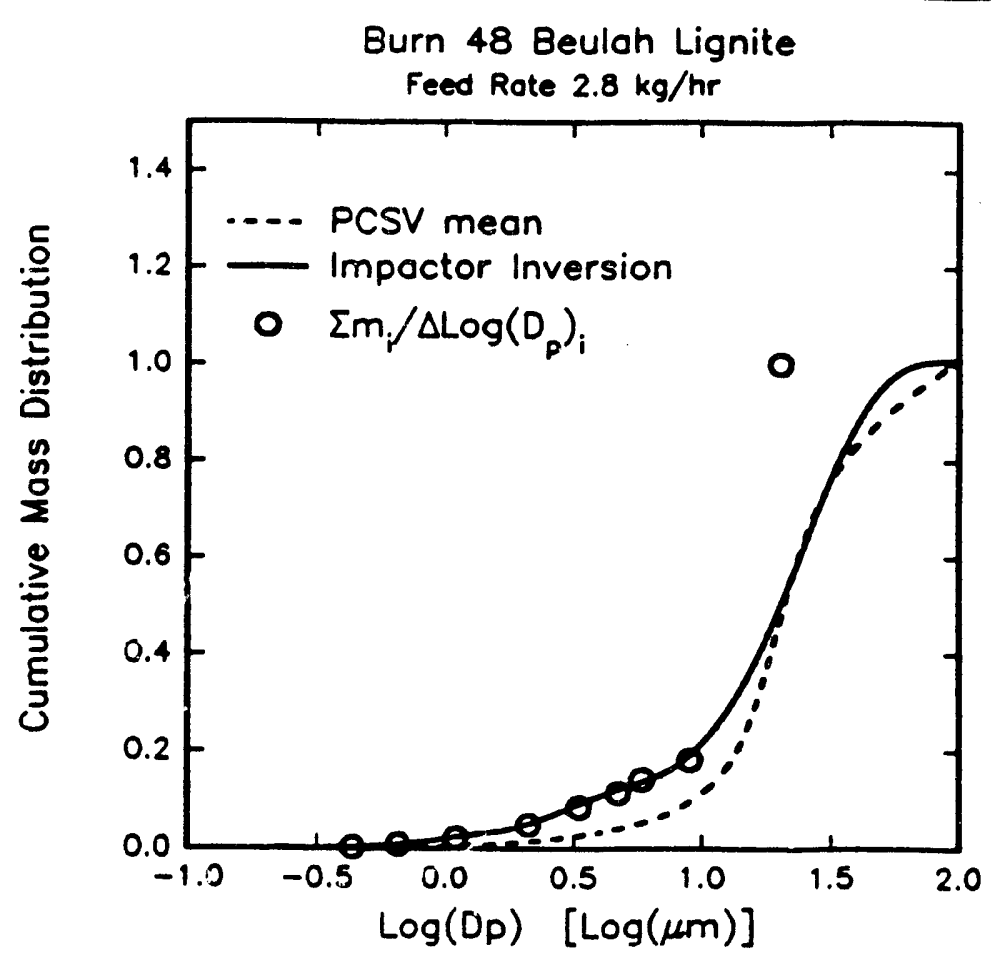

(b)

Figure 46. Impactor and PCSV for Burn 48 (feed rate $2.8 \mathrm{~kg} / \mathrm{hr}$ ) 


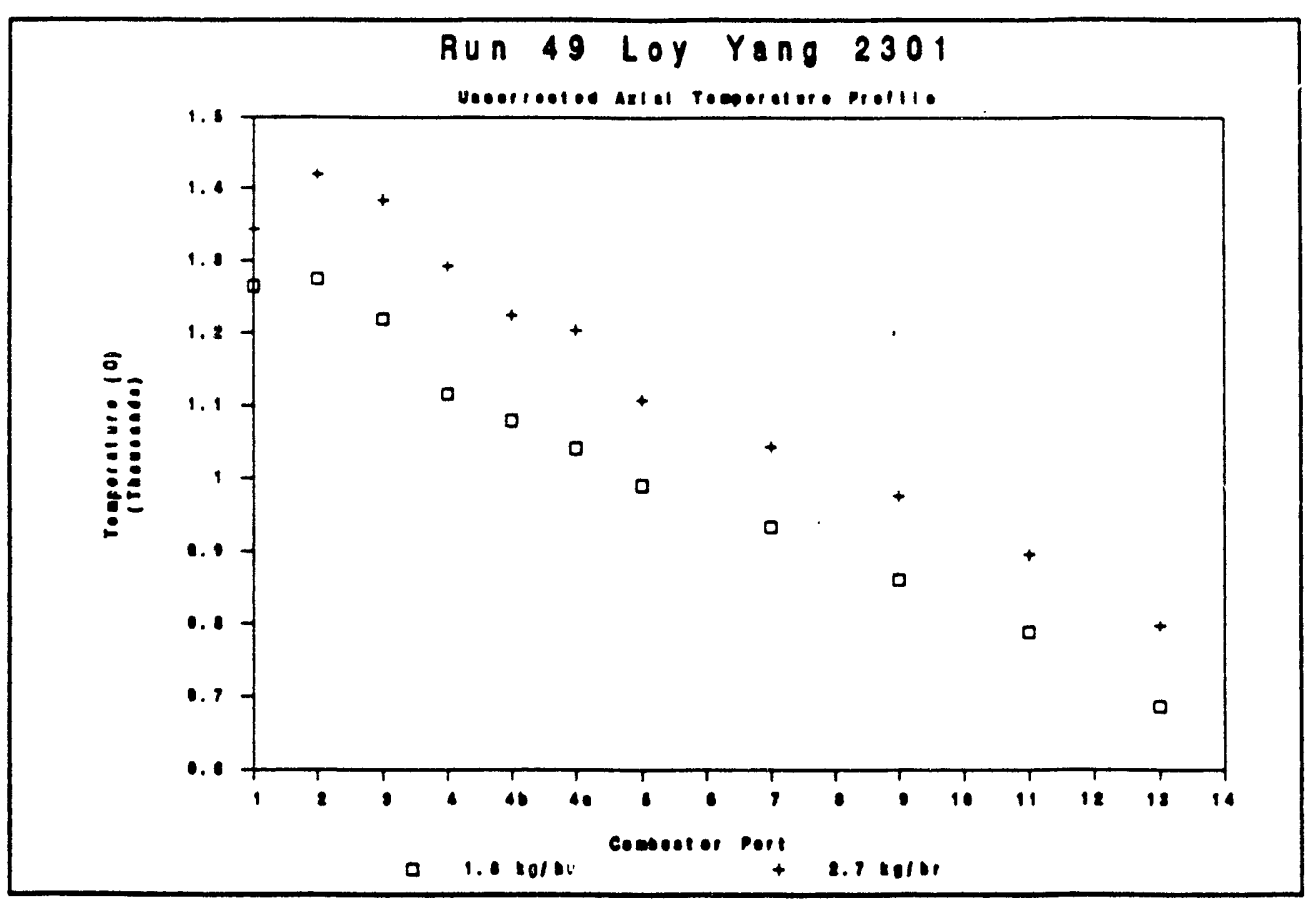

Figure 6-47. Temperature Profile for Burn 49

\subsubsection{Impactor Results}

Figure 6-48 shows the AA results as a fraction oxide versus cascade impactor stage plot for the lower feed rate. The fraction oxide plot for the higher feed rate is shown in Figure 6-49. As with previous burns of Loy Yang 2301, the sodium was highly enriched in the small sizes. Contrary to previous burns of Loy Yang 2301 however, samples acquired during burn 49 at the two feed rates differed significantly. Differences in the silicon behavior was the most notable: $98 \%$ of the sampled silicon was on stage 1 for the sample acquired at the lower feed rate whereas only $40 \%$ was found on plate 1 for the sample acquired at the higher feed rate. Differences in the calcium behavior were also significant: of the sampled calcium, 75\% was on stage 1 for the lower feed rate and $50 \%$ was on stage 1 for the higher feed rate. Magnesium also showed some differences with $50 \%$ and $30 \%$ of the sampled magnesium found on stage 1 for the low and high feed rates respectively.

Comparison to burn 39 which used the coal pulverized at the $U$ of $A$ (Boni et al, 1990) showed that Figure 6-49 was more representative of previous burns of the Loy Yang 2301 than Figure 6-48. However, the magnesium and calcium fractions were higher in Figure 6-49 than in burn 39. The relative differences between previous burns, Figure 6-48, and Figure 6-49 could be related to extraneous impurities in the coal, but this is difficult to discern.

Figures 6-50 and 6-51 show the concentration of ash in $\mathrm{mg} / \mathrm{sm}^{3}$ for the cascade impactor samples. As expected from the behavior of silicon, calcium, and magnesium, the mass of sample on stage 1 relative to the rest of the impaci or was higher for the sample acquired at the lower feed rate. 


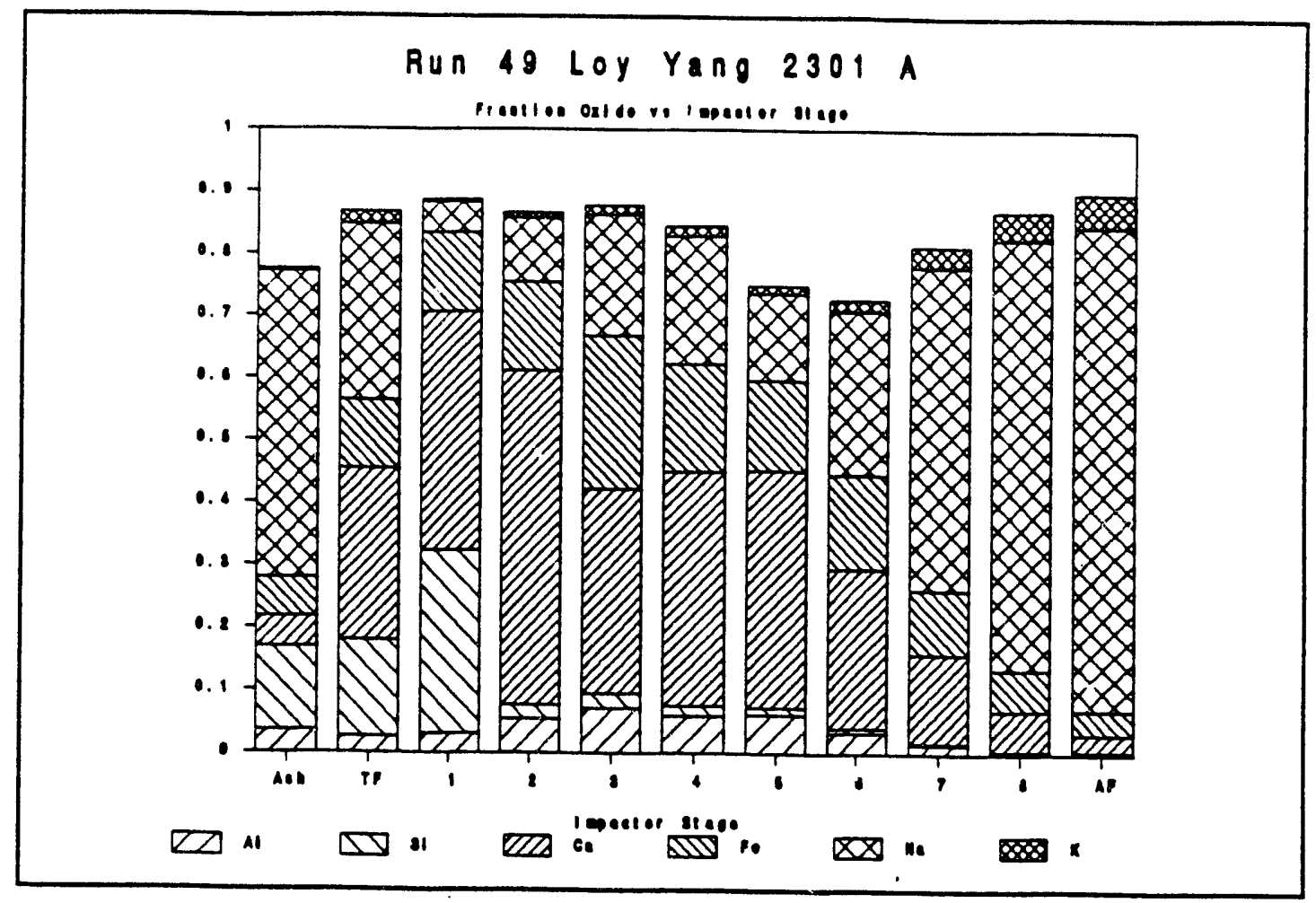

Figure 6-48. Fraction Oxide for $1.8 \mathrm{~kg} / \mathrm{hr}$ Feed Rate

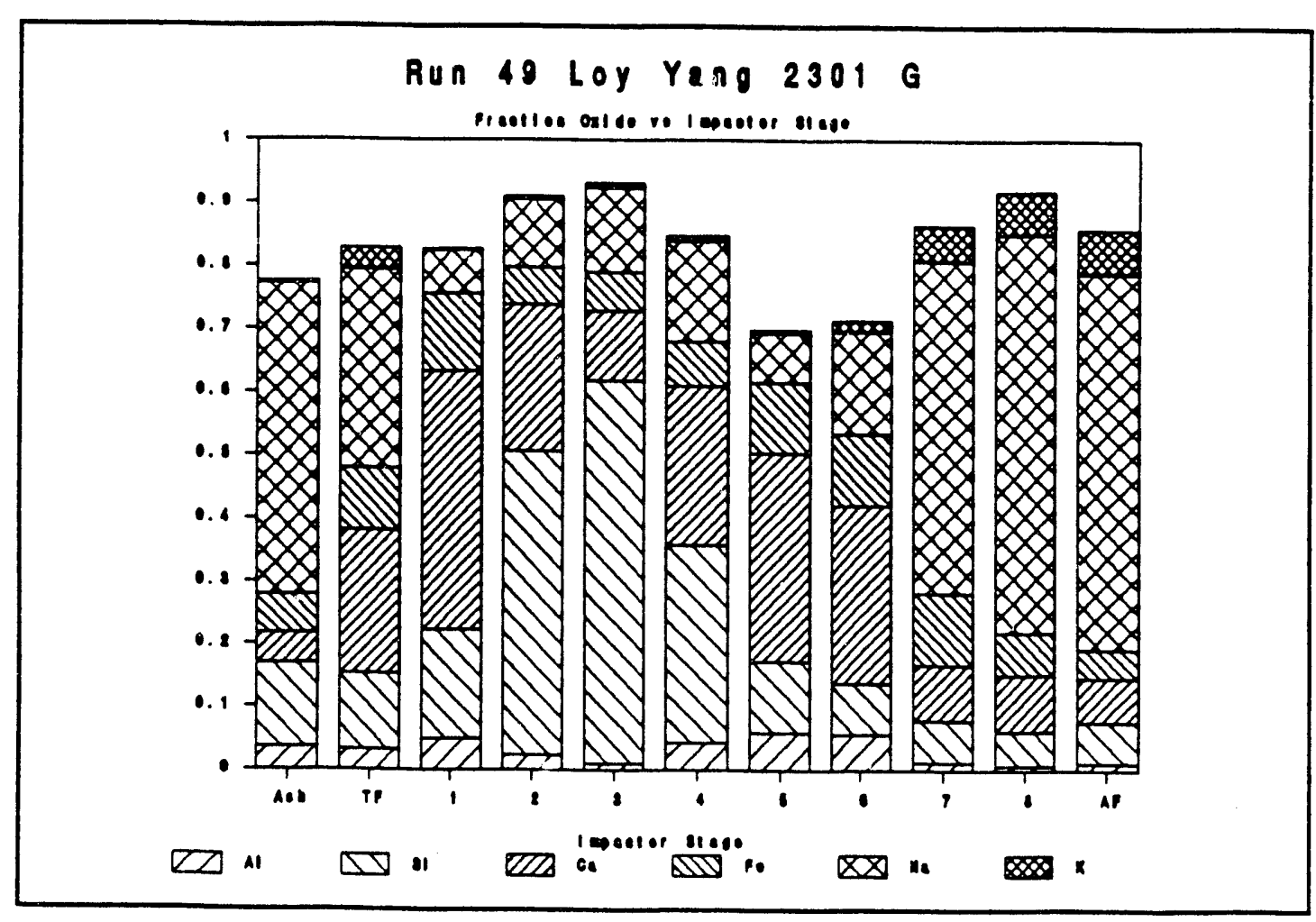

Figure 6-49. Fraction Oxide for $2.8 \mathrm{~kg} / \mathrm{hr}$ Feed Rate 


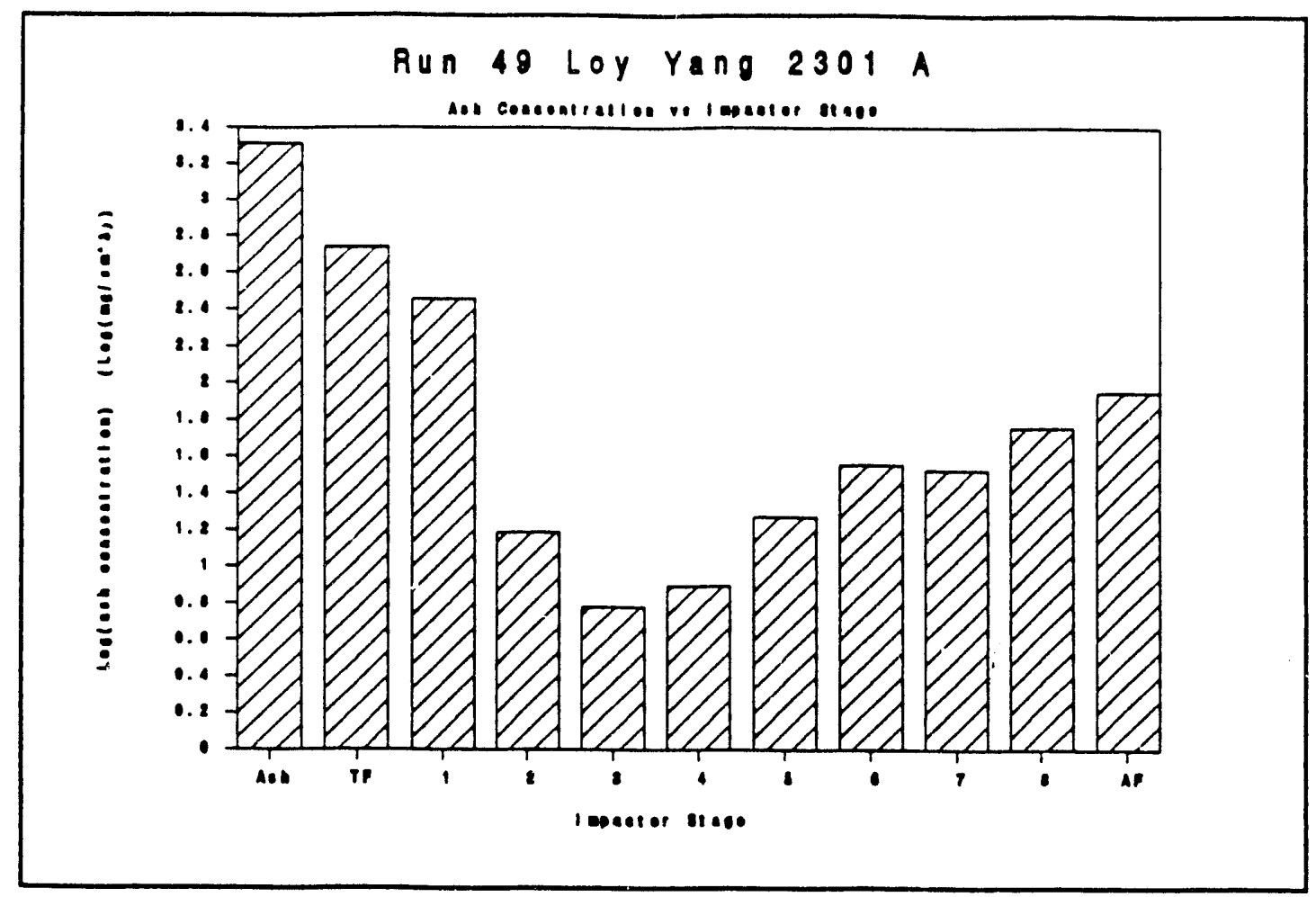

Figure 6-50. Ash Concentration for $1.8 \mathrm{~kg} / \mathrm{hr}$ Feed Rate

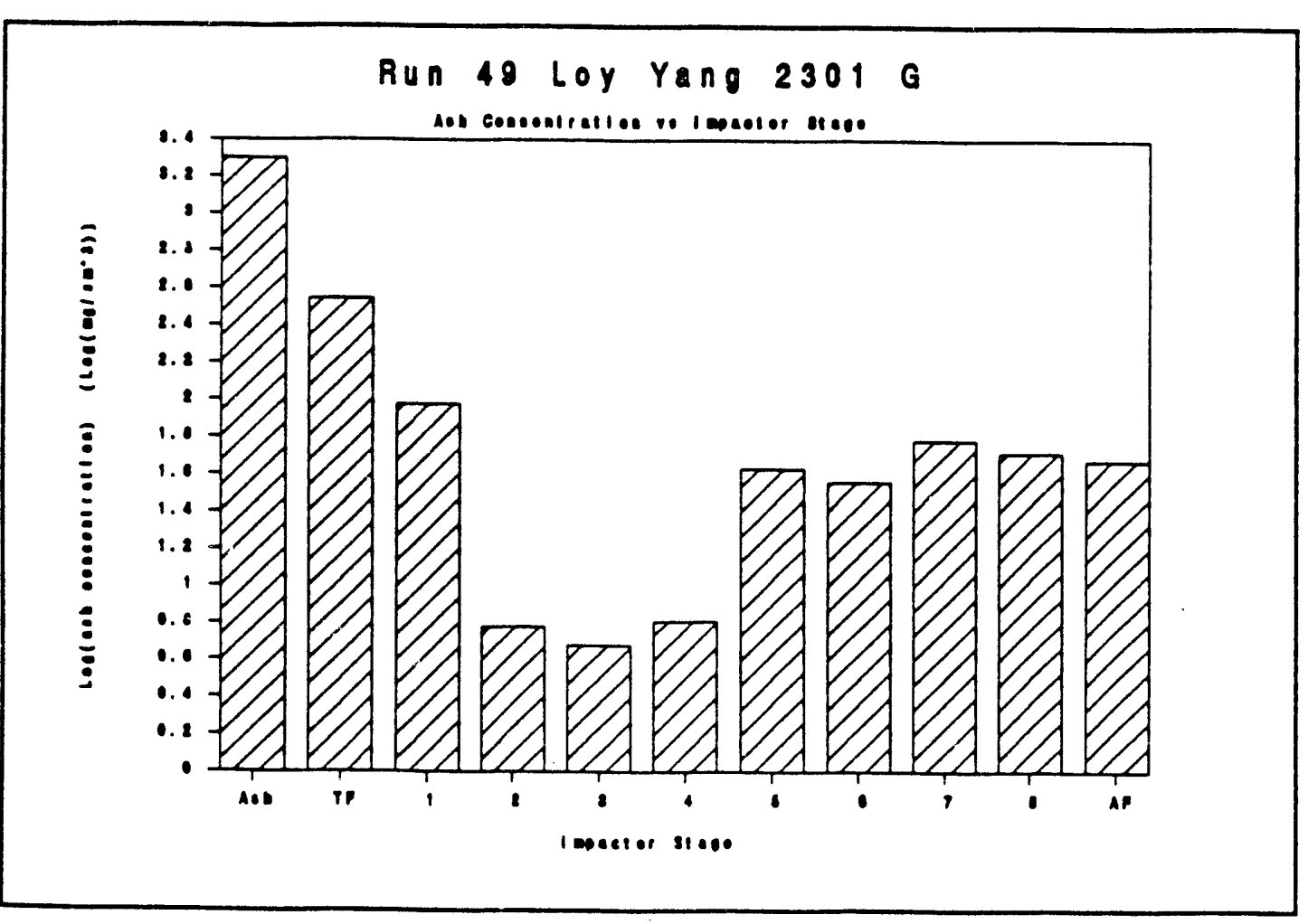

Figure 6-51. Ash Concentration for $2.8 \mathrm{~kg} / \mathrm{hr}$ Feed Rate 


\subsubsection{PCSV Results}

Figures 6-52 and 6-53 show the normalized cumulative mass and mass density distributions acquired with the PCSV during low and high feed rates of Loy Yang 2301 respectively. The mean distributions are also presented in these figures. A comparison of the mean mass distributions is shown in Figure 6-54 for the two feed rates. Figure 6-55 shows the mean of the area distributions and Figure 6-56 shows the mean of the number distributions.

Comparison of the PCSV mean mass distributions, maiss as determined from AA analysis, and the impactor inversion are shown in Figures 6-57 and 6-58 for both feed rates. Comparison of the impactor data to the PCSV distributions shows a significant shift to smaller sizes for the impactor results. One possible explanation considered was the relative insensitivity of the PCSV in the submicron range compared to the impactor. Since the lower cutoff size for the PCSV was approximately $0.4 \mu \mathrm{m}$, impactor inversions were performed for the impactor data at the low feed rate with the mass response of the lower two stages set to zero. This in effect removes mass from the impactor in sizes less than $0.43 \mu \mathrm{m}$. The comparison to the PCSV data is shown in Figure 6-59. Although the disparity between the two size measuring techniques is smaller, the comparisons still differ markedly.

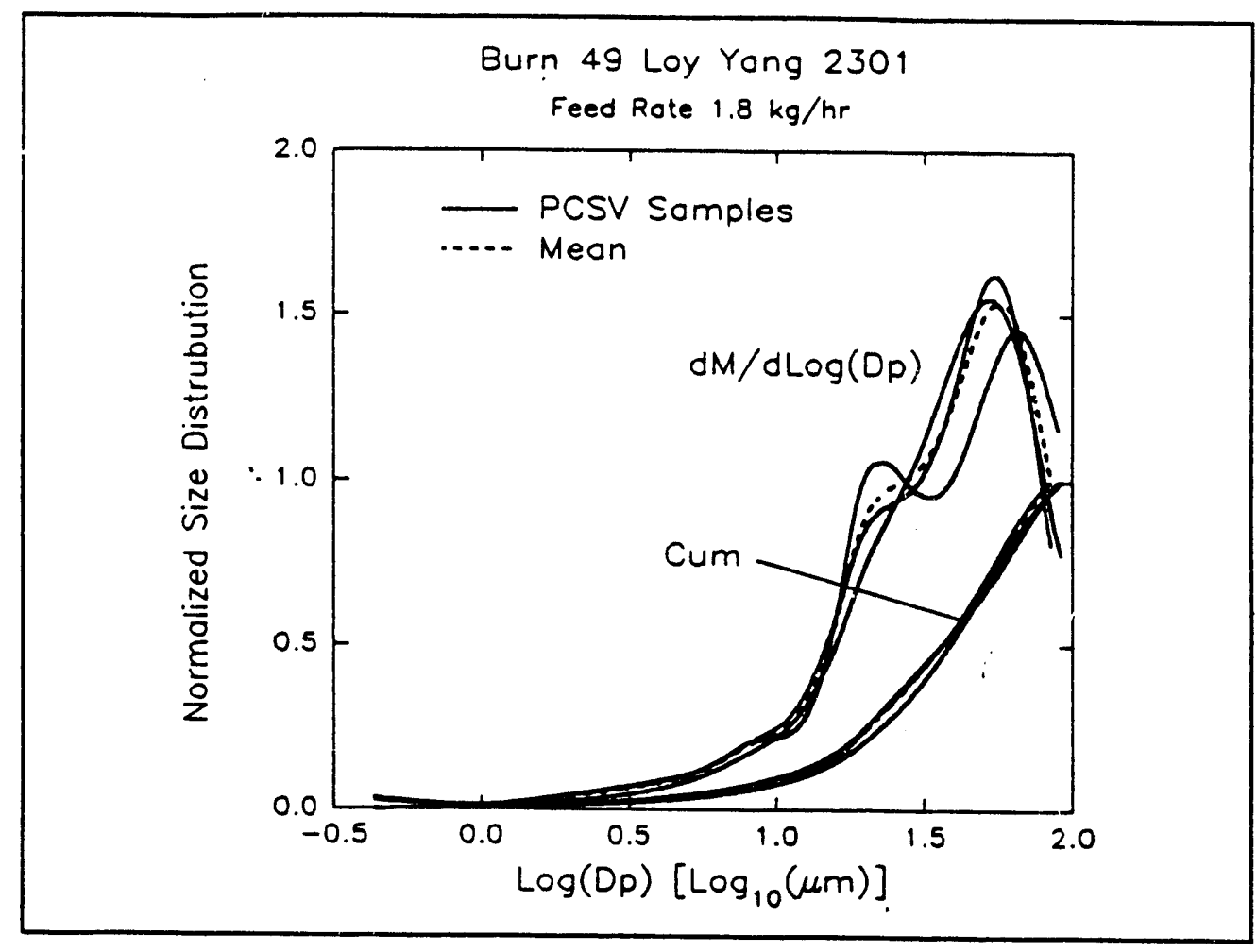

Figure 6-52. Mass Distribution for Burn 49 Low Feed Rate 


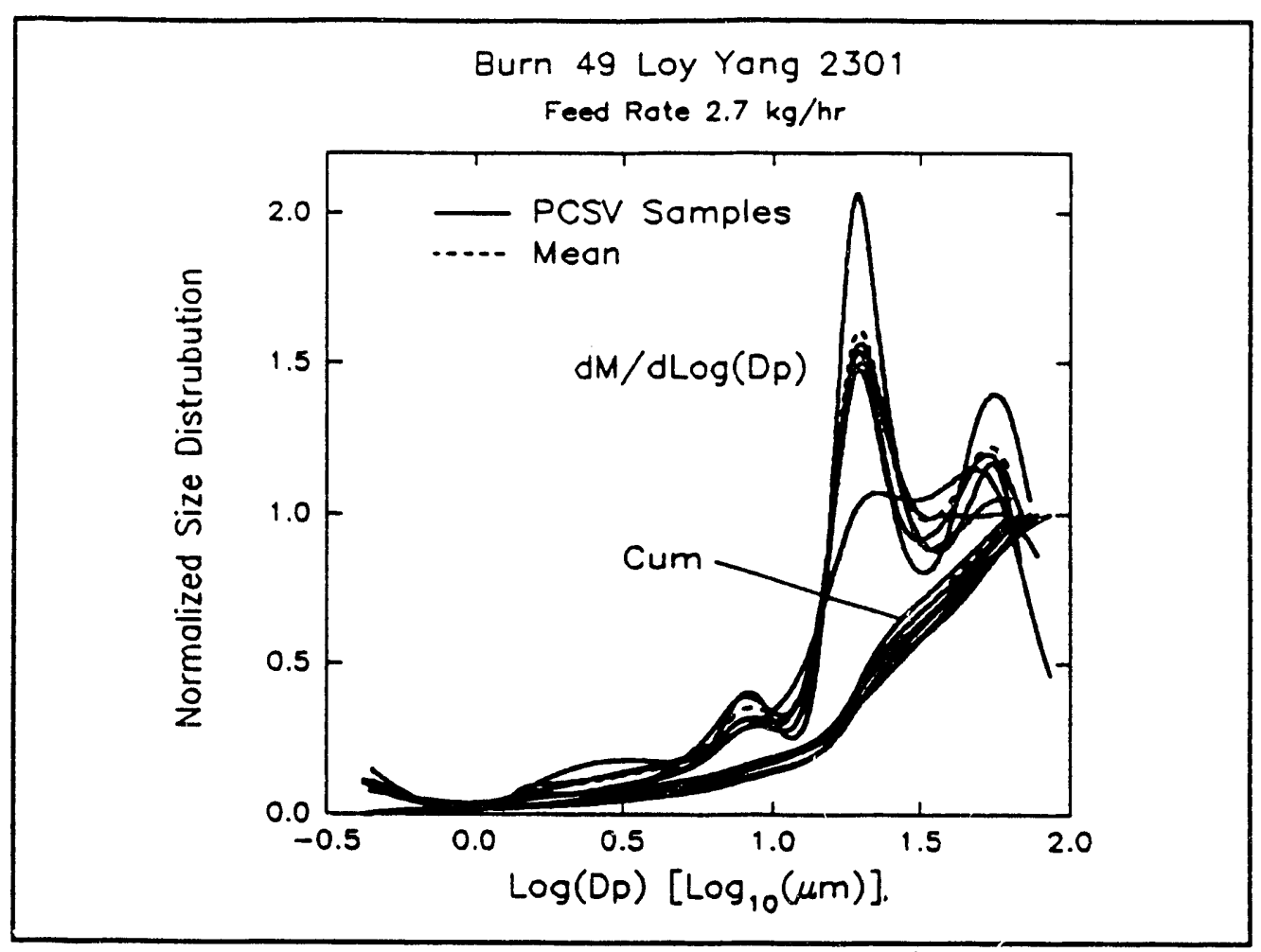

Figure 6-53. Mass Distribution for Burn 49 High Feed Rate

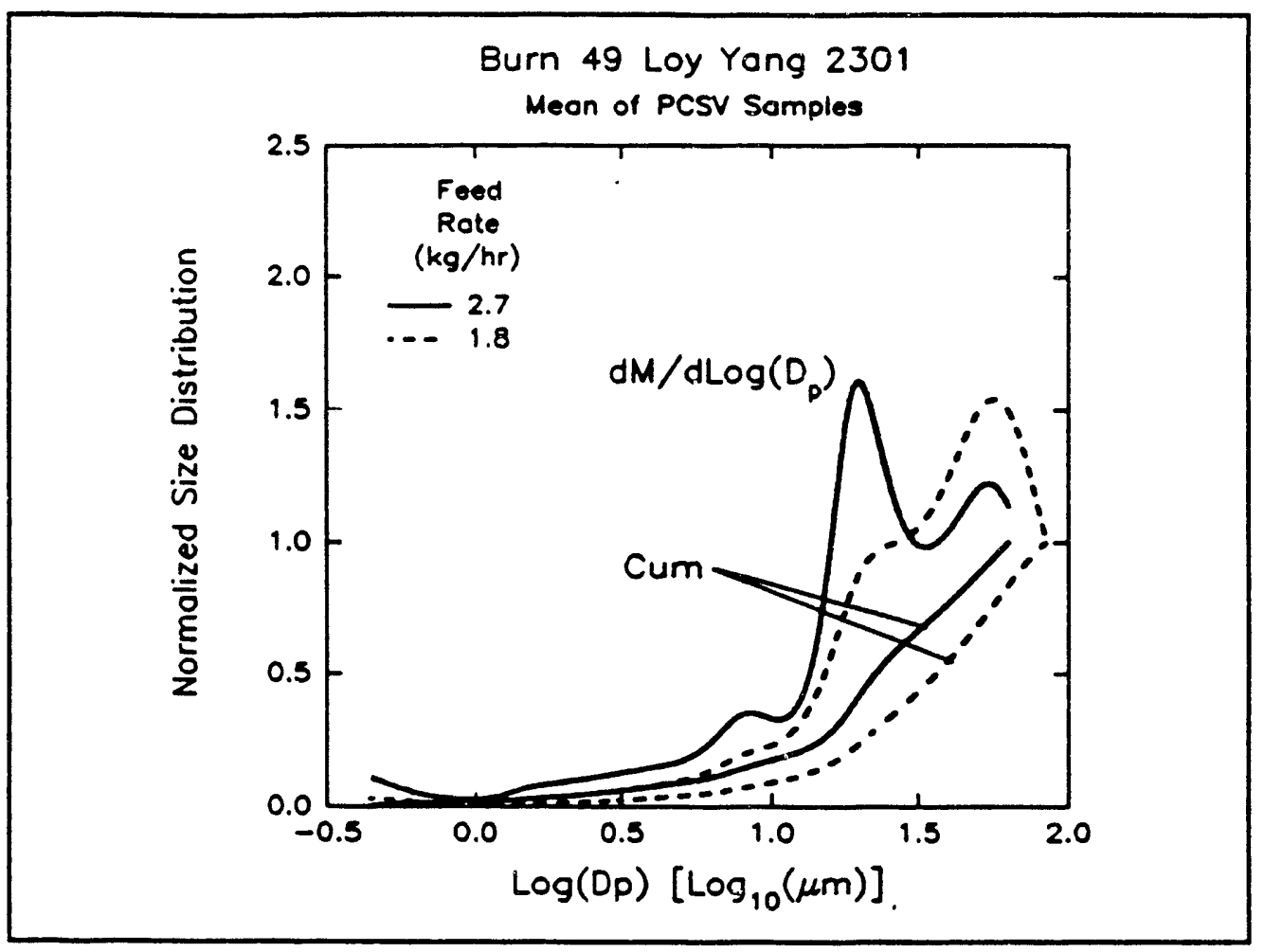

Figure 6-54. Mass Distributions for Burn 49 


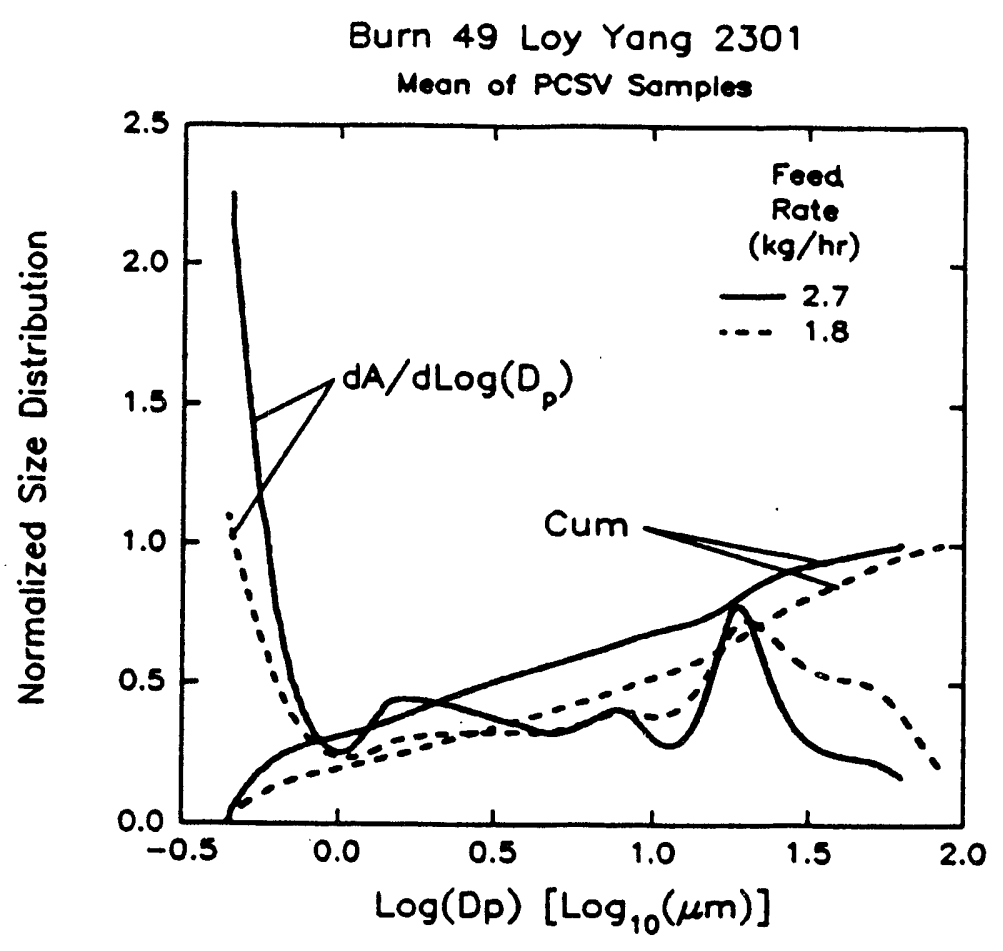

Figure 6-55. Area Distribution for Burn 49

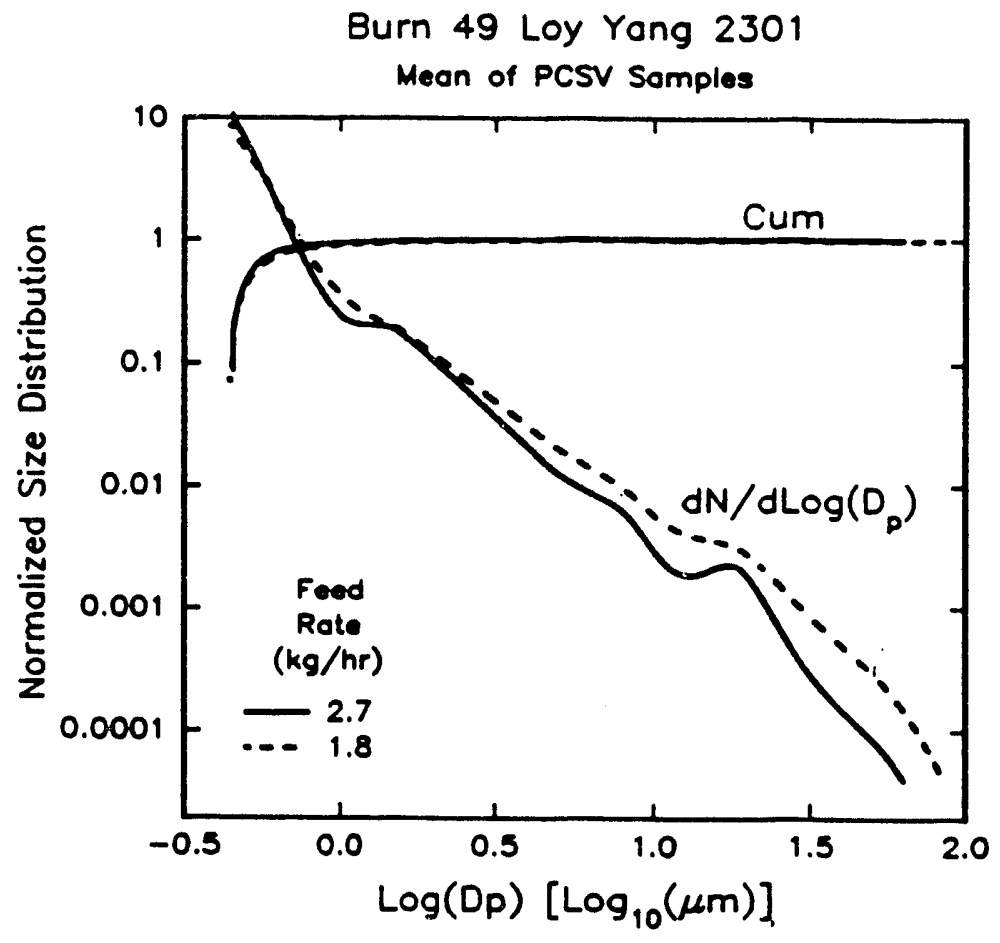

Figure 6-56. Number Distributions for Burn 49 


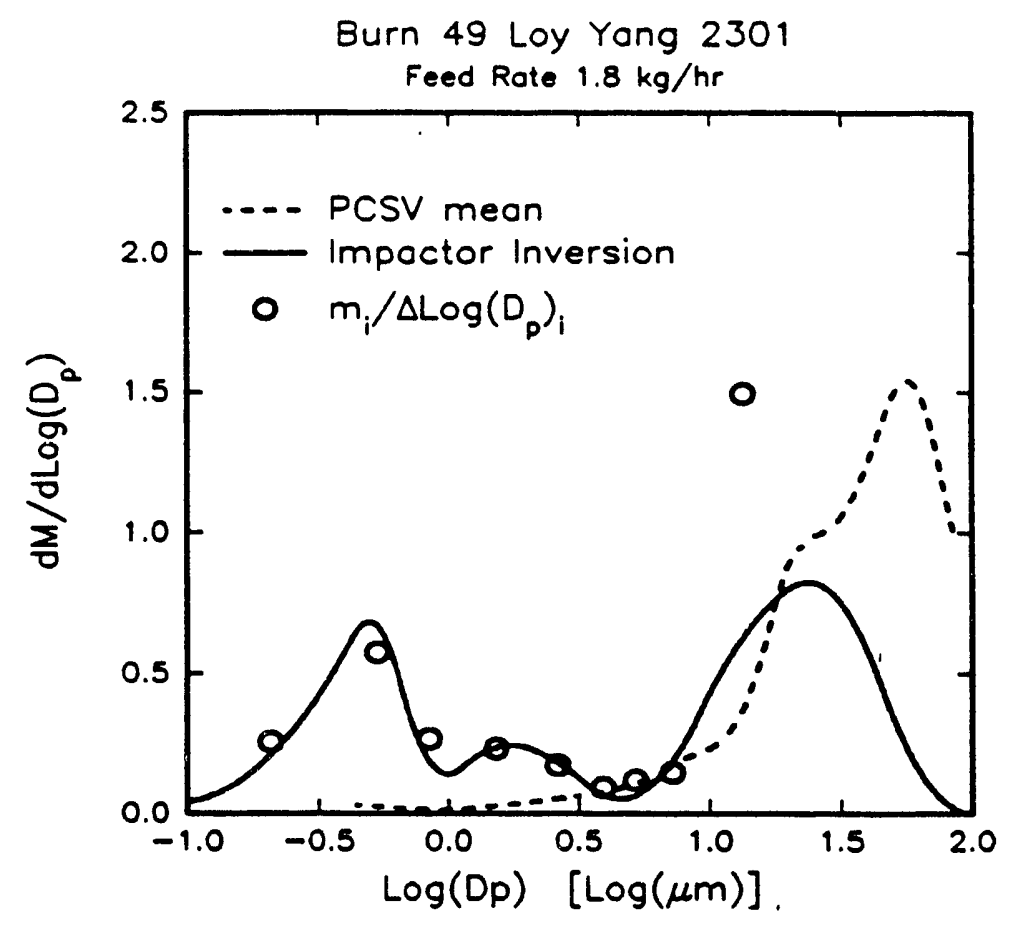

(a)

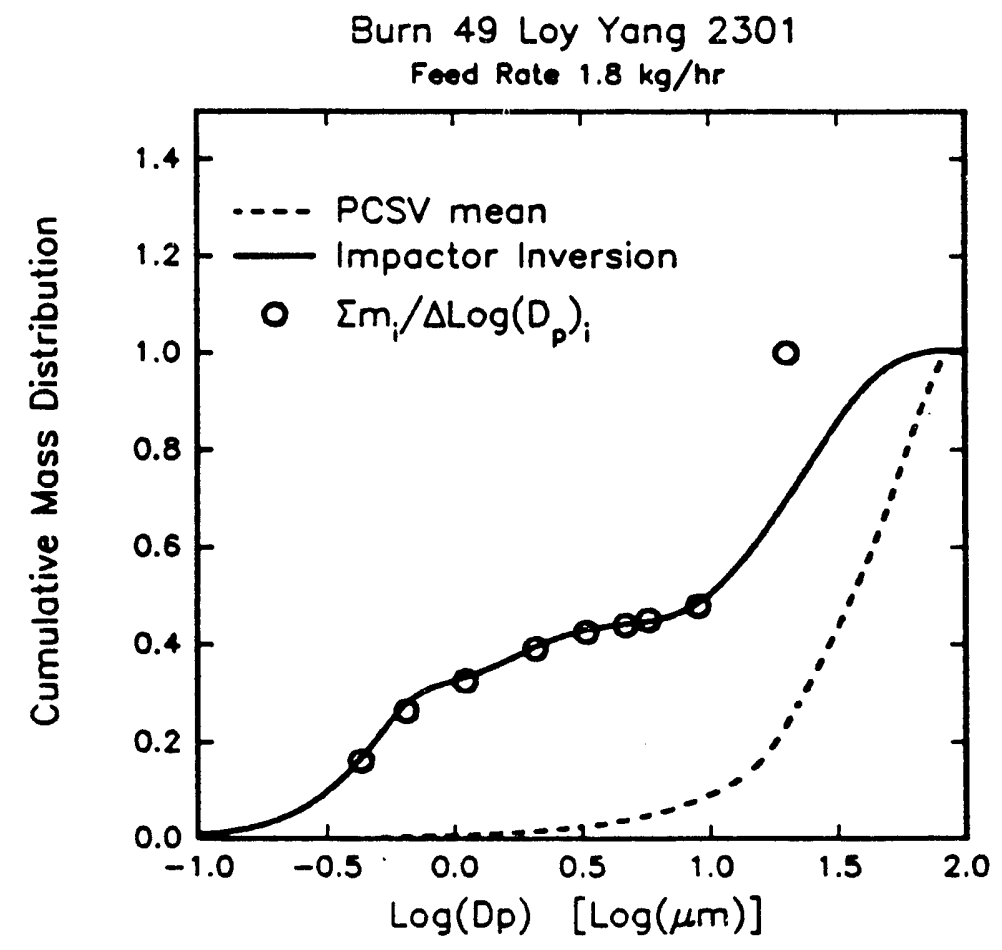

(b)

Figure 57. Impactor and PCSV for Burn $49(1.8 \mathrm{~kg} / \mathrm{hr})$ 


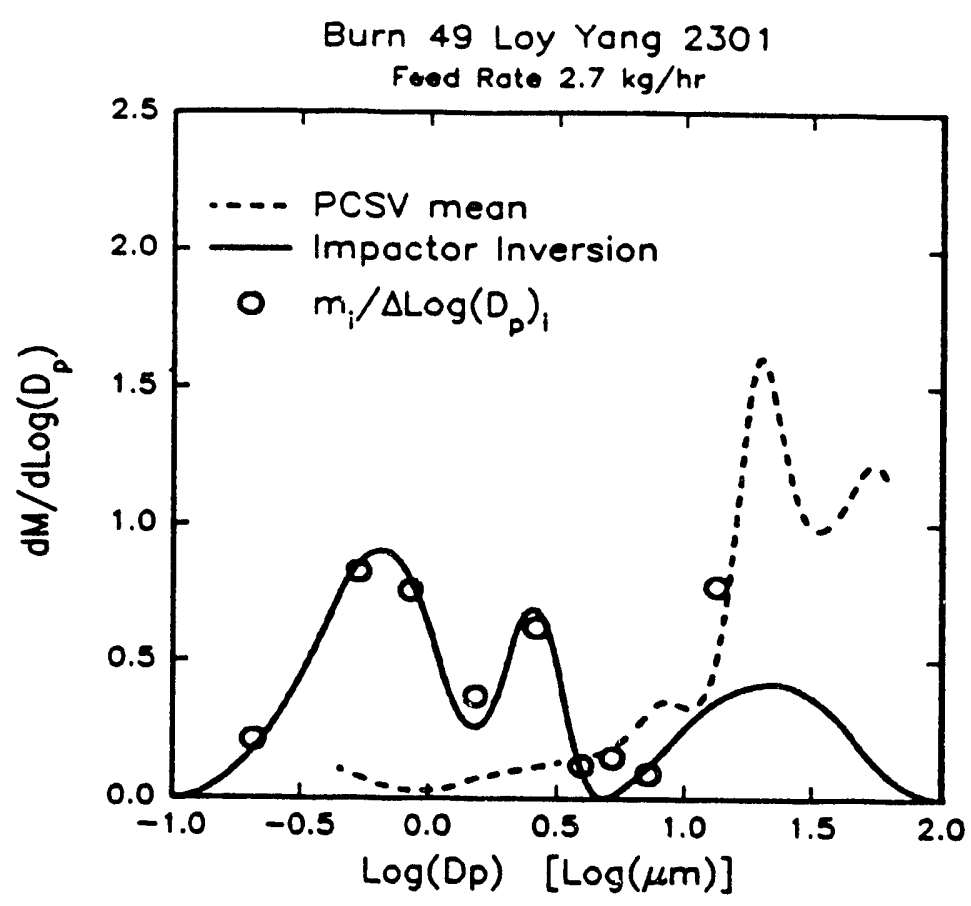

(a)

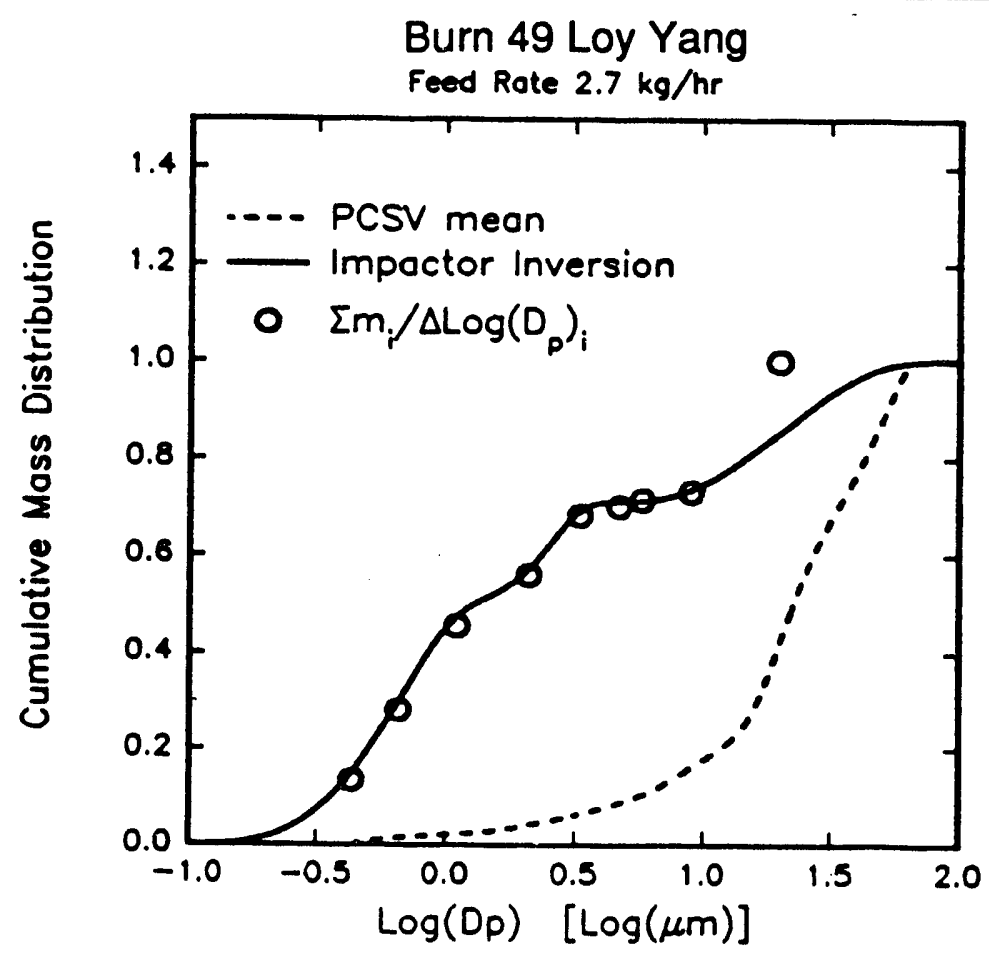

(b)

Figure 6-58. Impactor and PCSV for Burn $49(2.7 \mathrm{~kg} / \mathrm{hr})$ 
Burn 49 Loy Yang 2301

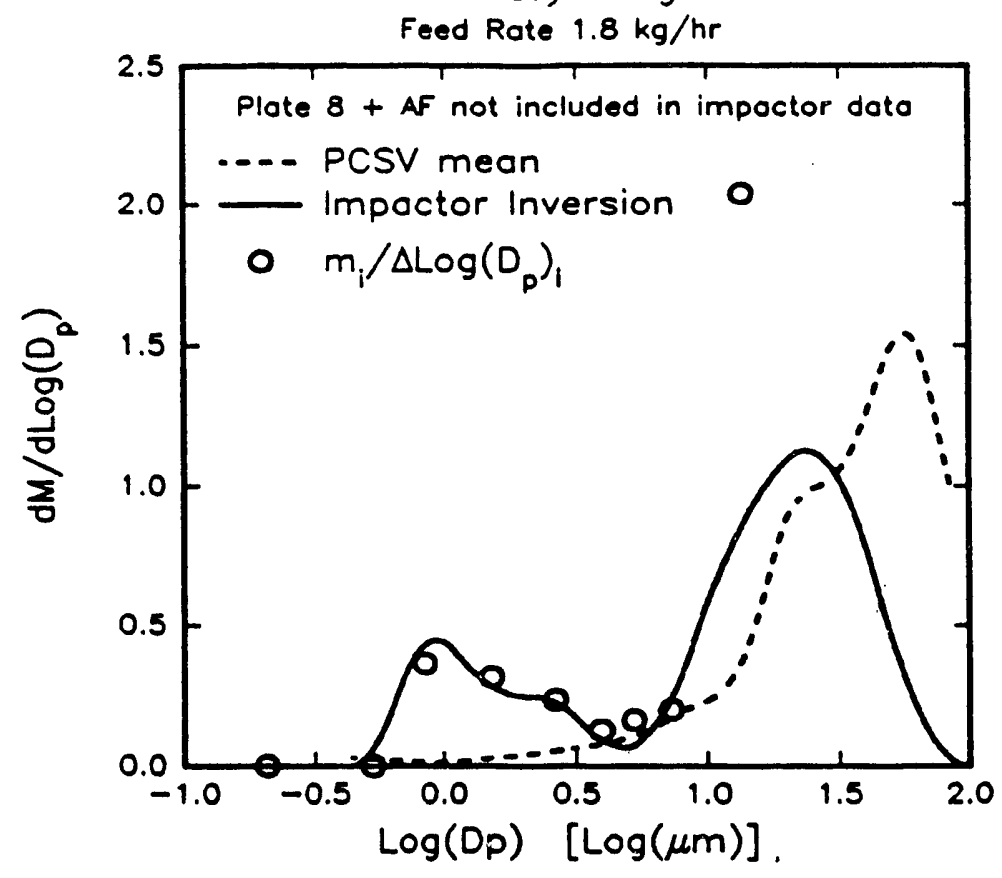

(a)

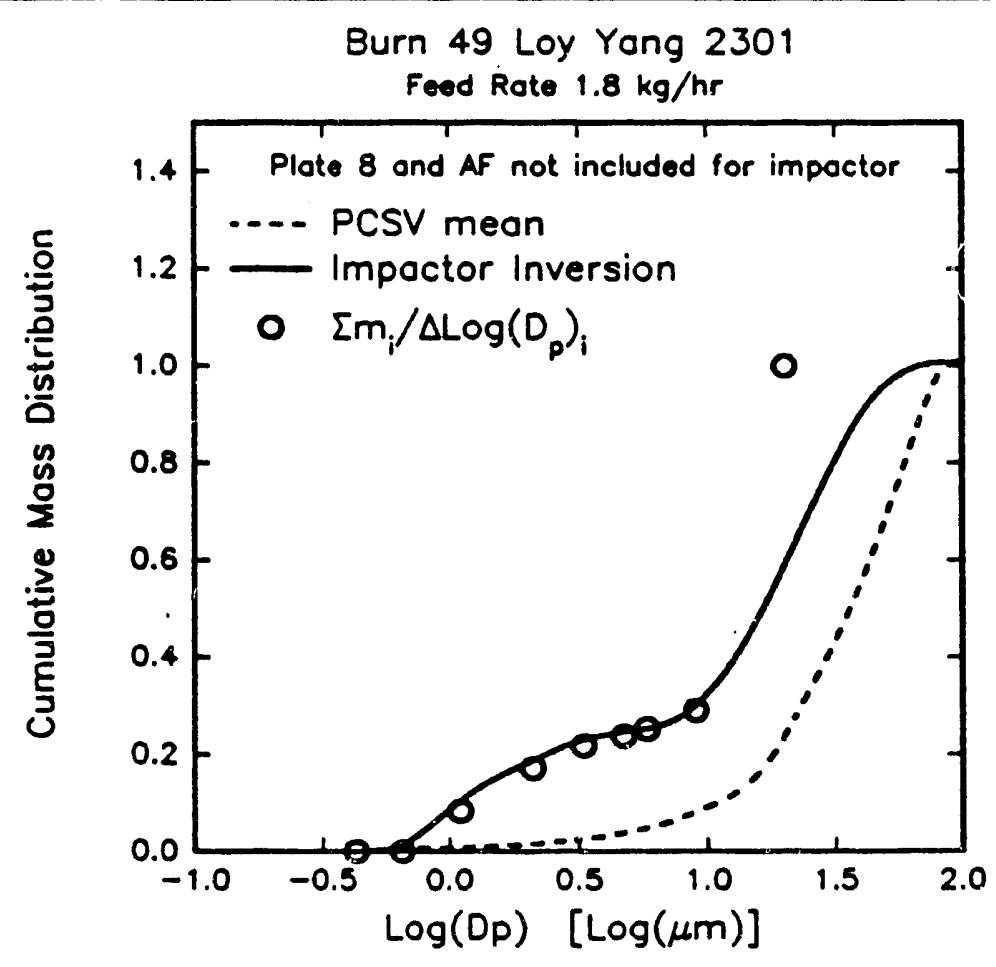

(b)

Figure 6-59. Imp w/o 8+AF and PCSV for Bum $49(1.8 \mathrm{~kg} / \mathrm{hr})$ 


\subsubsection{Burn 50: Loy Yang 1953}

Burn 50 used Loy Yang 1953 coal at one feed rate of approximately $2.5 \mathrm{~kg} / \mathrm{hr}$. Cascade impactor samples were acquired for AA and CCSEM analysis from port 11, and PCSV distributions were also measurea at that those rates. Figure 6-60 shows the uncorrected temperature profile for burn 50 .

\subsubsection{Impactor Results}

Figure 6-61 shows the AA results as fraction oxide versus cascade impactor stage for burn 50. Similar to the Loy Yang 2301 of burn 49, Figure 6-61 show a significant sodium enrichment of the small particles for the Loy Yang 1953. Figure 6-62 shows the concentration of ash in $\mathrm{mg} / \mathrm{sm}^{3}$ for the cascade impactor samples. Errors in the measurements of concentrations for the larger size cuts was estimated at less than approximately $\pm 5 \%$. For the smaller size cuts errors were estimated at less than $\pm 6 \%$. The total filter concentration of ash from the Loy Yang 1953 was similar to that for the Loy Yang 2301, however some differences did exist.

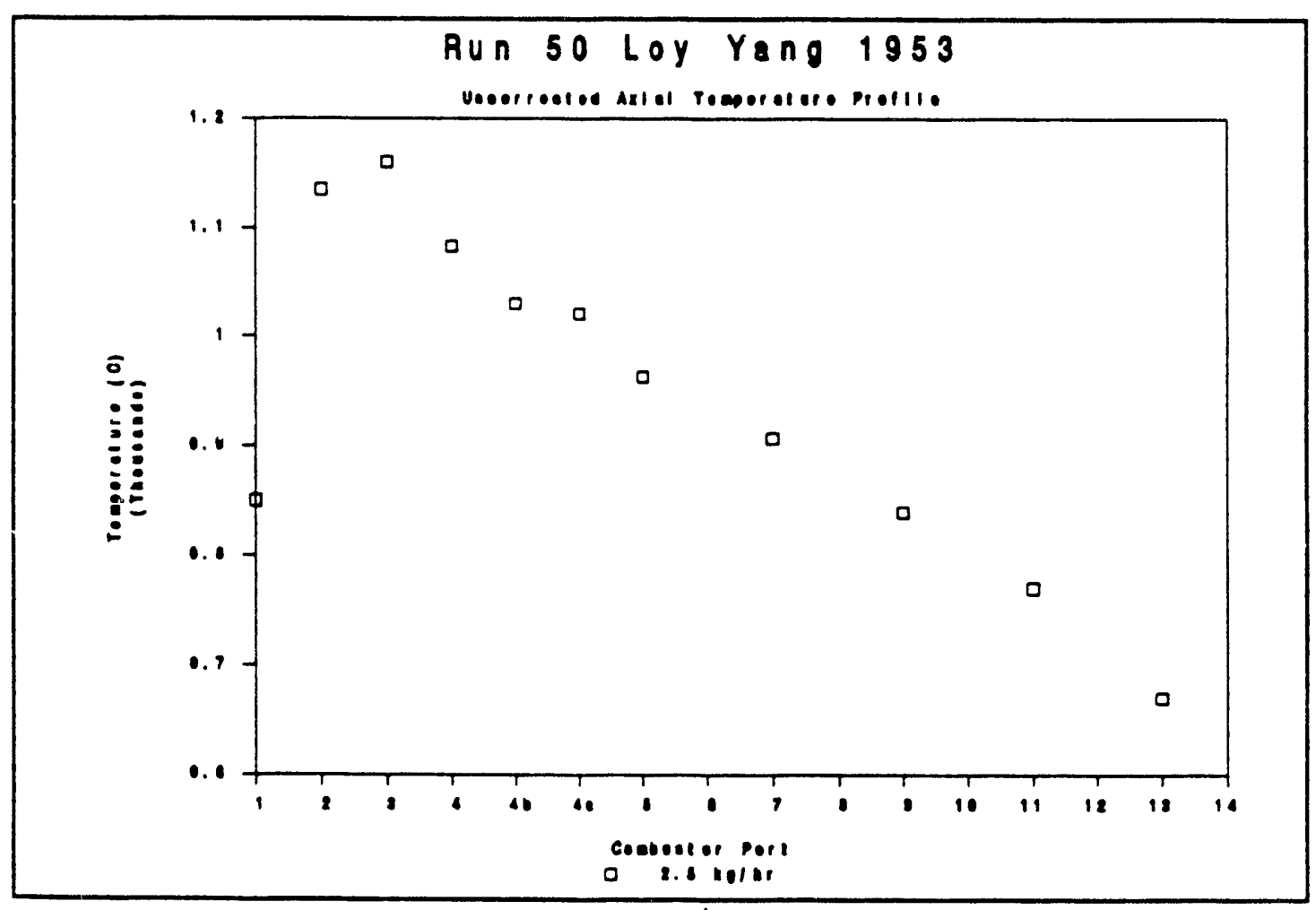

Figure 6-60. Temperature Profile for Bum 50 


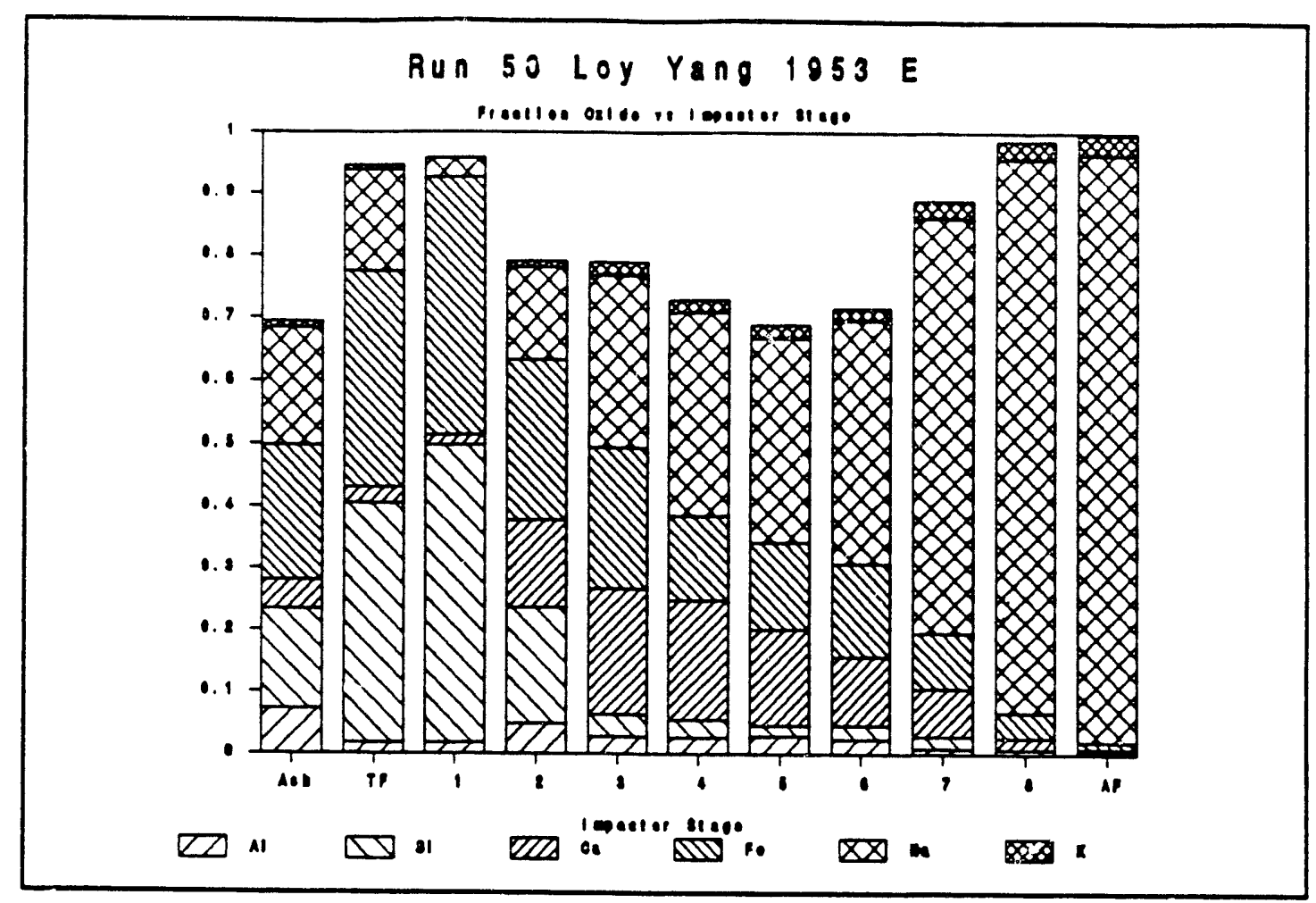

Figure 6-61. Fraction Oxide for $2.5 \mathrm{~kg} / \mathrm{hr}$ Feed Rate

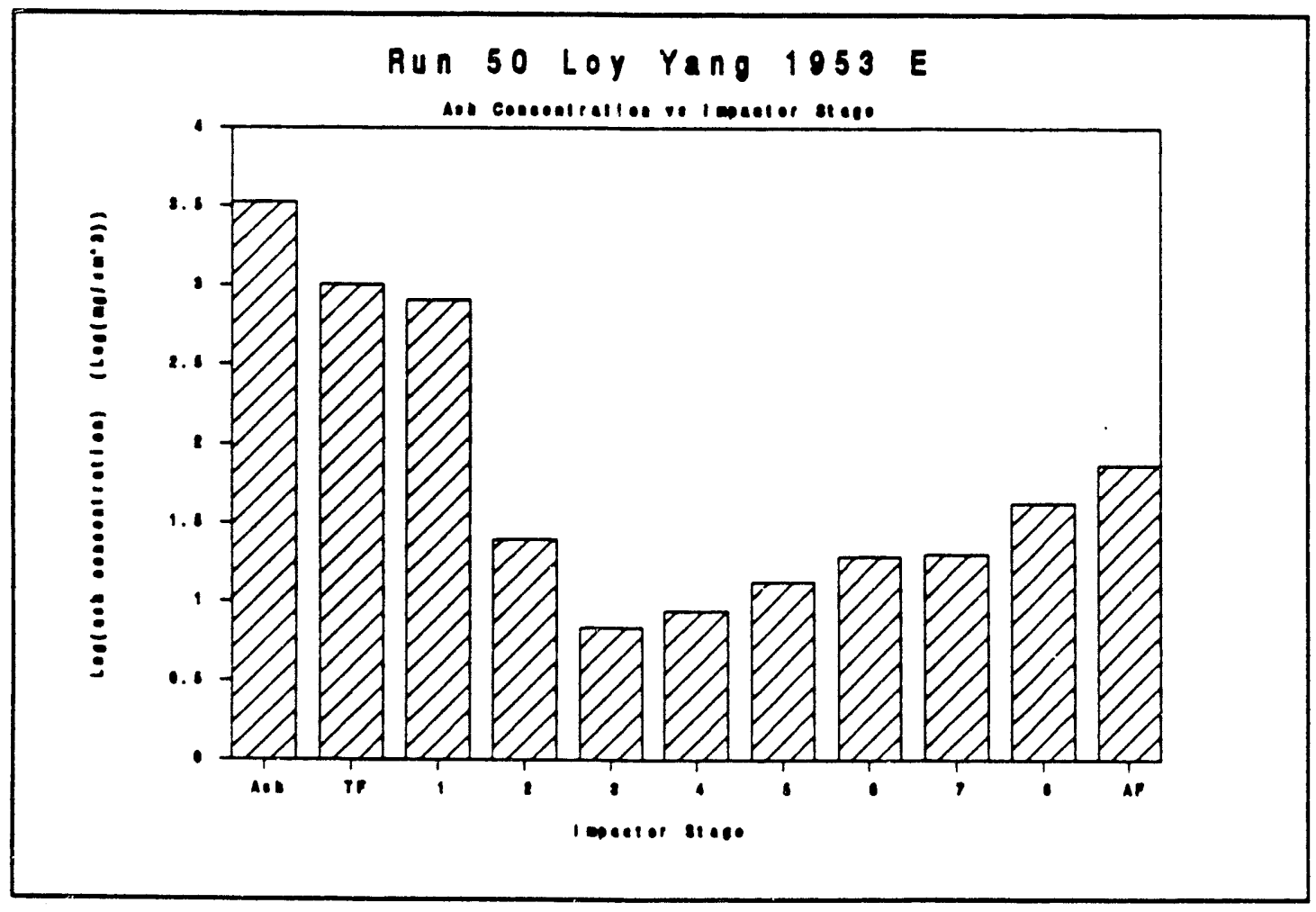

Figure 6-62. Ash Concentration for $2.5 \mathrm{~kg} / \mathrm{hr}$ Feed Rate 
Comparison of the cumulative fraction plots for sodium for Loy Yang 2301 (burn 49) and Loy Yang 1953 (burn 50) is shown in Figure 6-63. Although a significant fraction of the measured sodium for Loy Yang 1953 was found in the smallest sizes, the Loy Yang 2301 showed a greater fraction in the smallest sizes. The ratio of sodium to silicon was higher for the Loy Yang 2301. A greater fraction of sodium in the small sizes for the Loy Yang 2301 was consistent with previous results (Boni et al, 1991).

\subsubsection{PCSV Results}

Figure 6-64 shows the normalized cumulative mass and mass density distributions acquired with the PCSV for the bum of Loy Yang 1953. The mean distributions are also presented in these figures. Figure 6-65 shows the mean of the area distributions and Figure 6-66 shows the mean of the number distributions. Although not as marked as with burn 49 with Loy Yang 2301, comparison of the impactor data to the PCSV distributions (Figure 6-67) shows a shift to smaller sizes for the impactor results. It appears that the comparisons of the PCSV and impactor results show fairly good agreement for samples with a large fraction of the sample in large particle size ranges $(9$ to $10 \mu \mathrm{m})$. However, the results diverge as the fraction of mass in the small particle sizes $(<5 \mu \mathrm{m})$ increases.

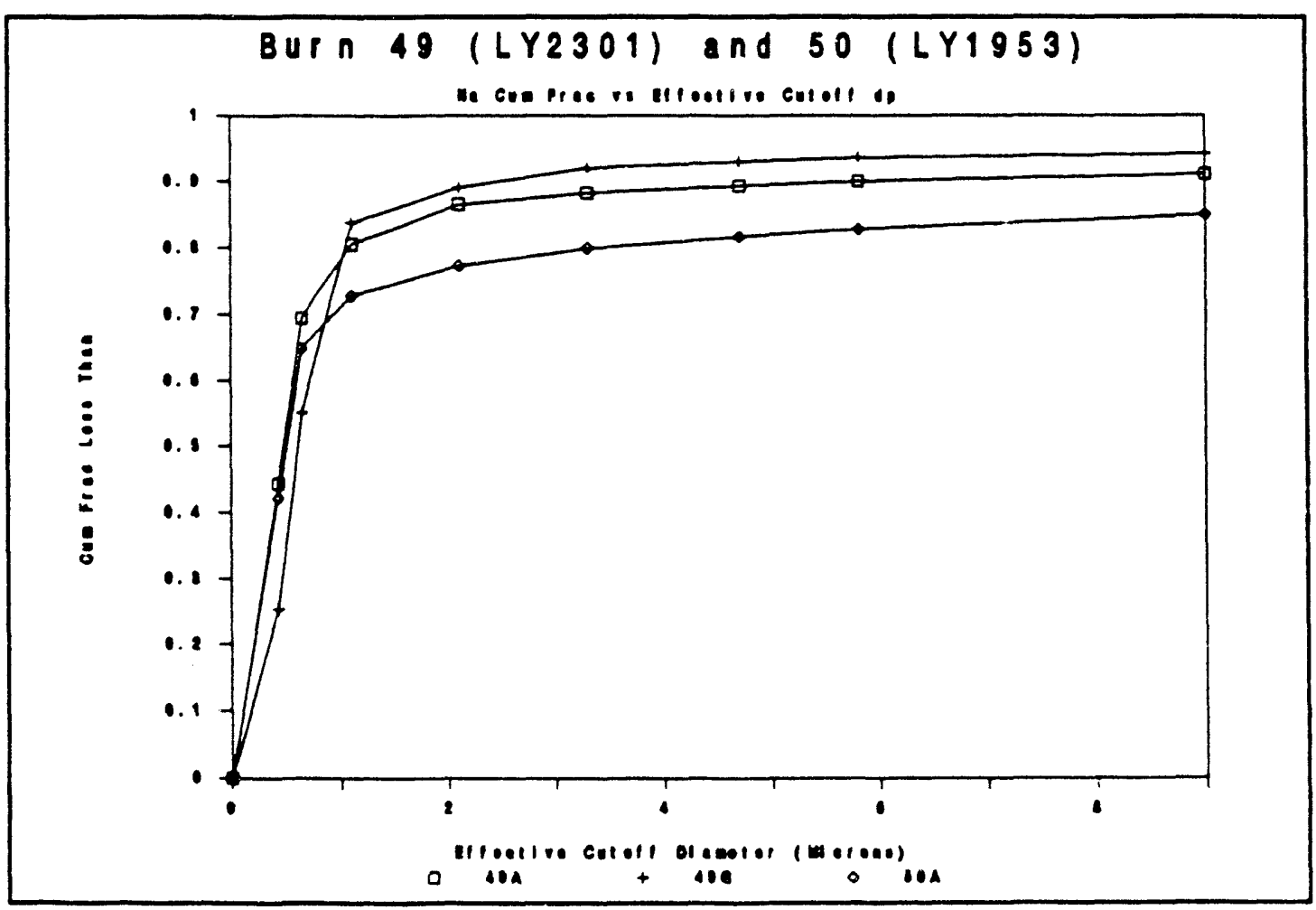

Figure 6-63. Sodium Cumulative Fraction for Burn 49 and 50 


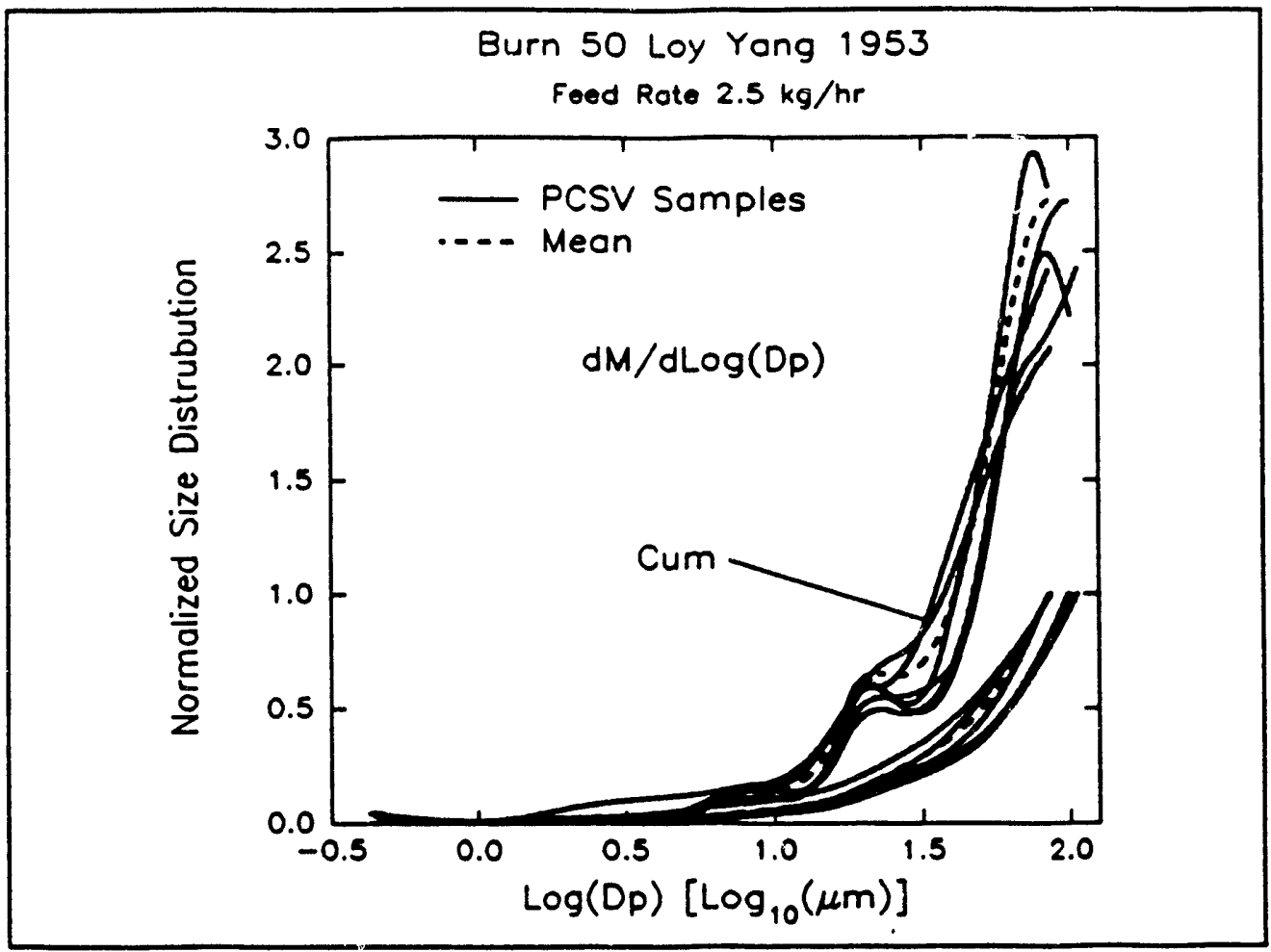

Figure 6-64. Mass Distribution Burn 50

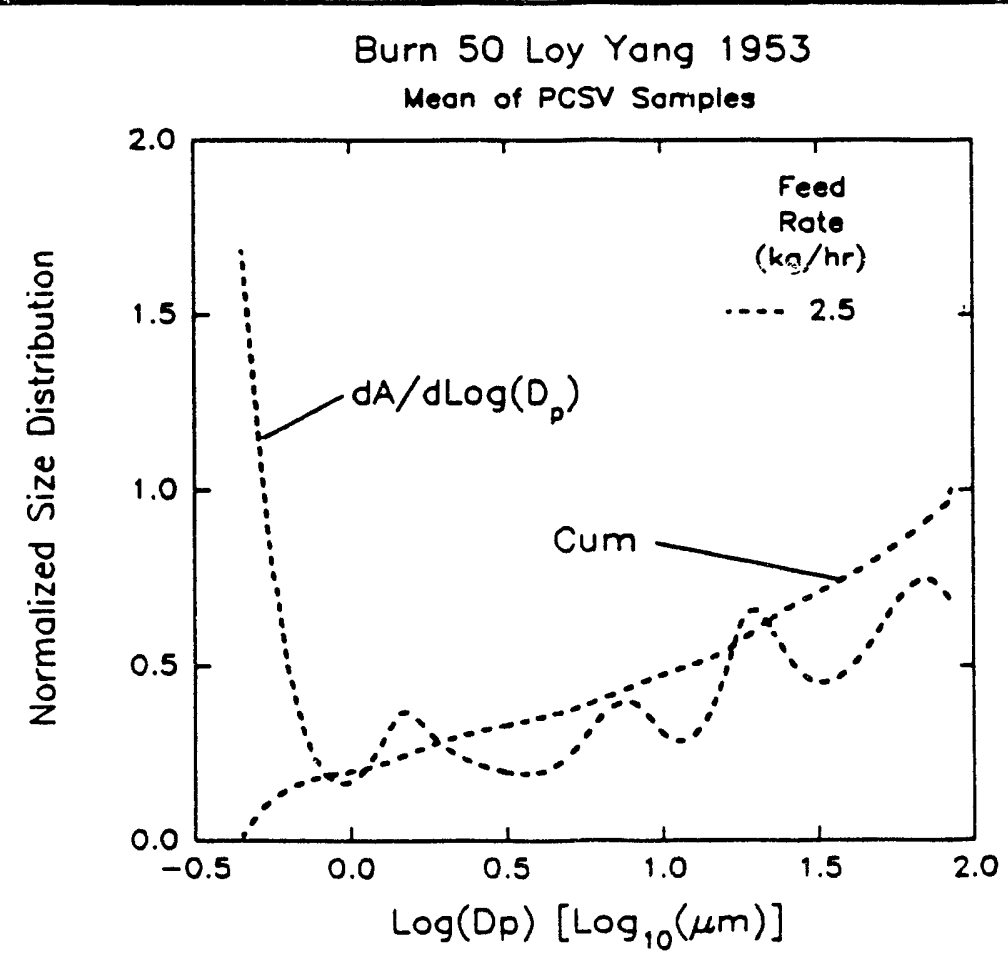

Figure 6-65. Area Distribution for Burn 50 


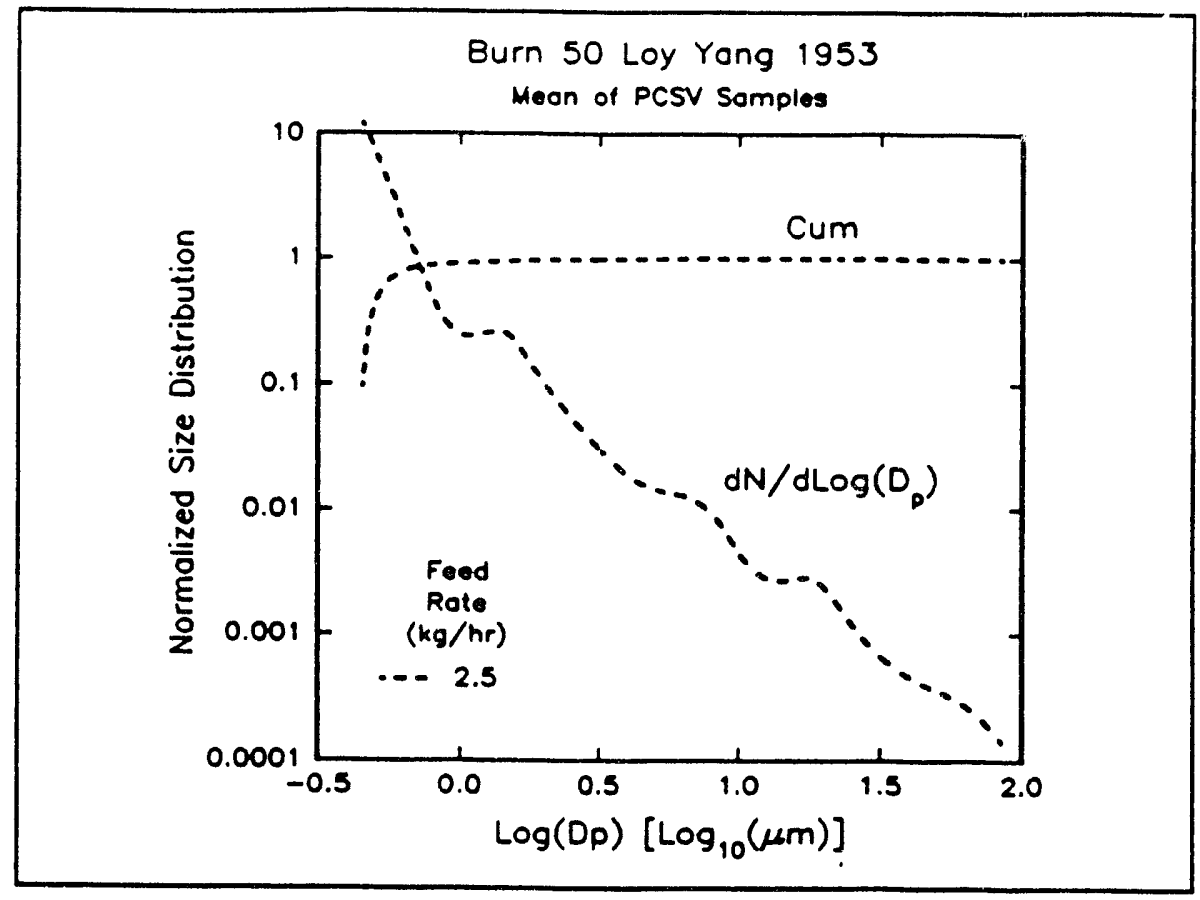

Figure 6-66. Number distribution Burn 50

\subsection{Burns 51 - 54: Cleaned Coals}

Comparisons between similar coals with differing mineral matter contents and compositions would focus on mineral matter transformations rather than coal matrix effects. Ideally, removing mineral matter from a coal and making comparisons between the cleaned coal and the parent coal would provide just such an opportunity. Although the cleaning process may, and likely does, change the coal matrix to some extent comparisons of cleaned and parent coals can provide some insights to mineral matter transformation during combustion.

Burns 51 through 54 used two coals that were cleaned prior to combustion: physically beneficiated Illinois No. 6 (SOAP) and chemically beneficiated Kentucky No. 9 (CB Kentucky No. 9). Results are presented below for four burns of cleaned coals. Table 6-4 summarizes the experiments with the cleaned coals.

\subsubsection{Burns 51 and 54: Illinois No. 6 SOAP}

Burns of the Illinois No. 6 SOAP (burns 51 and 54) proved difficult due to problems related to feeding. This is in contrast to burns of the Illinois No. 6 parent coal which showed good feeding characteristics (as in burn 47 of Subsection 6.2.1). Fresh barrels of SOAP emitted a strong odor of organic solvents when opened, suggesting a loss of solvent from the coal during shipment and storage.

During burns of the SOAP, gas analysis of samples extracted from port 12 showed very unsteady oxygen and carbon dioxide chart recorder traces and periodic spiking in the 


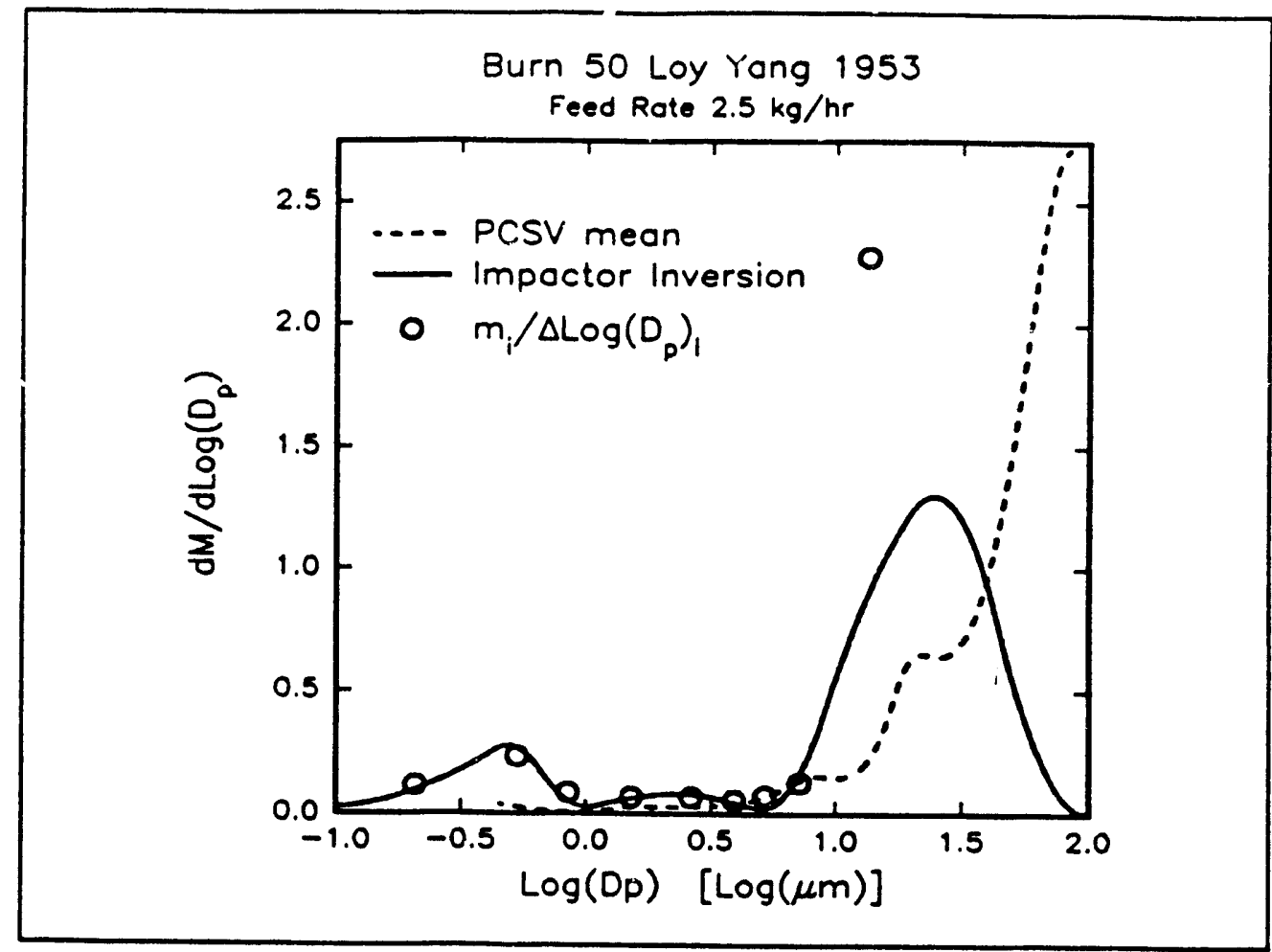

(a)

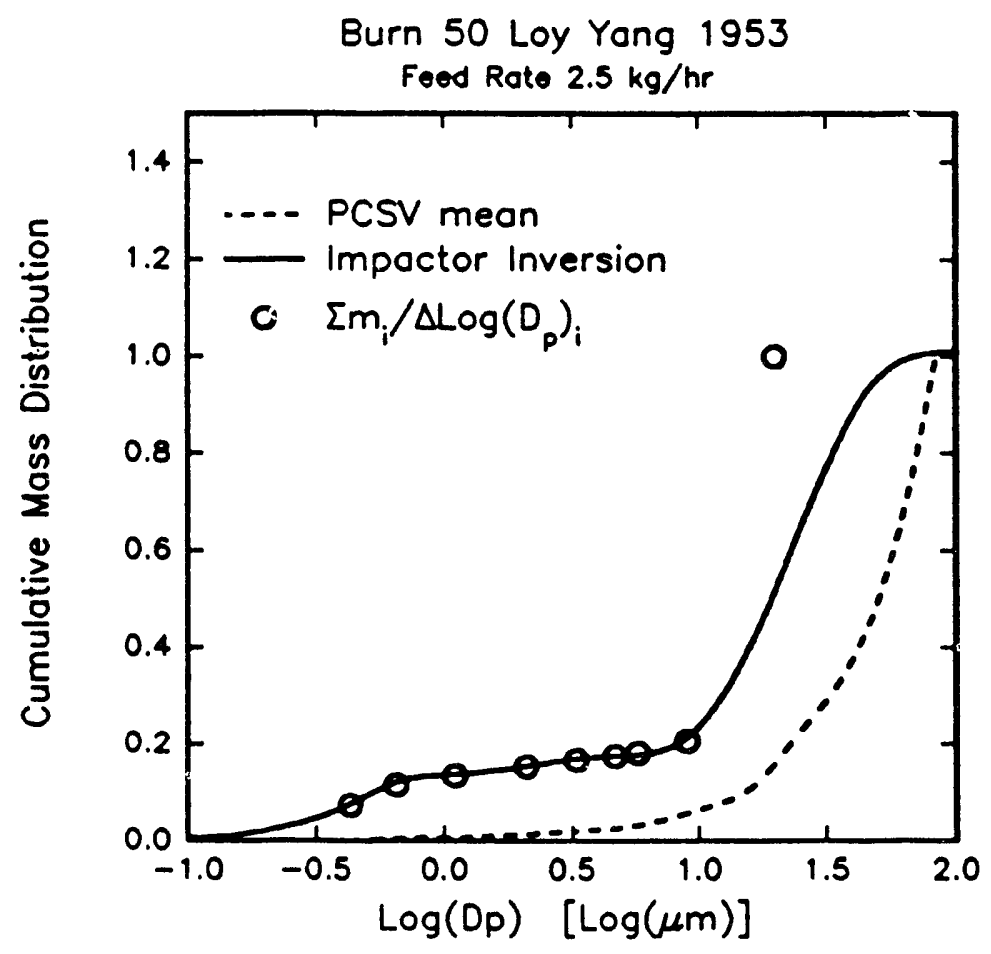

(b)

Figure 6-67. Impactor and PCSV for Burn 50 
Table 6-4. Summary of Experiments

\begin{tabular}{|c|c|c|}
\hline $\begin{array}{c}\text { Burn } \\
\text { No. }\end{array}$ & Coal & $\begin{array}{c}\text { Feed Rate } \\
(\mathrm{kg} / \mathrm{hr})\end{array}$ \\
\hline \hline 51 & Illinois No. 6 SOAP & 1.8 \\
\hline 52 & CB Kentucky No. 9 & 1.9 \\
\hline 53 & CB Kentucky No. 9 & 1.8 \\
\hline 54 & Illinois No. 6 SOAP & 2.3 \\
\hline
\end{tabular}

carbon monoxide trace. Visual inspection of the coal flame showed severe pulsing. In a 5-second span, observations of combustion might include a short period of typically observed combustion followed by a brief period of very active burning and relatively long periods of almost no combustion evident at all. It was difficult $t$ r ascertain if this was due to coal selfadhesion in the screw feeder or accumulation of unstable piles of feeding coal above the burner plenum. After the bum, inspection of the burner showed extensive fouling of the cooling tubis due to adhesion of sticky coal particles.

Temperatures above the plenum were atypically high and the coal appeared to ignite very quickly upon entering the combustor as evidenced by the temperature profiles shown in Figures 6-68 and 6-69 for burns 51 and 54 respectively. Changing the coal feed rate from approximately $1.8 \mathrm{~kg} / \mathrm{hr}$ in burn 51 to approximately $2.3 \mathrm{~kg} / \mathrm{hr}$ in burn 54 did not significantly change the temperature profile.

Fraction oxide plots for burns 51 and 54 are shown in Figures 6-70 and 6-71. Both plots show good agreement between the total filter sample (TF) and the ash analysis (Ash). This was also noted for the parent coal in burn 47 discussed in Subsection 6.2.1. Burn 51 at the lower feed rate suggests a slight enrichment of sodium and silicon in the small sizes compared to burn 54 at the higher feed rate. The sample acquired at the higher feed rate showed more iron in the smaller sizes than the sample acquired at the lower feed rate. It was interenting to note that the composition in each size class was very similar. This was also true of the parent coal.

The ash concentration plots are shown in Figures 6-72 and 6-73. Although the ash concentration measured for the lower feed rate was lower than that for the higher feed rate, the sampled mass distributions were very similar. The measured concentration for the SOAP was almost an order of magnitude lower than that measured in burn 47 of Subsection 2.1 for the parent coal. These runs are considered preliminary until additional experiments at more stable feeder conditions are conducted. 


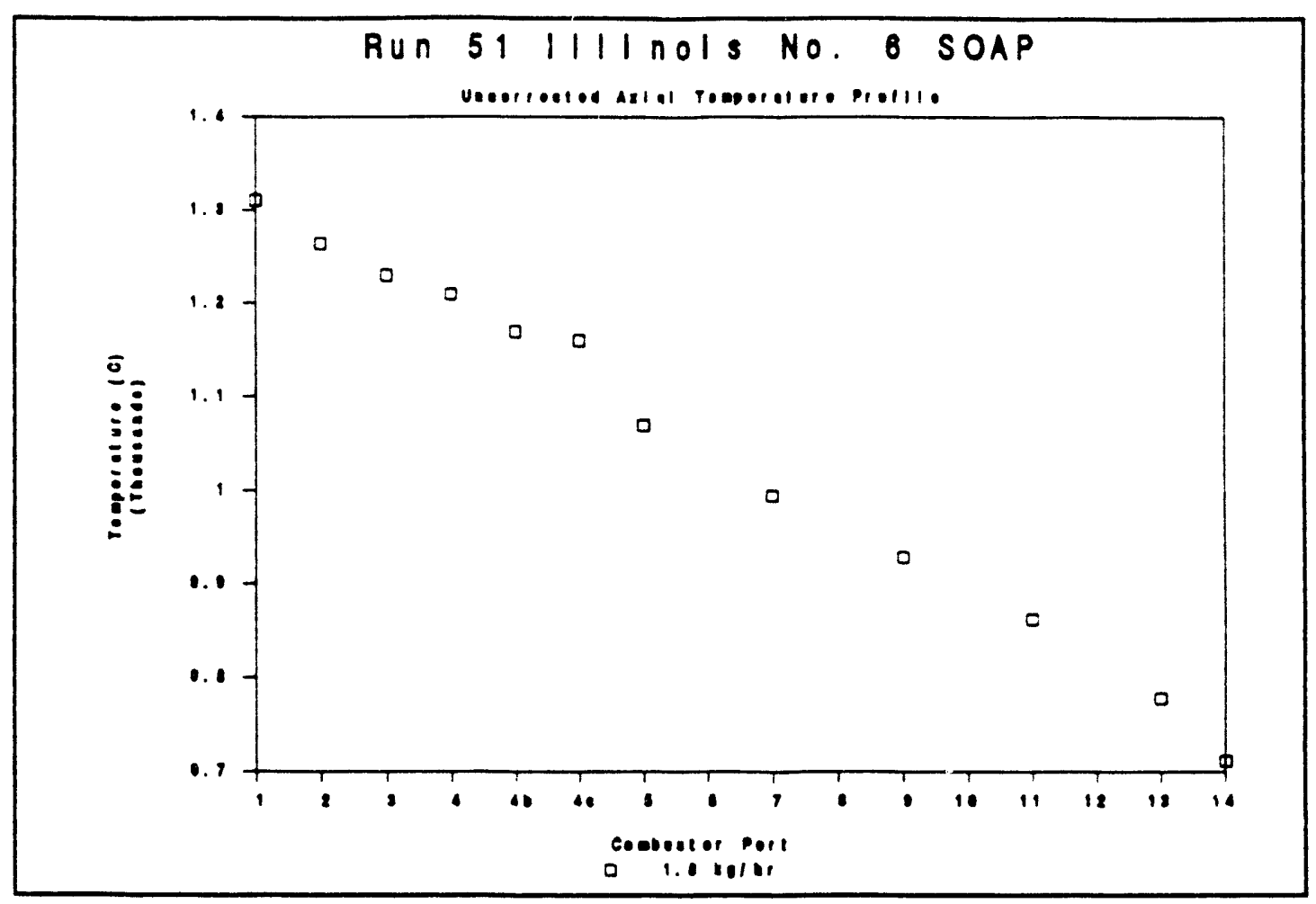

Figure 6-68. Temperature Profile for Bum 51

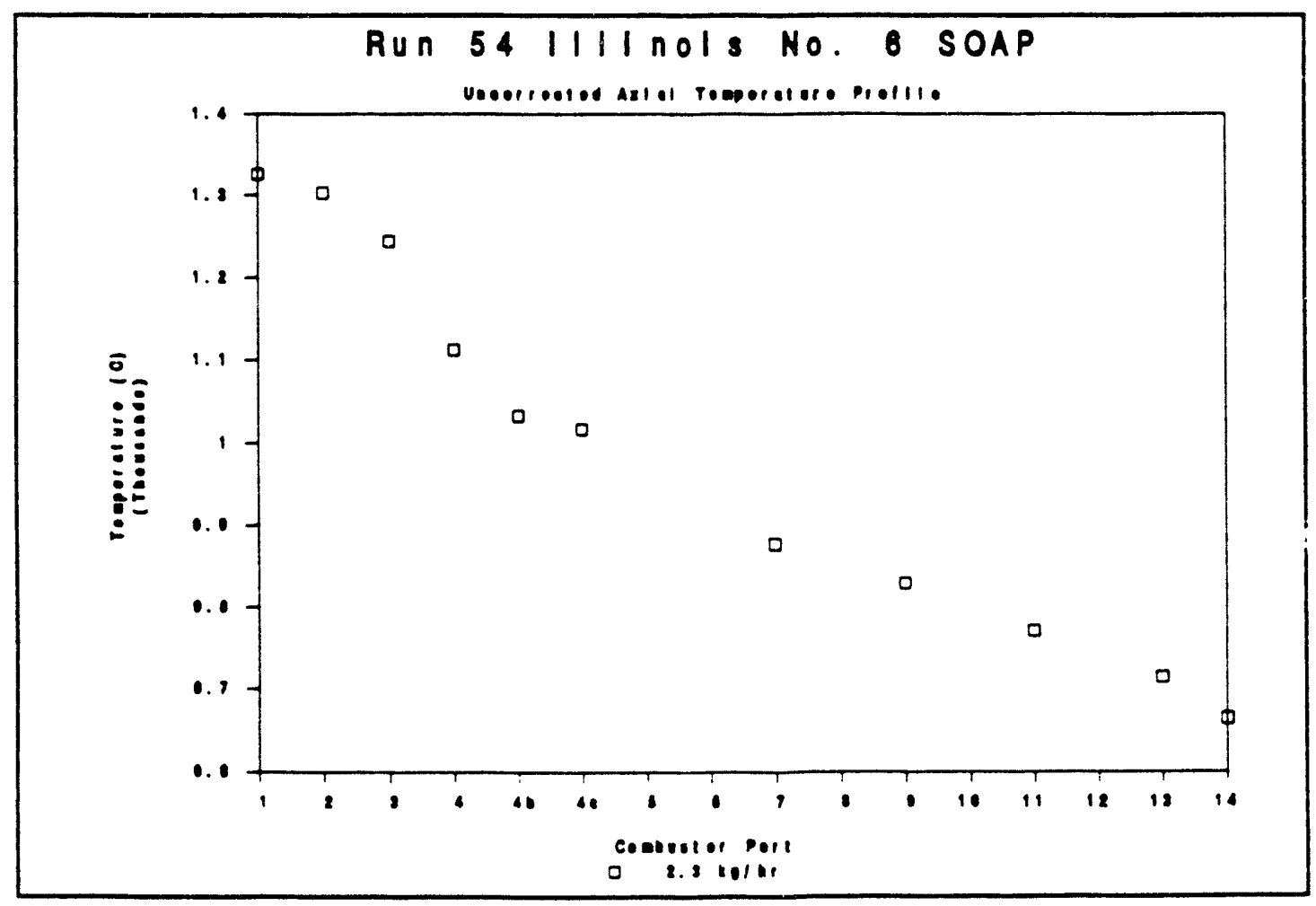

Figure 6-69. Temperature Profile for Burn 54 


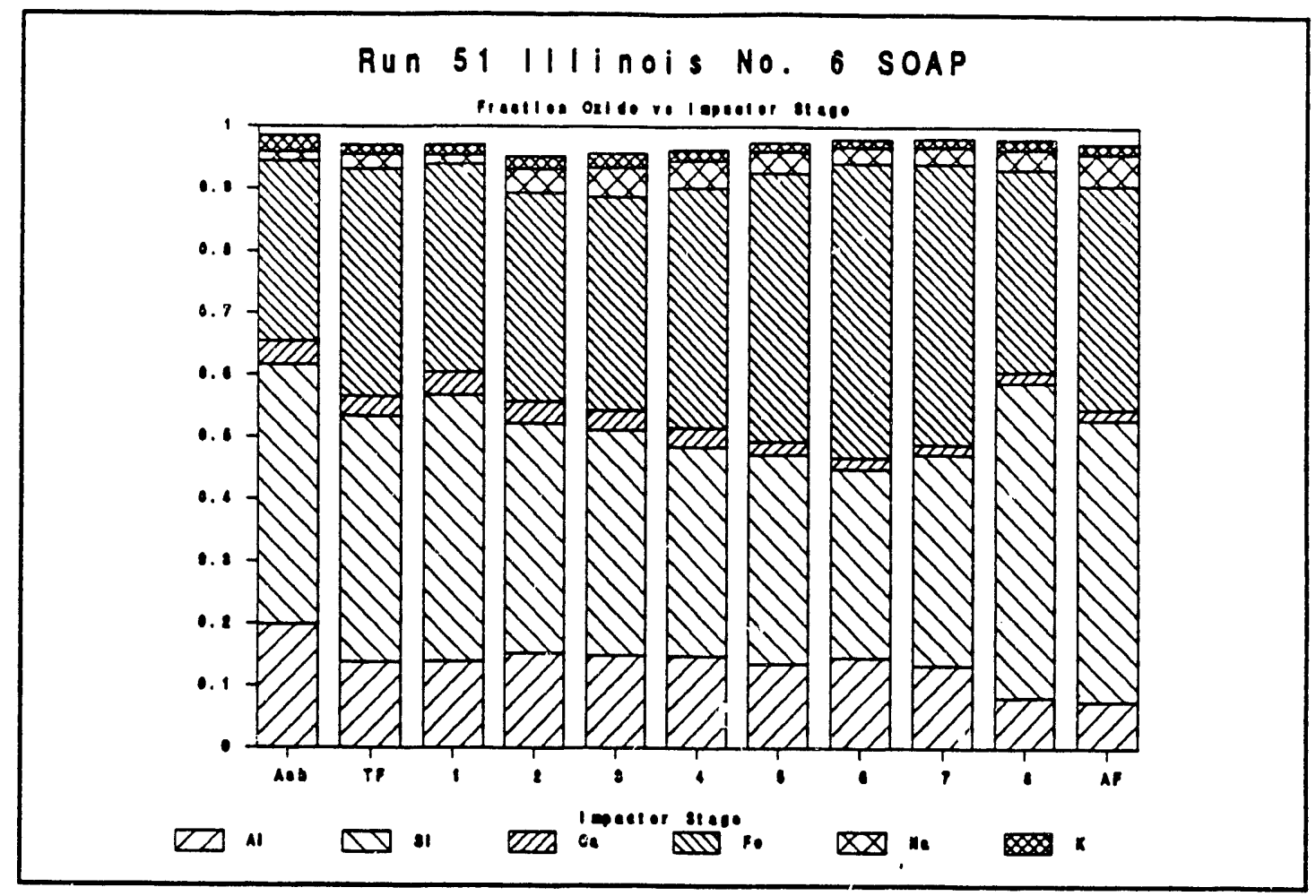

Figure 6-70. Fraction Oxide for Burn 51

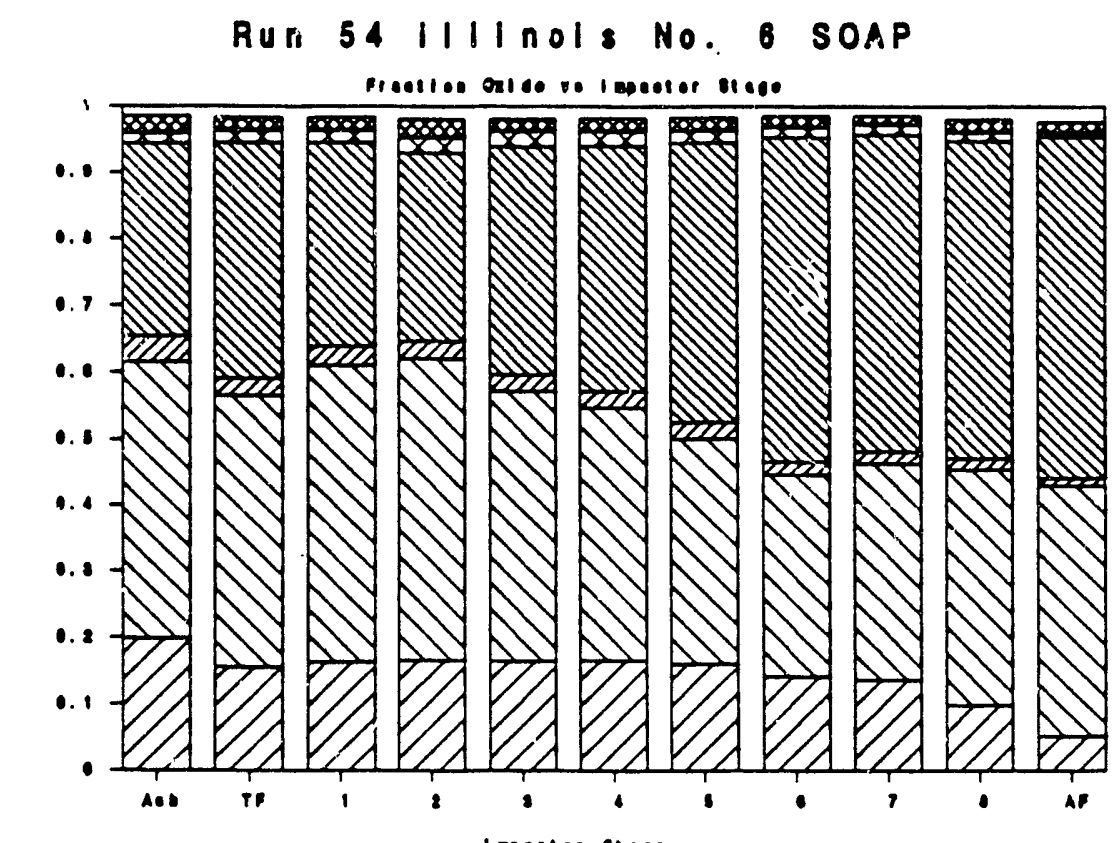

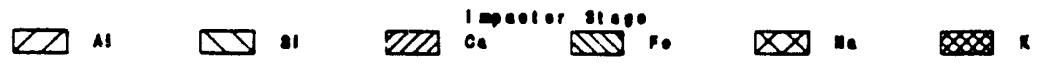

Figure 6-71. Fraction Oxide for Burn 54 


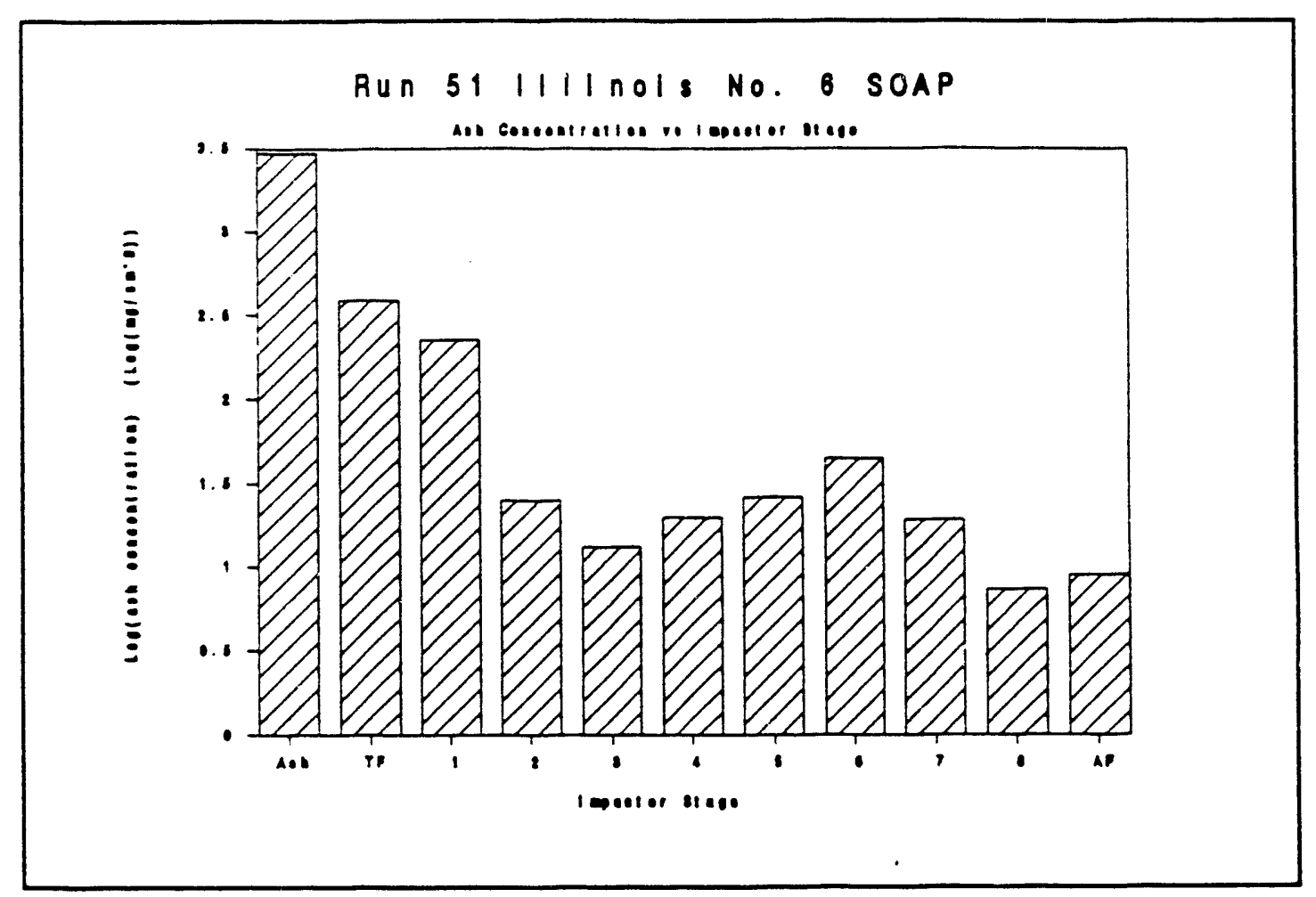

Figure 6-72. Ash Concentration for Burn 51

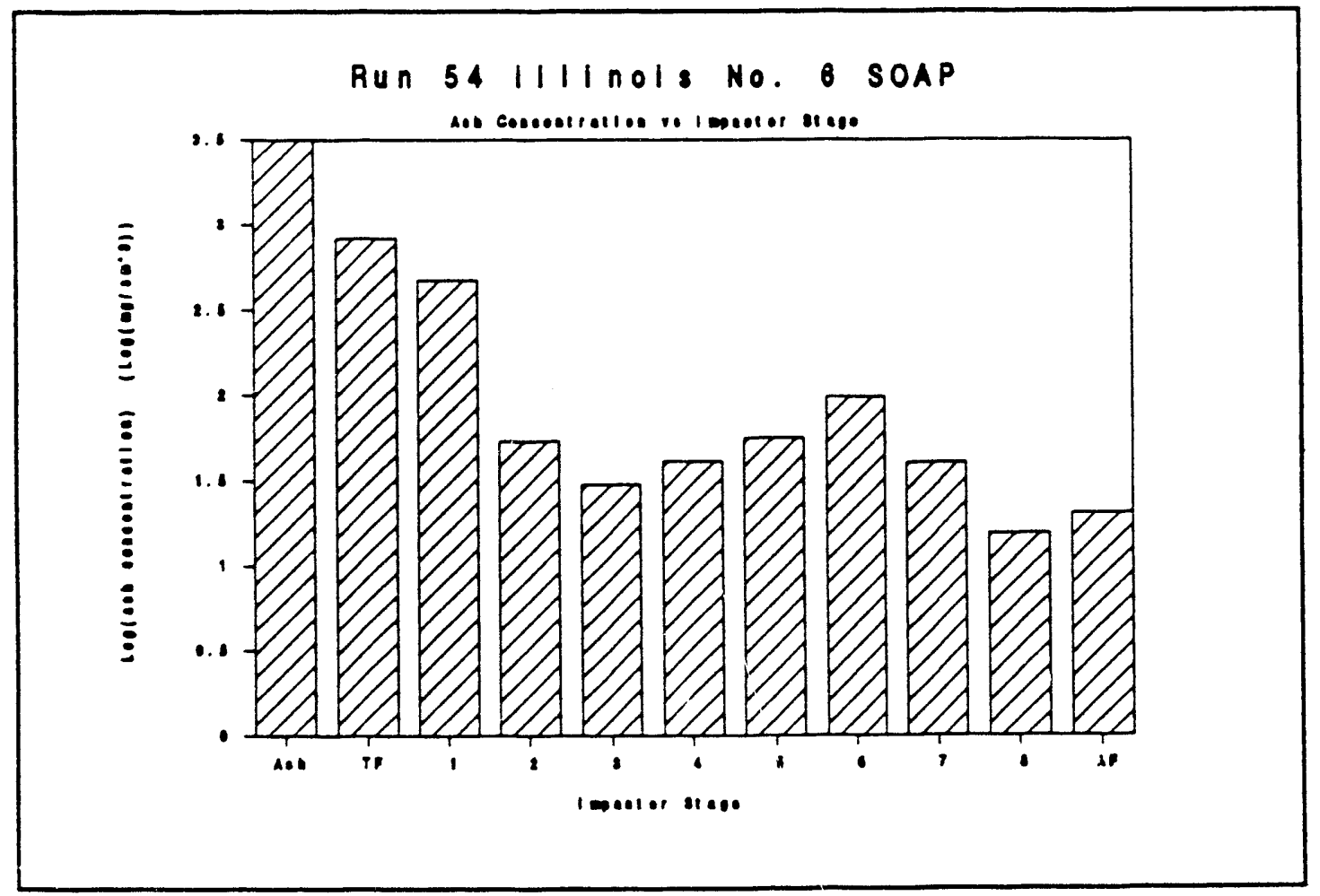

Figure 6-73. Ash Concentration for Burn 54 


\subsubsection{Burns 52 and 53: CB Kentucky No. 9}

Both the CB Kentucky No. 9 and the parent Kentucky No. 9 (during previous burns) showed good feeding and combustion characteristics, although the cleaned version had a high moisture content and required drying. This coal arrived enclosed in a plastic bag inside a 55 gallon drum that was lined with a plastic sleeve. On the inside sleeve and on the inside of the plastic bag was a significant amount of condensed moisture. Due to this large amount of water and the tendency for the coal to adhere to itself, it was laid out to dry in the open air before burning. A moisture analysis was performed on the as-received and dried coals.

The moisture analysis was conducted by placing a known mass of sample in an oven at approximately $110^{\circ} \mathrm{C}$. The mass of the sample was determined as a function of time. Results for the coal as received, dried coal used in burn 52, and dried coal used in burn 53 are shown in Figure 6-74. The asreceived coal was approximately $50 \%$ moisture. The dried coals had approximately 15 and $20 \%$ moisture for burns 52 and 53 respectively.

The temperature profiles for burns 52 and 53 are shown in Figures 6-75 and 6-76 respectively. Both temperature profiles show a large jump from port one to the peak at sample port two.

The fraction oxide plots for burns 52 and 53 are shown in Figures 6-77 and 6-78 respectively. Although the fraction oxide

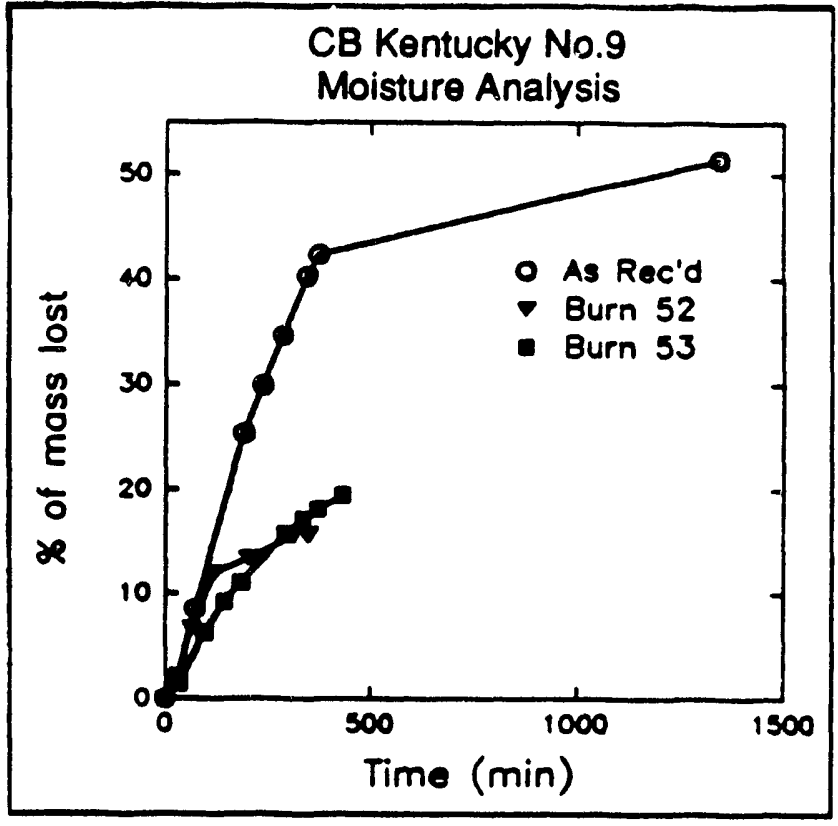

Figure 6-74. Moisture Analysis of Chemically Beneficiated Kentucky No. 9 plot for burn 52 shows a higher fraction of iron in all sizes than for burn 53, both plots are very similar. Both plots show a significant enrichment of the small sizes with sodium and especially potassium. This is most likely due to alkali introduced during the cleaning process. Figure 6-79 shows a fraction oxide plot for Kentucky No. 9 parent coal burned with a similar temperature profile (Boni, et al, 1990). The parent coal shows an enrichment of potassium in the small sizes but not as marked as with the cleaned version of this coal.

Figures 6-80 and 6-81 show the ash concentrations in $\mathrm{mg} / \mathrm{sm}^{3}$ for burns 52 and 53 respectively. Although there are slight differences in the distribution of the sampled mass, the same general trend for burns 52 and 53 was noted: the largest fraction of mass was found on stage 1 (the largest sizes). This was also true for the parent coal shown in Figure 6-82. Although a large fraction of alkali appears in the small sizes, the total ash concentration for the cleaned coal was significantly lower than for the parent coal. The total filter ash concentration was approximately an order of magnitude lower for the cleaned coal. 


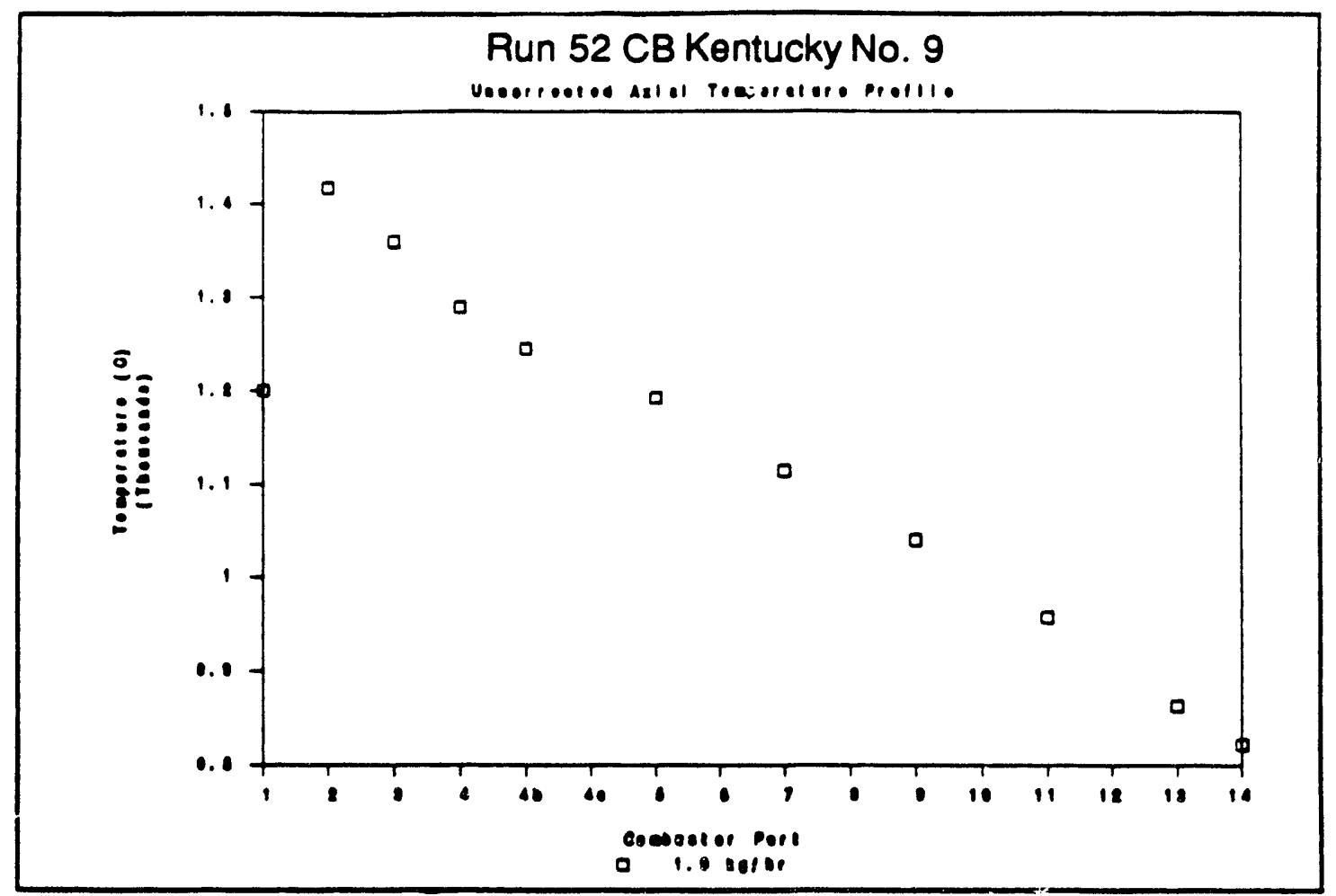

Figure 6-75. Temperature Profile for Burn 52

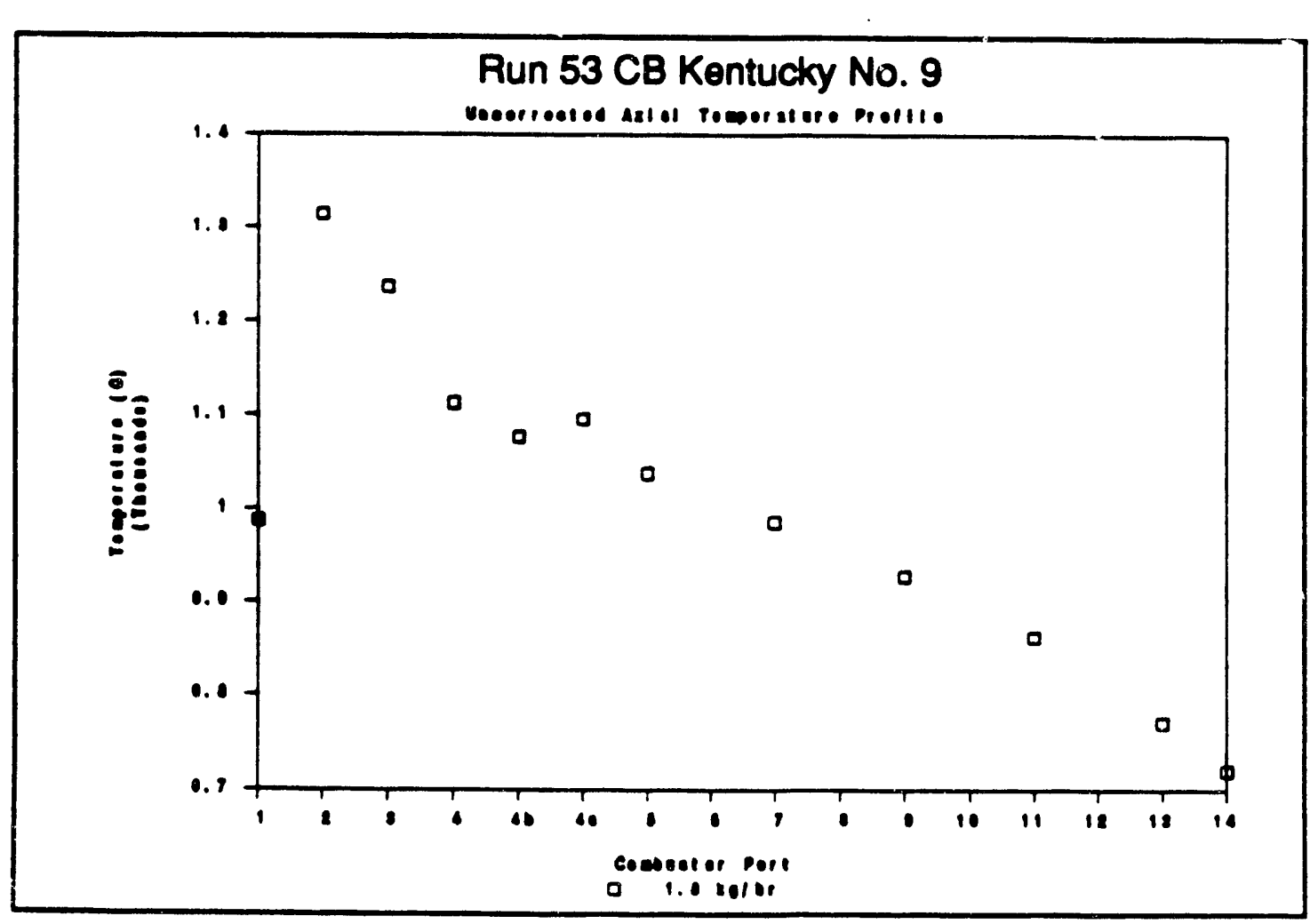

Figure 6-76. Temperature Profile for Burn 53 


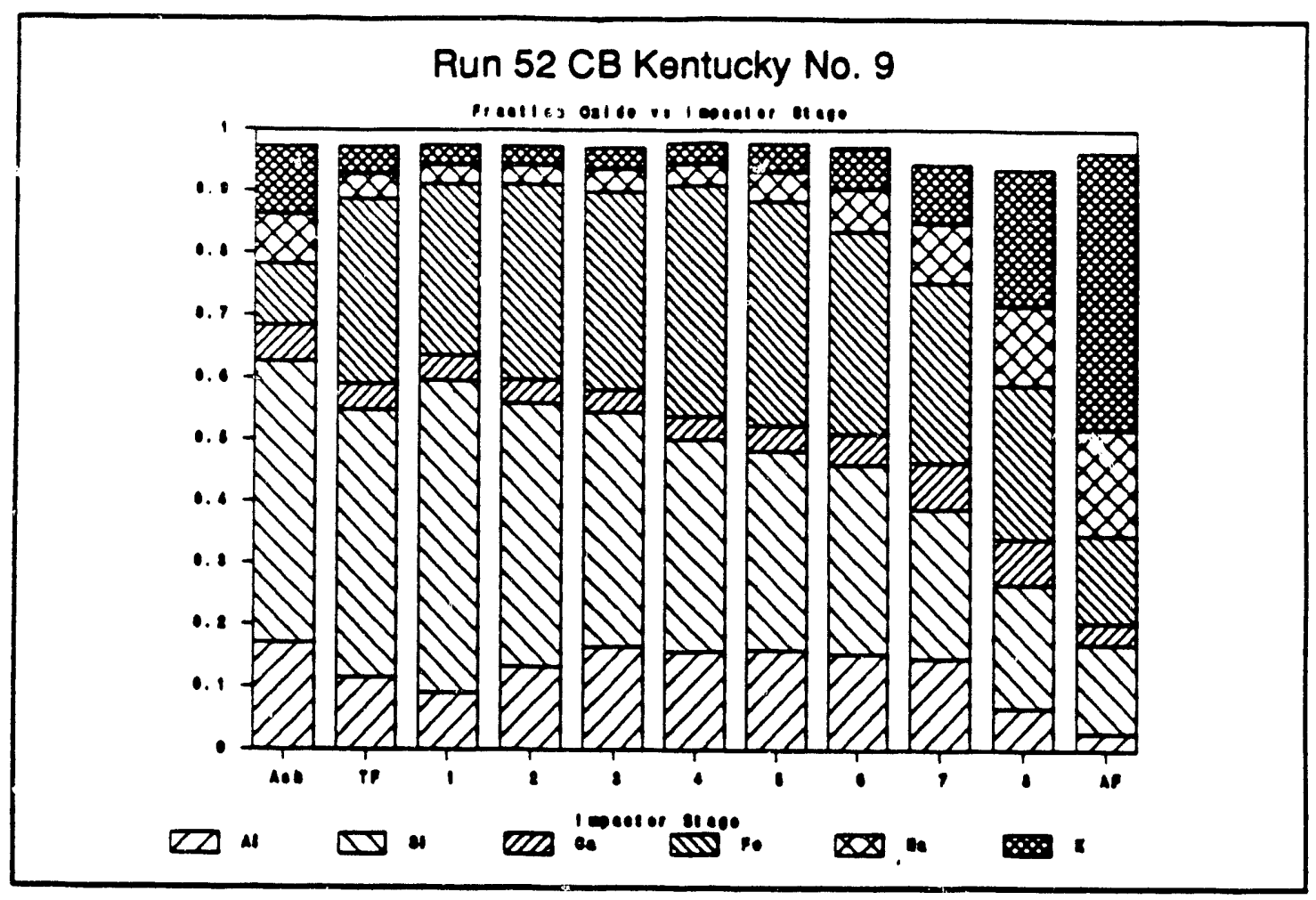

Figure 6-77. Fraction Oxide for Burn 52 at $1.9 \mathrm{~kg} / \mathrm{hr}$

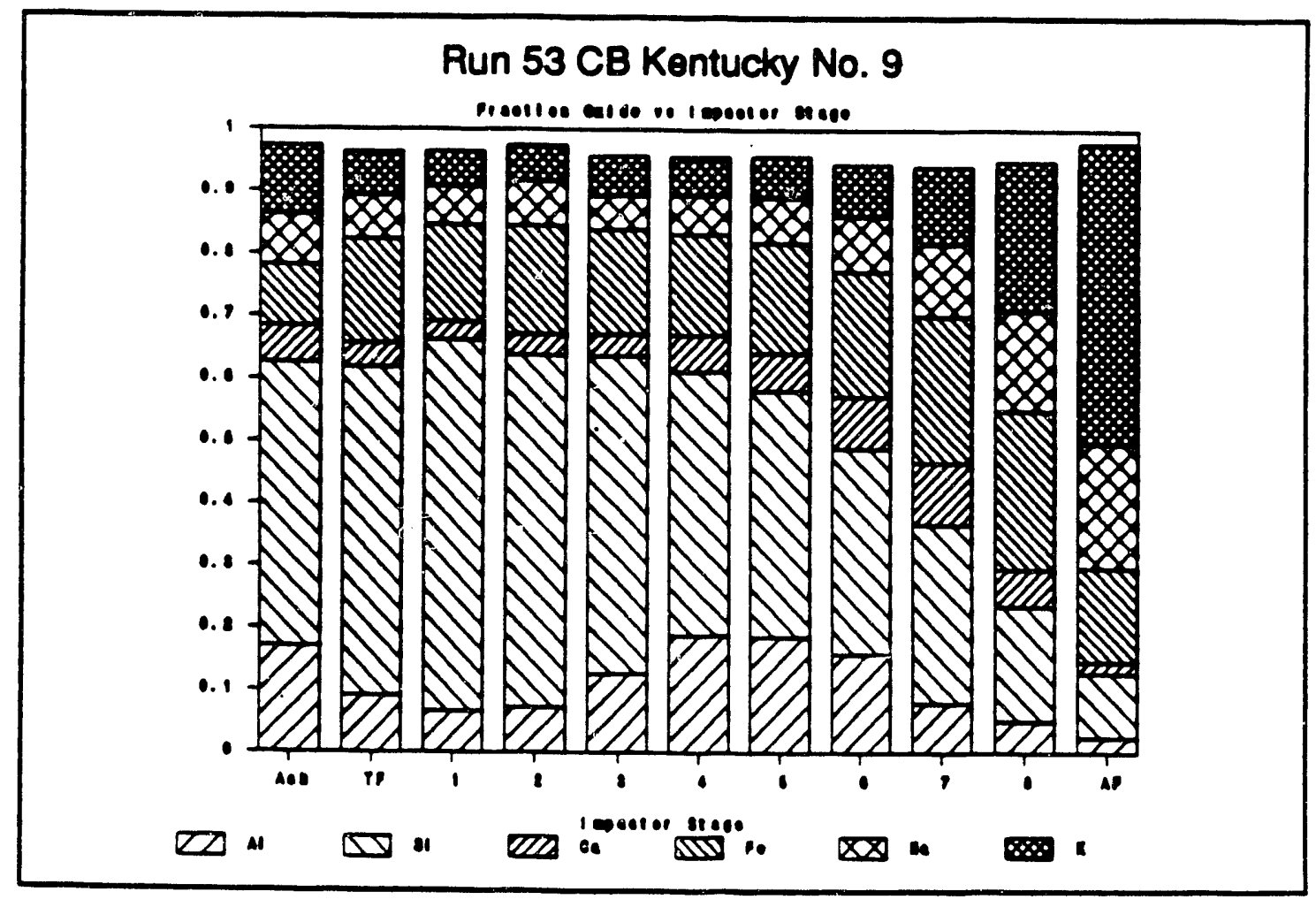

Figure 6-78. Fraction Oxide for burn 53 at $1.8 \mathrm{~kg} / \mathrm{hr}$ 


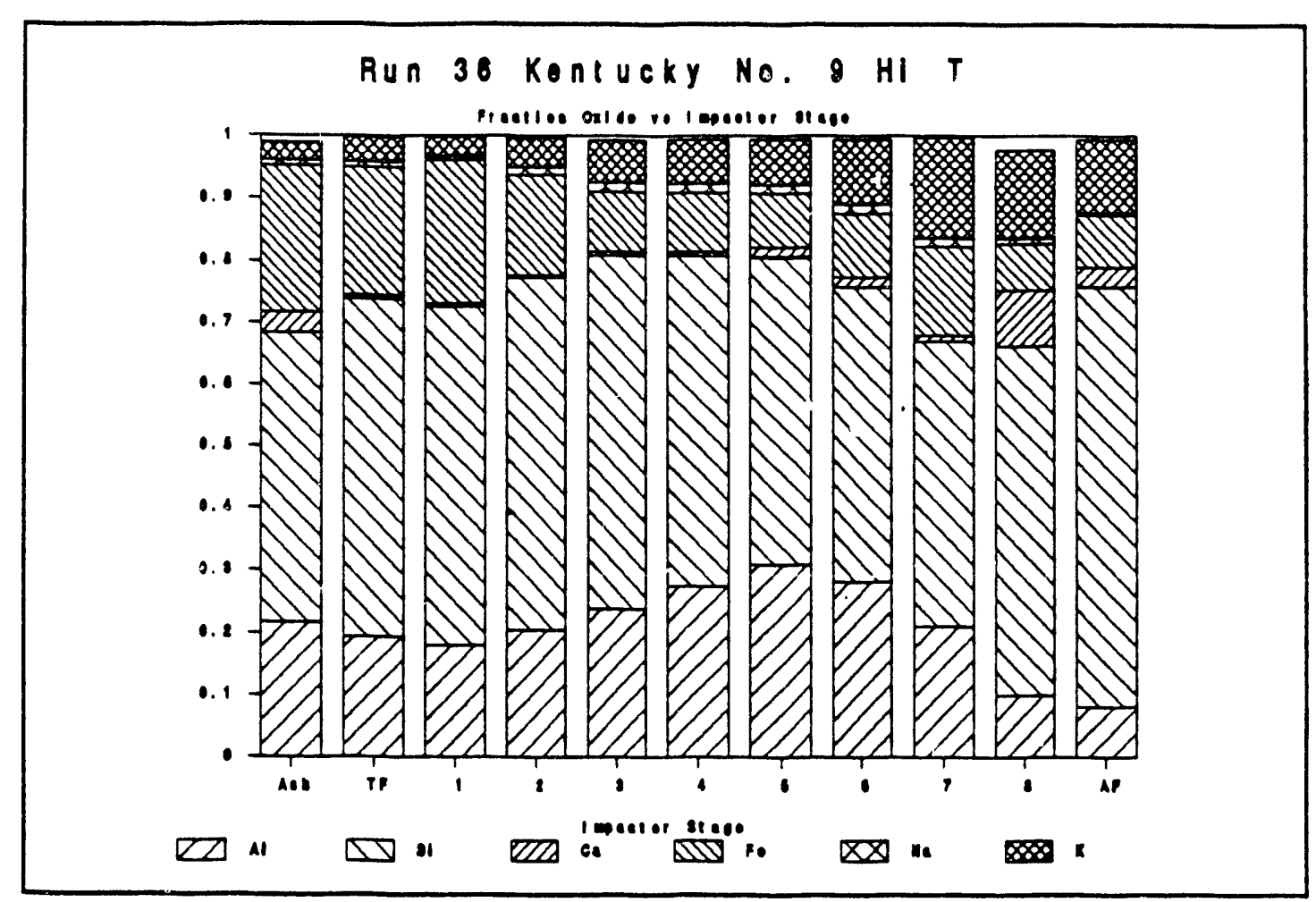

Figure 6-79. Fraction Oxide for Kentucky No. 9 Burn 36

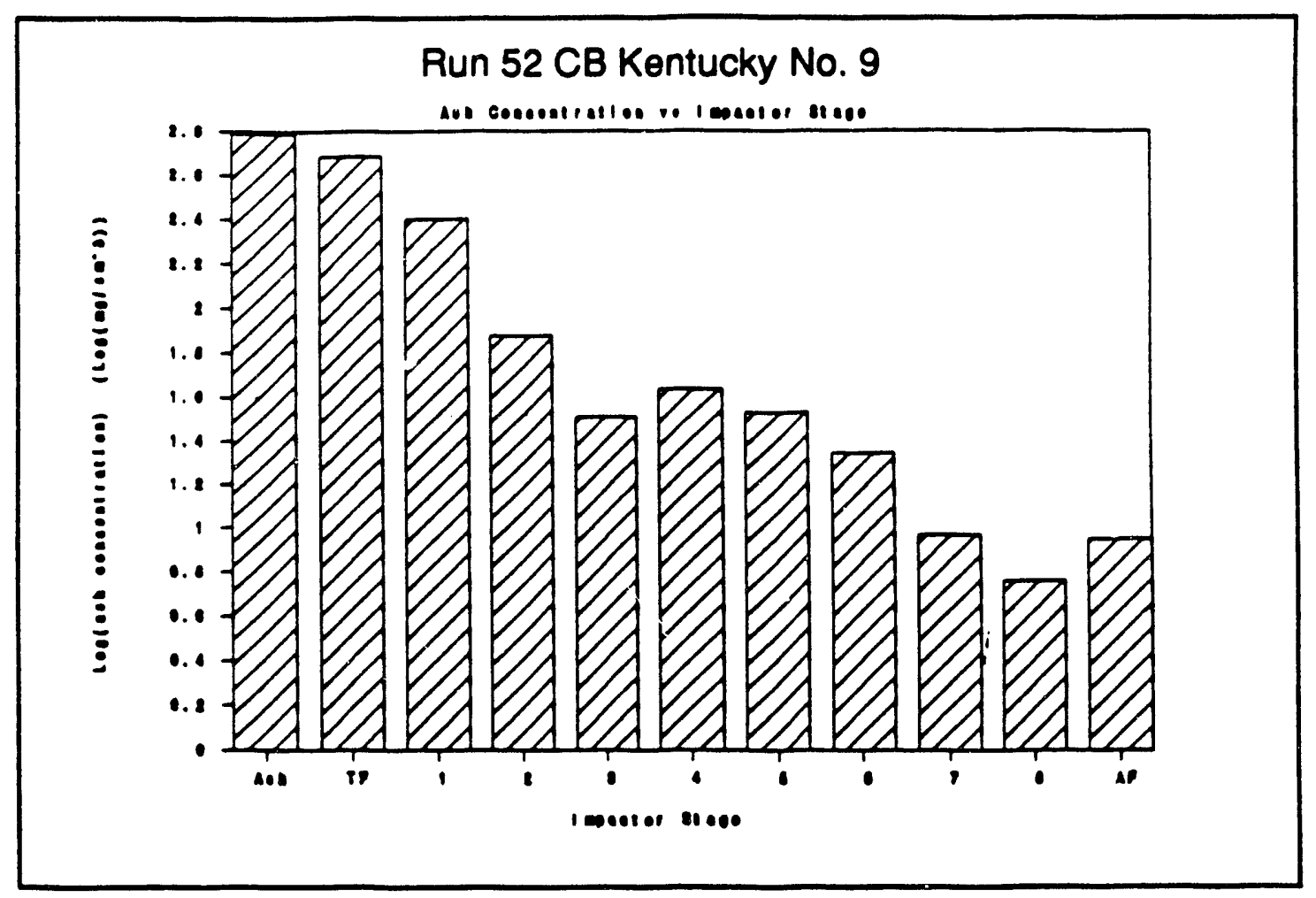

Figure 6-80. Ash Concentration for Burn 52 


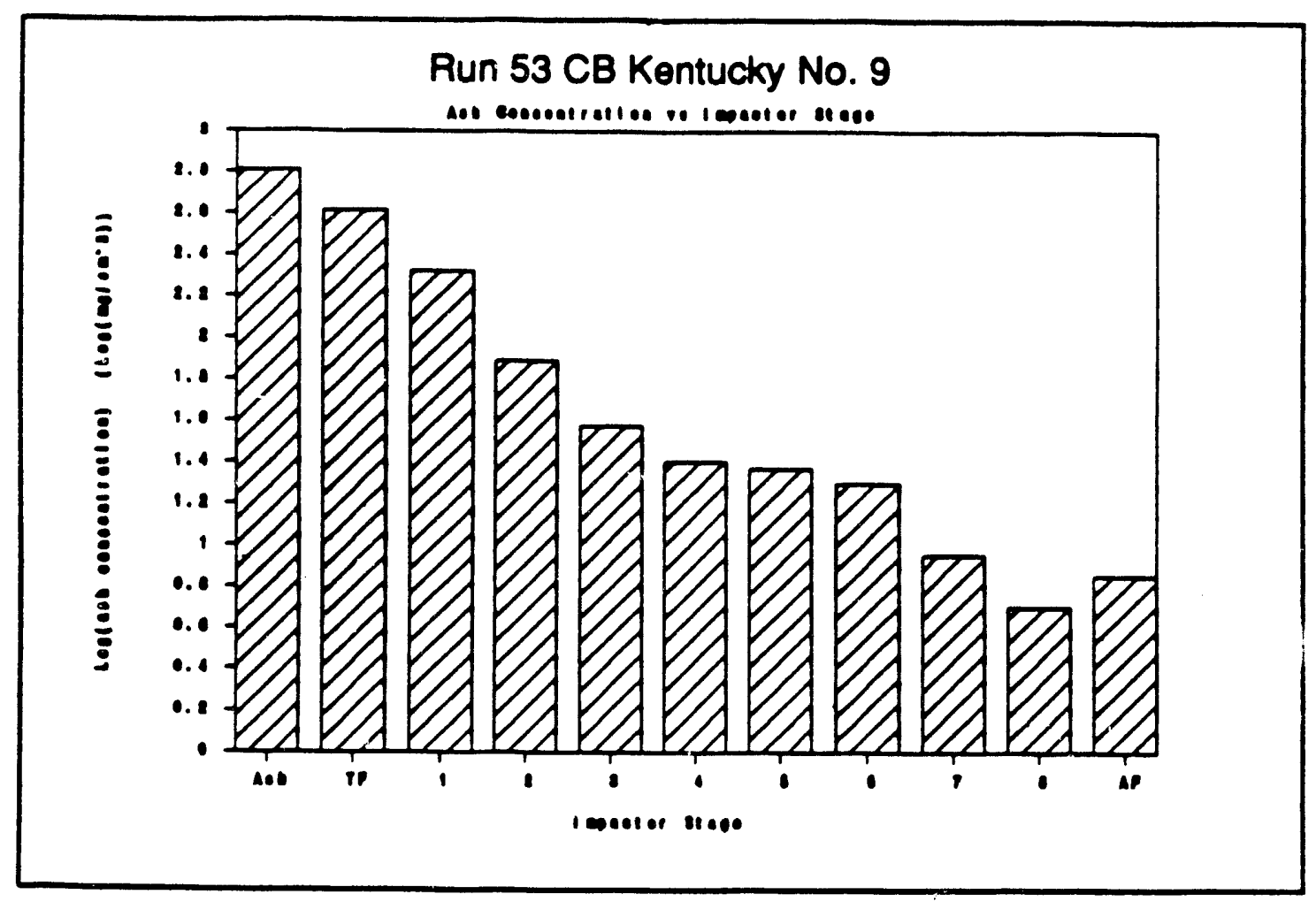

Figure 6-81. Ash Concentration for Burn 53

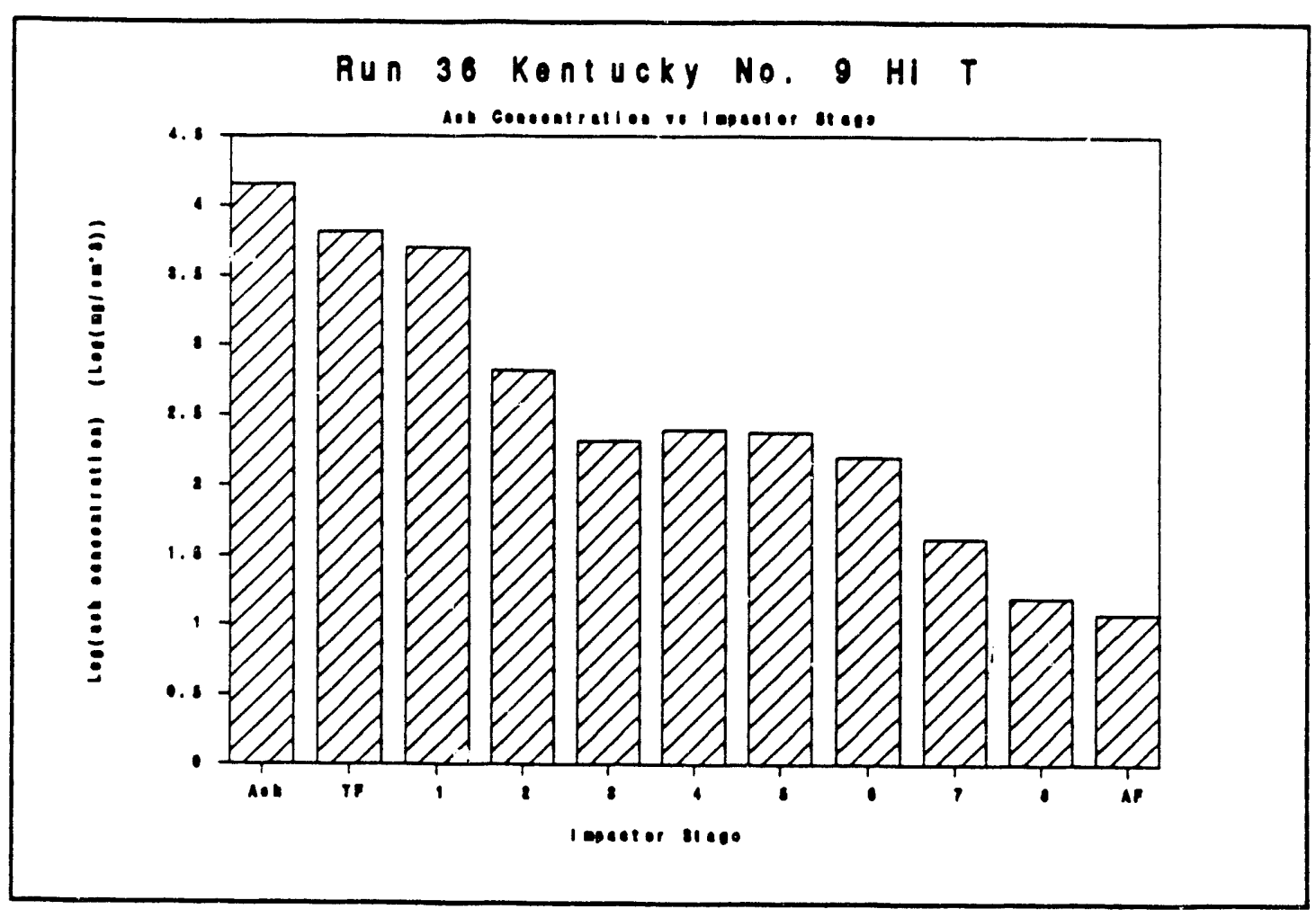

Figure 6-82. Ash Concentration Versus Impactor Plate for Kentucky No. 9 Burn 36 


\subsection{Conclusions and Results}

Initial investigations on the fate of iron during combustion has yielded some unusual results and introduced some interesting issues. Work done to date has produced information on both the iron-silicate association in the ash and extraneous pyrite-char interactions in the disperse phase. Initial comparison of ash analysis data from Mössbauer and CCSEM techniques suggested that the iron oxide and silicates were somehow physically, but not chemically, associated in the ash. Results from ash analysis utilizing various analytical techniques (specifically TEM and EDX mapping) indicated that iron oxide was predominantly found as discrete particles physically agglomerated with discrete silicate particles.

Comparison of the fraction of unagglomerated iron (that fraction as oxide from the CCSEM analysis) with the fraction of original pyrite greater than $40 \mu \mathrm{m}$ further suggested that some of the extraneous pyrite could coagulate through differential settling with the char during burnout. This hypothesis was explored in a simplified manner through the use of the MAEROS aerosol model. Modelling results suggested that some coagulation could take place, but experiments should be performed to confirm this hypothesis.

The results discussed above produced several interesting issues that must be addressed to elucidate the fate of iron during combustion. First, a set of experiments should be performed to determine if the coagulation of extraneous pyrite with the char is an important mechanism. These experiments would utilize a coal containing little or no extraneous mineral matter (eg. the Illinois No. 6 SOAP) doped with various concentrations of extraneous pyrite. CCSEM results from these runs could provide information on the extent of pyritechar coagulation. Secondly, a model could be proposed utilizing an iron-silicate association mechanism and pyrite-char coagulation. This model coidd predict the partitioning of iron between iron oxide and iron glass based on a competition between oxidation of the pyrite and agglomeration of the pyrite with molten silicates.

Comparisons of PCSV and cascade impactor mass distributions showed fairly good agreement for distributions with low mass loadings less than $9 \mu \mathrm{m}$. However, as the mass loading in the micron and submicron range increased differences in the two measurement techniques also increased.

Atomic absorbance analysis of cascade impactor samples obtained from sample port 11 compared well with previous data gathered on Illinois No. 6 and Beulah Lignite. Discrepancies between results acquired during the present quarter for Loy Yang 2301 and previous results could not be explained satisfactorily. Differences might have been related to the state of the coal received: the most recent Loy Yang 2301 was received pulverized compared to crushed and pulverized on site for previous samples. Differences might also have been related to previously discovered glass bottle fragments found in the crushed coal. First time results for Loy Yang 1953 showed a lower fraction of the sodium present in the flyash in the smallest sizes than for Loy Yang 2301. This was consistent with previous results since the Loy Yang 1953 also had a smaller sodium to silicate ratio. 


\section{SECTION 7}

Task 7

IDEALIZED COMBUSTION DETERMINATION OF ASH PARTICLE FORMATION AND SURFACE STICKINESS

J.J. Helble and J.W. Moore, PSI Technology Company and G. Domazetis, SECV 


\section{IDEALIZED COMBUSTION DETERMINATION OF ASH PARTICLE FORMATION AND SURFACE STICKINESS}

During the previous quarter, PSI Technology Co. (PSIT) completed experiments with a chemically beneficiated sample of Pittsburgh $\# 8$ coal and a physically beneficiated sample of Illinois \#6 coal, both obtained from DoE/PETC. In addition, iesting of Loy Yang 1953 and Beulah lignite coals was conducted in conjunction with the University of Arizona and the State Electricity Commission of Victoria's Herman Research Laboratories. Trace element concentrations in the Illinois 6 parent, SOAP, and ash products were also determined. Each of these activities is described in this section of the report.

\subsection{Combustion Testing of Chemically Cleaned Pittsburgh 8}

An experimental study of ash generation from combustion of a chemically beneficiated Pittsburgh $\# 8$ coal (denoted CB Pitts \#8) was completed during the last quarter. In the following sections, analysis of the coal, a discussion of ash formation pathways as inferred from laboratory combustion testing, and interpretation of ash particle stickiness testing are presented. In all cases, analysis of the coal and ash was conducted at the University of North Dakota Energy and Environmental Research Center (UNDEERC) through a co-operative agreement with DOE/PETC unless otherwise noted.

\subsubsection{Characterization of the Coal}

A compositional analysis of the organic and inorganic portions of the CB Pitts 8 coal is presented in Table 7-1. The total ash content of the coal calculated from the inorganic analysis was 0.2 percent. Silica was the major inorganic oxide in the ash, as indicated by $\mathbf{x}$-ray fluorescence analysis. Little enrichment is noted among iron, calcium, magnesium, and aluminum relative to typical ash chemistries for bituminous coals, suggesting that all of these elements were removed to a significant extent. High titania levels of 15 percent ( 2 percent or less is typical for coal ash) suggest that Ti was not as readily

Table 7-1. Coal and Ash Analysis - CB Pittsburgh No. 8 Coal

\begin{tabular}{|c|c|c|c|c|c|c|c|c|c|c|}
\hline Technique & $\mathrm{SiO}_{2}$ & $\mathrm{Al}_{2} \mathrm{O}_{3}$ & $\mathrm{Fe}_{2} \mathrm{O}_{3}$ & $\mathrm{TiO}_{2}$ & $\mathrm{P}_{2} \mathrm{O}_{5}$ & $\mathrm{CaO}$ & $\mathrm{MgO}$ & $\mathrm{Na}_{2} \mathrm{O}$ & $\mathrm{K}_{2} \mathrm{O}$ & $\mathrm{SO}_{3}$ \\
\hline $\mathrm{XRF}^{*}$ & 25.7 & 9.4 & 11. & 14.8 & 2.8 & 2.6 & 1.5 & 11.4 & 4.3 & 16.3 \\
\hline $\begin{array}{l}\text { PSIT } \\
\text { Kentucky } \\
\text { No. } 9 \\
\text { XRF }^{\dagger} \\
\end{array}$ & 44.6 & 20.6 & 22.4 & 1.1 & 0.1 & 3.1 & 1.1 & 0.9 & 2.6 & 4.7 \\
\hline $\begin{array}{l}\text { Coal (dry) } \\
\text { (PETC) }\end{array}$ & $\begin{array}{c}C \\
8.3\end{array}$ & $\begin{array}{c}\mathrm{H} \\
3 \\
\end{array}$ & $\begin{array}{c}0 \\
12 \\
\end{array}$ & $\begin{array}{l}\mathrm{N} \\
2\end{array}$ & $\begin{array}{c}0 \\
0.4\end{array}$ & & & & & \\
\hline \multicolumn{11}{|c|}{$\begin{array}{l}{ }^{*} \mathrm{Mn}=428 \mathrm{ppm} \text { of ash; } \mathrm{Cr}=7500 \mathrm{ppm} \text { of ash. } \\
{ }^{*} \mathrm{Cl}=53 \mathrm{ppm} \text { of coal; calculated ash content }(\mathrm{mf} \text { basis })=0.20 \% . \\
+\mathrm{R} \text {. Bryers, Foster-Wheeler Development Co. }\end{array}$} \\
\hline
\end{tabular}


removed as other species. Titanium is one of the few minerals generally present in high concentration as submicron inclusions in bituminous coals (Allen and VanderSande, 1984; Palmer and Filby, 1984); it is conceivable that these were not extracted with as high efficiency as the other minerals. High chromium levels in the ash $(7500 \mathrm{ppm})$ suggest that it was also ineffectively removed relative tho the other inorganic species. Sodium levels in the ash were also elevated as compared to a "typical" bituminous coal as indicated in Table 7-1. This is suggestive of retention of alkali from the beneficiation process.

Chemical fractionation of the coal inorganics was also performed to assess their chemical form within the coal. In this procedure, successive extractions are performed with $\mathrm{H}_{2} \mathrm{O}, \mathrm{NH}_{4} \mathrm{OOC}_{2} \mathrm{H}_{3}$, and $\mathrm{HCl}$ to remove chlorides, salts of organic acids, and oxides and carbonates, respectively (Benson and Holm, 1985). Insoluble clays and pyrite typically constitute the remainder. As Table 7-2 indicates, sodium, potassium, and chlorine were 100 percent water-extractable, indicating a lack of mineral forms of these species.

Magnesium, aluminum, and silicon were retained in the coal, a likely indication of the presence of small quantities of clay. Calcium was most probably present as the carbonate (calcite). The non-existence of "remaining" or non-extractable iron indicates a lack of pyritic iron detectable by this technique.

CCSEM analysis of the minerals, however, suggests that some pyritic iron did remain within the coal. This is shown in Table 7-3. Quartz is the other major identifiable mineral remaining in the coal after beneficiation, with moderate amounts of alumina, silica-rich phases, and aluminosilicate clays observed. Unknown phases (i.e., those not corresponding to one of the 32 common coal minerals categorized by UNDEERC CCSEM analysis) constitute $55 \mathrm{wt} \%$ of the minerals. Many of the "unknown" particles, however, are primarily chlorine, often containing potassium and sulfur as shown in the CCSEM ternary

Table 7-2. Chemical Fractionation of CB Pittsburgh No. 8 by UNDEERC

\begin{tabular}{|c|r|r|c|c|c|}
\hline Element & $\begin{array}{r}\text { ppm of } \\
\text { mf Coal }\end{array}$ & $\begin{array}{c}\text { Removed } \\
\text { by } \mathrm{H}_{2} \mathrm{O} \\
(\%)\end{array}$ & $\begin{array}{c}\text { Removed by } \\
\mathrm{NH}_{4} \mathrm{O} \mathrm{Ac} \mathrm{( \% )}\end{array}$ & $\begin{array}{c}\text { Removed by } \\
\mathrm{HCl}(\%)\end{array}$ & $\begin{array}{c}\text { Remaining } \\
(\%)\end{array}$ \\
\hline \hline $\mathrm{Na}$ & 220 & 100 & 0 & 0 & 0 \\
$\mathrm{Mg}$ & 14 & 0 & 0 & 0 & 100 \\
$\mathrm{Al}$ & 100 & 30 & 0 & 0 & 70 \\
$\mathrm{Si}$ & 240 & 27 & 0 & 0 & 73 \\
$\mathrm{Cl}$ & 53 & 100 & 0 & 0 & 0 \\
$\mathrm{~K}$ & 73 & 100 & 0 & 0 & 0 \\
$\mathrm{Ca}$ & 32 & 78 & 0 & 22 & 0 \\
$\mathrm{Fe}$ & 140 & 10 & 0 & 90 & 0 \\
\hline
\end{tabular}


Table 7-3. CCSEM Mineral Analysis of CB Pittsburgh No. 8 - wt\% of mineral matter -

\begin{tabular}{|l|r|r|}
\hline & \multicolumn{1}{|c|}{$\begin{array}{c}\text { Coal } \\
\text { Minerals }\end{array}$} & $\begin{array}{c}\text { Modified } \\
\text { Analysis }\end{array}$ \\
\hline \hline Quartz & 20.1 & 27.5 \\
Alumina & 4.7 & 6.5 \\
Kaolinite & 1.3 & 1.7 \\
Illite & 1.2 & 1.6 \\
Pyrite & 11.5 & 15.7 \\
Si-Rich & 6.3 & 8.7 \\
Other & 54.9 & 38.3 \\
\hline "Particles containing $\leq 10$ atom percent Cl only. \\
** Includes unknowns. \\
\hline
\end{tabular}

diagram of Figure 7-1. Removing these from the analysis results in the modified mineral distribution shown in the second column of Table 7-3. The low chlorine levels indicated by $\mathrm{XRF}$ ( $53 \mathrm{ppm}$ of the coal, $\approx 2.5$ percent of the ash) suggest that the high-Cl particles observed by CCSEM may have been an artifact. Note that CCSEM analysis of this coal is particularly difficult, given the low loading and small size of the few discrete minerals remaining after beneficiation.

Mineral size distributions determined by CCSEM for the CB Pittsburgh \#8 are presented in Table 7-4. The majority of the observed minerals were $<10 \mu \mathrm{m}$ in size, confirming removal of large mineral species during coal cleaning. Average atomic chemical compositions for each major mineral class as determined by CCSEM are presented in Table 7-5. These were calculated as follows: the stoichiometric amount of oxygen was added to the CCSEM atomic elemental analysis to balance charge as necessary for each particle. Individual elements were summed for each category via

$$
\text { Sum }=\Sigma \mathrm{Afx}_{\mathrm{i}} \rho / \mathrm{MW}_{\mathrm{i}}
$$

with

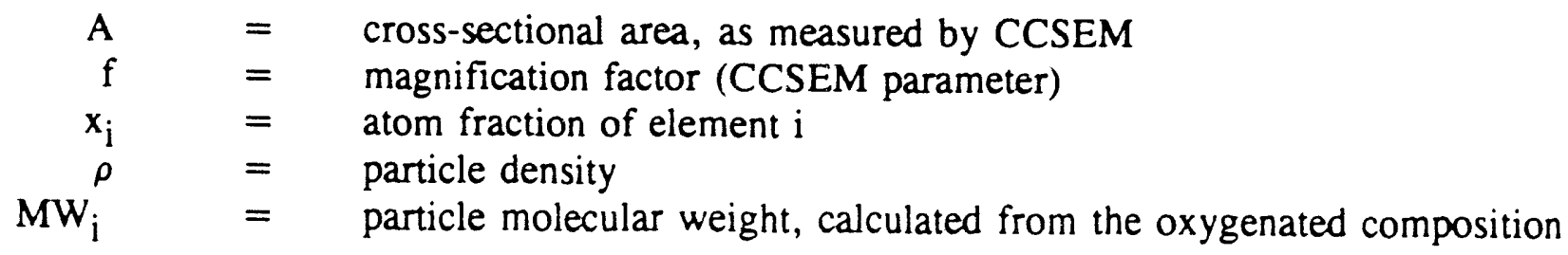




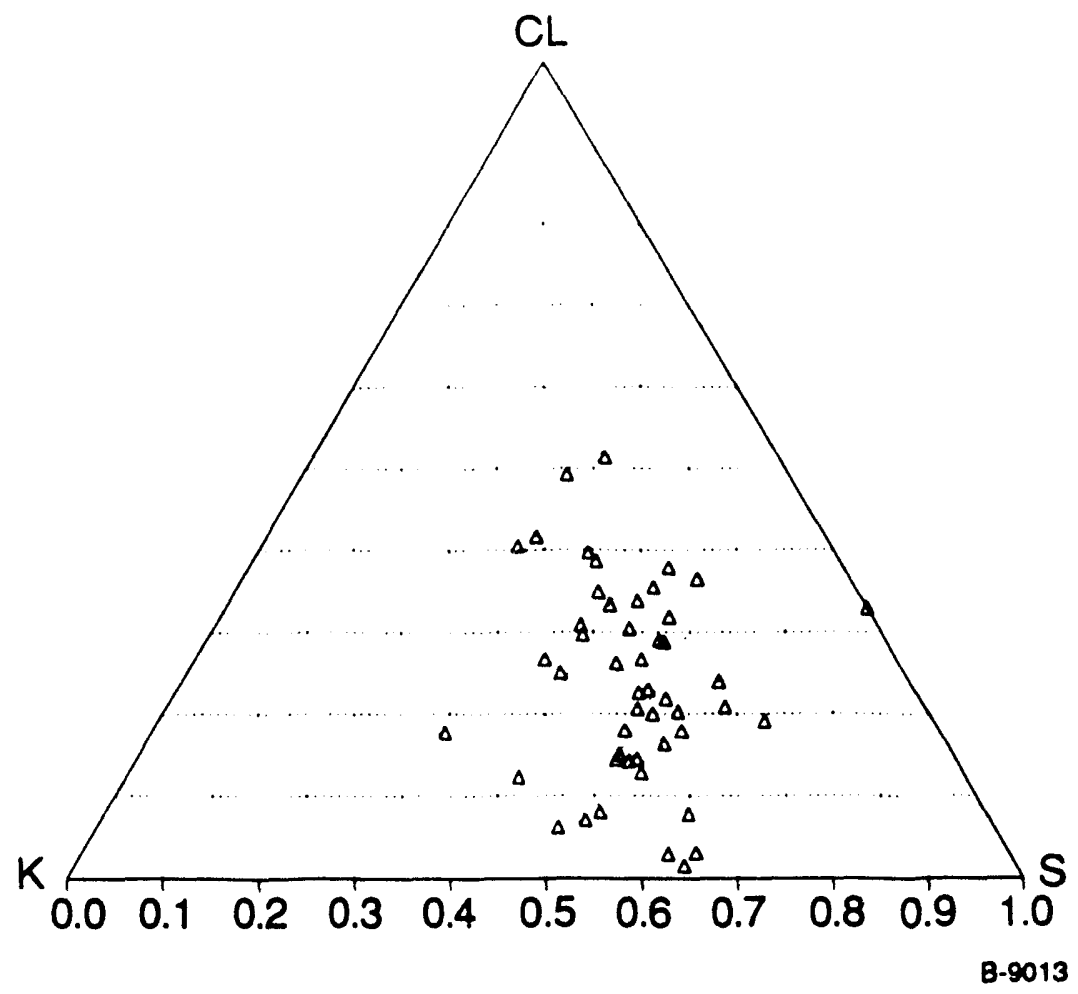

Figure 7-1. CCSEM mineral analysis of CB Pittsburgh \#8, showing all particles containing greater than 60 atom $\% \mathrm{~K}+\mathrm{Cl}+\mathrm{S}$ on an oxygen-free basis.

Table 7-4. CCSEM Mineral Size Distributions - CB

Pittsburgh No. 8 (area percent of minerals)

\begin{tabular}{|l|r|r|r|r|r|r|}
\hline & $\begin{array}{c}1.0 \text { to } \\
2.2 \mu \mathrm{m}\end{array}$ & $\begin{array}{c}2.2 \text { to } \\
4.6 \mu \mathrm{m}\end{array}$ & $\begin{array}{c}4.6 \text { to } \\
10 \mu \mathrm{m}\end{array}$ & $\begin{array}{c}14 \text { to } \\
22 \mu \mathrm{m}\end{array}$ & $>22 \mu \mathrm{m}$ & $\begin{array}{c}\text { wt\% in } \\
\text { Mineral } \\
\text { Matter }\end{array}$ \\
\hline \hline Quartz & 17 & 42 & 27 & 14 & 0 & 20.1 \\
Alumina & 8 & 56 & 36 & 0 & 0 & 4.7 \\
Pyrite & 73 & 27 & 0 & 0 & 0 & 11.5 \\
Si-Rich & 8 & 21 & 45 & 25 & 0 & 6.3 \\
Fe-Oxide & 13 & 44 & 44 & 0 & 0 & 2.7 \\
\hline Totals & 27.0 & 34.9 & 32.8 & 5.3 & 0 & 100.0 \\
\hline
\end{tabular}


Table 7-5. Average Discrete Mineral Composition - CB

Pittsburgh No. 8 (CCSEM, atom percent, O-free basis)

\begin{tabular}{|l|r|r|r|r|r|r|r|r|r|r|r|}
\hline & $\mathrm{Na}$ & $\mathrm{Mg}$ & $\mathrm{Al}$ & $\mathrm{Si}$ & $\mathrm{P}$ & $\mathrm{S}$ & $\mathrm{Cl}$ & $\mathrm{K}$ & $\mathrm{Ca}$ & $\mathrm{Fe}$ & $\mathrm{Ti}$ \\
\hline \hline Quartz & 0 & 0 & 0 & 96 & 0 & 1 & 1 & 0 & 1 & 1 & 0 \\
Alumina & 0 & 0 & 95 & 0 & 0 & 1 & 1 & 1 & 1 & 0 & 1 \\
Pyrite & 0 & 0 & 0 & 0 & 0 & 75 & 1 & 0 & 0 & 23 & 0 \\
Si-Rich & 2 & 1 & 7 & 81 & 0 & 0 & 1 & 1 & 3 & 3 & 1 \\
Unknowns & 1 & 1 & 4 & 10 & 4 & 2 & 67 & 1 & 2 & 6 & 2 \\
\hline Overali & 1 & 1 & 8 & 28 & 2 & 16 & 28 & 1 & 2 & 9 & 4 \\
Overall Mod & \\
\hline
\end{tabular}

and renormalized to yield the final element atom fractions. The reasoning behind this method of calculation is as follows: it has been shown that the apparent cross-sectional area fraction of each mineral, obtained from random sectioning of a uniform plug of coal/epoxy, is equal to the true volume fraction of each mineral class in the whole plug (PSI Technology Co., 1990b). The overall composition of the entire mineral distribution can therefore be obtained from the product of the volume fraction of each mineral class (i.e., apparent cross-sectional area fraction) and the elemental composition of that class. If the composition of individual particles within a class does not vary significantly from some mean value, then the individual particles can be summed in the above fashion. Clearly this is the case for all categories except the unknowns. For the unknowns, the above arguments cannot be used to justify calculation of an average composition, as the particle-to-particle composition varies widely within this category. In simulations conducted with computer generated mineral distributions, however, it has been empirically observed that the cross-sectioned area size fraction of minerals in a given diameter range corresponds closely to the true volume fraction in that range, as shown for one case in Figure 7-2. One can therefore argue that there is justification in determining composition from the sum of individual areas, as this sum in each size fraction will correspond to the correct volume fraction. Given these arguments (and lack of a better scheme, other than assigning probability density functions to each particie and computing probable overall compositions), the chemical composition of the unknown category was calculated using Eq (7-1). Note that for ash particles which have not been cross-sectioned for CCSEM analysis, the area must be converted to volume by taking (area) $^{3 / 2}$ for this to be true (Figure 7-2). 


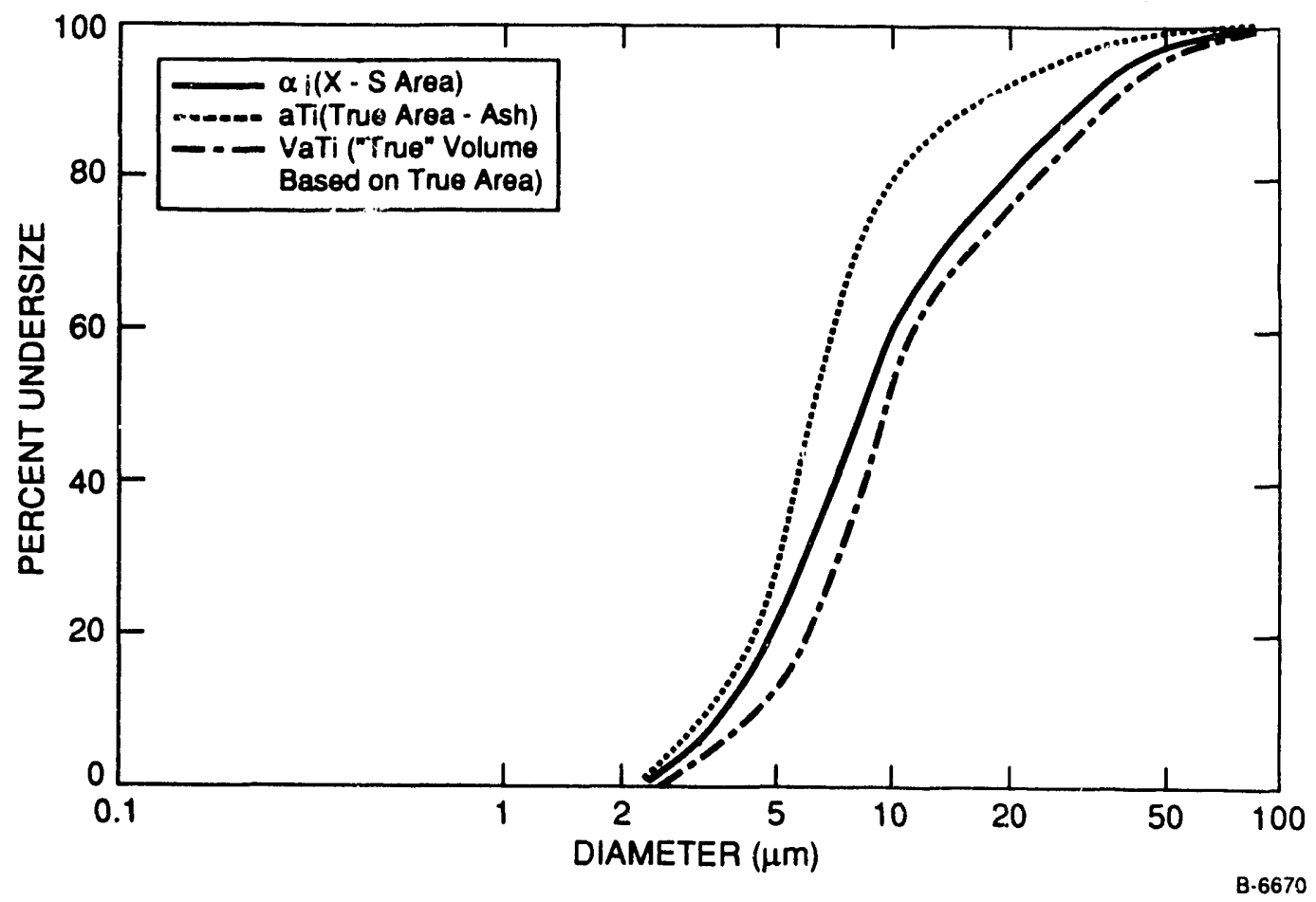

Figure 7-2. Comparison of computer-generated particle size distributions

\subsubsection{Ash Particle Formation During the Combustion of CB Pittsburgh 8}

Coinbustion experiments were conducted in the PSIT externally heated drop tube reactor facility. Coal samples were sieved to 100 percent $<90 \mu \mathrm{m}$ prior to testing to insure that complete combustion would occur in 7 percent oxygen atmosphere at gas tem eratures of $1450^{\circ}$ to $1475^{\circ} \mathrm{C}$ (corresponding to wall temperatures of $1500^{\circ} \mathrm{C}$ ). Gas flow raies were maintained at $21.2 \mathrm{slpm}$ in the $9 \mathrm{~cm}$ diameter $1.3 \mathrm{~m}$ long reactor for these experiments.

Particle size distributions of coal minerals and ash particles generated during these combustion experiments were determined by CCSEM and plotted in Figure 7-3. Comparing the uncorrected mineral and ash size distributions suggests that significant cra'escence of inorganics occurred during combustion, as the fraction greater than $8 \mu \mathrm{m} \mathrm{i}$ ', much greater for the ash. If both distributions are modified by el minating all particles containing greater than 10 atnm \% chlorine, however, the extent of coalescence is much less as shown in Figure 7-3. Because of the uncertainty in chlorine analysis (i.e., the apparent large difference between $\mathrm{XRF}$ and CCSEM reported levels), the modified curves are considered more accurate.

In Figure 7-4, the quartz mineral size distribution measured by CCSEM is compared with the $\mathrm{SiO}_{2}$ CCSEM ash particle size distribution. A slight increase in particles greater than $8 \mu \mathrm{m}$ is observed in the ash. This suggests limited coalescence of quartz minerals may be occurring. Given the low ( 0.20 percent) ash content of this coal, little coalescence was anticipated. 


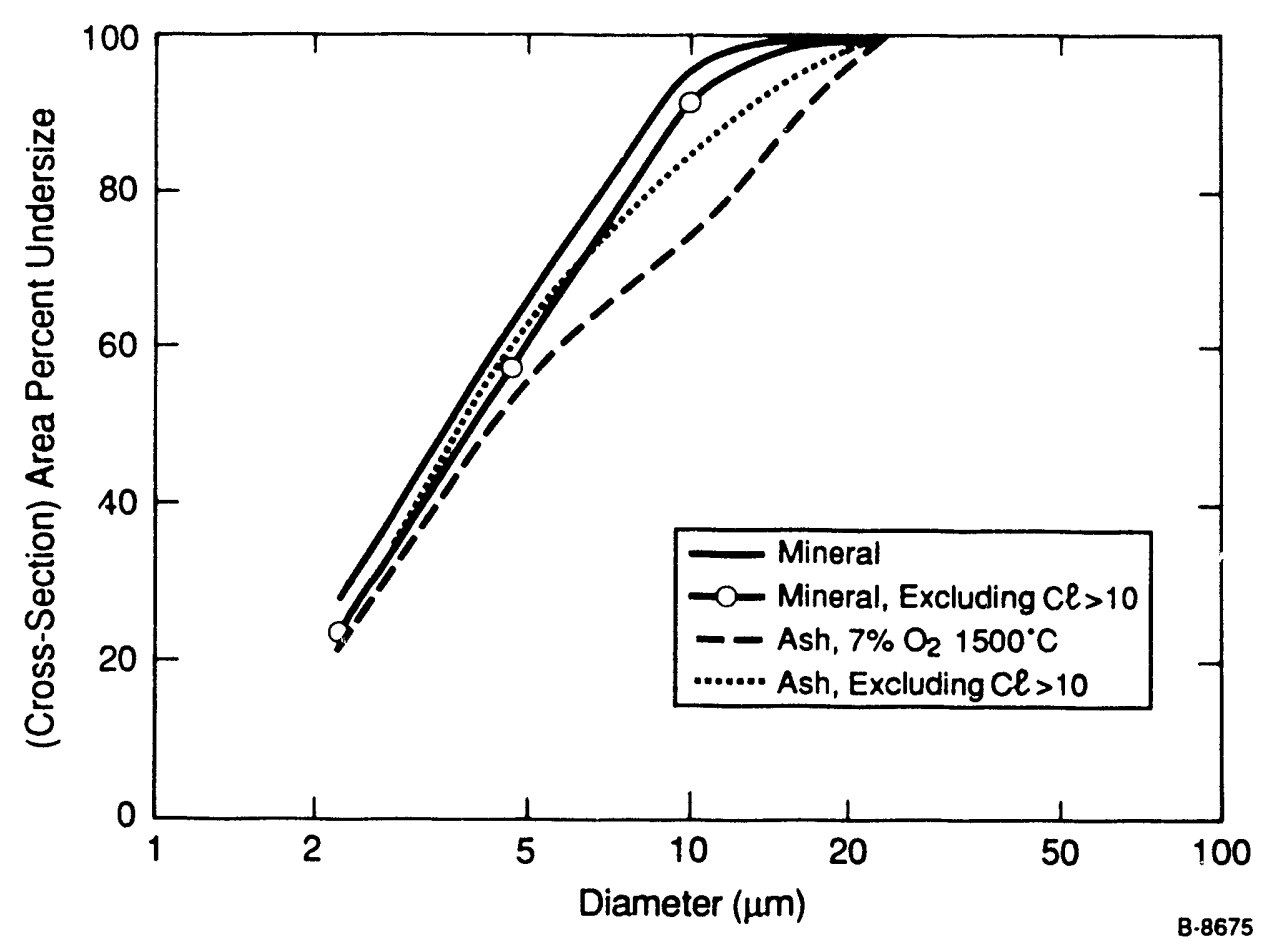

Figure 7-3. Mineral and ash size distributions for CB Pittsburgh 8, determined by CCSEM at UNDEERC.

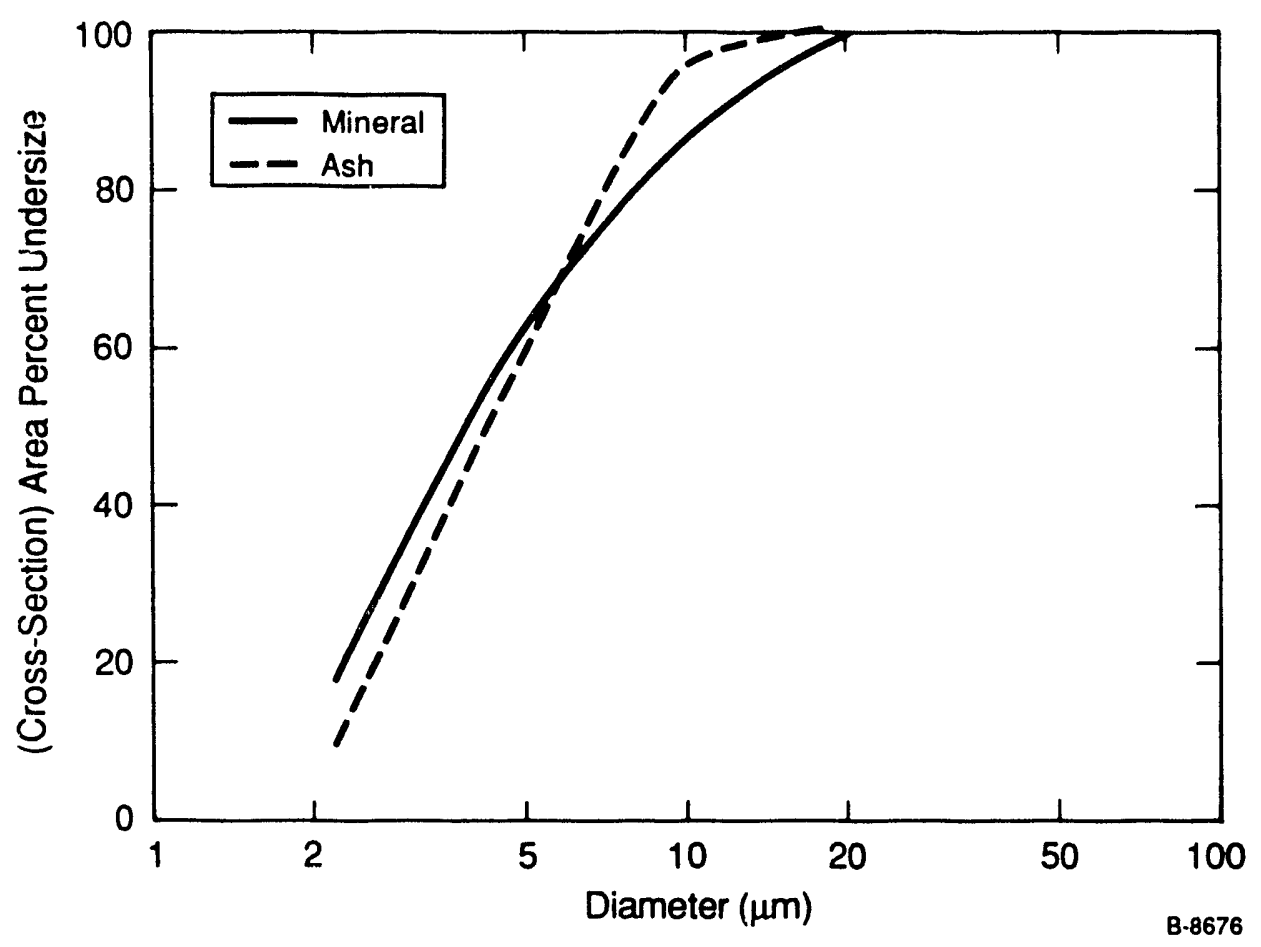

Figure 7-4. Quartz mineral and ash size distributions for CB Pittsburgh 8, determined by CCSEM at UNDEERC. 
The chemical composition of the combustion generated ash for CB Pittsburgh $\# 8$ measured by CCSEM is given in Table 7-6. Chemical composition information is presented for "whole" particle samples (i.e. not cross-sectioned) unless otherwise noted. The overall compositions reported at the bottom of Table 7-6, modified to eliminate chlorine-rich particles, differ from the overall mineral compositions reported in Table 7-5 in several areas. First, sulfur levels are reduced in the ash, as expected given the volatility of the element under combustion conditions. Second, iron levels are decreased in the ash relative to the coal minerals. Third, titanium levels are increased in the ash relative to the coal minerals. The reduction in iron levels may be the result of dilution by organically bound species which add to the ash, while the apparent increase in titania may result from addition of submicron titania inclusions too small to be observed by CCSEM analysis of the coal. Both of these proposed mechanisms are speculative, as detailed characterization of the submicron minerals by a technique such as STEM (scanning transmission electron microscopy) would be required to address the issues.

Distributions were measured on samples which were cast in epoxy and cross-sectioned as well as on whole particle samples attached to double-sided adhesive tape. Comparison of the two provides a means for determining whether surface enrichment of any particular element exists, as the whole particle technique provides information on the outer approximately $1 \mu \mathrm{m}$ of a particle. For this sample, silica-rich particles appear to be the only ones significantly surface enriched as shown in Table 7-7. This results in the slightly higher (53 versus 42 atom\%) silicon concentrations in the surface ash are reported at the bottom of Table 7-6.

Table 7-6. Chemical Composition of Combustion-Generated CB Pittsburgh No. 8 Ash (cross-sectioned sample)

\begin{tabular}{|c|c|c|c|c|c|c|c|c|c|c|c|c|}
\hline \multirow[b]{2}{*}{ Category } & \multirow[b]{2}{*}{$\begin{array}{c}\text { wt\% in } \\
\text { Ash }\end{array}$} & \multicolumn{11}{|c|}{ Atom Percent } \\
\hline & & $\mathrm{Na}$ & $\mathbf{M g}$ & A] & $\mathrm{Si}$ & $P$ & $\mathrm{~s}$ & $\mathrm{Cl}$ & $\mathrm{K}$ & $\mathrm{Ca}$ & $\mathrm{Fe}$ & $\mathrm{Ti}$ \\
\hline Si & 20.7 & 0 & 0 & 0 & 95 & 0 & 1 & 1 & 1 & 0 & 1 & 1 \\
\hline $\mathrm{Ti}$ & 6.7 & 0 & 0 & 2 & 3 & 1 & 1 & 2 & 2 & 4 & 7 & 78 \\
\hline Alsi & 4.2 & 1 & 0 & 41 & 49 & 0 & 1 & 2 & 4 & 1 & 1 & 1 \\
\hline KAlSi & 4.6 & 1 & 0 & 31 & 52 & 0 & 1 & 1 & 8 & 1 & 2 & 2 \\
\hline Si-Rich & 3.2 & 1 & 0 & 5 & 76 & 0 & 2 & 2 & 5 & 1 & 1 & 5 \\
\hline Unknowns & 54.2 & 1 & 2 & 9 & 22 & 2 & 11 & 10 & 9 & 7 & 8 & 20 \\
\hline Unknowns, Mod ${ }^{+}$ & - & 1 & 1 & 11 & 27 & 2 & 7 & 4 & 6 & 8 & 8 & 25 \\
\hline Overall & 100.0 & 1 & 1 & 14 & 53 & 1 & 1 & 1 & 2 & 4 & 6 & 15 \\
\hline Overall, X-S & 100.0 & 1 & 1 & 10 & 42 & 1 & 7 & 6 & 6 & 6 & 5 & 15 \\
\hline Overall, Mod ${ }^{+}$ & - & 1 & 1 & 11 & 49 & 1 & 4 & 2 & 4 & 6 & 4 & 16 \\
\hline
\end{tabular}


Table 7-7. Comparison of Surface and Cross-Sectionial CCSEM - CB Pittsburgh No. 8 Ash

\begin{tabular}{|l|r|r|r|}
\hline Category & $\begin{array}{c}\text { X-S } \\
\text { Percent }\end{array}$ & $\begin{array}{c}\text { Surface } \\
\text { Volume } \\
\text { Percent }\end{array}$ & $\begin{array}{c}\text { Mineral }^{* *} \\
(\mathrm{X}-\mathrm{S})\end{array}$ \\
\hline \hline $\mathrm{Si}$ & 21.6 & 32.4 & 23.3 \\
$\mathrm{Ti}$ & 3.8 & 3.7 & 0.1 \\
$\mathrm{Al} \mathrm{Si}$ & 4.4 & 6.1 & 1.5 \\
$\mathrm{KAl} \mathrm{Si}$ & 4.9 & 1.9 & 1.4 \\
$\mathrm{Si}-$ rich & 3.4 & 5.5 & 7.3 \\
Unknown & 55.4 & 40.5 & 44.4 \\
\hline * X-S area equivalent to volume; surface analysis values were \\
converted to volume \\
** N.B. - area percent; values in Table 7-3 are weight \\
percent.
\end{tabular}

Although most minerals did not coalesce to a significant extent for this fuel (cf. Figures 7-3, 7-4), extensive titanium-aluminosilicate interactions were observed. This can be seen in the series of ternary diagrams in Figures 7-5 through 7-7. In Figure 7-5, all coal minerals containing greater than 50 atom $\% \mathrm{Ti}+\mathrm{Al}+\mathrm{Si}$ are seen to have low titanium content. When ash particles containing greater than 80 percent $\mathrm{Ti}+\mathrm{Al}+\mathrm{Si}$ are considered, an increase in titanium concentrations is observed. Broadening the categorization to include all ash particles containing greater than 50 atom $\% \mathrm{Ti}+\mathrm{Al}+\mathrm{Si}$ reveals a much larger number of titanium containing particles, as shown in Figure 7-6b. The difference in the number of particles observed in Figure 7-6b versus 7-6a indicates a high concentration of titanium aluminosilicates containing 20 to 50 percent of other species. Similar conclusions can be drawn from analysis of the cross-sectioned CB Pittsburgh \#8 ash sample in Figure 7-7. Comparison with the whole-particle or surface-sensitive CCSEM results in Figure 7-6 indicates titanium enrichment on the particle surface relative to the core, as discussed previously in this section. Examination of ternary diagrams for other species including $\mathrm{K}-\mathrm{Al}-\mathrm{Si}$ did not reveal any significant interaction during combustion.

Ash particle stickiness testing was also conducted with an unclassified the CB Pittsburgh \#8 sample in air. Ash particle collection efficiencies measured for the as-received coal on an uncooled ceramic substrate, using a technique developed previously (PSI Technology Co., 1990a) were low at both conditions as shown in Table 7-8. Using the ash psd from the results of Figure 7-3, an impaction efficiency of $25 \%$ (low velocity) results in an adhesion efficiency (collection/impaction) of only $15 \%$ at the higher temperature. The 


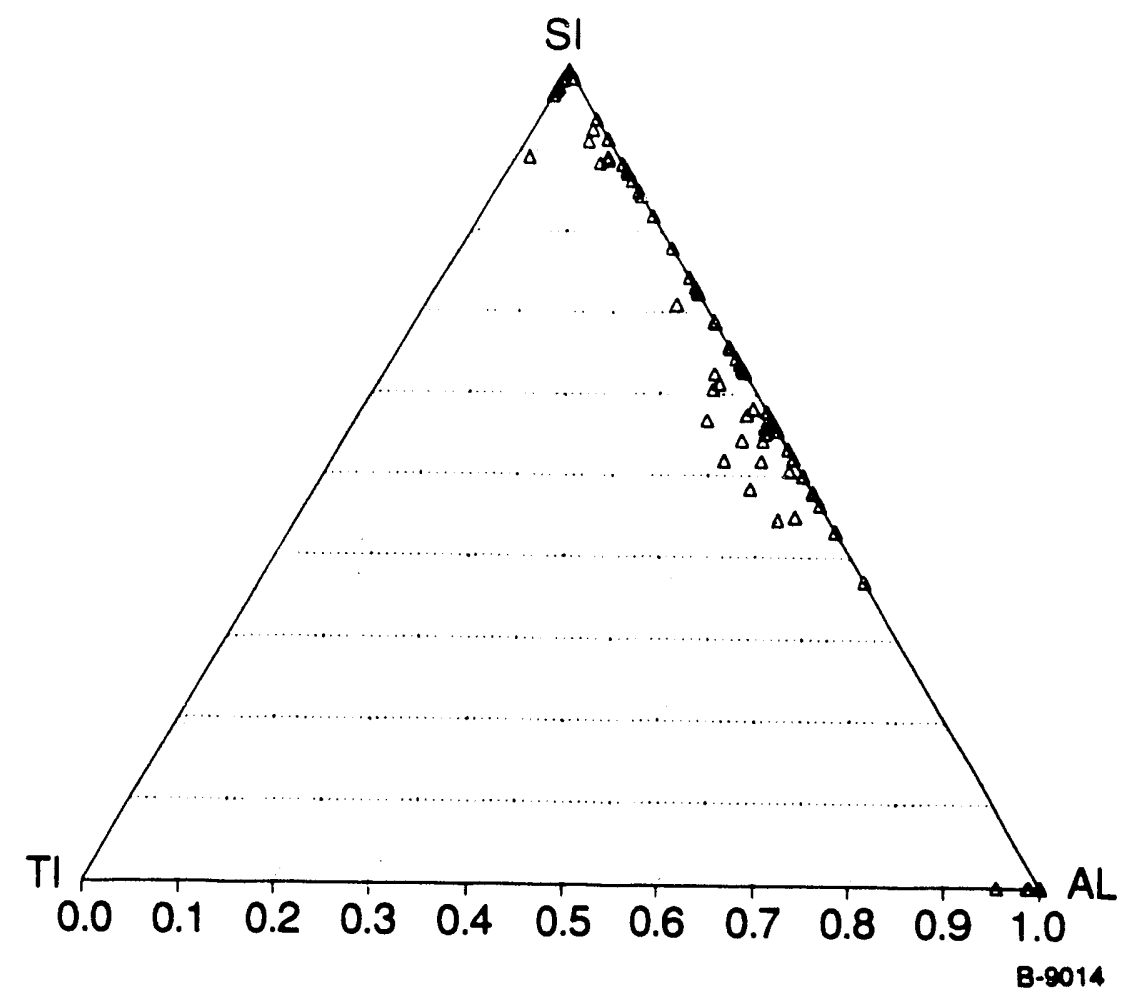

Figure 7-5. CCSEM Ti-Al-Si ternary for CB Pitts 8, showing all minerals containing $\geq 50$ atom $\% \mathrm{Ti}+\mathrm{Al}+\mathrm{Si}$

chemical composition of the adherent ash measured by SEM-point count (SEMPC) at UNDEERC was a mixture of aluminosilicates (Table 7-9). Note the absence of titanium in the deposit, suggesting that the titanium-rich particles formed during combustion were not sticky.

For a beneficiated fuel with the low ash levels and high alkali content of the CB Pittsburgh \#8, vapor-driven deposition (i.e. fouling) is expected to be a more serious problem than inertially-driven deposition of sticky ash particles in a boiler radiant zone. The high levels of submicron ash measured during laboratory combustion of this coal, suggestive of vaporization and recondensation of the volatile alkali (as well as refractory species; Graham, 1991) indicate this may be a concern. Two percent or less of the ash present in submicron size ranges is typical of bituminous coals examined under this program; slightly more than 10 percent was measured for this coal as shown in Figure 7-8. Chemical composition analysis of the submicron fume is required as a further step to assess the fouling potential of this coal.

In summary, examination of a 0.2 percent ash chemically beneficiated sample of Pittsburgh \#8 coal and its combustion products revealed the following:

coal low in ash, but ash contained high levels of alkali, sulfur.

coal ash contained 15 percent titanium by weight, indicating less effective titanium removal relative to other minerals. 


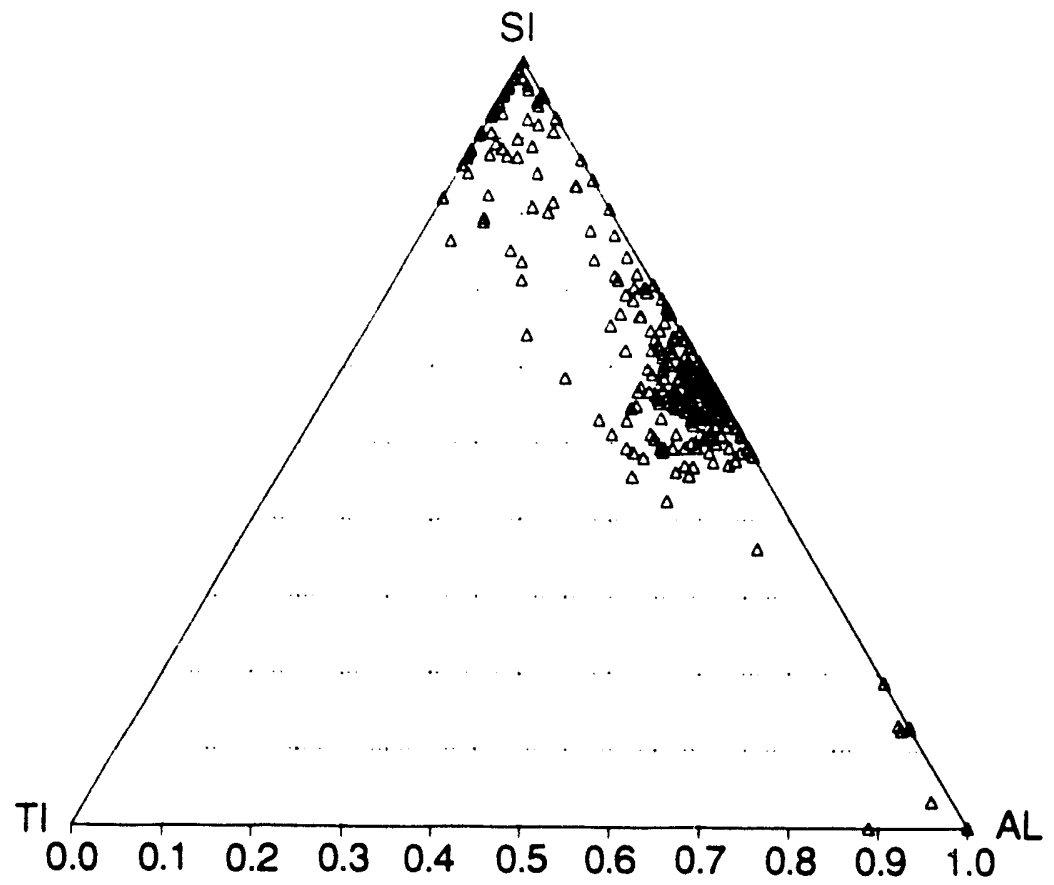

(a)

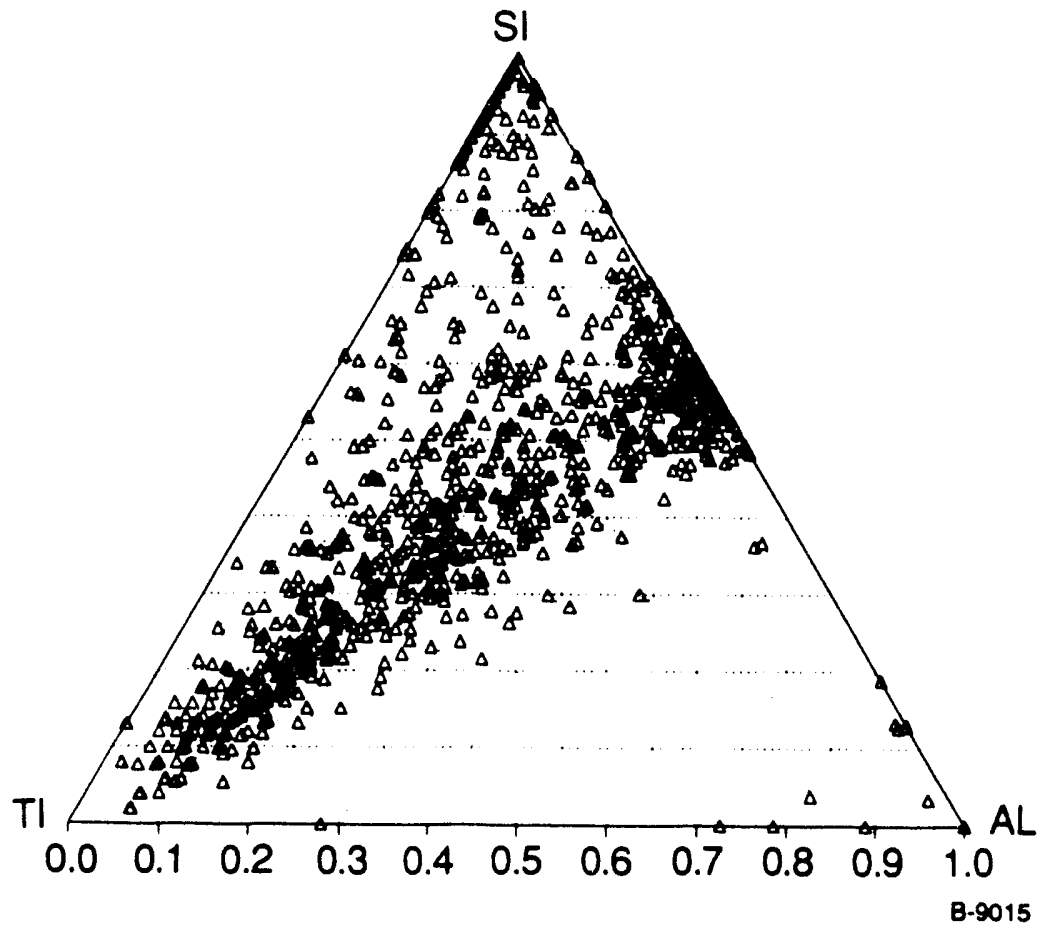

(b)

Figure 7-6. CCSEM Ti-Al-Si ternary for ash particles generated during combustion of CB Pitts $8(<90 \mu \mathrm{m}), 1500^{\circ} \mathrm{C} 7 \% \mathrm{O}_{2}$. (a) $\mathrm{Ti}+\mathrm{Al}+\mathrm{Si} \geq 80$ atom\%;

(b) $\mathrm{Ti}+\mathrm{Al}+\mathrm{Si} \geq 50$ atom $\%$. Surface CCSEM analysis. 


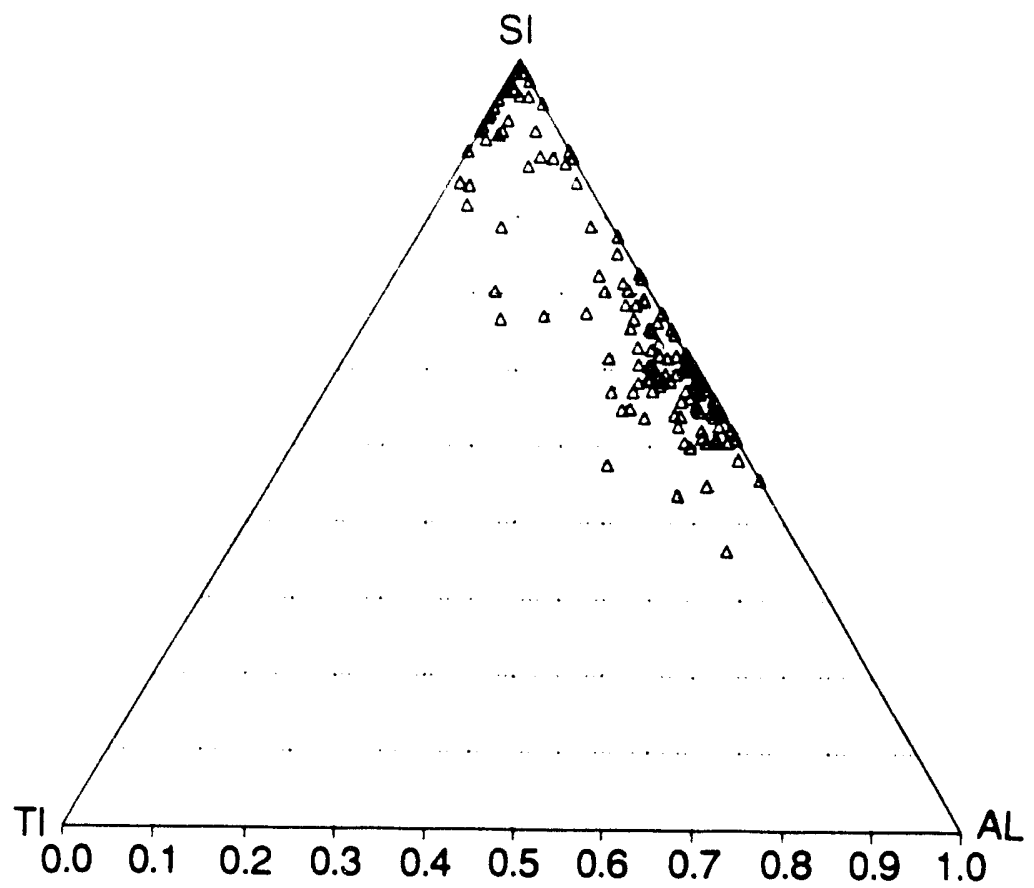

(a)

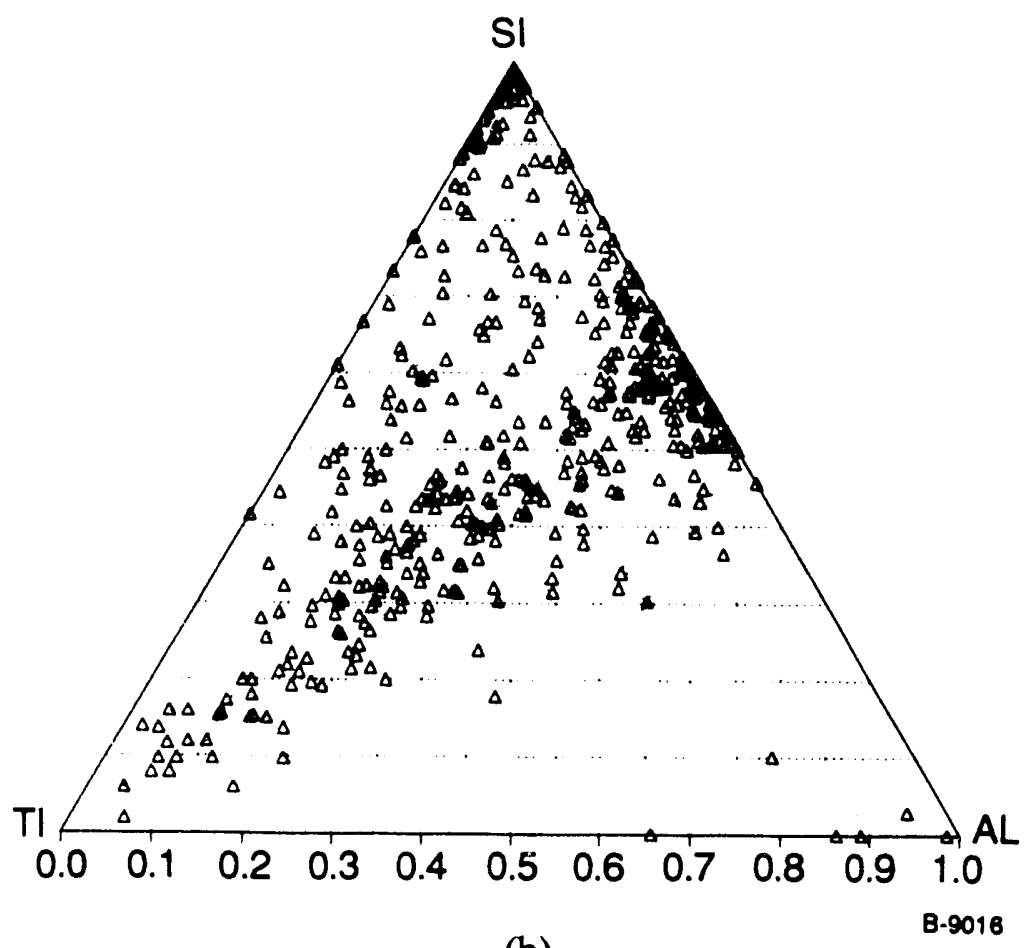

(b)

Figure 7-7. CCSEM Ti-Al-Si ternary for ash particles generated during combustion of CB Pitts $8(<90 \mu \mathrm{m}), 1500^{\circ} \mathrm{C} 7 \% \mathrm{O}_{2}$. (a) $\mathrm{Ti}+\mathrm{Al}+\mathrm{Si} \geq 80$ atom $\%$;

(b) $\mathrm{Ti}+\mathrm{Al}+\mathrm{Si} \geq 50$ atom $\%$. Cross-sectional analysis. 
Table 7-8. Stickiness Testing of CB Pittsburgh \#8 (as-received coal, $21 \% \mathrm{O}_{2}$ )

\begin{tabular}{|c|c|c|c|c|}
\hline $\mathrm{T}_{\text {wall }}$ & $\mathrm{T}_{\text {combustion gas }}$ & $\mathrm{T}_{\text {dep'n surface }}$ & $\begin{array}{c}\text { Collection } \\
\eta(1 \mathrm{~m} / \mathrm{s})\end{array}$ & $\begin{array}{c}\text { Collection } \\
\eta(4 \mathrm{~m} / \mathrm{s})\end{array}$ \\
\hline \hline $1500^{\circ} \mathrm{C}$ & $1450^{\circ} \mathrm{C}$ & $1425^{\circ} \mathrm{C}$ & 4.3 & 10.2 \\
$1300^{\circ} \mathrm{C}$ & $1250^{\circ} \mathrm{C}$ & $1225^{\circ} \mathrm{C}$ & 2.7 & 4.2 \\
\hline *impaction efficiency not incorporated \\
\hline
\end{tabular}

Table 7-9. CB Pittsburgh No. 8 Deposit Composition $1500^{\circ} \mathrm{C}, 21 \% \mathrm{O}_{2}$ (coal - as received) (wt\%)

\begin{tabular}{|c|c|}
\hline $\mathrm{SiO}_{2}$ & 50.2 \\
$\mathrm{Al}_{2} \mathrm{O}_{3}$ & 36.7 \\
$\mathrm{Fe}_{2} \mathrm{O}_{3}$ & 3.5 \\
$\mathrm{TiO}_{2}$ & 3.4 \\
$\mathrm{P}_{2} \mathrm{O}_{5}$ & 0.1 \\
$\mathrm{CaO}$ & 0.8 \\
$\mathrm{MgO}$ & 0.6 \\
$\mathrm{Na}_{2} \mathrm{O}$ & 0.4 \\
$\mathrm{~K}_{2} \mathrm{O}$ & 4.3 \\
\hline
\end{tabular}

chemical fractionation reveals that most elements were removed by extraction; retained $\mathrm{Al}$ and $\mathrm{Si}$ indicate some aluminosilicate minerals remained.

fine mineral distribution; 95 percent less than $10 \mu \mathrm{m}$ acc. to CCSEM.

chlorine-rich minerals and ash particles noted by CCSEM; need to be confirmed as chemical fractionation indicated substantially lower $\mathrm{Cl}$ levels.

combustion ash particle surfaces slightly enriched in silicon relative to cross-sectioned sample (CCSEM analysis); no other elements enriched.

extensive titanium aluminosilicate formation observed in combustion ash.

submicron ash represents over $10 \mathrm{wt} \%$ of total combustion ash, suggestive of more extensive inorganic vaporization than typically noted for a bituminous coal.

stickiness of inertially impacting ash particles low $-<5$ percent at $1250^{\circ} \mathrm{C}$. 


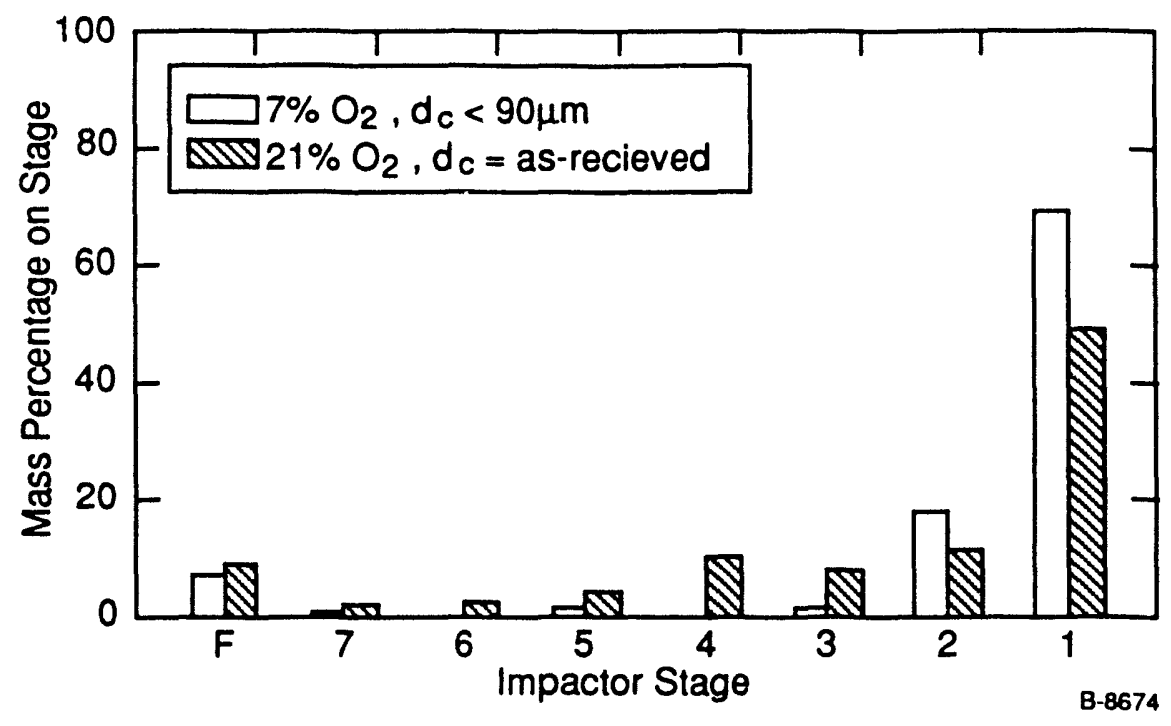

Figure 7-8. Cascade impactor mass distribution obtained from combustion of $\mathrm{CB}$ Pittsburgh \#8.

\subsection{Combustion Testing of Illinois \#6 SOAP}

In this section of the report, CCSEM characterization of ash generated in combustion testing of the Illinois \#6 physically beneficiated spherical oil agglomeration product (SOAP) coal is presented. Mineral analysis of the Illinois \#6 SOAP coal and preliminary characterization of the combustion-generated ash obtained from PSIT testing have been reported previously (PSI Technology Co., 1991). A summary of coal analyses including CCSEM mineral measurements made at the University of Kentucky is presented in Section 3 of this report.

Combustion testing of the Illinois \#6 SOAP coal was conducted at $1500^{\circ} \mathrm{C}$ and $1250^{\circ} \mathrm{C}$, gas temperature in the PSIT laminar-flow drop tube furnace facility. Oxygen levels corresponding to these temperatures were 7 and 16 percent, determined from the model of Graham (1991) to maintain approximately constant combusting particle temperature. Figure 7-9 compares CCSEM-determined particle size distributions from these experiments, measured at UNDEERC on cross-sectioned samples, with the CCSEM-determined mineral distribution measured previously at the University of Kentucky. Mineral coalescence to produce larger ash particles is indicated in both cases.

Compositional analysis of the major ash categuries identified by CCSEM under both combustion conditions is presented in Table 7-10 for both cross-sectioned and whole particle samples. Examining the $1500^{\circ} \mathrm{C}$ sample first, iron aluminosilicates are the dominant composition observed, and are enriched on the ash particle surfaces relative to the bulk. Little difference is noted between surface and interior (cross-sectional) concentration levels for the other phases identified. For the $1250^{\circ} \mathrm{C}$ sample, iron aluminosilicates are again dominant, and again are surface-enriched. Aluminosilicates (presumably kaolinite-derived 


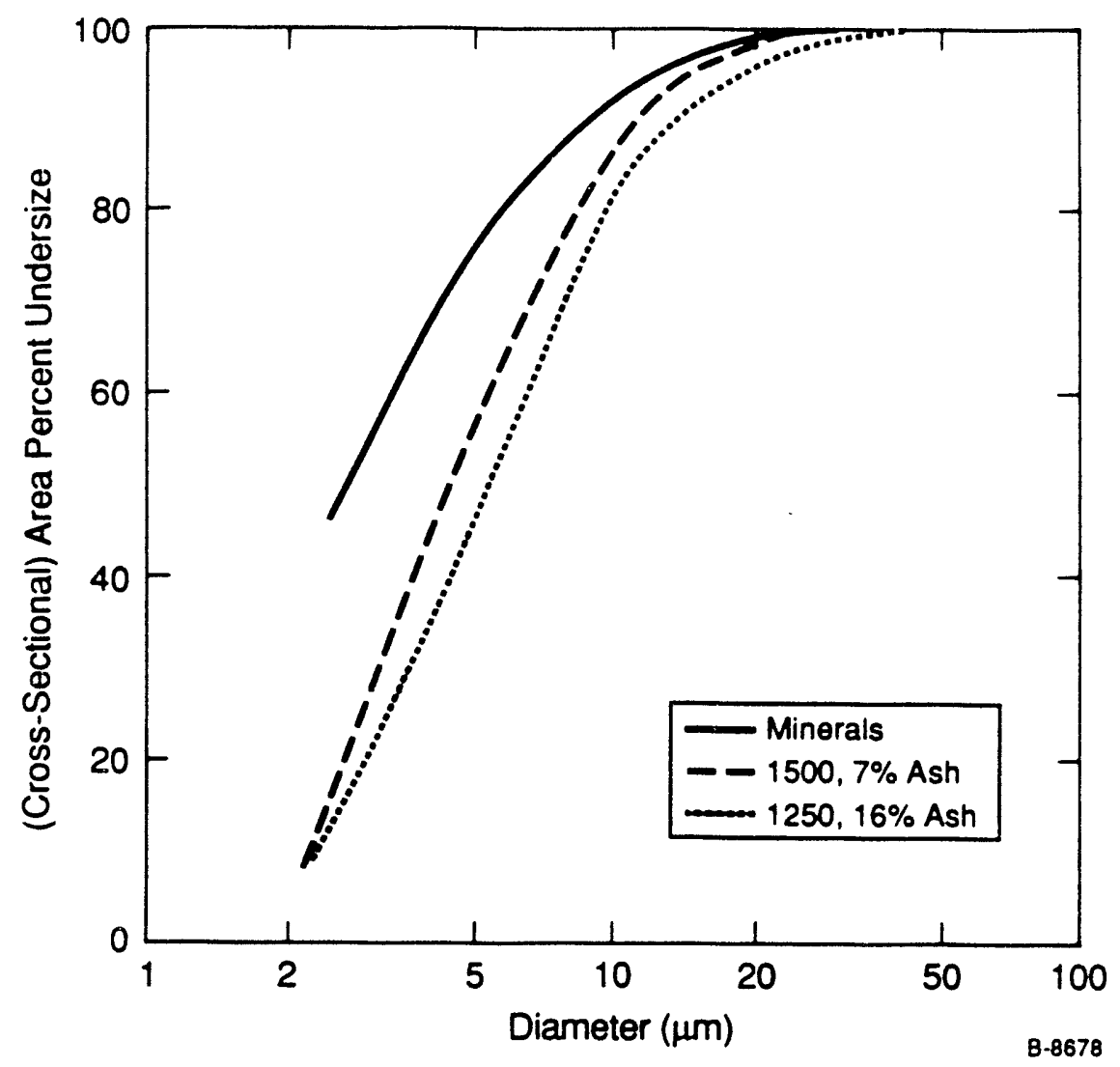

Figure 7-9. Mineral and ash size distributions for Illinois \#6 SOAP

Table 7-10. Ash Analysis of Illinois \#6 SOAP by CCSEM at UNDEERC (XS area $\%=$ volume $\%)$

\begin{tabular}{|l|r|r|r|r|}
\hline \multirow{2}{*}{} & \multicolumn{2}{|c|}{$1500^{\circ} \mathrm{C}, 7 \% \mathrm{O}_{2}$} & \multicolumn{2}{|c|}{$1250^{\circ} \mathrm{C}, 16 \% \mathrm{O}_{2}$} \\
\cline { 2 - 5 } & \multicolumn{1}{|c|}{$\mathrm{X}-\mathrm{S}$} & Surface & \multicolumn{1}{c|}{$\mathrm{X}-\mathrm{S}$} & Surface \\
\hline \hline $\mathrm{Si}$ & 3.5 & 5.2 & 3.7 & 7.2 \\
$\mathrm{Ca}$ & 0.8 & 0.2 & 3.3 & 0.3 \\
$\mathrm{~K} \mathrm{Al} \mathrm{Si}$ & 1.4 & 2.1 & 5.1 & 4.4 \\
$\mathrm{Fe} \mathrm{Al} \mathrm{Si}$ & 33.3 & 44.1 & 9.1 & 19.0 \\
$\mathrm{Al} \mathrm{Si}$ & 2.6 & 1.2 & 5.8 & 1.0 \\
Si-Rich & 4.5 & 5.2 & 5.6 & 5.1 \\
\hline
\end{tabular}

ash particles) are depleted on the particle surface. Relative to the $1500^{\circ} \mathrm{C}$ results, iron aluminosilicate formation is decreased and aluminosilicate levels are increased at the lower gas temperature. Given the observations of iron-aluminosilicate interactions reported by the University of Arizona (PSI Technology Co., 1991; also Section 6 of this report), these results suggest that iron coalescence with aluminosilicates is reduced at the lower temperatures. Although oxygen levels were adjusted to maintain constant particle 
temperature, the difference in iron-aluminosilicate levels suggests that temperatures may have been lower at the lower gas temperature. Particle temperature measurements would be needed to verify this. As indicated in the overall ash chemical compositions shown in Table 7-11, iron levels were identical in both cases as expected. Note that extraneous pyrite is not expected to be a factor in either case because it has been removed by the physical beneficiation process.

Table 7-11. Chemical Composition of Illinois \#6 SOAP Ash by CCSEM

\begin{tabular}{|l|c|c|c|c|c|c|c|c|c|c|c|}
\hline & \multicolumn{10}{|c|}{ Atom Percent } \\
\cline { 2 - 13 } & $\mathrm{Na}$ & $\mathrm{Mg}$ & $\mathrm{Al}$ & $\mathrm{Si}$ & $\mathrm{P}$ & $\mathrm{S}$ & $\mathrm{Cl}$ & $\mathrm{K}$ & $\mathrm{Ca}$ & $\mathrm{Fe}$ & $\mathrm{Ti}$ \\
\hline \hline $1500^{\circ} \mathrm{C}$ - surface & 1 & 1 & 19 & 50 & 0 & 1 & 1 & 2 & 5 & 19 & 3 \\
$1250^{\circ} \mathrm{C}$ - surface & 1 & 0 & 18 & 48 & 0 & 1 & 1 & 5 & 5 & 17 & 3 \\
$1250^{\circ} \mathrm{C}-\mathrm{XS}$ & 1 & 1 & 16 & 39 & 0 & 4 & 4 & 11 & 9 & 13 & 4 \\
\hline
\end{tabular}

The difference between surface and bulk iron-aluminosilicate levels can be seen more clearly in Figure 7-10. Figures 7-10a and 7-10b are ternary Fe-Al-Si diagrams for the whole particle samples (surface analysis) for both conditions considered. In both cases, a wide range of iron aluminosilicate compositions is noted. In Figure 7-10c, a cross-sectioned sample taken from the $1250^{\circ} \mathrm{C}$ experiment, fewer particles and a narrower range of iron concentrations are noted. In all cases, each point represents a single ash particle with the sum $\mathrm{Fe}+\mathrm{Al}+\mathrm{Si}$ equalling at least 80 atom\% of the particle on an oxygen-free basis.

As shown in Table 7-11, potassium levels in the cross-sectioned $1250^{\circ} \mathrm{C}$ sample were higher than potassium levels in the surface of the ash particles. This is reflected in the ternary diagrams of Figure 7-11, showing (a) the surfaces of the ash particles generated at $1500^{\circ} \mathrm{C}$ gas temperature; (b) the surfaces of the ash particles generated at $1250^{\circ} \mathrm{C}$ gas temperature; and (c) the interiors (cross-sectioned sample) of the ash particles generated at $1250^{\circ} \mathrm{C}$ gas temperature. Potassium concentrations are clearly the greatest in Figure $7-11 \mathrm{c}$. A possible mechanism is coating of illite-derived ash particles by iron aluminosilicates. Illite has been shown to coalesce rapidly for bituminous coals under these conditions (PSI Technology Co., 1990b), while iron appears to coalesce with the aluminosilicates more slowly. This would result in illite-derived cores coated with iron rich surfaces.

Calcium-aluminosilicate interactions are examined in the ternary diagrams of Figure 7-12. Low levels of calcium aluminosilicate formation are observed in surface and cross-sectioned samples at both experimental conditions, consistent with an Illinois \#6 examined previously and in contrast to the extensive calcium aluminosilicate formation observed for several Western coals examined previously under this program.

Stickiness experiments with ceramic tube surfaces in thermal equilibrium with the gas were also conducted with Illinois \#6 SOAP. The collection efficiencies obtained in these experiments were reported in the previous quarterly report, and are reproduced in 

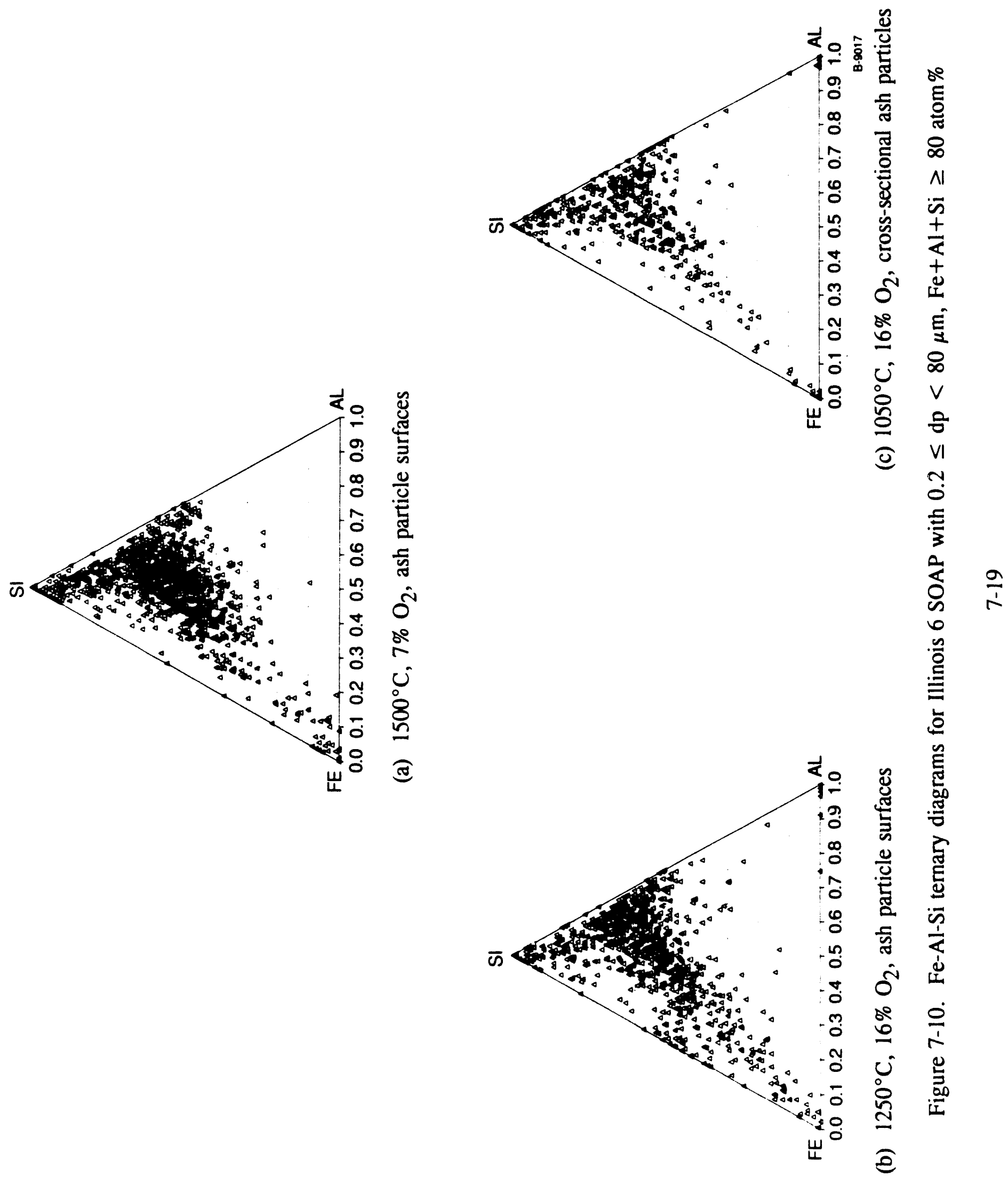

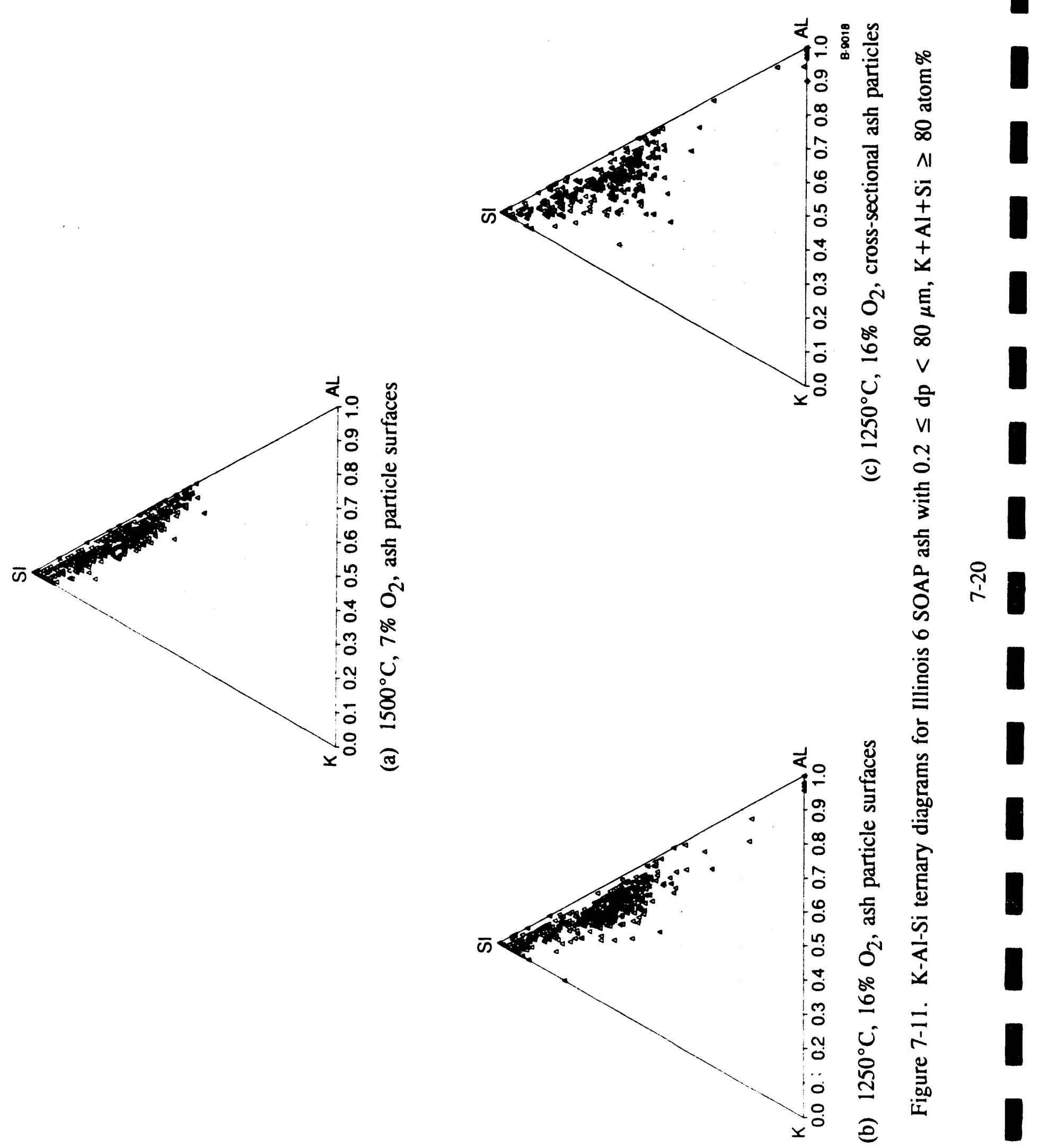

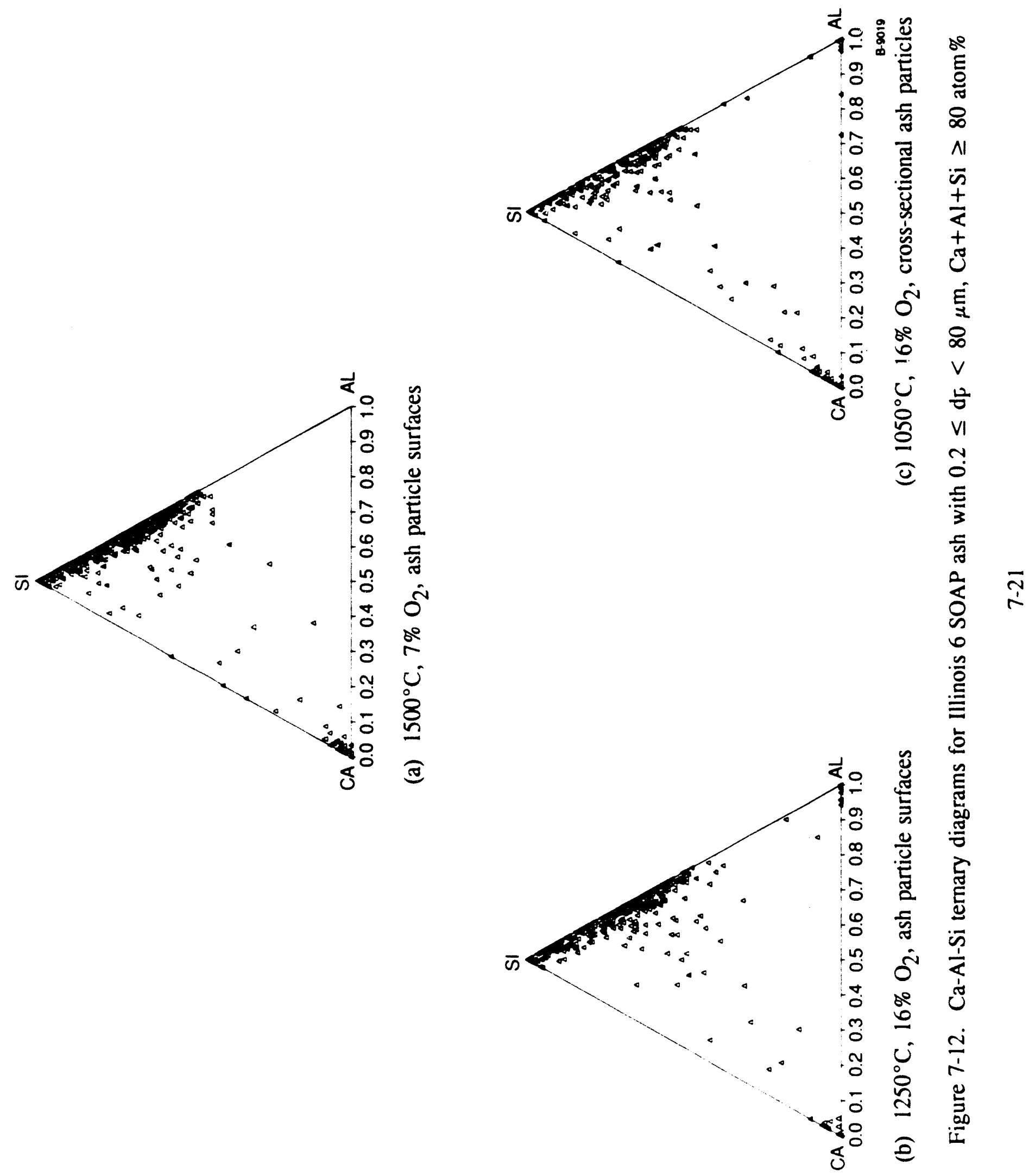
Figure 7-13. The chemical composition of three of these deposits, determined by SEMPC at UNDEERC, is given in Table 7-12. Iron concentrations were greatest in the deposit collected at the highest temperature, perhaps reflecting the increased iron-aluminosilicate interaction observed under those conditions.

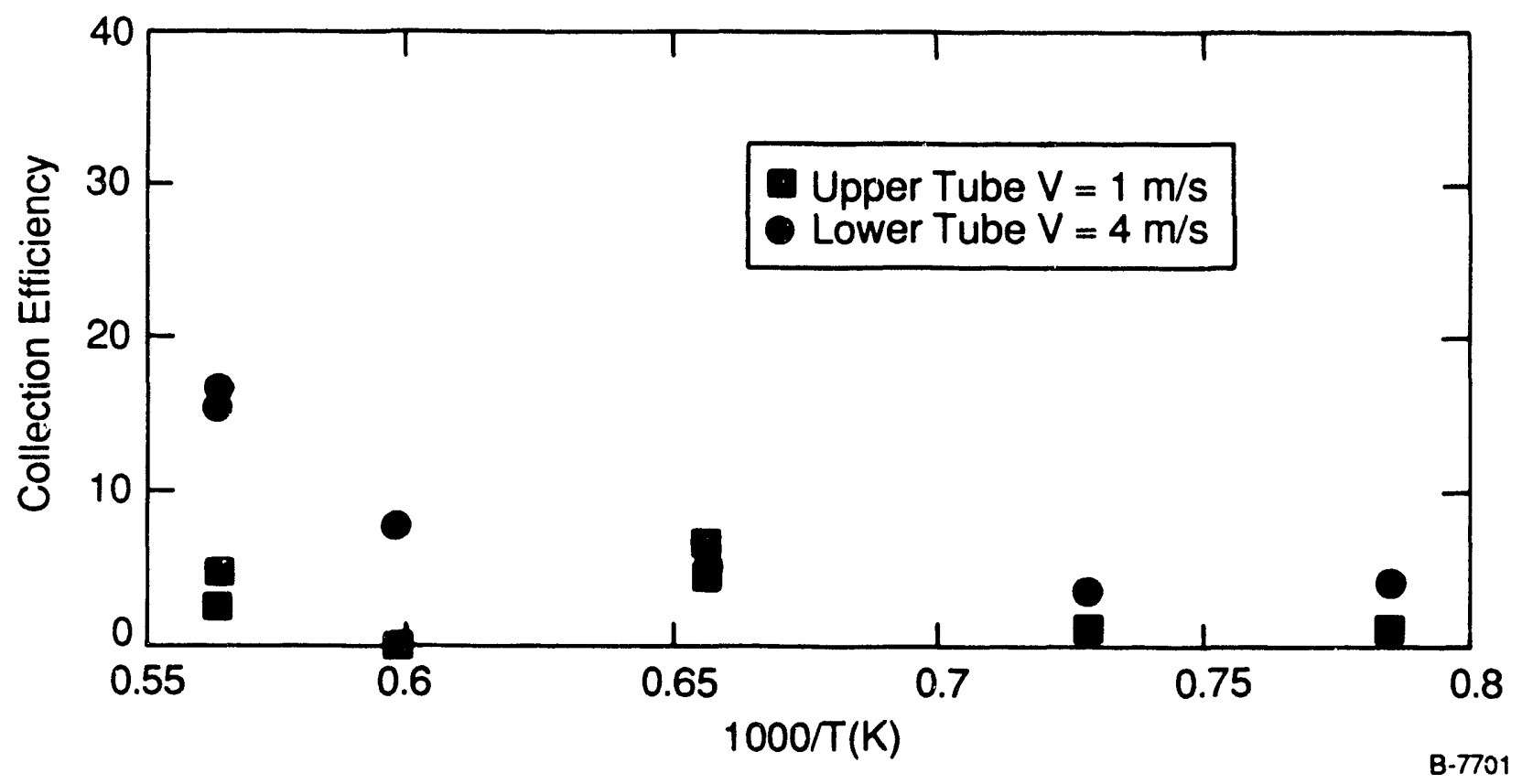

Figure 7-13. Collection efficiency, Illinois \#6 SOAP

Table 7-12. SOAP Deposit Composition by SEMPC

\begin{tabular}{|cc|c|c|c|c|c|c|c|c|}
\hline Combustion & Conditions & $\mathrm{SiO}_{2}$ & $\mathrm{Al}_{2} \mathrm{O}_{3}$ & $\mathrm{Fe}_{2} \mathrm{O}_{3}$ & $\mathrm{TiO}_{2}$ & $\mathrm{CaO}$ & $\mathrm{MgO}$ & $\mathrm{Na}_{2} \mathrm{O}$ & $\mathrm{K}_{2} \mathrm{O}$ \\
\hline \hline $1500^{\circ} \mathrm{C}$ & $7 \% \mathrm{O}_{2}$ & 34.8 & 20.0 & 36.5 & 2.2 & 1.7 & 0.7 & 0.6 & 3.3 \\
$1400^{\circ} \mathrm{C}$ & $10 \% \mathrm{O}_{2}$ & 45.3 & 20.4 & 23.7 & 2.0 & 2.7 & 1.1 & 0.6 & 4.1 \\
$1250^{\circ} \mathrm{C}$ & $16 \% \mathrm{O}_{2}$ & 46.8 & 20.3 & 21.4 & 2.4 & 3.6 & 1.4 & 0.7 & 3.2 \\
\hline
\end{tabular}




\subsection{Combustion Testing of Loy Yang 1953}

Results of PSIT combustion testing of the Loy Yang 1953 obtained from the State Electricity Commission of Victoria have been reported previously (PSI Technology Co., 1991). Recently obtained SEMPC analysis of the deposits resulting from stickiness testing of this coal are presented in Table 7-13. Iron levels are higher at the higher temperature, while the alkaline earth oxides comprise a greater percentage of the deposit at $1300^{\circ} \mathrm{C}$.

Table 7-13. Loy Yang 1953 Deposit Composition by SEMPC

\begin{tabular}{|cc|c|c|c|c|c|c|c|c|}
\hline Combustion & Conditions & $\mathrm{SiO}_{2}$ & $\mathrm{Al}_{2} \mathrm{O}_{3}$ & $\mathrm{Fe}_{2} \mathrm{O}_{3}$ & $\mathrm{TiO}_{2}$ & $\mathrm{CaO}$ & $\mathrm{MgO}$ & $\mathrm{Na}_{2} \mathrm{O}$ & $\mathrm{K}_{2} \mathrm{O}$ \\
\hline \hline $1500^{\circ} \mathrm{C}$ & $7 \% \mathrm{O}_{2}$ & 38.7 & 22.9 & 24.2 & 0.5 & 1.6 & 8.6 & 1.1 & 2.2 \\
$1300^{\circ} \mathrm{C}$ & $12 \% \mathrm{O}_{2}$ & 39.7 & 25.3 & 8.2 & 1.0 & 5.3 & 16.8 & 1.5 & 2.0 \\
\hline
\end{tabular}

\subsection{Arizona Testing}

Prior to conducting pilot-scale combustion testing at SECV, PSIT conducted a joint testing program with the University of Arizona at the UA $3 \mathrm{~kg} / \mathrm{hr}$ self-sustained reactor to assess operation of the PCSV-P in-situ measuring device. Experiments were conducted with several coals previously examined at PSIT and UA to permit comparison of the PCSV-P data with that measured by other sizing techniques. Some discussion of the results of the joint PSIT/UA program has been provided in Section 6 of this report; a general overview of the tests and a more detailed discussion of the PCSV-P results follows.

\subsubsection{Overview of Test Program}

The objectives of the joint PSIT/UA test program were as follows:

1) Examine the effects of combustion scale and combustion temperature on ash particle size distributions (PSD's) in the University of Arizona's (UA) 3.0 kilogram per hour reactor.

2) Obtain in-situ measurements of ash PDS's with the Insitec particle counter sizer velocimeter probe (PCSV-P).

3) Obtain extractive samples with UA's isokinetic sampling probe for both cascade impactor measurements and CCSEM measurements and compare these results to the PCSV-P data.

4) Obtain extractive ash samples for Computer Controlled Scanning Electron Microscopy (CCSEM) and Auger Analysis (AA). 
Four coals were tested, Illinois \#6 and Beulah Lignite, Loy Yang 2301 and Loy Yang 1953 obtained from the State Electricity Commission of Victoria, Australia. Measurements and samples taken included PCSV-P particle size, concentration, and velocity measurements, cascade impactor measurements, furnace temperature profiles, samples for CCSEM analysis, and continuous monitoring of $\mathrm{CO}, \mathrm{CO}_{2}$, total $\mathrm{NO}_{\mathrm{x}}$, and $\mathrm{O}_{2}$ concentrations. PSIT was responsible for the PCSV-P measurements while UA was responsible for the operation of the reactor and all extractive samples. The CCSEM analysis is being performed by the University of Kentucky. UA is conducting Auger analysis on the extractive samples.

A sketch of the UA reactor appears in Figure 7-14 along with labels showing where the sampling and the measurements took place.

Testing was scheduled so that coal was burned every other day. On the days between the coal runs, the reactor was run on gas to "clean off" any residual ash. A brief discussion of the results follows on a coal by coal basis.

\subsubsection{Illinois \# 6 (Parent)}

Testing of the Illinois \#6 coal was conducted at a nominal feed rate of $1.3 \mathrm{~kg} / \mathrm{hr}$ corresponding to a peak flame temperature of $1573 \mathrm{~K}$. Measurements made with the PCSV-P appear in Figure 7-15. Each curve in the figure represents a separate run, plotted as a cumulative mass distribution. For particles greater than 10 microns there was a large discrepancy from run to run. This was attributed to the high carbon content of the ash. Analysis showed a carbon content of approximately 27 percent.

\section{Beulah Lignite}

Two loads were examined in combustion testing of the Beulah lignite coal. The low load PCSV-P measurements appear in Figure 7-16. The conditions for the low load were a peak flame temperature of $1430 \mathrm{~K}$ and a feed rate of $1.6 \mathrm{~kg} / \mathrm{hr}$. Good agreement from run to run was achieved, with most of the variability taking place in the larger sized particles. The high load PCSV-P measurements appear in Figure 7-17. In these runs, the peak flame temperature was $1520 \mathrm{~K}$ and the feed rate was $2.8 \mathrm{~kg} / \mathrm{hr}$. Again, there was good agreement with only minor differences occurring with the measurement of particles greater than 20 microns. The carbon content of the ash was 6.5 percent, considerably lower than that of the Illinois \#6.

\section{Loy Yang 2301}

Loy Yang 2301 is an Australian coal that was studied in Phase I of this program as a collaborative effort between PSIT and the State Electricity Commission of Victoria (SECV). The coal contains 0.34 percent sodium and 1.5 percent ash. Quartz makes up 9.4 percent of the ash. The sodium to quartz "ratio" is 2.4 (ratio defined as $0.34 /(0.094 \times 1.5)$ ). 


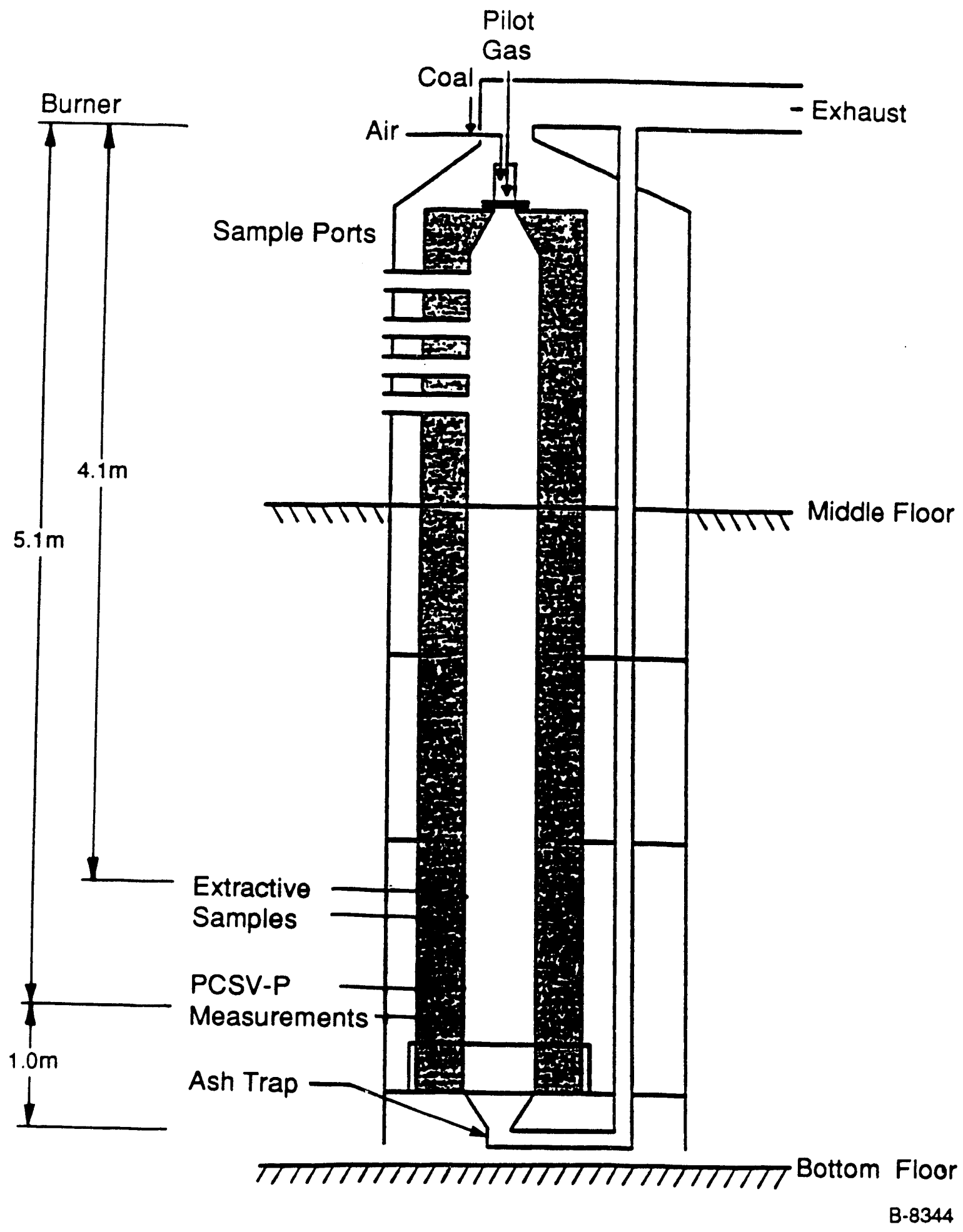

Figure 7-14. UA laboratory combustor 


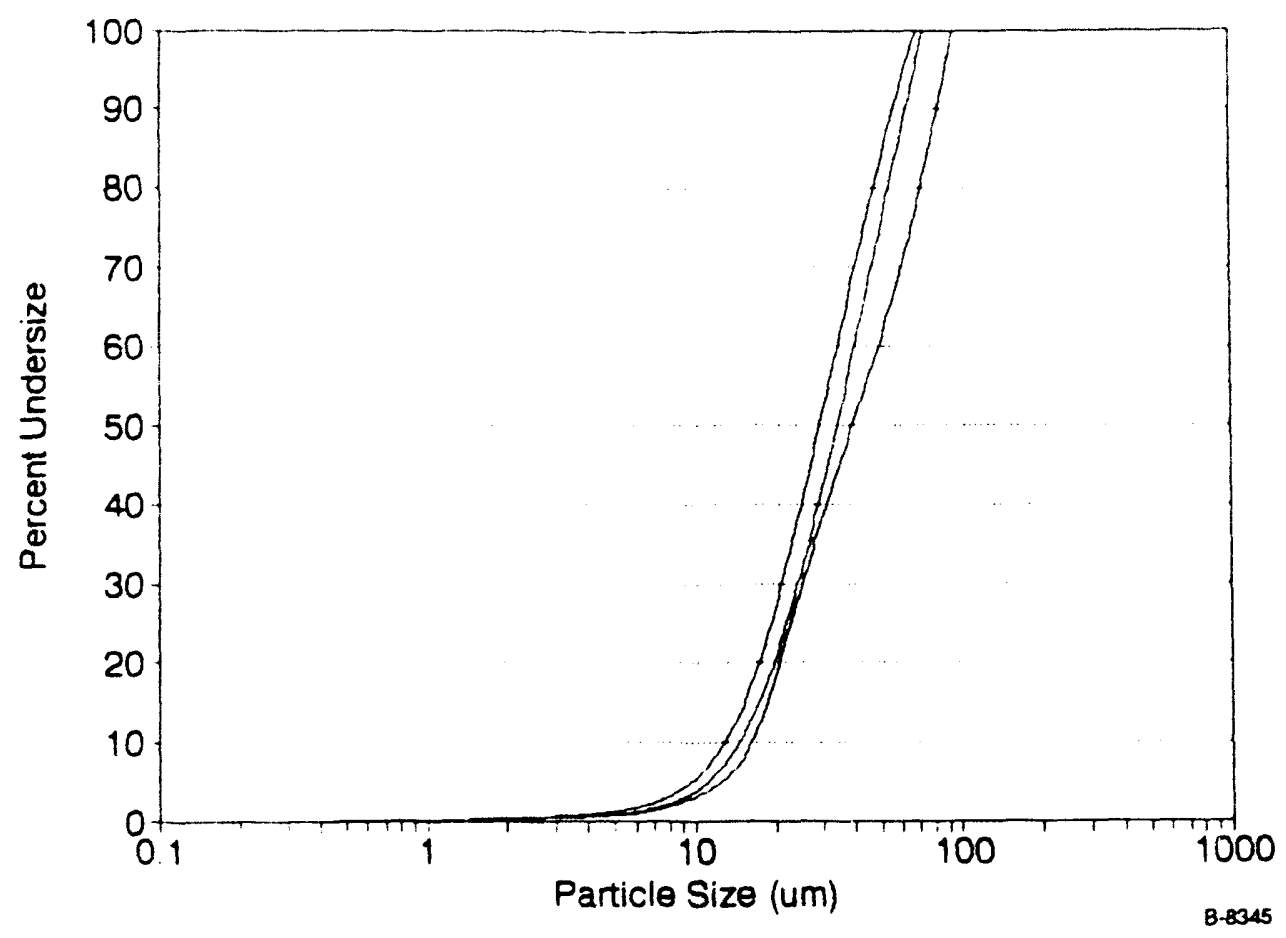

Figure 7-15. Illinois \#6 parent cumulative mass distributions

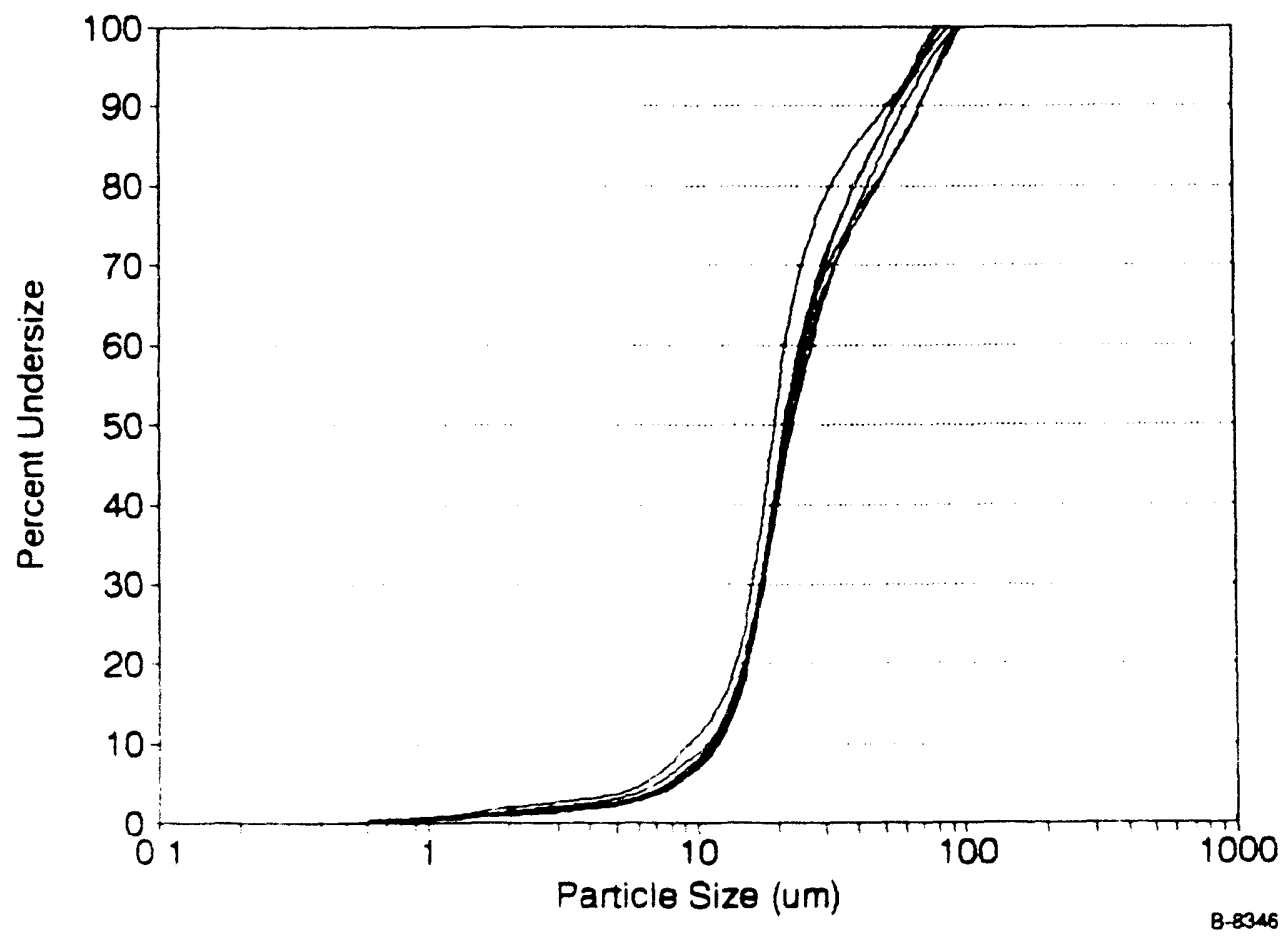

Figure 7-16. Beulah lignite cumulative mass distribution (low load) 


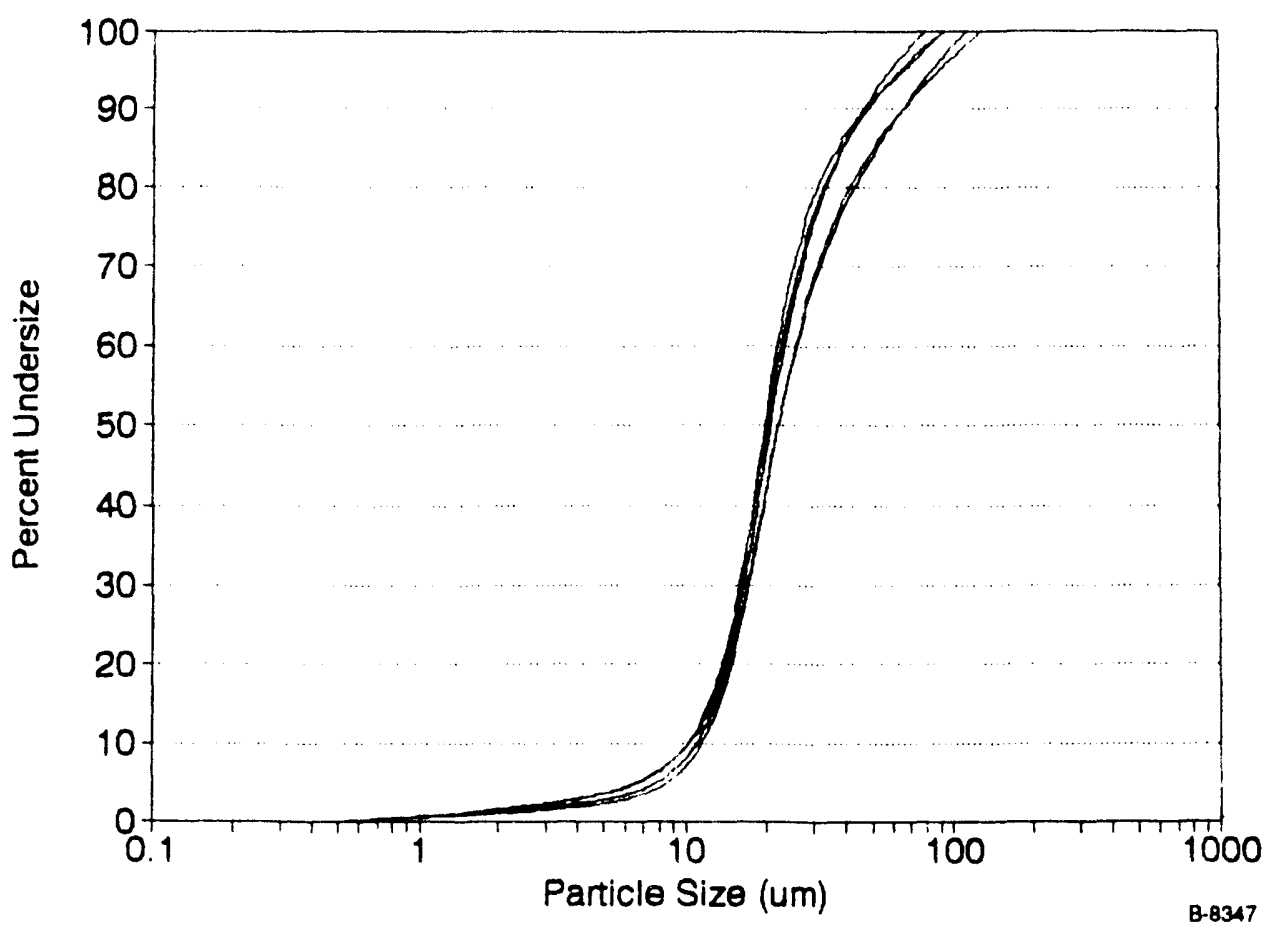

Figure 7-17. Beulah lignite cumulative mass distributions (high load)

This coal was also run at two feed rates. The PCSV-P measurements for the low load appear in Figure 7-18. The conditions for the low load were, a peak flame temperature of $1550 \mathrm{~K}$ and a feed rate of $1.8 \mathrm{~kg} / \mathrm{hr}$. There was good agreement between runs. The large particle measurements were very close to each other. Figure 7-19 shows the high load measurements. The high load measurements were in close agreement as well. The conditions for this load were a peak flame temperature of $1693 \mathrm{~K}$ and a feed rate of $2.7 \mathrm{~kg} / \mathrm{hr}$. Carbon content of the ash trap sample was 9 percent, so there was a moderate amount of unburned carbon. The ash trap sample was a combination of both loads.

\section{Loy Yang 1953}

Loy Yang 1953 is similar to Loy Yang 2301 in sodium content and ash content. This coal contains 0.32 percent sodium and has 2.0 percent ash. The difference occurs in the sodium to quartz ratio. The ash for this coal contains 11.8 percent quartz and the "ratio" of sodium to quartz is 1.4 .

The peak flame temperature for these tests was $1430 \mathrm{~K}$ and the feed rate was $2.5 \mathrm{~kg} / \mathrm{hr}$. The PCSV-P measurements appear in Figure 7-20. The agreement is very reasonable with three of the six runs almost a direct overlay of each other. The carbon content of the ash was 17 percent. This is high but it may be a result of the high moisture delaying ignition in the reactor. (Because of time constraints, the coal was air dried for 1 day only, rather than the typical three.) 


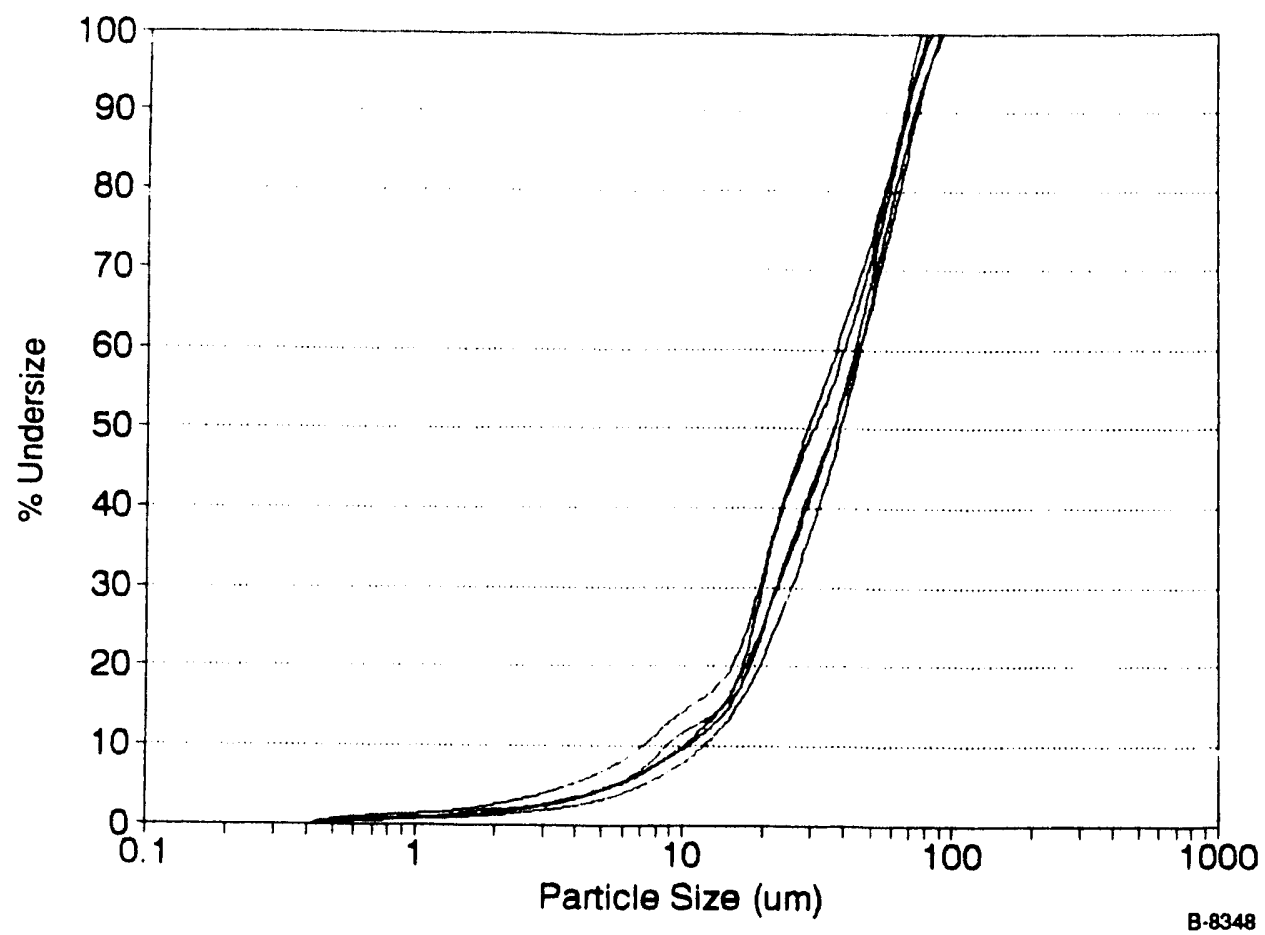

Figure 7-18. Loy Yang 2301 Low Load Cumulative Mass Distributions

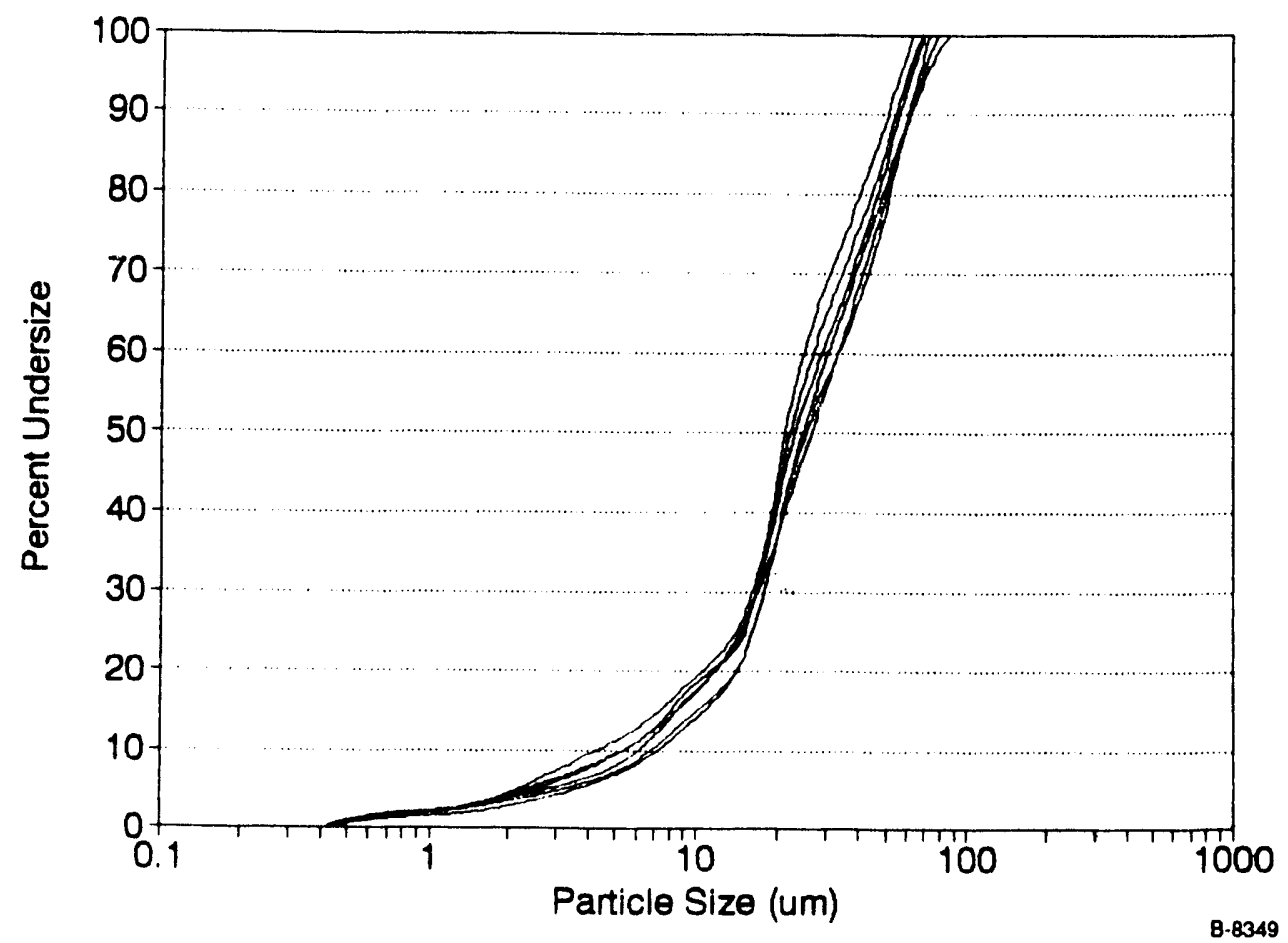

Figure 7-19. Loy Yang 2301 High Load Cumulative Mass Distributions 


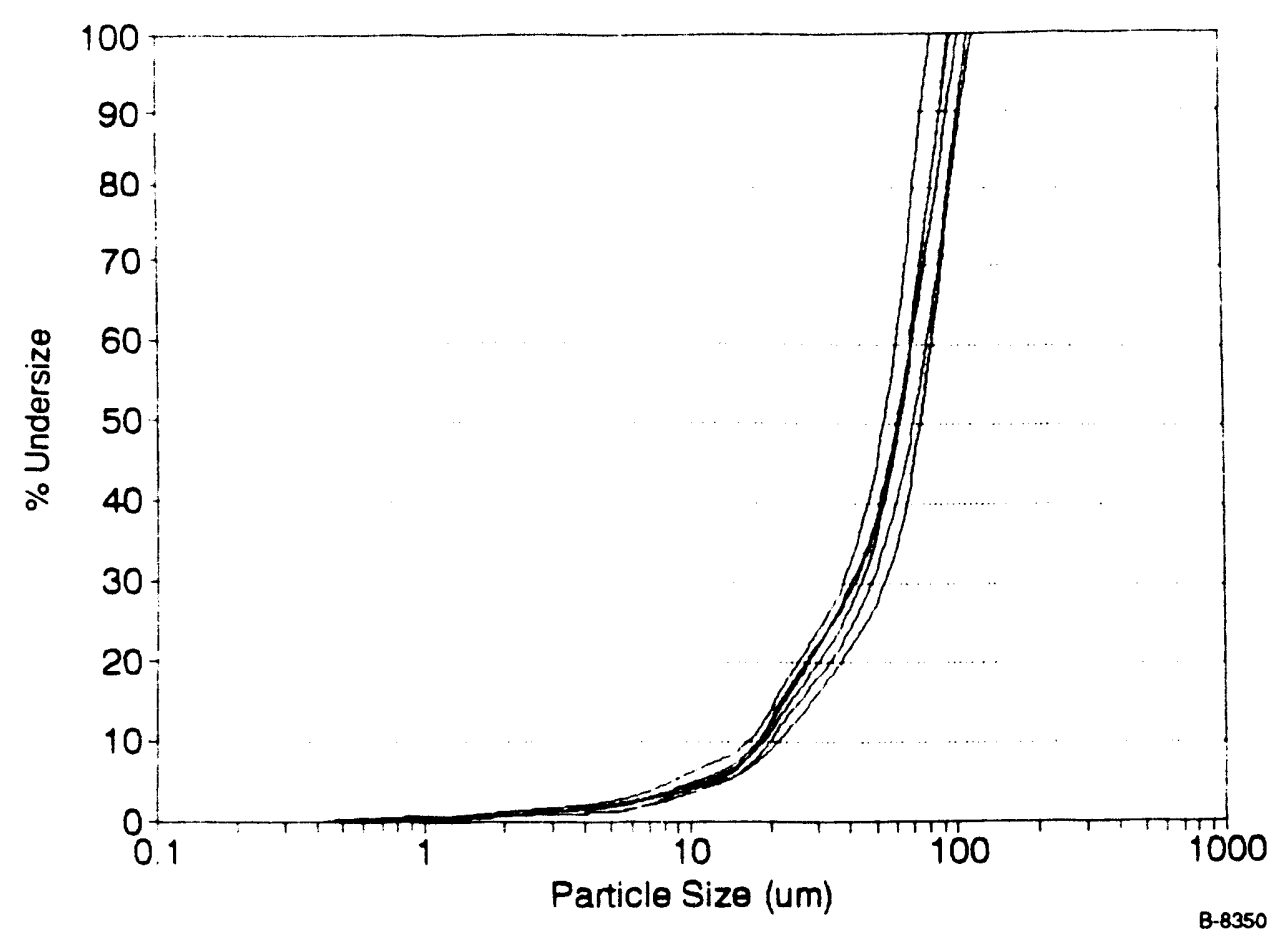

Figure 7-20. Loy Yang 1953 cumulative mass

\subsubsection{Temperature Comparisons}

A comparison of particle size distributions for Beulah Lignite at two different temperatures (loads) appears in Figures 7-21 and 7-22. The increase in particle number in the 2 to $10 \mu \mathrm{m}$ size range at higher temperature shown in the differential plot of Figure 7-21 leads to the differences in cumulative mass distribution observed in Figure 7-22. This trend is qualitatively consistent with that observed on PSIT samples by CCSEM - decreasing cumulative ash PSD with increasing combustion temperature (PSI Technology Co., 1990b).

For Loy Yang 2301, there was a definite shift towards smaller sized particles with an increase in temperature as seen in Figure 7-23. The temperature increase was approximately $150^{\circ} \mathrm{C}$. Recent analysis of the ash trap from the Loy Yang 2301 burn has shown a carbon content of approximately 9 percent. The different PSD's may also be due to a change in carbon burnout. Unfortunately, the ash trap sample is from both the high and low loads, and the carbon content of each separate load is not known. completed.

Further comparison shall be made once CCSEM analysis of the ash samples is 


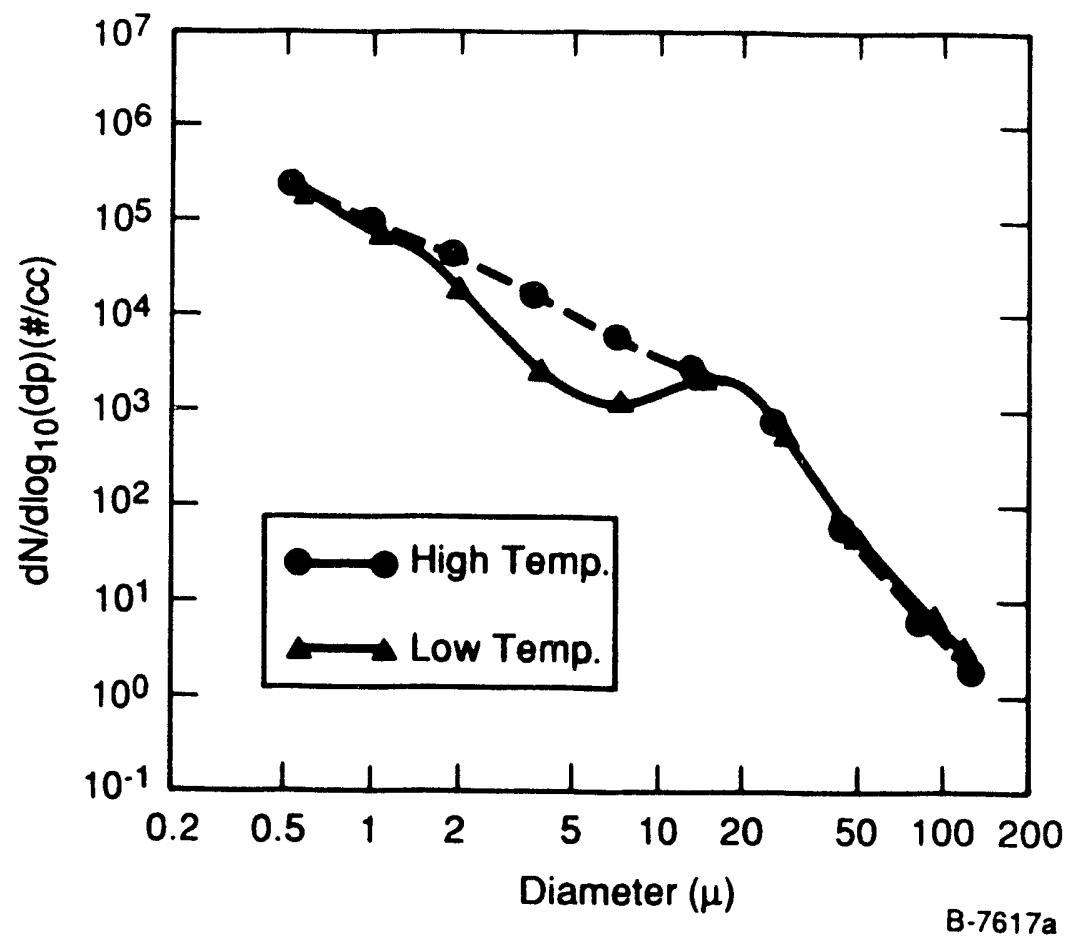

Figure 7-21. Differential Beulah Lignite ash particle size distributions (number basis) measured in-situ at the University of Arizona

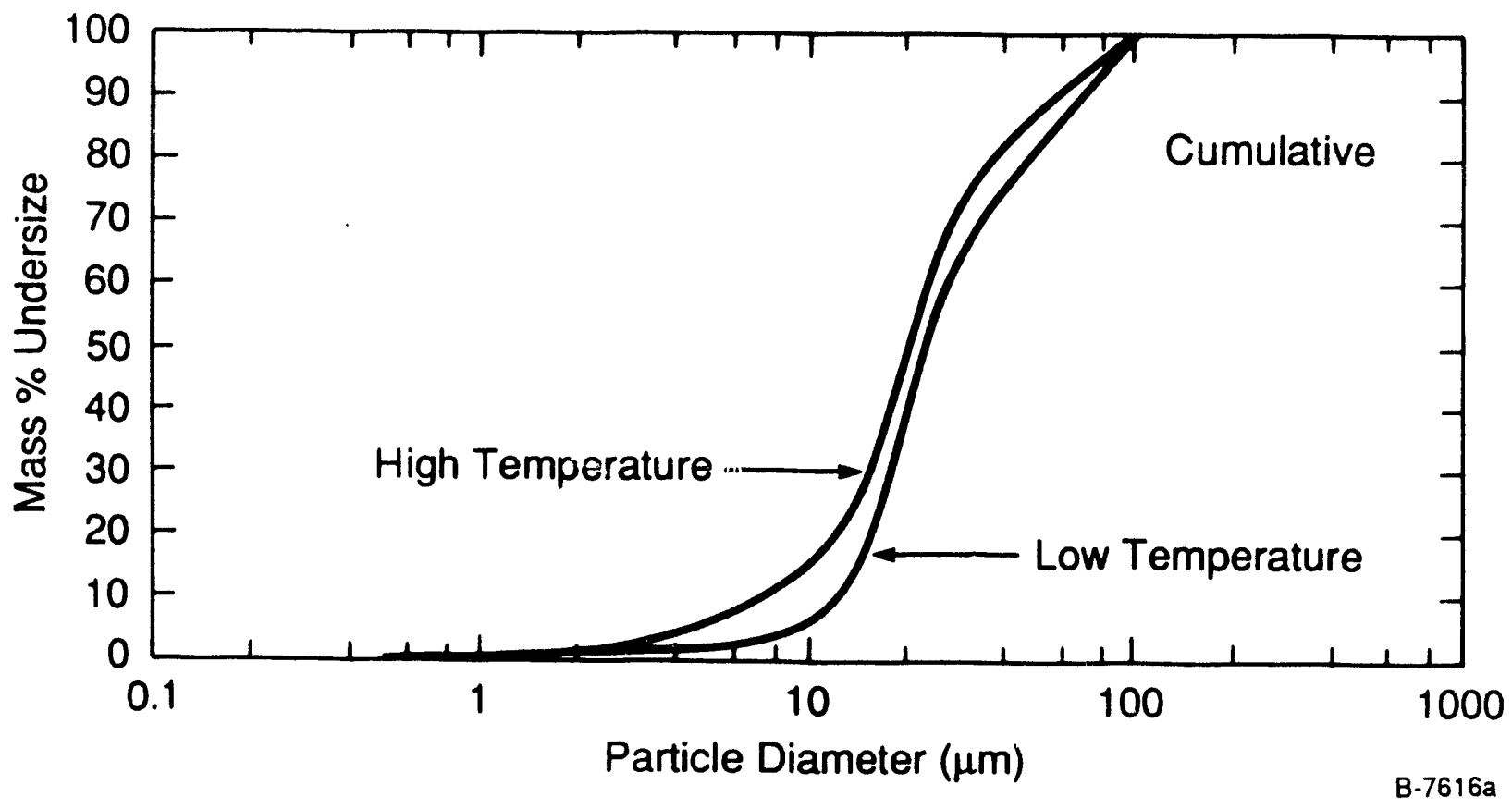

Figure 7-22. Cumulative ash PSD's (mass basis) measured in-situ at University of Arizona. Constant ash density assumed. 


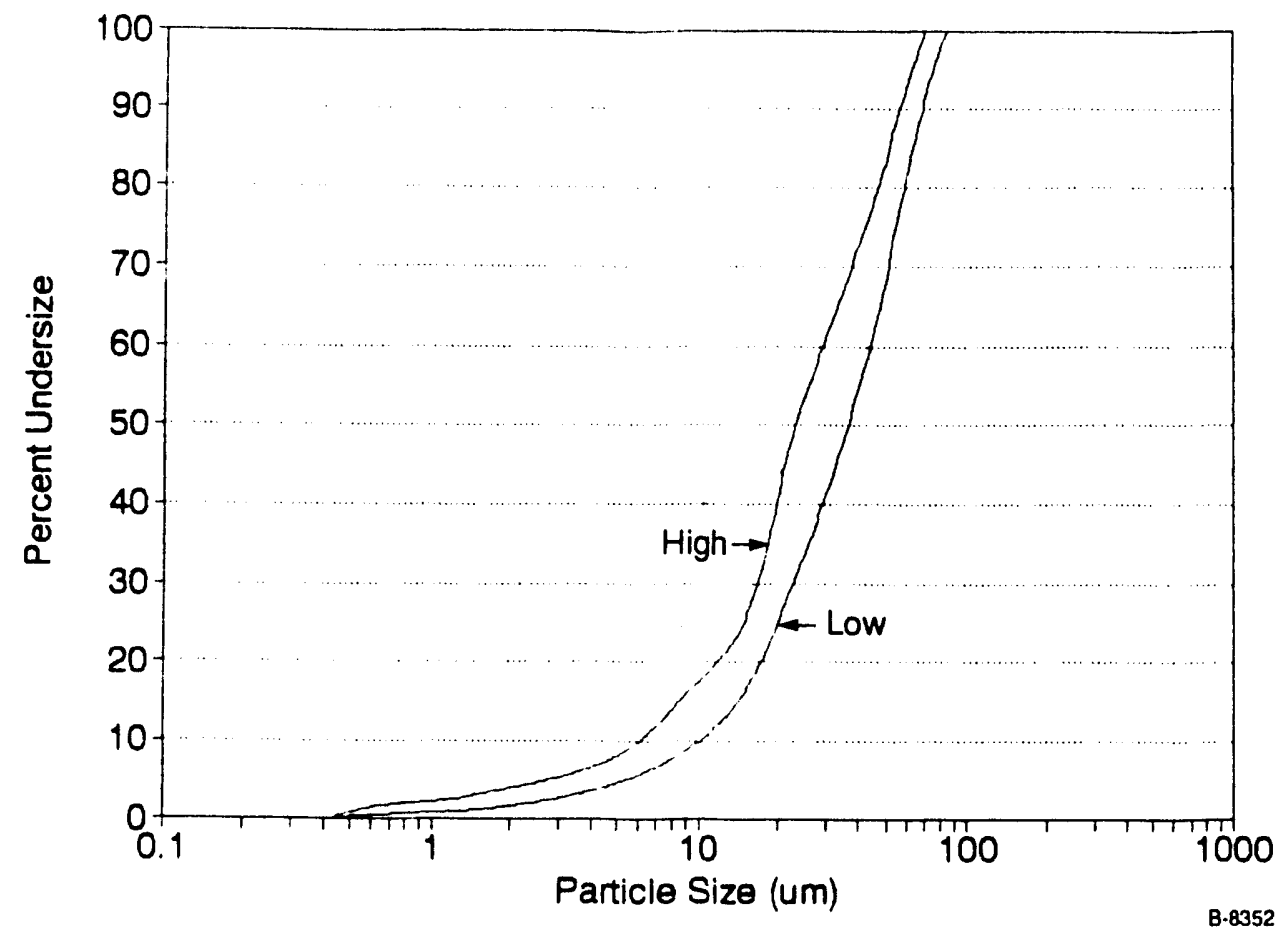

Figure 7-23. Loy Yang 2301 load ccinparison

\subsection{Joint PSIT/SECV Pilot-Scale Testing}

Under the auspices of an IEA Implementing Agreement on Coal Combustion Sciences (Annex I), PSIT conducted a joint testing program with the Herman Research Laboratories of the State Electricity Commission of Victoria (SECV), Australia, at the SECV $35 \mathrm{~kg} / \mathrm{hr}$ pilotscale combustion test facility. Experiments were conducted with Beulah lignite provided by this program, Loy Yang 1953, and Loy Yang 1953 treated with an $\mathrm{Mg}(\mathrm{OH})_{2} / \mathrm{MgCO}_{3}$ mixture and water-soluble $\mathrm{Al}_{2}\left(\mathrm{SO}_{4}\right)_{3}$ to reduce sodium levels (washing), produce refractory phases, and minimize fouling. Measurements/samples included complete coal characterization, reactor temperature profiles, $30 \mathrm{~min}$ and $4 \mathrm{hr}$ uncooled deposition tests, $4 \mathrm{hr}$ cooled deposition tests (furnace zone), extractive ash sampling, fouling test bank sampling, cascade impactor measurements, particle size/velocity/concentration measurements using the Insitec PCSV-P (by PSIT), and ESP ash hopper samples (size and chemical composition). A discussion of the initial results of these tests follows. A significant amount of analytical work is still ongoing at SECV and at PSIT (i.e., CCSEM and XAFS at the University of Kentucky) and will be reported as it becomes available in the coming months.

\subsubsection{Background}

Collaboration between the SECV and PSIT in the area of ash formation and deposition during low-rank coal combustion has been on-going for several years. Initially coals were exchanged, with SECV providing PSIT with a sample of high sodium, low silica Loy Yang 2301 for combustion testing, and PSIT in turn providing SECV with a sample of 
Beulah lignite. SECV then examined sodium evolution from the Beulah lignite in their electrothermal atomizer/atomic absorption apparatus, while the University of Kentucky examined the forms of chlorine in the Loy Yang (under a subcontract to PSIT) via XAFS spectroscopy. During a subsequent visit to PSIT, MIT, and CalTech by Dr. George Domazetis of SECV, results were exchanged. SECV also provided PSIT with a copy of their combustion furnace chemistry code SCCOFF during this visit. As a result of this interchange, a jointly authored manuscript was published in Progress in Energy and Combustion Science (Srinivasachar et.al., 1990). Subsequent to this visit, PSIT conducted the first in-situ measurements of alkali molecular species in a coal combustion environment, by measuring gas-phase $\mathrm{NaCl}$ levels via laser-induced photodissociation and fluorescence (LIPF), including the SECV Loy Yang 2301 coal as part of the test matrix.

The extensive interaction between PSIT and SECV has stemmed from their complementary activities in the area of low-rank coal combustion. PSIT and its subcontractors on this program - MIT, CalTech, University of Arizona, University of Kentucky, and Foster-Wheeler - possess considerable expertise in the areas of sodium evolution, sodium-ash and calcium-ash interactions, and the formation of sticky ash particles. SECV (as well as CSIRO and the University of Newcastle) possesses considerable expertise in understanding deposition of these species, and development of techniques to control deposition. In addition, the experimental facilities available to this program in the U.S. range from single particle reactors to $2 \mathrm{~kg} / \mathrm{hr}$ furnaces, while the SECV facility is a pilotscale $35 \mathrm{~kg} / \mathrm{hr}$ reactor. Continued collaboration, as implemented via an IEA Annex I agreement, provides PSIT with access to larger scale facilities and a wealth of practical experience in successfully controlling deposition.

\subsubsection{Qverview of Test Program}

The specific objectives of these tests were as follows:

1. continue the examination of the effects of combustor parameters ("combustion scale") on ash formation processes, by examining the Beulah lignite coal from this program in the SECV $35 \mathrm{~kg} / \mathrm{hr}$ facility $(\approx 1 \mathrm{MM} \mathrm{Btu} / \mathrm{hr})$ shown in Figure 7-24 and described in Table 7-14. SECV provided the test facilities and crew as part of the IEA Annex I Agreement.

2. obtain in-situ ash particle size distribution (PSD) measurements with the Insitec PCSV-P for comparison to PSD's obtained from measurement of extracted samples.

3. examine effects of refractory coal additive - soluble Al - on deposition.

4. examine deposit initiation for comparison with PSIT lab tests and study deposit buildup and growth (4 hr experiment). 


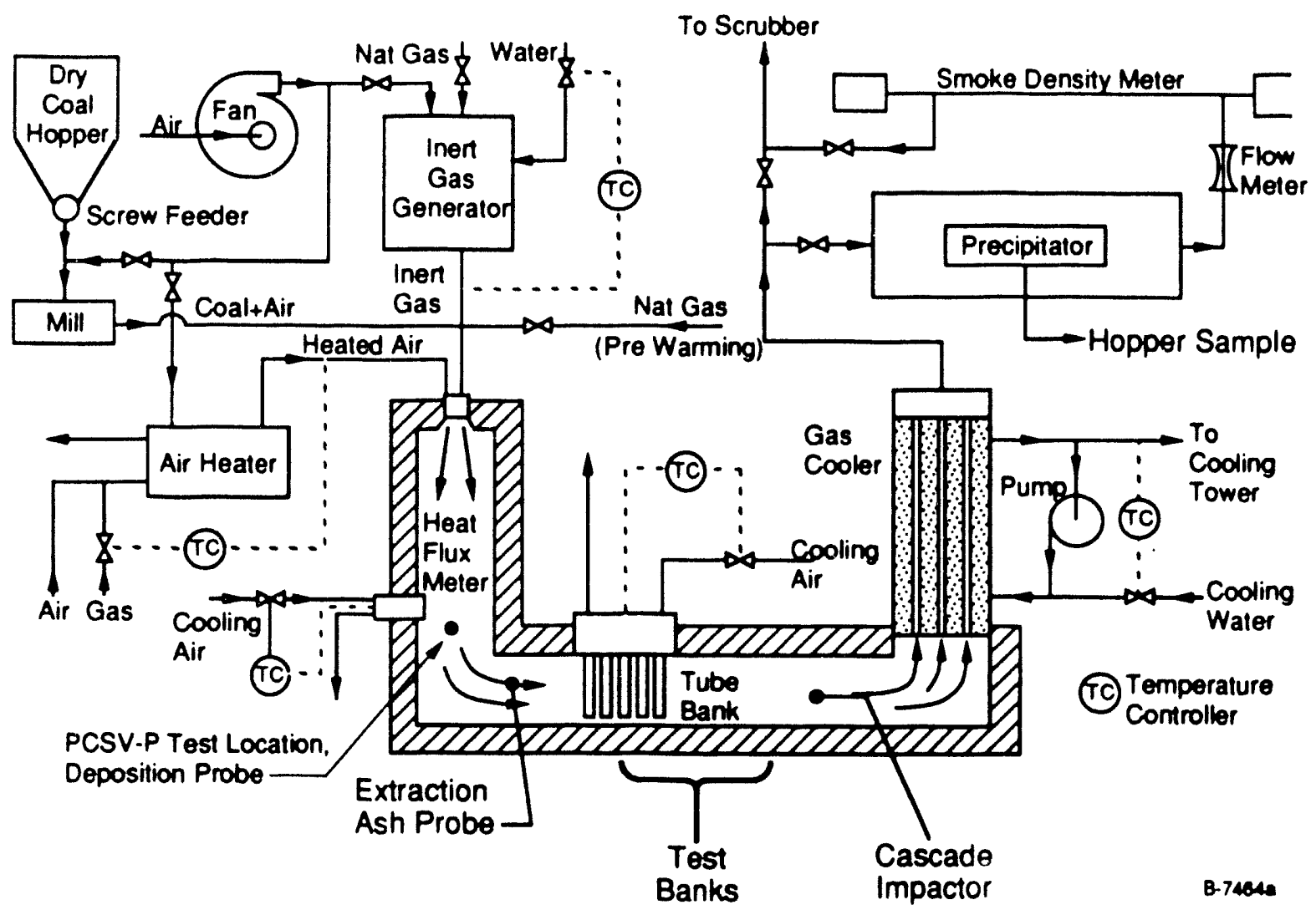

Figure 7-24. Schematic of SECV furnace showing sampling locations

Table 7-14. Operating Parameter Ranges for the SECV $35 \mathrm{~kg} / \mathrm{hr}$ Furnace

\begin{tabular}{|l|c|c|}
\hline \multicolumn{1}{|c|}{ Factor } & Limits & Typical \\
\hline \hline a) Coal feed rate at $15 \%$ moisture & 2 to $60 \mathrm{~kg} / \mathrm{hr}$ & $35 \mathrm{~kg} / \mathrm{hr}$ \\
b) Excess air at $35 \mathrm{~kg} / \mathrm{hr}$ coal & 0 to $100 \%$ & 2 to $100 \%$ \\
c) Water addition at flame & 0 to $70 \mathrm{~kg} / \mathrm{hr}$ & - \\
d) Steam addition to secondary air & 0 to $35 \mathrm{~kg} / \mathrm{hr}$ & - \\
e) Peak flame temperature & - & $1150^{\circ}$ to $1350^{\circ} \mathrm{C}$ \\
f) Coal particle size - medial & 10 to $200 \mu \mathrm{m}$ & \\
g) Tunnel gas temperature & $850^{\circ}$ to $1300^{\circ} \mathrm{C}$ & \\
h) Tube bank metal temperature & $350^{\circ}$ to $850^{\circ} \mathrm{C}$ & \\
i) Velocity in tunnel & 0.4 to $1.25 \mathrm{~m} / \mathrm{s}$ & \\
j) Combustion chamber diameter & $60 \mathrm{~cm}$ & \\
k) Test section diameter & $22.5 \mathrm{~cm}$ & \\
\hline
\end{tabular}


As mentioned above, tests were conducted with natural gas (as a background check), PSIT Beulah lignite, Loy Yang 1953, and Loy Yang 1953 treated with an $\mathrm{Mg}(\mathrm{OH})_{2} / \mathrm{MgCO}_{3}$ mixture and water-soluble $\mathrm{Al}_{2}\left(\mathrm{SO}_{4}\right)_{3}$ to reduce sodium levels, produce refractory phases, and minimize fouling. Proximate and ultimate analysis of the treated Loy Yang 1953 is presented in Table 7-15; confirmation of these results plus analysis of the other two coals is pending at SECV. The ash level of 3.5 percent is slightly greater than the 2.7 percent reported for the Loy Yang 1953 sample tested at SECV as a result of the additive treatment. Note that the Loy Yang 1953 sample provided to PSIT was 2.0 percent ash by weight, asreceived basis (PSI Technology Co., 1991). Coal particle size distributions for the three coal samples, as analyzed via Malvern (in ethanol) at UNDEERC, are presented in Tables 7-16 through 7-18. As the tables indicate, the Loy Yang coal was slightly coarser than either the treated Loy Yang or the Beulah. All, however, were approximately "utility grind," i.e., $70 \%<75 \mu \mathrm{m}$ : Beulah, $70 \%<86 \mu \mathrm{m}$; Loy Yang, $70 \%<105 \mu \mathrm{m}$; treated Loy Yang, $70 \%<75 \mu \mathrm{m}$.

Table 7-15. Analysis of Treated Loy Yang 1953

\begin{tabular}{|l|c|c|c|}
\hline & $\begin{array}{c}\text { As Received } \\
(\%)\end{array}$ & $\begin{array}{c}\text { Moist Free } \\
(\%)\end{array}$ & $\begin{array}{c}\text { Moist/Ash Free } \\
(\%)\end{array}$ \\
\hline \hline Proximate analysis & 23.40 & N/A & N/A \\
Moisturs & 42.97 & 56.13 & 58.83 \\
Volatile matter & 30.10 & 39.27 & 41.16 \\
Fixed carbon (ind) & 3.52 & 4.60 & N/A \\
Ash & & & 4.19 \\
\hline Ultimate Analysis & 5.67 & 4.00 & 63.03 \\
Hydrogen & 46.04 & 60.13 & 0.54 \\
Carbon & 0.40 & 0.52 & 0.56 \\
Nitrogen & 0.41 & 0.54 & 31.65 \\
Sulfur & 43.95 & 30.19 & N/A \\
Oxygen (ind) & 3.52 & 4.60 & $3.06 \%$ \\
Ash & 7676 & & $23.12 \%$ \\
\hline Calc. calorific value & \multicolumn{2}{|c|}{} & \\
(Btu/hr) & As received hydrogen not including hydrogen from moisture: & \\
As received oxygen not including oxygen from moisture: & & \\
\hline
\end{tabular}


Table 7-16. Malvern Coal PSD - Beulah

\begin{tabular}{|c|c|c|c|c|c|}
\hline $\begin{array}{c}\text { Size } \\
\text { Microns }\end{array}$ & Under & $\%$ in Band & $\begin{array}{c}\text { Size } \\
\text { Microns }\end{array}$ & Under & $\%$ in Band \\
\hline 564.0 & 100.0 & 0.0 & 53.1 & 53.1 & 3.6 \\
\hline 487.0 & 100.0 & 0.0 & 45.8 & 49.5 & 3.7 \\
\hline 420.0 & 100.0 & 0.0 & 39.5 & 45.8 & 4.4 \\
\hline 362.0 & 100.0 & 0.0 & 34.1 & 41.5 & 4.5 \\
\hline 312.0 & 100.0 & 0.0 & 29.4 & 37.0 & 3.7 \\
\hline 270.0 & 100.0 & 0.3 & 25.4 & 33.3 & 3.1 \\
\hline 233.0 & 99.6 & 1.5 & 21.9 & 30.2 & 2.8 \\
\hline 201.0 & 98.2 & 3.0 & 18.9 & 27.4 & 3.0 \\
\hline 173.0 & 95.1 & 4.9 & 16.3 & 24.3 & 3.3 \\
\hline 149.0 & 90.2 & 5.9 & 14.1 & 21.0 & 3.5 \\
\hline 129.0 & 84.3 & 6.0 & 12.1 & 17.5 & 2.5 \\
\hline 111.0 & 78.3 & 4.8 & 10.5 & 15.0 & 1.8 \\
\hline 95.9 & 73.5 & 5.0 & 9.0 & 13.2 & 1.5 \\
\hline 82.7 & 68.5 & 5.8 & 7.8 & 11.7 & 2.2 \\
\hline 71.4 & 52.8 & 5.4 & 6.7 & 9.5 & 2.8 \\
\hline 61.6 & 57.3 & 4.3 & 5.8 & 6.7 & \\
\hline Focal length & $=300 \mathrm{~mm}$ & & & & \\
\hline Beam length & $=14.3 \mathrm{~mm}$ & & & & \\
\hline Obscuration & $=0.3029$ & & & & \\
\hline Volume conc. & $=0.0165 \%$ & & & & \\
\hline $\begin{array}{l}\text { Log. diff. } \\
\text { Model indp }\end{array}$ & $=4.09$ & & & & \\
\hline$D(v, 0.5)$ & $=46.7 \mu \mathrm{m}$ & & & & \\
\hline$D(v, 0.9)$ & $=148.0 \mu \mathrm{m}$ & & & & \\
\hline $\mathrm{D}(\mathrm{v}, 0.1)$ & $=6.9 \mu \mathrm{m}$ & & & & \\
\hline $\mathrm{D}(4,3)$ & $=62.2 \mu \mathrm{m}$ & & & & \\
\hline $\mathrm{D}(3,2)$ & $=22.5 \mu \mathrm{m}$ & & & & \\
\hline Span & $=3.0$ & & & & \\
\hline
\end{tabular}


Table 7-17. Malvern Coal PSD - Loy Yang 1953

\begin{tabular}{|c|c|c|c|c|c|}
\hline $\begin{array}{c}\text { Size } \\
\text { Microns }\end{array}$ & Under & $\%$ in Band & $\begin{array}{c}\text { Size } \\
\text { Microns }\end{array}$ & Under & $\%$ in Band \\
\hline 564.0 & 100.0 & 0.0 & 53.1 & 45.1 & 4.1 \\
\hline 487.0 & 100.0 & 0.0 & 45.8 & 40.9 & 4.2 \\
\hline 420.0 & 99.9 & 0.0 & 39.5 & 36.7 & 4.6 \\
\hline 362.0 & 99.9 & 0.0 & 34.1 & 32.1 & 4.4 \\
\hline 312.0 & 99.9 & 0.0 & 29.4 & 27.7 & 3.6 \\
\hline 270.0 & 99.9 & 1.2 & 25.4 & 24.1 & 3.0 \\
\hline 233.0 & 98.7 & 3.8 & 21.9 & 21.1 & 2.6 \\
\hline 201.0 & 94.8 & 5.5 & 18.9 & 18.6 & 2.5 \\
\hline 173.0 & 89.4 & 5.9 & 10.3 & 16.0 & 2.5 \\
\hline 149.0 & 83.4 & 5.6 & 14.1 & 13.6 & 2.3 \\
\hline 129.0 & 77.8 & 5.7 & 12.1 & 11.2 & 1.6 \\
\hline 111.0 & 72.0 & 5.5 & 10.5 & 9.7 & 1.2 \\
\hline 95.9 & 66.5 & 5.7 & 9.0 & 8.5 & 1.2 \\
\hline 82.7 & 60.8 & 5.9 & 7.8 & 7.3 & 1.3 \\
\hline 71.4 & 55.0 & 5.4 & 5.7 & 6.0 & 1.9 \\
\hline 61.6 & 49.6 & 4.5 & 5.8 & 4.1 & \\
\hline Focal length & $=300 \mathrm{~mm}$ & & & & \\
\hline Beam length & $=14.3 \mathrm{~mm}$ & & & & \\
\hline Obscuration & $=0.3090$ & & & & \\
\hline Volume conc. & $=0.0224 \%$ & & & & \\
\hline Log. diff. & $=4.84$ & & & & \\
\hline Model indp & & & & & \\
\hline $\mathrm{D}(\mathrm{v}, 0.5)$ & $=62.2 \mu \mathrm{m}$ & & & & \\
\hline $\mathrm{D}(\mathrm{v}, 0.9)$ & $=175.4 \mu \mathrm{m}$ & & & & \\
\hline $\mathrm{D}(\mathrm{v}, 0.1)$ & $=10.8 \mu \mathrm{m}$ & & & & \\
\hline $\mathrm{D}(4,3)$ & $=76.4 \mu \mathrm{m}$ & & & & \\
\hline$D(3,2)$ & $=30.5 \mu \mathrm{m}$ & & & & \\
\hline Span & $=2.6$ & & & & \\
\hline
\end{tabular}


Table 7-18. Malvern Coal PSD - Treated LY 1953

\begin{tabular}{|c|c|c|c|c|c|}
\hline $\begin{array}{c}\text { Size } \\
\text { Microns }\end{array}$ & Under & $\%$ in Band & $\begin{array}{c}\text { Size } \\
\text { Microns }\end{array}$ & Under & $\%$ in Band \\
\hline 564.0 & 100.0 & 0.0 & 53.1 & 57.7 & 5.0 \\
\hline 487.0 & 100.0 & 0.0 & 45.8 & 52.6 & 5.0 \\
\hline 420.0 & 100.0 & 0.0 & 39.5 & 47.6 & 5.1 \\
\hline 362.0 & 99.9 & 0.0 & 34.1 & 42.5 & 4.8 \\
\hline 312.0 & 99.9 & 0.0 & 29.4 & 37.7 & 4.2 \\
\hline 270.0 & 99.9 & 0.7 & 25.4 & 33.5 & 3.8 \\
\hline 233.0 & 99.2 & 2.3 & 21.9 & 29.7 & 3.3 \\
\hline 201.0 & 96.9 & 3.3 & 18.9 & 26.4 & 3.0 \\
\hline 173.0 & 93.5 & 3.7 & 16.3 & 23.3 & 2.8 \\
\hline 149.0 & 89.9 & 3.6 & 14.1 & 20.5 & 2.8 \\
\hline 129.0 & 86.2 & 4.0 & 12.1 & 17.7 & 2.4 \\
\hline 111.0 & 82.3 & 4.2 & 10.5 & 15.3 & 2.3 \\
\hline 95.9 & 78.1 & 4.7 & 9.0 & 13.0 & 2.2 \\
\hline 82.7 & 73.4 & 5.2 & 7.8 & 10.7 & 2.6 \\
\hline 71.4 & 68.1 & 5.3 & 6.7 & 8.2 & 2.7 \\
\hline 61.6 & 62.8 & 5.1 & 5.8 & 5.5 & \\
\hline Focal length & \multirow{6}{*}{\multicolumn{5}{|c|}{$\begin{array}{l}=300 \mathrm{~mm} \\
=14.3 \mathrm{~mm} \\
=0.3984 \\
=0.0237 \% \\
=4.31\end{array}$}} \\
\hline Beam length & & & & & \\
\hline Obscuration & & & & & \\
\hline Volume cone. & & & & & \\
\hline Log. diff. & & & & & \\
\hline Model indp & & & & & \\
\hline $\mathrm{D}(\mathrm{v}, 0.5)$ & \multicolumn{5}{|l|}{$=42.3 \mu \mathrm{m}$} \\
\hline $\mathrm{D}(\mathrm{v}, 0.9)$ & \multicolumn{5}{|l|}{$=149.5 \mu \mathrm{m}$} \\
\hline $\mathrm{D}(\mathrm{v}, 0.1)$ & \multicolumn{5}{|l|}{$=7.4 \mu \mathrm{m}$} \\
\hline $\mathrm{D}(4,3)$ & \multicolumn{5}{|l|}{$=58.8 \mu \mathrm{m}$} \\
\hline $\mathrm{D}(3,2)$ & \multicolumn{5}{|l|}{$=22.8 \mu \mathrm{m}$} \\
\hline Span & \multicolumn{5}{|l|}{$=3.4$} \\
\hline
\end{tabular}




\subsubsection{Preliminary Ash Particle Size and Composition Results}

In general, the testing proceeded smoothly. Short term variations in coal feed rate from 25 to $50 \mathrm{~kg} / \mathrm{hr}$ (absolute) were occasionally observed, with corresponding changes in furnace exit gas temperature (FEGT) and exit oxygen levels (generally 5 to 7.5 percent). These variations were generally short-term, and often coincided with a person walking on the metal grate surrounding the coal feed hopper. Typically, feed rates were maintained at 35 to $40 \mathrm{~kg} / \mathrm{hr}$, with an FEGT of $900^{\circ}$ to $950^{\circ} \mathrm{C}$. These and other operating parameters are summarized in Table 7-19. Details of initial data analysis for each of these runs plus the natural gas background check follow.

Table 7-19. Furnace Parameters for SECV Coal Tests

\begin{tabular}{|l|c|c|c|}
\hline & Beulah & Loy Yang 1953 & $\begin{array}{c}\text { Loy Yang 1953, } \\
\text { Treated }\end{array}$ \\
\hline \hline $\begin{array}{l}\text { Furnace temperature } \\
\text { (ring 3) }\end{array}$ & $1080^{\circ}$ to $1115^{\circ} \mathrm{C}$ & $1090^{\circ}$ to $1130^{\circ} \mathrm{C}$ & $1075^{\circ}$ to $1125^{\circ} \mathrm{C}$ \\
Flame temperature $^{*}$ & $1300^{\circ} \mathrm{C}$ & $1250^{\circ} \mathrm{C}$ & $1160^{\circ} \mathrm{C}$ \\
Furnace exit temperature & $900^{\circ}$ to $950^{\circ} \mathrm{C}$ & $905^{\circ}$ to $950^{\circ} \mathrm{C}$ & $855^{\circ}$ to $900^{\circ} \mathrm{C}$ \\
Coal feed rate & 36 to $41 \mathrm{~kg} / \mathrm{hr}$ & 40 to $41 \mathrm{~kg} / \mathrm{hr}$ & 36 to $39 \mathrm{hg} / \mathrm{hr}$ \\
Furnace exit $\mathrm{O}_{2}$ & 7.1 to $8.8 \%$ & 5.5 to $7.3 \%$ & 5.6 to $9 \%$ \\
Test bank 3 temperature & $550^{\circ}$ to $600^{\circ} \mathrm{C}$ (est.) & $500^{\circ}$ to $550^{\circ} \mathrm{C}$ & $500^{\circ}$ to $550^{\circ} \mathrm{C}$ \\
\hline * Suction pyrometer measurement
\end{tabular}

\subsubsection{Natural Gas}

Because furnace walls are not cleaned between runs, there was some concern over residual particulate matter contributing to the observed ash particle size distribution measurements. Test burns using natural gas indicated that this was not a problem, as particle count rates detected by the PCSV-P were statistically insignificant.

\subsubsection{Beulah lignite}

Some difficulties in operating the PCSV-P were encountered during Beulah lignite combustion as a result of obscuration of probe optics. Nevertheless, several measurements on the furnace centerline, ring 7 (furnace exit region - see Figure 7-24) were made. Particle size distributions obtained during combustion of the Beulah at 36 to $41 \mathrm{~kg} / \mathrm{hr}$ feed rate, corresponding to a furnace temperature of $1080^{\circ}$ to $1115^{\circ} \mathrm{C}$ and furnace exit conditions of $900^{\circ}$ to $950^{\circ} \mathrm{C}$ and 7 to 9 percent oxygen, are shown in Figure 7-25. The median ash particle diameter for these experiments was approximately $15 \mu \mathrm{m}$, with 50 percent of the 


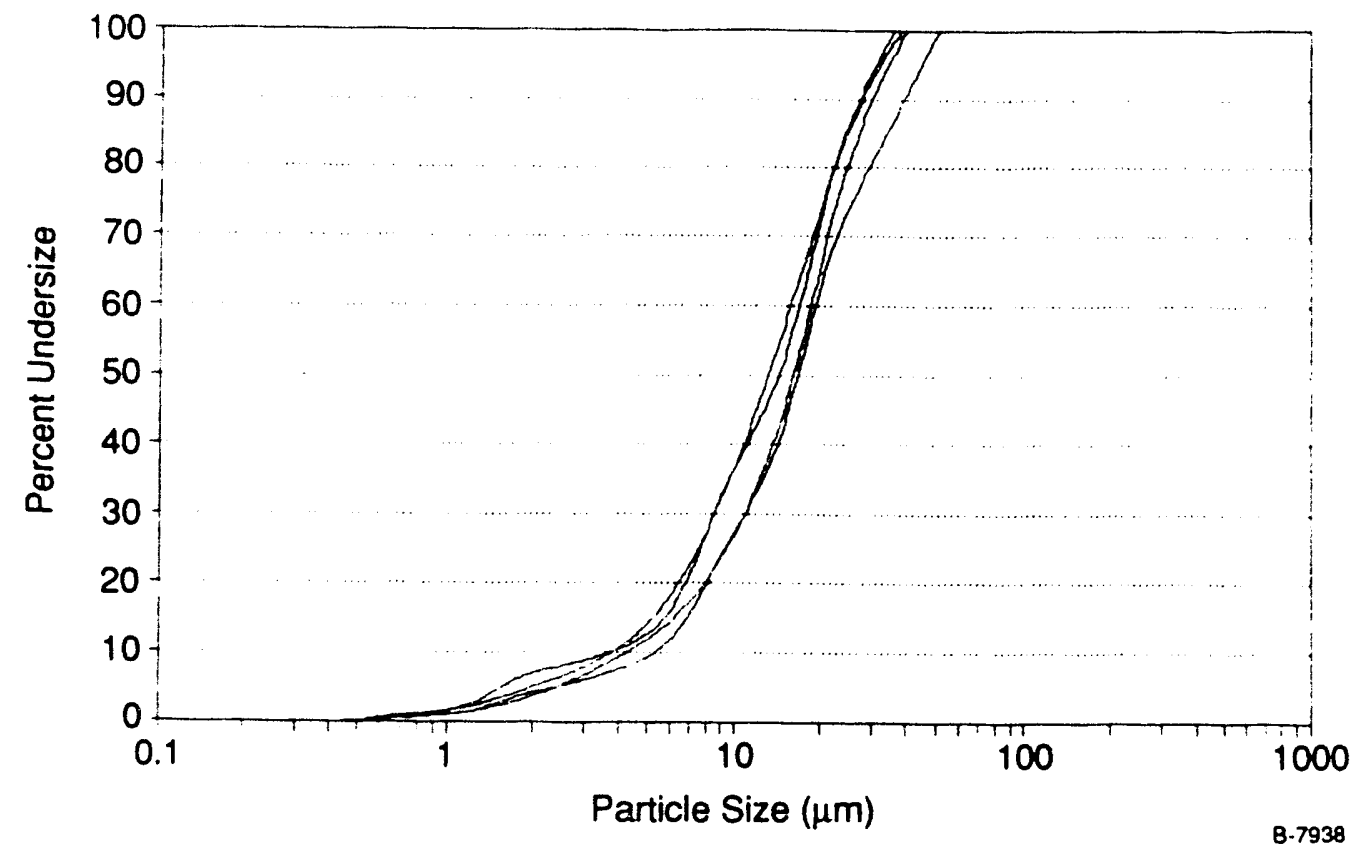

Figure 7-25. Beulah lignite ash PSD measured with the PCSV-P, ring 7 combustion chamber centerline

mass falling between 10 and $25 \mu \mathrm{m}$. This distribution was slightly smaller than the corresponding experiment conducted with this coal at the University of Arizona, where a median diameter of $20 \mu \mathrm{m}$ was observed. Differences in residual carbon levels in the ash may account for this discrepancy; this will be resolved pending analysis of the SECV ash samples. The University of Arizona (UA) results were also narrowly distributed, with 50 percent of the mass falling between approximately 15 and $25 \mu \mathrm{m}$ (Figure 7-17).

Examination of the chemical composition of the Beulah ash revealed composition ranges identical to those observed in smaller scale testing at PSIT and UA. As discussed in Section 4 of this report, aluminosilicates dominated the ash. The sodium aluminosilicate phase previously reported (PSI Technology Co., 1990a; Helble et.al., 1990) was again observed in samples obtained at SECV, as shown in Figure 7-26. Clearly this composition was not present in the coal initially (Figure 7-26a), but was formed during combustion at similar conditions at all facilities. This suggests that over the range of reactor sizes considered, reactor scale - i.e., particle mixing, oxygen profile (constant vs. decreasing), particle density, etc. - does not affect the chemical composition of the ash particles when combustion temperatures are comparable.

Calcium-rich silicates and aluminosilicates, however, were the dominant compositions observed in the ash, as discussed in Section 4 and seen in Figure 7-27. Calcium enrichment was observed in all particle size classes as shown in parts (b) and (c) of the figure. Similar trends and results were observed in prior testing of Beulah at PSIT and UA. 


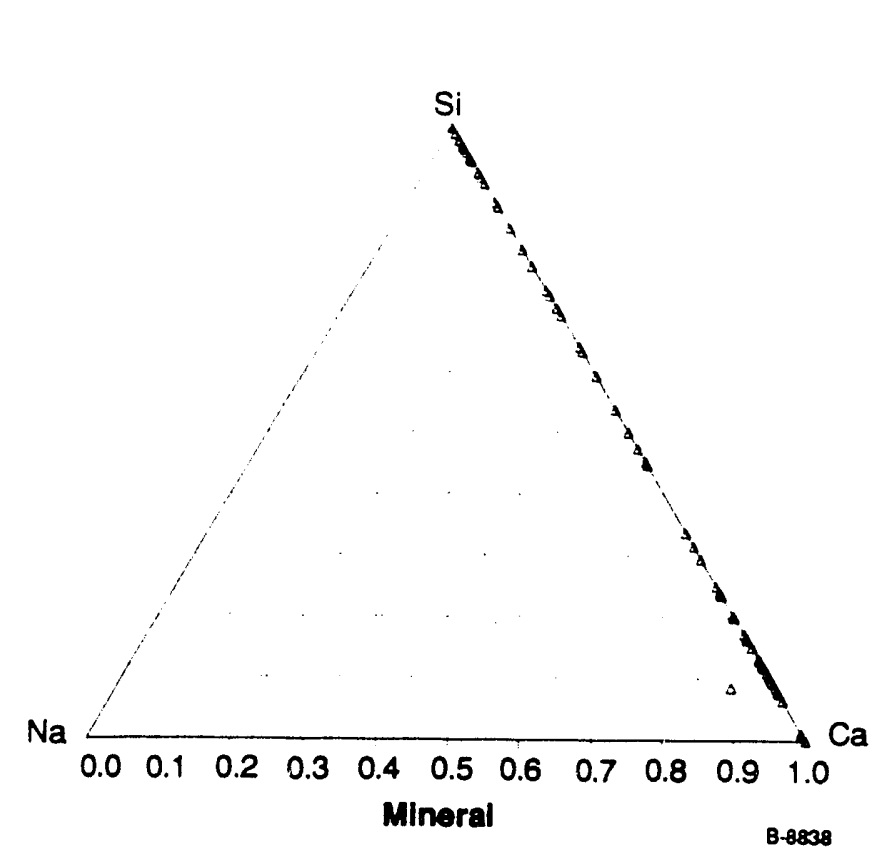

(a)

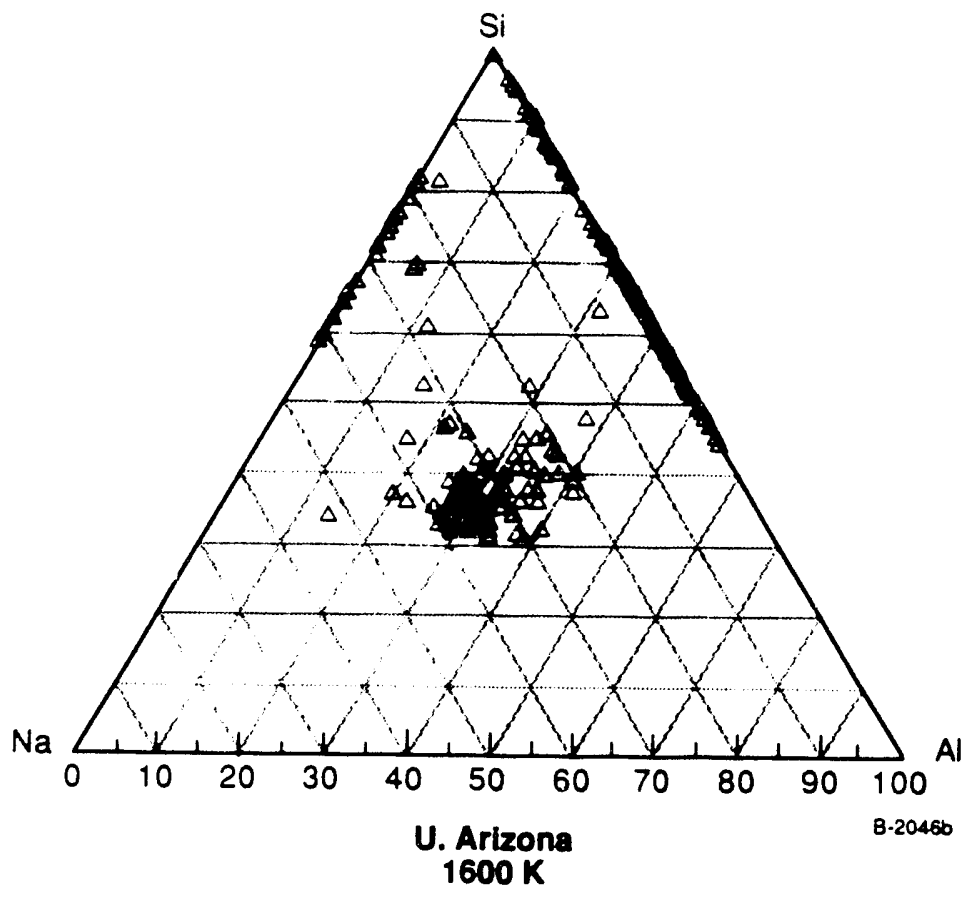

(c)

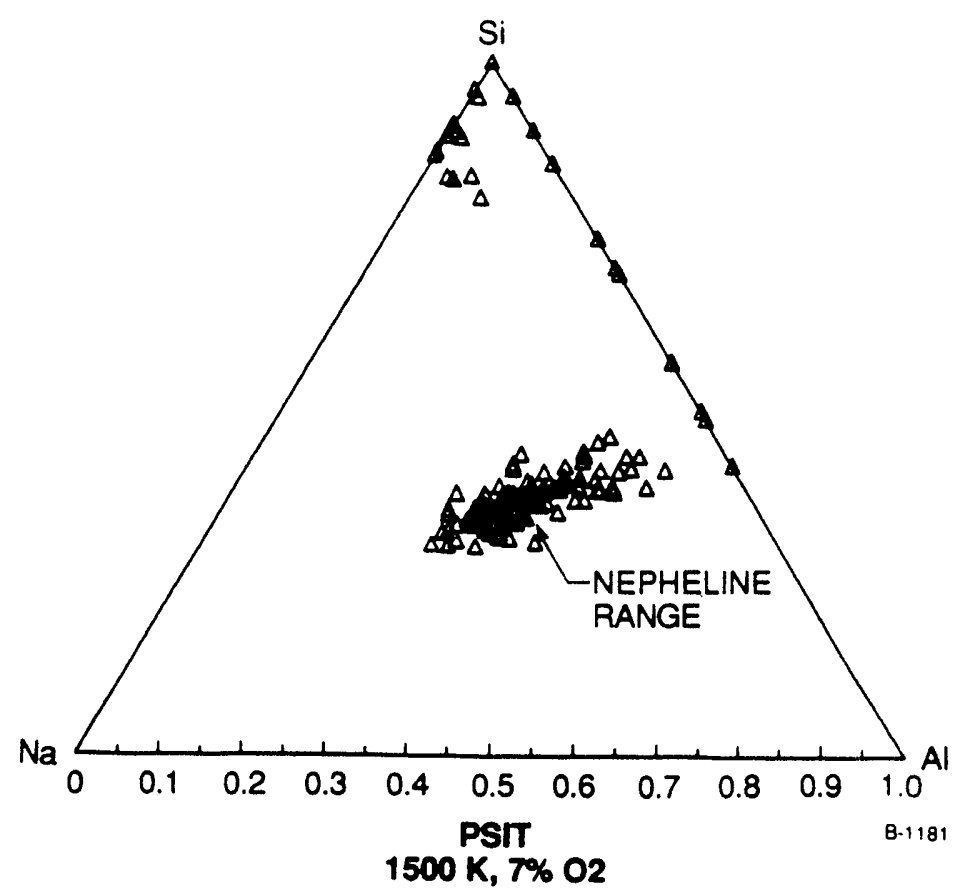

(b)

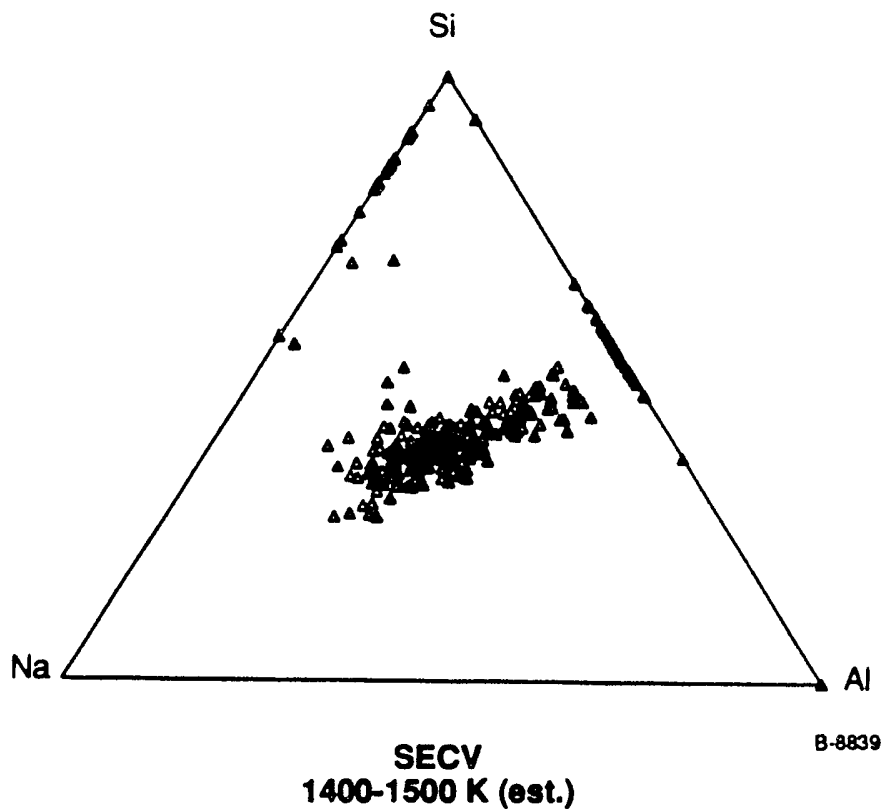

(d)

Figure 7-26. Beulah lignite ash Na-Al-Si ternary plots by CCSEM showing all particles with $\mathrm{Na}+\mathrm{Al}+\mathrm{Si} \geq 80$ atom\% (oxygen-free basis). a) mineral, b) PSIT, c) UA, d) SECV 

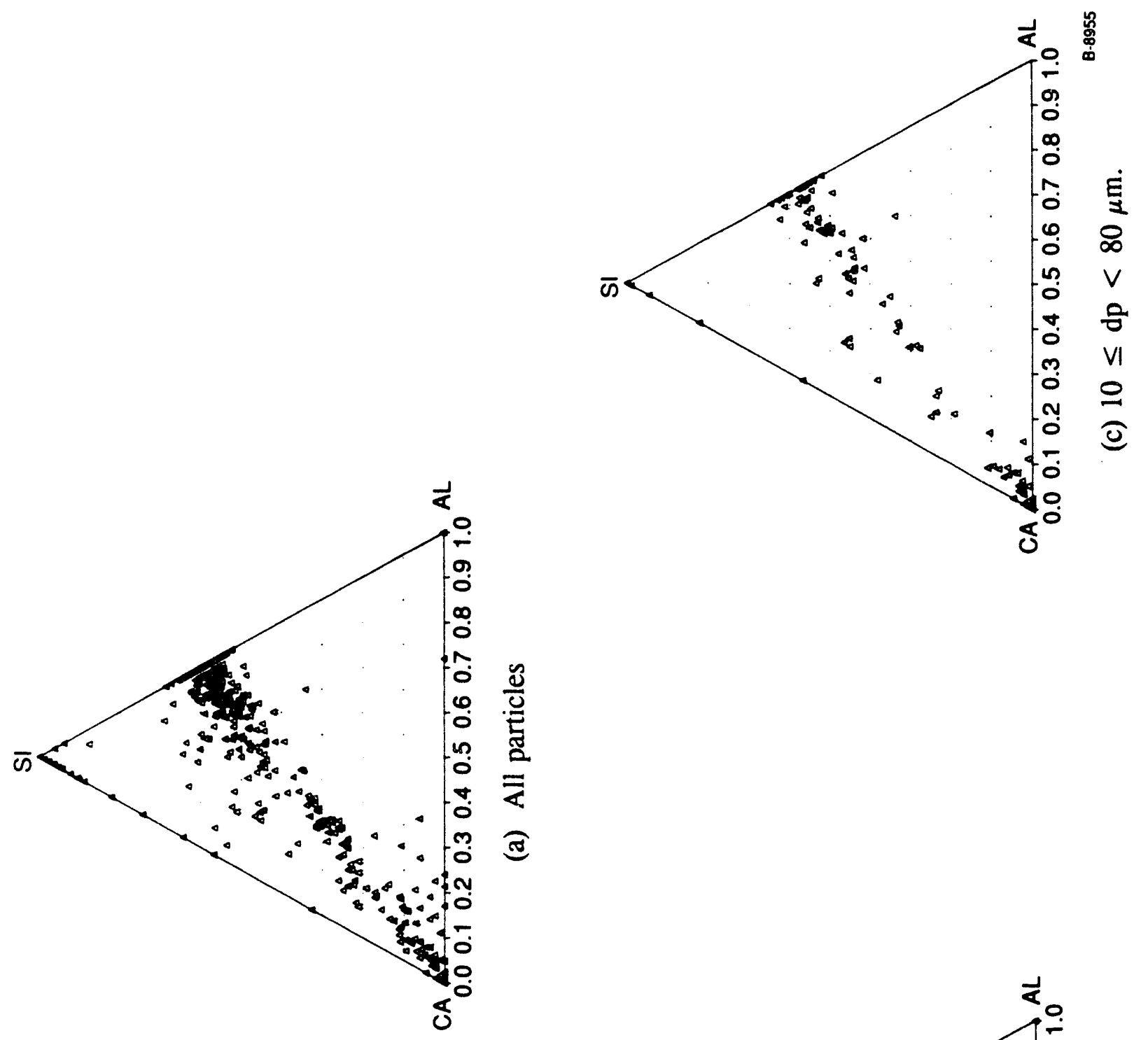

趇

$\frac{0}{0}$

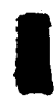

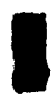

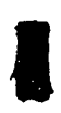

,
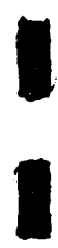

,

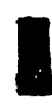

I

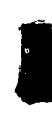

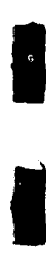

i 


\subsubsection{Loy Yang 1953 Brown Coal}

PCSV-P measurements of ash particle size distribution for the untreated LY 1953 at the ring 7 centerline are shown in Figure 7-28. For these runs, the coal feed rate was $30 \mathrm{~kg} / \mathrm{hr}$, corresponding to a furnace temperature of approximately $1100^{\circ} \mathrm{C}$ and an FEGT of $905^{\circ}$ to $950^{\circ} \mathrm{C}$ (Table 7-19). Three of the four runs shown were virtually identical, with a median particle diameter of $45 \mu \mathrm{m}$ observed. The size distribution was broader than that observed for the Beulah, with the middle 50 percent of the mass residing between 25 and $65 \mu \mathrm{m}$. Measurements obtained within $5 \mathrm{~mm}$ of the reactor wall (Figure 7-29) were also identical with these three, indicating uniform particle distribution throughout the combustor. The outlying run in Figure 7-28 demonstrated a 20 percent increase in the number of particles observed during the fixed measurement period, but was identical to the other runs in all other respects. Possible reasons for the observed increase in particle size are currently being explored.

The chemical composition of the ash particles extracted from the horizontal duct (just past the furnace exit and prior to the test banks - see Figure 7-24) was significantly different from the Beulah lignite, as expected. In Figure 7-30, a sodium-aluminum-silicon ternary plot if all particles containing greater than 80 atom $\% \mathrm{Na}+\mathrm{Al}+\mathrm{Si}$ demonstrates the absence of the

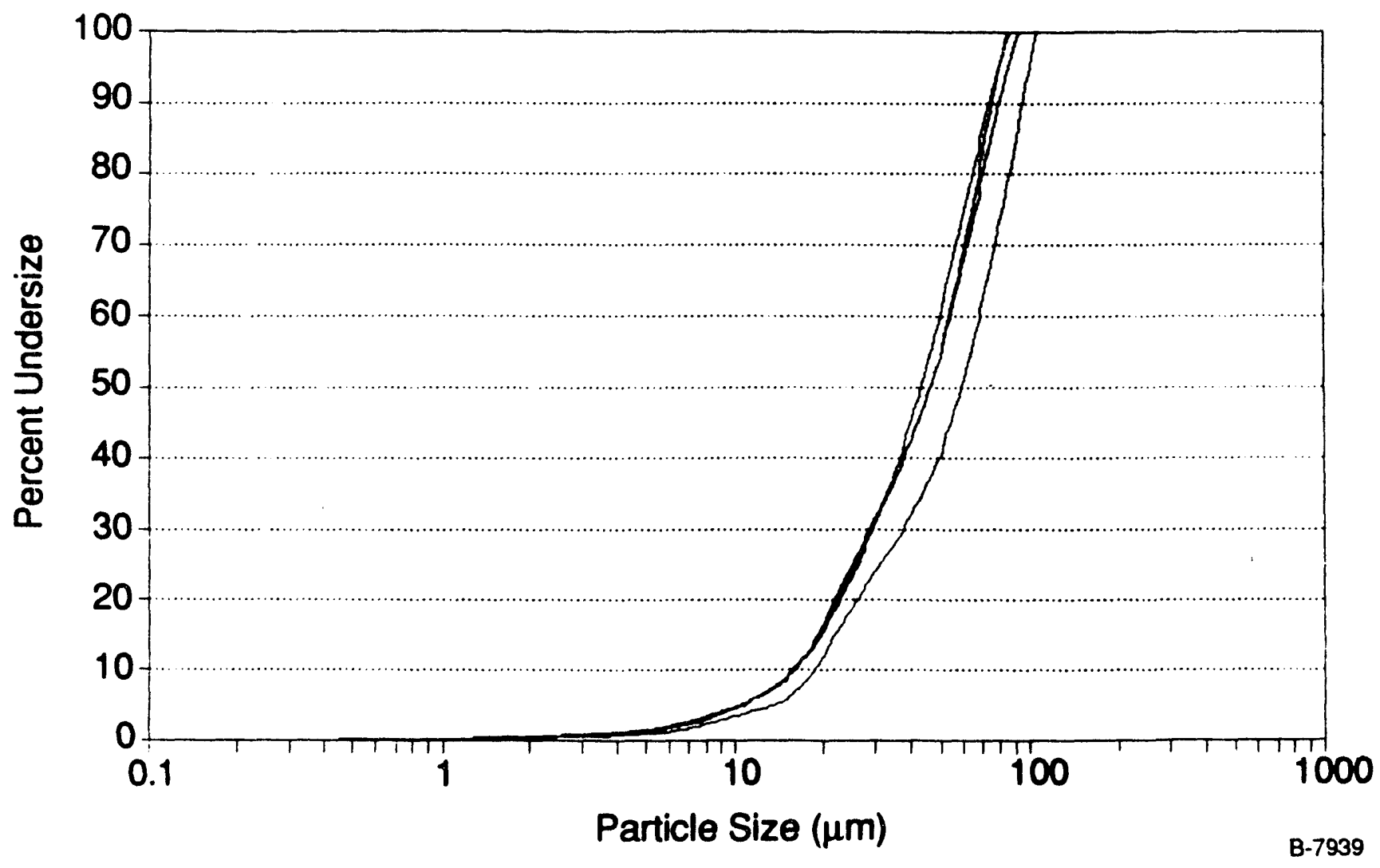

Figure 7-28. Loy Yang 1953 coal PSD measured with the PSCV-P, ring 7 combustion chamber centerline 


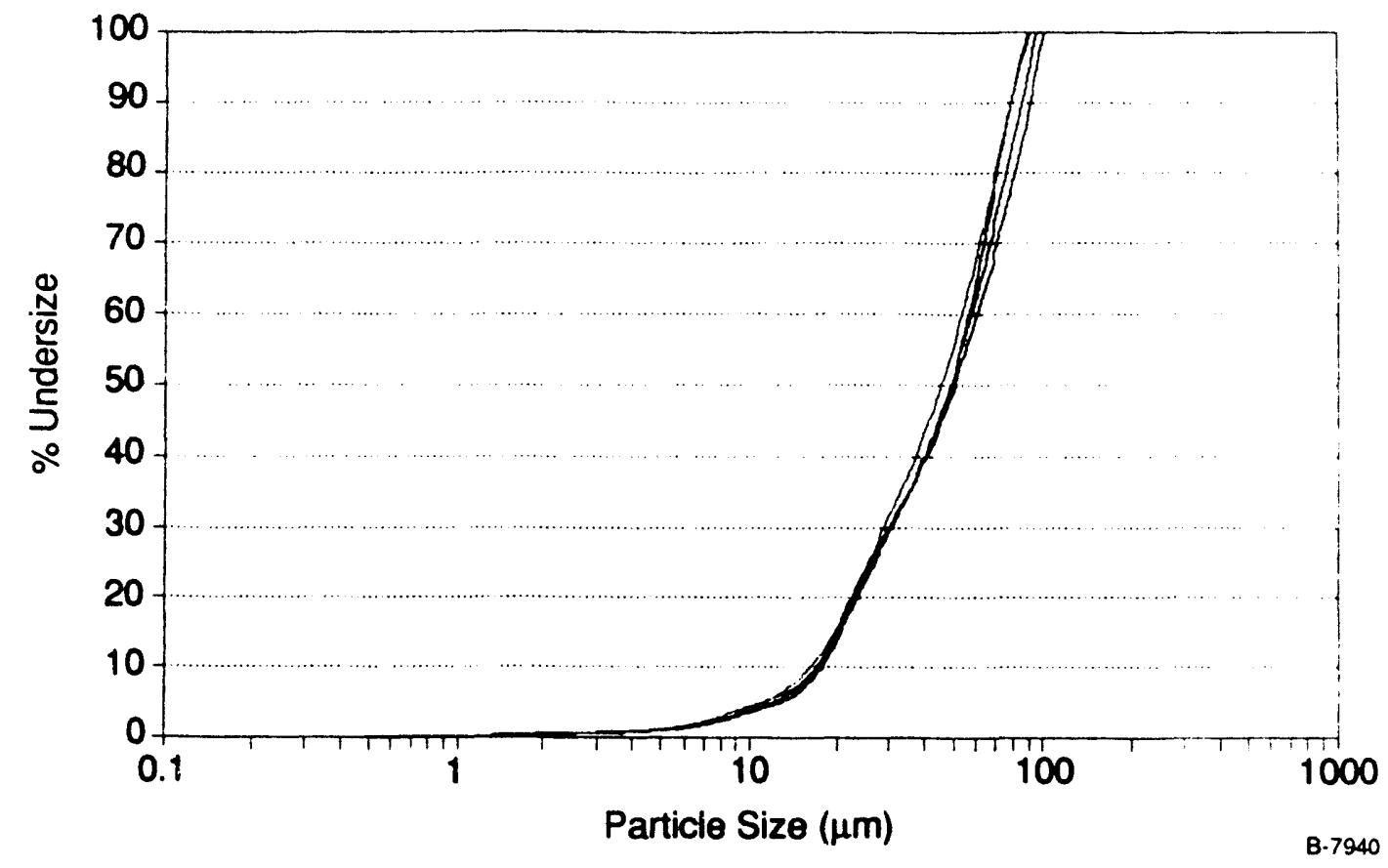

Figure 7-29. Loy Yang 1953 ash PSD measured $50 \mathrm{~mm}$ from the wall of the combustion chamber (ring 7) with the PCSV-P

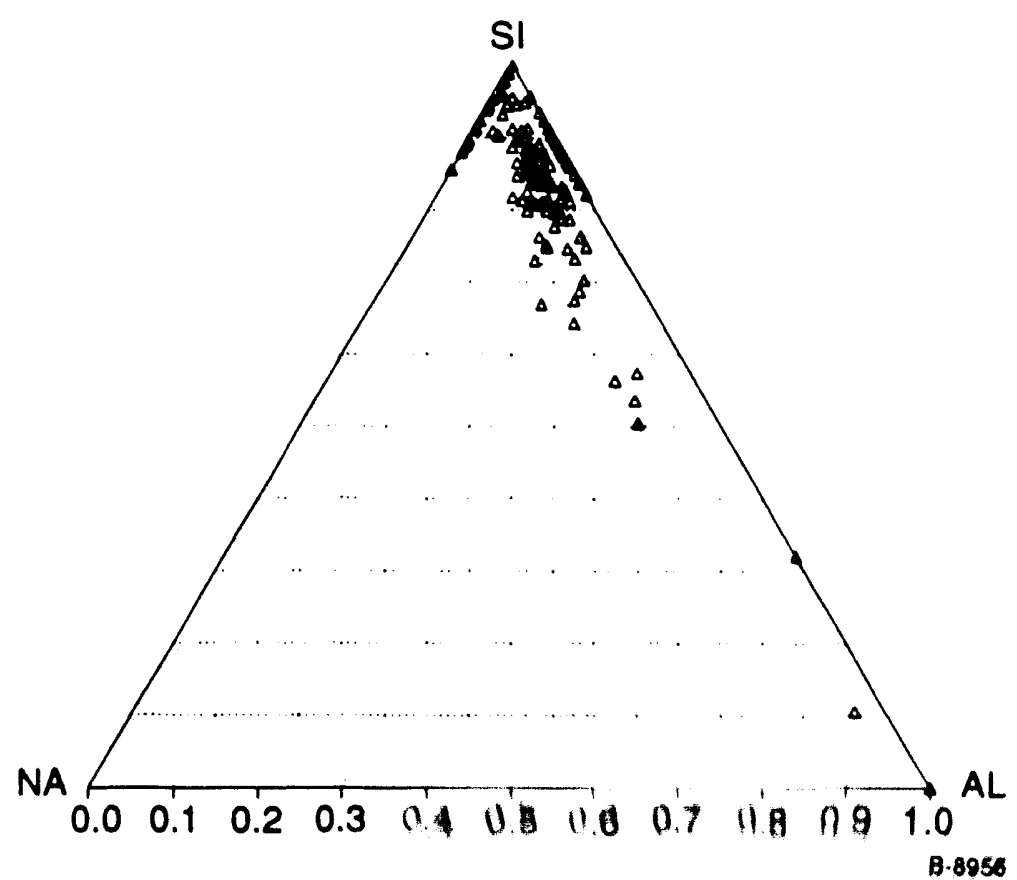

Figure 7-30. Na-Al-Si ternary, foy Yang 1953 ash extracted from the horim,ntal duct. All particles such that $\mathrm{Na}+\mathrm{Al}+\mathrm{Si} \geq 80$ atom $\%$. 
nepheline-like phase observed in combustion of the Beulah. Sodium aluminosilicate formation is minimal for this coal, suggesting that all of the sodium initially present in the Loy Yang (13.5 percent of the ASTM ash; PSI Technology Co., 1991) vaporizes during combustion and recondenses in the submicron size range, which is not characterized by CCSEM ( 0.5 to $1.0 \mu \mathrm{m}$ cutoff). Magnesium aluminates and aluminosilicates with a broad range of chemical composition were observed, as shown in Figure 7-31. The broad composition range suggests that a specific phase was not formed. The formation of the magnesium-containing particles likely results from the interaction of the organically bound magnesium with fine included aluminosilicate minerals; a lack of magnesium silicate formation suggests a lack of included quartz. Small numbers of zinc-containing particles were also observed, as shown in Figure 7-32.

\subsubsection{Loy Yang 1953 Brown Coal Treated with $\mathrm{Al}$ and $\mathrm{Mg}$}

Previous work has shown that addition of aluminum to Loy Yang brown coal reduces the amount of sodium-rich ash formed, and causes a decrease in deposition in a laboratory scale reactor (Vuthaluru et al., 1991). To assess the impact of additives on ash formation and deposition in a pilot scale combustor, a sample of the Loy Yang 1953 brown coal was treated with an $\mathrm{Mg}(\mathrm{OH})_{2} / \mathrm{MgCO}_{3}$ mixture and water-soluble $\mathrm{Al}_{2}\left(\mathrm{SO}_{4}\right)_{3}$ prior to testing.

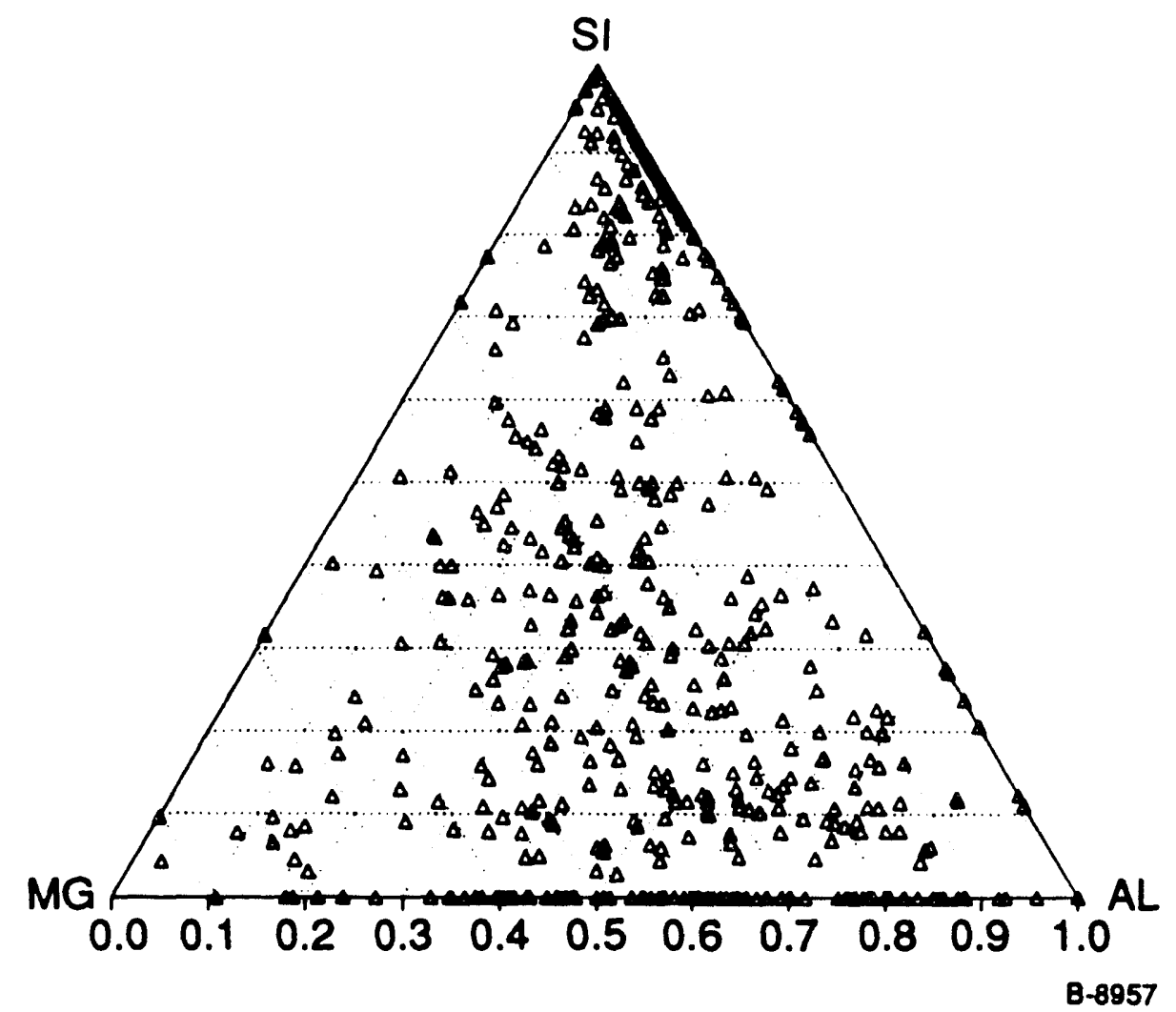

Figure 7-31. Mg-Al-Si ternary, Loy Yang 1953 ash, horizontal duct. All particles such that $\mathrm{Mg}+\mathrm{Al}+\mathrm{Si} \geq 60$ atom $\%$. 


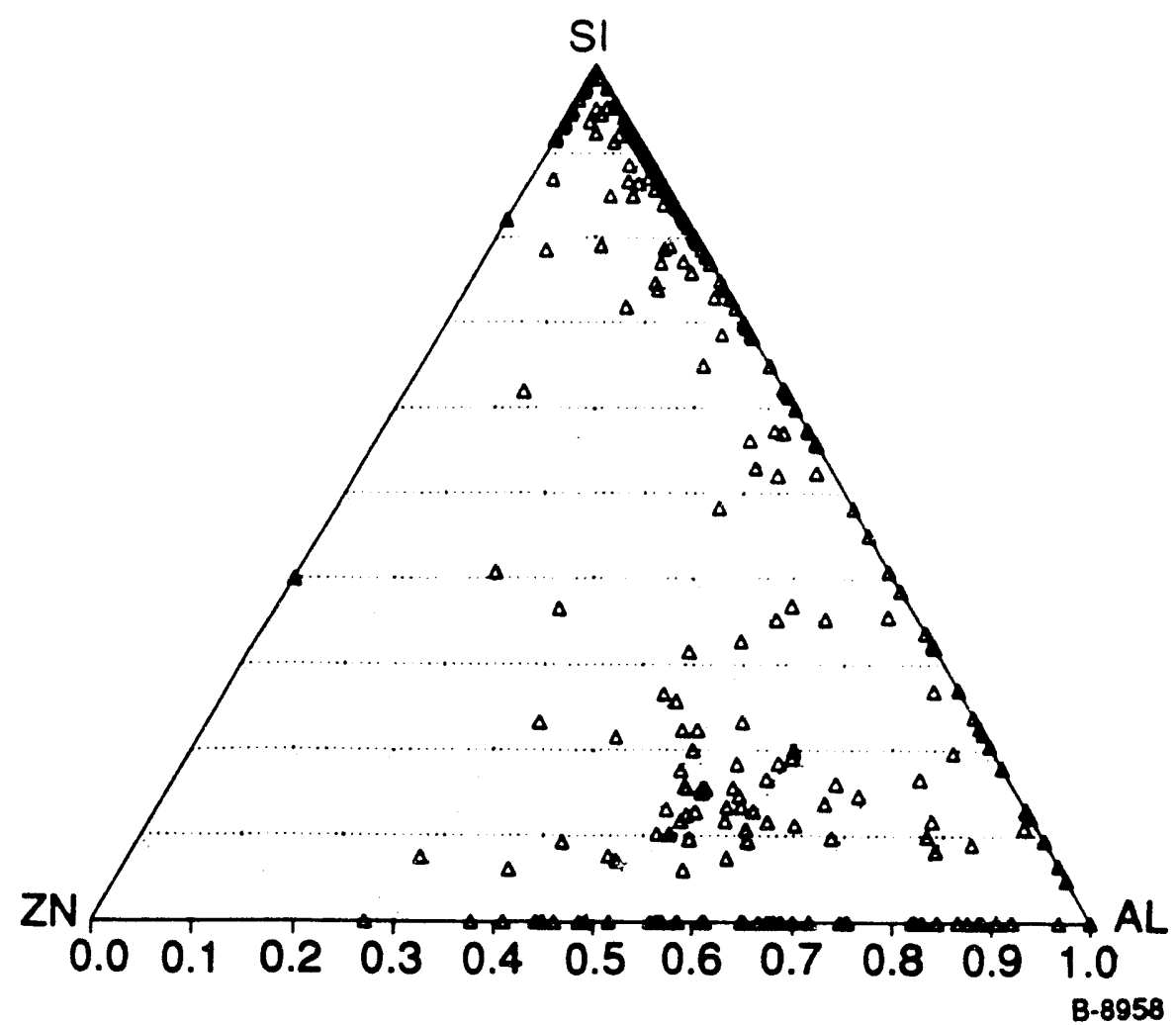

Figure 7-32. Zn-Al-Si ternary, Loy Yang 1953 ash, horizontal duct. All particles such that $\mathrm{Zn}+\mathrm{Al}+\mathrm{Si} \geq 60$ atom $\%$.

After drying to approximately 25 percent water by weight (for analysis, see Table 7-15), the coal was burned at $30 \mathrm{~kg} / \mathrm{hr}$ in the SECV reactor. Particle size distributions measured with the PCSV-P during combustion of the treated Loy Yang 1953 are presented in Figure 7-33. The five runs shown are nearly identical with one another, indicating extremely stable combustor operation with this fuel. Measurements were again taken at the centerline of ring 7, near the furnace exit. A median diameter of $60 \mu \mathrm{m}$ was observed for these experiments, perhaps due to the presence of residual carbon in the sample. Carbon analysis is pending; Malvern analysis of an extracted ash sample (in 80 percent iso-propanol/ 20 percent water) at SECV demonstrated a distinct peak near $500 \mu \mathrm{m}$, suggestive of large pieces of unburnt char.

CCSEM Chemical analysis of a treated Loy Yang ash sample extracted from the horizontal duct of the furnace (Figure 7-24) indicated fewer $\mathrm{Na}$ aluminosilicate particles, as seen in Figure 7-34. This is due in part to a reduction in coal sodium levels from $4000 \mathrm{ppm}$ to $1600 \mathrm{ppm}$ (SECV analysis); the addition of magnesium and aluminum to the coal may also contribute. Although the expected magnesium and aluminum - rich particles were observed in the sample (Figure 7-35), the most striking difference from the untreated Loy Yang was the increase in zinc concentrations in the ash (Figure 7-36). Zinc and magnesium did not interact significantly, as shown in Figure 7-37. Extensive zinc aluminate and aluminosilicate formation indicates high zinc levels in the coal, originating either from the additive or the water used to prepare the treated coal. 


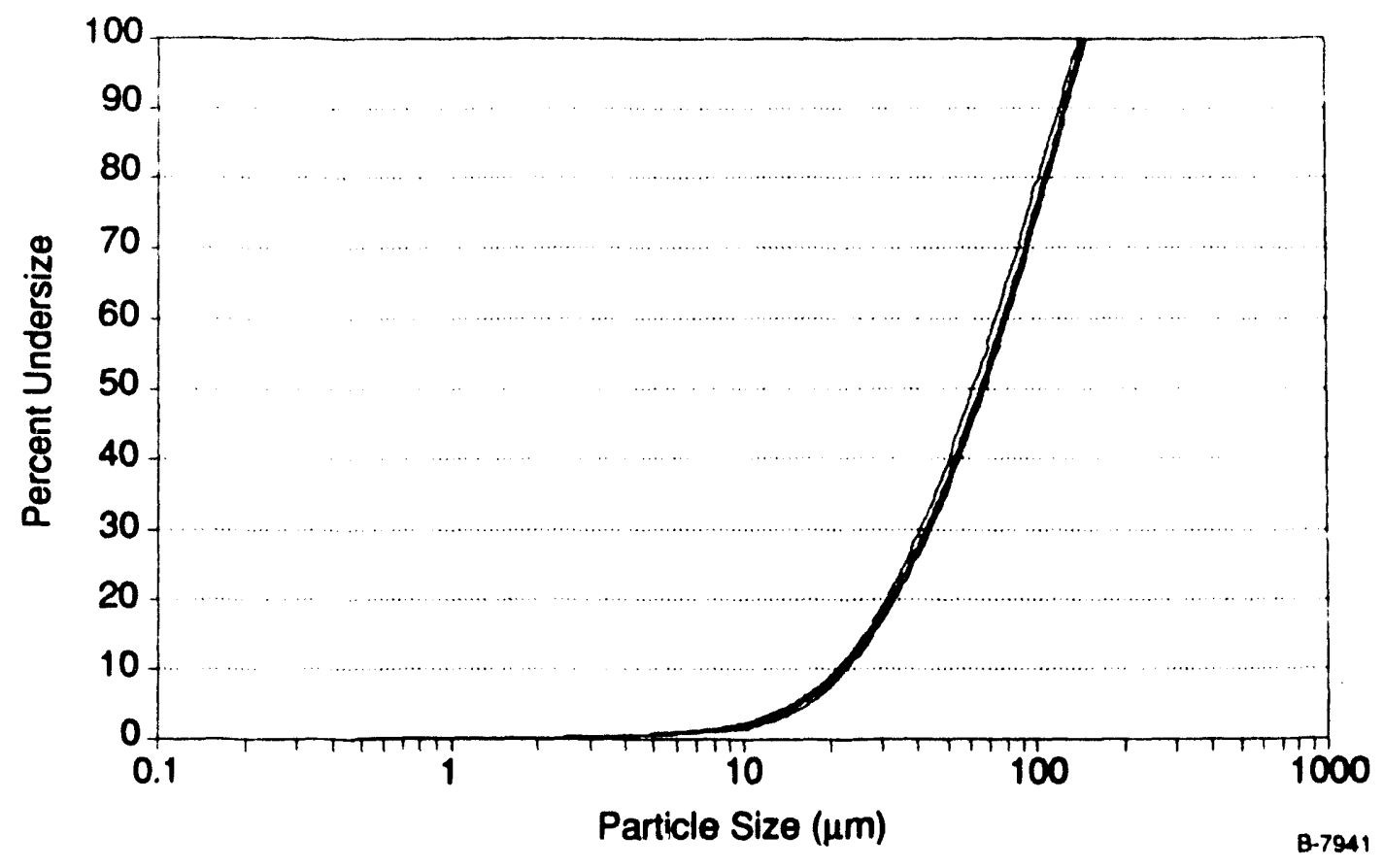

Figure 7-33. Loy Yang 1953 treated ash PSD measured at ring 7 combustion chamber (centerline) with the PCSV-P

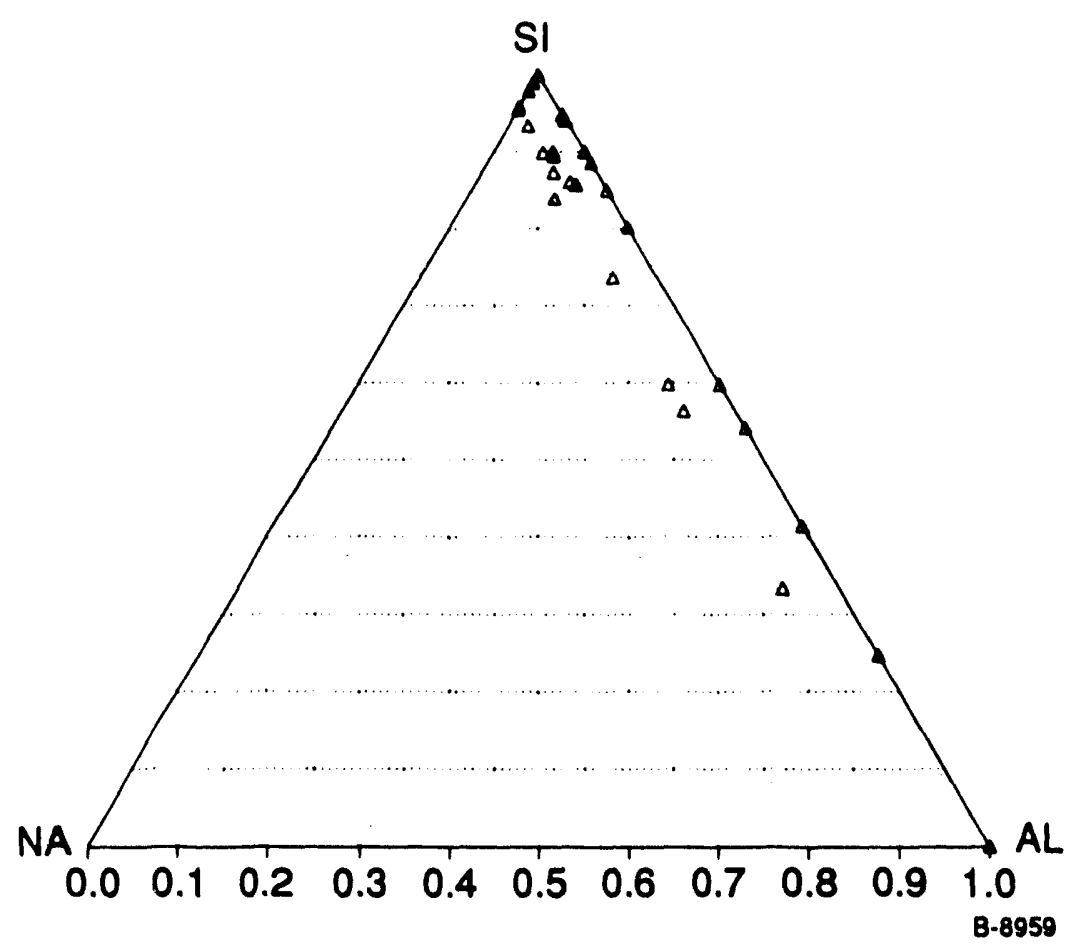

Figure 7-34. Na-Al-Si ternary, treated Loy Yang 1953 ash. Horizontal duct sample, all particles such that $\mathrm{Na}+\mathrm{Al}+\mathrm{Si} \geq 80$ atom\%. 


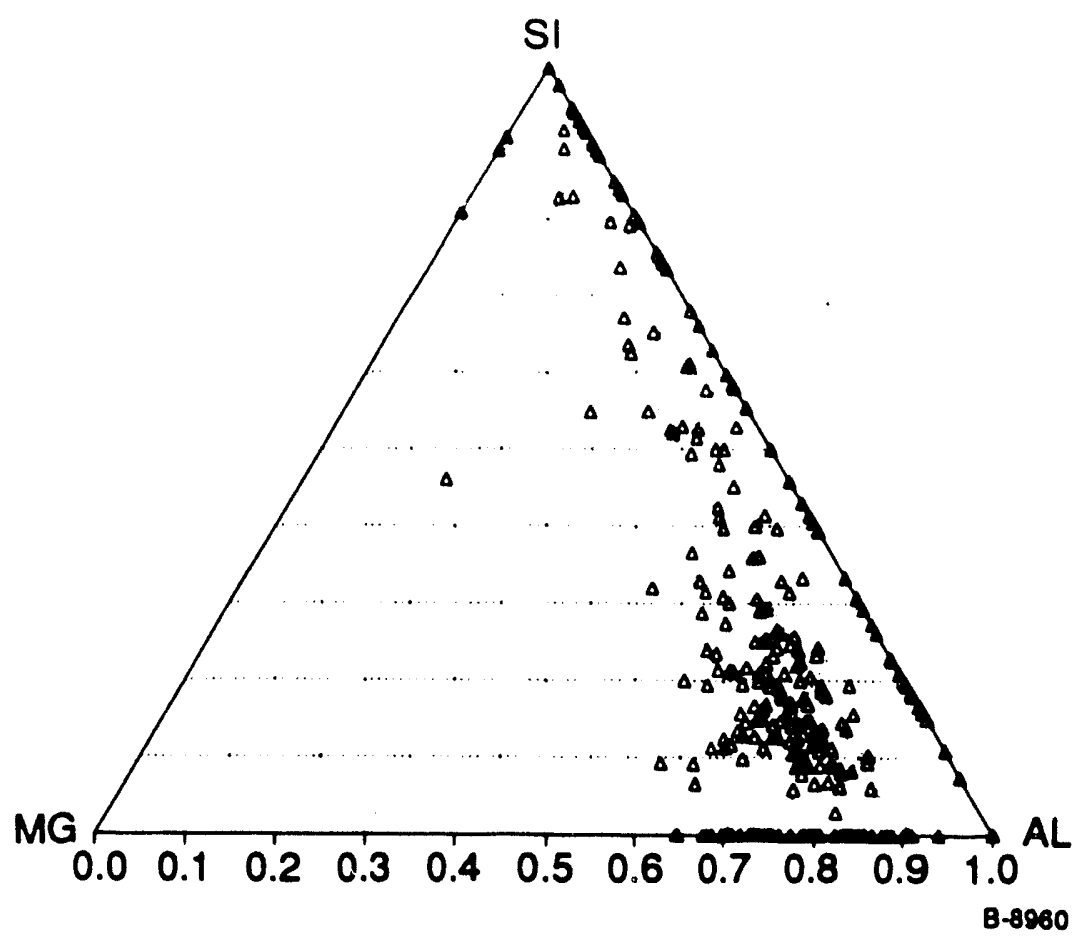

Figure 7-35. Mg-Al-Si ternary, treated Loy Yang 1953 ash. Horizontal duct sample, all particles such that $\mathrm{Mg}+\mathrm{Al}+\mathrm{Si} \geq 60$ atom $\%$.

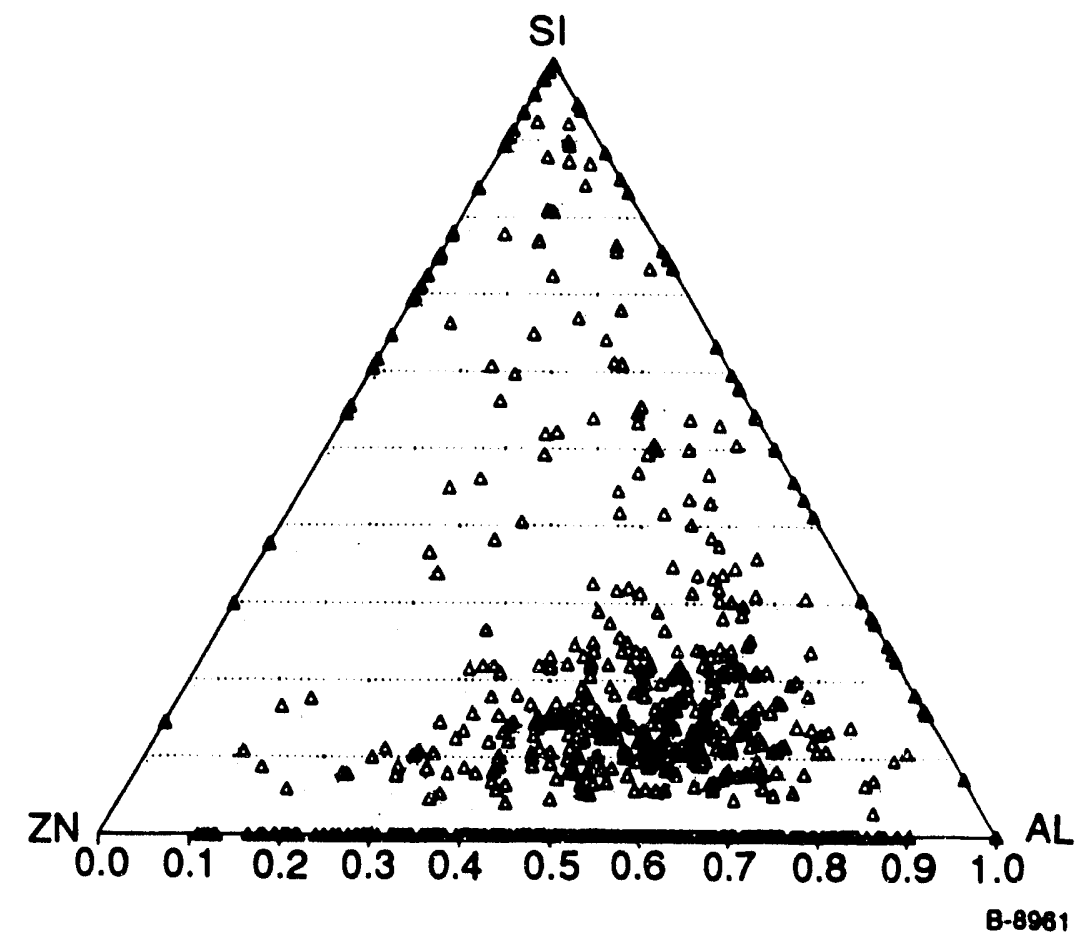

Figure 7-36. Zn-Al-Si ternary, treated Loy Yang 1953 ash. Horizontal duct sample, all particles such that $\mathrm{Zn}+\mathrm{Al}+\mathrm{Si} \geq 60$ atom $\%$. 


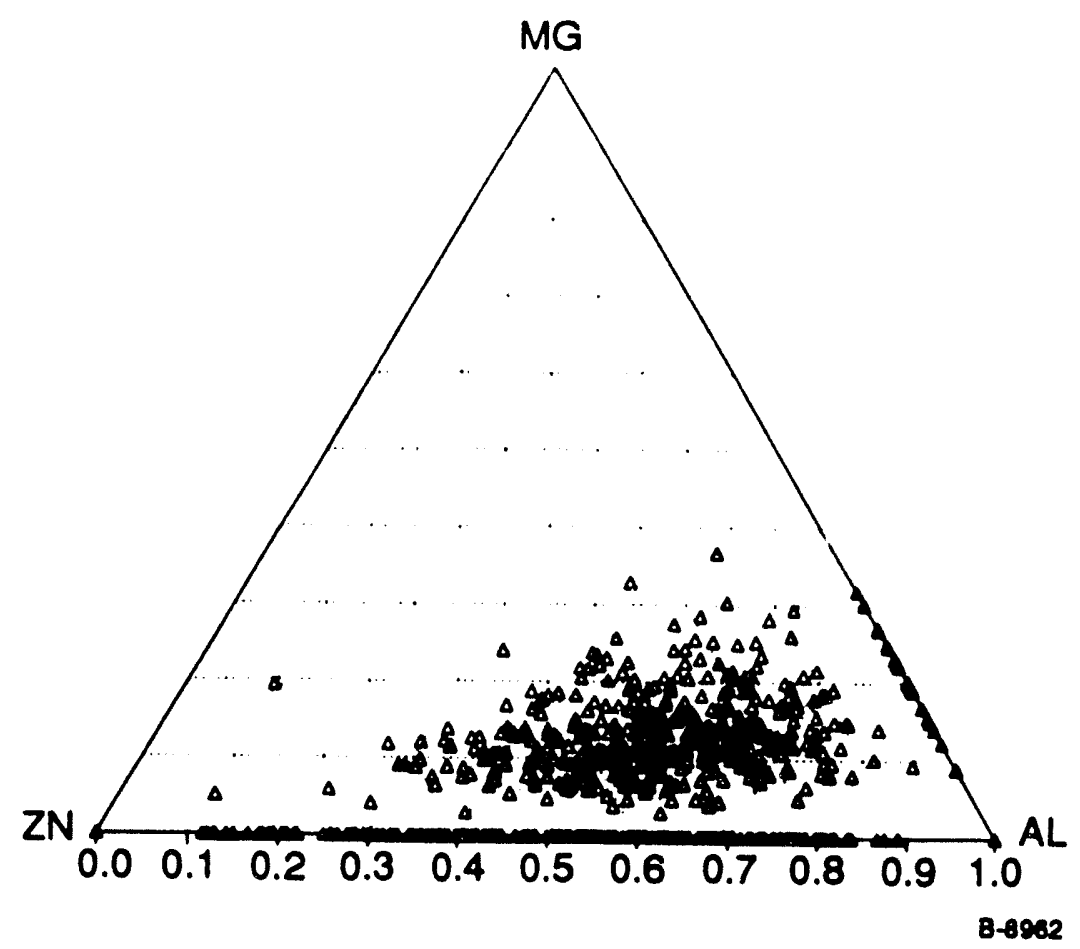

Figure 7-37. Zn-Al-Mg ternary, treated Loy Yang 1953 ash. Horizontal duct sample, all particles such that $\mathrm{Zn}+\mathrm{Al}+\mathrm{Mg} \geq 60$ atom\%.

\subsubsection{Comparison of Coals}

A comparison of PCSV-P measured particle size distributions for a typical experiment for each coal are plotted in Figure 7-38. The second line plotted for the LY 1953 represents a measurement taken at the combustor wall. Beulah lignite produced the smallest ash particles, while particles of $60 \mu \mathrm{m}$ median diameter were obtained from combustion of the treated Loy Yang. Residual carbon in the sample is expected to be the major cause of this difference. The general trend, however, was consistent with CCSEM-measured ash particle size distributions (Figure 7-39), which are blind to the presence of residual carbon. The difference between treated and untreated Loy Yang coals is, however, much smaller for the CCSEM-measured ash. Median diameters are smaller in all cases for the CCSEM as compared to the PCSV-P.

Cascade impactor measurements were used to determine the fraction of the ash present in the submicron size range, as the PCSV-P and the CCSEM are ineffective below 0.5 to $1 \mu \mathrm{m}$ in diameter. The treated Loy Yang produced the largest fraction of submicron ash (Table 7-20), while the Beulah at $3.3 \mathrm{wt} \%$ in the submicron range produced the smallest. For the Beulah lignite previously studied at PSIT and UA, 2 percent of the ash was present in the submicron range; for the Loy Yang 1953 at PSIT, 15 to 18 percent was in the submicron range (PSI Technology Co., 1990a, 1991). 


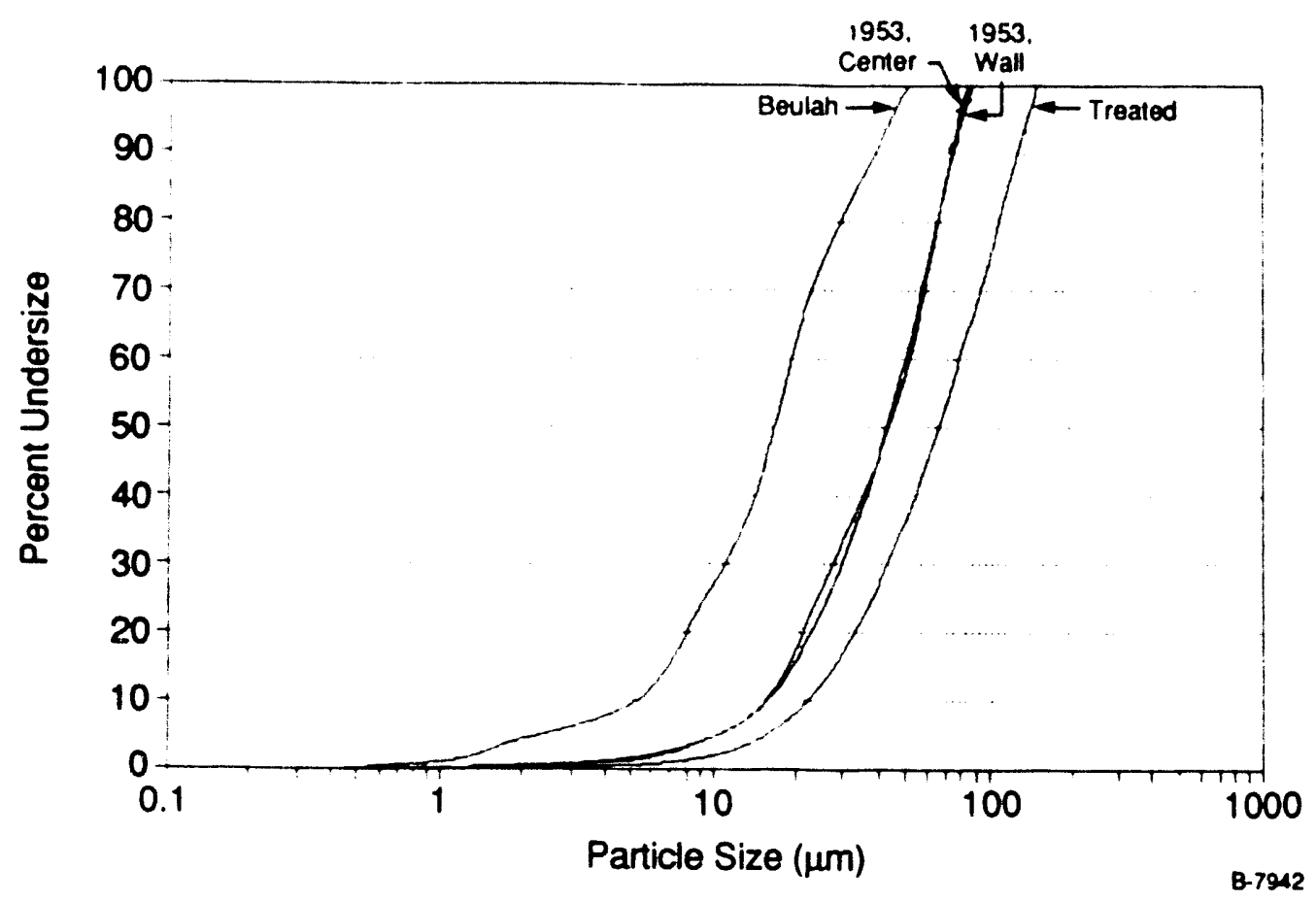

Figure 7-38. Comparison of ash particle size distributions measured with the PCSV-P at SECV

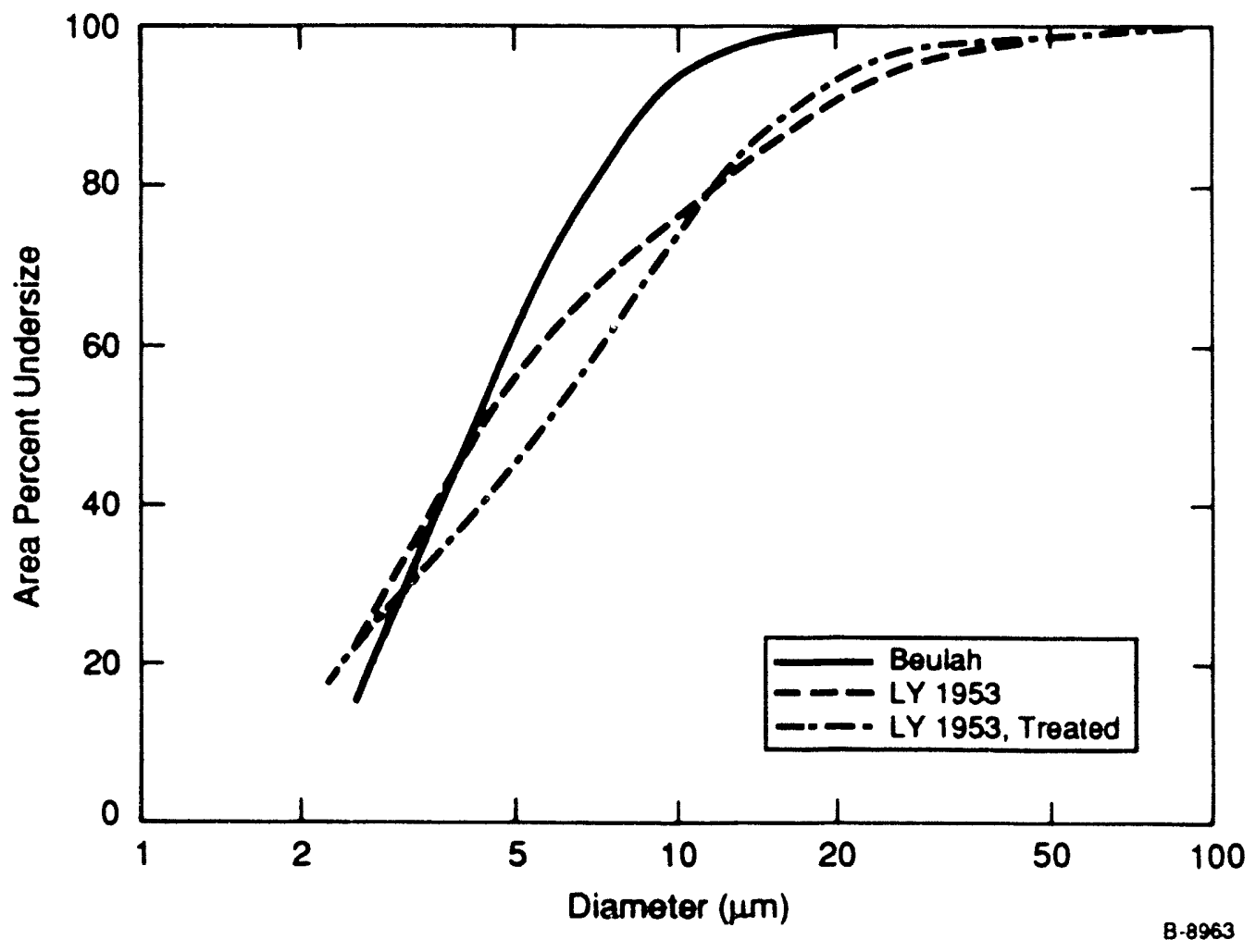

Figure 7-39. Comparison of CCSEM ash particle size distribution s obtained from sampling in the horizontal duct 
Table 7-20. Brink Cascade Impactor Data

\begin{tabular}{|l|c|c|c|}
\hline & $\begin{array}{c}\text { Beulah } \\
\text { Lignite }\end{array}$ & LY 1953 & $\begin{array}{c}\text { LY 1953, } \\
\text { Treated }\end{array}$ \\
\hline \hline Stages 0-6 & 96.7 & 81.6 & 65.8 \\
\hline Final filter & 3.3 & 18.4 & 34.2 \\
\hline
\end{tabular}

\subsubsection{Initial Deposition Results}

Deposits of 1.5 to 2 in. thickness in the test bank section were noted for the Beulah lignite, as shown in Figure 7-40 (lead test bank, \#1). These were significantly larger than those observed for either the Loy Yang 1953 (Figure 7-41) or the treated Loy Yang (Figure 7-42). Although the higher ash content of the Beulah certainly contributes, the thickness of the deposits is also indicative of a stickier ash at the conditions of the tests (see Table 7-19).

Phase analysis of the Beulah lignite deposits by $\mathrm{x}$-ray diffraction (XRD) at SECV is shown in Table 7-21. Calcium sulfate, calcium aluminosilicate, and iron oxide were all observed in the test bank deposit (test bank \#3). As the deposit was scraped from the test bank prior to analysis (the tubes are re-used), it was impossible to determine whether there was enrichment of certain phases nearer the tube surface. Using the ceramic deposition probe as an indicator of the state of the particles prior to impacting the cooled test banks, the presence of sodium aluminosilicates and calcium aluminosilicates suggests these may have been the species initiating the impaction-driven deposition. High calcium and low sulfur levels in the 30-min uncooled deposition probe sample are also consistent with this hypothesis. Chemical analysis of the test bank deposits (Table 7-22) indicates similarity to ash particles collected before (extractive) and after (precipitator) the cooled tubes, suggesting that over the course of the run $(4+\mathrm{hr})$, all ash species everitually deposited.

For the untreated Loy Yang, iron oxides and silica represented the only major species observed in uncooled deposits (Table 7-23). Because of the high sodium content of the coal, sodium chloride and sodium sulfate were observed in cooled deposition probe samples. As seen in Table 7-24, sticky particles at high temperatures (uncooled deposition probe sampl 3 ) were predominantly iron and silica-rich, while deposits collected on the tests bank surfaces contained sodium, chlorine, and sulfur, consistent with XRD analysis of the deposits.

Deposit samples collected during combustion of the treated Loy Yang coal were light, of low density, and easily removed from tube and test bank surfaces, suggesting the presence of refractory phases. For this coal, zinc oxide and other zinc phases dominated the ash (Table 7-25), owing to the elevated zinc levels discussed previously. Magnesium-rich phases were also observed in the deposition probe samples, although they did not appear in the test bank 3 deposits. 


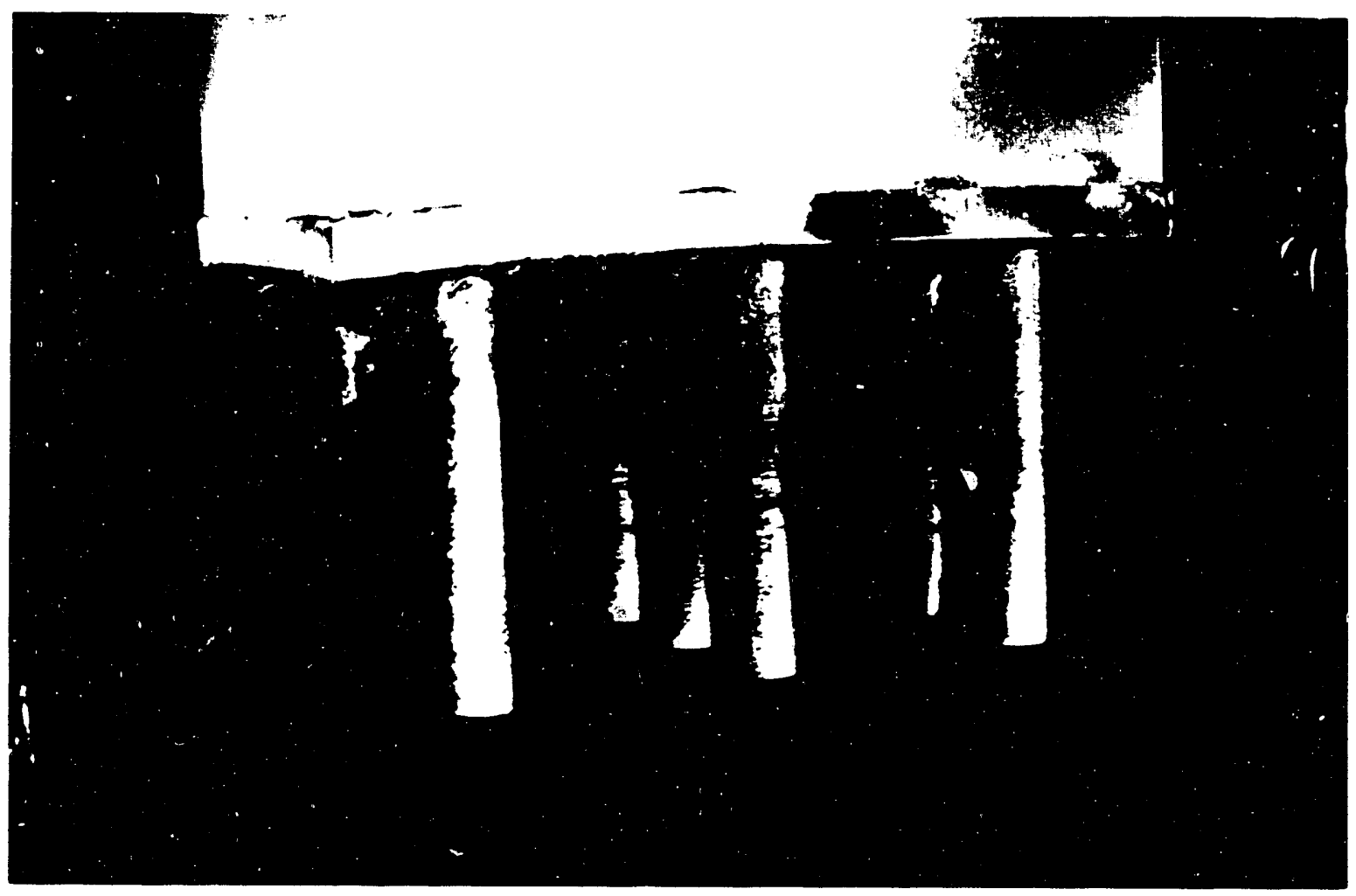

Figure 7-40. Test bank deposits, Beulah Lignite

Additional discussion of this testing shall appear in forthcoming quarterly reports, as analytical data become available. A joint PSIT/SECV report describing the results of the testing and analysis is also planned.

\subsection{Trace Element Concentrations: Effects of Coal Beneficiation}

To assess the impact of coal beneficiation on the transformations of trace elements i.e., those with concentrations typically $<0.1$ percent in coal ash - the physically beneficiated Illinois 6 SOAP and its parent were analyzed by neutron activation analysis. Combustion experiments were conducted at $1500^{\circ} \mathrm{C}, 7$ percent oxygen, and the resulting ash was size-segregated with a cascade impactor and re-analyzed for chemical composition. Beulah lignite coal and ash products generated at $1500^{\circ} \mathrm{C}$ (wall temperature), 7 percent oxygen were also examined for comparison.

Neutron activation analysis of these coal and ash samples is presented in Tables 7-26 through 7-28. In each table, coal represents the elemental concentration within the coal (not within the coal ash), TF represents the concentration of each element in a total filter sample generated during combustion in the laboratory furnace, and "Top 3" represents the concentration in a sample collected on the top t'aree stages of a Pollution Control Systems Corporation cascade impactor (i.e., dp $>2.2 \mu \mathrm{m}$ ). For the Illinois 6 parent, As, Sb, and Th levels were depleted in the largest sizes, indicating concentration in the smallest ash 

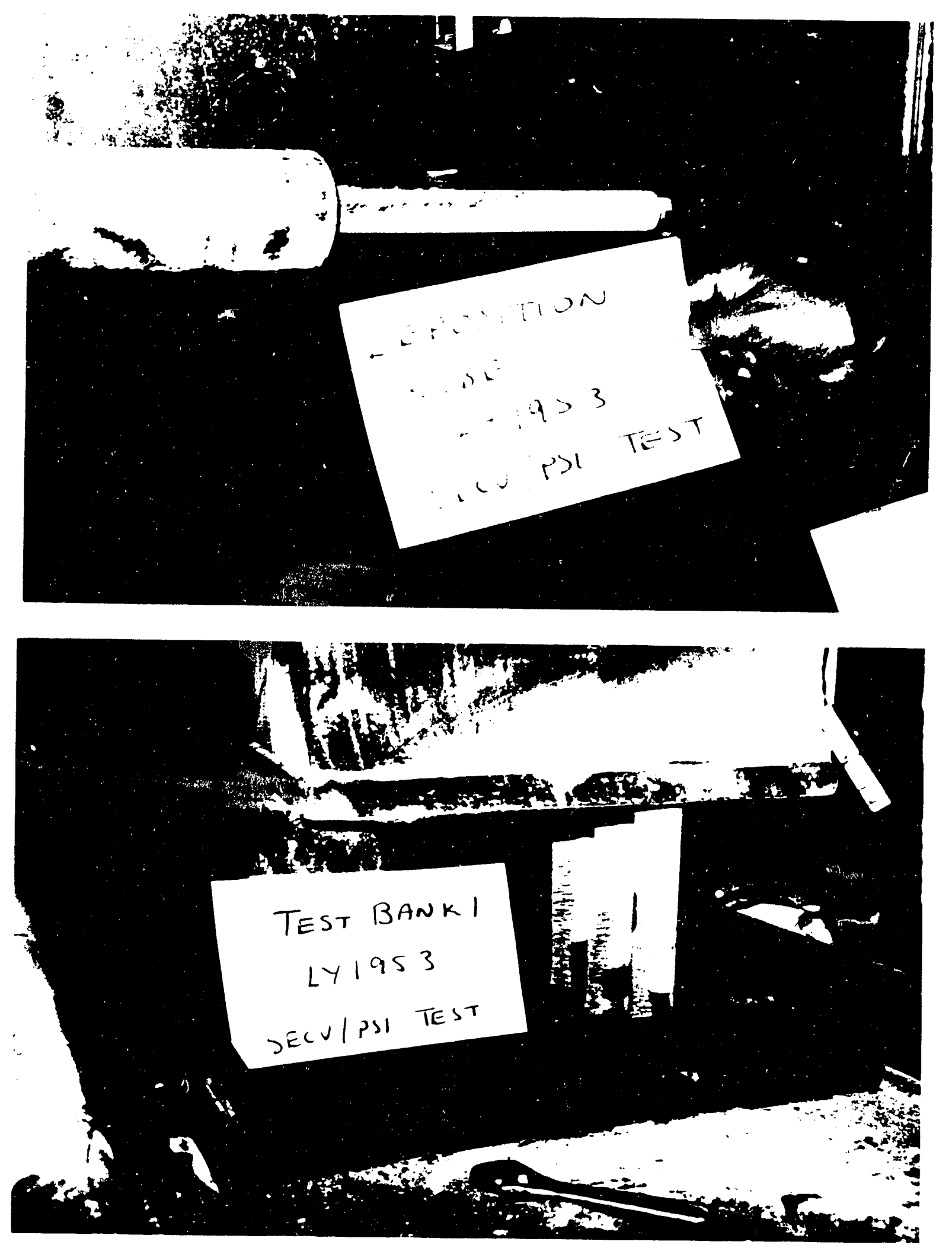

Figure 7-41. Combustion chamber (top) and test bank (bottom) deposits, Loy Yang 1953 


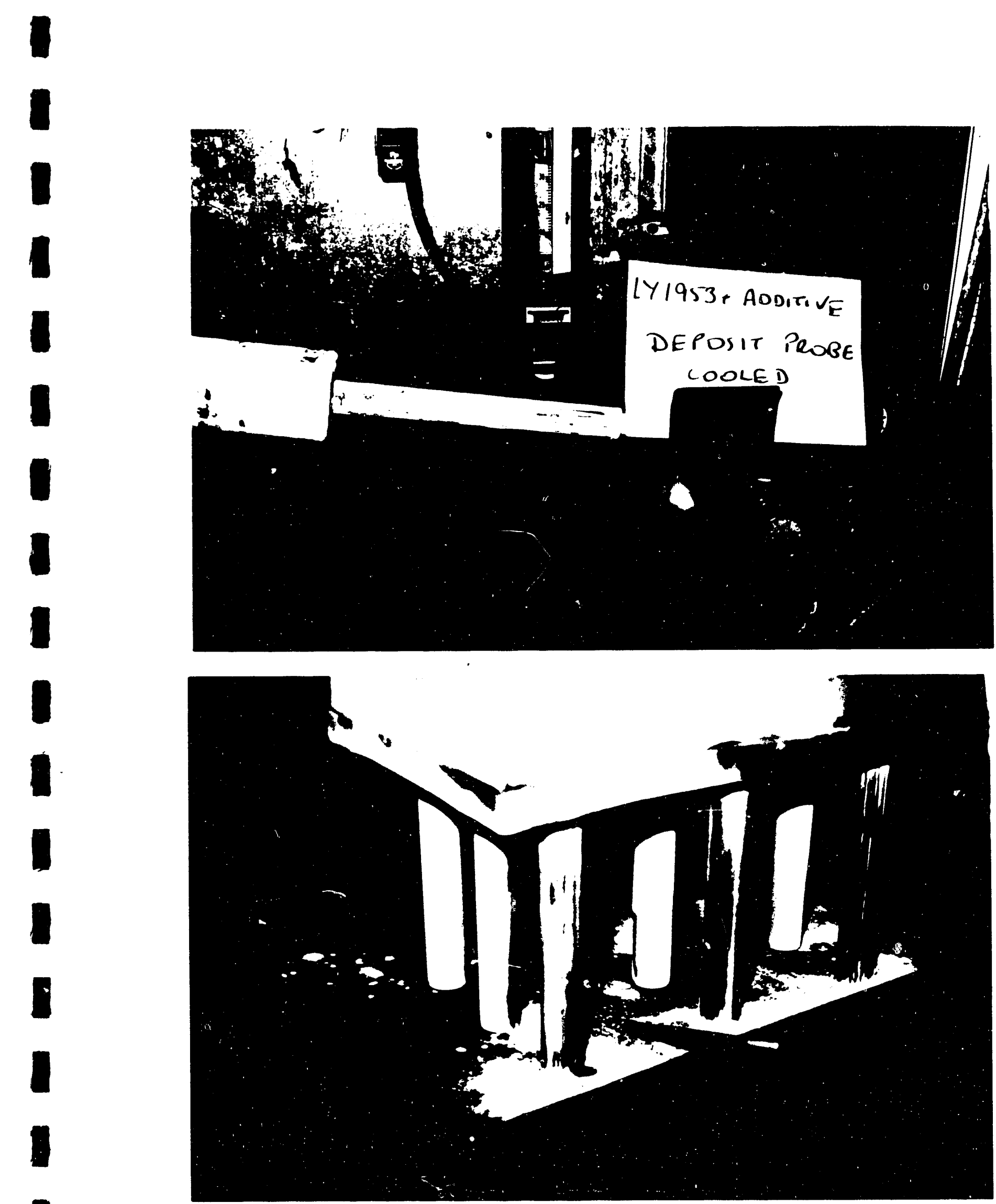

Figure 7-42. Combustion chamber and test bank deposits, treated LY 1953 
Table 7-21. Relative Ranking of Phases Observed in Beulah Lignite Testing - XRD Analysis -

\begin{tabular}{|c|c|c|c|c|c|}
\hline \multirow[b]{2}{*}{ Phase } & \multicolumn{5}{|c|}{ Location (read down each column) } \\
\hline & $\begin{array}{l}\text { Dep. Probe } \\
\text { ceramic }(\mathrm{S}) \\
\end{array}$ & $\begin{array}{c}\text { Dep. Probe } \\
\text { cooled }(\mathbf{S}) \\
\end{array}$ & $\begin{array}{l}\text { Dep. Probe } \\
\text { ceramic (L) } \\
\end{array}$ & $\begin{array}{c}\text { Test } \\
\text { Bank } 3 \\
\end{array}$ & $\begin{array}{c}\begin{array}{c}\text { Precipitator } \\
\text { (flyash) }\end{array} \\
\end{array}$ \\
\hline $\mathrm{Ca}_{2} \mathrm{Al}_{2} \mathrm{SiO}_{7}$ & 2 & 2 & 1 & 5 & 5 \\
\hline $\mathrm{CaSO}_{4}$ & - & 1 & - & 1 & 2 \\
\hline $\mathrm{Fe}_{2} \mathrm{O}_{3}$ & 3 & 3 & 3 & 2 & 3 \\
\hline $\mathrm{NaAlSiO}_{4}$ & 1 & 5 & 2 & - & - \\
\hline $\mathrm{Na}_{2} \mathrm{SO}_{4}$ & - & - & - & - & 1 \\
\hline $\mathrm{NaAlO}_{2}$ & - & 4 & - & - & - \\
\hline $\mathrm{SiO}_{2}$ & - & 6 & - & 4 & 4 \\
\hline $\begin{array}{l}\text { S } \\
\text { L } \\
\text { "Dep. Probe" }\end{array}$ & \multicolumn{5}{|c|}{$\begin{array}{l}\text { denotes short-term (approximately } 30 \mathrm{~min} \text { ) } \\
\text { denotes long-term (approximately } 4 \mathrm{hr} \text { ) } \\
\text { denotes deposition probe at or near ring } 7 \text { of combustion chamber } \\
\text { indiates phase not observed in sample. }\end{array}$} \\
\hline
\end{tabular}

Table 7-22. Chemical Analysis of Beulah Lignite Ash and Deposit Samples

\begin{tabular}{|l|c|c|c|c|c|c|c|}
\hline & \multicolumn{7}{|c|}{ (wt \%) } \\
\cline { 2 - 7 } Element & $\begin{array}{c}\text { Test } \\
\text { Bank 1 }\end{array}$ & $\begin{array}{c}\text { Test } \\
\text { Bank 3 }\end{array}$ & $\begin{array}{c}\text { Precip } \\
\text { (flyash) }\end{array}$ & $\begin{array}{c}\text { Extraction } \\
\text { (ring 7) }\end{array}$ & $\begin{array}{c}\text { Extraction } \\
\text { (horiz.) }\end{array}$ & $\begin{array}{c}\text { Dep. } \\
\text { Probe } \\
\text { (cooled) }\end{array}$ & $\begin{array}{c}\text { Dep. } \\
\text { Probe } \\
\text { (ceramic) }\end{array}$ \\
\hline \hline $\mathrm{SiO}_{2}$ & 23.7 & 24.1 & 20.8 & 24.5 & 24.6 & 26.8 & 28.8 \\
$\mathrm{Al}_{2} \mathrm{O}_{3}$ & 13.3 & 13.9 & 13.5 & 15.0 & 15.2 & 15.4 & 16.0 \\
$\mathrm{Fe}_{2} \mathrm{O}_{3}$ & 11.9 & 12.1 & 11.5 & 13.3 & 12.5 & 15.8 & 16.6 \\
$\mathrm{CaO}$ & 21.8 & 20.4 & 15.7 & 19.3 & 19.0 & 18.0 & 18.0 \\
$\mathrm{MgO}$ & 6.1 & 5.7 & 5.2 & 5.9 & 5.6 & 5.9 & 5.9 \\
$\mathrm{Na}_{2} \mathrm{O}$ & 6.0 & 6.8 & 11.2 & 7.4 & 9.3 & 5.0 & 6.7 \\
$\mathrm{~K}_{2} \mathrm{O}$ & 0.09 & 0.10 & 0.18 & 0.13 & 0.15 & 0.10 & 0.6 \\
$\mathrm{TiO}_{2}$ & 0.6 & 0.5 & 0.4 & 0.5 & 0.5 & 0.5 & 0.6 \\
$\mathrm{SO}_{3}$ & 16.9 & 12.7 & 13.9 & 7.3 & 9.1 & 8.8 & 3.8 \\
Other & 1.6 & 1.5 & 1.4 & 1.9 & 2.0 & 0.8 & 0.8 \\
Loss on & 0.7 & 0.2 & 2.7 & 2.6 & 1.3 & 0.1 & 0.9 \\
ignition & & & & & & \\
\hline nd - not determined
\end{tabular}


Table 7-23. Relative Ranking of Phases Observed in Loy Yang 1953 Testing - XRD Analysis

\begin{tabular}{|c|c|c|c|c|c|}
\hline & & \multicolumn{4}{|c|}{ Location } \\
\hline Phase & & $\begin{array}{l}\text { Dep. Probe } \\
\text { Ceramic (S) }\end{array}$ & $\begin{array}{l}\text { Dep. Probe } \\
\text { Cooled (S) }\end{array}$ & $\begin{array}{l}\text { Dep. Probe } \\
\text { Ceramic (L) }\end{array}$ & $\begin{array}{c}\text { Precipitator } \\
\text { (flyash) }\end{array}$ \\
\hline \multicolumn{2}{|l|}{$\mathrm{Na}_{2} \mathrm{SO}_{4}$} & - & 1 & - & - \\
\hline \multicolumn{2}{|l|}{$\mathrm{NaCl}$} & - & 3 & - & 3 \\
\hline \multicolumn{2}{|l|}{$\mathrm{Fe}_{2} \mathrm{O}_{3}$} & 2 & 4 & 2 & 4 \\
\hline \multicolumn{2}{|l|}{$\mathrm{SiO}_{2}$} & 1 & 2 & 1 & 2 \\
\hline \multicolumn{2}{|l|}{$\mathrm{MgAl}_{2} \mathrm{O}_{4}$} & - & - & - & 1 \\
\hline \multicolumn{2}{|l|}{$\mathrm{MgO}$} & - & - & - & 5 \\
\hline$S$ & & denotes sho & (approxim & $0 \mathrm{~min})$ & \\
\hline $\mathrm{L}$ & & denotes long & n (approximat & hr) & \\
\hline "Dep. Probe" & & $\begin{array}{l}\text { denotes depc } \\
\text { indicates } \mathrm{ph}\end{array}$ & $\begin{array}{l}\text { n probe at or } \\
\text { ot observed in }\end{array}$ & ring 7 of com & n chamber \\
\hline
\end{tabular}

Table 7-24. Chemical Analysis of Loy Yang 1953 Ash and Deposit Samples (wt \%)

\begin{tabular}{|l|r|r|r|r|r|r|}
\hline \multicolumn{1}{|c|}{ Element } & $\begin{array}{c}\text { Test } \\
\text { Bank 1 }\end{array}$ & $\begin{array}{c}\text { Test } \\
\text { Bank 2 }\end{array}$ & $\begin{array}{c}\text { Precip. } \\
\text { (flyash) }\end{array}$ & $\begin{array}{c}\text { Dep. Probe } \\
\text { Cooled }\end{array}$ & $\begin{array}{c}\text { Dep. Probe } \\
\text { Ceramic } \\
(30 \text { min) }\end{array}$ & $\begin{array}{c}\text { Dep. Probe } \\
\text { Ceramic } \\
\text { (L) }\end{array}$ \\
\hline \hline $\mathrm{SiO}_{2}$ & 36.1 & 32.3 & 20.3 & 53.1 & 82.9 & 79.2 \\
$\mathrm{Al}_{2} \mathrm{O}_{3}$ & 9.2 & 10.1 & 15.4 & 4.8 & 1.8 & 2.3 \\
$\mathrm{Fe}_{2} \mathrm{O}_{3}$ & 9.5 & 9.2 & 8.2 & 10.3 & 9.0 & 9.1 \\
$\mathrm{CaO}$ & 3.0 & 3.2 & 4.2 & 1.5 & 0.6 & 1.0 \\
$\mathrm{MgO}^{2}$ & 11.2 & 12.9 & 12.8 & 4.4 & 1.5 & 2.3 \\
$\mathrm{Na}_{2} \mathrm{O}$ & 13.6 & 14.8 & 9.6 & 12.2 & 2.2 & 3.4 \\
$\mathrm{~K}_{2} \mathrm{O}$ & 0.17 & 0.19 & 0.20 & 0.16 & 0.40 & 0.46 \\
$\mathrm{TiO}_{2}$ & 0.6 & 0.6 & 0.6 & 0.3 & 0.2 & 0.2 \\
$\mathrm{SO}_{3}$ & 12.9 & 14.0 & 5.0 & 7.6 & $<0.1$ & 0.6 \\
$\mathrm{P}_{2} \mathrm{O}_{5}$ & $<0.1$ & 0.1 & 0.2 & $<0.1$ & $<0.1$ & $<0.1$ \\
$\mathrm{Chloride}_{\mathrm{Cl} \text { (as }}$ & 1.5 & 2.5 & 2.6 & 5.5 & $\mathrm{nd}$ & $<0.1$ \\
Loss on ignition & 1.0 & 0.8 & 11.6 & 1.6 & 0.1 & 0.6 \\
$(\%)$ & & & & & \\
\hline
\end{tabular}


Table 7-25. Relative Ranking of Phases Observed in Loy Yang 1953 (Treated) Testing - XRD Analysis -

\begin{tabular}{|c|c|c|c|c|}
\hline \multirow[b]{2}{*}{ Phase } & & \multicolumn{3}{|c|}{ Location } \\
\hline & & $\begin{array}{l}\text { Dep. Probe } \\
\text { Cooled }(\mathbf{S}) \\
\end{array}$ & Test Bank 3 & $\begin{array}{c}\text { Precipitator } \\
\text { (flyash) }\end{array}$ \\
\hline \multicolumn{2}{|l|}{$\mathrm{CaAl}_{2} \mathrm{SiO}_{7}$} & - & - & 6 \\
\hline \multicolumn{2}{|l|}{$\mathrm{Na}_{2} \mathrm{SO}_{4}$} & 1 & 3 & - \\
\hline \multicolumn{2}{|l|}{$\mathrm{NaCl}$} & - & - & 4 \\
\hline \multicolumn{2}{|l|}{$\mathrm{Fe}_{2} \mathrm{O}_{3}$} & 4 & 5 & 5 \\
\hline \multicolumn{2}{|l|}{$\mathrm{FeAl}_{2} \mathrm{O}_{4}$} & - & - & 2 \\
\hline \multicolumn{2}{|l|}{$(\mathrm{MgFe})_{2} \mathrm{SiO}_{4}$} & 6 & - & 3 \\
\hline \multicolumn{2}{|l|}{$\mathrm{MgFe}_{2} \mathrm{O}_{4}$} & - & - & 7 \\
\hline \multicolumn{2}{|l|}{$\mathrm{MgAl}_{2} \mathrm{O}_{4}$} & 5 & - & - \\
\hline \multicolumn{2}{|l|}{$\mathrm{SiO}_{2}$} & 3 & 2 & - \\
\hline \multicolumn{2}{|l|}{$\mathrm{ZnO}$} & 2 & 1 & 1 \\
\hline \multicolumn{2}{|l|}{ Other $\mathrm{Zn}$} & - & 4,6 & - \\
\hline$S$ & & denotes short-term & mately $30 \mathrm{~min}$ & \\
\hline L & - & denotes long-term & nately $4 \mathrm{hr}$ ) & \\
\hline "Dep. Probe" & - & $\begin{array}{l}\text { denotes deposition } \\
\text { indicates phase not }\end{array}$ & $\begin{array}{l}\text { or near ring } 7 \\
1 \text { in sample }\end{array}$ & ustion chamber \\
\hline
\end{tabular}

particle sizes. For the SOAP, $\mathrm{Zn}, \mathrm{Cr}$ (slight), As, Se, and $\mathrm{Sb}$ (slight) were all enriched in the smallest particle size range.

Of interest is the change in concentration for several of the elements when the coal is beneficiated. Chromium, selenium, antimony, and uranium levels in the SOAP ash were all greater than in the parent coal ash, indicating that they were not removed as effectively as some of the major minerals.

For the Beulah lignite, As, Se, and Sb were depleted in the largest particle sizes, suggesting enrichment in the submicron fraction of the ash for these elements. 
Table 7-26. Trace Element Analysis, Illinois \#6 Parent and Ash (ppm, wt)

\begin{tabular}{|l|c|c|c|}
\hline \multirow{2}{*}{} & \multicolumn{3}{|c|}{ ppm, wt } \\
\cline { 2 - 4 } & I6 Coal & I6 TF & 16 top 3 \\
\hline \hline Sc & 1.9 & 27 & 24 \\
$\mathrm{Cr}$ & 16 & 140 & 135 \\
$\mathrm{Co}$ & 13 & 200 & 180 \\
$\mathrm{Zn}$ & 22 & 210 & 170 \\
$\mathrm{As}$ & 1.5 & 11 & 5.6 \\
$\mathrm{Se}$ & 1.8 & 3.4 & 2.6 \\
$\mathrm{Sr}$ & 1 & - & - \\
$\mathrm{Cd}$ & - & 2.2 & 1.7 \\
$\mathrm{Sb}$ & 0.26 & 1.9 & 1.4 \\
$\mathrm{Cs}$ & 0.76 & 11 & 8.0 \\
$\mathrm{Th}$ & 1.3 & 55 & 17 \\
$\mathrm{U}$ & 2.1 & 10 & 10 \\
$\mathrm{Ti}$ & 450 & 5100 & \\
\hline
\end{tabular}

$\%$ ash, I6 parent (as-received) 8.4 (dry basis) 9.4

$\%$ ash, I6 SOAP (as-received) 2.8 (dry basis 3.6 )

Fraction vaporized, parent $\approx 0.02$ (est. from Phase I results)

Fraction vaporized, SOAP $\approx 0.15$

Table 7-27. Trace Element Analysis, Illinois 6 SOAP and Ash

\begin{tabular}{|l|c|c|c|c|}
\hline \multirow{2}{*}{} & \multicolumn{4}{|c|}{ ppm, wt } \\
\cline { 2 - 5 } & SOAP Coal & SOAP TF & SOAP top 3 & SOAP bottom 3 \\
\hline \hline Sc & 1.4 & 46 & 44 & 4.3 \\
$\mathrm{Cr}$ & 16 & 290 & 440 & 530 \\
$\mathrm{Co}$ & 3.0 & 59 & 57 & 6.8 \\
$\mathrm{Zn}$ & 11 & 270 & 250 & 500 \\
$\mathrm{As}$ & 1.1 & 15 & 5.7 & 57 \\
$\mathrm{Se}$ & 1.3 & 13 & 5.6 & 13 \\
$\mathrm{Sr}$ & - & 130 & 245 & - \\
$\mathrm{Cd}$ & - & 4.2 & - & 3.9 \\
$\mathrm{Sb}$ & 0.28 & 3.0 & 1.5 & 11 \\
$\mathrm{Cs}$ & 0.41 & 6.4 & 5.0 & 9.6 \\
Th & 1.1 & 39 & 37 & 3.2 \\
$\mathrm{U}$ & 2.2 & 27 & 31 & 31 \\
Ti & 494 & 13500 & & \\
\hline$\%$ ash, I6 parent (as-received) 8.4 (dry basis) 9.4 \\
\% ash, I6 SOAP (as-received) 2.8 (dry basis 3.6) \\
Fraction vaporized, parent $\approx 0.02$ (est. from Phase I results) \\
Fraction vaporized, SOAP $\approx 0.15$ \\
\hline
\end{tabular}


Table 7-28. Trace Element Analysis, Beulah Coal and Ash

\begin{tabular}{|l|c|c|c|}
\hline \multirow{2}{*}{} & \multicolumn{3}{|c|}{ ppm, wt } \\
\cline { 2 - 4 } & Beulah Coal & Beulah TF & Beulah top 3 \\
\hline \hline Sc & 1.2 & 21 & 20 \\
$\mathrm{Cr}$ & 3.0 & 46 & 70 \\
$\mathrm{Co}$ & 1.2 & 11 & 13 \\
$\mathrm{Zn}$ & 9.8 & 110 & 120 \\
$\mathrm{As}$ & 8.7 & 136 & 47 \\
$\mathrm{Sc}$ & 0.96 & 9.3 & 2.5 \\
$\mathrm{Sr}$ & - & 7700 & 5500 \\
$\mathrm{Cd}$ & - & 1.1 & 2.0 \\
$\mathrm{Sb}$ & 0.43 & 7.5 & 2.3 \\
$\mathrm{Cs}$ & 0.16 & 0.69 & - \\
$\mathrm{Th}$ & 1.5 & 26 & 26.0 \\
$\mathrm{U}$ & 0.68 & 9.1 & 8.1 \\
$\mathrm{Ti}$ & 228 & - & - \\
\hline
\end{tabular}

\subsection{References}

Allen, R.M., and VanderSande, J.B., "Analysis of Submicron Mineral Matter in Coal via Scanning Transmission Electron Microscopy," Fuel 63:1, 24 (1984).

Graham, K.A., Ph.D. Thesis, Massachusetts Institute of Technology, Cambridge MA, January (1991).

Helble, J.J., Srinivasachar, S., Boni, A.A., Kang, S.G., Graham, K.A., Sarofim, A.F., Beer, J.M., Gallagher, N.B., Bool, L.E., Peterson, T.W., Wendt, J.O.L., Shah, N., Huggins, F.E., and Huffman, G.P., "Mechanisms of Ash Formation - A Fundamental Study Part I: Low Rank Coals and the Role of Calcium," Proc. Engineering Foundation Conference on Mineral Matter and Ash Deposition From Coal (in press) (1991).

Palmer, C.A., and Filby, R.H., "Distribution of Trace Elements in Coal from the Powhatan No. 6 Mine, Ohio," Fuel 63:3, 318 (1984).

PSI Technology Company, "Transformations of Inorganic Coal Constituents in Combustion Systems," Phase I Final report submitted to DOE/PETC under contract DE-AC22-86PCV90751, March (1990a). 
PSI Technology Company, "Transformations of Inorganic Coal Constituents in Combustion Systems," Quarterly Report Number 15 submitted to DOE/PETC under contract DE-AC22-86PC90751, August (1990b).

PSI Technology Company, "Transformations of Inorganic Coal Constituents in Combustion Systems," Quarterly Report Number 18 submitted to DOE/PETC under contract DE-AC22-86PC90751, May (1991).

Srinivasachar, S., Helble, J.J., Ham, D.O., and Domazetis, G., Progress Energy Combust. Sci. 16 (4), 303 (1990).

Vuthaluru, H.B., Gupta, R.P., Wall, T.F., and Domazetis, G., "Fouling Characteristics of Aluminium Treated Loy Yang Brown Coal," Proc. Engineering Foundation Conference on Mineral Matter and Ash Deposition From Coal (in press) (1991). 


\section{SECTION 8}

Task 8

DEVELOPMENT OF AN ENGINEERING MODEL OF ASH FORMATION DURING PULVERIZED COAL COMBUSTION

G. Wilemski and s. Srinivasachar, PSI Technology Company 


\section{DEVELOPMENT OF AN ENGINEERING MODEL OF ASH \\ FORMATION DURING PULVERIZED COAL COMBUSTION}

\subsection{Introduction}

The principal focus of this quarter's work was on the development of an algorithm for treating the effects of char fragmentation on ash particle release during char particle burnout. This initial effort was devoted to ash formation from the bituminous coals, Illinois \#6, Kentucky \#9 and 11, and Upper Freeport. Because these coals have moderate to high tendencies to form cenospheres, our attention centered on calculating ash release from cenospheric char particles. However, in a certain limit, the algorithm developed is also applicable to non-cenospheric char particles. The approach that we have taken is a direct outgrowth of many of the ideas developed at MIT by Kang (1991) in his Ph.D thesis. In the following sections we describe the basic ideas underlying the computation of the number and sizes of ash particles released from the char particle. Then we indicate in general terms how the ash release algorithm operates in the present mineral redistribution code. Finally, initial results are presented for Illinois \#6.

\section{Ash Release from Cenospheric Char Particles}

During the pyrolysis and devolatilization of pulverized bituminous coal, many particles become plastic and deform into thin-walled cenospheres due to high internal gas pressure. We will assume that most of the initial mineral content of each coal particle is retained in or on the cenosphere shell. During the subsequent burnout of the cenospheric char particle, the shell becomes thinner and weaker. Any large pores (blowholes) in the shell will lead to lateral buming of the shell and further weaken it. As the char matrix shrinks, mineral inclusions trapped in it are brought into contact. If the inclusions are molten, they may then coalesce. Eventually, the shell either burns out fully or breaks into a number of fragments. Either way, the coalesced mineral inclusions are released, producing ash particles whose size and composition are determined by the mineral particles found within localized sections of the shell or in the shell fragments.

The present mineral redistribution code provides us with a discrete set of coal particles of known mineral content giving us the capability of generating ash particles from each coal particle. In order to determine the number and size of the mineral inclusions that coalesce during burnout we adapt the ideas of Kang (1991) whose approach was analogous to that used to treat molecular collisions in the kinetic theory of gases. The basic idea is that as the cenosphere shell burns and becomes thinner, mineral inclusions at the edges of the shell are brought into contact with other inclusions that become exposed as the char burns away. If we assume that all such contacts result in coalescence, we need only estimate the number of such "collisions" that occurs for each mineral particle in order to calculate the final size of the ash particle released.

The number of mineral particles of diameter $\mathrm{D}_{\mathrm{j}}$ contacted by a larger mineral particle of diameter $D_{i}$ can be estimated by computing the volume encompassed by these two 
particles as the shell burns out and multiplying this volume by the number density of minerals of size $j$ in the shell. As sketched in Figure 8-1, this volume is proportional to the effective "collision cross-section" of the two particles times the thickness of the cenosphere. The volume of particle $i$ should also be subtracted from the volume swept out because the "collision partners" (the size $\mathrm{j}$ particles) are excluded from char occupied by the size $\mathrm{i}$ particle. Similarly, in computing the number density of mineral particles of a given size in the cenosphere, the shell volume should be corrected for the volume of all larger mineral particles. Mineral particles are obviously excluded from shell volume occupied by the larger minerals, effectively increasing their number density in the remaining carbon matrix. Thus the number of size $\mathrm{j}$ particles encountered by a size $\mathrm{i}$ particle, $\mathrm{N}_{\mathrm{ij}}$, is simply

$$
\mathbf{N}_{\mathrm{ij}}=\mathrm{V}_{\mathrm{ij}} \rho_{\mathrm{j}},
$$

where, assming spherical mineral particles, the encounter volume $V_{i j}$ is given by

$$
V_{i j}=\pi\left(D_{i}+D_{j}\right)^{2} \delta_{e} / 4-\pi D_{i}^{3 / 6},
$$

and $\delta_{\mathrm{e}}$ is an effective length discussed below. The number density $\rho_{\mathrm{j}}$ of size $\mathrm{j}$ particles is

$$
\rho_{\mathrm{j}}=\mathrm{n}_{\mathrm{j}} / \mathrm{V}_{\mathrm{j}}^{s_{\mathrm{j}}},
$$

where $n_{j}$ is the number of size $j$ mineral particles in the shell, and the effective shell volume, $\mathrm{V}_{\mathrm{j}}^{\mathrm{j}}$, for these particles is

$$
v_{j}^{s}=(\pi / 6)\left[\left(D_{O}^{3}-D_{I}^{3}\right)-\sum_{i>j} D_{i}^{3}\right]
$$

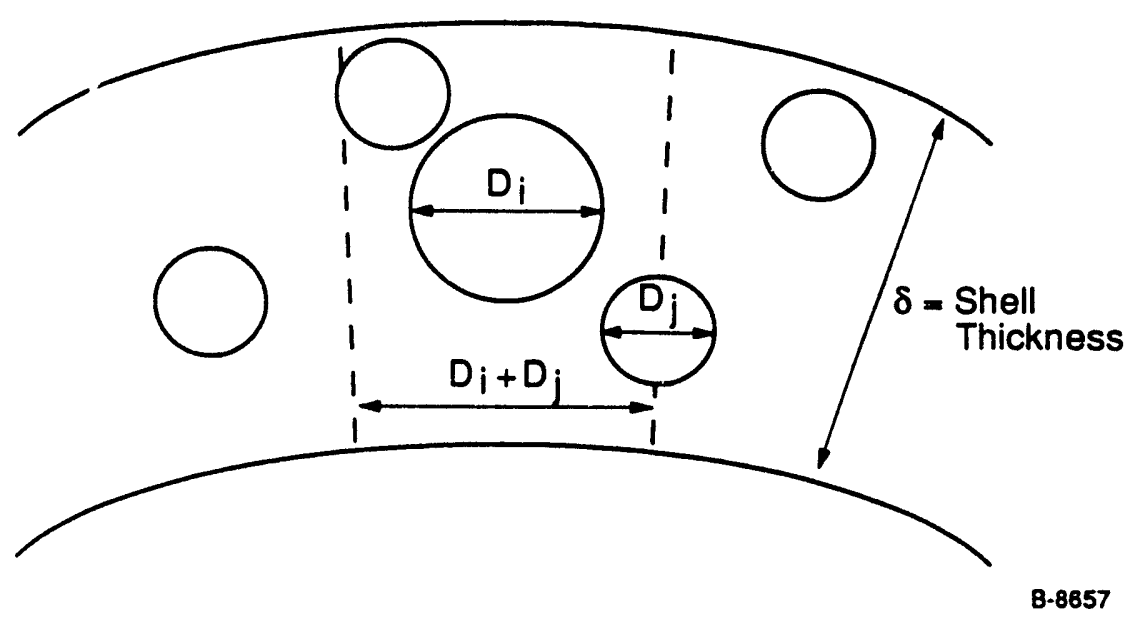

Figure 8-1. Two-Dimensional Schematic of Interaction Region Swept Out by Mineral Particles of Diameter $D_{i}$ and $D_{j}$ During Burnout. Only particles whose centers lie within the circular cross section of diameter $D_{i}+D_{j}$ will be intercepted by the larger mineral particle. 
In these equations, $\mathrm{D}_{\mathrm{O}}$ and $\mathrm{D}_{\mathrm{I}}$ are the outer and inner diameters, respectively, of the cenospheric particle. The effective length, $\delta_{e}$, in Eq. (8-2) is related to $\delta$, the thickness of the cenosphere shell,

$$
\delta=\left(\mathrm{D}_{\mathrm{O}}-\mathrm{D}_{\mathrm{I}}\right) / 2,
$$

but its specific value depends on two principal considerations. First, $\delta_{\mathrm{e}}$ should reflect the radial dimension of the shell volume containing all the mineral particles destined to end up as a single ash particle. Clearly, $\delta$ is an upper bound for this value. A smaller value is possible if the shell contained a sizeable fraction of pores large enough to disengage any ash particle encountering such a pore. Kang (1991) has shown that the separation length can be estimated from the formula

$$
\mathrm{L}_{\mathrm{s}}=(2 / 3) \mathrm{D}_{\mathrm{p}}\left(1-\phi_{\mathrm{p}}\right) / \phi_{\mathrm{p}},
$$

where $D_{p}$ is the diameter of the pore encountered by the ash particle and $\phi_{p}$ is the porosity associated with those pores. Obviously, in most situations, $D_{p}$ must exceed the ash particle diameter in order for the ash particle to be released. As discussed later, $\delta$ is typically 10 to $30 \%$ of $\mathrm{D}_{\mathrm{O}}$, that is, between 1 and $3 \mu \mathrm{m}$ for the smallest coal particles and between 20 and $60 \mu \mathrm{m}$ for the largest. Mineral particles larger than $\delta$ will not undergo coalescence for geometric reasons unless they are captured within the cenosphere interior - a special case. Purely geometric considerations imply that for mineral particles occupying a substantial fraction of the shell thickness, for example those with $D_{i}>\delta / 3$, it is unlikely that large pores with $D_{p}>D_{i}$ will be found between the mineral particle and the shell boundaries often enough to effect significant ash release. Thus, for this case we must have $\mathrm{L}_{s} \approx \delta$. In larger coal particles, smaller mineral particles will be captured efficiently by larger mineral particles precluding their release by intercepting a smaller pore. Again, we have $\mathrm{L}_{\mathrm{s}} \approx \delta$. Finally, if we consider small mineral particles $(D=2.5 \mu \mathrm{m})$ in small coal particles $\left(\mathrm{D}_{\mathrm{O}}=10\right.$ to $20 \mu \mathrm{m}$ ), we find from Eq. (8-6) (with $\mathrm{D}_{\mathrm{p}}=2.5 \mu \mathrm{m}$ and $\phi_{\mathrm{p}}=0.2$ ) that $\mathrm{L}_{\mathrm{s}}=6.7 \mu \mathrm{m}, \mathrm{a}$ value larger or, at best, comparable to $\delta$. Thus we conclude that $\delta$ is a suitable initial estimate for the separation length. A second consideration addressed by Kang (1991) concerns the effect of the geometry of the spherical shell on the coalescence process. As burning proceeds, particles initially too far apart to coalesce in a linear burniag geometry can approach each other as the spherical particle shrinks. Thus additional volume is consumed bringing more mineral particles together. The situation is illustrated in Figure 8-2. Kang (1991) estimated a conical correction factor for this effect by taking the shell volume times the ratio of the mineral particle cross-sectional area to the total area of the spherical surface at the inner ash separation distance. In this case, that corresponds to the inner surface of the cenosphere. Thus we find

$$
\pi\left(D_{i}+D_{j}\right)^{2} \delta_{e} / 4=(\pi / 6)\left(D_{O}^{3}-D_{I}^{3}\right) \pi\left(D_{i}+D_{j}\right)^{2} /\left(4 \pi D_{I}^{2}\right) .
$$




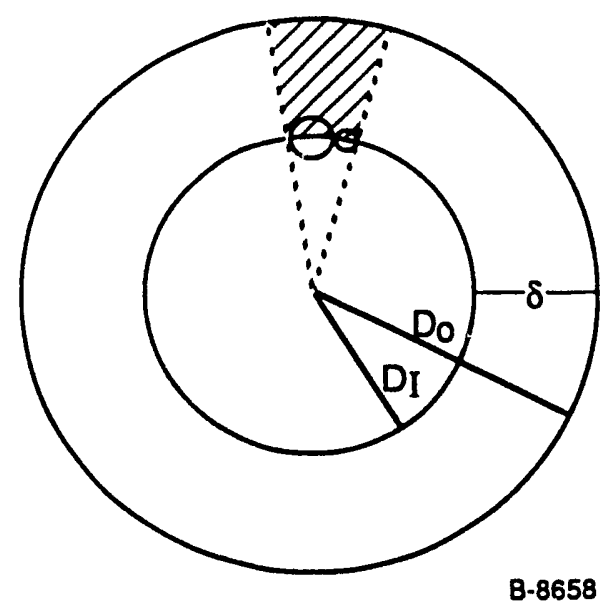

Figure 8-2. Two-Dimensional Illustration of conical Volume Swept Out by Two Mineral Particles Due to Spherical Shape of Char Particle

Upon simplifying, we obtain

$$
\delta_{\mathrm{e}}=(\delta / 3)\left(1+\gamma^{-1}+\gamma^{-2}\right)
$$

where

$$
\gamma=\mathrm{D}_{\mathrm{I}} / \mathrm{D}_{\mathrm{O}}
$$

From Eq. (8-8) and (8-9), we see that in the limit of very thin shells (i.e., $\gamma=1$ ), $\delta_{e}=\delta$, but that for thicker shells the conical correction factor can become significant.

We next address the calculation of $\delta$, the shell thickness. The following considerations based on conserving volume lead to apparently reasonable estimates. Let $\mathrm{V}$ be the initial total volume of the coal particle and $V_{M}$ be the volume of its included mineral matter. Then the initial "carbon" volume is simply $V-V_{M}$. If $f_{v}$ is the volatile carbon fraction and $\phi$ is the total porosity of the shell after swelling and devolatilization, then the total volume of the shell is $\left(V-V_{M}\right)\left(1-f_{v}\right) /(1-\phi)+V_{M}$. In terms of $D_{I}$ and $D_{O}$, we have

$$
(\pi / 6)\left(D_{O}{ }^{3}-D_{I}^{3}\right)=\left(V-V_{M}\right)\left(1-f_{V}\right) /(1-\phi)+V_{M}
$$

To account for the possibility of swelling, we introduce an empirical swelling index $S$, such that

$$
(\pi / 6) \mathrm{D}_{\mathrm{O}}^{3}=\mathrm{SV}
$$

Upon combining Eq. (8-10) and (8-11) and solving for $\mathrm{D}_{\mathrm{I}} / \mathrm{D}_{\mathrm{O}}$, we find

$$
\gamma=\mathrm{D}_{\mathrm{I}} / \mathrm{D}_{\mathrm{O}}=\left\{1-\mathrm{S}^{-1}\left[\left(1-\mathrm{V}_{\mathrm{M}} / \mathrm{V}\right)\left(1-\mathrm{f}_{\mathrm{V}}\right) /(1-\phi)+\mathrm{V}_{\mathrm{M}} / \mathrm{V}\right]\right\}^{1 / 3} \text {. }
$$


Finally, Eq. (8-5) and (8-9) enable us to express $\delta$ in terms of $\gamma$ :

$$
\delta=\mathrm{D}_{\mathrm{O}}(1-\gamma) / 2
$$

For coal particles large enough to representatively sample the entire mineral size distribution, $V_{M} / V$ and, hence $\gamma$, will be independent of coal particle size. To make a simple estimate of $\delta$, let $V_{M} / V=0.1, f_{v}=0.4, \phi=0.2$, and $S=1$. We then find $\gamma=0.61$ and $\delta=0.2 \mathrm{D}_{\mathrm{O}}$, which seems reasonable.

We conclude this description of ash release by considering one other possible ash coalescence mechanism. If the cenospheric shell contains one or more large blowholes, the transport of oxygen into the particle interior will not be hindered, and burning of the interior shell surface is likely to proceed at a rate comparable to that of the external surface. In this case, ash particles will be formed on the inner side of the shell where, due to their spatial confinement, they have a high probability of coalescing with each other to form a larger, "interior" ash particle. To estimate the fraction of ash particles that may coalesce in this way, we imagine that the inner and outer shell surfaces have the same linear recession rate, and we compute the fraction of shell volume consumed by interior burning. The two fronts meet halfway through the shell (an excellent approximation for $D_{O} \approx D_{I}$, i.e. thin walled cenospheres). Thus the fraction $x_{c}$ of mineral particles coalescing to form the interior ash particle is given by the volume ratio,

$$
\mathrm{x}_{\mathrm{c}}=\left[\left(\mathrm{D}_{\mathrm{O}^{-\delta}}\right)^{3}-\left(\mathrm{D}_{\mathrm{O}}-2 \delta\right)^{3}\right] /\left[\mathrm{D}_{\mathrm{O}^{3}}-\left(\mathrm{D}_{\mathrm{O}}-2 \delta\right)^{3}\right] \text {. }
$$

With Eq. (8-13) this expression can be simplified to read

$$
x_{c}=\left[(1+\gamma)^{3 / 8}-\gamma^{3}\right] /\left(1-\gamma^{3}\right) \text {. }
$$

With the above estimate of $\gamma=0.61$, we find $x_{c}=0.38$. Thus for situations in which this interior ash coalescence mechanism can occur, we expect a significant reduction in the number of ash particles released per coal particle.

To get a rough idea of the number and size dependence of the ash particles released as a function of coal particle size, we adapt another argument of Kang (1991). To simplify matters we assume that all mineral particles are the same size. Kang argued that the number of mineral particles coalescing to form a single ash particle could be estimated as the ratio of the separation length $\mathrm{L}_{\mathbf{s}}$ and a coalescence length $\mathrm{L}_{\mathbf{c}}$. We have already suggested that for cenospheric ash release $L_{s} \approx \delta$. From the mineral particle number density $\rho$, we may estimate that $\mathrm{L}_{\mathrm{c}} \approx(\rho)^{-1 / 3}$. Thus the number $\mathrm{N}_{\mathrm{af}}$ of ash particles/char fragments may be obtained by dividing the number of mineral particles per coal particle by the number of mineral particles per ash particle. We find

$$
\mathrm{N}_{\mathrm{af}} \propto\left(\rho \delta \mathrm{D}_{\mathrm{O}}^{2}\right) /\left(\delta /(\rho)^{-1 / 3},\right.
$$


which simplifies to

$$
\mathrm{N}_{\mathrm{af}} \propto \mathrm{D}_{\mathrm{O}}^{2} \rho^{2 / 3}
$$

Since $\rho$ is independent of $\mathrm{D}_{\mathrm{O}}$, at least for larger coal particles, we see that $\mathrm{N}_{\mathrm{af}}$ is predicted to vary as the square of the coal particle diameter for this model of cenospheric ash release. The average fragment size $V_{f}$ is also predicted to increase linearly with coal particle diameter,

$$
\mathrm{V}_{\mathrm{f}} \propto\left(\delta \mathrm{D}_{\mathrm{O}}^{2}\right) / \mathrm{N}_{\mathrm{af}}=\delta / \rho^{2 / 3}
$$

since $\delta$ varies linearly with $\mathrm{D}_{\mathrm{O}}$ as seen in Eq. (8-13).

\section{Description of Ash Release Algorithm}

To implement the above description of ash release in the engineering model computer code, the following procedure is used. The initial stages of the calculation are carried out using the mineral redistribution code described in previous quarterly reports and a conference paper (Wilemski et al., 1991). After the mineral inventory of each coal particle is established, the ash release procedure is begun. In the present version of the code, to simplify the bookkeeping involved, coal particles are analyzed in order of largest to smallest, followed by the analysis of all excluded mineral particles. To compute the ash released from a given coal particle, the code first calculates $\delta$ and $D_{O}$ via Eqs. (8-11) through (8-13). Next the number densities $\rho_{\mathrm{i}}$ of the different sized mineral particles are computed from Eq. (8-3) and (8-4). The final preliminary step involves Eq. (8-1) and (8-2) to calculate the $\mathrm{N}_{\mathrm{ij}}$ factors, the average numbers of various sized mineral particles that coalesce into a single ash particle.

The next step determines the fate of all mineral particles whose diameter exceeds $\delta$. The fraction $x_{c}$ of these particles is retained as part of the interior ash particle, if that option is in force. The remainder are placed into the excluded mineral category on the grounds that they would be released from the char during burnout with little or no coalescence with smaller particles. After this step only minerals smaller than $\delta$ are left in the shell. Of these the fraction $x_{c}$ of each size and type is randomly selected for inclusion in the interior ash particle, if one is being formed. The remaining particles are then combined to form ash particles in a sequential process beginning with the largest mineral particles, since these occupy the largest volume of char.

The mineral particles of each size to be combined with a given particle are selected randomly (averages are used if the numbers are large), and the inventory of mineral sizes and types is adjusted at each step. After the smallest mineral particles have been added, organically bound inorganics are added in proportion to the char volume "consumed" in forming this ash particle. The ash particle is then analyzed, as in the earlier code, to determine its size and composition, and the results are stored to await statistical analysis after all ash particles have been treated. When particles of a given size are exhausted in the shell, 
mineral particles of the next smaller size are then considered as the seed particles for the accumulation of the remaining smaller mineral particles. In this way, a sequence of ash particles of descending size is generated from each coal particle. Figure 8-3 schematically illustrates the ash generation procedure from a cenospheric char particle.
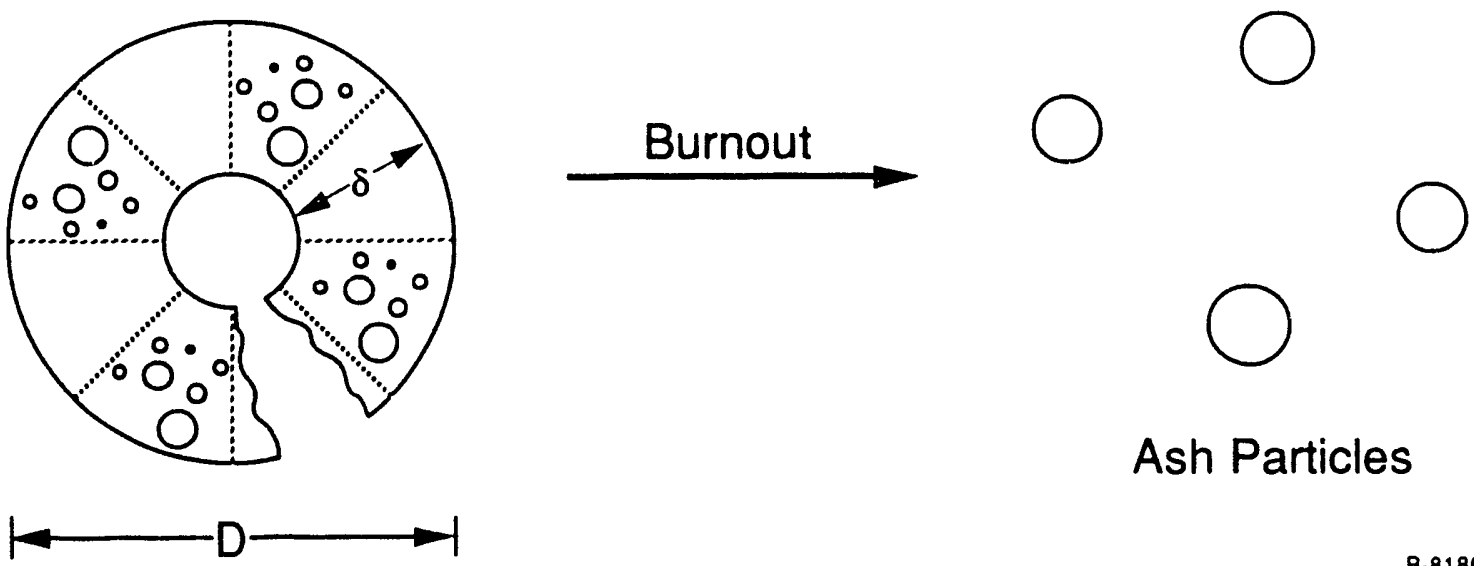

Ash Particles

Figure 8-3. Schematic representation of ash particle formation and release from a cenospheric char particle. Minerals within the dashed sectors come into contact and coalesce during burnout. Only four ash particles are shown, although many hundreds are typically produced from the larger coal particles.

\section{Present State of Code Development}

The algorithm outlined above has been fully coded (with one exception noted below) and debugged. The code runs successfully and appears to give satisfactory results in qualitative accord with our intuitive expectations. However, much testing and refinement of the algorithm remains to be done. In addition, the treatment of ash release from the $10 \mu \mathrm{m}$ coal particles is presently incomplete. Because they are much more numerous than any other size range, these particles are stored as several hundred classes of the most probable types rather than individually. This complicates the ash release algorithm somewhat, and the resolution of these difficulties will be carried out in the next quarter. The current treatment of the $10 \mu \mathrm{m}$ coal particles results in every particle of each class being treated identically, whereas some allowance should be made for the statistical variations that are bound to occur. The net effect on the results is that there is some uncertainty regarding the ash particle distribution in the smallest two ash size classes. A further complication stems from the simulation of ash formation using a small number (6) of discrete mineral sizes. As a consequence, the resulting ash particles are distributed over discrete sizes that are a 
particularly poor representation of a continuous size spectrum at the small end, i.e. for ash diameters $<20 \mu \mathrm{m}$. Various strategies for accurately simulating a continuous size spectrum are being considered, and the status of this problem will be addressed in the next report.

An example of the results produced by the current version of the model is shown in Tables 8-1 and 8-2 for Illinois \#6. The full ash release procedure, as described above, was used to generate these results, which should be considered merely as indicative of the capabilities of the model and not as an ultimate prediction to be compared with experiment. Nevertheless, the total number percents listed in Table 8-1 agree reasonably well with the 


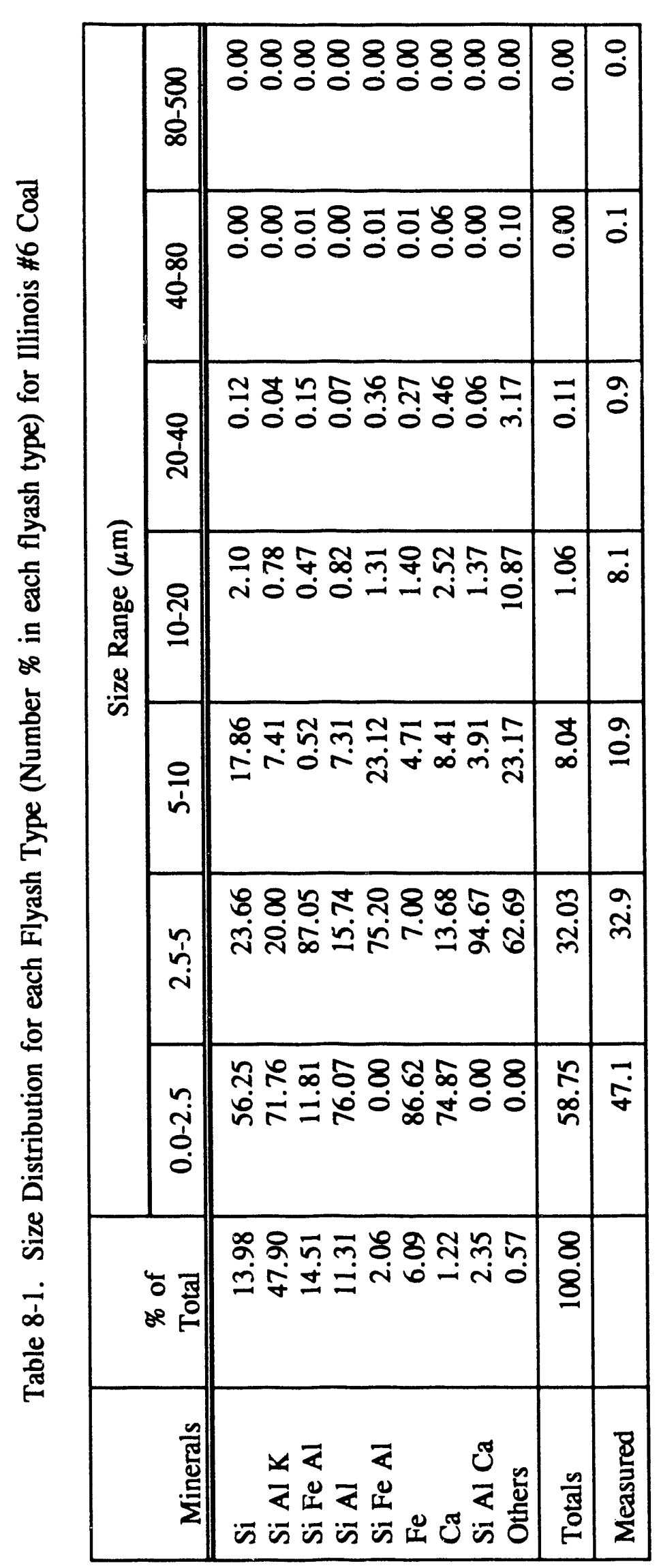




\begin{tabular}{|c|c|c|}
\hline \multirow{7}{*}{ 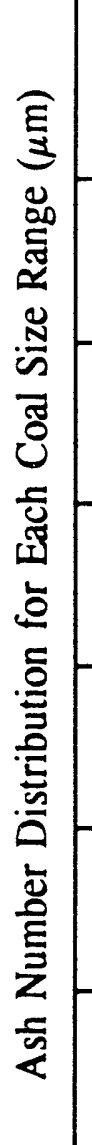 } & 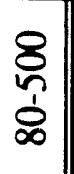 & 00000000000000000 \\
\hline & $\begin{array}{l}8 \\
\infty \\
0 \\
\dot{y}\end{array}$ & $\pm 00000-1-n-0000 \mathrm{mn}$ \\
\hline & \begin{tabular}{c} 
o \\
\multirow{2}{0}{}
\end{tabular} & 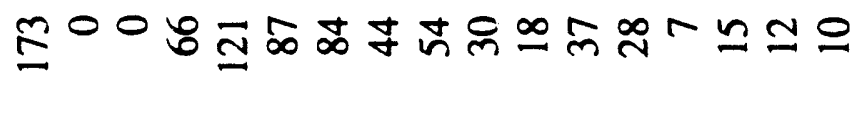 \\
\hline & 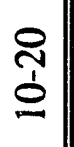 & 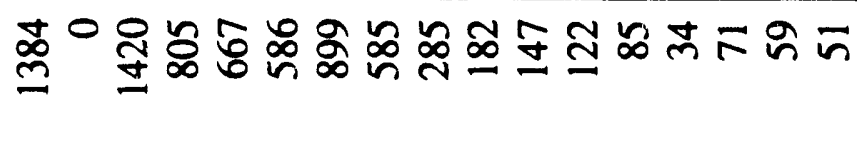 \\
\hline & $\frac{0}{n}$ & 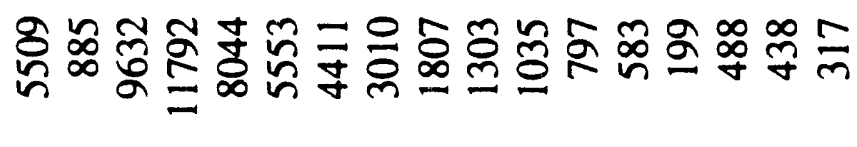 \\
\hline & $\underset{n}{n}$ & 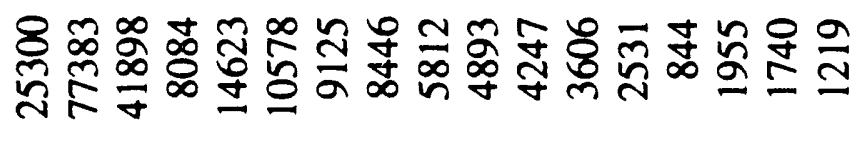 \\
\hline & $\underset{\tilde{c}}{\sim}$ & 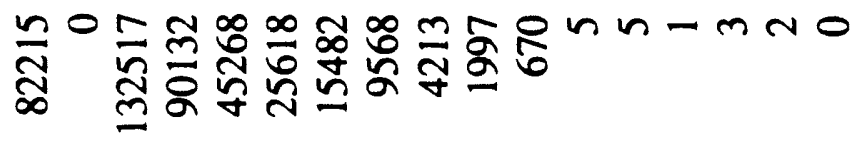 \\
\hline \multirow{3}{*}{$\overline{\overline{\bar{z}}}$} & 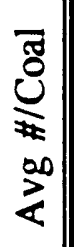 & 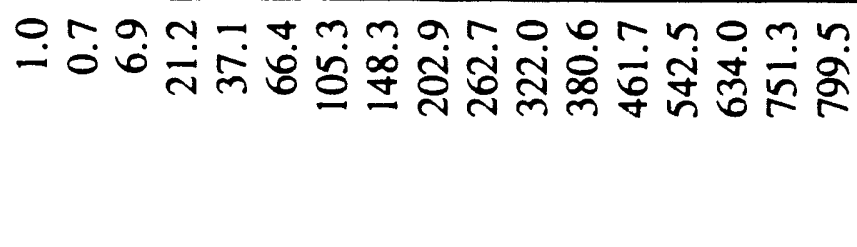 \\
\hline & 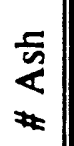 & 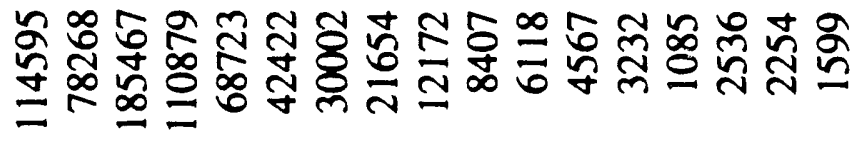 \\
\hline & نे & 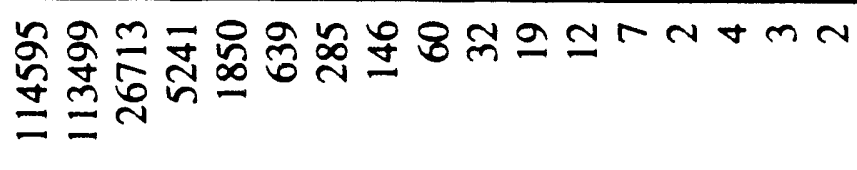 \\
\hline 言 & نे & 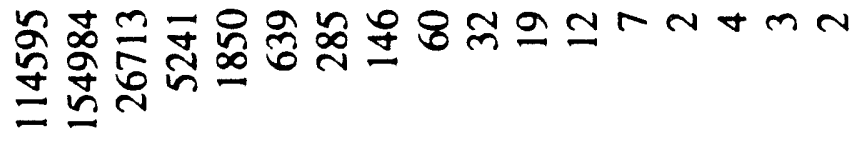 \\
\hline \multicolumn{2}{|c|}{ 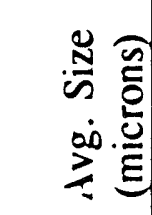 } & 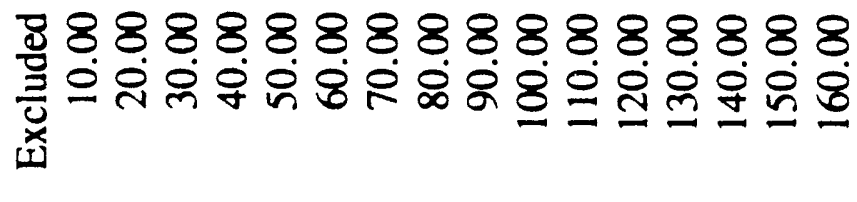 \\
\hline
\end{tabular}


measured values, which are listed for comparison, except for the 10 to $20 \mu \mathrm{m}$ particles. The discrepancies could easily be due to the generation of discrete ash sizes mentioned above, although more work is needed to confirm this. Table $8-2$ provides a detailed breakdown of the numbers and sizes of ash particles produced by each coal particle size class. The first two columns list, respectively, the number of coal particles initially generated in each size class and the number analyzed for ash release. The discrepancy in the $10 \mu \mathrm{m}$ class is due to the presence of small coal particles without any included mineral particles. Mineral particles that are reclassified as excluded during the ash release procedure are also not counted as ash particles produced from a class of coal particles. This accounts for the further reduction in the number of ash particles produced by $10 \mu \mathrm{m}$ coal particles that is evident in column 3 . Results of this type will assist us in ascertaining whether the char fragmentation model presented herein is correctly simulating the key physical features responsible for ash coalescence and release during burnout.

\section{$\underline{\text { References }}$}

Kang, S.-G. (1991) "Fundamental Studies of Mineral Matter Transformation during Pulverized Coal Combustion: Residual Ash Formation," Ph. D. Thesis, Massachusetts Institute of Technology.

Wilemski, G., Srinivasachar, S., and Sarofim, A.F. (1991) "Modeling of Mineral Matter Redistribution and Ash Formation in Pulverized Coal Combustion," to appear in Proceedings of the Engineering Foundation Conference on Inorganic Transformations and Ash Deposition, Palm Coast, Florida. 


\author{
APPENDIX A \\ Chemically Beneficiated Pittsburgh \#8 \\ Coal Minerals \\ CCSEM Data from UNDEERC
}

A-1/A-2 


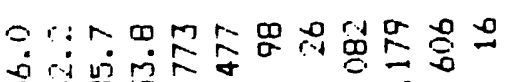

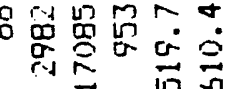

i

$\sum_{-1} \quad$ in

$\vec{D}$

m

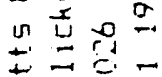

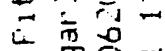

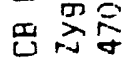

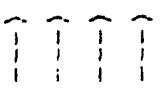

总崖

它焉焉出

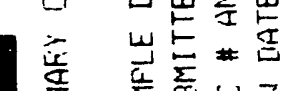

in

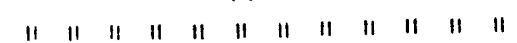

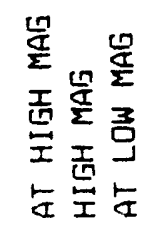

m

空皆

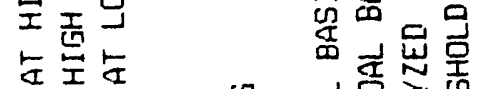

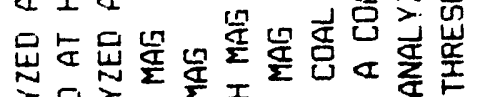

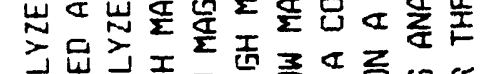

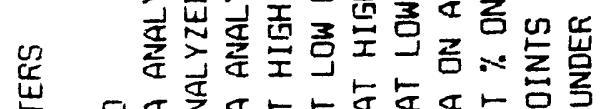

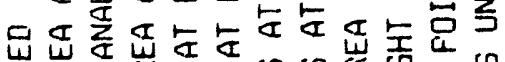

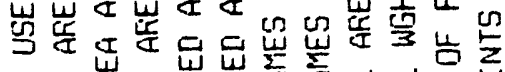

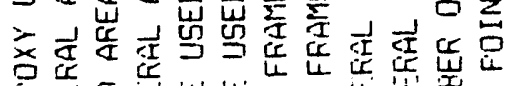

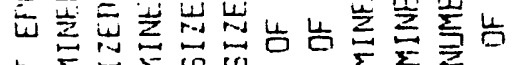

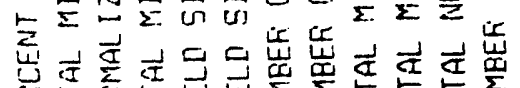

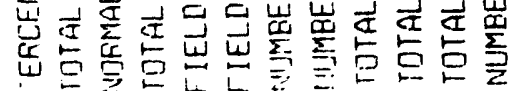

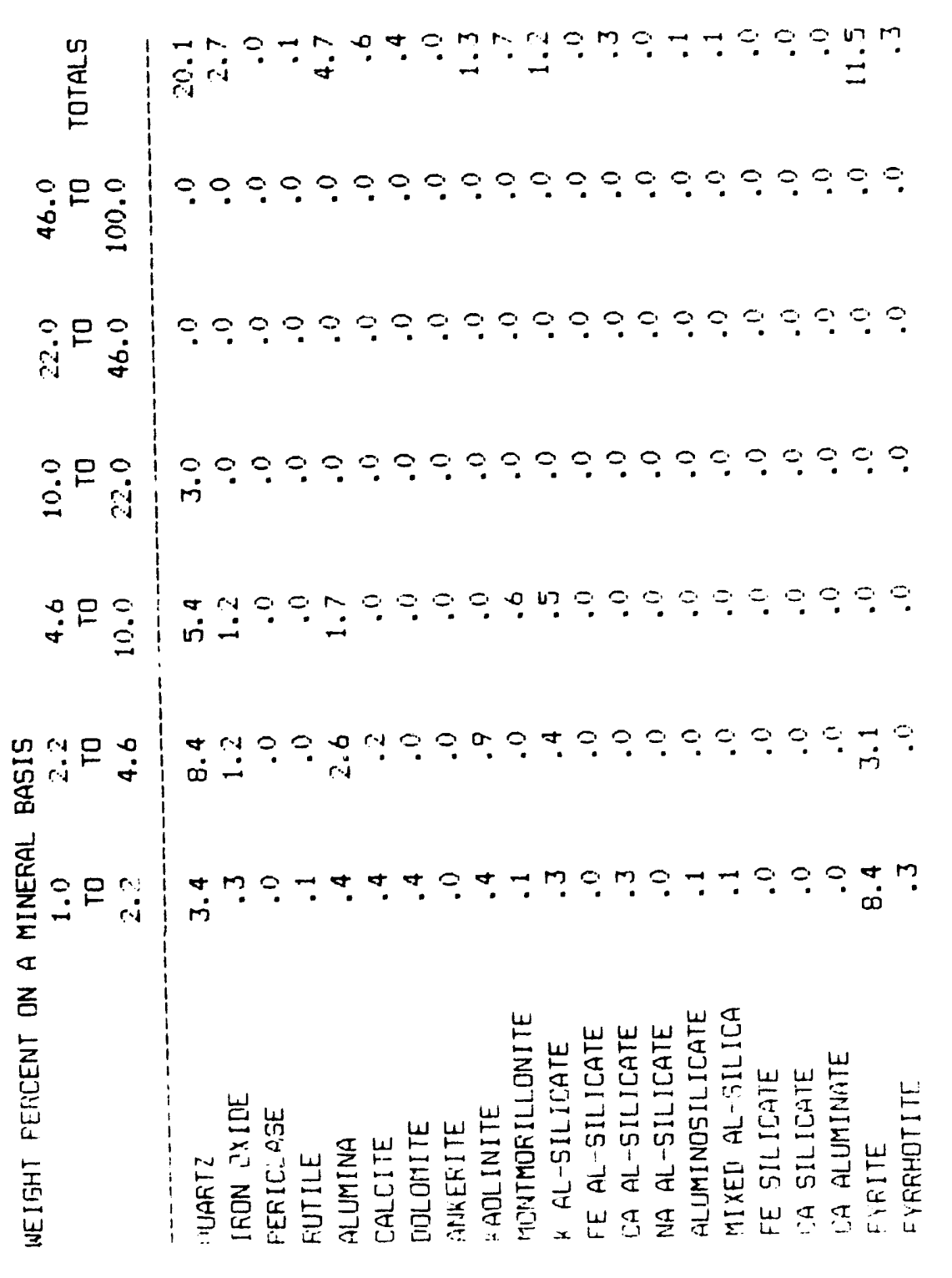



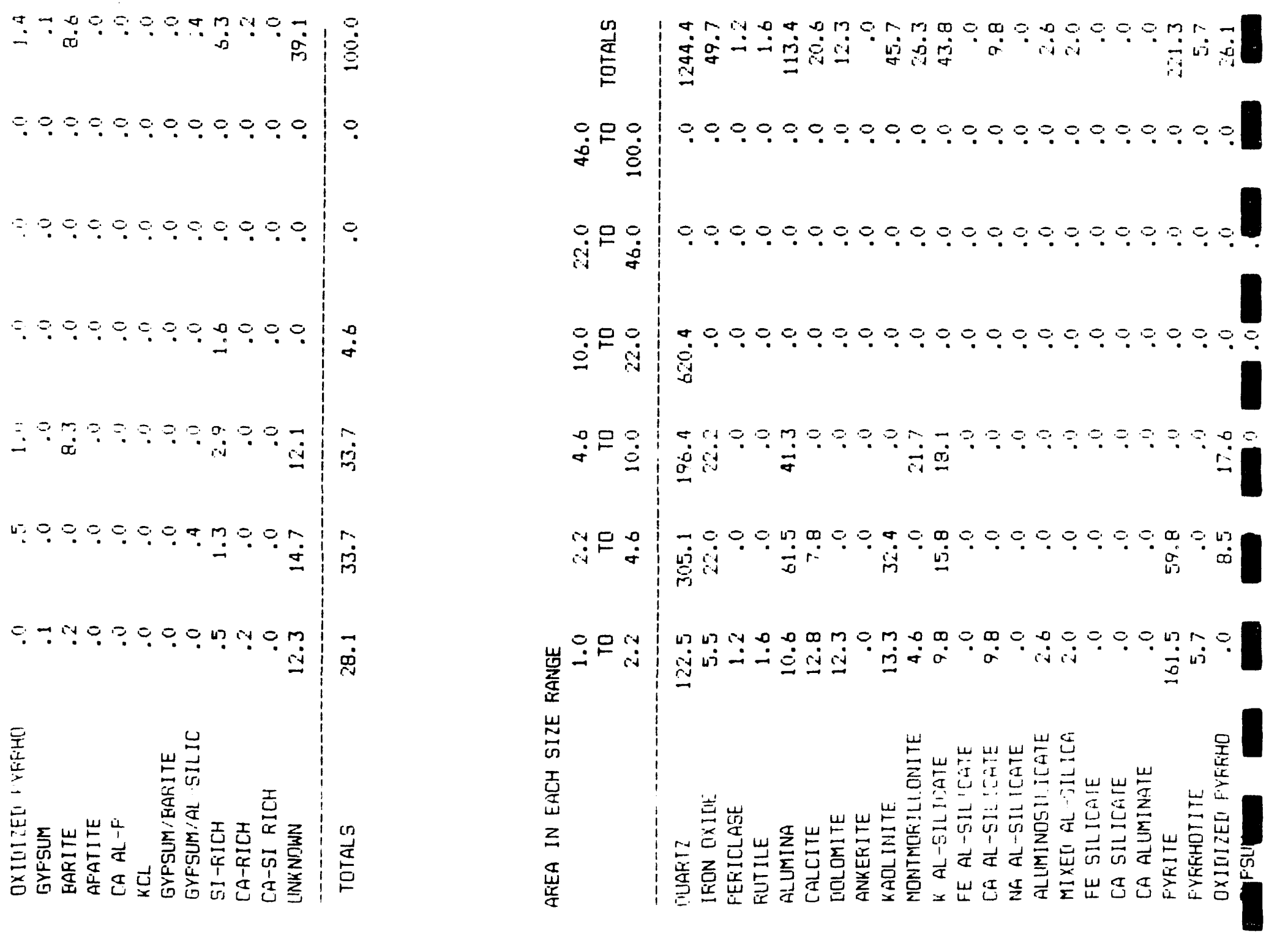


\begin{tabular}{|c|c|}
\hline 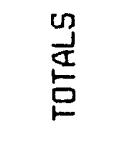 & 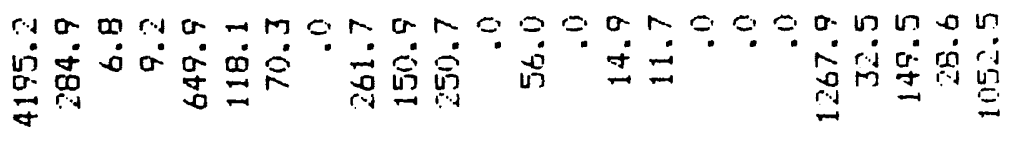 \\
\hline$\stackrel{9}{\dot{8}}$ & $0: 0: 090:$ \\
\hline 是口 & $9: 0: 0: 0: 0$ \\
\hline$\stackrel{0}{0}$ & $\stackrel{0}{\circ}: 0: 0:$ \\
\hline$\stackrel{\circ}{\circ}:$ & 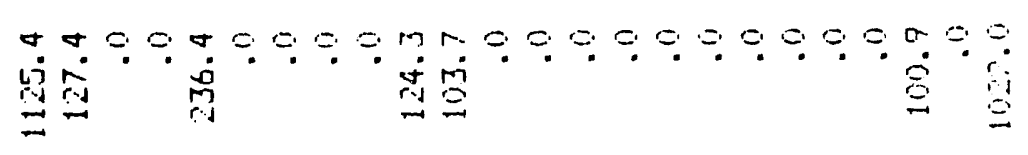 \\
\hline : & 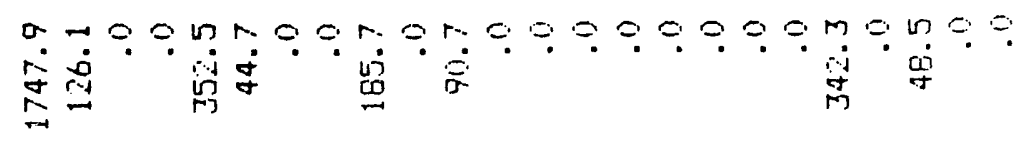 \\
\hline 뭉 & 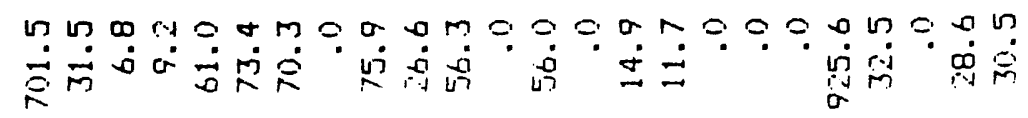 \\
\hline & 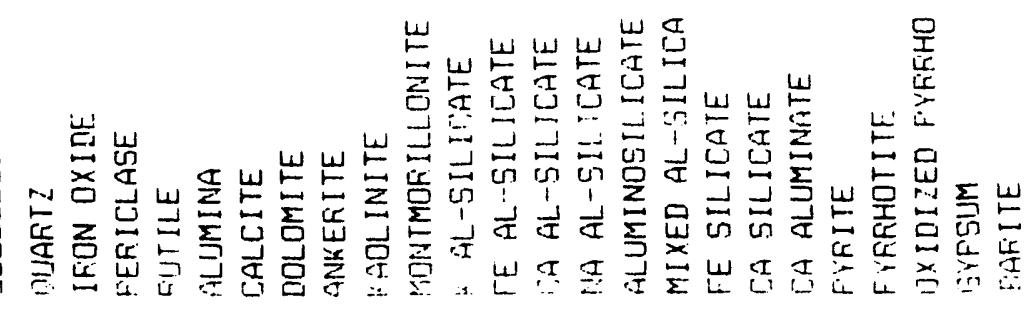 \\
\hline
\end{tabular}




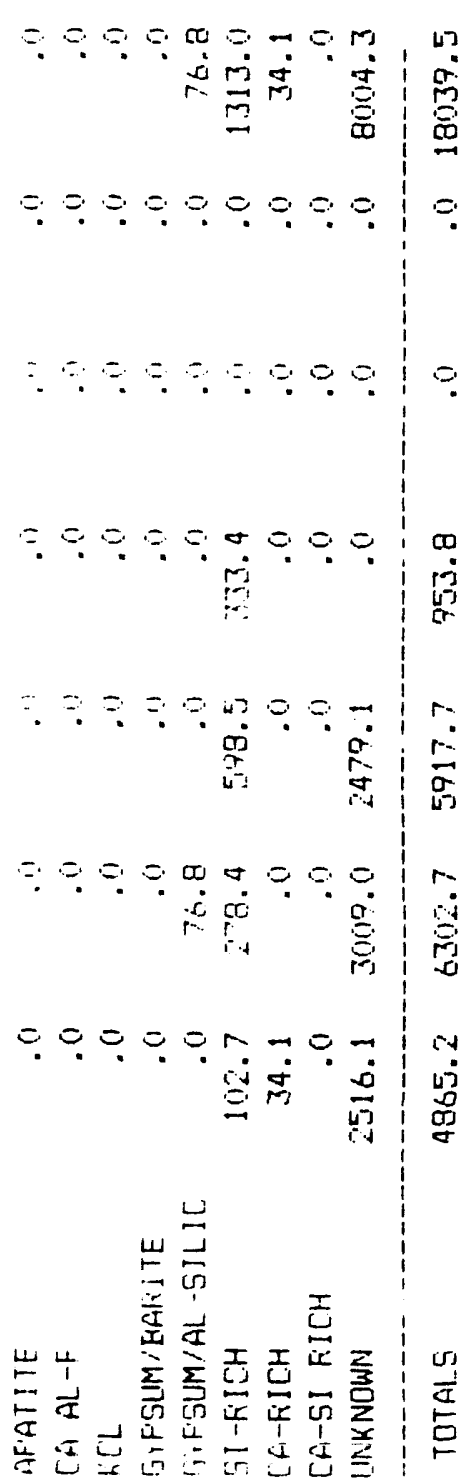

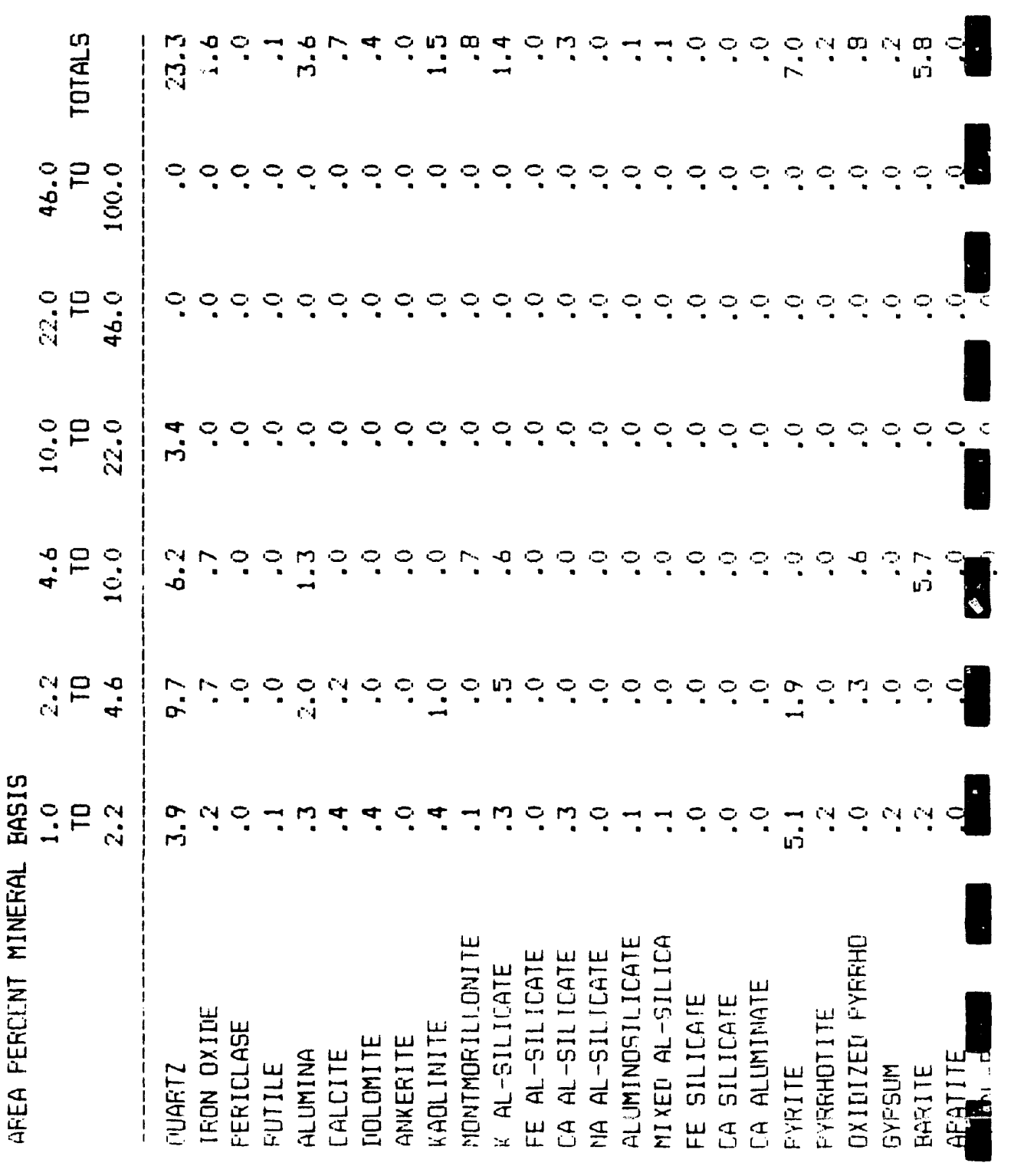


I

I

,

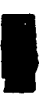

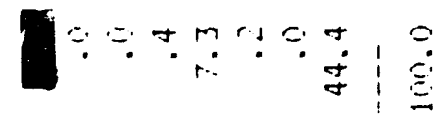

10005000

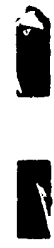

1989

$\because=\because m=\because r ; \quad r i$

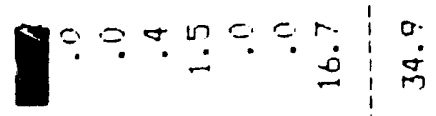

T- $=0 r+0 \%$ a

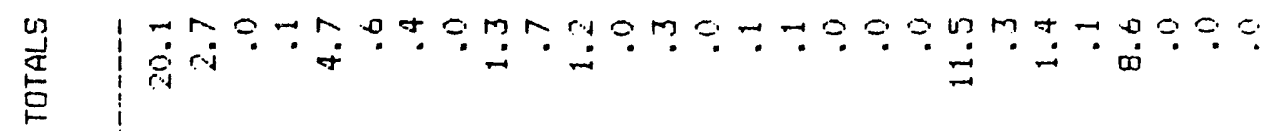

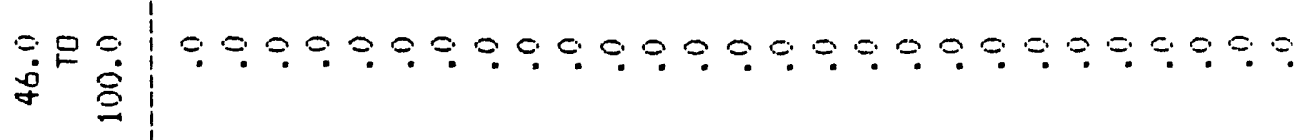

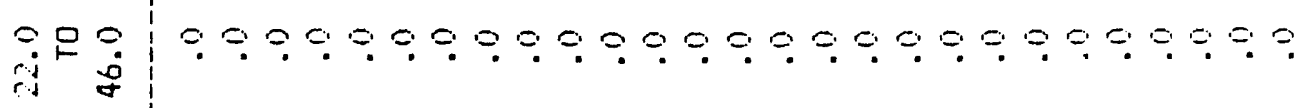

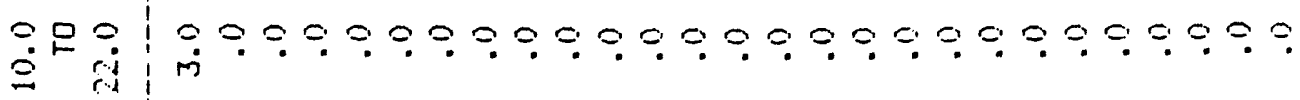

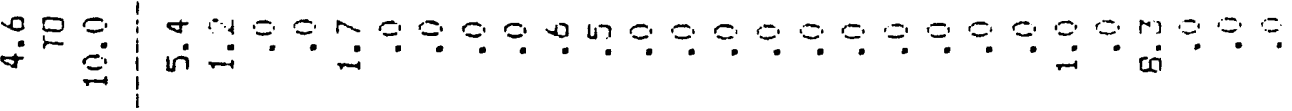

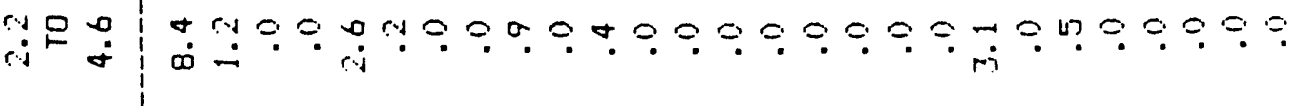

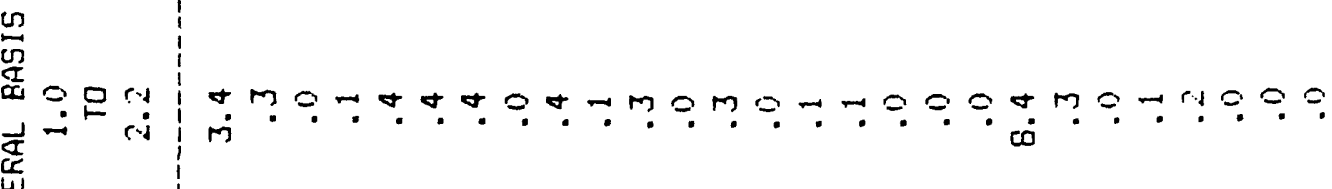

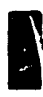

$\omega \stackrel{-1}{=}$

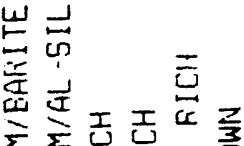

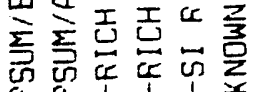

$\frac{\sqrt[1]{2}}{\frac{1}{5}}$

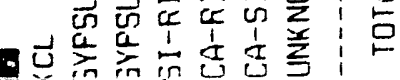

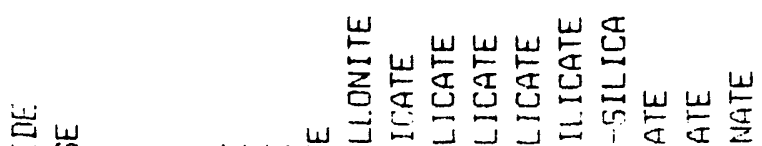

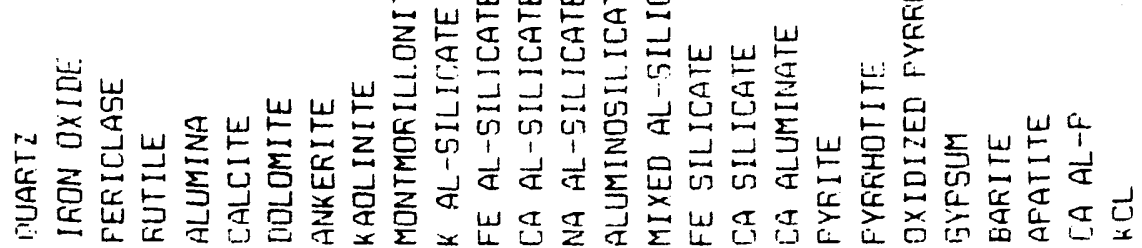



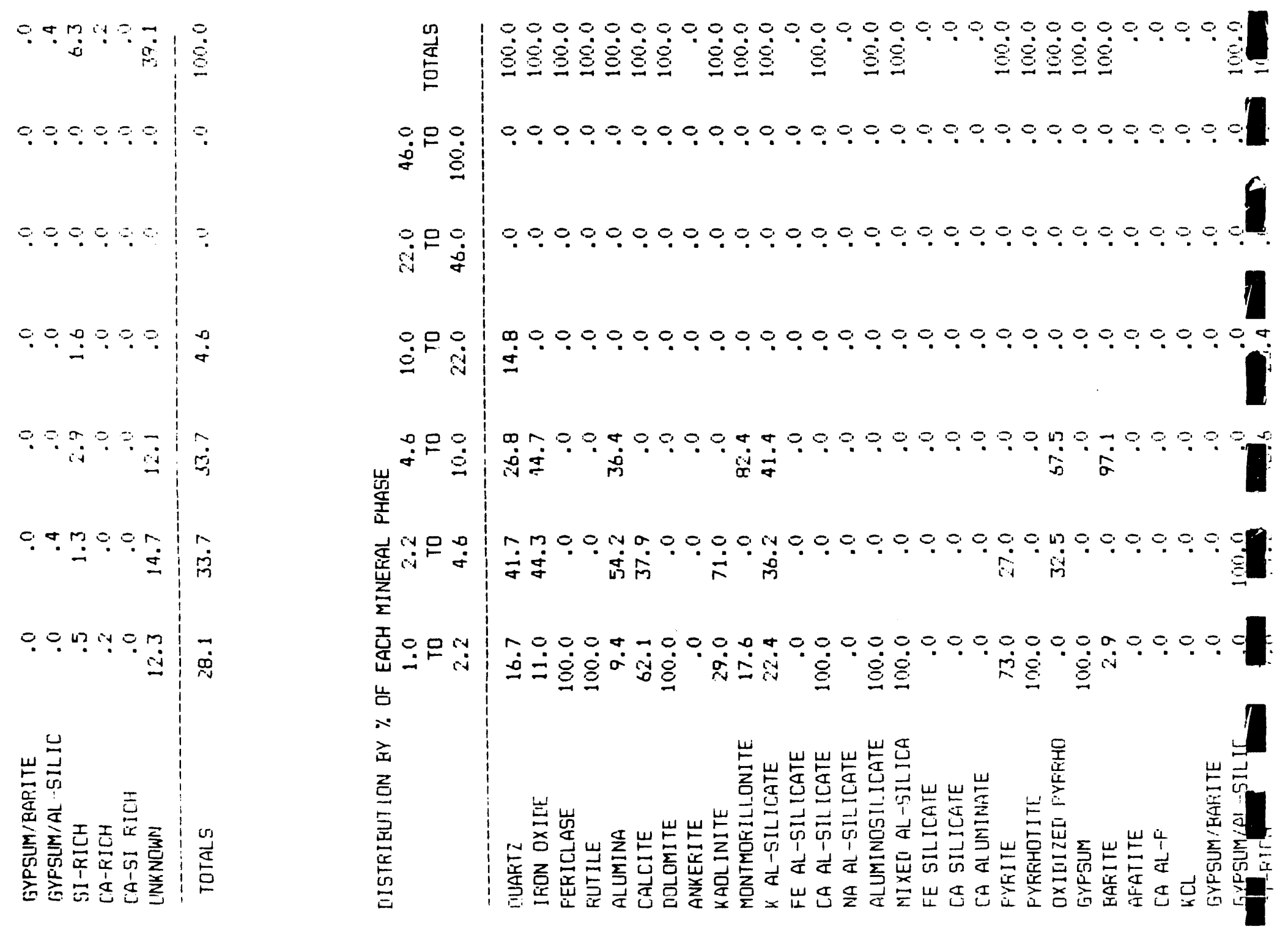


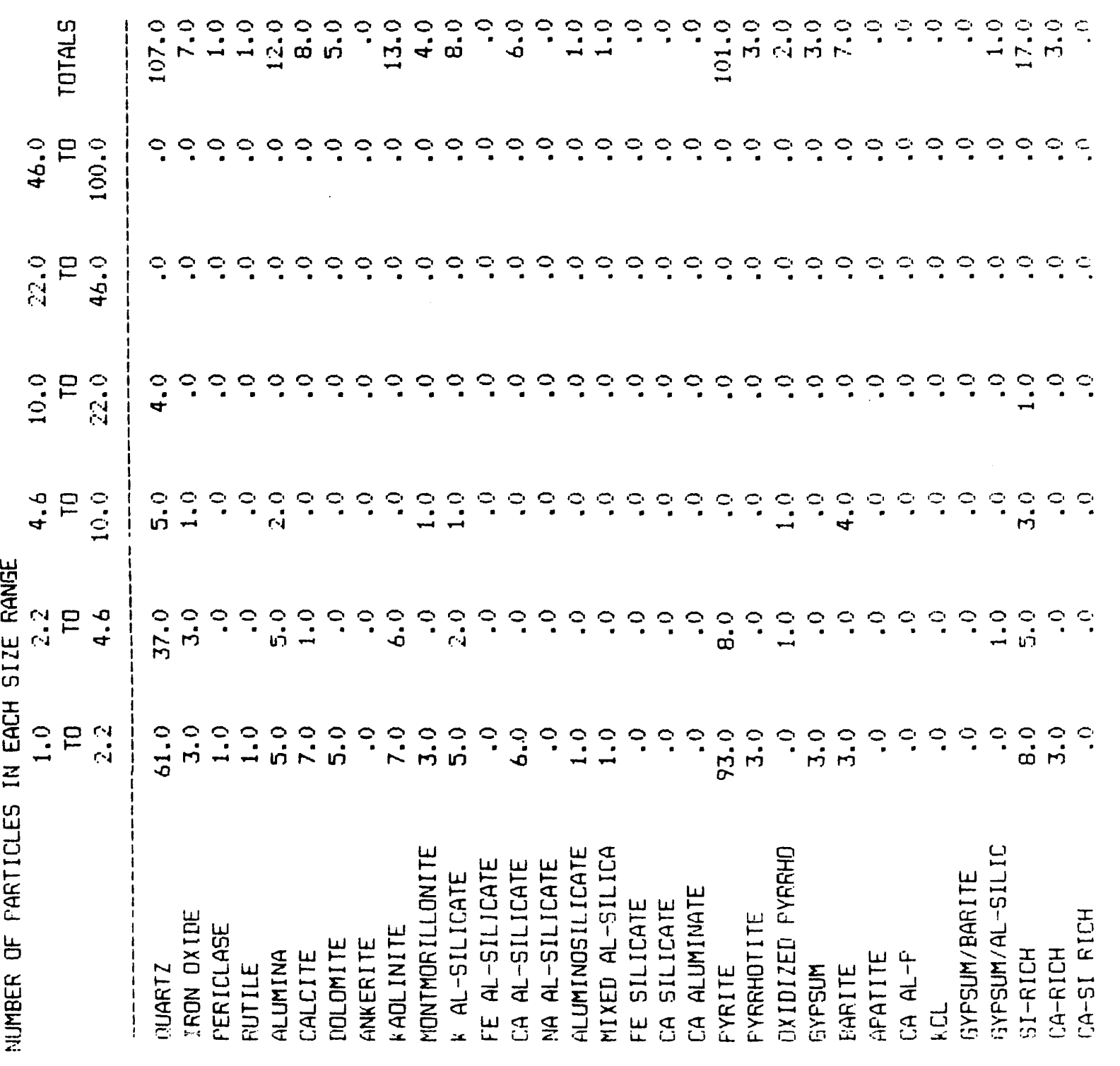




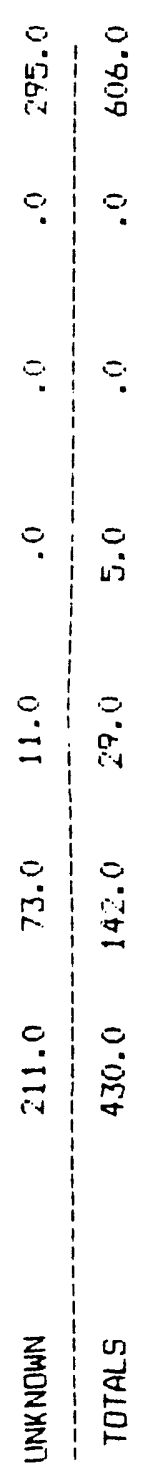

蛋

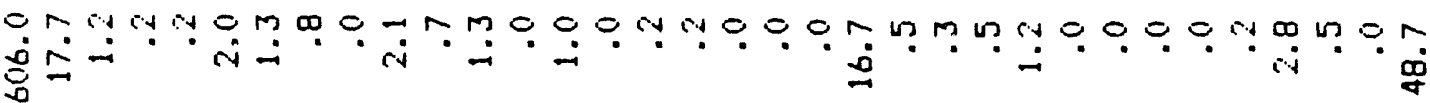

咊

台台

을 荡岂

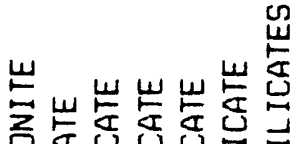

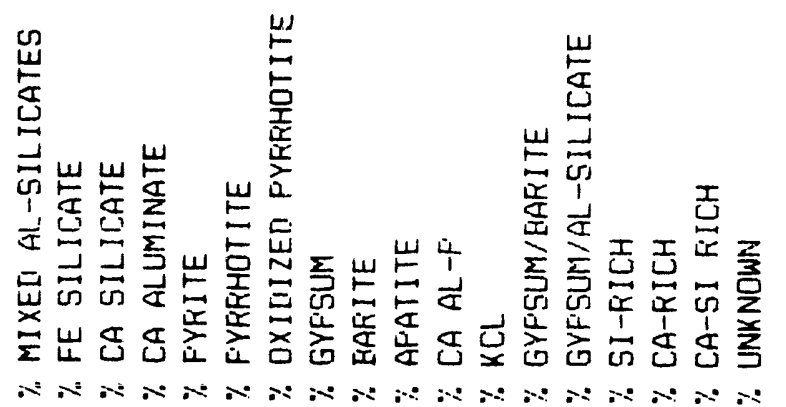




\section{APPENDIX B \\ Chemically Beneficiated Pittsburgh \#8 \\ $1500^{\circ} \mathrm{C}, 7 \% \mathrm{O}_{2}, \mathrm{~d}_{\text {coal }}<90 \mu \mathrm{m}$ PSIT ash CCSEM Data from UNDEERC}


GIMIMARY OF CCSEM RESULTS: PROG VERSION 2BF $8 / 21 / 90$

SAMPLE DESCRIPTION --> 47062561. CCS PSI-CIT TSK2 RUN\#.MCL2-T-6 TOT FIITER 150C SUBMITTER $\quad-\rightarrow$ ZYGARL

ICC \# AND FUND \# $-\rightarrow 47062561$

$7 \% 0 \mathrm{O}_{2},<10 \mathrm{um}$

RUN DATE AND TIME $\quad-->\quad 5 \quad 291991 \quad 13: 47$

Filter Wispersion!

SUMMARY OF PARAMETERS

TOTAL MINERAL AREA ANALYZED AT HIGH MAG

$=\quad 5608.3$

NORMALIZED AREA ANALYZED AT HIGH MAG

TOTAL MINERAL AREA ANALYZED AT LOW MAG

$=2179957.0$

FIELD SIZE USED AT HIGH MAG

19578.1

FIELD SIZE USED AT LOW MAG

NUMBER OF FRAMES AT HIGH MAG

NUMBER OF FRAMES AT LOW MAG

TOTAL NUMBER OF POINTS ANALYZED

NUMBER OF POINTS UNDER THRESHOLD

$=115519.773$

$=2494610.477$

$=$

$=$

$=$

36

(-)

1765

$=$

3

WEIGHT PERCENT ON A MINERAL BASIS

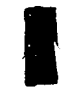

EIGHT PERCENT ON A MINERAL BASIS

$\begin{array}{ll}1.0 & 2.2 \\ T O & T O\end{array}$

TO

TO

2.2

4.6

4.6

TO

10.0

10.0

22.0

TO

$?: \therefore 7$

2.9

QUARTZ

IRON OXIDE

.3

PERICLASE

.1

9.2

RUTILE

ALUMINA

CALCITE

DOLOMITE

ANKERITE

KAOLINITE

.0

.0

.0

.0

1.7

22.0

46.0

TO

100.0

TOTALS

MONTMORILLONITE

K AL-SILICATE

FE AL-SIIICATE

CA AL-SILICATE

NA AL-SILICATE

ALUMINOSILICATE

MIXED AL-SILICA

FE SILICATE

CA SIIICATE

CA ALUMINATE

PYRITE

PYRRHOTITE

OXIDIZED PYRRHO

GYPSUM

BARITE

APATITE

CA AL-P

KCL

GYPSUM/BARITE

.5

1.3

.2

.0

.0

.1

.9

.0

.1

.0

.0

.0

.0

.0

.0

.0

.0

.0

.0

.0

.5

.0

.0

23.8
CA-SI RICH

UNKNOWN

GYPSUM/AL-SILIC

CA-RICH
SI-RICH
11.1

.7

.0

.7
.0

7.0

.6

.0

.0

1.5

.0

.4

.0

2.8

.9

.3

1.0

.0

.0

.3

$\div 0$

.0

.5

.0

.0

.0

.0

.0

.0

.0

.0

.0

.0

.0

.0

.0

.0

1.4

2.0

.0

.0

3.1
.4

.0

.0

.0

.0

.1

.0

.0

.0

.0

.0

.0

.0

.0

.0

.0

.0

.0

.0

.0

.0

.0

.0

.0

.0

.0

.0

.0

.0

.0

.0

.1
.0

.0

.0

.0

.0

.0

.0

.0

.0

.0

.0

.0

.0

.0

.0

.0

.0

.0

.0

.0

.0

.0

.0

.0

.0

.0

.0

.0

.0

.0

$-0$

.0

.0
.0

.0

.0

.0

.0

.0

.0

.0

.0

.0

.0

.0

.0

.0

.0

.0

.0

.0

.0

.0

.0

.0

.0

.0

.0

. 0

$.0^{\circ}$

.0

.0

.0

.0

. 0

.0

21.5

1.6

.1

11.5

1.6

.0

.5

5.0

1. 6

2.3

.5

.5

.0

.8

1.0

.0

.1

.1

.0

.0

.0

.0

.0

.0

.0

.0

.0

.0

4.1 
TOTALS

41.7

41.3

16.2

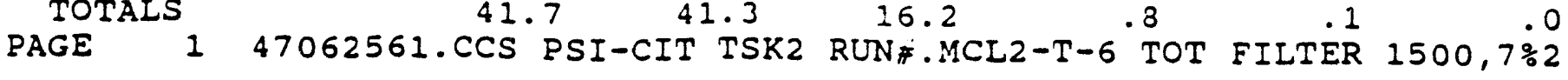

$100 . \mathrm{C}$

AREA IN EACH SIZE RANGE

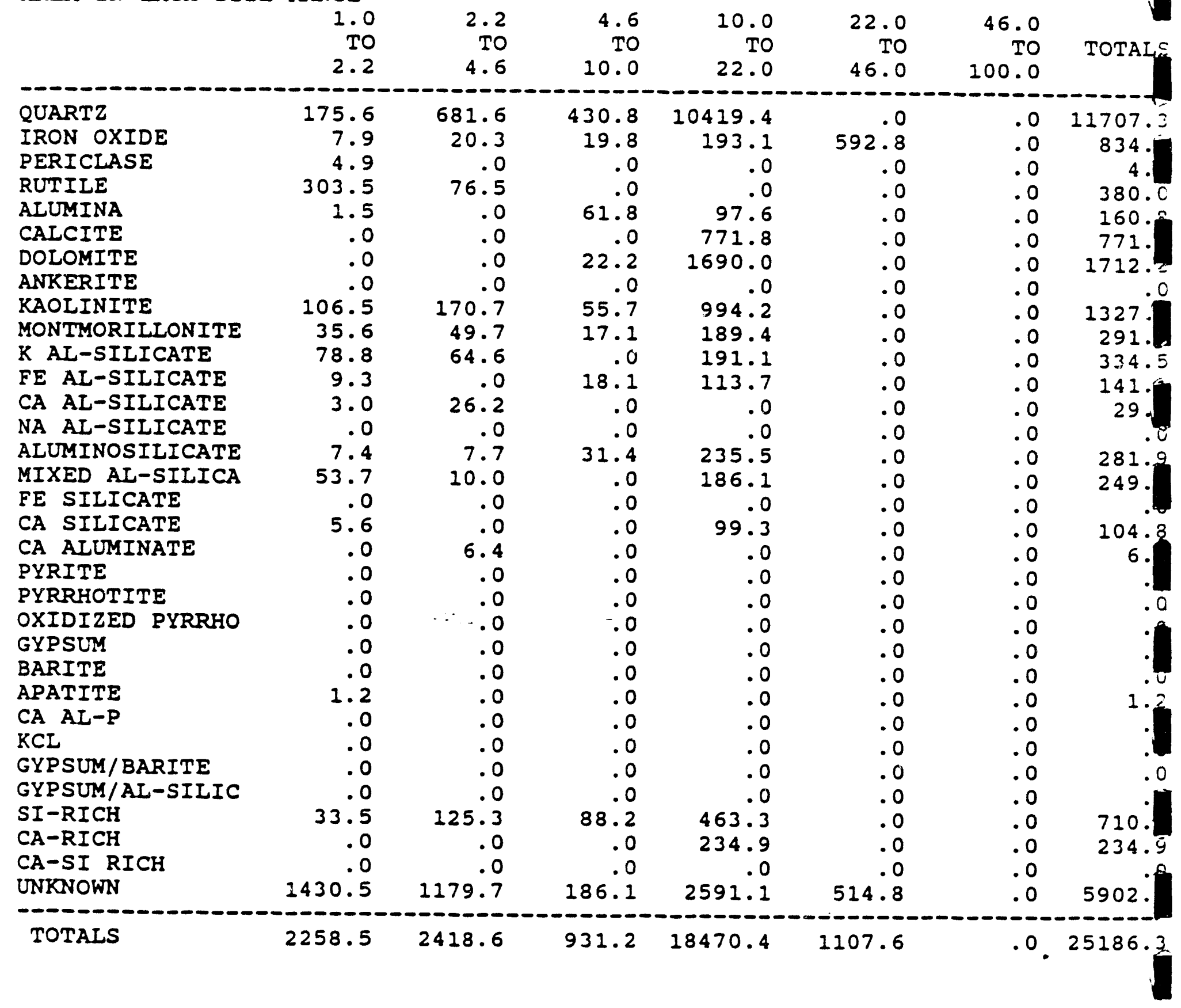


PAGE 2 47062561.CCS PSI-CIT TSK2 RUN\#.MCL2-T-6 TOT FILTER 1500,782

NORMALIZED AREA IN EACH SIZE RANGE

\begin{tabular}{|c|c|c|c|c|c|c|c|}
\hline-8 & $\begin{array}{r}1.0 \\
\text { TO } \\
2.2\end{array}$ & $\begin{array}{r}2.2 \\
\text { TO } \\
4.6\end{array}$ & $\begin{array}{r}4.6 \\
\text { TO } \\
10.0\end{array}$ & $\begin{array}{r}10.0 \\
\text { TO } \\
22.0\end{array}$ & $\begin{array}{r}22.0 \\
\text { TO } \\
46.0\end{array}$ & $\begin{array}{r}46.0 \\
\text { TO } \\
100.0\end{array}$ & TOTALS \\
\hline QUARTZ & 68272.0 & 264932.8 & 167442.0 & 10419.4 & .0 & .0 & 511066.2 \\
\hline IRON OXIDE & 3090.2 & 7890.7 & 7708.0 & 193.1 & 592.8 & .0 & 19474.9 \\
\hline PERICLASE & 1900.8 & .0 & .0 & .0 & .0 & .0 & 1900.8 \\
\hline RUTILE & 117983.3 & 29739.7 & .0 & .0 & .0 & .0 & 147723.0 \\
\hline ALUMINA & 579.2 & .0 & 24010.2 & 97.6 & .0 & .0 & 24687.0 \\
\hline CALCITE & .0 & .0 & .0 & 771.8 & .0 & .0 & 771.8 \\
\hline DOLOMITE & .0 & .0 & $86 i 7.6$ & 1690.0 & .0 & .0 & 10307.6 \\
\hline ANKERITE & .0 & .0 & .0 & .0 & .0 & .0 & .0 \\
\hline KAOLINITE & 41393.1 & 66355.6 & 21654.7 & 994.2 & .0 & .0 & 130397.6 \\
\hline MONTMORILLONITE & 13849.5 & 19306.9 & 6658.5 & 189.4 & .0 & .0 & 40004.4 \\
\hline K AL-SILICATE & 30629.9 & 25102.5 & .0 & 191.1 & .0 & .0 & 55923.5 \\
\hline FE AI-SILICATE & 3630.5 & .0 & 7027.8 & 113.7 & .0 & .0 & 10772.0 \\
\hline CA AL-SILICATE & 1181.7 & 10187.9 & .0 & .0 & .0 & .0 & 11369.6 \\
\hline NA AL-SILICATE & & .0 & .0 & .0 & .0 & .0 & .0 \\
\hline ALUMINOSILICATE & 2860.9 & 2985.2 & 12189.8 & 235.5 & .0 & .0 & 18271.4 \\
\hline MIXED AL-SILICA & 20854.0 & 3875.4 & .0 & 186.1 & .0 & .0 & 24915.4 \\
\hline FE SILICATE & .0 & .0 & .0 & .0 & .0 & .0 & .0 \\
\hline CA SILICATE & 2169.0 & .0 & .0 & 99.3 & .0 & .0 & 2268.2 \\
\hline CA ALUMINATE & .0 & 2487.7 & .0 & .0 & .0 & .0 & 2487.7 \\
\hline PYRITE & .0 & $\because \quad .0$ & $\because 0$ & .0 & .0 & .0 & .0 \\
\hline PYRRHOTITE & .0 & .0 & .0 & .0 & .0 & .0 & .0 \\
\hline OXIDIZED PYRRHO & .0 & .0 & .0 & .0 & .0 & .0 & .0 \\
\hline GYPSUM & .0 & .0 & .0 & .0 & .0 & .0 & .0 \\
\hline BARITE & .0 & .0 & .0 & .0 & .0 & .0 & .0 \\
\hline APATITE & 454.8 & .0 & .0 & .0 & .0 & .0 & 454.8 \\
\hline$C A \quad A L-P$ & .0 & .0 & .0 & .0 & .0 & .0 & .0 \\
\hline KCL & .0 & .0 & .0 & .0 & .0 & .0 & .0 \\
\hline GYPSUM/BARIT & .0 & .0 & .0 & .0 & .0 & .0 & .0 \\
\hline GYPSUM/AL-SILIC & .0 & .0 & .0 & .0 & .0 & .0 & .0 \\
\hline SI-RICH & 13013.8 & 48720.2 & 34295.3 & 463.3 & .0 & .0 & 96492.6 \\
\hline CA-RICH & .0 & .0 & .0 & 234.9 & .0 & .0 & 234.9 \\
\hline CA-SI RICH & .0 & .0 & .0 & .0 & .0 & .0 & .0 \\
\hline UNKNOWN & 556021.6 & 458538.4 & 72345.6 & 2591.1 & 514.8 & .0 & 090011.0 \\
\hline TOTALS & 877884.0 & 940123.2 & 361949.4 & 18470.4 & 1107.6 & .0 & 2199535.0 \\
\hline
\end{tabular}


AREA PERCENT MINERAL BASIS

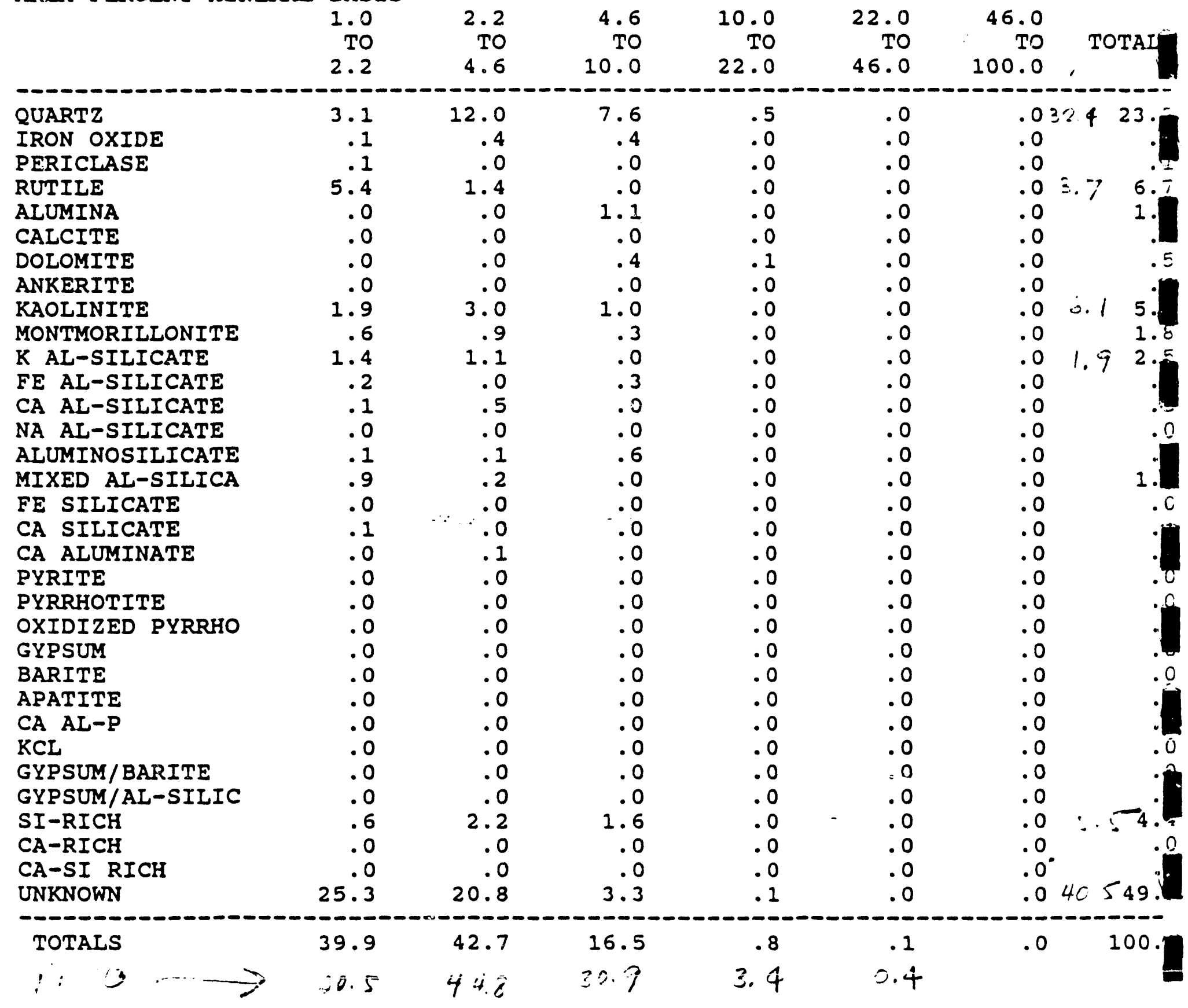


PAGE 4 47062561.CCS PSI-CIT TSK2 RUN\#.MCL2-T-6 TOT FILTER 1500,7\%2

WEIGHT PERCENT MINERAL BASIS

$\begin{array}{rrrrrrr}1.0 & 2.2 & 4.6 & 10.0 & 22.0 & 46.0 & \\ \text { TO } & \text { TO } & \text { TO } & \text { TO } & \text { TO } & \text { TO } & \text { TOTALS } \\ 2.2 & 4.6 & 10.0 & 22.0 & 46.0 & 100.0 & \end{array}$

QUARTZ

IRON OXIDE

PERICLASE

RUTI LE

ALUMINA

CALCITE

DOLOMITE

ANKERITE

KAOLINITE

MONTMORILLONITE

K AL-SILICATE

FE AL-SILICATE

CA AL-SIIICATE

NA AL-SILICATE

ALUMINOSILICATE

MIXED AL-SILICA

FE SILICATE

CA SILICATE

CA ALUMINATE

PYRITE

PYRRHOTITE

OXIDIZED PYRRHO

GYPSUM

BARITE

APATITE

CA AL-P

KCL

GYPSUM/BARITE

GYPSIM/AL-SILIC

SI-RICH

CA-RICH

CA-SI RICH

UNKNOWN

TOTALS
2.9

.3

.1

9.2

.0

.0

.0

.0

1.7

.5

1.3

.2

.0

.0

.1

.9

.0

.1

.0

.0

.0

.0

.0

.0

.0

.0

.0

.0

.0

. 5

.0

.0

23.8

41.7
4.6

11.1

.7

.0

2.3

.0

.0

.0

.0

2.8

.8

1.0

.0

.4

.0

.1

.2

.0

.0

.1

.0

.0

.0

.0

.0

.0

.0

0

.0

.0

2.0

.0

.0

19.7

41.3

.6

.0

.0

1.5

.0

.4

.0

.9

.3

.0

.3

.0

.0

.5

.0

.0

.0

.0

.0

.0

.0

.0

.0

.0

.0

.0

.0

.0

1.4

.0

.0

3.1

16.2

.0
.1

.0

.0

.0

.0

.0

.0

.0

.0

.0

.0

.0

.0

.0

.0

.1

.8
.0

.0

.0

.0

.0

.0

.0

.0

.0

.0

.0

.0

.0

.0

.0

.0

.0

.0

.0

.0

.0

.0

.0

.0

. 0

.0

. 0

.0

.0

.0

.0

.1

.0

.0

.0

.0

.0

.0

.0

.0

.0

.0 .

.0

.0

.0
46.7

21.5

1.6

11.5

1.6

.0

.5

.0

5.5

1.6

2.3

.5

.5

.0

. 8

.0

.1

.1

.0

.0

.0

.0

.0

.0

.0

.0

.0

.0

4.1

.0

.0 
PAGE 6 47062561.CCS PSI-CIT TSK2 RUN\#.MCL2-T-6 TOT FILTER 1500,7\%2

NUMBER OF PARTICLES IN EACH SIZE RANGE

\begin{tabular}{|c|c|c|c|c|c|c|c|}
\hline 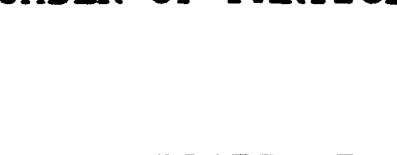 & $\begin{array}{r}1.0 \\
\text { TO } \\
2.2\end{array}$ & $\begin{array}{r}2.2 \\
\text { TO } \\
4.6\end{array}$ & $\begin{array}{r}4.6 \\
\text { TO } \\
10.0\end{array}$ & $\begin{array}{r}10.0 \\
\text { TO } \\
22.0\end{array}$ & $\begin{array}{r}22.0 \\
\text { TO } \\
46.0\end{array}$ & $\begin{array}{r}46.0 \\
\mathrm{TO} \\
100.0\end{array}$ & TOTALS \\
\hline IARTZ & 75.0 & 82.0 & 16.0 & 94.0 & .0 & .0 & 267.0 \\
\hline RON OXIDE & 4.0 & 3.0 & 1.0 & 1.0 & 1.0 & .0 & 10.0 \\
\hline RICLASE & 3.0 & .0 & .0 & .0 & .0 & .0 & 3.0 \\
\hline JTILE & 189.0 & 14.0 & .0 & .0 & .0 & .0 & 203.0 \\
\hline UMINA & 1.0 & .0 & 2.0 & 1.0 & .0 & .0 & 4.0 \\
\hline ILCITE & .0 & .0 & .0 & 5.0 & .0 & .0 & 5.0 \\
\hline OLOMITE & .0 & .0 & 1.0 & 11.0 & .0 & .0 & 12.0 \\
\hline LNKERITE & .0 & .0 & .0 & .0 & .0 & .0 & .0 \\
\hline OLINITE & 57.0 & 21.0 & 3.0 & 7.0 & .0 & .0 & 88.0 \\
\hline NTMORIILONITE & 19.0 & 7.0 & 1.0 & 2.0 & .0 & .0 & 29.0 \\
\hline AL-SILICATE & 51.0 & 9.0 & .0 & 2.0 & .0 & .0 & 62.0. \\
\hline AL-SILICATE & 4.0 & .0 & $1: 0$ & 1.0 & .0 & .0 & 6.0 \\
\hline A AL-SILICATE & 2.0 & 3.0 & .0 & .0 & .0 & .0 & 5.0 \\
\hline AL-SILICATE & .0 & .0 & .0 & .0 & .0 & .0 & .0 \\
\hline LLUMINOSILICATE & 3.0 & 1.0 & 1.0 & 2.0 & .0 & .0 & 7.0 \\
\hline MIXED AL-SILICA. & 28.0 & 2.0 & .0 & 1.0 & .0 & .0 & 31.0 \\
\hline E SILICATE & .0 & .0 & .0 & .0 & .0 & .0 & .0 \\
\hline SILICATE & 3.0 & .0 & .0 & 1.0 & .0 & .0 & 4.0 \\
\hline ALUMINATE & .0 & 1.0 & .0 & .0 & .0 & .0 & 1.0 \\
\hline ZRITE & .0 & .0 & .0 & .0 & .0 & .0 & .0 \\
\hline IRRHOTITE & .0 & .0 & .0 & .0 & .0 & .0 & .0 \\
\hline OXIDIZED PYRRHO & .0 & .0 & .0 & .0 & .0 & .0 & .0 \\
\hline GYPSUM & .0 & .0 & .0 & .0 & .0 & .0 & .0 \\
\hline ARITE & .0 & .0 & .0 & .0 & .0 & .0 & .0 \\
\hline PATTE & 1.0 & .0 & .0 & .0 & .0 & .0 & 1.0 \\
\hline$A L-P$ & .0 & .0 & .0 & .0 & .0 & .0 & .0 \\
\hline L & .0 & .0 & .0 & .0 & .0 & .0 & .0 \\
\hline GYPSUM/BARITE & .0 & .0 & .0 & .0 & .0 & .0 & .0 \\
\hline GYPSUM/AL-SILIC & .0 & .0 & .0 & .0 & .0 & .0 & .0 \\
\hline -RICH & 20.0 & 16.0 & 4.0 & 3.0 & .0 & .0 & 43.0 \\
\hline -RICi & .0 & .0 &.$\overline{0}$ & $\overline{2} . \overline{0}$ & .0 & .0 & 2.0 \\
\hline -SI RICH & .0 & .0 & .0 & .0 & .0 & .0 & .0 \\
\hline
\end{tabular}


SUMM:RY OF CCSEM RESULTS: PROG VERSION 2BF $8 / 21 / 90$

SAMPLE DESCRIPTION - - 47062570. CCS PSI-CIT-TSK2RUN\#MCL2 T6 TOT FILTER1500,7\%2. SUBMITTER - -

ICC \# AND FUND\# ---> 47062579

RUN DATE AND TIME - -> $\quad 6 \quad 601991 \quad 9: 20$

Epoxy x-section!

SUMMARY OF PARAMETERS

TOTAL MINERAL AREA ANALYZED AT HIGH MAG=

NORMALIZED AREA ANALYZED AT HIGH MAG =

TOTAL MINERAL AREA ANALYZED AT LOW MAG

4367.3

106098.0

$=41909.3$

$=115519.77 \overline{3}$

FIELD SIZE USED AT HIGH MAG

FIELD SIZE USED AT LOW MAG

NUMBER OF FRAMES AT HIGH MAG

NUMBER OF FRAMES AT LOW MAG

TOTAL NUMBER OF POINTS ANALYZED

NUMBER OF POINTS UNDER THRESHOLD
$=$

$=$

$=$

=

WEIGHT PERCENT ON A MINERAL BASIS

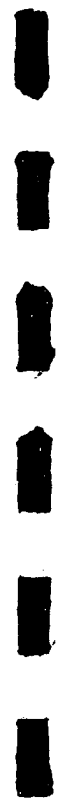

$\begin{array}{ll}1.0 & 2.2\end{array}$

TO

2.2

TO

4.6

1.9

QUARTZ

IRON OXIDE

PERICLASE

RUTILE

ALUMINA

CALCITE

DOLOMITE

ANKERITE

KAOLINITE

MONTMORILLONITE

$K$ AL-SILICATE

FE AL-SILICATE

CA AL-SILICATE

NA AL-SILICATE

ALUMINUSILICATE

MIXED AL-SI ICA

FE SILICATE

CA SILICATE

CA ALUMINATE

PYRITE

PYRRHOTITE

OXIDIZED PYRRHO

GYPSUM

BARITE

APATITE

CA $A L-P$

$\mathrm{KCL}$

GYPSUM/BARITE

GYPSUM/AL-SILIC

.0

.0

3.5

.0

.1

.2

.0

.4

.3

.7

.1

.0

.0

.0

.4

.0

.0

.1

.0

.0

.0

.0

.0

.0

.0

.0

9.2

.0

.0

3.2

.0

.0

.4

.0

2.0

.8

1.6

.2

$\therefore 2$

.0

.0

.3

.0

.0

.0

.0

.0

.0

.0

.0

.1

.0

.0

. 0

.0
.0

1.1

SI-RICH

.0

.9

CA-RICH

CA-SI RICH

UNKNOWN

.0

13.1

.2

.0

13.7

\section{6}

TO

10.0

8.7

.0

.0

.0

.0

.6

.4

.0

1.5

1. 0

1.3

.0

.0

.0

.3

.0

.0

.0

.0

.0

.0

. 0

.0

.0

.0

.0

.0

.0

.0

.6

.0

.0

3.5
23.2

10.0

22.0

22.0

. 9

.0

.0

.0

.2

.0

.0

.3

.2

.7

.0

.1

.0

.0

.2

.0

.0

.0

.0

.0

.0

.0

.0

.0

.0

.0

.0

.0

.6

.3

.0

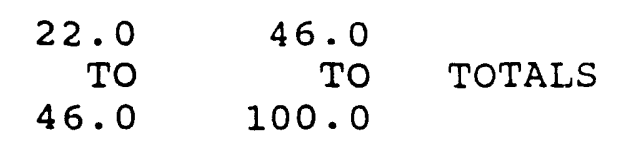

.0

.0

.0

.0

.0

.0

.0

.0

.0

.0

.3

.0

.0

.0

.0

.0

.0

.0

.0

.0

.0

.0

.0

.0

.0

.0

.0

. 0

.0

.0

.0

.0

.7

.0

.0

.0

.0

.0

.0

.0

.0

.0

.0

.0

.0

.0

.0

.0

.0

.0

.0

.0

.0

.0

.0

.0

.0

.0

.0

.0

.0

.0

.0

.0

.0

.0

54.2 
PAGE 247062570. CCS PSI-CIT-TSK2RUN\#MCL2 T6 TOT FIITER1500,7\%2, <90UM

\begin{tabular}{|c|c|c|c|c|c|c|c|}
\hline NORMALIZED AREA & $\begin{array}{r}\text { IN EACH } \\
1.0 \\
\text { TO } \\
2.2\end{array}$ & $\begin{array}{c}\text { SIZE RANGE } \\
2.2 \\
\text { TO } \\
4.6\end{array}$ & $\begin{array}{r}4.6 \\
\text { TO } \\
10.0\end{array}$ & $\begin{array}{r}10.0 \\
\text { TO } \\
22.0\end{array}$ & $\begin{array}{r}22.0 \\
\text { TO } \\
46.0\end{array}$ & $\begin{array}{r}46.0 \\
\text { TO } \\
100.0\end{array}$ & TOTALS \\
\hline QUARTZ & 3003.0 & 14225.6 & 13412.2 & 1324.6 & .0 & .0 & 31965.4 \\
\hline IRON OXIDE & .0 & .0 & .0 & .0 & .0 & .0 & .0 \\
\hline PERICLASE & .0 & .0 & .0 & .0 & .0 & .0 & .0 \\
\hline RUTILE & 2927.4 & 2668.7 & .0 & .0 & .0 & .0 & 5596.1 \\
\hline ALUMINA & .0 & .0 & .0 & .0 & .0 & .0 & .0 \\
\hline CALCITE & 197.3 & .0 & 828.4 & 315.3 & .0 & .0 & 1341.0 \\
\hline DOLOMITE & 224.2 & 504.8 & 547.6 & .0 & .0 & .0 & 1276.6 \\
\hline ANKERITE & .0 & .0 & .0 & .0 & .0 & .0 & .0 \\
\hline KAOLINITE & 628.0 & 3065.7 & 2299.4 & 455.9 & .0 & .0 & 6449.0 \\
\hline MONTMORILLONITE & 535.9 & 1251.4 & 1649.1 & 263.5 & .0 & .0 & 3699.8 \\
\hline K AL-SILICATE & 1079.6 & 2568.6 & 2012.8 & 1033.6 & 488.9 & .0 & 7183.4 \\
\hline FE AL-SILICATE & 126.3 & 241.5 & .0 & .0 & .0 & .0 & 367.8 \\
\hline CA AL-SILICATE & 20.2 & 294.9 & .0 & 89.2 & .0 & .0 & 404.3 \\
\hline NA AL-SILICATE & .0 & .0 & .0 & .0 & .0 & .0 & .0 \\
\hline ALUMINOSILICATE & .0 & .0 & 421.3 & .0 & .0 & .0 & 421.3 \\
\hline MIXED AL-SILICA & 621.0 & 390.6 & .0 & 379.9 & .0 & .0 & 1391.5 \\
\hline FE SILICATE & .0 & .0 & .0 & .0 & .0 & .0 & .0 \\
\hline CA SILICATE & .0 & .0 & .0 & .0 & .0 & .0 & .0 \\
\hline CA ALUMINATE & 86.2 & .0 & .0 & .0 & .0 & .0 & 86.2 \\
\hline PYRITE & .0 & $\because .0$ & .0 & .0 & .0 & .0 & .0 \\
\hline PYRRHOTITE & .0 & .0 & .0 & .0 & .0 & .0 & .0 \\
\hline OXIDIZED PYRRHO & .0 & .0 & .0 & .0 & .0 & .0 & .0 \\
\hline GYPSUM & 36.4 & .0 & .0 & .0 & .0 & .0 & 36.4 \\
\hline BARITE & .0 & .0 & .0 & .0 & .0 & .0 & .0 \\
\hline APATITE & .0 & 135.8 & .0 & .0 & .0 & .0 & 135.8 \\
\hline CA $A L-P$ & .0 & .0 & .0 & .0 & .0 & .0 & .0 \\
\hline$K C L$ & .0 & .0 & .0 & .0 & .0 & .0 & .0 \\
\hline GYPSUM/BARITE & .0 & .0 & .0 & .0 & .0 & .0 & .0 \\
\hline GYPSUM/AL-SILIC & .0 & .0 & .0 & .0 & .0 & .0 & .0 \\
\hline SI-RICH & 1317.7 & 1754.5 & 919.0 & 990.2 & .0 & .0 & 4981.5 \\
\hline $\mathrm{CA}-\mathrm{RICH}$ & 35.0 & 251.9 & .0 & 443.1 & .0 & .0 & 730.0 \\
\hline CA-SI RICH & .0 & .0 & .0 & .0 & .0 & .0 & .0 \\
\hline UNKNOWN & 19856.5 & 20703.8 & 5255.5 & 35070.2 & 1055.1 & .0 & 81941.1 \\
\hline TOTALS & 30694.7 & 48057.9 & 27345.3 & 40365.3 & 1544.0 & .0 & 148007.3 \\
\hline
\end{tabular}


PAGE 447062570. CCS PSI-CIT-TSK2RUN\#MCL2 T6 TOT FILTER1500,7\%2, <90UM

WEIGHT PERCENT MINERAL BASIS

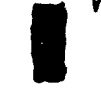

\begin{tabular}{|c|c|c|c|c|c|c|c|}
\hline & $\begin{array}{r}1.0 \\
\text { TO } \\
2.2\end{array}$ & $\begin{array}{r}2.2 \\
\text { TO } \\
4.6\end{array}$ & $\begin{array}{r}4.6 \\
\text { TO } \\
10.0\end{array}$ & $\begin{array}{r}10.0 \\
\text { TO } \\
22.0\end{array}$ & $\begin{array}{l}2: ? \\
46.0\end{array}$ & $\begin{array}{r}46.0 \\
\text { TO } \\
100.0\end{array}$ & TOTALS \\
\hline ARTZ & 1.9 & 9.2 & 8.7 & .9 & .0 & .0 & 20.7 \\
\hline ON OXIDE & .0 & .0 & .0 & .0 & .0 & .0 & .0 \\
\hline RICLASE & .0 & .0 & .0 & .0 & .0 & .0 & .0 \\
\hline TILE & 3.5 & 3.2 & .0 & .0 & .0 & .0 & 6.7 \\
\hline UMINA & .0 & .0 & .0 & .0 & .0 & .0 & .0 \\
\hline LCITE & .1 & .0 & .6 & .2 & .0 & .0 & .9 \\
\hline LOMITE & .2 & .4 & .4 & .0 & .0 & .0 & .9 \\
\hline KERITE & .0 & .0 & .0 & .0 & .0 & .0 & .0 \\
\hline OLINITE & .4 & 2.0 & 1.5 & .3 & .0 & .0 & 4.2 \\
\hline NTMORILLONITE & .3 & .8 & 1.0 & .2 & .0 & .0 & 2.3 \\
\hline AL-SILICATE & .7 & 1.6 & 1.3 & .7 & .3 & .0 & 4.6 \\
\hline AL-SILICATE & .1 & .2 & .0 & .0 & .0 & .0 & .3 \\
\hline AL-SILIC.TE & .0 & .2 & .0 & .1 & .0 & .0 & .3 \\
\hline AL-SILICATE & .0 & .0 & .0 & .0 & .0 & .0 & .0 \\
\hline LUMINOSILICATE & .0 & .0 & .3 & .0 & .0 & .0 & .3 \\
\hline IXED AL-SILICA & .4 & $\because \because 3$ & .0 & .2 & .0 & .0 & .9 \\
\hline SILICATE & .0 & .0 & .0 & .0 & .0 & .0 & .0 \\
\hline SILICATE & .0 & .0 & .0 & .0 & .0 & .0 & .0 \\
\hline ALUMINATE & .1 & .0 & .0 & .0 & .0 & .0 & .1 \\
\hline RITE & .0 & .0 & .0 & .0 & .0 & .0 & .0 \\
\hline RRHOTITE & .0 & .0 & .0 & .0 & .0 & .0 & .0 \\
\hline IDIZED PYRRHO & .0 & .0 & .0 & .0 & .0 & .0 & .0 \\
\hline PSUM & .0 & .0 & .0 & .0 & .0 & .0 & .0 \\
\hline RITE & .0 & .0 & .0 & .0 & .0 & .0 & .0 \\
\hline ATITE & .0 & .1 & .0 & .0 & .0 & .0 & .1 \\
\hline$A L-P$ & .0 & .0 & .0 & .0 & .0 & .0 & .0 \\
\hline & .0 & .0 & .0 & .0 & .0 & .0 & .0 \\
\hline PSUM/BARITE & .0 & .0 & .0 & .0 & .0 & .0 & .0 \\
\hline PSUM/AL-SILIC & .0 & .0 & .0 & .0 & .0 & .0 & .0 \\
\hline -RICH & .9 & 1.1 & .6 & .6 & .0 & .0 & 3.2 \\
\hline -RICH & .0 & .2 & .0 & .3 & .0 & .0 & .5 \\
\hline -SI RICH & .0 & .0 & .0 & .0 & .0 & .0 & .0 \\
\hline KNOWN & 13.1 & 13.7 & 3.5 & 23.2 & .7 & .0 & 54.2 \\
\hline TALS & 21.8 & 32.9 & 17.8 & 26.6 & 1.0 & .0 & 100.0 \\
\hline
\end{tabular}


PAGE 647062570. CCS PSI-CIT-TSK2RUN\#MCL2 T6 TOT FIITER1500,7\%2, <90UM

NUMBER OF PARTICLES IN EACH SIZE RANGE

\begin{tabular}{|c|c|c|c|c|c|c|c|}
\hline 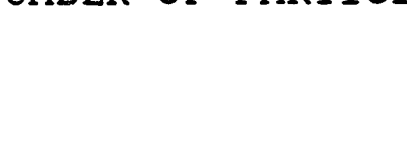 & $\begin{array}{r}1.0 \\
\text { TO } \\
2.2\end{array}$ & $\begin{array}{r}2.2 \\
\text { TO } \\
4.6\end{array}$ & $\begin{array}{r}4.6 \\
\text { TO } \\
10.0\end{array}$ & $\begin{array}{r}10.0 \\
\text { TO } \\
22.0\end{array}$ & $\begin{array}{r}22.0 \\
\text { TO } \\
46.0\end{array}$ & $\begin{array}{r}46.0 \\
\mathrm{TO} \\
100.0\end{array}$ & TOTALS \\
\hline QUARTZ & 53.0 & 72.0 & 18.0 & 11.0 & .0 & .0 & 154.0 \\
\hline IRON OXIDE & .0 & .0 & .0 & .0 & .0 & .0 & .0 \\
\hline PERICLASE & .0 & .0 & .0 & .0 & .0 & .0 & .0 \\
\hline RUTILE & 67.0 & 17.0 & .0 & .0 & .0 & .0 & 84.0 \\
\hline ALUMINA & .0 & .0 & .0 & .0 & .0 & .0 & .0 \\
\hline CALCITE & 4.0 & .0 & 1.0 & 3.0 & .0 & .0 & 8.0 \\
\hline DOLOMITE & 3.0 & 3.0 & 1.0 & .0 & .0 & .0 & 7.0 \\
\hline ANKERITE & .0 & .0 & .0 & .0 & .0 & .0 & .0 \\
\hline KAOLINITE & 12.0 & 15.0 & 3.0 & 4.0 & .0 & .0 & 34.0 \\
\hline MONTMORILLONITE & 10.0 & 8.0 & 3.0 & 2.0 & .0 & .0 & 23.0 \\
\hline $\mathrm{K}$ AL-SILICATE & 22.0 & 14.0 & 3.0 & 8.0 & 1.0 & .0 & 48.0 \\
\hline FE AL-SILICATE & 3.0 & $-1: 0$ & $=0$ & .0 & .0 & .0 & 4.0 \\
\hline CA AL-SILICATE & 1.0 & 1.0 & .0 & 1.0 & .0 & .0 & 3.0 \\
\hline NA AL-SILICATE & .0 & .0 & .0 & .0 & .0 & .0 & .0 \\
\hline ALUMINOSILICATE & .0 & .0 & 1.0 & .0 & .0 & .0 & 1.0 \\
\hline MIXED AL-SILICA & 14.0 & 2.0 & .0 & 2.0 & .0 & .0 & 18.0 \\
\hline FE SILICATE & .0 & .0 & .0 & .0 & .0 & .0 & .0 \\
\hline CA SILICATE & .0 & .0 & .0 & .0 & .0 & .0 & .0 \\
\hline CA ALUMINATE & 1.0 & .0 & .0 & .0 & .0 & .0 & 1.0 \\
\hline PYRITE & .0 & .0 & .0 & .0 & .0 & .0 & .0 \\
\hline PYRRHOTITE & .0 & .0 & .0 & .0 & .0 & .0 & .0 \\
\hline OXIDIZED PYRRHO & .0 & .0 & .0 & .0 & .0 & .0 & .0 \\
\hline GYPSUM & 1.0 & .0 & .0 & .0 & .0 & .0 & 1.0 \\
\hline BARITE & .0 & .0 & .0 & .0 & .0 & .0 & .0 \\
\hline APATITE & .0 & 1.0 & .0 & .0 & .0 & .0 & 1.0 \\
\hline$C A$ AL-P & .0 & .0 & .0 & .0 & .0 & .0 & .0 \\
\hline KCL & .0 & .0 & .0 & .0 & .0 & .0 & .0 \\
\hline GYPSUM/BARITE & .0 & .0 & .0 & .0 & .0 & .0 & .0 \\
\hline GYPSUM / AL-SILIC & .0 & .0 & .0 & .0 & .0 & .0 & .0 \\
\hline SI-RICH & 23.0 & 8.0 & 2.0 & 7.0 & .0 & .0 & 40.0 \\
\hline CA-RICH & 1.0 & 2.0 & .0 & 3.0 & .0 & .0 & 6.0 \\
\hline CA-SI RICH & .0 & .0 & .0 & .0 & .0 & .0 & .0 \\
\hline
\end{tabular}


APPENDIX C

Illinois \#6 SOAP

$$
\begin{aligned}
& 1500^{\circ} \mathrm{C}, 7 \% \mathrm{O}_{2} \text { - PSIT Ash } \\
& 1250^{\circ} \mathrm{C}, 16 \% \mathrm{O}_{2} \text { - PSIT Ash }
\end{aligned}
$$

CCSEM Data from UNDEERC 
STIMMARY OF CCSEM RESULTS: PROG VERSION 2BF $8 / 21 / 90$

SAMPLE DESCRIPTION - - 470 2568. CCS PSI-CIT TSK2 RUN\#I6SOAP-T-1500 TOT FILTER7

SUBMITTER $\quad-->$ ZYGARL

ICC \# AND FUND \#---> 47062568

RUN DATE AND TIME $-->\quad 5291991 \quad 14: 19$

Filter Dispersion ! !

SUMMARY OF PARAMETERS

TOTAL MINERAL AREA ANALYZED AT HIGH MAG = NORMALIZED AREA ANALYZED AT HIGH MAG = TOTAL MINERAL AREA ANALYZED AT LOW MAG= FIELD SIZE USED AT HIGH MAG

FIELD SIZE USED AT LOW MAG

NUMBER OF FRAMES AT HIGH MAG

NUMBER OF FRAMES AT LOW MAG

TOTAL NUMBER OF POINTS ANALYZED

NUMBER OF POINTS UNDER THRESHOLD

$\begin{array}{rr}= & 7864.7 \\ = & 6793457.0 \\ = & 95920.6 \\ = & 115519.773 \\ = & 2494610.477 \\ = & 1 \\ = & 40 \\ = & 1879 \\ = & 7\end{array}$

WEIGHT PERCENT ON A MINERAL BASIS

\begin{tabular}{|c|c|c|c|c|c|c|c|}
\hline & $\begin{array}{r}1.0 \\
\text { TO } \\
2.2\end{array}$ & $\begin{array}{r}2.2 \\
\text { TO } \\
4.6\end{array}$ & $\begin{array}{r}4.6 \\
\text { TO } \\
10.0\end{array}$ & $\begin{array}{r}10.0 \\
\text { TO } \\
22.0\end{array}$ & $\begin{array}{r}22.0 \\
\text { TO } \\
46.0\end{array}$ & $\begin{array}{r}46.0 \\
\text { TO } \\
100.0\end{array}$ & TOTALS \\
\hline QUARTZ & .1 & .6 & 2.1 & .2 & .0 & .0 & 3.0 \\
\hline IRON OXIDE & .1 & .7 & .0 & .0 & .0 & .0 & .8 \\
\hline PERICLASE & .0 & .0 & .0 & .0 & .0 & .0 & .0 \\
\hline RUTILE & .0 & .1 & .0 & .0 & .0 & .0 & .1 \\
\hline ALUMINA & .0 & .0 & .0 & .0 & .0 & .0 & .0 \\
\hline CALCITE & .0 & .0 & .0 & .1 & .0 & .0 & .1 \\
\hline DOLOMITE & .0 & .0 & .0 & .0 & .0 & .0 & .0 \\
\hline ANKERITE & .1 & .0 & .0 & .0 & .0 & .0 & .1 \\
\hline KAOLINITE & .0 & .1 & .4 & .1 & .0 & .0 & .5 \\
\hline MONTMORILLONITE & .0 & .1 & .4 & .0 & .0 & .0 & .5 \\
\hline K AL-SILICATE & .0 & .0 & .7 & .0 & .0 & .1 & .8 \\
\hline FE AL-SILICATE & 4.9 & 25.1 & 14.9 & .3 & .0 & .0 & 45.2 \\
\hline CA AL-SILICATE & .0 & $\because \quad: 1$ & $\therefore$ & .0 & .0 & .0 & .1 \\
\hline NA AL-SILICATE & .0 & .0 & .0 & .0 & .0 & .0 & .0 \\
\hline ALUMINOSILICATE & .0 & .0 & .2 & .0 & .0 & .0 & .2 \\
\hline MIXED AL-SILICA & .1 & .3 & .4 & .0 & .0 & .0 & .7 \\
\hline FE SILICATE & .1 & .3 & .9 & .0 & .0 & .0 & 1.3 \\
\hline CA SILICATE & .0 & .0 & .0 & .0 & .0 & .0 & .0 \\
\hline CA ALUMINATE & .0 & .0 & .0 & .0 & .0 & .0 & .0 \\
\hline PYRITE & .0 & .0 & .0 & .0 & .0 & .0 & .0 \\
\hline PYRRHOTITE & .0 & .0 & .0 & .0 & .0 & .0 & .0 \\
\hline OXIDIZED PYRRHO & .0 & .0 & .0 & .0 & .0 & .0 & .0 \\
\hline GYPSUM & .0 & .0 & .0 & .0 & .0 & .0 & .0 \\
\hline BARITE & .0 & .0 & .0 & .0 & .0 & .0 & .0 \\
\hline APATITE & .0 & .0 & .0 & .0 & .0 & .0 & .0 \\
\hline CA AL-P & .0 & .0 & .0 & .0 & .0 & .0 & .0 \\
\hline $\mathrm{KCL}$ & .0 & .0 & .0 & .0 & .0 & .0 & .0 \\
\hline GYPSUM/BARITE & .0 & .0 & .0 & .0 & .0 & .0 & .0 \\
\hline GYPSUM/AL-SIIIC & .0 & .0 & .0 & .0 & .0 & .0 & .0 \\
\hline SI-RICH & $=2$ & 1.6 & 2.3 & .1 & .0 & .0 & 4.2 \\
\hline $\mathrm{CA}-\mathrm{RICH}$ & .0 & .2 & .0 & .0 & .0 & .0 & .2 \\
\hline CA-SI RICH & .0 & .0 & .0 & .0 & .0 & .0 & .0 \\
\hline UNKNOWN & 9 & 20.3 & 11.6 & .4 & .0 & .0 & 42.2 \\
\hline
\end{tabular}


AREA IN EACH SIZE RANGE

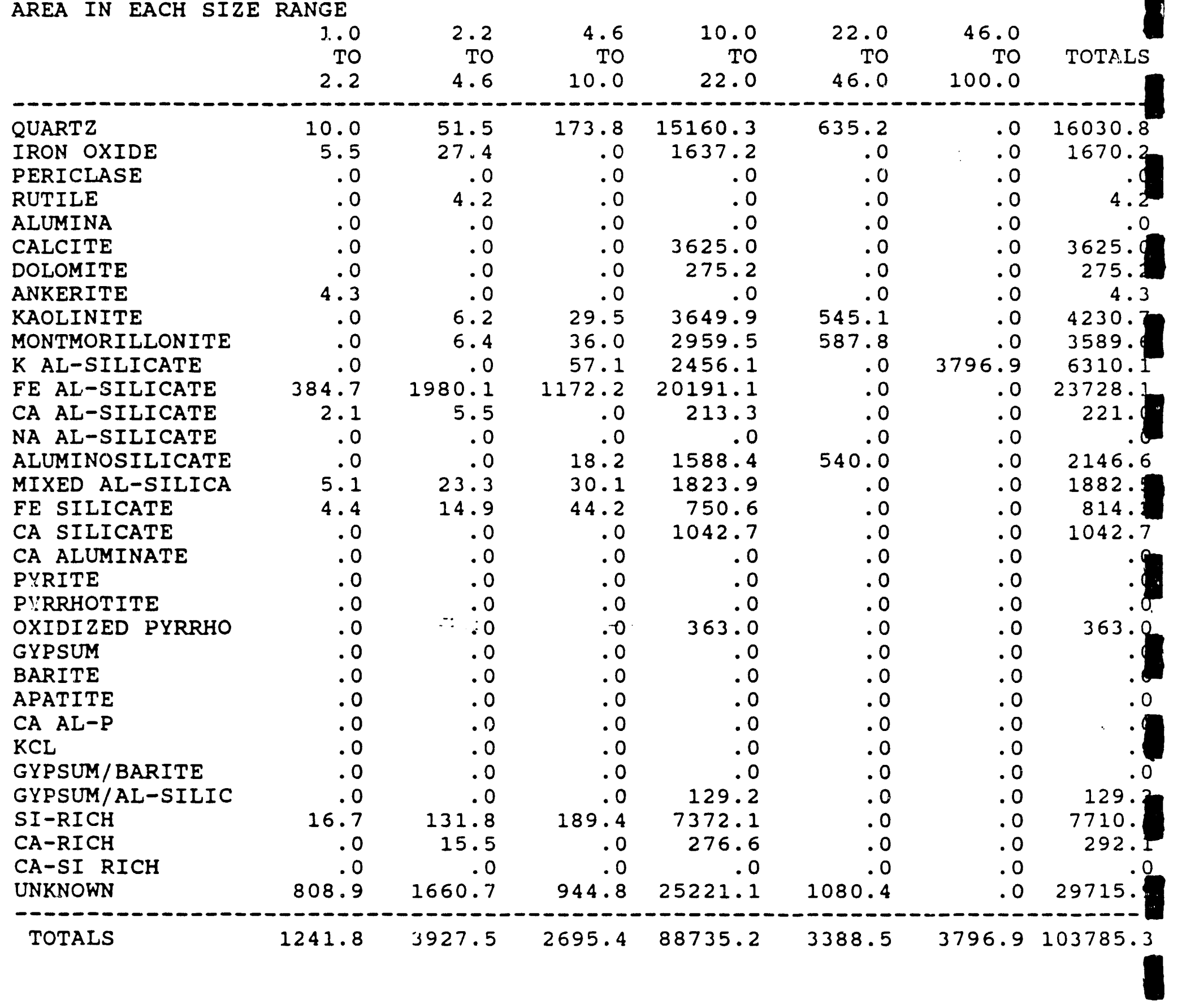


PAGE $247062568 . C C S$ PSI-CIT TSK2 RUN\#I6SOAP-T-1500 TOT FILTER7\%02

NORMALIZED AREA IN EACH SIZE RANGE

\begin{tabular}{|c|c|c|c|c|c|c|c|}
\hline & $\begin{array}{r}1.0 \\
\text { TO } \\
2.2\end{array}$ & $\begin{array}{r}2.2 \\
\text { TO } \\
4.6\end{array}$ & $\begin{array}{r}4.6 \\
\text { TO } \\
10.0\end{array}$ & $\begin{array}{r}10.0 \\
\text { TO } \\
22.0\end{array}$ & $\begin{array}{r}22.0 \\
\text { TO } \\
46.0\end{array}$ & $\begin{array}{r}46.0 \\
\text { TO } \\
100.0\end{array}$ & TOTALS \\
\hline QUARTZ & 8672.4 & 44450.5 & 150091.5 & 15160.3 & 635.2 & .0 & 219010.0 \\
\hline IRON OXIDE & 4785.4 & 23702.3 & .0 & 1637.2 & .0 & .0 & 30124.9 \\
\hline PERICLASE & .0 & .0 & .0 & .0 & .0 & .0 & .0 \\
\hline RUTILE & .0 & 3645.2 & .0 & .0 & .0 & .0 & 3645.2 \\
\hline ALUMINA & .0 & .0 & .0 & .0 & .0 & .0 & .0 \\
\hline CALCITE & .0 & .0 & .0 & 3625.0 & .0 & .0 & 3625.0 \\
\hline DOLOMITE & .0 & .0 & .0 & 275.2 & .0 & .0 & 275.2 \\
\hline ANKERITE & 3688.4 & .0 & .0 & .0 & .0 & .0 & 3688.4 \\
\hline KAOLINITE & .0 & 5346.8 & 25507.6 & 3649.9 & 545.1 & .0 & 35049.4 \\
\hline MONTMORILLONITE & .0 & 5502.3 & 31105.0 & 2959.5 & 587.8 & .0 & 40154.5 \\
\hline K AL-SILICATE & .0 & .0 & 49339.5 & 2456.1 & .0 & 3796.9 & 55592.5 \\
\hline FE AL-SILICATE & 332298.51 & .710375 .01 & 1012522.0 & 20191.1 & .0 & .03 & 3075387.0 \\
\hline CA AL-SILICATE & 1814.0 & 4785.4 & .0 & 213.3 & .0 & .0 & 6812.6 \\
\hline NA AL-SILICATE & .0 & .0 & .0 & .0 & .0 & .0 & .0 \\
\hline ALUMINOSILICATE & .0 & .0 & 15686.4 & 1588.4 & 540.0 & .0 & 17814.8 \\
\hline MIXED AL-SILICA & 4396.7 & 20143.5 & 26034.5 & 1823.9 & .0 & .0 & 52398.6 \\
\hline FE SILICATE & 3809.3 & 12844.5 & 38213.9 & 750.6 & .0 & .0 & 55618.4 \\
\hline CA SILICATE & .0 & .0 & .0 & 1042.7 & .0 & .0 & 1042.7 \\
\hline CA ALUMINATE & .0 & .0 & .0 & .0 & .0 & .0 & .0 \\
\hline PYRITE & .0 & $\because: 0$ & .0 & .0 & .0 & .0 & .0 \\
\hline PYRRHOTITE & .0 & .0 & .0 & .0 & .0 & .0 & .0 \\
\hline OXIDIZED PYRRHO & .0 & .0 & .0 & 363.0 & .0 & .0 & 363.0 \\
\hline GYPSUM & .0 & .0 & .0 & .0 & .0 & .0 & .0 \\
\hline BARITE & .0 & .0 & .0 & .0 & .0 & .0 & .0 \\
\hline APATITE & .0 & .0 & .0 & .0 & .0 & .0 & .0 \\
\hline$C A$ AL-P & .0 & .0 & .0 & .0 & .0 & .0 & .0 \\
\hline KCL & .0 & .0 & .0 & .0 & .0 & .0 & .0 \\
\hline GYPSUM/BARITE & .0 & .0 & .0 & .0 & .0 & .0 & .0 \\
\hline GYPSUM / AL-SILIC & .0 & .0 & .0 & 129.2 & .0 & .0 & 129.2 \\
\hline SI-RICH & 14459.8 & 113829.8 & 163627.1 & 7372.1 & .0 & .0 & 299288.7 \\
\hline CA-RICH & .0 & 13423.2 & .0 & 276.6 & .0 & .0 & 13699.8 \\
\hline CA-SI RICH & .0 & .0 & .0 & .0 & .0 & .0 & .0 \\
\hline UNKNOWN & 698725.91 & 1434482.0 & 816148.6 & 25221.1 & 1080.4 & .02 & 2975658.0 \\
\hline TOTALS & 1072650.03 & 3392531.02 & 2328276.0 & 88735.2 & 3388.5 & 3796.96 & 6889377.0 \\
\hline
\end{tabular}


AREA PERCENT MINEEAL BASIS

\begin{tabular}{|c|c|c|c|c|c|c|c|}
\hline & $\begin{array}{r}1.0 \\
\text { TO } \\
2.2\end{array}$ & $\begin{array}{r}2.2 \\
\text { TO } \\
4.6\end{array}$ & $\begin{array}{r}4.6 \\
\text { TO } \\
10.0\end{array}$ & $\begin{array}{r}10.0 \\
\mathrm{TO} \\
22.0\end{array}$ & $\begin{array}{r}22.0 \\
\text { TO } \\
46.0\end{array}$ & $\begin{array}{r}46.0 \\
\mathrm{TO} \\
100.0\end{array}$ & TOTAL \\
\hline QUARTZ & .1 & .6 & 2.2 & .2 & .0 & .0 & \\
\hline IRON OXIDE & .1 & .3 & .0 & .0 & .0 & .0 & \\
\hline PERICLASE & .0 & .0 & .0 & .0 & .0 & .0 & \\
\hline RUTILE & .0 & .1 & .0 & .0 & .0 & .0 & \\
\hline ALUMINA & .0 & .0 & .0 & .0 & .0 & .0 & \\
\hline CALCITE & .0 & .0 & .0 & .1 & .0 & .0 & \\
\hline DOLOMITE & .0 & .0 & .0 & .0 & .0 & .0 & \\
\hline ANKERITE & .1 & .0 & .0 & .0 & .0 & .0 & \\
\hline KAOLINITE & .0 & .1 & .4 & .1 & .0 & .0 & \\
\hline MONTMORILLONITE & .0 & .1 & .5 & .0 & .0 & .0 & \\
\hline K AL-SILICATE & .0 & .0 & .7 & .0 & .0 & .1 & \\
\hline FE AL-SILICATE & 4.8 & 24.8 & 14.7 & .3 & .0 & .0 & 44 \\
\hline CA AL-SILICATE & .0 & .1 & .0 & .0 & .0 & .0 & \\
\hline NA AL-SILICATE & .0 & .0 & .0 & .0 & .0 & .0 & \\
\hline ALUMINOSILICATE & .0 & .0 & .2 & .0 & .0 & .0 & \\
\hline MIXED AL-SILICA & .1 & .3 & .4 & .0 & .0 & .0 & \\
\hline FE SILICATE & .1 & .2 & .6 & .0 & .0 & .0 & \\
\hline CA SILICATE & .0 & $\because \quad: 0$ & .0 & .0 & .0 & .0 & \\
\hline CA ALUMINATE & .0 & .0 & .0 & .0 & .0 & .0 & \\
\hline PYRITE & .0 & .0 & .0 & .0 & .0 & .0 & \\
\hline PYRRHOTITE & .0 & .0 & .0 & .0 & .0 & .0 & \\
\hline OXIDIZED PYRRHO & .0 & .0 & .0 & .0 & .0 & .0 & \\
\hline GYPSUM & .0 & .0 & .0 & .0 & .0 & .0 & \\
\hline BARITE & .0 & .0 & .0 & .0 & .0 & .0 & 0 \\
\hline APATITE & .0 & .0 & .0 & .0 & .0 & .0 & \\
\hline$C A \quad A L-P$ & .0 & .0 & .0 & .0 & .0 & .0 & \\
\hline $\mathrm{KCL}$ & .0 & .0 & .0 & .0 & .0 & .0 & \\
\hline GYPSUM/BARITE & .0 & .0 & .0 & .0 & .0 & .0 & \\
\hline GYPSUM/AL-SILIC & .0 & .0 & .0 & .0 & .0 & .0 & \\
\hline SI-RICH & .2 & 1.7 & 2.4 & .1 & .0 & .0 & 4 \\
\hline $\mathrm{CA}-\mathrm{RICH}$ & .0 & .2 & .0 & .0 & .0 & .0 & \\
\hline CA-SI RICH & .0 & .0 & .0 & .0 & .0 & .0 & \\
\hline UNKNOWN & 10.1 & 20.8 & 11.8 & .4 & .0 & .0 & 43 \\
\hline TOTALS & 15.6 & 49.2 & 33.8 & 1.3 & .0 & .1 & 100 \\
\hline$\therefore \quad \therefore / 3$ & 6.4 & $4: 2$ & 48.0 & $3 \%$ & $c=$ & $\therefore 1$ & \\
\hline
\end{tabular}


PAGE 447062568. CCS PSI-CIT TSK2 RUN\#I6SOAP-T-1500 TOT FILTER7\%02

WEIGHT PERCENT MINERAL BASIS

$\begin{array}{rrrrrrr}1.0 & 2.2 & 4.6 & 10.0 & 22.0 & 46.0 & \\ \text { TO } & \text { TO } & \text { TO } & \text { TO } & \text { TO } & \text { TO } & \text { TOTALS } \\ 2.2 & 4.6 & 10.0 & 22.0 & 46.0 & 100.0 & \end{array}$

QUARTZ

IRON OXIDE

PERICLASE

RUTILE

ALUMINA

CALCITE

DOLOMITE

ANKERITE

KAOLINITE

MONTMORILLONITE

K AL-SILICATE

FE AL-SILICATE

CA AL-SILICATE

NA AL-SILICATE

ALUMINOSILICATE

MIXED AL-SILICA

FE SILICATE

CA SILICATE

CA ALUMINATE

PYRITE

PYRRHOTITE

OXIDIZED PYRRHO

GYPSUM

BARITE

APATITE

CA AL-P

KCL

GYPSUM/BARITE

GYPSUM/AL-SILIC

SI-RICH

CA-RICH

CA-SI RICH

UNKNOWN
4.6

.1

.1

.0

.0

.0

.0

0

.1

.0

.0

.0

4.9

.0

.0

.0

.1

.1

.0

.0

.0

.0

.0

.0

.0

.0

.0

.0

.0

.0

.2

.0

.0

9.9
.6

.7

.0

.1

.0

.0

.0

.0

.1

.1

.0

25.1

.1

.0

.0

$: 3$

.3

.0

.0

.0

.0

.0

.0

.0

.0

.0

.0

.0

.0

1.6

.2

.0

20.3

\section{1}

.0

.0

.0

.0

.0

.0

.0

.4

.4

.7

14.9

.0

.0

.2

.4

.9

.0

.0

.0

.0

.0

.0

.0

.0

.0

.0

.0

.0

2. 3

.0

.0

11.6

22.0

46.0

. 0

.0

3.0

.0
.0

.0

.0

.0

.0

.0

.0

.0

.0

.0

.0

.0

.0

.0

.0

.0

. 0

.0

.0

.0

.0

.0

.0

.0

.0

.0

.0

.0

.0

.0

.0
.0

.0

.0

.1

.0

.0

.0

.0

.4

.0

1.3

0

.0

.0

.0

.0

.0

.0

.0

.0

.1

.0

.0

.0

.0

.0

.0

.0

.0

.0

.0

.0

.0

.0

.0

. 0

.0

.0

.0

.0

.0

.0

.0

49.4

33.7

.1

100.0 
DISTRIBUTION BY \& OF EACH MINERAL PHASE

\begin{tabular}{|c|c|c|c|c|c|c|c|}
\hline 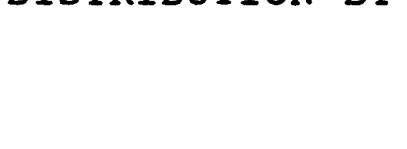 & $\begin{array}{r}1.0 \\
\text { TO } \\
2.2\end{array}$ & $\begin{array}{r}2.2 \\
\text { TO } \\
4.6\end{array}$ & $\begin{array}{r}4.6 \\
\text { TO } \\
10.0\end{array}$ & $\begin{array}{r}10.0 \\
\text { TO } \\
22.0\end{array}$ & $\begin{array}{r}22.0 \\
\text { TO } \\
46.0\end{array}$ & $\begin{array}{r}46.0 \\
\text { TO } \\
100.0\end{array}$ & TOT \\
\hline QUARTZ & 4.0 & 20.3 & 68.5 & 6.9 & .3 & .0 & 100 \\
\hline IRON OXIDE & 15.9 & 78.7 & .0 & 5.4 & .0 & .0 & 100 \\
\hline PERICLASE & .0 & .0 & .0 & .0 & .0 & .0 & \\
\hline RUTILE & .0 & 100.0 & .0 & .0 & .0 & .0 & 100 \\
\hline ALUMINA & .0 & .0 & .0 & .0 & .0 & .0 & \\
\hline CALCITE & .0 & .0 & .0 & 100.0 & .0 & .0 & 100 \\
\hline DOLOMITE & .0 & .0 & .0 & 100.0 & .0 & .0 & 100 \\
\hline ANKERITE & 100.0 & .0 & .0 & .0 & .0 & .0 & 100 \\
\hline KAOLINITE & .0 & 15.3 & 72.8 & 10.4 & 1.6 & .0 & 100 \\
\hline MONTMORILLONITE & .0 & 13.7 & 77.5 & 7.4 & 1.5 & .0 & 100 \\
\hline K AL-SILICATE & .0 & .0 & 88.8 & 4.4 & .0 & 6.8 & 100 \\
\hline FE AL-SILICATE & 10.8 & 55.6 & 32.9 & .7 & .0 & .0 & 100 \\
\hline CA AL-SILICATE & 26.6 & 70.2 & .0 & 3.1 & .0 & .0 & 100 \\
\hline NA AL-SILICATE & .0 & $\because \quad \because 0$ & $\therefore 0$ & .0 & .0 & .0 & \\
\hline ALUMINOSILICATE & .0 & .0 & 88.1 & 8.9 & 3.0 & .0 & 10 \\
\hline MIXED AL-SILICA & 8.4 & 38.4 & 49.7 & 3.5 & .0 & .0 & 100 \\
\hline FE SILICATE & 6.8 & 23.1 & 68.7 & 1.3 & .0 & .0 & 100 \\
\hline CA SILICATE & .0 & .0 & .0 & 100.0 & .0 & .0 & 100 \\
\hline CA ALUMINATE & .0 & .0 & .0 & .0 & .0 & .0 & \\
\hline PYRITE & .0 & .0 & .0 & .0 & .0 & .0 & \\
\hline PYRRHOTITE & .0 & .0 & .0 & .0 & .0 & .0 & \\
\hline OXIDIZED PYRRHO & .0 & .0 & .0 & 100.0 & .0 & .0 & 100 \\
\hline GYPSUM & .0 & .0 & .0 & .0 & .0 & .0 & \\
\hline BARITE & .0 & .0 & .0 & .0 & .0 & .0 & \\
\hline APATITE & .0 & .0 & .0 & .0 & .0 & .0 & \\
\hline$C A \quad A L-P$ & .0 & .0 & .0 & .0 & .0 & .0 & \\
\hline KCL & .0 & .0 & .0 & .0 & .0 & .0 & \\
\hline GYPSUM/BARITE & .0 & .0 & .0 & .0 & .0 & .0 & \\
\hline GYPSUM/AL-SILIC & .0 & .0 & .0 & 100.0 & .0 & .0 & 100 \\
\hline SI-RICH & 4.8 & 38.0 & 54.7 & 2.5 & .0 & .0 & 100 \\
\hline CA-RICH & .0 & 98.0 & .0 & 2.0 & .0 & .0 & 100 \\
\hline CA-SI RICH & .0 & .0 &.$\overline{0}$ & .0 & .0 & .0 & \\
\hline UNKNOWN & 23.5 & 48.2 & 27.4 & .8 & .0 & .0 & 10 \\
\hline
\end{tabular}


NUMBER OF PARTICLES IN EACH SIZE RANGE

\begin{tabular}{|c|c|c|c|c|c|c|c|}
\hline 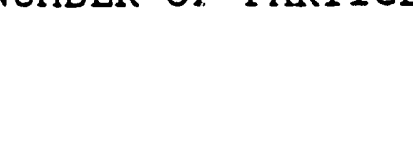 & $\begin{array}{r}1.0 \\
\text { TO } \\
2.2\end{array}$ & $\begin{array}{r}2.2 \\
\text { TO } \\
4.6\end{array}$ & $\begin{array}{r}4.6 \\
\text { TO } \\
10.0\end{array}$ & $\begin{array}{r}10.0 \\
\text { TO } \\
22.0\end{array}$ & $\begin{array}{r}22.0 \\
\text { TO } \\
46.0\end{array}$ & $\begin{array}{r}46.0 \\
\mathrm{TO} \\
100.0\end{array}$ & TOTALS \\
\hline QUARTZ & 4.0 & 5.0 & 5.0 & 121.0 & 1.0 & .0 & 136.0 \\
\hline IRON OXIDE & 2.0 & 3.0 & .0 & 12.0 & .0 & .0 & 17.0 \\
\hline PERICLASE & .0 & .0 & .0 & .0 & .0 & .0 & .0 \\
\hline RUTILE & .0 & 1.0 & .0 & .0 & .0 & .0 & 1.0 \\
\hline ALUMINA & .0 & .0 & .0 & .0 & .0 & .0 & .0 \\
\hline CALCITE & .0 & .0 & .0 & 31.0 & .0 & .0 & 31.0 \\
\hline DOLOMITE & .0 & .0 & .0 & 2.0 & .0 & .0 & 2.0 \\
\hline ANKERITE & 2.0 & .0 & .0 & .0 & .0 & .0 & 2.0 \\
\hline KAOLINITE & .0 & 1.0 & 1.0 & 30.0 & 1.0 & .0 & 33.0 \\
\hline MONTMORILLONITE & .0 & 1.0 & 1.0 & 22.0 & 1.0 & .0 & 25.0 \\
\hline $\mathrm{K}$ AL-SILICATE & .0 & .0 & 2.0 & 19.0 & .0 & 1.0 & 22.0 \\
\hline FE AL-SILICATE & 161.0 & $238: 0$ & $45: 0$ & 169.0 & .0 & .0 & 613.0 \\
\hline CA AL-SILICATE & 1.0 & 1.0 & .0 & 2.0 & .0 & .0 & 4.0 \\
\hline NA AL-SILICATE & .0 & .0 & .0 & .0 & .0 & .0 & .0 \\
\hline ALUMINOSILICATE & .0 & .0 & 1.0 & 10.0 & 1.0 & .0 & 12.0 \\
\hline MIXED AL-SILICA & 3.0 & 3.0 & 1.0 & 15.0 & .0 & .0 & 22.0 \\
\hline FE SILICATE & 2.0 & 1.0 & 1.0 & 6.0 & .0 & .0 & 10.0 \\
\hline CA SILICATE & .0 & .0 & .0 & 6.0 & .0 & .0 & 6.0 \\
\hline CA ALUMINATE & .0 & .0 & .0 & .0 & .0 & .0 & .0 \\
\hline PYRITE & .0 & .0 & .0 & .0 & .0 & .0 & .0 \\
\hline PYRRHOTITE & .0 & .0 & .0 & .0 & .0 & .0 & .0 \\
\hline OXIDIZED PYRRHO & .0 & .0 & .0 & 2.0 & .0 & .0 & 2.0 \\
\hline GYPSUM & .0 & .0 & .0 & .0 & .0 & .0 & .0 \\
\hline BARITE & .0 & .0 & .0 & .0 & .0 & .0 & .0 \\
\hline APATITE & .0 & .0 & .0 & .0 & .0 & .0 & .0 \\
\hline$C A$ AL-P & .0 & .0 & .0 & .0 & .0 & .0 & .0 \\
\hline KCL & .0 & .0 & .0 & .0 & .0 & .0 & .0 \\
\hline GYPSUM / BARITE & .0 & .0 & .0 & .0 & .0 & .0 & .0 \\
\hline GYPSUM/AL-SILIC & .0 & .0 & .0 & 1.0 & .0 & .0 & 1.0 \\
\hline SI-RICH & 8.0 & 15.0 & 7.0 & 67.0 & .0 & .0 & 37.0 \\
\hline $\mathrm{CA}-\mathrm{RICH}$ & .0 & 1.0 & .0 & 3.0 & .0 & .0 & 4.0 \\
\hline CA-SI RICH & .0 & .0 & .0 & .0 & .0 & .0 & .0 \\
\hline
\end{tabular}




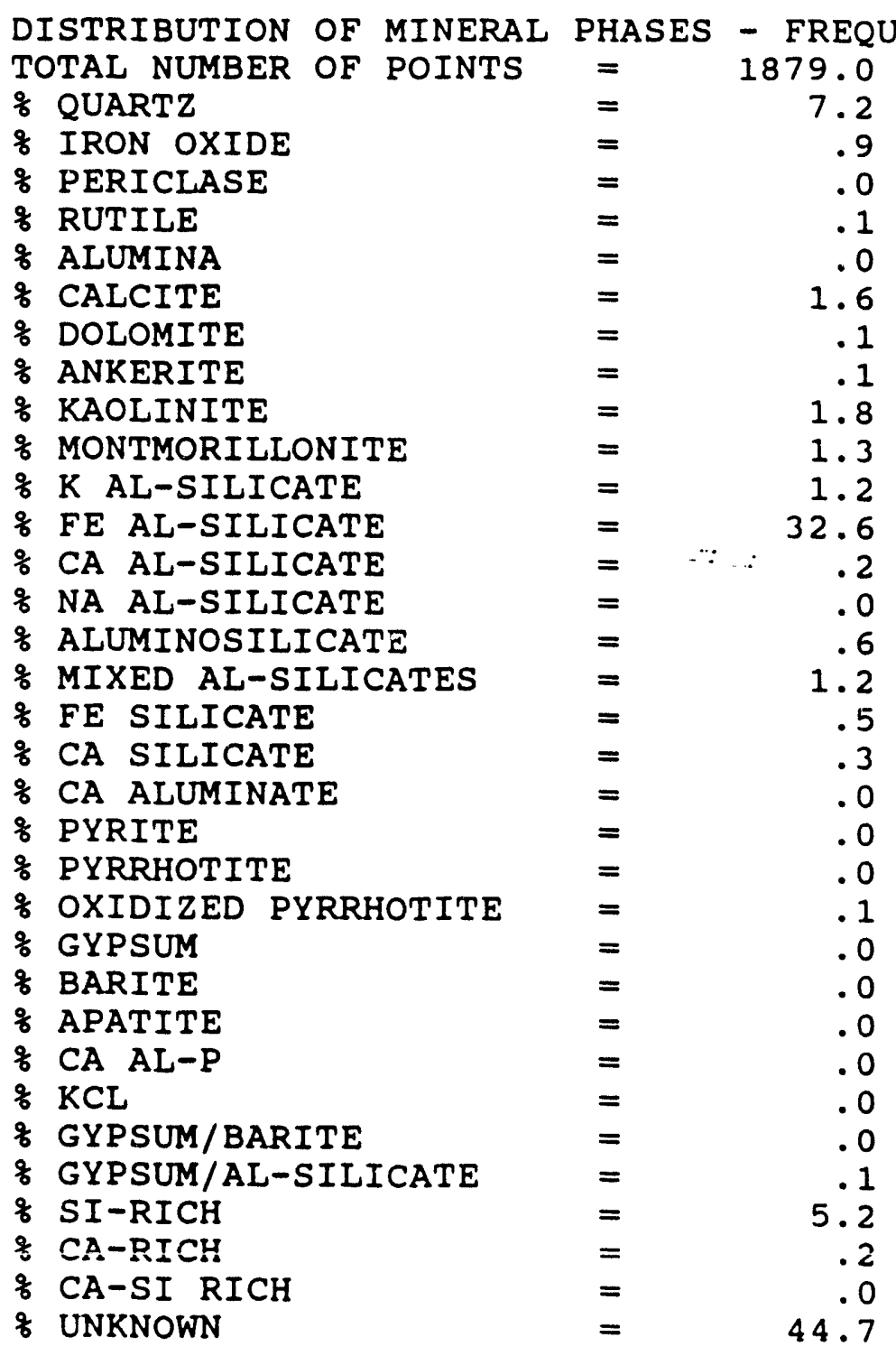


SFMPLE DESCRIPTION -- 47062571. CCS PSI-CIT TSK2RUN\#I6SOAP T1500 TOTFILTER7\%2, SUBMITTER $\quad-\rightarrow$ ZYGARL

ICC \# AND FUND \#---> 47062571

RUN DATE AND TIME ---> $6 \quad \begin{array}{rrrr} & 10 & 1991 & 9: 25\end{array}$

SUMMARY OF PARAMETERS

TOTAL MINERAL AREA ANALYZED AT HIGH MAG=

$=9534.4$

NORMALIZED AREA ANALYZED AT HIGH MAG

TOTAL MINERAL AREA ANALYZED AT LOW MAG

FIELD SIZE USED AT HIGH MAG

FIELD SIZE USED AT LOW MAG

NUMBER OF FRAMES AT HIGH MAG

NUMBER OF FRAMES AT LOW MAG

TOTAL NUMBER OF POINTS ANALYZED

NUMBER OF POINTS UNDER THRESHOLD
$=257366.5$

$=39978.1$

$=115519.773$

$=2494610.477$

$=$

$=$

$=$

$=$

\section{Epory trsection}

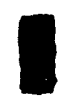

WEIGHT PERCENT ON A MINERAL BASIS

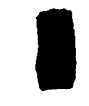

\begin{tabular}{|c|c|c|c|c|c|c|c|}
\hline & $\begin{array}{r}1.0 \\
\text { TO } \\
2.2\end{array}$ & $\begin{array}{r}2.2 \\
\text { TO } \\
4.6\end{array}$ & $\begin{array}{r}4.6 \\
\text { TO } \\
10.0\end{array}$ & $\begin{array}{r}10.0 \\
\text { TO } \\
22.0\end{array}$ & $\begin{array}{r}22.0 \\
\text { TO } \\
46.0\end{array}$ & $\begin{array}{r}46.0 \\
\mathrm{TO} \\
100.0\end{array}$ & TOTALS \\
\hline JARTZ & .1 & 1.8 & .8 & .7 & .0 & .0 & 3.4 \\
\hline IRON OXIDE & .0 & .1 & .0 & .2 & .0 & .0 & .4 \\
\hline PERICLASE & .0 & .0 & .0 & .0 & .0 & .0 & .0 \\
\hline RUTILE & .0 & .1 & .0 & .0 & .0 & .0 & .1 \\
\hline ALUMINA & .0 & .0 & .0 & .0 & .0 & .0 & .0 \\
\hline ALCITE & .0 & .2 & .4 & .3 & .0 & .0 & .8 \\
\hline OLOMITE & .0 & .0 & .0 & .0 & .0 & .0 & .0 \\
\hline NKERITE & .0 & .0 & .0 & .0 & .0 & .0 & .1 \\
\hline KAOLINITE & .0 & .0 & .2 & .1 & .0 & .0 & .3 \\
\hline MONTMORILLON ITE & .0 & .3 & .6 & .2 & .0 & .0 & 1.2 \\
\hline AL-SILICATE & .0 & .3 & .4 & .6 & .0 & .0 & 1.4 \\
\hline FE AL-SILICATE & 1.7 & 15.8 & 14.2 & 2.4 & .0 & .0 & 34.1 \\
\hline CA AL-SILICATE & .0 & $\because 0$ & .0 & .0 & .0 & .0 & .0 \\
\hline IA AT,-SILICATE & .0 & .0 & .0 & .0 & .0 & .0 & .0 \\
\hline ALUMNOSILICATE & .0 & .0 & .0 & .0 & .0 & .0 & .0 \\
\hline MIXED AL-SILICA & .1 & .9 & 1.0 & .2 & .0 & .0 & 2.2 \\
\hline FE SILICATE & .0 & .1 & .0 & .1 & .0 & .0 & .3 \\
\hline CA SILICATE & .0 & .0 & .0 & .0 & .0 & .0 & .0 \\
\hline CA ALUMINATE & .0 & .0 & .0 & .0 & .0 & .0 & .0 \\
\hline PYRITE & .0 & .0 & .0 & .0 & .0 & .0 & .0 \\
\hline PYRRHOTITE & .0 & .0 & .0 & .0 & .0 & .0 & .0 \\
\hline OXIDIZED PYRRHO & .0 & .0 & .0 & .0 & .0 & .0 & .0 \\
\hline IPSUM & .0 & .0 & .0 & .0 & .0 & .0 & .0 \\
\hline ARITE & .0 & .0 & .0 & .0 & .0 & .0 & .0 \\
\hline ATITE & .0 & .0 & .0 & .0 & .0 & .0 & .0 \\
\hline$A L-P$ & .0 & .0 & .0 & .0 & .0 & .0 & .0 \\
\hline L & .0 & .0 & .0 & .0 & .0 & .0 & .0 \\
\hline PSUM/BARITE & .0 & .0 & .0 & .0 & .0 & .0 & .0 \\
\hline PSUM / AL-SILIC & .0 & .0 & .0 & .0 & .0 & .0 & .0 \\
\hline$-\mathrm{RICH}$ & .3 & 2.1 & 1.5 & .4 & .2 & .0 & 4.4 \\
\hline -RICH & .0 & .0 & .3 & $=0$ & $=0$ & .0 & .3 \\
\hline -SI RICH & .0 & .0 & .6 & .2 & .0 & .0 & .8 \\
\hline KNOWN & 6.5 & 21.7 & 14.2 & 7.2 & .6 & .0 & 50.2 \\
\hline
\end{tabular}


AREA IN EACH SIZE RANGE

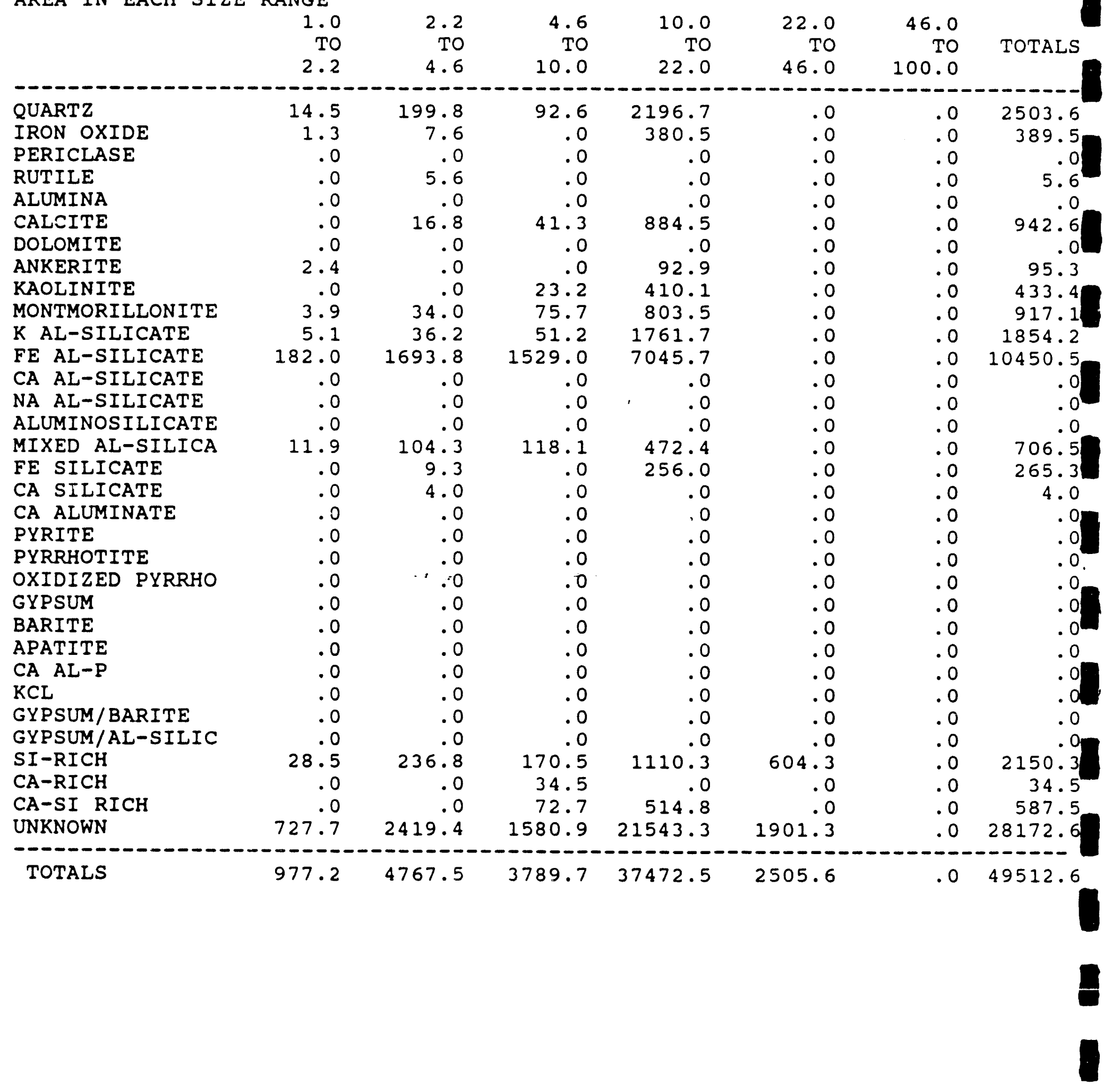


PAGE $247062571 . C C S$ PSI-CIT TSK2RUN\#I6SOAP T1500 TOTFILTER7\%2, AS REC'D

NORMALIZED AREA IN EACH SIZE RANGE

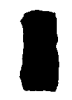

$\begin{array}{cc}1.0 & 2.2\end{array}$

$\begin{array}{rr}1.0 & 2.2 \\ \text { TO } & \text { TO } \\ 2.2 & 4.6\end{array}$

4.6
TO

$.6 \quad 10.0$

TO

22.0

TO

46.0

$10.0 \quad 22.0$

46.0

TO

TOTALS

IRON OXIDE

PERIC AASE

RUTILE

ALUMINA

CALCITE

DOLOMITE

ANKERITE

KAOLINITE

MONTMORILLONITE

$K$ AL-SILICATE

FE AL-SILICATE

CA AL-SILICATE

NA AL-SILICATE

ALUMINOSILICATE

MIXED AL-SILICA

FE SILICATE

CA SILICATE

CA ALUMINATE

PYRITE

PYRRHOTITE

OXIDIZED PYRRHO

GYPSUM

BARITE

APATITE

CA $A L-P$

KCL

GYPSUM/BARITE

GYPSUM/AL-SILIC

SI-RICH

CA-RICH

CA-SI RICH UNKNOWN
391.4

36.2

5392.2

206.2

150.9

.0

.0

.0

.0

65.9

.0

106.1

137.4

4911.7

.0

.0

.0

320.1

.0

.0

.0

.0

.0

.0

.0

.0

.0

.0

.0

.0

.0

768.0

. 0

.0

19642.0
.0

454.3

.0

.0

918.0

978.2

45720.8

.0

.0

250.5

108.0

.0

$\cdots: 0$

.0

. 0

.0

.0

.0

.0

.0

.0

.0

6390.9

.0

.0

65307.3
2814.0
2499.3

.0

.0

. 0

1113.7

.0

.0

626.5

2044.5

1381.2

41272.3

.0

.0

3186.8

.0

.0

.0

.0

.0

.0

.0

.0

.0

.0

.0

.0

.0

4602.9

932.1

1962.7

42674.3
2196.7

380.5

.0

.0

884.5

92.9

410.1

803.5

1761.7

7045.7

.0

.0

472.4

256.0

.0

.0

.0

.0

.0

.0

.0

.0

.0

.0

.0

. 0

1110.3

.0

514.8

21543.3
.0

.0

.0

.0

.0

.0

.0

.0

.0

.0

.0

.0

.0

.0

.0

.0

.0

. 0

.0

.0

.0

.0

.0

.0

.0

.0

.0

. 0

.0

604.3

.0

.0

1901.3
10479.6

622.9

.0

.0

.0

.0

.0

.0

.0

.0

.0

.0

.0

.0

.0

.0

.0

.0

.0

.0
.0

.0

. 0

. 0

.0

.0

.0

.0

.0

. 0

.0
.0

3476.4

932.1

2477.5

.0151068 .3 
AREA PERCENT MINERAL BASIS

\begin{tabular}{|c|c|c|c|c|c|c|c|}
\hline & $\begin{array}{r}1.0 \\
\text { TO } \\
2.2\end{array}$ & $\begin{array}{r}2.2 \\
\text { TO } \\
4.6\end{array}$ & $\begin{array}{r}4.6 \\
\text { TO } \\
10.0\end{array}$ & $\begin{array}{r}10.0 \\
\text { TO } \\
22.0\end{array}$ & $\begin{array}{r}22.0 \\
\text { TO } \\
46.0\end{array}$ & $\begin{array}{r}46.0 \\
\text { TO } \\
100.0\end{array}$ & TOTALS \\
\hline QUARTZ & .1 & 1.8 & .8 & .7 & .0 & .0 & 3.5 \\
\hline IRON OXIDE & .0 & .1 & .0 & .1 & .0 & .0 & .2 \\
\hline PERICLASE & .0 & .0 & .0 & .0 & .0 & .0 & .0 \\
\hline RUTILE & .0 & .1 & .0 & .0 & .0 & .0 & .1 \\
\hline ALUMINA & .0 & .0 & .0 & .0 & .0 & .0 & .0 \\
\hline CALCITE & .0 & .2 & .4 & .3 & .0 & .0 & .8 \\
\hline DOLOMITE & .0 & .0 & .0 & .0 & .0 & .0 & .0 \\
\hline ANKERITE & .0 & .0 & .0 & .0 & .0 & .0 & .1 \\
\hline KAOLINITE & .0 & .0 & .2 & .1 & .0 & .0 & .3 \\
\hline MONTMORILLONITE & .0 & .3 & .7 & .3 & .0 & .0 & 1.3 \\
\hline K AL-SILICATE & .0 & .3 & .5 & .6 & .0 & .0 & 1.4 \\
\hline FE AL-SILICATE & 1.7 & 15.4 & 13.9 & 2.4 & .0 & .0 & 33.3 \\
\hline CA AL-SILICATE & .0 & .0 & .0 & .0 & .0 & .0 & .0 \\
\hline NA AL-SILICATE & .0 & .0 & .0 & .0 & .0 & .0 & .0 \\
\hline ALUMTNOSILICATE & .0 & .0 & .0 & .0 & .0 & .0 & .0 \\
\hline MIXED AL-SILICA & .1 & .9 & 1.1 & .2 & .0 & .0 & 2.3 \\
\hline FE SILICATE & .0 & .1 & .0 & .1 & .0 & .0 & .2 \\
\hline CA SILICATE & .0 & $\therefore \quad \therefore 0$ & .0 & .0 & .0 & .0 & .0 \\
\hline CA ALUMINATE & .0 & .0 & .0 & .0 & .0 & .0 & .0 \\
\hline PYRITE & .0 & .0 & .0 & .0 & .0 & .0 & .0 \\
\hline PYRRHOTITE & .0 & .0 & .0 & .0 & .0 & .0 & .0 \\
\hline OXIDIZED PYRRHO & .0 & .0 & .0 & .0 & .0 & .0 & .0 \\
\hline GYPSUM & .0 & .0 & .0 & .0 & .0 & .0 & .0 \\
\hline BARITE & .0 & .0 & .0 & .0 & .0 & .0 & .0 \\
\hline APATITE & .0 & .0 & .0 & .0 & .0 & .0 & .0 \\
\hline CA AL-P & .0 & .0 & .0 & .0 & .0 & .0 & .0 \\
\hline KCL & .0 & .0 & .0 & .0 & .0 & .0 & .0 \\
\hline GYPSUM / BARITE & .0 & .0 & .0 & .0 & .0 & .0 & .0 \\
\hline GYPSUM/AL-SILIC & .0 & .0 & .0 & .0 & .0 & .0 & .0 \\
\hline SI-RICH & .3 & 2.1 & 1.5 & .4 & .2 & .0 & 4.5 \\
\hline $\mathrm{CA}-\mathrm{RICH}$ & .0 & .0 & .3 & .0 & .0 & .0 & .3 \\
\hline CA-SI RICH & .0 & .0 & .7 & .2 & .0 & .0 & .8 \\
\hline UNKNOWN & 6.6 & 22.0 & 14.4 & 7.2 & .6 & .0 & 50.8 \\
\hline TOTALS & 8.9 & 43.3 & 34.4 & 12.6 & .8 & .0 & 100.0 \\
\hline
\end{tabular}


PAGE 4 47062571.CCS PSI-CIT TSK2RUN\#I6SOAP T1500 TOTFILTER7\%2, AS REC'D

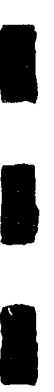

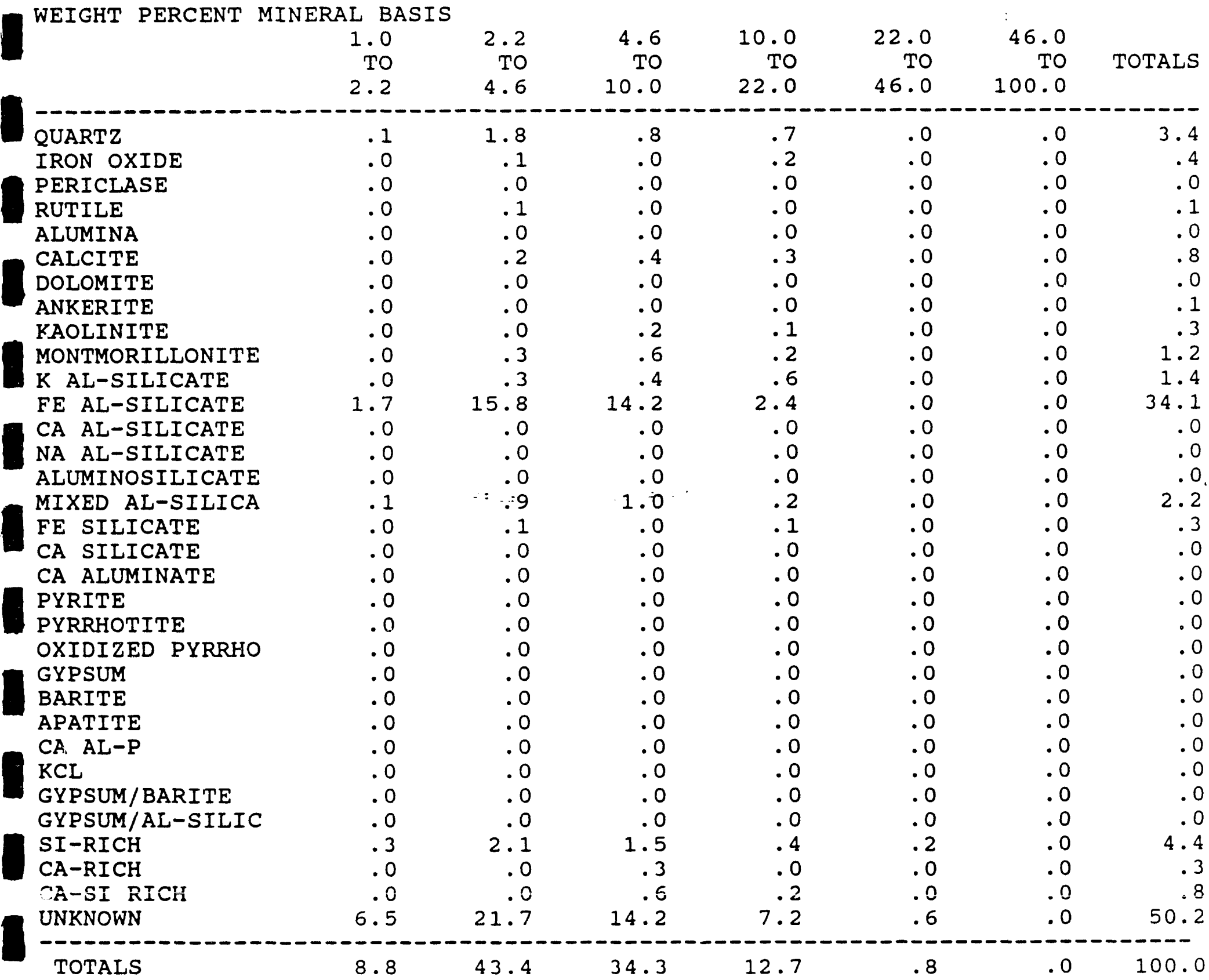


DISTRIBUTION BY \% OF EACH MINERAL PHASE

\begin{tabular}{|c|c|c|c|c|c|c|c|}
\hline & $\begin{array}{r}1.0 \\
\text { TO } \\
2.2\end{array}$ & $\begin{array}{r}2.2 \\
\text { TO } \\
4.6\end{array}$ & $\begin{array}{r}4.6 \\
\text { TO } \\
10.0\end{array}$ & $\begin{array}{r}10.0 \\
\text { TO } \\
22.0\end{array}$ & $\begin{array}{r}22.0 \\
\text { TO } \\
46.0\end{array}$ & $\begin{array}{r}46.0 \\
\text { TO } \\
100.0\end{array}$ & TOTALS \\
\hline QUARTZ & 3.7 & 51.5 & 23.8 & 21.0 & .0 & .0 & 100. \\
\hline IRON OXIDE & 5.8 & 33.1 & .0 & 61.1 & .0 & .0 & 100 \\
\hline PERICLASE & .0 & .0 & .0 & .0 & .0 & .0 & \\
\hline RUTILE & .0 & 100.0 & .0 & .0 & .0 & .0 & 100. \\
\hline ALUMINA & .0 & .0 & .0 & .0 & .0 & .0 & \\
\hline CALCITE & .0 & 18.5 & 45.4 & 36.1 & .0 & .0 & 100. \\
\hline DOLOMITE & .0 & .0 & .0 & .0 & .0 & .0 & \\
\hline ANKERITE & 41.5 & .0 & .0 & 58.5 & .0 & .0 & 100. \\
\hline KAOLINITE & .0 & .0 & 60.4 & 39.6 & .0 & .0 & 100. \\
\hline MONTMORILLONITE & 2.7 & 23.7 & 52.8 & 20.8 & .0 & .0 & 100.0 \\
\hline K AL-SILICATE & 3.2 & 23.0 & 32.4 & 41.4 & .0 & .0 & 100 \\
\hline FE AL-SILICATE & 5.0 & 46.2 & 41.7 & 7.1 & .0 & .0 & 100. \\
\hline CA AL-SILICATE & .0 & .0 & .0 & .0 & .0 & .0 & \\
\hline NA AL-SILICATE & .0 & $\because 0$ & .0 & .0 & .0 & .0 & \\
\hline ALUMINOSILICATE & .0 & .0 & .0 & .0 & .0 & .0 & \\
\hline MIXED AL-SILICA & 4.7 & 41.4 & 46.9 & 7.0 & .0 & .0 & 100. \\
\hline FE SILICATE & .0 & 49.5 & .0 & 50.5 & .0 & .0 & 100.0 \\
\hline CA SILICATE & .0 & 100.0 & .0 & .0 & .0 & .0 & 100. \\
\hline CA ALUMINATE & .0 & .0 & .0 & .0 & .0 & .0 & \\
\hline PYRITE & .0 & .0 & .0 & .0 & .0 & .0 & \\
\hline PYRRHOTITE & .0 & .0 & .0 & .0 & .0 & .0 & \\
\hline OXIDIZED PYRRHO & .0 & .0 & .0 & .0 & .0 & .0 & \\
\hline GYPSUM & .0 & .0 & .0 & .0 & .0 & .0 & \\
\hline BARITE & .0 & .0 & .0 & .0 & .0 & .0 & \\
\hline APATITE & .0 & .0 & .0 & .0 & .0 & .0 & \\
\hline$C A$ AL-P & .0 & .0 & .0 & .0 & .0 & .0 & \\
\hline $\mathrm{KCL}$ & .0 & 0 & .0 & .0 & .0 & .0 & .0 \\
\hline GYPSUM/BARITE & .0 & 0 & .0 & .0 & .0 & .0 & \\
\hline GYPSUM/AL-SILIC & .0 & .0 & .0 & .0 & .0 & .0 & \\
\hline$S I-R I C H$ & 5.7 & 47.4 & 34.2 & 8.2 & 4.5 & .0 & 100. \\
\hline $\mathrm{CA}-\mathrm{RICH}$ & .0 & .0 & 100.0 & .0 & .0 & .0 & 100 \\
\hline CA-SI RICH & .0 & .0 & 79.2 & 20.8 & .0 & .0 & 100 \\
\hline UNKNOWN & 13.0 & 43.2 & 28.2 & 14.3 & 1.3 & .0 & 100 \\
\hline
\end{tabular}


PAGE 647062571. CCS PSI-CIT TSK2RUN\#I6SOAP T1500 TOTFILTER7\%2, AS REC'D

TNumber of particles IN EACH SIZE RANGe

\begin{tabular}{|c|c|c|c|c|c|c|c|}
\hline 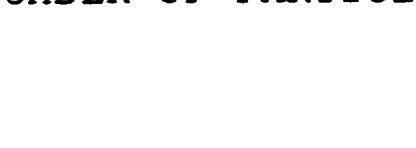 & $\begin{array}{r}1.0 \\
\text { TO } \\
2.2\end{array}$ & $\begin{array}{r}2.2 \\
\text { TO } \\
4.6\end{array}$ & $\begin{array}{r}4.6 \\
\text { TO } \\
10.0\end{array}$ & $\begin{array}{r}10.0 \\
\text { TO } \\
22.0\end{array}$ & $\begin{array}{r}22.0 \\
\text { TO } \\
46.0\end{array}$ & $\begin{array}{r}46.0 \\
\mathrm{TO} \\
100.0\end{array}$ & TOTALS \\
\hline QUARTZ & 4.0 & 17.0 & 3.0 & 15.0 & .0 & .0 & 39.0 \\
\hline IRON OXIDE & 1.0 & 1.0 & .0 & 3.0 & .0 & .0 & 5.0 \\
\hline PERICLASE & .0 & .0 & .0 & .0 & .0 & .0 & .0 \\
\hline RUTILE & .0 & 1.0 & .0 & .0 & .0 & .0 & 1.0 \\
\hline ALUMINA & .0 & .0 & .0 & .0 & .0 & .0 & .0 \\
\hline CALCITE & .0 & 2.0 & 2.0 & 6.0 & .0 & .0 & 10.0 \\
\hline DOLOMITE & .0 & .0 & .0 & .0 & .0 & .0 & .0 \\
\hline ANKERITE & 1.0 & .0 & .0 & 1.0 & .0 & .0 & 2.0 \\
\hline KAOLINITE & .0 & .0 & 1.0 & 3.0 & .0 & .0 & 4.0 \\
\hline MONTMORILLONITE & 2.0 & 3.0 & 2.0 & 5.0 & .0 & .0 & 12.0 \\
\hline K AL-SIIICATE & 3.0 & 3.0 & 2.0 & 11.0 & .0 & .0 & 19.0 \\
\hline FE AL-SILICATE & 70.0 & $177: 0$ & $58: 0$ & 56.0 & .0 & .0 & 361.0 \\
\hline CA AL-SILICATE & .0 & .0 & .0 & .0 & .0 & .0 & .0 \\
\hline NA AL-SILICATE & .0 & .0 & .0 & .0 & .0 & .0 & .0 \\
\hline ALUMINOSILICATE & .0 & .0 & .0 & .0 & .0 & .0 & .0 \\
\hline MIXED AL-SILICA & 4.0 & 10.0 & 4.0 & 4.0 & .0 & .0 & 22.0 \\
\hline FE SILICATE & .0 & 1.0 & .0 & 2.0 & .0 & .0 & 3.0 \\
\hline CA SILICATE & .0 & 1.0 & .0 & .0 & .0 & .0 & 1.0 \\
\hline CA ALUMINATE & .0 & .0 & .0 & .0 & .0 & .0 & .0 \\
\hline PYRITE & .0 & .0 & .0 & .0 & .0 & .0 & .0 \\
\hline PYRRHOTITE & .0 & .0 & .0 & .0 & .0 & .0 & .0 \\
\hline OXIDIZED PYRRHO & .0 & .0 & .0 & .0 & .0 & .0 & .0 \\
\hline GYPSUM & .0 & .0 & .0 & .0 & .0 & .0 & .0 \\
\hline BARITE & .0 & .0 & .0 & .0 & .0 & .0 & .0 \\
\hline APATITE & .0 & .0 & .0 & .0 & .0 & .0 & .0 \\
\hline$C A$ AL-P & .0 & .0 & .0 & .0 & .0 & .0 & .0 \\
\hline $\mathrm{KCL}$ & .0 & .0 & .0 & .0 & .0 & .0 & .0 \\
\hline GYPSUM / BARITE & .0 & .0 & .0 & .0 & .0 & .0 & .0 \\
\hline GYPSUM/AL-SILIC & .0 & .0 & .0 & .0 & .0 & .0 & .0 \\
\hline$S I-R I C H$ & 14.0 & 28.0 & 7.0 & 10.0 & 1.0 & .0 & 60.0 \\
\hline$C A-R I C H$ & .0 & .0 & 1.0 & .0 & .0 & .0 & 1.0 \\
\hline $\mathrm{CA}-\mathrm{SI}$ RICH & .0 & .0 & 2.0 & 3.0 & .0 & .0 & 5.0 \\
\hline
\end{tabular}




\begin{tabular}{|c|c|c|c|c|c|c|}
\hline UNKNOWN & 353.0 & 291.0 & 61.0 & 157.0 & 4.0 & .0 \\
\hline TOTALS & 452.0 & 535.0 & 143.0 & 276.0 & 5.0 & .0 \\
\hline
\end{tabular}

PAGE 747062571. CCS PSI-CIT TSK2RUN\#I6SOAP T1500 TOTFILTER7\%2, AS REC'D

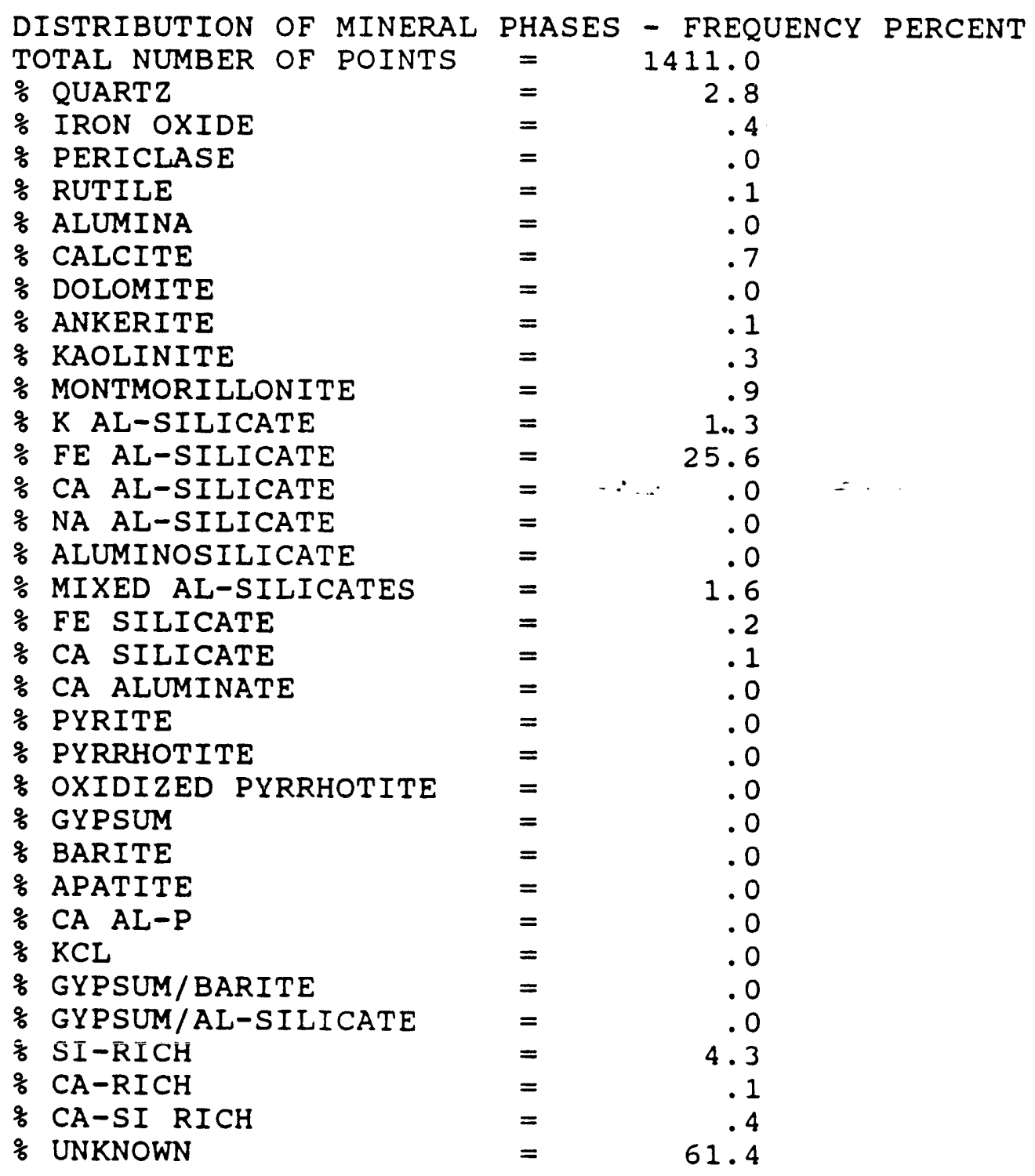


SUMM:RY OF CCSEM RESULTS: PROG VERSION 2BF $8 / 21 / 90$

SAMPLE DESCRIPTION --> 47062569.CCS PSI-CIT TSK2 RUN\#I6SOAP-T-1250 TOT FILTERI SUBMITTER $\quad-\rightarrow$ ZYGARL

ICC \# AND FUND \# -- 47062569

RUN DATE AND TIME $\quad-\rightarrow \quad 6 \quad 51991 \quad 3: 42$

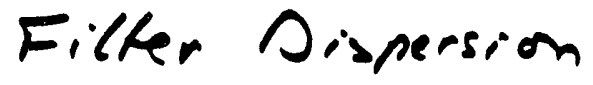

SUMMARY OF PARAMETERS

TOTAL MINERAL AREA ANALYZED AT HIGH MAG= NORMALIZED AREA ANALYZED AT HIGH MAG

$=8257.6$

TOTAL MINERAL AREA ANALYZED AT LOW MAG

$=1497890.0$

$=60458.2$

FIELD SIZE USED AT HIGH MAG

$=115519.773$

FIELD SIZE USED AT LOW MAG

NUMBER OF FRAMES AT HIGH MAG

$=2494610.477^{\circ}$

NUMBER OF FRAMES AT LOW MAG

TOTAL NUMBER OF POINTS ANALYZED

NUMBER OF POINTS UNDER THRESHOLD

$=$

$=$

$=$

$42-$

1.584

WEIGHT PERCENT ON A MINERAL BASIS

\begin{tabular}{|c|c|c|c|c|c|c|c|}
\hline & $\begin{array}{r}1.0 \\
\text { TO } \\
2.2\end{array}$ & $\begin{array}{r}2.2 \\
\text { TO } \\
4.6\end{array}$ & $\begin{array}{r}4.6 \\
\text { TO } \\
10.0 \\
\end{array}$ & $\begin{array}{r}10.0 \\
\text { TO } \\
22.0\end{array}$ & $\begin{array}{r}22.0 \\
\text { TO } \\
46.0\end{array}$ & $\begin{array}{r}46.0 \\
\text { TO } \\
100.0\end{array}$ & TOTALS \\
\hline QUARTZ & .1 & 2.0 & 2.3 & .4 & .1 & .0 & 4.9 \\
\hline IRON OXIDE & .1 & .3 & .0 & .1 & .0 & .0 & .5 \\
\hline PERICLASE & .0 & .0 & .0 & .0 & .0 & .0 & .0 \\
\hline RUTILE & .0 & .0 & .0 & .0 & .0 & .0 & .0 \\
\hline ALUMINA & .0 & .2 & .0 & .1 & .0 & .0 & .3 \\
\hline CALCITE & .0 & .0 & .0 & .1 & .0 & .0 & .1 \\
\hline DOLOMITE & .0 & .0 & .0 & .0 & .0 & .0 & .0 \\
\hline ANKERITE & .0 & .0 & .0 & .0 & .0 & .0 & .0 \\
\hline KAOLINITE & .1 & .4 & .0 & .2 & .0 & .0 & .6 \\
\hline MONTMORILLONITE & .0 & .2 & .4 & .1 & .0 & .0 & .7 \\
\hline K AL-SILICATE & .2 & 2.3 & .9 & .4 & .0 & .0 & 3.8 \\
\hline FE AL-SILICATE & .8 & 7.7 & 7.8 & .5 & .0 & .0 & 16.9 \\
\hline CA AL-SILICATE & .0 & $\ldots .2$ & $-\theta$ & .0 & .0 & .0 & .3 \\
\hline NA AL-SILICATE & .0 & .0 & .0 & .0 & .0 & .0 & .0 \\
\hline ALUMINOSILICATE & .0 & .0 & .0 & .1 & .0 & .0 & .1 \\
\hline MIXED AL-SILICA & .5 & 2.9 & 1.8 & .1 & .0 & .0 & 5.3 \\
\hline FE SILICATE & .4 & 1.4 & .0 & .0 & .0 & .0 & 1.8 \\
\hline CA SILICATE & .0 & .0 & .0 & .0 & .0 & .0 & .0 \\
\hline CA ALUMINATE & .0 & .0 & .0 & .0 & .0 & .0 & .0 \\
\hline PYRITE & .0 & .0 & .0 & .0 & .0 & .0 & .0 \\
\hline PYRRHOTITE & .0 & .0 & .0 & .0 & .0 & .0 & .0 \\
\hline OXIDIZED PYRRHO & .0 & .0 & .0 & .0 & .0 & .0 & .0 \\
\hline GYPSUM & .0 & .0 & .0 & .0 & .1 & .0 & .1 \\
\hline BARITE & .0 & .0 & .0 & .0 & .0 & .0 & .0 \\
\hline APATITE & .0 & .0 & .0 & .0 & .0 & .0 & .0 \\
\hline CA AL-P & .0 & .0 & .0 & .0 & .0 & .0 & .0 \\
\hline $\mathrm{KCL}$ & .0 & .0 & .0 & .0 & .0 & .0 & .0 \\
\hline GYPSUM/BARITE & .0 & .0 & .0 & .0 & .0 & .0 & .0 \\
\hline GYPSUM/AL-SILIC & .0 & .0 & .4 & .0 & .0 & .0 & .4 \\
\hline SI-RICH & .2 & 1.3 & 2.3 & .2 & .1 & .0 & 4.1 \\
\hline $\mathrm{CA}-\mathrm{RICH}$ & .0 & .1 & .2 & .0 & .0 & .0 & .3 \\
\hline CA-SI RICH & .0 & .0 & .0 & .0 & .0 & .0 & .0 \\
\hline UNKNOWN & 11.9 & 31.2 & 15.4 & 1.1 & .2 & .0 & 59.9 \\
\hline
\end{tabular}


AREA IN EACH SIZE RANGE

\begin{tabular}{|c|c|c|c|c|c|c|c|}
\hline & $\begin{array}{r}1.0 \\
\text { TO } \\
2.2\end{array}$ & $\begin{array}{r}2.2 \\
\text { TO } \\
4.6\end{array}$ & $\begin{array}{r}4.6 \\
\text { TO } \\
10.0\end{array}$ & $\begin{array}{r}10.0 \\
\text { TO } \\
22.0\end{array}$ & $\begin{array}{r}22.0 \\
\text { TO } \\
46.0\end{array}$ & $\begin{array}{r}46.0 \\
\text { TO } \\
100.0\end{array}$ & TOTAI \\
\hline QUARTZ & 10.6 & 179.9 & 204.2 & 5785.1 & 1274.5 & .0 & 7454 \\
\hline IRON OXIDE & 4.9 & 14.8 & .0 & 504.7 & .0 & .0 & 524 \\
\hline PERICLASE & .0 & .0 & .0 & .0 & .0 & .0 & \\
\hline RUTILE & .0 & .0 & .0 & 89.5 & .0 & .0 & 89 \\
\hline ALUMINA & .0 & 10.3 & .0 & 1256.3 & .0 & .0 & 1266 \\
\hline CALCITE & .0 & .0 & .0 & 1416.5 & .0 & .0 & 1416 \\
\hline DOLOMITE & .0 & .0 & .0 & 185.4 & .0 & .0 & 185 \\
\hline ANKERITE & .0 & .0 & .0 & .0 & .0 & .0 & \\
\hline KAOLINITE & 5.0 & 31.2 & .0 & 2711.2 & .0 & .0 & 2747 \\
\hline MONTMORILLONITE & .0 & 16.8 & 39.4 & 1981.0 & .0 & .0 & 2037 \\
\hline K AL-SILICATE & 15.5 & 206.8 & 83.6 & 6131.9 & .0 & .0 & 6437 \\
\hline FE AL-SILICATE & 67.6 & 647.8 & 656.8 & 7021.9 & 635.2 & .0 & 9029 \\
\hline CA AL-SILICATE & 1.7 & 21.9 & .0 & 96.9 & .0 & .0 & 120 \\
\hline NA AL-SILICATE & .0 & .0 & .0 & .0 & .0 & .0 & \\
\hline ALUMINOSILICATE & .0 & .0 & .0 & 1089.4 & .0 & .0 & 1089 \\
\hline MIXED AL-SILICA & 43.1 & 252.9 & 159.8 & 1618.7 & 790.3 & .0 & 2864 \\
\hline FE SILICATE & 20.8 & 75.0 & .0 & 323.3 & .0 & .0 & 419 \\
\hline CA SILICATE & .0 & .0 & .0 & .0 & .0 & .0 & \\
\hline CA ALUMINATE & .0 & .0 & .0 & .0 & .0 & .0 & \\
\hline PYRITE & .0 & .0 & .0 & .0 & .0 & .0 & \\
\hline PYRRHOTITE & .0 & .0 & .0 & .0 & .0 & .0 & \\
\hline OXIDIZED PYRRHO & .0 & .0 & .0 & .0 & .0 & .0 & \\
\hline GYPSUM & .0 & .0 & .0 & 378.5 & 1152.7 & .0 & 1531 \\
\hline BARITE & .0 & .0 & .0 & .0 & .0 & .0 & \\
\hline APATITE & .0 & .0 & .0 & .0 & .0 & .0 & \\
\hline CA AL-P & .0 & .0 & .0 & .0 & .0 & .0 & \\
\hline KCL & .0 & .0 & .0 & .0 & .0 & .0 & \\
\hline GYPSUM/BARITE & .0 & .0 & .0 & .0 & .0 & .0 & \\
\hline GYPSUM/AL-SILIC & .0 & .0 & 35.4 & 98.3 & .0 & .0 & 133 \\
\hline SI-RICH & 20.8 & 115.9 & 204.5 & 3887.4 & 818.9 & .0 & 5047 \\
\hline CA-RICH & .0 & 7.1 & 17.6 & 237.2 & .0 & .0 & 261 \\
\hline CA-SI RICH & .0 & .0 & .0 & 122.5 & .0 & .0 & 122 \\
\hline UNKNOWN & $1036 . \dot{6}$ & 2709.6 & 1339.9 & 17517.6 & 3333.3 & .0 & 25937 \\
\hline TOTALS & 1226.6 & 4289.9 & 2741.1 & 52453.2 & 8005.0 & .0 & 68715 \\
\hline
\end{tabular}




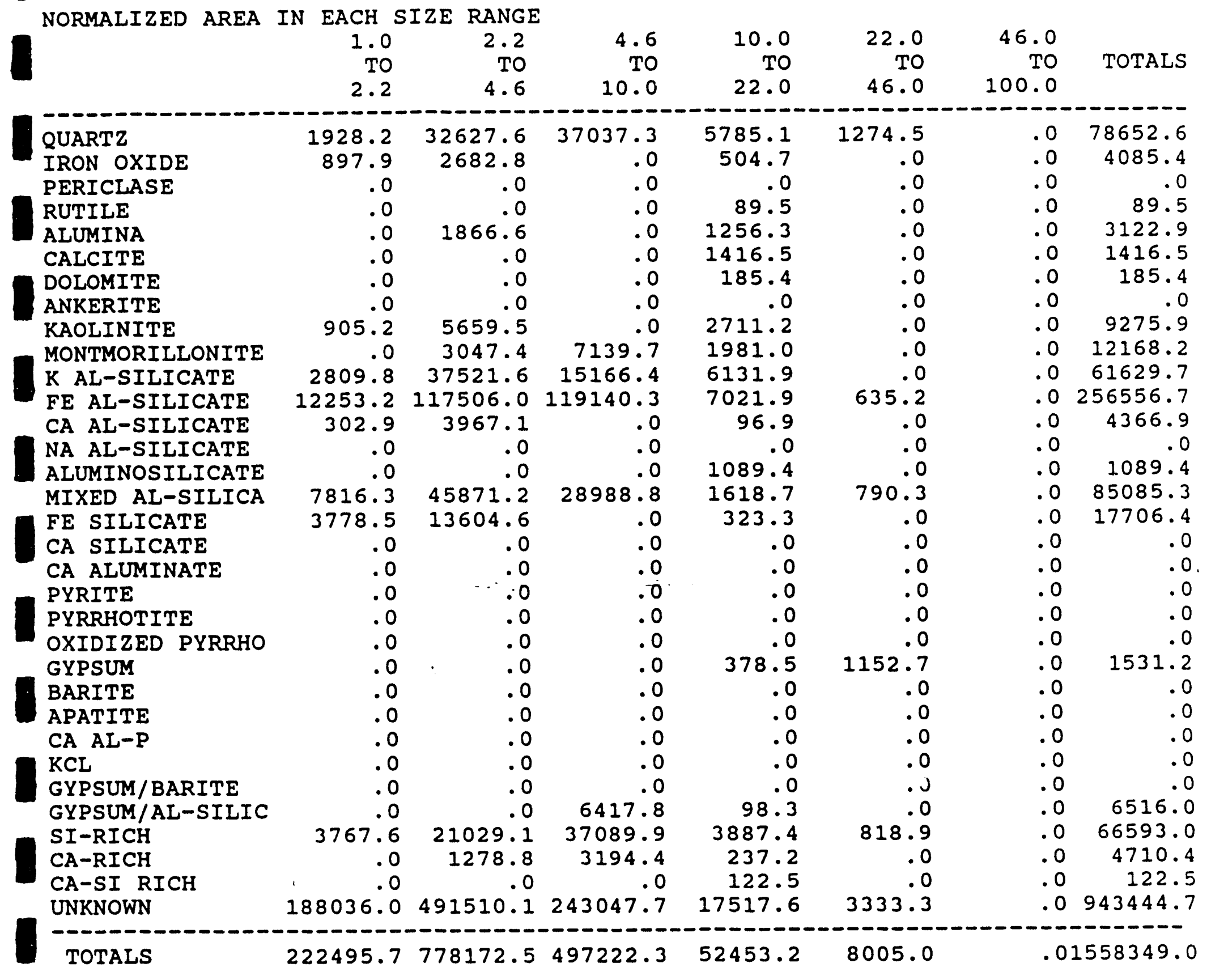


AREA PERCENT MINERAL BASIS

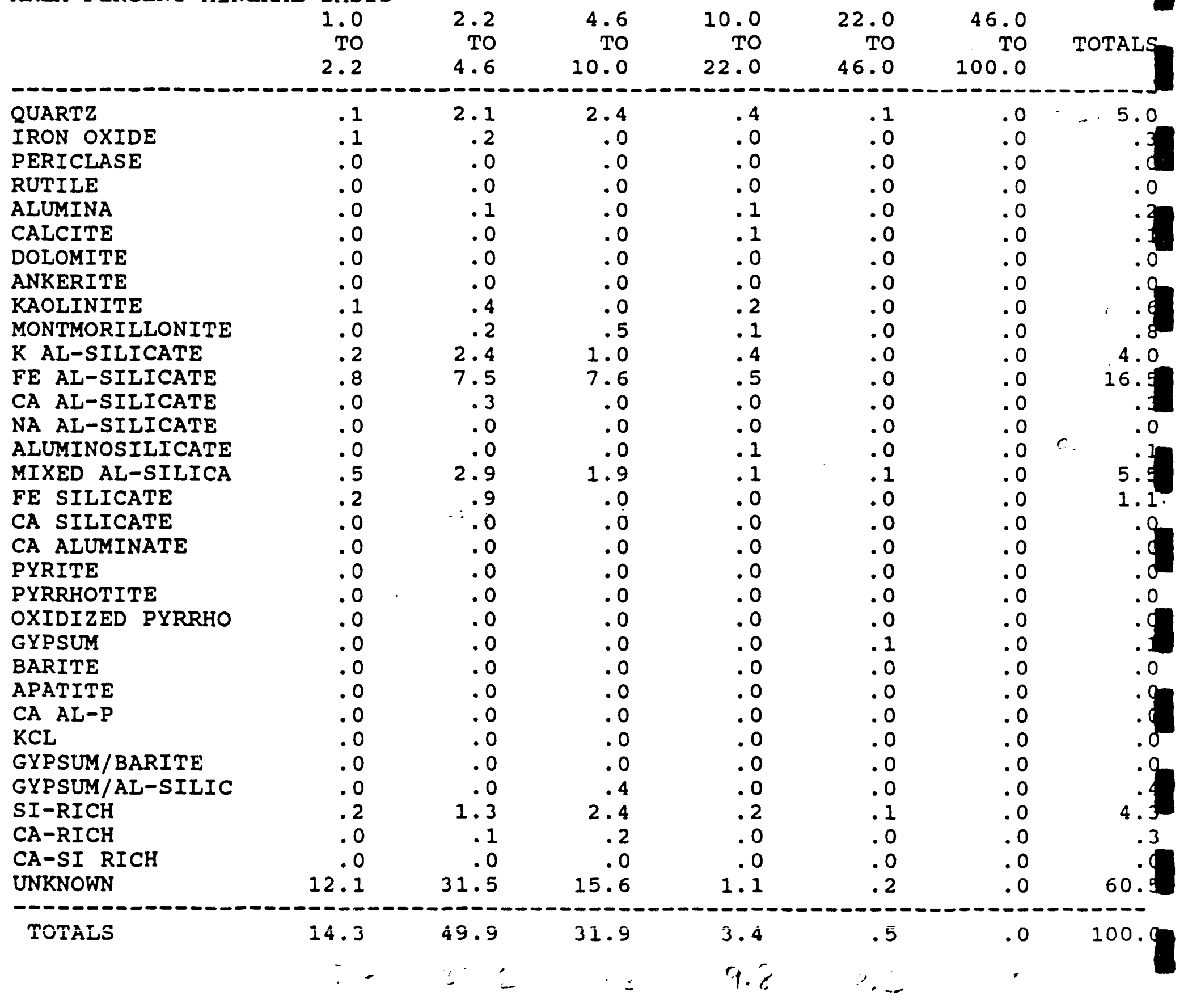


PAGE $447062569 . \mathrm{CCS}$ PSI-CIT TSK2 RUN\#I6SOAP-T-1250 TOT FILTER16\%02

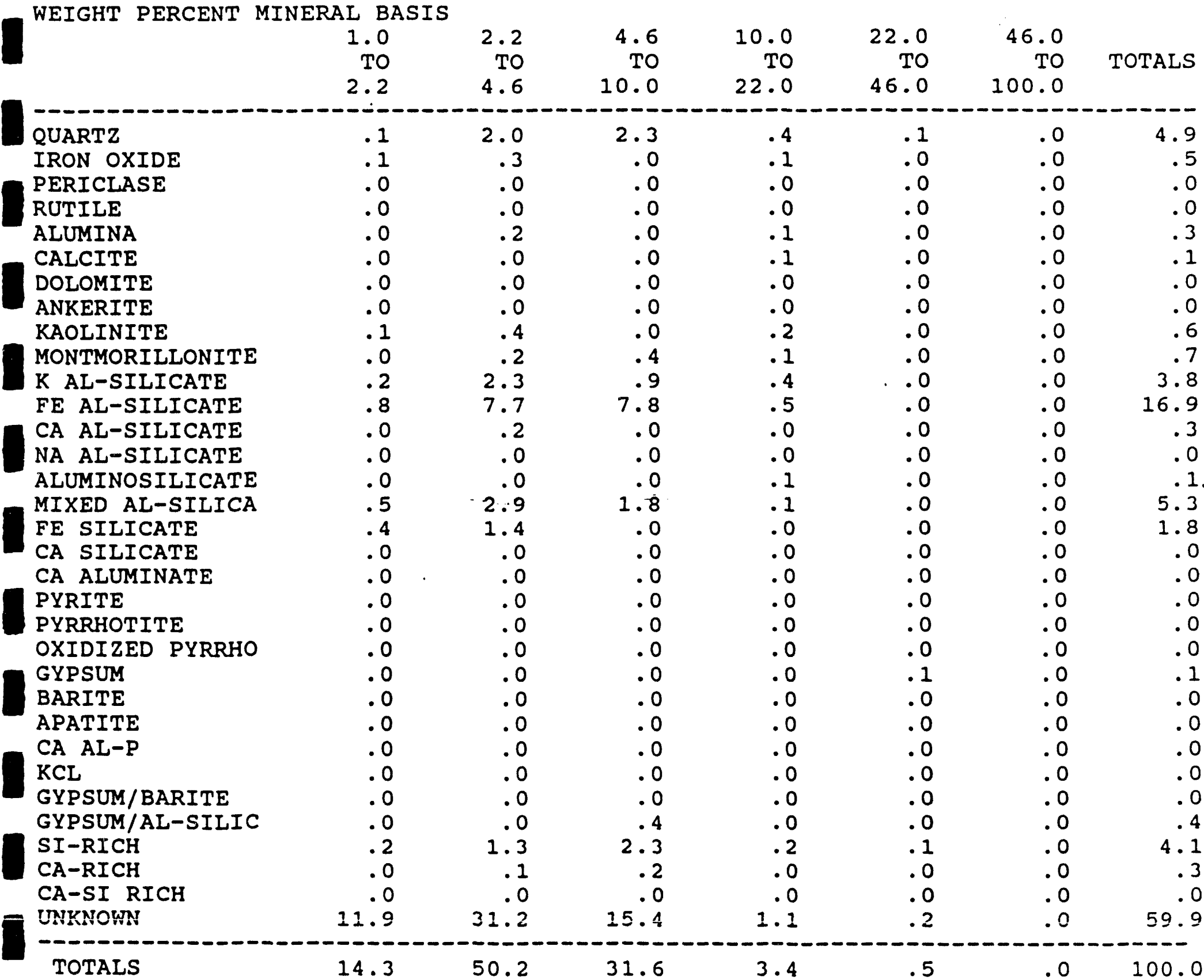


DISTRIBUTION BY $\%$ OF EACH MINERAL PHASE

\begin{tabular}{|c|c|c|c|c|c|c|c|}
\hline & $\begin{array}{r}1.0 \\
\text { TO } \\
2.2\end{array}$ & $\begin{array}{r}2.2 \\
\text { TO } \\
4.6\end{array}$ & $\begin{array}{r}4.6 \\
\text { TO } \\
10.0\end{array}$ & $\begin{array}{r}10.0 \\
\text { TO } \\
22.0\end{array}$ & $\begin{array}{r}22.0 \\
\text { TO } \\
46.0\end{array}$ & $\begin{array}{r}46.0 \\
\text { TO } \\
100.0\end{array}$ & TOT \\
\hline QUARTZ & 2.5 & 41.5 & 47.1 & 7.4 & 1.6 & .0 & \\
\hline IRON OXIDE & 22.0 & 65.7 & .0 & 12.4 & .0 & .0 & 10 \\
\hline PERICLASE & .0 & .0 & .0 & .0 & .0 & .0 & \\
\hline RUTILE & .0 & .0 & .0 & 100.0 & .0 & .0 & \\
\hline ALUMINA & .0 & 59.8 & .0 & 40.2 & .0 & .0 & 10 \\
\hline CALCITE & .0 & .0 & .0 & 100.0 & .0 & .0 & 10 \\
\hline DOLOMITE & .0 & .0 & .0 & 100.0 & .0 & .0 & 100 \\
\hline ANKERITE & .0 & .0 & .0 & .0 & .0 & .0 & \\
\hline KAOLINITE & 9.8 & 61.0 & .0 & 29.2 & .0 & .0 & \\
\hline MONTMORILLONITE & .0 & 25.0 & 58.7 & 16.3 & .0 & .0 & 100 \\
\hline K AL-SILICATE & 4.6 & 60.9 & 24.6 & 9.9 & .0 & .0 & \\
\hline FE AL-SILICATE & 4.8 & 45.8 & 46.4 & 2.7 & .2 & .0 & 100 \\
\hline CA AL-SILICATE & 6.9 & 90.8 & .0 & 2.2 & .0 & .0 & 10 \\
\hline NA AL-SILICATE & .0 & $\because 0$ & .0 & .0 & .0 & .0 & \\
\hline ALUMINOSILICATE & .0 & .0 & .0 & 100.0 & .0 & .0 & 1 \\
\hline MIXED AL-SILICA & 9.2 & 53.9 & 34.1 & 1.9 & .9 & .0 & 10 \\
\hline FE SILICATE & 21.3 & 76.8 & .0 & 1.8 & .0 & .0 & \\
\hline CA SILICATE & .0 & .0 & .0 & .0 & .0 & .0 & \\
\hline CA ALUMINATE & .0 & .0 & .0 & .0 & .0 & .0 & \\
\hline PYRITE & .0 & .0 & .0 & .0 & .0 & .0 & \\
\hline PYRRHOTITE & .0 & .0 & .0 & .0 & .0 & .0 & \\
\hline OXIDIZED PYRRHO & .0 & .0 & .0 & .0 & .0 & .0 & \\
\hline GYPSUM & .0 & .0 & .0 & 24.7 & 75.3 & .0 & \\
\hline BARITE & .0 & .0 & .0 & .0 & .0 & .0 & \\
\hline APATITE & .0 & .0 & .0 & .0 & .0 & .0 & \\
\hline$C A$ AL-P & .0 & .0 & .0 & .0 & .0 & .0 & \\
\hline KCL & .0 & .0 & .0 & .0 & .0 & .0 & \\
\hline GYPSUM/BARITE & .0 & .0 & .0 & .0 & .0 & .0 & \\
\hline GYPSUM/AL-SILIC & .0 & .0 & 98.5 & 1.5 & .0 & .0 & 10 \\
\hline SI-RICH & 5.7 & 31.6 & 55.7 & 5.8 & 1.2 & .0 & \\
\hline CA-RICH & .0 & 27.1 & 67.8 & 5.0 & .0 & .0 & \\
\hline CA-SI RICH & .0 & .0 & .0 & 100.0 & .0 & .0 & 100 \\
\hline UNKNOWN & 19.9 & 52.1 & 25.8 & 1.9 & .4 & .0 & 10 \\
\hline
\end{tabular}


PAGE 6 47062569.CCS PSI-CIT TSK2 RUN\#I6SOAP-T-1250 TOT FILTER16\%02

NUMBER OF PARTICLES IN EACH SIZE RANGE

\begin{tabular}{|c|c|c|c|c|c|c|c|}
\hline 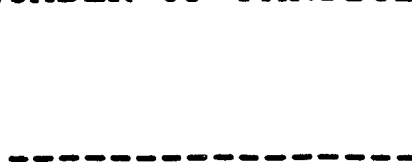 & $\begin{array}{r}1.0 \\
\text { TO } \\
2.2\end{array}$ & $\begin{array}{r}2.2 \\
\text { TO } \\
4.6\end{array}$ & $\begin{array}{r}4.6 \\
\text { TO } \\
10.0\end{array}$ & $\begin{array}{r}10.0 \\
\text { TO } \\
22.0\end{array}$ & $\begin{array}{r}22.0 \\
\text { TO } \\
46.0\end{array}$ & $\begin{array}{r}46.0 \\
\text { TO } \\
100.0\end{array}$ & TOTALS \\
\hline QUARTZ & 4.0 & 17.0 & 6.0 & 46.0 & 1.0 & .0 & 74.0 \\
\hline IRON OXIDE & 3.0 & 1.0 & .0 & 3.0 & .0 & .0 & 7.0 \\
\hline PERICLASE & .0 & .0 & .0 & .0 & .0 & .0 & .0 \\
\hline RUTILE & .0 & .0 & .0 & 1.0 & .0 & .0 & 1.0 \\
\hline ALUMINA & .0 & 1.0 & .0 & 9.0 & .0 & .0 & 10.0 \\
\hline CALCITE & .0 & .0 & .0 & 9.0 & .0 & .0 & 9.0 \\
\hline DOLOMITE & .0 & .0 & .0 & 2.0 & .0 & .0 & 2.0 \\
\hline ANKERITE & .0 & .0 & .0 & .0 & .0 & .0 & .0 \\
\hline KAOLINITE & 2.0 & 5.0 & .0 & 20.0 & .0 & .0 & 27.0 \\
\hline MONTMORILLONITE & .0 & 2.0 & 2.0 & 14.0 & .0 & .0 & 18.0 \\
\hline K AL-SILICATE & 7.0 & 22.0 & 3.0 & 50.0 & .0 & .0 & 82.0. \\
\hline FE AL-SILICATE & 30.0 & 67.0 & 21.0 & 59.0 & 1.0 & .0 & 178.0 \\
\hline CA AL-SILICATE & 1.0 & 3.0 & .0 & 1.0 & .0 & .0 & 5.0 \\
\hline NA AL-SILICATE & .0 & .0 & .0 & .0 & .0 & .0 & .0 \\
\hline ALUMINOSILICATE & .0 & .0 & .0 & 7.0 & .0 & .0 & 7.0 \\
\hline MIXED AL-SILICA & 16.0 & 30.0 & 6.0 & 15.0 & 1.0 & .0 & 68.0 \\
\hline FE SILICATE & 8.0 & 8.0 & .0 & 3.0 & .0 & .0 & 19.0 \\
\hline CA SILICATE & .0 & .0 & .0 & .0 & .0 & .0 & .0 \\
\hline CA ALUMINATE & .0 & .0 & .0 & .0 & .0 & .0 & .0 \\
\hline PYRITE & .0 & .0 & .0 & .0 & .0 & .0 & .0 \\
\hline PYRRHOTITE & .0 & .0 & .0 & .0 & .0 & .0 & .0 \\
\hline OXIDIZED PYRRHO & .0 & .0 & .0 & .0 & .0 & .0 & .0 \\
\hline GYPSUM & .0 & .0 & .0 & 1.0 & 2.0 & .0 & 3.0 \\
\hline BARITE & .0 & .0 & .0 & .0 & .0 & .0 & .0 \\
\hline APATITE & .0 & .0 & .0 & .0 & .0 & .0 & .0 \\
\hline CA AL-P & .0 & .0 & .0 & .0 & .0 & .0 & .0 \\
\hline KCL & .0 & .0 & .0 & .0 & .0 & .0 & .0 \\
\hline GYPSUM/BARITE & .0 & .0 & .0 & .0 & .0 & .0 & .0 \\
\hline GYPSUM/ALI=SILIC & .0 & .0 & 1.0 & 1.0 & .0 & .0 & 2.0 \\
\hline SI-RICH & 7.0 & 14.0 & 8.0 & 31.0 & 2.0 & .0 & 62.0 \\
\hline CA-RICH & .0 & 1.0 & 1.0 & 2.0 & .0 & .0 & 4.0 \\
\hline CA-SI RICH & .0 & .0 & .0 & 1.0 & .0 & .0 & 1.0 \\
\hline
\end{tabular}




\begin{tabular}{|c|c|c|c|}
\hline 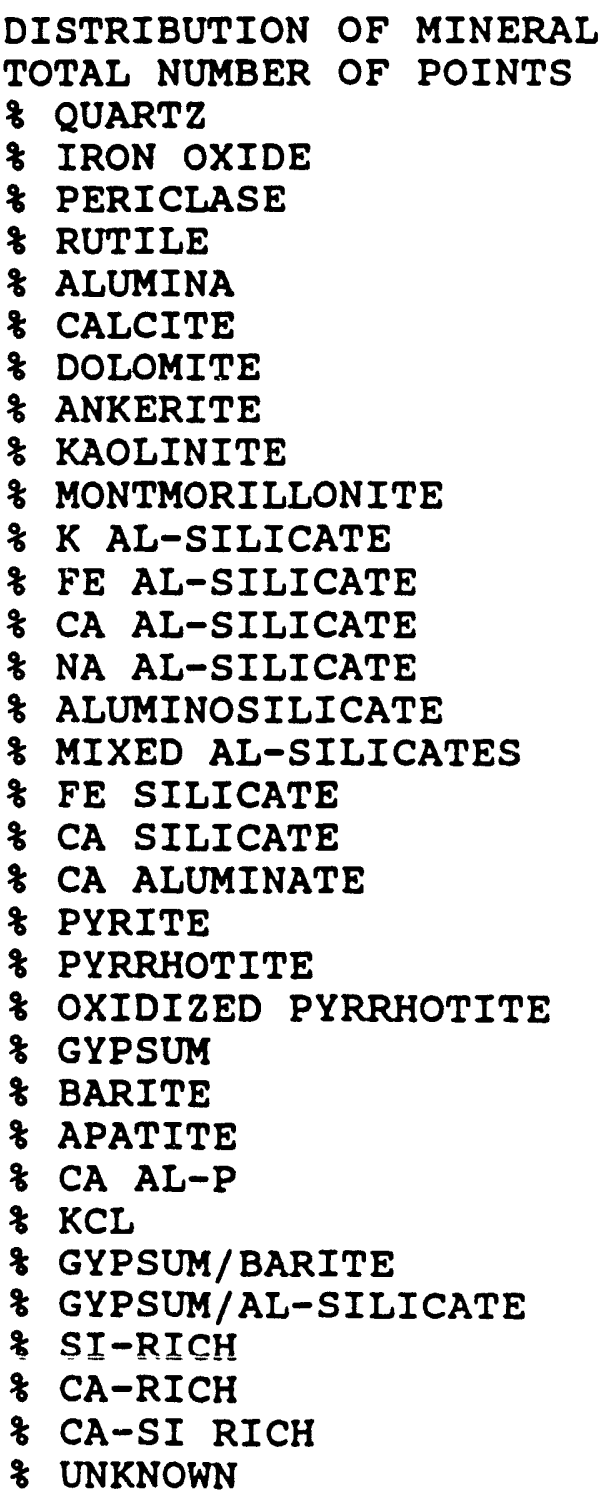 & $\begin{aligned} \text { PHASES } \\
= \\
= \\
= \\
= \\
= \\
= \\
= \\
= \\
= \\
= \\
= \\
= \\
= \\
= \\
= \\
= \\
= \\
= \\
= \\
= \\
= \\
= \\
= \\
= \\
= \\
= \\
= \\
= \\
= \\
= \\
= \\
= \\
= \\
= \\
= \\
= \\
= \\
= \\
= \\
= \\
= \\
= \\
= \\
= \\
= \\
= \\
= \\
= \\
=\end{aligned}$ & $\begin{array}{c}\text { FREQUENCY } \\
1584.0 \\
4.7 \\
.4 \\
.0 \\
.1 \\
.6 \\
.6 \\
.1 \\
.0 \\
1.7 \\
1.1 \\
5.2 \\
11.2 \\
.3 \\
.0 \\
.4 \\
4.3 \\
1.2 \\
.0 \\
.0 \\
.0 \\
.0 \\
.0 \\
.2 \\
.0 \\
.0 \\
.0 \\
.0 \\
.0 \\
.1 \\
3.9 \\
.3 \\
.1 \\
63.4\end{array}$ & Y PERCENT \\
\hline
\end{tabular}


SUMMARY OF CCSEM RESULTS: PROG VERSION 2BF $8 / 21 / 90$

SAMPLE DESCRIPTION -- 47062572 . CCS PSI-CIT TSK2RUN\#I6SOAP T1250 TOT FILTER16?

SUBMITTER $\quad-\infty>$ ZYGARL

ICC \# AND FUND \#---> 47062572

RUN DATE AND TIME ---> $6101991 \quad 9: 15$

Epoxy-xisection

SUMMARY OF PARAMETERS

TOTAL MINERAL AREA ANALYZED AT HIGH MAG NORMALIZED AREA ANALYZED AT HIGH MAG

TOTAL MINERAL AREA ANALYZED AT LOW MAG

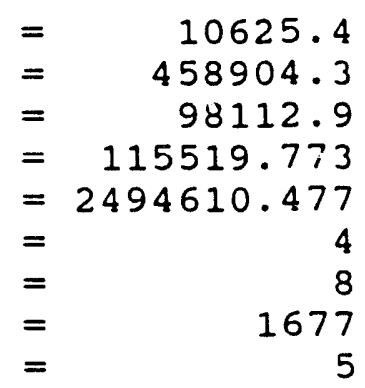

FIELD SIZE USED AT HIGH MAG

FIELD SIZE USED AT LOW MAG

NUMBER OF FRAMES AT HIGH MAG

NUMBER OF FRAMES AT LOW MAG

TOTAL NUMBER OF POINTS ANALYZED

NUMBER OF POINTS UNDER THRESHOLD

$\begin{array}{rr}9: 15 & \text { Epoxy - } \\ & \\ = & 10625.4 \\ = & 458904.3 \\ = & 115519.773 \\ = & 2494610.477 \\ = & 4 \\ = & 8 \\ = & 1677 \\ = & 5\end{array}$

1

WEIGHT PERCENT ON A MINERAL BASIS

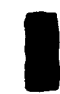

QUART
IRON OXIDE
PERICLASE
RUTILE
ALUMINA
CALCITE
DOLOMITE
ANKERITE
KAOLINITE
MONTMORILLONITE
K AL-SILICATE
FE AL-SILICATE
CA AI,-SILICATE
NA AL-SILICATE
ALUMINOSILICATE
MIXED AL-SILICA
FE SILICATE
CA SILICATE
CA ALUMINATE
PYRITE
PYRRHOTITE
OXIDIZED PYRRHO
GYPSUM
BARITE
APATITE
CA AL-P
KCL
GYPSUM/BARITE
GYPSUM/AL-SILIC
SI-RICH
CA-RICH
CA-SI RICH
ONKNOWN
$:$
$:$
$:$

$\begin{array}{rr}.0 & 2.2 \\ \text { TO } & \text { TO } \\ .2 & 4.6\end{array}$

4.6

10.0

22.0

46.0

$\mathrm{T}$

0

22.0

46.

TO

TOTALS

0

1.8

. 1

.0

.8

0

.0

.0

.0

2.3

.0

.0

1.4

1.1

2.7

6.6

1.2

.3

.0

.1

.0

.0

.3

.0

.6

.0

1.2

.3

.0

2.2

.0

.0

.0

.0

.0

.0

.0

.0

.0

.0

.0

.0

.0

.3

.1

.0

7.1

.0

.2

.0

.0

.0

.0

.0

.0

.0

.0

.0

.0

.0

3.4

1.0

.5

. 2

.0

UNKNOWN

23.4

.2

18.6

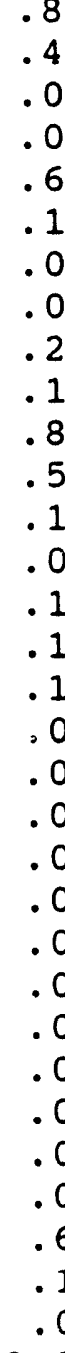

.4
.0

.0

.6

.1

.0

.0

.2

.1

.8

.5

.1

.0

.1

.1

.1

.0

.0

.0

.0

.0

$\begin{array}{ll}.0 & .0 \\ .0 & .0 \\ .0 & .0 \\ .0 & .0 \\ .7 & .5 \\ .0 & .0 \\ .0 & .0 \\ .0 & .0 \\ .1 & . \\ .0 & .\end{array}$
100.0

.0

3.6

.0

.0

.0

.5

.0

.0

. 0

.1

.0

.0

.0

.0

.0

.0

.0

.0

.0

.0

.0

.0

.0

.0

.0

.0

.0

.0

.0

.6

.1

9.9

.0

.0

.0

.1

.0

.0

2.1

.

$\checkmark$

.0

.0

.0

.0

.0

.0

.0

.0

.0

.0

.0

.0

.0

.0

.0

.0

.0

.0

.

.0

.0

.5

.0

1.8

3.4

.0

.0

2. 1

1.4

4. 9

9.3

.5

.0

.6

3.6

.4

.2

.0

.0

.1

.0

.0

.0

.0

.0

.0

.0

5.4

.8

.2

61.1 
PAGE 147062572. CCS PSI-CIT TSK2RUN\#I6SOAP T1250 TOT FILTER16\%2,AS REC'

AREA IN EACH SIZE RANGE

\begin{tabular}{|c|c|c|c|c|c|c|c|}
\hline 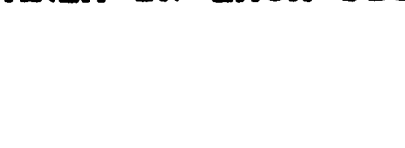 & $\begin{array}{r}1.0 \\
\text { TO } \\
2.2\end{array}$ & $\begin{array}{r}2.2 \\
\text { TO } \\
4.6\end{array}$ & $\begin{array}{r}4.6 \\
\text { TO } \\
10.0\end{array}$ & $\begin{array}{r}10.0 \\
\text { TO } \\
22.0\end{array}$ & $\begin{array}{r}22.0 \\
\text { TO } \\
46.0\end{array}$ & $\begin{array}{r}46.0 \\
\mathrm{TO} \\
100.0\end{array}$ & TOTALS \\
\hline QUARTZ & 3.1 & 137.7 & 234.2 & 4545.2 & .0 & .0 & 4920 \\
\hline IRON OXIDE & .0 & 4.1 & .0 & 1145.6 & .0 & .0 & 1149 \\
\hline PERICLASE & .0 & .0 & .0 & .0 & .0 & .0 & \\
\hline RUTILE & .0 & .0 & .0 & 148.4 & .0 & .0 & 148 \\
\hline ALUMINA & .0 & .0 & .0 & 2440.7 & 2709.5 & 1779.2 & 6929 \\
\hline CALCITE & 7.2 & 114.4 & 286.9 & 733.8 & .0 & .0 & 1142. \\
\hline DOLOMITE & 3.4 & .0 & .0 & .0 & .0 & .0 & 3. \\
\hline ANKERITE & .0 & .0 & .0 & .0 & .0 & .0 & \\
\hline KAOLINITE & .0 & 42.0 & 190.8 & 1030.6 & 695.5 & .0 & 1958 \\
\hline MONTMORILLONITE & .0 & 29.3 & 156.5 & 750.6 & .0 & .0 & 936 \\
\hline K AL-SILICATE & 15.3 & 159.0 & 361.7 & 4617.9 & 780.9 & .0 & 5934 \\
\hline FE AL-SILICATE & 6.3 & 275.9 & 827.3 & 2549.0 & .0 & .0 & 3658 \\
\hline CA AL-SILICATE & 5.6 & 4.5 & 44.2 & 519.2 & .0 & .0 & 573 \\
\hline NA AL-SILICATE & .0 & .0 & .0 & .0 & .0 & .0 & \\
\hline ALUMINOSILICATE & .0 & .0 & 74.1 & 366.1 & .0 & .0 & 440. \\
\hline MIXED AL-SILICA & 19.0 & 293.0 & 153.6 & 720.7 & .0 & .0 & 1186. \\
\hline FE SILICATE & .0 & .0 & 21.3 & 368.1 & .0 & .0 & 389 \\
\hline CA SILICATE & .0 & .0 & 21.1 & .0 & .0 & .0 & 21. \\
\hline CA ALUMINATE & .0 & .0 & .0 & 172.9 & .0 & .0 & 172 \\
\hline PYRITE & .0 & .0 & .0 & .0 & .0 & .0 & \\
\hline PYRRHOTITE & .0 & .0 & .0 & .0 & .0 & .0 & \\
\hline OXIDIZED PYRRHO & .0 & $4: 0$ & $\therefore$ & .0 & .0 & .0 & \\
\hline GYPSUM & .0 & .0 & .0 & .0 & .0 & .0 & \\
\hline BARITE & .0 & .0 & .0 & .0 & .0 & .0 & \\
\hline APATITE & .0 & .0 & .0 & .0 & .0 & .0 & \\
\hline$C A \quad A L-P$ & .0 & .0 & .0 & .0 & .0 & .0 & \\
\hline KCL & .0 & .0 & .0 & .0 & .0 & .0 & \\
\hline GYPSUM/BARITE & .0 & .0 & .0 & .0 & .0 & .0 & \\
\hline GYPSUM/AL-SILIC & .0 & .0 & .0 & 140.0 & .0 & .0 & 140 \\
\hline SI-RICH & 39.3 & 138.4 & 450.3 & 3263.6 & 543.0 & .0 & 4434 \\
\hline $\mathrm{CA}-\mathrm{RICH}$ & 7.1 & 24.0 & 68.9 & 347.6 & .0 & .0 & 447. \\
\hline CA-SI RICH & .0 & .0 & 21.0 & 112.7 & .0 & .0 & 133. \\
\hline UNKNOWN & 918.9 & 3045.1 & 2416.9 & 55671.6 & 11960.7 & .0 & 74013 \\
\hline TOTALS & 1025.1 & & 5329.0 & 79644.1 & $16689 \cdot 6$ & 1779.2 & 03738 \\
\hline TOTALS & 1025.1 & 4271.3 & 5329.0 & 79644.1 & 16689.6 & 1779.2 & 03738 \\
\hline
\end{tabular}


PAGE 247062572. CCS PSI-CIT TSK2RUN\#I6SOAP T1250 TOT FILTER16\%2,AS REC'

NORMALIZED AREA IN EACH SIZE RANGE

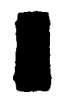

$\begin{array}{lll}1.0 & 2.2\end{array}$

TO

TO

2.2

4.6

\begin{tabular}{r}
4.6 \\
TO \\
10.0 \\
\hdashline 10115.4 \\
.0 \\
.0 \\
.0 \\
.0 \\
12390.2 \\
.0 \\
.0 \\
8241.4 \\
6760.9 \\
15622.0 \\
35731.4 \\
1909.0 \\
.0 \\
3202.1 \\
6635.6 \\
921.7 \\
912.2 \\
.0 \\
.0 \\
.0 \\
.0 \\
.0 \\
.0 \\
.0 \\
.0 \\
.0 \\
.0 \\
.0 \\
2974.4 \\
908.7 \\
19446.0 \\
04383.9
\end{tabular}

10.0
TO
22.0

$22.0 \quad 46.0$

$\begin{array}{rrr}\text { TO } & \text { TO TOTALS } \\ 46.0 & 100.0\end{array}$

QUARTZ

IRON OXIDE

132.6

5945.4

4545.2

1145.6

.0

176.6

PERICLASE

RUTILE

ALUMINA

CALCITE

DOLOMITE

ANKERITE

KAOLINITE

MONTMORILLONITE

K AL-SILICATE

FE AL-SILICATE

CA AL-SILICATE

NA AL-SILICATE

ALUMINOSILICATE

MIXED AL-SILICA

FE SILICATE

CA SILICATE

CA ALUMINATE

PYRITE

PYRRHOTITE

OXIDIZED PYRRHO

GYPSUM

BARITE

APATITE

CA AL-P

KCL

GYPSUM/BARITE

GYPSUM/AL-SILIC

SI-RICH

CA-RICH

CA-SI RICH

UNKNOWN

.0

310.5

148.1

.0

.0

.0

659.1

273.4

241.4

.0

.0

819.7

.0

.0

. 0

.0

.0

.0

.0

.0

.0

.0

.0

1696.9

306.2

.0

39686.2131516 .7
.0

4939.6

.0

1814.8

1263.7

6866.7

11915.5

194.4

.0

.0

12655.3

.0

.0

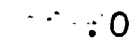

.0

172.8

.0

.0

.0

.0

.0

$5977^{\circ} .0$

1037.0
.0

908.7
148.4

2440.7

733.8

.0

.0

1030.6

750.6

4617.9

2549.0

519.2

.0

366.1

720.7

368.1

.0

172.9

.0

.0

.0

.0

.0

.0

.0

.0

.0

140.0

3263.6

347.6

112.7

55671.6

$44274.2 \quad 184475: 4230154=6 \quad 79644.1 \quad 16689.6$

$1779.2 \quad 557017.1$

.020738 .6

.0 1322.3

$\begin{array}{rr}.0 & 148.4\end{array}$

$2709.5 \quad 1779.2 \quad 6929.3$

$.0 \quad 18374.1$

$.0 \quad 148.1$

.0

. 11782.2

$.0 \quad 8775.2$

.028546 .5

$.0 \quad 50469.3$

.02863 .9

$.0 \quad .0$

. 03568.1

.020831 .4

$.0 \quad 1289.7$

$.0 \quad 912.2$

$.0 \quad 172.9$

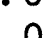

.0

.0

.0

.0

.0

.0

.0

.0

.0

.0

.0

. $0 \quad 1021.4$

.0343219 .0 
AREA PERCENT MINERAL BASIS

\begin{tabular}{|c|c|c|c|c|c|c|c|}
\hline & $\begin{array}{r}1.0 \\
\text { TO } \\
2.2\end{array}$ & $\begin{array}{r}2.2 \\
\text { TO } \\
4.6\end{array}$ & $\begin{array}{r}4.6 \\
\text { TO } \\
10.0\end{array}$ & $\begin{array}{r}10.0 \\
\mathrm{TO} \\
22.0\end{array}$ & $\begin{array}{r}22.0 \\
\text { TO } \\
46.0\end{array}$ & $\begin{array}{r}46.0 \\
\mathrm{TO} \\
100.0\end{array}$ & TOTALS \\
\hline QUARTZ & 0 & $17+1$ & $18+8>-1$ & 8 & 0 & 0 & \\
\hline IRON OXIDE & .0 & 1.1 & $\begin{array}{r}1.8 \\
.0\end{array}$ & $\begin{array}{r}.8 \\
2\end{array}$ & $\cdot 0$ & $\cdot 0$ & 3.7 \\
\hline PERICLASE & .0 & .0 & .0 & .0 & .0 & .0 & \\
\hline RUTILE & .0 & .0 & .0 & .0 & .0 & .0 & \\
\hline ALUMINA & .0 & .0 & .0 & .4 & .5 & .3 & $1 .+2>>$ \\
\hline CALCITE & .1 & .9 & 2.2 & .1 & .0 & .0 & 3 \\
\hline DOLOMITE & .0 & .0 & .0 & .0 & .0 & .0 & \\
\hline ANKERITE & .0 & .0 & .0 & .0 & .0 & .0 & \\
\hline KAOLINITE & .0 & .3 & 1.5 & .2 & .1 & .0 & 2 \\
\hline MONTMORILLONITE & .0 & .2 & 1.2 & .1 & .0 & .0 & \\
\hline K AL-SILICATE & .1 & 1.2 & 2.8 & .8 & .1 & .0 & 5.1 \\
\hline FE AL-SILICATE & .0 & 2.1 & 6.4 & .5 & .0 & .0 & 9 \\
\hline CA AL-SILICATE & .0 & .0 & .3 & .1 & .0 & .0 & \\
\hline NA AL-SILICATE & .0 & .0 & .0 & .0 & .0 & .0 & \\
\hline ALUMINOSILICATE & .0 & .0 & .6 & .1 & .0 & .0 & \\
\hline MIXED AL-SILICA & .1 & 2.3 & 1.2 & .1 & .0 & .0 & 3 \\
\hline FE SILICATE & .0 & .0 & .2 & .1 & .0 & .0 & \\
\hline CA SILICATE & .0 & $\therefore \quad .0$ & .2 & .0 & .0 & .0 & \\
\hline CA ALUMINATE & .0 & .0 & .0 & .0 & .0 & .0 & \\
\hline PYRITE & .0 & .0 & .0 & .0 & .0 & .0 & \\
\hline PYRRHOTITE & .0 & .0 & .0 & .0 & .0 & .0 & \\
\hline OXIDIZED PYRRHO & .0 & .0 & .0 & .0 & .0 & .0 & \\
\hline GYPSUM & .0 & .0 & .0 & .0 & .0 & .0 & \\
\hline BARITE & .0 & .0 & .0 & .0 & .0 & .0 & \\
\hline APATITE & .0 & .0 & .0 & .0 & .0 & .0 & \\
\hline$C A \quad A L-P$ & .0 & .0 & .0 & .0 & .0 & .0 & \\
\hline $\mathrm{KCL}$ & .0 & .0 & .0 & .0 & .0 & .0 & \\
\hline GYPSUM / BARITE & .0 & .0 & .0 & .0 & .0 & .0 & \\
\hline GYPSUM / AL-SILIC & .0 & .0 & .0 & .0 & .0 & .0 & \\
\hline SI-RICH & .3 & 1.1 & 3.5 & .6 & .1 & .0 & 5 \\
\hline CA-RICH & .1 & .2 & .5 & .1 & .0 & .0 & \\
\hline CA-SI RICH & .0 & .0 & .2 & .0 & .0 & .0 & \\
\hline UNKNOWN & 7.1 & 23.6 & 18.7 & 10.0 & 2.1 & .0 & 61. \\
\hline TOTALS & 7.9 & 33.1 & 41.3 & 14.3 & 3.0 & .3 & $100+\div$ \\
\hline
\end{tabular}


PAGE 447062572. CCS PSI-CIT TSK2RUN\#I6SOAP T1250 TOT FILTER16\%2, AS REC'

\begin{tabular}{|c|c|c|c|c|c|c|c|}
\hline WEIGHT PERCENT & $\begin{array}{r}\mathrm{L} \\
1.0 \\
\mathrm{TO} \\
2.2\end{array}$ & $\begin{array}{r}2.2 \\
\text { TO } \\
4.6\end{array}$ & $\begin{array}{r}4.6 \\
\text { TO } \\
10.0\end{array}$ & $\begin{array}{r}10.0 \\
\text { TO } \\
22.0\end{array}$ & $\begin{array}{r}22.0 \\
\text { TO } \\
46.0\end{array}$ & $\begin{array}{r}46.0 \\
\text { TO } \\
100.0\end{array}$ & TOTALS \\
\hline OUARTZ & .0 & 1.0 & 1.8 & .8 & .0 & .0 & 3.6 \\
\hline IRON OXIDE & .0 & .1 & .0 & .4 & .0 & 0 & .5 \\
\hline PERICLASE & .0 & .0 & .0 & .0 & .0 & .0 & .0 \\
\hline RUTILE & .0 & .0 & .0 & .0 & .0 & .0 & .0 \\
\hline ALUMINA & .0 & .0 & .0 & .6 & .7 & .5 & 1.8 \\
\hline CALCITE & .1 & .9 & $2 \cdot 3$ & .1 & .0 & .0 & 3.4 \\
\hline DOLOMITE & .0 & .0 & .0 & .0 & .0 & .0 & .0 \\
\hline ANKERITE & .0 & .0 & .0 & .0 & .0 & .0 & .0 \\
\hline KAOLINITE & .0 & .3 & 1.4 & .2 & .1 & .0 & 2.1 \\
\hline MONTMORILLONITE & .0 & .2 & 1.1 & .1 & .0 & .0 & 1.4 \\
\hline K AL-SILICATE & .1 & 1.2 & 2.7 & .8 & .1 & .0 & 4.9 \\
\hline FE AL-SILICATE & .1 & 2.2 & 6.6 & .5 & .0 & .0 & 9.3 \\
\hline CA AL-SILICATE & .0 & .0 & .3 & .1 & .0 & .0 & .5 \\
\hline NA AL-SILICATE & .0 & .0 & .0 & .0 & .0 & .0 & .0 \\
\hline ALUMINOSILICATE & .0 & .0 & .6 & .1 & .0 & .0 & .6 . \\
\hline MIXED AL-SILICA & .1 & 2.2 & 1.2 & .1 & .0 & .0 & 3.6 \\
\hline FE SILICATE & .0 & .0 & .3 & .1 & .0 & .0 & .4 \\
\hline CA SILICATE & .0 & .0 & .2 & .0 & .0 & .0 & .2 \\
\hline CA ALUMINATE & .0 & .0 & .0 & .0 & .0 & .0 & .0 \\
\hline PYRITE & .0 & .0 & .0 & .0 & .0 & .0 & .0 \\
\hline PYRRHOTITE & .0 & .0 & .0 & .0 & .0 & .0 & .0 \\
\hline OXIDIZED PYRRHO & .0 & .1 & .0 & .0 & .0 & .0 & .1 \\
\hline GYPSUM & .0 & .0 & .0 & .0 & .0 & .0 & .0 \\
\hline BARITE & .0 & .0 & .0 & .0 & .0 & .0 & .0 \\
\hline APATITE & .0 & .0 & .0 & .0 & .0 & .0 & .0 \\
\hline$C A$ AL-P & .0 & .0 & .0 & .0 & .0 & .0 & .0 \\
\hline KCL & .0 & .0 & .0 & .0 & .0 & .0 & .0 \\
\hline GYPSUM / BARITE & .0 & .0 & .0 & .0 & .0 & .0 & .0 \\
\hline GYPSUM/AL-SILIC & .0 & .0 & .0 & .0 & .0 & .0 & .0 \\
\hline SI-RICH & .3 & 1.0 & 3.4 & .6 & .1 & .0 & 5.4 \\
\hline$C A-R I C H$ & .1 & .2 & .5 & .1 & .0 & .0 & .8 \\
\hline CA-SI RICH & .0 & .0 & .2 & .0 & .0 & .0 & .2 \\
\hline UNKNOWN & 7.1 & 23.4 & 18.6 & 9.9 & 2.1 & .0 & 61.1 \\
\hline TOTALS & 7.9 & 32.9 & 41.0 & 14.6 & 3.2 & .5 & 100.0 \\
\hline
\end{tabular}


DISTRIBUTION BY OF EACH MINERAL PHASE

\begin{tabular}{|c|c|c|c|c|c|c|c|}
\hline & $\begin{array}{r}1.0 \\
\text { TO } \\
2.2\end{array}$ & $\begin{array}{r}2.2 \\
\text { TO } \\
4.6\end{array}$ & $\begin{array}{r}4.6 \\
\text { TO } \\
10.0\end{array}$ & $\begin{array}{r}10.0 \\
\text { TO } \\
22.0\end{array}$ & $\begin{array}{r}22.0 \\
\text { TO } \\
46.0\end{array}$ & $\begin{array}{r}46.0 \\
\text { TO } \\
100.0\end{array}$ & TOTA \\
\hline QUARTZ & .6 & 28.7 & 48.8 & 21.9 & .0 & 0 & 100 \\
\hline IRON OXIDE & .0 & 13.4 & .0 & 86.6 & .0 & .0 & 100 \\
\hline PERICLASE & .0 & .0 & .0 & .0 & .0 & .0 & \\
\hline RUTILE & .0 & .0 & .0 & 100.0 & .0 & .0 & 100 \\
\hline ALUMINA & .0 & .0 & .0 & 35.2 & 39.1 & 25.7 & 100 \\
\hline CALCITE & 1.7 & 26.9 & 67.4 & 4.0 & .0 & .0 & 100 \\
\hline DOLOMITE & 100.0 & .0 & .0 & .0 & .0 & .0 & 100. \\
\hline ANKERITE & .0 & .0 & .0 & .0 & .0 & .0 & \\
\hline KAOLINITE & .0 & 15.4 & 69.9 & 8.7 & 5.9 & .0 & 100 \\
\hline MONTMORILLONITE & .0 & 14.4 & 77.0 & 8.6 & .0 & .0 & 100. \\
\hline K AL-SILICATE & 2.3 & 24.1 & 54.7 & 16.2 & 2.7 & .0 & 100 \\
\hline FE AL-SILICATE & .5 & 23.6 & 70.8 & 5.1 & .0 & .0 & 100 \\
\hline CA AL-SILICATE & 8.4 & 6.8 & 66.7 & 18.1 & .0 & .0 & 100 \\
\hline NA AL-SILICATE & .0 & $\because 0$ & $\therefore$ & .0 & .0 & .0 & \\
\hline ALUMINOSILICATE & .0 & .0 & 89.7 & 10.3 & .0 & .0 & 100 \\
\hline MIXED AL-SILICA & 3.9 & 60.8 & 31.9 & 3.5 & .0 & .0 & 100 \\
\hline FE SILICATE & .0 & .0 & 71.5 & 28.5 & .0 & .0 & 100. \\
\hline CA SILICATE & .0 & .0 & 100.0 & .0 & .0 & .0 & 100 \\
\hline CA ALUMINATE & .0 & .0 & .0 & 100.0 & .0 & .0 & 100 \\
\hline PYRITE & .0 & .0 & .0 & .0 & .0 & .0 & \\
\hline PYRRHOTITE & .0 & .0 & .0 & .0 & .0 & .0 & \\
\hline OXIDIZED PYRRHO & .0 & 100.0 & .0 & .0 & .0 & .0 & 100 \\
\hline GYPSUM & .0 & .0 & .0 & .0 & .0 & .0 & \\
\hline BARITE & .0 & .0 & .0 & .0 & .0 & .0 & \\
\hline APATITE & .0 & .0 & .0 & .0 & .0 & .0 & \\
\hline$C A \quad A L-P$ & .0 & .0 & .0 & .0 & .0 & .0 & \\
\hline KCL & .0 & .0 & .0 & .0 & .0 & .0 & \\
\hline GYPSUM / BARITE & .0 & .0 & .0 & .0 & .0 & .0 & \\
\hline GYPSUM/AL-SILIC & .0 & .0 & .0 & 100.0 & .0 & .0 & 100 \\
\hline$S I-R I C H$ & 5.5 & 19.3 & 62.9 & 10.6 & 1.8 & .0 & 100.0 \\
\hline CA-RICH & 6.6 & 22.2 & 63.8 & 7.5 & .0 & .0 & 100 \\
\hline CA-SI RICH & .0 & .0 & 89.0 & 11.0 & .0 & .0 & 100 \\
\hline UNKNOWN & 11.6 & 38.3 & 30.4 & 16.2 & 3.5 & .0 & 100 \\
\hline
\end{tabular}


NuMBer of PARTICLES IN EACH SIZE RANGE

\begin{tabular}{|c|c|c|c|c|c|c|c|}
\hline & $\begin{array}{r}1.0 \\
\text { TO } \\
2.2\end{array}$ & $\begin{array}{r}2.2 \\
\text { TO } \\
4.6\end{array}$ & $\begin{array}{r}4.6 \\
\text { TO } \\
10.0\end{array}$ & $\begin{array}{r}10.0 \\
\text { TO } \\
22.0\end{array}$ & $\begin{array}{r}22.0 \\
\text { TO } \\
46.0\end{array}$ & $\begin{array}{r}46.0 \\
\text { TO } \\
100.0\end{array}$ & TOTALS \\
\hline QUARTZ & 2.0 & 15.0 & 7.0 & 36.0 & .0 & .0 & 60.0 \\
\hline IRON OXIDE & .0 & 1.0 & .0 & 7.0 & .0 & .0 & 8.0 \\
\hline PERICLASE & .0 & .0 & .0 & .0 & .0 & .0 & .0 \\
\hline RUTILE & .0 & .0 & .0 & 1.0 & .0 & .0 & 1.0 \\
\hline ALUMINA & .0 & .0 & .0 & 12.0 & 4.0 & 1.0 & 17.0 \\
\hline CALCITE & 2.0 & 10.0 & 5.0 & 5.0 & .0 & .0 & 22.0 \\
\hline DOLOMITE & 1.0 & .0 & .0 & .0 & .0 & .0 & 1.0 \\
\hline ANKERITE & .0 & .0 & .0 & .0 & .0 & .0 & .0 \\
\hline KAOLINITE & .0 & 3.0 & 6.0 & 7.0 & 1.0 & .0 & 17.0 \\
\hline MONTMORILLONITE & .0 & 3.0 & 5.0 & 5.0 & .0 & .0 & 13.0 \\
\hline K AL-SILICATE & 6.0 & 18.0 & 13.0 & 26.0 & 1.0 & .0 & 64.0. \\
\hline FE AL-SILICATE & 2.0 & $27: 0$ & 30.0 & 19.0 & .0 & .0 & 78.0 \\
\hline CA AL-SILICATE & 2.0 & 1.0 & 1.0 & 3.0 & .0 & .0 & 7.0 \\
\hline NA AL-SILICATE & .0 & .0 & .0 & .0 & .0 & .0 & .0 \\
\hline ALUMINOSILICATE & .0 & .0 & 2.0 & 2.0 & .0 & .0 & 4.0 \\
\hline MIXED AL-SILICA & 7.0 & 31.0 & 4.0 & 6.0 & .0 & .0 & 48.0 \\
\hline FE SILICATE & .0 & .0 & 1.0 & 2.0 & .0 & .0 & 3.0 \\
\hline CA SILICATE & .0 & .0 & 1.0 & .0 & .0 & .0 & 1.0 \\
\hline CA ALUMINATE & .0 & .0 & .0 & 1.0 & .0 & .0 & 1.0 \\
\hline PYRITE & .0 & .0 & .0 & .0 & .0 & .0 & .0 \\
\hline PYRRHOTITE & .0 & .0 & .0 & .0 & .0 & .0 & .0 \\
\hline OXIDIZED PYRRHO & .0 & 1.0 & .0 & .0 & .0 & .0 & 1.0 \\
\hline GYPSUM & .0 & .0 & .0 & .0 & .0 & .0 & .0 \\
\hline BARITE & .0 & .0 & .0 & .0 & .0 & .0 & .0 \\
\hline APATITE & .0 & .0 & .0 & .0 & .0 & .0 & .0 \\
\hline$C A \quad A L-P$ & .0 & .0 & .0 & .0 & .0 & .0 & .0 \\
\hline KCL & .0 & .0 & .0 & .0 & .0 & .0 & .0 \\
\hline GYPSUM / BARITE & .0 &.$\overline{0}$ & .0 & .0 & .0 & .0 & .0 \\
\hline GYPSUM/AL-SILIC & .0 & .0 & .0 & 1.0 & .0 & .0 & 1.0 \\
\hline SI-RICH & 13.0 & 15.0 & 13.0 & 21.0 & 1.0 & .0 & 63.0 \\
\hline $\mathrm{CA}-\mathrm{RICH}$ & 3.0 & 3.0 & 3.0 & 3.0 & .0 & .0 & 12.0 \\
\hline CA-SI RICH & .0 & .0 & 1.0 & 1.0 & .0 & .0 & 2.0 \\
\hline
\end{tabular}




\begin{tabular}{|c|c|c|c|}
\hline 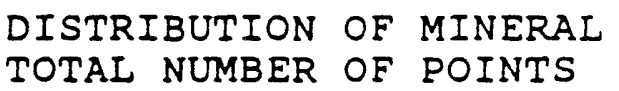 & $\begin{array}{l}\text { PHASES } \\
=\end{array}$ & $\begin{array}{l}\text { - FREQUENCY } \\
1677.0\end{array}$ & PERCEN \\
\hline Q QUARTZ & $=$ & 3.6 & \\
\hline IRON OXIDE & $=$ & .5 & \\
\hline$\%$ PERICLASE & $=$ & .0 & \\
\hline \% RUTILE & $=$ & .1 & \\
\hline$\%$ ALUMINA & $=$ & 1.0 & \\
\hline$\%$ CALCITE & $=$ & 1.3 & \\
\hline \& DOLOMITE & $=$ & .1 & \\
\hline 울 ANKERITE & $=$ & .0 & \\
\hline$\%$ KAOLINITE & $=$ & 1.0 & \\
\hline MONTMORILLONITE & $=$ & .8 & \\
\hline $\mathrm{K}$ AL-SILICATE & $=$ & 3.8 & \\
\hline$\because$ FE AL-SILICATE & $=$ & 4.7 & \\
\hline$\because$ CA AL-SILICATE & $=$ & .4 & $\therefore$ \\
\hline$\because$ NA AL-SILICATE & $=$ & .0 & \\
\hline$\frac{3}{\partial}$ ALUMINOSILICATE & $=$ & .2 & \\
\hline \% MIXED AL-SIIICATES & $=$ & 2.9 & \\
\hline$\div$ FE SILICATE & $=$ & .2 & \\
\hline \% CA SILICATE & $=$ & .1 & \\
\hline CA ALUMINATE & $=$ & .1 & \\
\hline PYRITE & $=$ & .0 & \\
\hline \& PYRRHOTITE & $=$ & .0 & \\
\hline \% OXIDIZED PYRRHOTITE & $=$ & .1 & \\
\hline GYPSUM & $=$ & .0 & \\
\hline BARITE & $=$ & .0 & \\
\hline APATITE & $=$ & .0 & \\
\hline$\because C A \quad A L-P$ & $=$ & .0 & \\
\hline \& $\mathrm{KCL}$ & $=$ & 0 & \\
\hline GYPSUM/BARITE & $=$ & .0 & \\
\hline GYPSUM/AL-SILICATE & $=$ & .1 & \\
\hline SI-RICH & $=$ & 3.8 & \\
\hline $\mathrm{CA}-\mathrm{RICH}$ & $=$ & .7 & \\
\hline CA-SI RICH & $=$ & .1 & \\
\hline UNKNOWN & $=$ & 74.7 & \\
\hline
\end{tabular}



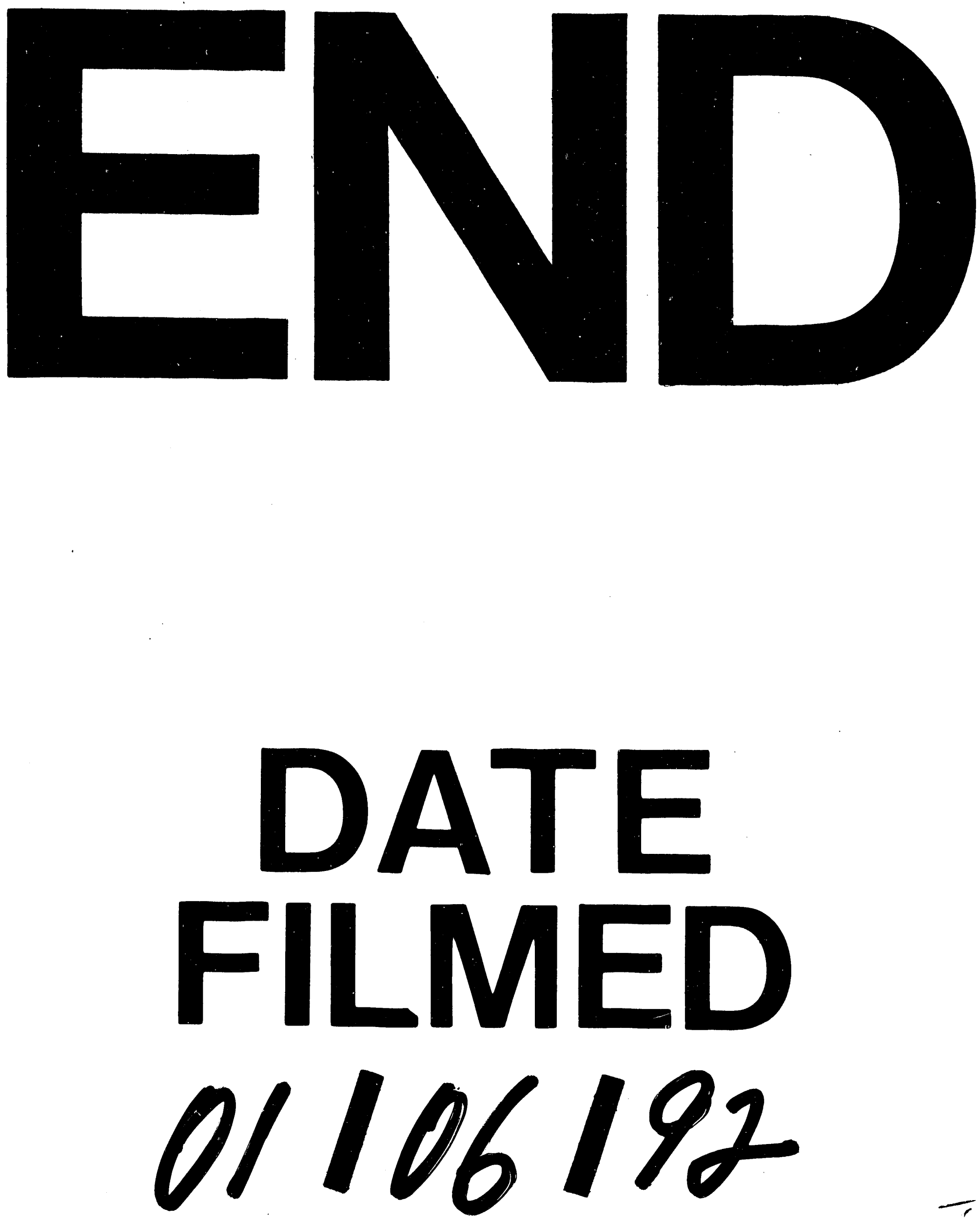
